\title{
Directory of United States Standardization Activities
}

Sophie J. Chumas, Editor

Institute for Applied Technology

National Bureau of Standards

Washington, D.C. 20234

Supersedes Miscelleous Publication 288

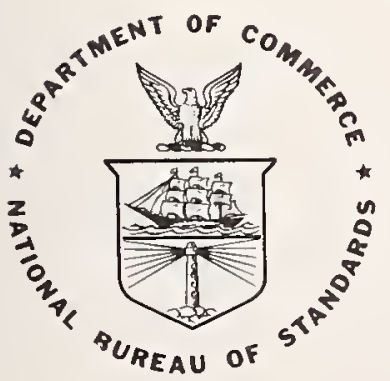

U.S. DEPARTMENT OF COMMERCE, Rogers C. B. Morton, Secretary James A. Baker, III, Under Secretary

Dr. Betsy Ancker-Johnson, Assistant Secretary for Science and Technology

NATIONAL BUREAU OF STANDARDS, Ernest Ambler, Acting Director 


\section{Library of Congress Cataloging in Publication Data}

Chumas, Sophie J

Directory of United States standardization activities

(NBS Special Publication; 417)

Supersedes a publication of the same title by J. E. Hartman, issued in 1967 as the Bureau's Miscellaneous publication No. 288. "CODEN : XNBSAV."

Includes indexes.

Supt. of Docs. No. C 13.10:417.

1. Standardization-United States-Directories.

I. Hartman, Joan E. Directory of United States standardization activities. II. Title. III. Series: United States. National Bureau of Standards. Special Publication; 417.

QC100.U57 No. 417 389'.08s [389'.6'02573] 75-619012

\section{National Bureau of Standards Special Publication 417}

Nat. Bur. Stand. (U.S.), Spec. Publ. 417, 228 pages (Nov. 1975)

CODEN: XNBSAV 


\section{Foreword}

Standards are critical to the smooth, efficient functioning of our highly technical society. So important are standards that over 580 organizations in this country consider standardization to be a major or important part of their work. Their efforts in developing and disseminating standards contribute directly to the success of our nation's standardization programs. This directory describes their activities in the fields, products, and services in which they specialize.

The National Bureau of Standards assists these organizations under Congressional authorization which directs "cooperation with other Government Agencies and with private organizations in the establishment of standard practices, incorporated in codes and specifications." Special needs of standardizing groups are met through additional Bureau functions which include provision of new and better standards for measurement, determination of physical constants and properties of materials and development of methods for testing.

This Directory is designed to sarve the needs of those interested or engaged in national standardization activities. It should be of particular value to manufacturers, engineers, purchasing agents, and writers of standards and specifications.

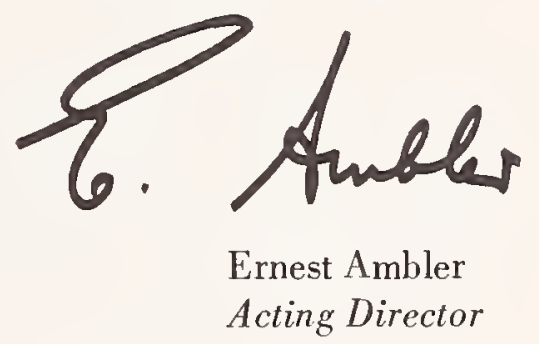





\section{Contents}

Foreword ...

1. Introduction -

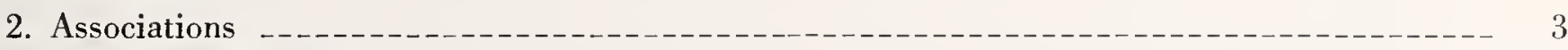

3. State Governments _-

4. Federal Governments _.

5. Indexes

5.1. Association Index by Subject Heading Areas 197

5.2. Subject Index 



\title{
Directory of United States Standardization Activities
}

\author{
Sophie J. Chumas, Editor*
}

\begin{abstract}
This Directory serves as a guide to standardization activities in the United States. It supersedes a Directory of the same title, issued in 1967, as National Bureau of Standards Miscellaneous Publication 288. Included in the Directory are summaries of the standardization activities of trade associations, technical and other professional societies representing industry and commerce, and state and Federal governments. For the first time this Directory covers nonengineering and nonindustry organizations. SP 417 contains current descriptive summaries of more than 580 organizations.

Criteria for inclusion are that the organizations have standardization activities such as standardswriting groups, that they assist in the development of standards, or that they issue standards or disseminate standards information.

The standardization activities summaries are grouped into three sections: associations, states, and agencies of the Federal Government. In each section, the summaries are arranged alphabetically by organization. Two types of indexes are included in SP 417 to assist the reader in identifying an activity: (1) a subject index of key words taken from the summaries; and (2) a listing of organizations classified into 24 subject heading areas.
\end{abstract}

Key words: Codes; consensus system; Directory; Federal Government-standardization; industry standards activities; national standards activities; recommended practices; specifications; standardization activities; standards; states-standardization activities; test methods.

\section{Introduction}

\section{History}

This revised Directory has been compiled at the direction of William E. Andrus, Jr., while he was Program Manager for Engineering and Information Processing Standards. This Directory of U.S. standardization activities was first published in 1941, as Standardization Activities of National Technical and Trade Organizations, National Bureau of Standards (NBS) Miscellaneous Publication (MP) 169, edited by Robert A. Martino. The second edition was issued in 1960 and entitled Standardization Activities in the United States-a Descriptive Directory, NBS MP 230, edited by Sherman Booth. This publication supersedes the third edition, Directory of United States Standardization Activities, NBS MP 288, edited by Joan Hartman, issued in 1967. Standards Information Services of the Institute for Applied Technology has since assumed the responsibility of updating the standards information contained in SP 417 and will continue to revise and issue the Directory.

\section{Scope}

This Directory provides summaries of the standardization activities of private associations, state governments, and the Federal Government. In previous editions, the associations covered were primarily technical and trade groups representing industry and commerce. The scope of this current edition has been broadened to include the standardization activities of professional groups in such areas as medicine, health, education, recreation, and athletics and sports. The

*Present address: Consumer Product Safety Commission, Washington, D.C 20201.
Directory includes a key word subject index and a subject area heading index.

For the purpose of this Directory, the term "standards" encompasses the following words: specifications, tests and test methods, analyses, assays, reference samples, recommended practices, guides to good practice, nomenclature, symbols, grading rules, codes, forms and contracts, criteria, methods and codes of practice.

\section{Criteria}

Criteria for inclusion are that the organizations have standardization activities such as standards-writing groups, that they contribute toward the development of standards, or that they issue standards or disseminate standards information. International groups were included if they involved a large American membership and conducted a major portion of their standardization activities in the United States.

\section{The Survey}

A survey was conducted to gather the information needed to assemble this Directory. The survey included inquiries to all organizations listed in MP 288, organizations selected from Gale's Encyclopedia of Associations that appeared likely to have standardization programs, states and territories, and Federal Government agencies which were considered to possibly have either voluntary or mandatory standardization programs. Government approval for the survey was obtained from the Office of Management and Budget. There were 966 technical and trade organizations, 50 states and three outlying U.S. areas, and 109 Federal Government departments and independent agencies and offices therein surveyed for this project. Submission of information for consideration for inclusion in this Directory was voluntary. The results of the project 
provided this Directory with current descriptive summaries of 506 technical and nontechnical, trade, and other professional organizations; 26 state agencies; and 50 Federal Government agencies that met the criteria for inclusion. The survey forms varied slightly depending on the type of organization surveycd. For the associations, the form requested information on the scope of the association's activities; the percentage of its standardization program to the total program; the names of the groups within the association that administer the standardization activities; the association's participation in international programs; the involvement of the association with the Federal Government; the association's certification program activities; the total number of current standards issued and their titles; the active standards committees and new projects under consideration; the promotional methods for the standards; and the former names of the association.

The state inquiry differed in that it requested the commencement date of the standardization program. An attempt was also made to determine whether the state had a standardization program other than that for purchasing. The Federal Government inquiry dif. fered in that it requested the legislative authority for the agency's standardization programs. Finally, a follow-up letter was sent to all organizations that did not respond to the original inquiry.

\section{Explanation of the Sections}

The section entitled Associations (sec. 2) consists primarily of trade and professional organizations related to industry and commerce; however, other professional groups meeting the criteria of this Directory have been listed.

These include: groups dedicated to a cause such as protection of the environment; service-oriented organizations; pet clubs and animal laboratories; barber and beautician groups; organizations that certify professional individuals, institutions, companies or laboratories; and sports and recreation organizations.

The survey did not uncover any standards-writing consumer groups. However, included are professional groups that write standards for consumer products and the consumer organizations that assist in the development of these standards.

Care was taken to screen the organizations for assurance that actual standardization efforts existed and that the word "standards" was not used merely in an ethical (code of conduct) sense of the word.

Most of the organizations included are nonprofit. There was no attempt to survey independent testing laboratories concerned with standardization since there are special publications devoted to the subject; however, a few do appear in the Directory.
The section entitled State Governments (sec. 3) includes all states that responded affirmatively to the survey. Almost all of the summary entries in that section pertain to purchasing offices. Some states are in the stage of developing standards activities and a few do not yet have any program. The summaries are indexed under the name of the state, followed by its legal form of address, whether state or commonwealth.

The section entitled Federal Government (sec. 4) contains information on all the Government agencies that responded affirmatively to the survey. They include the agencies which are involved with mandatory standardization activities as well as voluntary. Unless they are independent agencies, offices are in alphabetical order under major department and then agency; for example, Commerce, Department of, National Bureau of Standards, Office of Engineering Standards Services. Committees and conferences with Government agency sponsors or secretariats, regardless of their legislative authority, are listed in alphabetical order by their exact name, followed by the name of the sponsor or secretariat of the committee, i.e., Interdepartmental Screw Thread Committee, National Bureau of Standards.

\section{Use of Indexes}

The indexes are an important and integral key to the use of this Directory. Since the organizations are arranged in alphabetical order by exact name in their respective sections, a name in its entirety does not appear in the Subject Index (sec. 5.2). Instead, key words extracted from the names of the organizations appear in the Subject Index as well as other key words taken from the summaries. Exceptions to this are the names of subordinate or constituent societies, institutes and bureaus of a listed association, and the state and Federal Government agencies (Federal Government offices are by key words only). It is suggested that the reader consult the Subject Heading Areas listing (sec. 5.1).

Organizations which are not included in this Directory are asked to send information on their standardization activities to the National Bureau of Standards, Standards Information Services (SIS). SIS can thus be kept abreast of current information and continue to serve as the national source of information and referral for standardization activities in the United States. A request is also made to organizations already included to keep SIS informed of organizational name and address changes; and continue to send current copies of standards for the SIS collection to the:

Standards Information Services

National Bureau of Standards

Building 225, Room B162

Washington, D.C. 20234 


\section{Associations}

\section{ABRASIVE GRAIN ASSOCIATION, 2130 Keith Building, Cleveland, Ohio 44115}

This organization was founded in the early thirties and its members include manufacturers of natural and manufactured abrasives, i.e., silicon carbide, aluminum oxide, corundum, emery, garnet, etc. The membership is national in scope.

Its standardization activities represent approximately 50 percent of its total program. These activities are administered by the Standards Committee and several subcommittees operating thereunder. It participates in international standardization work cooperating with the International Organization for Standardization (ISO) and the Federation of European Producers of Abrasives (FEPA). It cooperates with various Federal agencies such as the U.S. Department of the Navy. No certification programs are in existence nor being contemplated.

The association has published nine standards through the American National Standards Institute. These are:

B74.4-1964 (R1971) Bulk Density of Abrasive Grains, Test for

B74.5-1964 (R1971) Capillarity of Abrasive Grains, Test for

B74.6-1964 (R1971) Sampling of Abrasive Grains, Procedure for

B74.8-1965 (R1971) Friability of Abrasive Grain, Ball Mill Test for

B74.10-1972 Abrasive Microgrits, Grading of

B74.11-1967 Tumbling Chip Abrasives, Specification for

B74.12-1968 Checking the Size of Abrasive Grain for Grinding Wheels, Polishing and General Industrial Uses

B74.14-1971 Chemical Analysis of Aluminum Oxide Abrasive Grain and Abrasive Crude, Methods of B74.15-1971 Chemical Analysis of Silicon Carbide Abrasive Grain and Abrasive Crude, Methods of

These industry standards are promoted by member companies and the association office, and in the latter case, as new standards are issued, announcements are sent to the trade press advising industry of their availability.

\section{ACCREDITING BUREAU OF MEDICAL LABORATORY SCHOOLS, Oak Manor Offices, 3038 West Lexington, Elkhart, Indiana 46514}

The Accrediting Bureau of Medical Laboratory Schools established in 1964 is an independent accrediting agency of the American Medical Technologists. Its primary objectives are to serve as a nationally recog- nized accrediting agency of schools teaching medical laboratory technician and medical assistant ducation programs below the baccalaureate degree lev (Junior and Community College through the private sector), to establish criteria and standards for the administration and operation of medical laboratory and medical assistant schools, to enhance the profession through the improvement of schools, courses and quality of graduates, to provide sound business and ethical standards in the field of medical laboratory technician and medical assistant education and, finally, to maintain standards consistent with the philosophies and bestknown practices of other educational accrediting agencies.

The Accrediting Bureau of Medical Laboratory Schools is the agency recognized by the U.S. Office of Education to accredit medical laboratory technician education programs below the baccalaureate degree level and it, at the present time, has a petition pending before the U.S. Office of Education for an expansion of its scope to include recognition in the medical assistant education area.

All decisions relative to accreditation of school programs are made by nine commissioners who are selected in the following manner: three by the accredited schools, three by the American Medical Technologists and three by the Bureau Commissioners.

Accrediting manuals which list the criteria and standards for evaluation by the Accrediting Bureau are available upon request as are training guides, brochures and documents relative to the accrediting process.

\section{ACOUSTICAL AND BOARD \\ PRODUCTS ASSOCIATION, 205 West Touhy Avenue, Park Ridge, Illinois 60068}

This is an association of manufacturers of fiberboard sheathings, sound deadening board; ceiling tile and lay-in panels; and mineral and nonwood ceiling tile and lay-in panels.

The association began operations on January 1, 1969 and assumed many functions of the former Acoustical Materials Association and Insulation Board Institute. The association and its members are concerned with combating noise pollution and providing protection against excessive heat and cold in buildings.

AIMA sponsors a U.S. Department of Commerce Voluntary Product Standard for Insulation Board PS 57-73, as well as American Society for Testing and Materials (ASTM) standards and test methods-i.e., C208 and C209 for insulation board. In addition the association issues product and application specifications (Tech Specs.) for many industry products. The AlMA bulletin, Performance Data for Architectural Acoustical Materials, is used by architects and specifiers involved in ceilings for commercial building. This publication also covers fire-rated floor ceiling assemblies.

AIMA actively participates in ASTM; American Society of Heating, Refrigerating and Air-Conditioning 
Engineers (ASHRAE) and other technical organizations in the development of standards and test procedures.

Formed by merger of: Acoustical Materials Association (founded 1933) and Insulation Board Institute (founded 1932).

\section{ACOUSTICAL SOCIETY OF AMERICA, 335 East 45th Street, New York, New York 10017}

Since 1932, this society has sponsored sectional committees of the American National Standards Institute for the purpose of preparing standards in the broad field of acoustics.

In 1969, the Acoustical Society formed a secretariat to administer the three committees of the American National Standards lnstitute concerned with domestic and international standardization activities in acoustics; nationally, to foster development of American National Standards and, internationally, to act as technical advisory groups for the International Organization for Standardization, ISO/TC 43 Acoustics, ISO/ TC 108 Mechanical Vibration and Shock, and International Electrotechnical Commission, IEC/TC 29, Electroacoustics. The three committees are: (1) Acoustics-standards, specifications, methods of measurement and test, and terminology, in the fields of physical acoustics, including noise, architectural acoustics, electroacoustics, sonics and ultrasonics, and underwater sound, but excluding those aspects which pertain to safety, tolerance and comfort. (2) Mechanical Shock and Vibration (for which the American Society of Mechanical Engineers is cosecretariat) standards, specifications, methods of measurement and test, and terminology, in the fields of mechanical shock and vibration, but excluding those aspects which pertain to biological safety, tolerance and comfort. (3) Bioacoustics - standards, specifications, methods of measurement and test, and terminology, in the fields of psychological and physiological acoustics, including aspects of general acoustics, noise and shock and vibration which pertain to biological safety, tolerance and comfort.

Standards developed by these three committees are listed in the catalog of the American National Stand. ards Institute, which is responsible for this publication. When new standards become available, they are publicized in the Journal of the Acoustical Society of America. Current activities center on noise, particularly on community noise, and hearing conservation criteria.

\section{ADHESIVE AND SEALANT COUNCIL, 1410 Higgins Road, Park Ridge, Illinois 60068}

The purpose and object of the council is to promote, encourage, and advance the uses of products of the industry. In the field of specification writing and endorsement, the council achieves this purpose through its Technical Committee. This committee is charged with the establishment of practical and realistic product performance and end use standards for adhesives and sealants sold primarily for resale to users who lack testing facilities and who do not purchase to specifications, but are desirous of procuring to a consistent and known quality standard.

The council was founded in 1957. As a matter of policy, the council serves its industry through cooperative activities of national and international standardization bodies, and/or other industry trade groups. The council devotes 25 percent of the total program to its standardization activities. Currently the council is cooperating with the aluminum industry in developing a performance standard for backerboard adhesives.

Formerly: Rubber and Plastic Adhesives and Sealant Manufacturers' Council.

\section{AEROSPACE INDUSTRIES ASSOCIATION, 1725 DeSales Street NW., Washington, D.C. 20036}

The Aerospace Industries Association of America, Inc. (AIA) is the national trade association of companies in the United States presently engaged in the research, development, and manufacture of aerospace and aircraft vehicles and equipment. AIA was founded in 1919 as the Aeronautical Chamber of Commerce. Current membership is 50 manufacturing companies. AIA's primary function is to provide an effective twoway communication link between the member companies and their customers, including Government agencies.

The standardization activity comprises approximately 10 percent of the total AIA program, and is administered principally through the Technical Specifications Division of the Aerospace Technical Council, and its Standards Management Policy Group. The National Aerospace Standards Committee (NASC) is responsible for the development, maintenance, and promotion of the AIA standards document series of National Aerospace Standards (NAS). Standards in the NAS series are also developed under the Manufacturing Committee (machine tools) and the Transport Airworthiness Requirements Committee (transport and cargo).

AIA, through a number of its technical committees, participates actively in the international standardization activities of the International Organization for Standardization, ISO/TC20 Committee on Aircraft and Space Vehicles.

The standardization activities of the association are predicted on a base policy of effectively fulfilling industry requirements without duplication of Government agency or other industrial programs. A close working alliance exists with the Department of Defense, National Aeronautics and Space Administration, and other Government agencies and industry organizations to insure that AIA standards are not duplicative of existing Government or industry standards, and will meet all the necessary requirements of Government and industry. This liaison involves the direct participation of these agency representatives in 
the meetings and activities of the National Aerospace Standards Committee. Similarly, the NASC as well as other AIA committees, review and make recommendations on Government standards documents. Government agencies participating in the NASC program include: Defense Supply Agency, Defense Item Entry Control Office, Defense Electronics Supply Center, Defense Industrial Supply Center, Air Force Systems Command, Air Force Logistics Command, Aeronautical Systems Division (AFSC), Army Aviation Systems Command, Army Missile Command, Army Weapons Command, Naval Air Systems Command, Naval Air Engineering Center, and the Marshall Space Flight Center (NASA).

National Aerospace Standards are nationally recognized and used by manufacturers, airlines and maintenance facilities for civil transport and general aviation aircraft, and are generally accepted by military and Government agencies in lieu of developing new Government standards. More than 1200 NAS documents have been published since 1946, with approximately 840 of these currently active.

National Aerospace Standards are published and distributed through the documentation services of: National Standards Association, Inc., 1321 Fourteenth Street NW., Washington, D.C. 20005.

Formerly: Aeronautical Chamber of Commerce of America (1945); Aircraft Industries Association of America (1959).

\section{AIR-CONDITIONING AND REFRIGERATION INSTITUTE, 1815 North Fort Myer Drive, Arlington, Virginia 22209}

The institute, known in the industry as ARI, is a trade association of manufacturers of air-conditioning, heating, and commercial and industrial refrigeration equipment and components, but does not include within its scope such appliances as room air-conditioners, household freezers and refrigerators, portable humidifiers and dehumidifiers, etc.

It was formed in May 1953 by a merger of the Refrigeration Equipment Manufacturers' Association (REMA) and the Air-Conditioning and Refrigeration Machinery Association (ACRMA). In 1965 its scope was further enlarged when manufacturer members of the National Warm Air Heating and Air-Conditioning Association voted to transfer their memberships to ARI. During this year the Air Filter Institute also disbanded and most of its members became members of the Air Filters Section of ARI.

The standardization activities of ARI fall into the following general classification: Equipment standards - standards pertaining to the physical and operating characteristics of items and equipment. Testing standards-standard procedures for testing equipment in order to determine its performance and operating characteristics. Rating standards - standards containing provisions for converting data into general statements of capacity and performance which can be applied to a series of production items. Application standards- standards specifying acceptable installation criteria, including initial selection of equipment. Safety standards - standards containing provisions intended to safeguard life, health and property.

At the present time, ARI has issued standards covering the following types of equipment and components: unitary air-conditioning equipment and heat pumps, air-cooling and air-heating coils, forced-circulation, free-delivery air-coolers for refrigeration, central station air-handling units, room air-induction units, refrigerant condensers, refrigerant-cooled liquid coolers, liquid receivers, ammonia compressors and compressor units, refrigerant compressor and condensing units, centrifugal liquid-chilling packages, reciprocating chilling packages, liquid line driers, self-contained mechanically-refrigerated drinking water coolers, transport refrigeration units, and sound rating and application standards.

In addition to equipment standards, ARI has published a number of application standards, including cooling load estimate forms for various applications, and a standard for application, installation and servicing of unitary air-conditioning systems.

ARI also administers many certification programs for certain types of equipment, and these programs involve the use of an ARI seal of approval of equipment manufactured and rated in accordance with the applicable ARI standards, following validation by an independent laboratory.

\section{AIR DIFFUSION COUNCIL, 435 North Michigan Avenue, Chicago, Illinois 60611}

This is a trade association formed in 1961, whose members are manufacturers of grilles, registers, ceiling diffusers, high velocity terminal control devices, and flexible ducts used in conjunction with air-conditioning systems in commercial construction. Four test codes have been developed through Air Diffusion Council (ADC) action.

The major standardization activity of the council has been the promulgation of a code to standardize the testing and rating of products manufactured by the industry to establish a basis of performance characteristics. Under the provisions of this code, ADC Equipment Test Code 1062R3, testing is performed in company laboratories which have been previously certified as meeting minimum industry standards in compliance with the code. The test data thus developed, utilizing the test procedure established by the code, may be submitted to the council for certification under the code.

A second code developed by the council for the purpose of testing sound transmission through air-conditioning plenum systems is entitled, Measurement of Room-to-Room Sound Transmission (AD.63). This code establishes test procedures for the testing of sound transmission through plenum systems by the two room method.

A third code standardizes testing procedures for the testing of heat rejecting characteristics in troffer light 
fixtures and is entitled Air Diffusing Troffer Heat Removal Test Code TC 66R1.

A fourth code establishes the requirements for the determination and presentation of air friction loss, leakage, and sound data for flexible air ducting used as a means of conveying conditioned air in heating and air-conditioning systems. This code is entitled Flexible Air Duct Test Code (FD-72).

\section{AIR MOVING AND CONDITIONING ASSOCIATION,}

30 West University Drive, Arlington Heights, Illinois 60004

This association was formed in 1955 by a merger of several organizations, including the National Association of Fan Manufacturers, the Power Fan Manufacturers' Association and the Industrial Unit Heater Association. Its membership comprises some 70 companies in the U.S. and Canada which manufacture air moving and conditioning devices.

The main technical effort of the association is aimed at the development of accurate and reliable testing procedures which are adopted as standard test codes and are used as a basis for rating the industry's products. Codes have been adopted to measure the performance of all air moving devices and steam and hot water unit heaters, and the sound power of this equipment. The codes are periodically reviewed and revised when further knowledge and experience show that this is necessary.

Other technical standards cover a wide variety of subjects including nomenclature and arrangements, standard sizes, spark resistant construction, operating limits for centrifugal fans, and flue gas and air densities.

As a service to users of the industry's products, AMCA publishes information on the application of various types of equipment. Subjects covered include the installation and maintenance of unit heaters and the application of sound power and sound loudness ratings.

Products which have been performance rated in accordance with AMCA standards are eligible to be licensed under the Certified Ratings Program and are identified by the display of the AMCA Certified Ratings Seal. The certification program includes provisions for approval of test laboratories, checking of published ratings and a recheck procedure to insure continuing product performance.

\section{AIR POLLUTION CONTROL ASSOCIATION, 4400 Fifth Avenue, Pittshurgh, Pennsylvania 15213}

APCA is the only voluntary, cooperative, nonprofit organization devoted solely to air pollution control. It is an expanding organization both in number, more than 6600 members and 20 local sections, and in influence.

The growing membership is composed of engineers, scientists, enforcement officials, industrial organiza- tions, manufacturers of control equipment and instrumentation, scientific and educational institutions, and consultants. It is through this variety of disciplines in the membership that the technical proficiency and forum capability of the 66-year old association is maintained, thereby making APCA a prime resource in the field of air pollution control.

The Air Pollution Control Association contributes to the development of standards through representation in the following committees of standards-setting organizations: American National Standards Committee Z-21; Subcommittee on Standards for Domestic GasFired Incinerators; American National Standards Z-105; Air Cleaning Equipment Committee; American National Standards Z.91; Committee of Installation Standards for Oil Burners and Oil Burning Equipment; American National Standards Z-228; Incinerator Committee; International Organization for Standardization; Technical Committee ISO/TC 146; Air Purity and Intersociety Committee (Manual of Methods of Ambient Air Sampling Analysis).

To summarize, APCA is a technical society, educational in nature and international in scope with the capability to consider air pollution scientifically, not politically, and to take effective action based on fact not conjecture. In 1974, for example, APCA will sponsor or will be directly involved with over 100 separate technical meetings throughout the States and Canada at the local, national and international levels.

\section{AIR TRANSPORT ASSOCIATION OF AMERICA, \\ 1709 New York Avenue NW., Washington, D.C. 20006}

This association, founded in 1936, is concerned with the following areas of standardization: (a) Engineering and maintenance-The association has published ATA Spec 100, the industry standard specification for the preparation of aircraft manuals by manufacturers for the use of airline operators; and ATA Spec 101, the industry standard specification for the preparation of ground equipment manuals by manufacturers for the use of airline operators. (b) Supply - The association publishes ATA Spec 200, the industry integrated data processing standard specification for the procurement of aircraft parts; and ATA Spec 300, the industry standard for packaging of parts and components of aircraft and aircraft systems. (c) Communications-The ATA and the International Air Transport Association (IATA) jointly prepare and issue an ATA/IATA Interline Communications Manual prescribing standard methods for interline communication of record communications and data. Included are standards covering message composition (including machinable texts), message handling procedures for stations and switching centers, standard addressing using either the ATA/IATA five or seven bit code, asynchronous and synchronous link control procedures, and additional characteristics and procedures for network operation. (d) Airborne 
navigation and communications equipment-The airline industry, through the Airlines Electronics Engineering Committee of Aeronautical Radio, Inc. (ARINC) develops standard characteristics, including case sizes and wiring for much of the radio communications and navigation and other electronics equipment installed in airline aircraft. The Air Transport Association guides and advises ARINC in the preparation of these ARINC Specs.

\section{ALUMINA CERAMIC MANUFACTURERS' ASSOCIATION, 331 Madison Avenue, New York, New York 10017}

The Alumina Ceramic Manufacturers' Association (ACMA) is a group of manufacturers engaged in the production of high quality impcrvious. high alumina ceramics for a wide variety of dielectric, mechanical, chemical and abrasion-resistant applications.

Through its Technical Committee, standards have been developed to help the consumer select the alumina ceramic best suitcd for his purpose. The standards include sections on properties, test procedures, design criteria and recommendations for the use of these materials. The association also has available other ACMA test procedures. Copies may be obtained by writing to the secretary.

\section{ALUMINUM ASSOCIATION, 750 Third Avenue, New York, New York 10017}

The Aluminum Association, founded November 1933, serves the public as a source of nonconmercial, industrywide information on aluminum and the aluminum industry. Its membership embraces most producers of primary ingot, most producers of sheet and plate and leading extruders, foundries, sccondary smelters, forging firms and producers of aluminum electrical conductor. Approximately 95 percent of primary aluminum shipments and 82 percent of semifabricated aluminum shipments are accounted for by association member companies.

Its functions include developing, publishing and distributing technical data, collecting and publishing industry statistics, and conducting school programs and industry seminars.

The association currently lists over 45 titles including the following technical publications: Aluminum Standards and Data (published biennially), Drafting Standards-Aluminum Extruded and Tubular Products, Designation System for Aluminum Finishes and Specifications for Aluminum Structures.

Aluminum Association standards are the basis for the majority of government, American Society for Testing and Materials, company and other specifications for aluminum and aluminum alloy products. The association also publishes, in cooperation with the European Primary Aluminum Association and the
American Society for Metals, a monthly abstract journal of the world's technical literature on aluminum.

\section{AMATEUR ATHLETIC UNION OF THE UNITED STATES, INC., 3400 West 86th Street, Indianapolis, Indiana $\mathbf{4 6 2 6 8}$}

The Amateur Athletic Union of the United States was founded in 1888. Among the several objects of this organization are the establishment and maintenance throughout the United States of a uniform dcfinition of amateurism, and uniform rules for the administration and conduct of all athletic sports within its jurisdiction, the institution, regulation, and awarding of amateur athletic championships of the United States in the sports under its jurisdiction and the institution of a bureau of records for the sports of swimming, track and field, and weightlifting.

This organization is charged with the duties and responsibilities of administering, as the sole United States member of world governing sports organizations (and as such acts as the governing body for international purposes in these sports), the following: basketball, bobsled, boxing, handball, judo, karate, luge, swimming and diving, track and field, water polo, weightlifting, and wrestling (both freestyle and greco-roman). The union conducts championships of the United States in these sports and, as well, national programs in baton twirling, horseshoe pitching, volleyball and gymnastics. The AAU is divided into 58 district associations encompassing all 50 States and each district association annually conducts championships in several AAU sports.

The establishment of standard definitions of rules for the government of athletic sports are formulated by the Board of Governors, which is elected each year and is representative of the active and allied member associations of the union. The AAU is comprised of such allied members as the National Association of Intercollegiate Athletics, comprising nearly $600 \mathrm{col}$ leges and universities in the United States, the Young Men's Christian Association (YMCA), Young Men's Hebrew Association (YMHA), National Jewish Welfare Board and others. Besides the adoption of standard contest rules for various sports under its jurisdiction, the union also fixes standards on dimensions, weights, material, and shapes of the various implements, balls, etc. entering into athletic contests.

The Amateur Athletic Union also conducts annually Junior Olympic competition in 14 sports for athletes ages 6 to 18. Such competition annually provides millions of young athletes the opportunity and exposure to compete in healthy sporting events. Moreover, the AAU also conducts a program of National Physical Fitness testing which in 1973 reached over 6 million youngsters. In providing age group competition across the board, the AAU conducts Masters competitions for athletes 25 and older (in swimming) and 40 and older (in track and field) across the nation with national championships in these events. 
AMERICAN AMATEUR BASEBALL CONGRESS, INC.,

212 Plaza Building,

2855 West Market Street, P.O. Box 5332,

Akron, Ohio 44313

The American Amateur Baseball Congress, Inc., founded in 1935, is a nonprofit, tax-exempt organization, incorporated as such in Ohio and Michigan. Its objcctives are to enlarge and advance the scope of amateur baseball by stimulating interest and competition; to provide a sound, experienced organization to assist at local, state, regional and national levels to obtain the maximum health and citizenship values; and to provide standard rules of play.

It is national in scope, embracing 46 states in the United States; plus two Canadian provinces and Puerto Rico.

It administers amateur baseball programs in five age divisions: Stan Musial Division (unlimited age), Connie Mack Division (18 and under), Mickey Mantle Division (16 and under), Sandy Koufax Division (14 and under) and Pee Wee Reese Division (12 and under).

It provides national competition, including postseason tournaments, at state, regional and national levels; leading to national champions in each of its five age divisions.

Formerly: American Baseball Congress (1955).

\section{AMERICAN ASSOCIATION FOR HEALTH, PHYSICAL EDUCATION, AND RECREATION, \\ 1201 Sixteenth Street NW. Washington, D.C. 20036}

The American Association for Health, Physical Education, and Recreation (AAHPER), established in 1885 , is a voluntary professional organization for education in these related fields. Its purpose is the improvement of education through such professional services as consultation, periodicals and special publications, leadership development, determination of standards, public information and research.

Standards comprise approximately 15 percent of the total program and are established by the following substructures: Dance Division, Division of Girls and Women's Sports, Division of Men's Athletics, Physical Education Division, and the General Division. The International Relations Council participates in an international book program and maintains a binational commission with Mexico.

Guidelines for Professional Preparation for Personnel Involved in Physical Education and Recreation for Handicapped was prepared with funds from the Department of Health, Education and Welfare. AAHPER has more than 30 books and pamphlets that deal with guidelines and standards. The standards offered by AAHPER are national in scope. They are promoted through the education of teachers and professionals in allied fields.
Ccrtification programs are implemented at the state level through activities of AAHPER members. Professional preparation programs in colleges are developed using AAHPER standards.

\section{AMERICAN ASSOCIATION FOR REIABILITATION THERAPY, INC., (Registry of Medical Rehalilitation Therapists and Specialists), Box No. 93. \\ North Little Rock, Arkansas 72116}

The American Association for Rehabilitation Therapy (AART), founded in 1950, is a national organization with rehabilitation personnel from private, state, and Federal agencies and institutions comprising its membership. These include: therapists, therapy assistants, coordinators or specialists, counselors, administrators, nurses, psychologists, social workers, and physicians. It is the only national organization for the certification of Medical Rehabilitation Therapists and a major representative of the field in certifying medical rehabilitation coordinators.

The organization devotes 15 percent of its total program to their standardization activities. The Registry Council administers the standardization activities. AART is involved with the Federal Government in standardization activities in an advisory and liaison capacity. Current relationships are with the Department of Health, Education and Welfare and the Veterans Administration. Directory, No. 14, 1973, Registry of Medical Rehabilitation Therapists and Specialists (Coordinators), contains a list of the eight current standards. Certification programs activities are university-affiliated training programs; stratified training of therapists and assistants.

\section{AMERICAN ASSOCIATION OF ADVERTISING AGENCIES/ MAGAZINE PUBLISHERS ASSOCIATION, 200 Park Avenue, \\ New York, New York, 10017; 575 Lexington Avenue, New York, New York 10022}

Since its formation in 1948, the AAAA/MPA Joint Committee on Advertising Reproduction has enlisted the cooperation of other industry organizations, and as a result, five standards for the graphic arts industry dealing with magazine publication have been issued, periodically revised, and are in use today. They are as follows: (1) Recommended Standard Specifications for Advertising Reproduction Material in Magazine Letterpress Wet Printing, Joint Committee Report No. 5 dated June 1967; (2) Standard Color Control Bars, approved by the American Photoengravers Association, October 1959, and recommended by the American Association of Advertising Agencies, Magazine Publishers Association, and Printing Industries of America; and (3) AAAA/MPA Standard 4-Color Process Proofing Inks, issued by the National Association of Printing Ink Makers, September 1964, and 
recommended and approved by the American Association of Advertising Agencies, Magazine Publishers Association, American Business Press, American Photoengravers Association, and Printing Industries of America; (4) Production Operating Communication Standards for Magazine Paper Mills, Printers and Publishers issued October 1967 recommended and endorsed by Printing Paper Division, American Paper Institute, Technical Association of the Pulp and Paper Industry, Printing Industries of America, Inc., Gravure Technical Association, Magazine Publishers Association, Inc.; (5) Recommended Standard Specifications for Advertising Production Material for Magazine Web Offset Printing revised December 1972 issued by AAAA/MPA/ABP.

These standards have the common purpose of improving the reproduction of advertisements in magazines, following the Joint Committee's stated objective: "The improvement of the physical presentation of advertising in magazines."

\section{AMERICAN ASSOCIATION OF BIOANALYSTS,}

411 North Seventh Street, 805 Ambassador Building, St. Louis, Missouri 63101

The American Association of Bioanalysts (AAB) was founded in 1954 with the merger of the National Association of Clinical Laboratories and American Bioanalysts' Association. It is an association of bioanalyst laboratory directors and is active in certification and accreditation of bioanalyst laboratory directors, laboratory supervisors and clinical laboratories as a sponsoring organization of the American Board of Bioanalysis.

AAB maintains a national program of external quality control known as The Proficiency Testing Service, one of the programs in which independent laboratories, hospitals and physician office laboratories must participate as a condition for Medicare approval. In the Proficiency Testing Service AAB is involved in the developing, handling, and shipping of various materials, and is required to examine such materials for stability. Included also are control and standards for use in the many clinical laboratory disciplines. $A A B$ 's program is under the guidance of the Board of Scientific Advisers.

\section{AMERICAN ASSOCIATION OF CEREAL CHEMISTS, 3340 Pilot Knob Road, St. Paul, Minnesota 55121}

The objectives of this association, founded in 1915, are to advance and encourage scientific and technical research on cereal grains and related materials, development and standardization of analytical methods used in cereal chemistry and technology, and scientific cooperation among all workers in the field of cereal science. The association's Approved Methods Committee supervises and coordinates the work of technical committees on the standardization of analytical methods, laboratory baking procedures, testing methods and apparatus for flours and doughs, flour specifications, and sanitation methods. Results of work by the technical committees is embodied in the association's publication Approved Methods of the AACC, now in looseleaf format with replacements and additions appearing annually. This publication is a two-volume, 872-page laboratory manual which includes 330 methods, over 90 pages of reference tables, and 45 full-color photos of insect fragments in its Extraneous Matter section. To maintain uniformity the association cooperates formally with the Association of Official Analytical Chemists, American Oil Chemists' Society, and American Society for Testing and Materials. Active technical committees are listed annually in the journal, Cereal Science Today and in the association's membership directory. Progress on current standardization projects is reported annually in the October issue of Cereal Science Today. The association also offers a National Check Sample Service which allows members to check their analytical techniques and provides a certification program for certified sanitation analysts.

Absorbed: American Society of Milling and Baking Technology (1923).

\section{AMERICAN ASSOCIATION OF CLINICAL CHEMISTS, P.O. Box 15053 , \\ Winston-Salem, North Carolina 27103}

The American Association of Clinical Chemists, founded 1948, is a non-profit organization of professional chemists who specialize in clinical chemistry. Its Standards Committee is a standing committee which carries out background development of standard methodology and materials, amounting to about 10 percent of the total association effort. The Standards Committee collaborates closely with the International Federation of Clinical Chemists, particularly in programs on nomenclature, proteins and enzymes. Close alliance is also maintained with the clinical laboratory programs of the U.S. National Bureau of Standards in developing specifications for new standard reference materials, and with the Center for Disease Control and the Food and Drug Administration in evaluating methods and their performance in the field. Topics under active consideration by subcommittees are proteins and albumin, enzymes, spectophotometry, nomenclature, and referee methods for glucose, lead and uric acid. Methods and recommendations are published in the journal, Clinical Chemistry or in the book series Standard Methods in Clinical Chemistry. 


\section{AMERICAN ASSOCIATION OF MEDICAL MILK COMMISSIONS, INC. AND CERTIFIED MIL PRODUCERS OF AMERICA, INC.,}

2266 North Prospeci Avenue, Milwaukee, Wisconsin $\mathbf{5 3 2 0 2}$

The American Association of Medical Milk Commissions, Inc. and Certified Milk Producers of America, Inc. comprise a national body consisting of physicians and owners of certificd milk dairies and committee membcrs serving without pay for development of the cleanest, most nutritious milk to be found anywhere.

Certificd Milk originated in 1893 by the medical profession and by 1909 the Medical Milk Commissions functioned in many parts of the country. At that time a Manual of Mcthods and Standards was in use. This manual is revised annually and copies are in the libraries of every medical school in the United States. Permanent committees control medical examination of employees, chemical standards, bacteriological standards, vcterinary inspections and protection against tuberculosis.

Certified Milk, thc name copyrighted and trademarked, may not be used by any dairy not certified as producing under the stringent rules of methods and standards. Certification has familiarized state and municipal health officials with bacteriological standards and has continuously raised the quality of all milk on the market, cven though certified dairies comprise only 6 pcrcent of dairy products sold.

Certified raw milk and milk products, as well as pasteurized, must be the product of healthy animals (both cows and goats), fed carefully controlled forages in which natural Vitamins $A$ and $C$ and trace minerals are contained and supplemented whenever necessary by seasonal change.

\section{AMERICAN ASSOCIATION OF MOTOR VEHICLE ADMINISTRATORS, 1828 L Street NW., Suite 500 , Washington, D.C. 20036}

The AAMVA, founded in 1933, is a voluntary, nomprofit organization of state and provincial officials responsible for the administration and enforcement of motor vehicle and traffic laws in the United States and Canada. Membership includes all 50 States, the District of Columbia, Puerto Rico, the 10 Canadian provinces, and the Northwest Yukon Tcrritories. Among AAMVA's basic objectives are: to promote uniform laws and regulations for motor vehicle administration, traffic law enforcement, and highway safety; and to promote standardization and uniform enforcemcnt of these laws.

Under the general direction of the Executive Director, AAMVA works principally with the American National Standards Institute (ANSI) and the Society of Automotive Engineers (SAE) in standards development. The subunits of AAMVA that are responsible for the development of specific standards are as follows: (1) Safety equipment and product safety-The
AAMVA Equipment Approval Division; (2) Vehicle records and procedures-Vehicle Services Division; (3) Driver licensing procedures-Driver License Division. In addition to AAMVA's standards development work, the Equipment Approval Division also applies many equipment standards in its certification program. The AAMVA Equipment Approval Program certifies after market safety equipment commonly utilized in the operation of a motor vehicle. AAMVA does not issue standards; all of its programs are coordinated through the ANSI, SAE, or National Highway Traffic Safcty Administration (NHTSA) programs, on a cooperative basis. Approximately 50 to 60 percent of the total program is devoted to standardization activities.

On an international level the AAMVA Vehicle Services Division is involved in the effort by the Inter. national Organization for Standardization (ISO) to develop a system for vehicle identification numbering. The Equipment Approval Program, via its certification and laboratory accreditation programs, is involved with foreign auto and equipment manufacturers and foreign testing laboratories. Other standardization activities are projects that are coordinated with the Federal Government. An AAMVA Driver Services Division Task Force developed the system which the National Highway Traffic Safety Administration incorporated into the Federal Highway Safety Program Standard on Driver Licensing for developing a Classified Driver Licensing System. Both the Vehicle Services Division and the Equipment Approval Division are in close and constant contact with the appropriate elements of NHTSA in their work in standards development.

The following is a list of active standards committees and new projects under consideration: Society of Automotive Engineers (SAE); Vehicle Identification Number (VIN) Committee; American National Standards Committee D-19; for the development of model registration and certificate of ownership procedures; American National Standards Committee D.20, for the development of a state-oriented model motorist data base; International Organization for Standardization (ISO) Technical Committee 22, on road vehicles; Subcommittee 20, on identification of vehicles; American National Standards Committee D.7, on motor vehicle inspection procedures; and the American National Standards Committee D-18, on training of motor vehicle inspection mechanics.

Note: AAMVA is either the sponsor or cosponsor of the American National Standards Committees D-7, D.18, D.19, and D-20 projects. It is a principal participant in the SAE VIN Committee's activities, and a member of the ISO TC 22/SC20 project.

\section{AMERICAN ASSOCIATION OF NURSER YMEN, INCORPORATED, 230 Southern Building, Washington, D.C. 20005}

The association was founded in 1875 , to enable nurserymen to jointly work on those projects and 
activities which would foster the general welfare of the industry and to improve their ability to meet the desires of their customers.

Through its Horticultural Standards Committee, this association has continued to develop grades and standards for the use of nurserymen, landscape architects, landscape contractors, governmental agencies and others preparing lists and specifications for trading in trees, shrubs, roses, vines, fruit trees, small fruit, bulbs, tubers and forest tree seedlings. These became an official national standard in 1947 when they were approved by the then American Standards Association, currently American National Standards Institute. The current edition is the Z60.1-1973. The standards con. tain height, caliper, root size, root ball, container size and various other standardized means of describing nursery plants.

\section{THE AMERICAN ASSOCIATION OF PETROLEUM GEOLOGISTS, 1444 South Boulder, Tulsa, Oklahoma 74119}

The American Association of Petroleum Geologists was founded in 1917. Two association committees are involved in standardization operations. The Stratigraphic Correlations Committee has developed and published a Code of Stratigraphic Nomenclature, 1961, revised 1970, which has been adopted by the American Commission on Stratigraphic Nomenclature. The alphanumeric code was designed for both human and computer sensibility. The Committee on Statistics of Drilling, working jointly with the American Petroleum Institute and various governmental agencies has developed and put into use a standardized form for the recording of data from wells drilled for oil or gas. The form is formatted for keypunching to three 80-column computer cards. In addition, the CSD has participated in the development of standard definitions for the petroleum industry.

Formerly: Southwest Association of Petroleum Geologists (1917).

\section{THE AMERICAN ASSOCIATION OF POISON CONTROL CENTERS, Childrens Memorial Hospital, 44th and Dewey Avenue, Omaha, Nebraska 68105}

The American Association of Poison Control Centers was founded in 1957. In pursuance of its main purposes of promoting and encouraging the develop. ment of improved methods for the prevention and treatment of acute poisoning, and of furthering the exchange of information about such activities among its members, the association has established certain committees.

The Committee on Educational Activities has been active in efforts to develop materials that will be of value to poison control and information centers in educating the lay public about the hazards of, and the prevention of acute poisoning in and about the home.
It is anticipated that the Committee on Public Education will later devote its attention to developing aids for the training of professional personnel in the prevention and treatment of acute poisoning.

The Committee on Operation of Centers has prepared standard recommended practices for poison control and poison information centers. At the third annual meeting of the American Association of Poison Control Centers, these were accepted as tentative standard recommended practices for the establishment and operation of properly qualified centers. Realizing that standards must be as specific as possible, the committee felt that certain recommendations should be made which fell outside the strict definition of "standards," but nevertheless were important in the overall poison control program. Accordingly, they termed the standard recommended practices as "recommendations." These are periodically revised. Copies of these standard recommended practices have been distributed to members and to state and local health departments.

\section{THE AMERICAN ASSOCIATION OF PSYCHIATRIC SERVICES FOR CHILDREN, 1701 Eighteenth Street NW., Washington, D.C. 20009}

Founded in 1948 as the American Association of Psychiatric Clinics for Children, the American Association of Psychiatric Services for Children's (AAPSC) cur. rent membership consists of 180 child psychiatric serv. ices in all parts of the U.S. that fulfill AAPSC standards of competence. From its inception, AAPSC has provided leadership in defining and maintaining standards of clinical practice, organization of treatment, and specialized training.

To meet AAPSC's professional standards, a child psychiatric facility must provide proof of its continuity of service, together with the training background of its key staff members. The AAPSC membership committee reviews treatment approaches and case histories submitted by the applicant. This is followed by a site visit. Training clinics are similarly evaluated before accreditation. AAPSC provides certificates to member services, to approved training programs in career child psychiatry and child psychology as well as to individ. uals who have been trained in career child psychiatry.

\section{AMERICAN ASSOCIATION OF STATE HIGHWAY AND TRANSPORTATION OFFICIALS,}

341 National Press Building, W ashington, D.C. 20004

Organized in 1914, AASHO's basic purpose is to foster the development, operation and maintenance of our nationwide integrated system of highways. To accomplish this end, AASHO cooperates with other appropriate agencies in considering matters of mutual interest with the other modes of transportation in serving the public need.

The association, through its committee structure, 
works to develop and improve methods of administration, planning, research, design, construction, maintenance and operation of highways; to provide the efficient transportation of persons and goods in support of national goals and objectives. As such, one of the major functions is the development of technical, administrative and operational standards and policies needed to carry out the highway program in the United States.

Committees are broken into two general categories: Standing Committee on Administrative Practices and Standing Committee on Engineering Policies, which report to an Executive Committee and, in turn, to a Policy Committee. Subcommittees under the two standing committees cover such areas as legal affairs; right-of-way; uniform accounting; computer technology; highway planning; public information; urban affairs and socio-economic factors; highway finance policies and planning; personnel development; highway transport; roadway design; bridges and structures; communications and electronic applications for highways; materials; traffic engineering; roadside development; maintenance; construction; secondary roads; Select Committee on Research Activities; Select Committee on Highway Safety; Special Liaison Committee on Environmental Quality; as well as cooperative committee with other major national associations.

These various committees promote and develop the intimate contacts that are essential in (1) keeping their respective specifications, manuals and standards representative of the best current practice, (2) encouraging their adoption and use, and (3) promoting engineering research in their respective fields to obtain factual data and improvements in materials and practices.

\section{AMERICAN ASSOCIATION OF TEXTILE CIIEMISTS AND COLORISTS, AATCC National Headquarters, P.O. Box 12215, Research Triangle Park, North Carolina 22709}

This association (AATCC) was founded in 1921 for the purpose of promoting the increase of knowledge of the application of dyes and chemicals in the textile industry, encouraging in any practical way research work on chemical processes and materials of importance to the textile industry, and establishing for the members channels by which the interchange of professional knowledge among them might be increased.

The membership of the association of approximately 10,000 includes most of the leading textile chemists and colorists in nearly every state and in 50 other countries. Some 300 companies in the textile. chemical and related industries support the association as corporate members.

The association is recognized nationally and internationally for its standard methods of testing dyed and chemically treated fibers and fabrics to measure such performance characteristics as colorfastness to light and washing, crease resistance, shrinkage, wash-and- wear, water resistance, flammability and the many other conditions to which textiles may be subjected.

Practically all of the textile dyes, finishes and many chemicals produced in the United States are controlled and checked by AATCC test methods. These test methods are a major factor in insuring the satisfactory performance of the billions of yards of textiles that find their way across the retail counters and into the hands of the consumer.

AATCC maintains cooperative relationships with many other societies of kindred interests and with departments and agencies of the Federal Government. At the international level, the association participates in the International Organization for Standardization (ISO) and the Pan American Standards Commission (COPANT) in an effort to bring about worldwide uniformity in testing procedures.

The association publishes its journal, Textile Chemists and Colorists, issued monthly. The annual 400 . page Technical Manual contains the association's test methods. With its sister society in England, The Society of Dyers and Colorists, AATCC collaborated in the publication of the third edition of the fivevolume Colour Index.

\section{AMERICAN AUTOMOBILE ASSOCIATION, 1712 G Street NW., W ashington, D.C. 20006}

The AAA was founded in 1902 and developed independently or in cooperation with other organizations, numerous standards and models for motor vehicle legislation in the states and cities, designed to promote the safe and efficient movement of traffic. It developed a Model Safety Responsibility Bill and cooperated actively in the development of the Uniform Vehicle Code and the Model Traffic Ordinance.

It developed a guide as to standards for state legislation on roadside development and control.

The association participated in the development of standards for traffic signs, signals, markings, and islands set forth in a Manual on Uniform Traffic Control Devices.

The association has formulated a model ordinance for municipal regulation of offstreet parking facilities.

The association has developed proposed standards of various types relating to increasing the safety and convenience of pedestrians in traffic.

It has developed detailed methods and various proposed standards for training new drivers.

The AAA has representatives on committees of the following organizations and associations: American Society for Testing and Materials, American National Standards Institute, Highway Research Board, Illuminating Engineering Society, National Safety Council, and the National Committee on Uniform Traffic Laws and Ordinances. A major purpose of most of these committees is to develop standards which pertain to highway safety.

The association has developed, in cooperation with other organizations, standards for the operation of school safety patrols. 
The association cooperates with other organizations in the field of traffic law enforcement, traffic training procedures, etc.

\section{AMERICAN BANKERS' ASSOCIATION, 1120 Connecticut Avenue NW., Washington, D.C. 20036}

American Bankers' Association (ABA) was founded July 20, 1875 to promote the general welfare and usefulness of banks and banking institutions, and to secure uniformity of action, together with the practical benefits to be derived from personal acquaintance, and from the discussion of subjects of importance to the banking and commercial interests of the country; and especially in order to secure the proper consideration of questions regarding the financial and commercial usages, customs and laws which affect the banking interests of the country.

The Standards Department of the association administers the standards activities. The scope of our standards are akin to the scope of the association in that they are pursued to promote the general welfare of the national banking community. The extent to which they are followed nationally is difficult to determine since standards are voluntary. However, the nature of our industry with the interchange necessity makes it a reasonable certainty to assume that the standards published by the association are followed by the U.S. banking industry. ABA's published standards include: (a) Bank Card Standards Manual-outlines physical specifications of a bank card and defines data information and format; (b) MICR-standard for magnetic ink character recognition to enhance processing ad interchange MICR encoded checks. The standard puts parameters on the physical size and weight of checks, and specifies the location, content and signal level of the encoding; (c) Committee on Uniform Security Interchange Procedures-standard numbering system used as the universal identifier of stock certificates; and (d) ABA Routing Number-standardized numbering system used to identify and properly route check and other such negotiable instruments.

The active Standards Committees are: (a) Banking $X 9$ - an American National Standards Committee, for which the association is secretariat, on the Standardization for Facilitating Domestic Banking Operations, Subcommittees 1-Bank Data Interchange, and 2Bank Operations. In addition to $X 9$, the association actively participates on many other American National Standards Committees. (b) Bank Card Task Forcehas published the Bank Card Standards Manual and is continuing work in the area of magnetic stripe encoding on bank cards. (c) $A B A / F R S$ (Federal Reserve System) Routing Number Task Force-this committee reviews existing guidelines for the issuance, use and eligibility requirements of "the number" in the current payments system environment. (d) CUSIP Board-responsible for overseeing usage and issuance of the CUSIP number to identify stock certificates. An ABA staff representative works as secretary for this board composed of members from interested industry groups. (e) Bank Identification Number Directorythe association is the interim registration authority for the issuance and maintenance of the number used by issuers of credit cards. The term "Bank" is a misnomer since the number is used by other industries such as travel and entertainment, and airlines as well. (f) $S W I F T$ and (g) ISO-each explained under "International Participation."

Involvement with the Federal Government-The association, at the request of the Florida Bankers Association, was instrumental in forming a study of the Florida Sear Project. This is a system of standardized auditing reports being used by the State of Florida. The Federal Reserve, Comptroller of the Currency, Federal Deposit Insurance Corporation (FDIC) and Conference of State Bank Examiners are presently undergoing a study to determine whether this type of arrangement is workable on a nationwide scale.

ABA lists a published standard as a publication in Aids to ABA, which is a compilation of the associations' publications. In addition, $\mathrm{ABA}$ conducts periodic review and update of its standards to insure their usefulness in the real world. Such a review is now underway on the ABA Routing Number Standard.

International participation of $\mathrm{ABA}$ consists of cooperation with the Society for Worldwide Interbank Financial Telecommunications (SWIFT) on the: Board-responsible for developing plans for implementing an international bank communications network; Standards Committee-responsible for reviewing the work of the various working groups as to the details of the standard; and U.S. Steering Conmittee - establish United States position on facets of the standard as it progresses in formulation. The association, in addition, is active on many International $\mathrm{Or}$ ganization for Standardization committees where the work affects the U.S. banking industry.

\section{AMERICAN BOARD FOR CERTIFICATION IN ORTHOTICS AND PROSTHETICS, 1440 N Street NW., Washington, D.C. 20005}

The American Board for Certification in Orthotics and Prosthetics was founded in 1948 in order to establish a credentials program for identifying orthotic and prosthetic practitioners, as well as facilities, qualified to render essential public health services related to artificial limbs and braces. The board's activities are sponsored by the American Orthotic and Prosthetic Association, the American Academy of Orthotists and Prosthetists, and the American Academy of Orthopedic Surgeons. In addition to setting standards for professional practice as three discrete levels of competence, the board also is concerned with the accreditation of qualified educational programs for the training of such practitioners. Certification is granted at the technician, assistant, and the professional practitioner levels in the two disciplines of orthotics and prosthetics. Accreditation of facilities is based upon evaluation of physical layout of each location. Recommendations from three medical references, and a site appraisal by 
a competent practitioner. In many jurisdictions, facility accreditation and personal certification is a requirement for participation in state rehabilitation service programs.

The three boards of the American Boards of Examiners in Speech Pathology and Audiology are: the Education and Training Board, to whom ABESPA has delegated the responsibility for receiving and evaluating applications for the accreditation of master's degree programs in speech pathology and/or audiology and recommending to ABESPA that such accreditation be granted or withheld; the Professional Services Board, to whom ABESPA has delegated the responsibility for receiving and evaluating applications for accreditation in speech pathology and/or audiology from clinical services programs and for recommending to ABESPA as to whether such accreditation should be granted or withheld; and, finally, the Clinical Certification Board, to whom ABESPA has delegated the responsibility for receiving and evaluating applications for the Certificate of Clinical Competence in Speech Pathology and/or Audiology submitted by individuals who wish to provide services to the communicatively handicapped. Applicants for such certificates must not only meet academic course work, clinical practicum, and professional experience criteria in order to achieve certification, they must also pass the National Examination in Speech Pathology and/or Audiology, prepared by the Clinical Certification Board for Administration as an area examination of the National Teacher Examinations division of Educational Testing Service, Princeton, New Jersey. The American Speech and Hearing Association, through the American Boards of Examiners in Speech Pathology and Audiology, is recognized as the sole accrediting agency for master's degree programs in speech pathology and/or audiology by the National Commission on Accrediting and the Commissioner of the United States Office of Education. As of September 15, 1973, 85 master's degree programs have been accredited in speech pathology and/or audiology on the recommendation of the Education and Training Board; 575 clinical services programs have been accredited in speech pathology and/or audiology on the recommendation of the Professional Services Board and 11,919 Certificates of Clinical Competence in Speech Pathology and/or Audiology have been issued to individuals on the recommendation of the Clinical Certification Board.

\section{THE AMERICAN BOARDS OF EXAMINERS IN SPEECH PATHOLOGY AND AUDIOLOGY,}

\section{American Speech and Hearing Association,} 9030 Old Georgetown Road, Washington, D.C. 20014

The American Boards of Examiners in Speech Pathology and Audiology (ABESPA) of the American Speech and Hearing Association was established in 1959 to formulate standards and procedures for the determination of qualifications of individuals, organizations and institutions applying for Certificates of Accreditation or Clinical Competence; to establish, maintain and monitor Boards of Examiners responsible for arranging and conducting examinations to determine the qualifications of applicants for such certificates; to grant and to issue appropriate certificates; to maintain a registry of holders of such certifiagencies, lists of individuals, organizations and institutions who have been issued such certificates.

\section{AMERICAN BOAT AND YACHT COUNCIL, INC., 15 East 26th Street, Room 1603, New York, New York 10010}

The American Boat and Yacht Council (ABYC) is an independent, nonprofit, membership organization founded in 1954 to be broadly representative of recreational boating including members from industry, insurance, Government and the boating public. The council's sole activity is the development of safety standards and recommended practices for the design, construction, equipage and maintenance of boats and their related accessories. The standards are generated by project technical committees and reviewed by the ABYC Technical Board and Board of Directors prior to publication.

The council has published about 60 standards in a large looseleaf volume entitled Safety Standards for Small Craft which is continuously updated with new revisions and supplements. These standards provide a basis for certification programs of other organizations and also are used as source material by the U.S. Coast Guard in their development of safety regulations under the Boating Safety Act of 1971.

The current membership consists of over 700 individuals and about 30 corporations and associations. The individual members work voluntarily through committees and boards to implement the boating safety standards program.

\section{AMERICAN BOILER MANUFACTURERS' ASSOCIATION, 1500 Wilson Boulevard, Arlington, Virginia 22209}

This association, established in 1888 , participates in the following standardization work: (1) publication by the Technical Committee, Packaged Firetube Boiler Section, of ratings standards entitled Packaged Firetube Boiler Ratings for Heating Boilers; (2) lexicon of industry terminology, coal analysis and accessory product definitions; (3) acts as secretariat to the National Fire Protection Association's Committee on Boiler Furnace Explosions and the Sectional Committees on Public Utility Units, and Industrial Units.

Formerly: American Boiler Manufacturers Association and Affiliated Industries (1960). 


\section{AMERICAN BOWLING CONGRESS, 5301 South 76th Street, Greendale, Wisconsin 53129}

The American Bowling Congress ( $\mathrm{ABC}$ ) was organized in 1895 as a nonprofit, noncommercial membership service organization for male bowlers. Its 4 million members participate in leagues and tournaments sanctioned by the $\mathrm{ABC}$ in 50 states, Canada, Puerto Rico, Bermuda, Grand Bahamas, Saudi Arabia and American military bases around the world. Its specifications for playing equipment are used by the 8 million league bowlers in the United States and Canada, including women and children, and by the hundreds of thousands of players in the 45 countries that are members of the Federation Internationale des Quilleurs, the world bowling tournament organization headquartered in Europe.

All bowling lanes (approximately 143,000 in 9,100 bowling centers) under the jurisdiction of the $\mathrm{ABC}$ are certified annually by representatives of the 2,850 local bowling associations chartered by $\mathrm{ABC}$. This means the lanes are measured and checked to make sure their physical properties and dimensions correspond to $A B C$ specifications, including such specifics as that no part of the 60 feet of playing surface from foul line to head pin can be more than $40 / 1000$ ths of an inch from perfect levelness. When found to meet all specifications, an $\mathrm{ABC}$ decal is issued for posting in the establishment.

Additionally, the $\mathrm{ABC}$ maintains an equipment testing and research department that works with new products brought to it for consideration and also maintains a constant check on products already in use. The department works with an official ABC New Equipment Committee and also uses the services of an outside testing laboratory.

Over the years, in cooperation with manufacturers, $A B C$ testing and research has been instrumental in the development of the plastic base for bowling pins, the plastic coated and all-synthetic pins, the automatic pinsetting machine, the automatic foul detector and the plastic bowling ball. In the early 1950's, for example, the $A B C$ conducted tests in more than 900,000 games of bowling before it approved the first plastic coated bowling pin. A number of criteria had to be met among them that the application of plastic to a maple core would not change the scoreability in comparison to the all-wood pin, that it would be at least as durable and that it would not affect the playability of the game.

Standardization has been a keynote of tenpin bowling. The height of a pin $38.10 \mathrm{~cm}(15 \mathrm{in})$, the circumference of a ball $68.58 \mathrm{~cm}$ (27 in) and many, many other specifications have remained unchanged since the $A B C$ was organized in 1895 . Synthetics have been accepted only after having met rigid test under league conditions and passing the major philosophical test, "Is it good for the game?" Change has not been made merely for the sake of change.

Equipment specifications are printed annually in the ABC Constitution, Rules and Specifications book.
Results of tests and proceedings of the New Equipment Committee are reported to officers, directors and delegates in annual convention session, in the ABC Annual Report and periodically in Bowling, the offcial monthly magazine. A list of pins approved for use in $\mathrm{ABC}$ sanctioned competition is carried monthly in the latter.

Absorbed: As Seniors Division: United States Seniors Bowling Association. (1964).

\section{AMERICAN BUREAU OF SHIPPING, 45 Broad Street, New York, New York 10004}

This bureau is an international ship classification society and nonprofit corporation organized under the laws of the State of New York, in 1862. It has no stockholders and pays no dividends. The bureau's work may be briefly summarized as follows: (1) the preparation of standards, called "rules" for the construction of hulls and machinery of merchant ships, including material specifications and regulations for periodical surveys. The rules are published annually and are modified to keep pace with developments in shipbuilding and marine engineering; (2) the analysis of plans of vessels projected to be built, or conversions of existing vessels, to verify if they meet the standards set by the rules; (3) the verification of the building to approved plans of the new hull and its main machinery, boilers and vital auxiliaries, and the conversion of existing vessels; (4) the witnessing of the testing of materials of construction for hull and machinery as required by the rules; (5) the carrying out of periodic and damage surveys as called for by the rules; (6) the carrying out of load line surveys, safety equipment surveys, radio-telegraphy surveys and the issuance of tonnage certificates, all under the authority of various governments and international conventions; (7) the annual publication of the Record of the American Bureau of Shipping which contains essential details of hull and machinery and survey status of bureau-classed vessels and others; (8) the issuance of certificates of character for bureau-classed vessels, i.e., classification certificates, seaworthy certificates, confirmation of class certificates, etc.; and (9) the issuance of cargo gear registers.

The operations of the bureau are worldwide in scope. Offices are maintained in the principal seaports and shipbuilding centers of the world. These offices are staffed with experienced ship surveyors.

The bureau maintains technical committees in the United States, Belgium, Great Britain, France Germany, Italy, Japan, the Netherlands, Greece, Scandinavia, and Spain.

\section{THE AMERICAN CERAMIC SOCIETY, INC., 65 Ceramic Drive, Columbus, Ohio 43214}

The American Ceramic Society, founded in 1899 at Columbus, Ohio, under the leadership of Edward Orton, Jr., has more than 10,000 members and sub- 
scribers in 62 countries. The main function of the society is to disseminate scientific and technical ceramic information. This is done primarily through the society's publications and numerous yearly meetings.

The Society's divisions are: Basic Science, Cements, Ceramic-Metal Systems, Electronics, Glass, Materials and Equipment, Nuclear, Refractories, Structural Clay Products, and White Wares. It also has committees on Classification, Nomenclature and Standards. These committees cooperate with the American Society for Testing and Materials, American National Standards Institute, National Safety Council (Glass and Ceramic Section) as well as with U.S. Government agencies in the development of methods of test and standards related to ceramic materials and products. The sponsoring organizations and agencies are responsible for promulgating the standards. The Ceramic Educational Council and the National Institute of Ceramic Engineers, classes within the society, are concerned with objective criteria in engineering education and professional ethics and status respectively.

\section{AMERICAN CHAIN ASSOCIATION, 101 Second Avenue North, Room 203,}

St. Petersburg, Florida 33701

The American Chain Association was formerly the American Chain Sprocket Chain Manufacturers' Association, which was the successor to the Association of Roller and Silent Chain Manufacturers' and Malleable Chain Manufacturers' Institute. This organization is interested in standardization of dimensions of roller, silent, engineering steel and malleable iron chains, sprockets and wheels for the purpose of securing interchangeability, and also in standard recommendations for power capacity and speed for these chains. Subcommittees of engineers are appointed from time to time to deal with specified subjects, and their work is reviewed and approved by the entire association. The association does not publish standards, preferring to sponsor standards for adoption through the procedures of the American National Standards Institute (ANSI). It cooperates with the American Society of Mechanical Engineers, Society of Automotive Engieers, American Petroleum Institute, Conveyor Equipment Manufacturers' Association, and the American Gear Manufacturers' Association in standardization matters of mutual interest. ANSI standards covering chain include the following: B29.1 through B29.14.

Working through ANSI, the association participates in the work of Technical Committee 100 of the International Organization for Standardization.

\section{AMERICAN COLLEGE OF SURGEONS, 55 East Erie Street, Chicago, Illinois 60611}

The college is the only organization responsible at the national level for the standardization and approval of hospital cancer programs in the United States. The college cooperates with other recognized national medical organizations in the accreditation of hospitals and in the approval of graduate training programs in general surgery and the surgical specialties. Since 1953, the college has been engaged in a cooperative effort to standardize hospital statistical procedures and methods and to develop a method to evaluate the quality of patient care in hospitals. The college was founded in 1913 as a voluntary, nonprofit association of surgeons of the United States and Canada. It has 34,000 members (Fellows).

\section{AMERICAN CONCRETE INSTITUTE, 22400 West Seven Mile Road, Detroit, Michigan 48219}

Since its organization in 1905, this institute has been devoted to the solution of technical problems related to the design, construction, and maintenance of concrete and reinforced concrete structures and to the dissemination of information in this field.

More than 84 technical committees study specialized problems through the evaluation of published information, reports of research, and majority opinion based on field practices leading to the development of committee reports. The eventual aim of committee activity is the evolution of the committee reports into standards after discussion by the institute membership and consideration by the Standards Board and letter ballot of the members.

Institute standards are confined to specifications and recommended practices related to structures as a whole. Standardization of basic materials and "overthe-counter" components are deliberately excluded from the scope of its standardization procedures.

Current standards of the institute are building code requirements for reinforced concrete; manual of standard practice for detailing reinforced concrete structures; notation for concrete; structural plain concrete for buildings; specifications for concrete chimneys and for concrete pavements and bases; and cast-in-place nonreinforced concrete pipe; minimum standard requirements for precast concrete floor and roof units; and recommended practices for evaluation of strength test results of field concrete; design of concrete pavements, winter and hot weather concreting; selecting proportions for normalweight, lightweight, and noslump concrete; measuring, mixing, and placing concrete; application of portland cement base paint to concrete surfaces; inspection of concrete; formwork for concrete; thin-shell precast concrete; curing concrete; consolidation of concrete; shotcreting; and atmospheric pressure steam curing of concrete. The application of these standards is supplemented by more detailed information in such publications as ACI Manual of Concrete Inspection, Strength Design Handbook, Reinforced Concrete Design Handbook, and Formwork for Concrete.

Work is in progress on a new standard on concrete highway bridge decks and the updating and revising of several previous standards. 
The institute cooperates in related standardization work with the American National Standards Institute, American Society for Testing and Materials, American Society of Mechanical Engineers, and the American Welding Society.

Formerly: National Association of Cement Users (1913).

\section{AMERICAN CONCRETE PAVING ASSOCIATION, 1211 West 22nd Street, Oak Brook, Illinois 60523}

The American Concrete Paving Association (ACPA) was formed in 1964 as a national organization representing the concrete paving industry. Its membership includes contractors, equipment manufacturers, suppliers of materials and essential services to the concrete paving industry, and allied associations and individuals. The high standards to which this nonprofit organization aspires are reflected in its statement of purpose: "To develop a source of information that will maintain and improve quality of workmanship; to promote and advance the use of proven new developments and improved equipment and construction methods; to diligently act upon all needs to achieve the highest interests and quality performance of the concrete industry."

The association's standardization activities are carried out by its Technical Comnittee which is made up of subcommittees concentrating on specific facets of concrete paving for roads, streets, and airports. The Technical Committee issues recommendations on the design and construction of concrete pavements. It reviews concrete pavement specifications for Federal agencies such as the Federal Highway Administration, Federal Aviation Administration, U.S. Army Corps of Engineers, and U.S. Navy, plus state highway departments.

ACPA is also active in the standardization work of other national associations such as the American Concrete Institute, American Road Builders' Association, and Highway Research Board.

ACPA recommendations are published in technical bulletins and special publications.

\section{AMERICAN CONCRETE PIPE ASSOCIATION, 1501 Wilson Boulevard, Arlington, Virginia 22209}

The American Concrete Pipe Association (ACPA) is an international trade association, founded in 1907, to represent the precast concrete pipe industry in all matters affecting the industry's welfare. The scope of the association includes activities in the areas of research, product specifications, technical services, promotion and advertising, education, safety, government and legislative liaison and the publication of technical and industry information.
Thirteen standards have been developed for precast concrete pipe and these cover small diameter nonreinforced circular pipe; reinforced circular pipe: pipe for irrigation or drainage; reinforced low-head pressure pipe; drain tile; joints for circular sewer and culvert pipe, using flexible, watertight rubber gaskets; perforated pipe; precast manhole sections; tests to determine the physical properties of concrete pipe or tile; nonreinforced irrigation pipe with rubber gasket joints; reinforced arch pipe; reinforced horizontal and vertical elliptical pipe; and a specification for reinforced concrete D-load culvert, storm drain, and sewer pipe.

ACPA cooperates with Federal, state and local government agencies and other specifying agencies to promote the use of these standards. The association also publishes technical information on the hydraulic and structural design and installation of concrete pipe for sewers, culverts, irrigation and drainage. This is augmented by the conduct and participation in technical seminars for producers, consumers and general interest groups.

\section{AMERICAN CONFERENCE OF GOVERNMENTAL INDUSTRIAL HYGIENISTS, P.O. Box 1937, \\ Cincinnati, Ohio $\mathbf{4 5 2 0 1}$}

This conference, founded in 1938, is a national professional association of practicing industrial hygiene personnel in Federal, state, and local agencies. Through its committees, the ACGIH assembles guides, recommended practices, and methods for the evaluation and control of the industrial environment.

The conference publishes an annual listing, Threshold Limit Values, containing TLVs for over 500 substances (mostly chemicals and chemical compounds) in dusts, fumes, gases, vapors, mists, and physical agents. The values, which are under continuous review, are used as guides in the control of health hazards and should not be regarded as fine lines between safe and dangerous concentrations. Several states, the U.S. Department of Labor, and the British Ministry of Labour incorporate the TLV's in codes or regulations.

The Manual of Recommended Analytical Methods describes chemical procedures and techniques for analysis of airborne contaminants (inplant as opposed to air pollution) which can be performed without expensive specialized equipment. Fifteen methods have been published to date and are verified in a number of cooperating laboratories.

The conference also publishes Industrial Ventilation -A Manual of Recommended Practice. This manual is a practical reference for the design and construction of ventilation exhaust systems. Basic ventilation principles are discussed and there are about 150 illustrations. Other guides and manuals are published as appropriate. 


\section{AMERICAN CONGRESS ON SURVEYING AND MAPPING. \\ 733 - 15th Street NW., Suite 430, \\ W ashington, D.C. 20005}

The American Congress on Surveying and Mapping (ACSM), established in 1941, has operated as a national nonprofit membership organization of more than 6000 professionals in the field of land surveying, control surveying (including gcodesy), and cartogra. phy. It is incorporated in the District of Columbia.

Membership in ACSM is through one of three professional Divisions on Land Surveys, Control Surveys, and Cartography. Technical work is accomplished by committees within the divisions. Professional level committees under ACSM consider problems involving all three divisions. National contacts are maintained through 46 institutionally affiliated state land surveyor societies and through 26 geographical sections of ACSM.

ACSM is a participating member of the National Council of Engineering Examiners (NCEE), the International Federation of Surveyors (IFS), and the International Cartographic Association (ICA), and maintains liaison with the National Research Council (Division of Earth Sciences), the American Society of Photogrammetry, and the American Society of Civil Engineers.

ACSM has nationally issued Technical Standards for Property Surveys, Minimum Standard Detail Requirements and Land Title Surveys, and National Guide. lines for the Procedure and Requirements of Performing Mortgage Inspections.

Promotion of ACSM standards is by liaison with other professional societies and publicity via pages of ACSM publications: Surveying and Mapping, ACSM Bulletin, and ACSM's The American Cartographer.

\section{AMERICAN COUNCIL OF INDEPENDENT LABORATORIES, INC., $1725 \mathrm{~K}$ Street NW. Washington, D.C. 20006}

The American Council of Independent Laboratories, Inc. (ACIL) was established in 1937. It is a profes. sional association of independent scientific laboratories. Its membership includes many of the leading testing and inspection firms in the United States, some of which operate also in Mexico, Central America, Japan and Canada.

ACIL promotes standards of ethics employed by independent laboratories in special fields of interest and activity. These include sampling, inspection, physical or nondestructive testing and chemical analysis of raw, intermediate and finished materials and products; research and development; the improvement of products or processes; the quality control of composition and performance; and professional consulation in various fields of scientific technology. These are published periodically by ACIL and are available from the council.
ACIL's Committee on Laboratory Qualification has produced a standard entitled, Recommended Requirements for Independent Laboratory Qualification. This standard encompasses a quality control system for personnel and equipment evaluation as well as calibration and standardization in the system.

ACIL does not write standards for products or materials but its members participate in writing test procedures and methodology in other standards-writing organizations.

ACIL has cooperated on standard programs with the National Bureau of Standards; Department of Defense and particularly the Army Corps of Engineers; General Services Administration; Department of Transportation; Department of Housing and Urban Development; Department of Labor, Occupational Safety and Health Administration; Department of Health, Education and Welfare; Food and Drug Administration; and the Department of Agriculture. Many of our member firms work on certification programs for Government agencies but the ACIL itself does not conduct certification work except for a minor program with the Food and Drug Administration that involved training for certain selected personnel.

From its founding in 1937 until 1954, the council was known as the American Council of Commercial Laboratories.

\section{AMERICAN CRYSTALLOGRAPHIC ASSOCIATION, 335 East 45th Street, New York, New York 10017}

The American Crystallographic Association (ACA) was founded in 1949 by merger of the Crystallographic Society of America and the American Society for X-Ray and Electron Diffraction. The objective of the association is to promote the study of the arrangement of the atoms in matter, its causes, its nature and its consequences, and of the tools and methods used in such studies.

Prevalent notions of the nature of the scientific role played by the modern crystallographer are apt to be both foggy and erroneous. The present-day crystallographer, like his predecessors, is interested in the form and symmetry of ideal crystals as well as in the growth of crystals and the measurement of their physical properties. However, the range of his interests encompasses vastly more than this. He apprehends nearly all solid objects as being more or less fully crystalline, and he uses the powerful techniques of X-ray, electron and neutron diffraction to establish their lattice types and to determine the positions of their constituent atoms in the lattice. He is aware that actual crystals deviate more or less from ideality, and he devotes much effort to diagnosing the nature and extent of the imperfections prevailing in the actual structures of crystals.

Such quantitative studies of crystalline structure require prodigious amounts of mathematical calculations, which are, however, quite feasible because of the present accessibility of large electronic computers. 
Thus we find crystallographers unravelling the atomic arrangements and molecular structures of such diverse substances as minerals, metals and alloys, building materials, antibiotics, proteins, transistors, missile materials, and polymers. A great many crystallographers are busy extending our fundamental knowledge in these areas, while a much greater number are engaged in the technological applications and to a small extent standardize some of the instrumentation used in their field.

The Apparatus and Standards Committee has promulgated standards for camera tracks, and bases and has adopted dimensional specifications for goniometer heads.

An ACA appointed representative serves as a liaison to the National Bureau of Standards for the issuance of Crystal Data. Although this compiled publication is not exactly a standard, it does give a quite complete list of crystalline substances as identified from unit cell dimensions.

\section{AMERICAN DEFENSE PREPAREDNESS ASSOCIATION, Union Trust Building, 15 th and $H$ Streets NW., W ashington, D.C. 20005}

Founded in 1919 as the Army Ordnance Association, then after changing its name to American Ordnance Association in 1948, this organization assumed its current name in 1973. The successive name changes reflect its ever expanding area of interest.

Included within the technical divisions of the ADPA, in addition to divisions covering all types of armament systems, are the following: standards and metrology; materials; mobilization readiness; quality and reliability; technical documentation; value engineering; safety; and the packaging, handling, and transportation functions.

\section{AMERICAN DENTAL ASSOCIATION, 211 East Chicago Avenue, Chicago, Illinois 60611}

This association (ADA), through first its Council on Dental Research and now through its Council on Dental Materials and Devices, has had a specification and certification program for dental materials and devices since 1928. To date, 25 specifications and 5 standards, national in scope, have been adopted. The council acts as administrative secretariat and sponsor of American National Standards Committee Z156 for Dental Materials and Devices which acts as the principal consultant to the Council on Dental Materials and Devices in revision and formulation of ADA specifications for dental materials and devices with submission to American National Standards Institute (ANSI) for adoption as American National Standards. In addition the ADA acts as proprietary sponsor on a project to handle standards for dental radiographic film. All of the ADA specifications and standards have been adopted as American National Standards. The ADA also sponsors participation of ANSI in activities of the International Organization for Standardization (ISO) Technical Committee 106 on Dentistry and acts as secretariat for ANSI for Working Group 2 of ISO/TC-106. Thus, the ADA works both nationally and internationally in the formulation of standards for dental materials and devices.

The association also operates two evaluation programs: a certification program based upon the physical standards, and an acceptance program based upon proof of biological and clinical safety and effectiveness. The certification program involves the testing by ADA of materials certified by manufacturers to comply with specifications of the ADA. If found to comply with the specification the product is added to either the List of Certified Dental Materials and Devices for the certification program, or the List of Classified Dental Materials and Devices for the acceptance program.

The Guide to Dental Materials and Devices, published biannually by ADA and of about 300 pages, gives pertinent information on dental materials and devices, details about specification and evaluation programs, the specifications and the lists of certified and classified dental materials and devices. Over 700 products currently are listed.

Formerly: National Dental Association (18971922).

Absorbed: Southern Dental Association (1897).

\section{AMERICAN DENTAL TRADE ASSOCIATION, 1140 Connecticut Avenue NW., Washington, D.C. 20036}

This association was founded in 1882. For the past 40 years the association has maintained a Standard Manual of Accounting for Dental Dealers which is revised about every five years to keep it up to date with modern accounting practices and procedures.

\section{AMERICAN DIE CASTING INSTITUTE, 366 Madison Avenue, New York, New York 10017}

This institute (ADCI) was founded in 1923, as a service to the customers of the die casting industry. ADCI publishes Product Standards for Die Castings to guide designers and engineers to the most economical use of die castings. These product standards are not intended as maximal specifications. The information set forth is based on normal practices of the die casting industry which, if followed, can bring about the production of serviceable and quality die castings on the most economical basis. Product Standards for Die Castings is composed of three series covering engineering, metallurgical and commercial practice data. A quality control series was introduced in 1973. 
AMERICAN DRY MILK INSTITUTE,

130 North Franklin Street, Chicago, Illinois 60606

The American Dry Milk Institute (ADMI), established in 1928, is a national trade association of dry milk manufacturers. The purposes are: to stimulate and conduct research and educational work for the education of the public and consumer as to the character, quality, convenience, economy and general virtue of dry milk products and related products, and to promote the use and consumption of such products, and collect and disseminate such statistics and information as will further such purposes.

The standardization activities are from 25-30 percent of the total ADMI program. Active committees contributing to the standardization program are the Buttermilk, Dry Whole Milk, the Instant Nonfat Dry Milk, and Standards/Research Committees. ADMI is internationally involved, as advisable, with the Codex Alimentarius.

ADMI is also involved in standardization with the U.S. Department of Agriculture, the National Bureau of Standards, and the Food and Drug Administration. ADMI has no certification program activities. ADMI has issued standards on product definition and nomenclature; specifications and grade classification; and promotes the use of its standards through publications and publicity.

\section{AMERICAN ELECTROENCEPHALOGRAPHIC SOCIETY,}

36391 Maple Grove Roarl, Willoughlby Hills, Ohio 44094

The American Electroencephalographic Society was founded in 1946. The bylaws of this society state that, "The purposes of this Society shall be to promote personal contacts between investigators in Electroencephalography and in closely related fields of interest, and between this society and other similar societies throughout the world, thus facilitating the exchange of scientific and professional information and opinions; to further in this way the greater understanding and knowledge of electroencephalography and related studies; to arrange for the exchange of journals and other public data in these fields, and to review manuscripts for any interested publication; to assist in the formation of international committees or the establishment of uniform standards, techniques, and procedure throughout the world; to assist in setting up standards for training, examination, and qualification of clinical electroencephalographers and technicians, and to draw up minimum specifica. tions for apparatus used, in order that high standards of clinical electroencephalography may be established and maintained."

Currently, the society has 620 members. The membership is composed primarily of physicians and Ph.D. scientists. The physician members are primarily neurologists and psychiatrists. The Ph.D. are primarily psychologists and neurophysiologists.
AMERICAN ELECTROPLATERS' SOCIETY,

56 Melmore Gardens,

East Orange, New Jersey 07017

This society founded in 1909, is actively interested in standards pertaining to electroplated coatings. It relies on the work of American Society for Testing and Materials (ASTM) Committee B.8 on Electrodeposited Metallic Coatings and endorses the standards prepared by Committee B-8, whose members are for the most part, members of the American Electroplaters' Society. Formal representation is also maintained on ASTM Committees A-5 on Corrosion of Iron and Steel, D-19 on Industrial Water, and B-7 on the Anodic Oxidation of Aluminum and Magnesium Alloys, as well as American National Standards Institute Committee Z9 on Safety Codes for Exhaust Systems.

Formerly: National Electro-Platers' Association of the United States and Canada (1913).

\section{AMERICAN FEED MANUFACTURERS' ASSOCIATION, 1701 North Fort Myer Drive, Arlington, Virginia 22209}

The association is the national trade association of the animal feed manufacturing industry, which is one of the nation's 20 largest manufacturing industries. The association was founded in 1909 and carries out substantial activities in the fields of transportation, animal nutrition, feed production, state and Federal legislation and regulations, liquid feed, computers, public relations, state and Federal feed control, marketing, purchasing, environmental controls, occupational safety and health, and market research.

The association cooperates very closely with the Association of American Feed Control Officials. The two organizations work together and have developed a model state feed law, and model state feed regulations. The objective is to bring as much uniformity as possible into the state feed laws and regulations. Every state but one has legislation which regulates the production and distribution of commercial feed. AFMA also cooperates closely with the U.S. Food and Drug Administration in its enforcement of the Federal Food, Drug and Cosmetic Act.

\section{AMERICAN FISHING TACKLE MANUFACTURERS' ASSOCIATION, 20 North Wacker Drive, Suite 2014, Chicago, Illinois 60606}

American Fishing Tackle Manufacturers' Association (AFTMA) was founded in 1933. The basic objective of AFTMA is to educate, guide, and assist the members of the association in matters of common interest so that the members shall maintain a high standard of conduct, efficiency, and usefulness to the industry, to the Government, and to the public.

The fly line standards which were administered by 
the AFTMA Fly Line Standards Committee, are universal standards which were prepared in cooperation with the American Casting Association and the International Casting Federation. These standards are universally accepted by the manufacturers of fly lines. AFTMA supplied each manufacturer with these standards for packaging with their fly lines.

\section{AMERICAN FOOTWEAR INDUSTRIES ASSOCIATION, 1611 North Kent Street, Arlington, Virginia 22209}

The American Footwear Industries Association (AFIA) has developed recommended manufacturing standards for the United States footwear industry. These standards relate to the lasts on which the shoes are produced and thus affect all related components. They now refer to both men's and women's shoes.

Each recommendation has been based on a consenus after a study by working parties and a review by the AFIA Technical Committee on Standards.

The standards will be of great benefit to the consumer as well as to the footwear manufacturer. It will provide the consumer with a more consistent product as well as contribute to the widest possible choice in shoe styling, shoe construction, and materials. The recommended standards will create greater opportunities for all footwear manufacturers to assure product improvement and to create greater operator efficiency.

Formerly: National Boot and Shoe Manufacturers' Association; National Shoe Manufacturers' Association (1965) ; National Footwear Manufacturers' Association (1969); and American Footwear Manufacturers' Association (1972).

\section{AMERICAN FOUNDRYMEN'S SOCIETY, Golf and Wolf Roads, Des Plaines, Illinois 60016}

The American Foundrymen's Society was founded in 1896. With the exception of standards which the society has developed for the evaluation of foundry sands, standardization has been carried out in cooperation with the American Society for Testing and Materials (ASTM) and the American National Standards Institute (ANSI) by the appointment of representatives to serve on committees of these organizations.

Realizing the need for having industry-developed foundry process codes, it has continued its activities in the fields of safety, hygiene, and air pollution control. Currently, at the request of the Government and in conjunction with ANSI, the society is writing vertical safety standards, which will be followed at a later date by noise and ventilation standards. As a result of its program in environmental affairs, the society has published Control of Internal Foundry Environment. This publication is comprised of 12 basic sections on the subjects of: (a) Visual Environment-Light and Color; (b) Heat Stress and Nonionizing Radiation; (c) General Principles of
Foundry Ventilation; (d) Exhaust Systems and Hood Design; (e) Design of Sand-Handling Systems; (f) Molding, Coremaking and Pattern-making; (g) Melting and Pouring; (h) Cleaning Room; (i) Maintenance, Fans and Testing Ventilation Systems; (j) Industrial Hygiene; (k) Ionizing Radiations; and (l) Control of Noise.

A second volume to be published will be based on foundry environmental control outside of the shop and will concern itself with air pollution control, water pollution control, neighborhood noise and similar environmental subjects.

As a result of representation on a sizable number of technical committees of ASTM, it has cooperated in the development of specifications dealing with both cast metallic and nonmetallic materials covering a broad range of commodities.

AFS is indirectly involved with the International Organization for Standardization through the American National Standards Institute and also internationally involved with the International Committee of Foundry Technical Associations which in a sense has some influence on standardization.

The society's involvement with standards has always been on a national basis or with technical standards affecting the entire industry, many of which are used outside of this country.

Formerly: Foundrymen's Association (1948).

$$
\begin{gathered}
\text { AMERICAN GAS ASSOCIATION, } \\
\text { Headquarters: 1515 Wilson Boulevard, } \\
\text { Arlington, Virginia 22209; } \\
\text { Standardization Laboratories, } \\
8501 \text { East Pleasant Valley Road, } \\
\text { Cleveland, Ohio 44131 }
\end{gathered}
$$

The American Gas Association (AGA), a trade association of the gas distribution industry in the United States was established in 1918. The association coordinates gas industry activities concerning research, standardization and information related to the production, distribution and utilization of gas.

A committee of the Board of Directors of the American Gas Association supervises the association's participation in the development of national standards for gas utilization equipment, installation of gas utilization equipment, and gas operating equipment and supplies. Under the direction of this AGA Standards Committee, the American Gas Association functions as secretariat to four independent American National Standards Committees operating under the principles established by the American National Standards lnstitute (ANSI) and the membership of each committee is of a balanced representation in accordance with ANSI's procedures. Support of American National Standards Committees comprises less than one percent of the association's activities.

American National Standards Committee Z21 is responsible for developing and maintaining standards for domestic type gas equipment and some types of commercial gas equipment and presently has 18 subcommittees which develop and maintain 45 existing 
Z21 standards covering a variety of gas-burning appliances, related accessories and certain installations. As necessary, this committec authorizes its subcommittees or appoints additional subcommittees to develop standards for new types of gas utilization equipment within its scope. New or revised draft standards developed by these subcommittees, following distribution for review and comment to all known interested parties, are reviewed by the Z21 committee and, if approved, are submitted to the American National Standards Institute for consideration for approval as American National Standards.

American National Standards Committee Z83 is responsible for developing and maintaining standards for industrial types of gas equipment and presently has four technical subcommittees which develop and maintain six Z83 standards covering several types of gas equipment and certain installations. This Z83 committee and its subcommittees function in much the same manner as the $\mathrm{Z} 2 \mathrm{l}$ committee and the standards developed are submitted to the American National Standards Institute.

American National Standards Committee Z223 is responsible for developing and maintaining a National Fuel Gas Code which covers gas piping systems having a maximum operating pressure of $60 \mathrm{psig}$ and the installation of gas utilization equipment, related accessories, and their ventilation and venting on customer's premises. The standards developed by this committee are submitted to the American National Standards Institute.

American National Standards Committee B109 is responsible for developing and maintaining standards for gas displacement metering. The standards developed by this committee are submitted to the American National Standards Institute.

The composition of these independent American National Standards Committees include representation from gas companies, manufacturing interests, Federal Government agencies, insurance companies, and other organizations which have expressed an interest in a particular committee's activities. It is through its support of these independent standards-making committees, which have representation from several agencies of the Federal Government, that the American Gas Association is only indirectly involved in standardization activities with the Federal Government.

The American Gas Association also operates and maintains a nationally recognized certification program for gas equipment. This certification program is conducted by AGA Testing Laboratories in Cleveland, Ohio, and Los Angeles, California. Under this certification program, gas equipment is submitted to the AGA Laboratories voluntarily by manufacturers for test under applicable American National Standards, the laboratories certify those designs found to comply with the standards, and regular inspections are made to monitor construction in accordance with the design certified. Those appliances and appliance accessories certified by the AGA Laboratories carry the certification seal or the listing symbol of the American Gas Association and are included in the AGA Laboratories'
Directory of Certified Appliances and Accessories, which is updated in monthly supplements.

Formed by merger of: Gas Institute; National Commercial Gas Association (1918).

\section{AMERICAN GEAR MANUFACTURERS' ASSOCIATION, \\ 1330 Massachusetts Avenue NW., Washington, D.C. 20005}

This association was founded in 1916; its membership includes a majority of the principal manufacturers of gears, speed reducers and increasers in the United States and Canada.

One of the objectives of American Gear Manufacturers' Association (AGMA) is the creation and maintenance of gearing standards. These standards are intended to create a common-language bridge between the manufacturer, designer, and user so that they may better understand one another to the end that the gears will fit the users' needs.

These standards cover such areas as: gear industry nomenclature; gear specification drawings; hobs and shaper-cutters; application classification of gear motors and other types of speed reducers; standards on tooth form geometry; strength and durability formulas; inspection methods and practices; gear blank materials; lubrication of open or enclosed gearing; design and rating of speed reducers; spur, helical, herringbone, worm, bevel, fine pitch, aircraft, rocket, and missile gears. About 50 percent of the association's program is expended on its standardization activities. Currently there are 80 AGMA standards that are considered national in scope. The active standards committees are included in the Annual AGMA Directory.

Among the best gear-engineering brains in the United States and Canada representing manufacturers, designers and users, as well as teachers of mechanical engineering and the gear art in the major universities have contributed to the creation of this literature.

AGMA has always maintained close liaison with the American National Standards Institute (ANSI), American Society of Mechanical Engineers, Society of Automotive Engineers, Metal Cutters' Institute, Cooling Tower Institute, Machinery and Allied Products Institute, National Machine Tool Builders' Association, American Petroleum Institute, and other such technical organizations. Recently AGMA has agreed to participate in the International Organization for Standardization (ISO), through the facilities of ANSI. From time to time AGMA participates with the Federal Government in standardization activities, specifically, the Naval Ships Engineering Center in Hyattsville, Maryland.

\section{AMERICAN GEM SOCIETY, 3142 Wilshire Boulevard, Los Angeles, California 90005}

This society numbers among its committees a Nomenclature Committee, whose personnel consist primarily of retail jewelers throughout the United 
States and Canada, and advisory groups of diamond importers and jewelry manufacturers. This committee considers recommendations from its members in the various branches of the trade, and makes recommen. dations regarding definitions, standards, and practices for consideration and adoption by the entire membership of the society at its annual meetings. In carrying forth its work, this committee cooperates with the recommendations and rules of the Jewelers' Vigilance Committee, National Association of Better Business Bureaus and its affiliated bodies, and the Federal Trade Commission.

\section{AMERICAN HARDBOARD ASSOCIATION, 20 North Wacker Drive, Chicago, Illinois 60606}

This association, organized in 1952, comprises nine domestic companies operating 24 plants and represents approximately 90 percent of the domestic production of hardboard.

In cooperation with the Office of Engineering Standards Services of the National Bureau of Standards, the association assisted in the promulgation of three new Voluntary Product Standards: Basic Hardboard, PS58-73; Prefinished Hardboard Paneling, PS59-73; and Hardboard Siding, PS60.73; issued in 1973 and which succeeded former Commercial Standards CS252-63 and CS176-58.

Formerly: Hardboard Association (1959).

\section{AMERICAN HOME ECONOMICS ASSOCIATION, 2010 Massachusetts Avenue NW., Washington, D.C. 20036}

This association, founded in 1909 , is an educational and scientific organization of approximately 50,000 men and women; 35,000 with bachelors or advanced degrees in home economics or one of its specializa. tions, and 15,000 college student members enrolled in undergraduate programs in home economics. Its purpose is to improve the quality and standards of individual and family life through education, research, cooperative programs, and public information.

AHEA is the administrative secretariat of the American National Standard Z61.1-1970-Dimensions, Tolerances, and Terminology for Home Cooking and Baking Utensils. In addition, the association expresses its interest in standards through representation on the American National Metric Council and the American National Standards Institute's Consumer Council, Miscellaneous Technical Advisory Board, Textile Technical Advisory Board, and the following committees dealing with such subjects as household refrigerators, electric ranges, textile test methods, and heat producing portable household appliances. AHEA is represented on two International Organization for Standardization committees: ISO/TC 133, Clothing Sizes: and ISO/TC 38, Textiles.

AHEA works closely with the National Bureau of Standards (NBS) and assisted in developing the Vol. untary Product Standard PS 54-72, Body Measurements for the Sizing of Girls' Apparel, and other standards by NBS.

\section{AMERICAN HOME LIGHTING INSTITUTE, 230 North Michigan Avenue, Chicago, Illinois 60601}

This institute (AHLI), founded in 1940, is composed of manufacturers of residential lighting fixtures, distributor showrooms and component parts manufacturers.

The AHLI introduced its Minimum Light for Liv. ing Standards for houses and apartments in 1957 and revised them in 1965. With comfort, beauty, convenience and security as criteria, the standards recommend locations and wattages for lighting fixtures for various rooms and exterior.

The standards are cited as a guide in the Mininum Property Standards for One and Two Family Dwellings of the U.S. Department of Housing and Urban Development, Federal Housing Administration. They are recommended in the National Minimum Medal. lion Home Standards, and are widely required as a qualification for the medallion.

Builders who meet the standards qualify for the Light for Living Award of the American Home Lighting Institute.

The standards are continually reprinted or quoted in numerous publications. The AHLI distributes single and bulk copies to builders, electrical contractors, architects, interior designers, lighting consultants, home service advisors and consumers.

\section{AMERICAN HOSPITAL ASSOCIATION, 840 North Lake Shore Drive, Chicago, Illinois 60611}

"Better health care for all the people" is the goal of the American Hospital Association, which was founded in 1898. In support of this goal, the association provides education, research and representation services for 7,000 institutional and 17.000 personal members.

The Bureau of Management and Planning, through its Division of Design and Construction, has primary responsibility for standardization activities related to hospital supplies, equipment and facilities. The association maintains liaison with over 30 national organizations and Government agencies concerned with the development of standards. Government agencies include the National Bureau of Standards, Secretariat of the National Conference of States on Building Codes and Standards, and appropriate agencies within the Departments of Health, Education and Welfare, and the Department of Labor. In representing the hospital industry, the association seeks the development of standards which create the least expense for member institutions without compromising safety.

Liaison activities include recommendation, review and revision of standards after consultation with membership and the appropriate agency or organization. 
The association has been active in the development of standards for all manner of hospital supplies, equipment and facilities, including bedding materials, clinical and surgical instruments, electrical fixtures and disposal systems. Concerns range from flammability, to structural integrity to infection control-all those factors which pose a threat to the safety of hospital patients and employees.

Formerly: Association of Hospital Superintendents of United States and Canada (1906).

\section{AMERICAN HOT DIP GALVANIZERS ASSOCIATION,}

1000 Vermont Avenue,

Washington, D.C. 20005

This association was founded in 1935. The objectives of this association are to improve the efficiency of the after-fabrication galvanizing industry, to encourage the application of the latest advances in technology, and to promote the wider use of hot dip galvanized products.

The association supports and maintains extensive technical and market development programs on the evaluation and application of new materials and techniques to existing and emerging markets. It also maintains an active participative interest in the preparation of codes, specifications, and recommended practices. The association serves as the focal point for technically related inquiries from both the industry and from users of hot dip galvanized products.

The association is represented on American Society for Testing and Materials subcommittees concerned with development and review of specifications for galvanizing and corrosion protection. It is also a member of the American Road Builders' Association and the National Association of Corrosion Engineers.

\section{AMERICAN HOTEL AND MOTEL ASSOCIATION, 888 Seventh Avenue,} New York, New York 10019

The American Hotel and Motel Association (AHMA) was founded in 1910 as an international trade association representing the hotel and motel industry with primary efforts directed to the United States. The activities of AHMA in the field of standardization are carried out in cooperation with other organizations, and are administered and coordinated through the AHMA's Director of Membership Service and Research.

Under the procedure of the United States of America Standards Institute, now the American National Standards Institute (ANSI), it cooperated through representation on sectional committees, in the development of USA Standard Safety Code for Elevators, Dumbwaiters, and Escalators; and USA Recommended Practice for the Inspection of Elevators. It is also represented on ANSI sectional committees on standards and specifications for refrigerators, and on minimum requirements for plumbing and standardization of plumbing equipment.

Between 1950 and April 1958 the association sponored a project under the auspices of ANSI to develop minimum performance requirements for institutional textiles, which resulted in the establishment of American National Standard L24, Performance Requirements for Institutional Textiles.

AHMA is represented on various committees of ANSI, the American Society for Testing and Materials, Underwriters' Laboratories and the National Fire Protection Association for the purpose of assisting in the development of standards of interest and importance to the industry. It continues as sponsor of American National Standards Committee L24; and is represented on the ANSI Consumer Council, and the American National Standards Committee X4, Office Machines and Supplies.

Formerly: American Hotel Protective Association (1917) ; American Hotel Association (1962).

\section{AMERICAN INDUSTRIAL HYGIENE ASSOCIATION, 66 South Miller Road, Akron, Ohio 44313}

The association was established in 1939 by leading industrial hygienists as a result of need for an association devoted exclusively to industrial hygiene.

The objectives of the association are: (1) to increase the knowledge of industrial hygiene through interchange and dissemination of information; (2) to promote the study and control of environmental factors affecting the health and well-being of industrial workers; (3) to correlate such activities as are conducted by individuals and agencies throughout industrial, educational, and governmental groups; and (4) to bring together persons interested in the various phases of industrial hygiene.

The association speaks or acts for industrial hygienists in matters of general interest, e.g., dissemination of information on the fundamentals of industrial hygiene; definition of the scope of industrial hygiene; development of nomenclature in industrial hygiene; improvement of the education, training, and status of industrial hygienists; solutions of problems of industrial hygiene in national and other emergencies, in part by encouraging the optimum use of available industrial hygienists and the training of new ones; cooperation with various organizations such as the American National Standards Institute and governmental agencies in the preparation of various codes and approval schedules; and presentation of awards to members of the association for outstanding service in the field of industrial hygiene.

The association publishes a monthly journal containing not only professional articles, but guides for industrial health practices and procedures. 


\section{AMERICAN INSTITUTE OF ARCHITECTS, Department of Professional Practice, AIA Codes and Regulations Center, 1735 New York Avenue NW., W ashington, D.C. 20006}

The American Institute of Architects was founded in 1857 and is the nationally recognized society of over 24,000 licensed architects in the United States.

The AIA maintains active liaison with over 80 national professional and Federal organizations involved in the art and science of building code and standards-writing as related to the practice of architecture. Approximately 300 AIA members, working within the framework of the Codes and Regulations Center, serve as advisory and active members on numerous national committees dealing with standardization and simplification of construction, materials and building techniques. The institute is represented on approximately 25 individual committees of the American National Standards Institute, 25 committees of the American Society for Testing and Materials and 25 committees of the National Fire Protection Association.

AIA issues a variety of contract forms and has been instrumental in the formulation of recommendations concerning size and character of building product literature directed to the architect. It has also been active in development of a uniform system for correlation of a specifications outline, a filing system for product data, and project cost accounting guide.

\section{AMERICAN INSTITUTE OF CHEMICAL ENGINEERS, 345 East 47 Street, New York, New York 10017}

The active standards work of this institute (AIChE) beran in the late 1940's when a committee was established to formulate procedures for testing chemical engineering equipment under unideal conditions that occur in plants using the equipment. At the present time, this Equipment Testing Procedures Committee pcrforms its work through seven equipment subcommittees: distillation columns, dryers, evaporators and crystallizers, heat exchangers, filters, fired heaters, mixers, and pumps; and one staff/service subcommittee, measurements. Twelve testing procedures have been published.

In December 1954, a Standards Committee was created which was designed to cooperate with and contribute to the program, carried out under American National Standards Institute procedures, of developing and promoting national standards affecting the chemical and related industries.

To carry out and strengthen its standards program, an Executive Board was created in 1964, each member of which has direct responsibilities for some area of standardization activity. Through this board, the institute controls and monitors its participation in standards activities (1) by representation of certain of its members on the American National Standards Mem- ber Body Council and on American National Standards Technical Advisory Boards operating in the areas of interest to chemical engineers and the chemicaI industry, (2) by liaison representation on the board of the chairman of any AIChE committees having active standardization programs, (3) by specific action within the committee itself in such fields as symbols and nomenclature, and (4) by working participation in the standards-writing activities of over 20 American National Standards committees. The American Institute of Chemical Engineers sponsors Subcommittee N46, Nuclear Reactor Fuel Cycle, of the American National Standards Institute and has published 15 standards originating in this committee and its predecessors.

\section{AMERICAN INSTITUTE OF MINING, METALLURGICAL, AND PETROLEUM ENGINEERS, 345 East 47 th Street, New York, New York 10017}

AIME was founded in Wilkes-Barre, Pennsylvania, May 1871. Organizationally, it is composed of three constituent societies: the Society of Mining Engineers, The Metallurgical Society, and the Society of Petroleum Engineers.

Briefly, the Society of Mining Engineers of AIME deals with the discovery, mining, and initial processing of ferrous and nonferrous minerals; The Metallurgical Society of AIME encompasses the science and technoIogies involved in the making of metals and other materials such as metal alloys; and the Society of Petroleum Engineers of AIME covers the drilling and production of oil and natural gas but not the refining process.

Many of the standards, specifications and codes that have engaged the attention of this institute were developed in cooperation with national technical bodies, principally the American National Standards Institute and the American Society for Testing and Materials.

In February 1968, the AIME delegated the participation on any of the standards committees of the American National Standards Institute or the American Society for Testing and Materials to its constituent societies. Presently, the Society of Petroleum Engineers has representatives on one of the American National Standards Institute Committees.

Formerly: American Institute of Mining and Metallurgical Engineers (1952).

\section{AMERICAN INSTITUTE OF STEEL CONSTRUCTION, INC., 1221 Avenue of the Americas, New York, New York 10020}

The American Institute of Steel Construction is a nonprofit trade association representing and serving the fabricated structural steel industry in the United States. Its purpose is to improve and advance the use of fabricated structural steel and, through research and engineering studies, to develop the most efficient, safe, 
and economical design and fabrication of steel framed structures.

The institute provides a wide variety of services to the design professions, the construction industry, and the steel fabricating companies who sponsor and support its activities. These include specifications, technical publications, computer design aids, regional engineering services, research and development, technical seminars, design award competitions, engineering fellowship awards, and programs of quality control and safety in both shop and field.

The institute promotes steel construction through the efforts of a large national engineering staff of registered professional engineers, all expert in structural steel design, and it enjoys a unique relationship with engineers, architects, building code officials and educators, who recognize its profcssional status in the fields of specification writing, structural research, design development, and performance standards.

Its two major documents are The AISC Specification for the Desion, Fabrication and Erection of Structural Steel for Buildings, and the Manual of Steel Construction. In addition, it publishes the AISC Code of Standard Practice, and a number of specifications for materials, products, and assemblies which may be used in steel framed structures. The specifications and the manual are accepted and used universally by architects, engineers, building code bodies, and Government agencies.

\section{AMERICAN INSTITUTE OF TIMBER CONSTRUCTION, 333 West Hampden Avenue, Englewood, Colorado 80110}

This institute was founded 1952. AITC is the national trade association of the structural timber fabricating industry. About 25 percent of its activities relate to standardization. Standardization activities are administered by the institute's staff with the advice and assistance of the AITC Technical Advisory Committee.

Under the procedures of the U.S. Department of Commerce, AITC has worked with the National Bureau of Standards to develop Voluntary Product Standard PS 56-73 for structural glued laminatcd timber. The institute maintains a quality control and inspection program for structural glued laminated timber based on PS 56-73 and the Inspection Manual, AITC 200. Under the program, AITC licenses qualified laminators to stamp and certify their products as being in conformance with PS 56-73.

AITC has about 20 current standards on various phases of structural timber fabrication and, particularly, on structural glued laminated timber. These standards are listed in AITC publications lists and, in addition, are promoted through various construction-industry filing systems such as the Sweet's Architectural and Industrial Construction Catalog files and the Construction Specifications Institute Spec-Data programs.

\section{AMERICAN INSURANCE ASSOCIATION, 85 John Street, New York, New York 10038}

The American Insurance Association is a nonprofit trade association created in 1964 by the merger of three organizations: the National Board of Fire Underwriters, founded in 1866; the Association of Casualty and Surety Companies, organized in 1926; and the former American Insurance Association, founded in 1952. It is the largest business association serving property and casualty insurance companies and acts as spokesman for the industry. Through its work in accident and fire prevention, loss and claim adjustment practices, research, and a variety of other services, the association contributes to public safety and helps keep insurance services at a high level of performance.

Standardization activities are administered by its Engineering and Safety Committee. Current codes issued by the association are the National Building Code, Fire Prevention Code, and Code for Installation of Heat Producing Appliances, Heating, Ventilating, Air Conditioning. Blower and Exhaust Systems. The association is represented on more than 175 standardswriting committees of the American National Standards Institute, National Fire Protection Association, American Society for Testing and Materials, and others. Information on standards is disseminated to the American Insurance Association's subscriber insurance companies, and municipal officials.

\section{AMERICAN IRON AND STEEL INSTITUTE, 1000 16th Street NW. W ashington, D.C. 20036}

A major activity of the American Iron and Steel Institute, founded in 1908, involves the selection and standardization of a group of steels known as standard steels. This work is carried on under the auspices of the institute by product technical committees which cover carbon and alloy steel bars, sheet, strip, plate, pipe and tubing, wire, and structural shapes as well as tool steel, stainless steel, and railroad materials.

Each of these individual technical committees does considerable work in classifying and defining the products, in collecting and compiling manufacturing tolerances and methods relative to standard methods of inspection for the respective products, and in reviewing existing specifications with a view toward standardizing those which are found to be most common. The work of the respective committees is presented in a series of sections of the Steel Products Manual. These committees cooperate with agencies of the Federal Government, including the Department of Defense and Department of Commerce, as well as with technical and trade organizations in matters relating to technical problems and specifications.

The institute has developed and published manuals containing recommended design criteria for cold. formed steel structural members, light gauge coldformed stainless steel structural members and structural applications of steel cables for buildings. 
These design standards are widely recognized and adopted in building codes throughout the United States.

The American Iron and Steel Institute is officially represented on standards committees of the American National Standards Institute, American Society for Testing and Materials, National Fire Protection Association, and many other organizations.

Absorbed: American Iron and Steel Association (1912).

\section{AMERICAN LADDER INSTITUTE, 111 East Wacker Drive, Chicago, Illinois 60601}

The American Ladder Institute (ALI) was founded in the early 1930's. The institute represents manufacturers of portable steel and extension ladders made from wood, metal, and fiberglass. A substantial part of the association's activities and programming is the cosponsorship of the American National Standards Institute Safety Code for Portable Wood Ladders, Al4.1. In addition, the ALI fosters safe ladder usage through the development and distribution of a pamphlet, Ladder Safety and You, and the distribution of a point of purchase ladder selection chart for the assistance of retail dealers and consumers in selecting the right ladder for the right job. The ALI also sponsors educational meetings for its members.

\section{AMERICAN LEATHER CHEMISTS' ASSOCIATION, c/o University of Cincinnati, Cincinnati, Ohio 45221}

This association, organized in 1903, is the technical society of the tanning and leather industry. Its membership consists of active and associate members and also subscribers to its journal.

The association has a number of technical committees which develop methods of analyses and testing. The final methods are published as the official methods of the association. The American Leather Chemists' Association and the American Society for Testing and Materials have a joint committee on the coordination of physical test methods. The ALCA is a member of the International Union of Leather Chemists' Society and participates in the development of methods of international use.

The methods of ALCA which are reviewed and amended as necessary, are incorporated in industry specifications. Full cooperation is maintained with its members which include representatives from practically every Government agency concerned with leather or leather products. ALCA is closely affiliated with the Tanners' Council of America, the national trade association of the leather industry. The membership of ALCA includes members from the United States, Canada, Mexico, and 34 foreign countries.
AMERICAN LIBRARY ASSOCIATION,

50 East Huron Street, Chicago, Illinois 60611

This association (ALA), founded in 1876, has long been active in developing standards and guidelines, both quantitative and qualitative, for library service and librarianship. Standards are developed by pertinent units of the association. The following publications are some of the standards and guidelines adopted by ALA or its units: AAJC-ACRL Guidelines for Two-Year College Library Learning Resource Centers; ALA Standards for College Libraries (under revision); Guidelines for Audio-Visual Materials and Services for Public Libraries; Guidelines for AudioVisual Services in Academic Libraries; Interim Standards for Small Public Libraries: Guidelines toward achieving the goals of Public Library Service; Library Education and Manpower: a Statement of Policy; Library Statistics: A Handbook of Concepts, Definitions, and Terminology (under revision); The Measurement and Comparison of Physical Facilities for Libraries; Minimum Standards for Public Library Systems, 1966 (Statistical Standards, Addenda to above, 1967) (under revision) ; Standards for Accreditation, 1972; Standards for Children's Services in Public Libraries; Standards for Library Functions at the State Level; Standards for Library Services for the Blind and Visually Handicapped; Standards for Library Services in Health Care Institutions; and Standards for School Media Programs (under revision).

The association also sponsors Sectional Committee Z85 of the American National Standards Institute.

The Library Technology Reports (of the testing programs) are available from ALA.

The ALA also assists in the development of uniform codes for analyzing and cataloging information.

\section{AMERICAN LUMBER STANDARDS COMMITTEE,} 340 Hungerford Drive, Rockville, Maryland 20850

This committee is the successor to the Central Committee on Lumber Standards. It consists of 23 representatives and 23 alternate representatives of groups of lumber manufacturers, lumber inspection agencies, engineers, architects, contractors, home builders, wholesalers, retailers, millwork manufacturers, and other consumers as well as five ex officio nonvoting government agency representatives, all of which are appointed by the Secretary of Commerce.

The latest standard, NBS Voluntary Product Standard 20-70, the American Softwood Lumber Standard became effective September 1, 1970. This edition sets the purpose, formation and functions of the committee and its Board of Review. It provides for classification of American standard lumber, standards for grading, standards for grademarking, size standards, and has appendices on nomenclature, definitions, and abbreviations. It also contains a brief history of lumber standardization. 
One of the functions of the American Lumber Standards Committee is to act as the standing committee for the purpose of considering revisions or amendments to voluntary Product Standard 20-70. It also elects a Board of Review and adopts policies used by the Board of Review in carrying out is functions.

The principal functions of the Board of Review are to: (1) review and approve rules submitted by agencies if they conform to the American Lumber Standards requirements; (2) review and approve agencies to grade under approved rules if agencies demonstrate necessary competency; and to (3) sit in continuing review of adequacy, competency and reliability of approved agencies.

The committee and its Board of Review set the standards under which virtually all of the lumber in the United States and Canada is produced.

Formerly: Central Committee on Lumber Standards (1941).

\section{AMERICAN LUNG ASSOCIATION, 1740 Broadway, New York, New York 10019}

The American Lung Association, composed of its national office as well as state and local lung associations is devoted to the prevention and control of lung disease. The American Thoracic Society, as the medical section of this association, is a professional society dedicated to all aspects of respiratory disease. Both the ALA and the ATS, either jointly or singularly, publish standards, guidelines, and statements relating to all aspects of lung disease prevention, control and patient care, including respiratory therapy and medical devices.

Current publications include: (1) Diagnostic Standards and Classification of Tuberculosis; (2) Standards for the Care of Patients with Chronic Respiratory Disease: (3) Standards for Tuberculosis Treatment in the 1970 's; (4) Guidelines for the General Hospital in Admission and Care of Tuberculosis Patients; and (5) Bacteriologic Standards for Discharge of Patients.

The various standards and guidelines are developed by the various committees of the ALA and Scientific Assemblies of the ATS. Publication of such standards is made in the American Review of Respiratory Disease and reprints are made available nationally for distribution throughout the entire ALA-ATS organization at the state and local level. All such standards and statements are of national scope. No participation is devoted to international standardization activities.

Formerly: National Tuberculosis and Respiratory Disease Association.

\section{AMERICAN MEDICAL ASSOCIATIION, 535 North Dearborn Street, Chicago, Illinois 60610}

The American Medical Association (AMA) was founded in 1846 as a national organization of physicians whose objectives are to foster the advancement of medical science and the health of the American people. AMA's standardization activities are administered by the Division of Medical Education and the Division of Scientific Activities. Many of the standards are advisory only: drug evaluation, medical terminology, guides to evaluation of physical impairment, physical fitness standards for industry, undergraduate medical education, hospital residency training programs, and continuing medical education. The association has established liaison with the Federal Government in matters of drug nomenclature, United States Adopted Names Council, and drug evaluation, Food and Drug Administration.

\section{COUNCIL ON MEDICAL EDUCATION OF THE} AMERICAN MEDICAL ASSOCIATION

The Council on Medical Education, a standing committee of the House of Delegates of the American Medical Association, since 1904 has functioned to develop and maintain standards of medical education, as well as education in fields allied to medicine. The council, in cooperation with the Executive Council of the Association of American Medical Colleges, through the Liaison Committee on Medical Education accredits all medical schools in the United States and Canada. One of the important functions of accreditation is to establish minimum standards for use by various Government agencies such as state licensing bodies. Other Government agencies, such as the Bureau of Health Manpower Education and the Veterans Administration, consult with the Liaison Committee for recommendations regarding grants to establish new schools and to develop existing schools. The document Functions and Structure of a Medical School describes standards for accreditation of medical schools in the United States and Canada.

The Council on Medical Education, in cooperation with specialty boards, specialty societies, and other national organizations, through 24 committees accredits graduate training programs throughout the United States. The council through the Liaison Committee for Specialty Boards also sets the standards for the examining boards of medical specialties. In collaboration with 28 organizations the council also sets the standards for approval of educational programs in 24 allied health occupations. The council certifies continuing education courses offered for the practicing physician. A list of the accrediting committees and copies of the standards may be obtained from the Secretary of the Council on Medical Education.

\section{AMERICAN MINING CONGRESS, 1100 Ring Building, Washington, D.C. 20036}

AMC was founded in 1897 to foster, promote and develop the welfare of the minerals industries in all their various branches within the United States, to cooperate with Government in furthering the national welfare and in developing mining and metallurgy, and to encourage and provide a medium for education in practical and scientific mining and metallurgy. It is 
deeply involved in standardization efforts through the activities of various staff members including those involved in safety, environmental control, Coal Division, Manufacturers Division projects, the Mining Congress Journal, and all other technical endeavors.

AMC works with other organizations and agencies such as the National Bureau of Standards, American National Standards Institute, the Department of the Interior, and the U.S. Bureau of Mines. Standards activities of AMC are generally national in scope and not specifically intended to be applied internationally.

\section{AMERICAN MUTUAL INSURANCE ALLIANCE, 20 North Wacker Drive, Chicago, Illinois 60606}

The standardization work of this organization (AMIA) pertaining to occupational safety and health, and traffic safety, is carried on with the American National Standards Institute (ANSI), of which it is a member body. It is officially represented on the ANSI Board of Directors, Board of Standards Review, Safety Technical Advisory Board, Highway Traffic Advisory Board, Nuclear Technical Advisory Board, Member Body Council and over 75 technical standards committees. The organization is administrative sponsor of the Safety Standard for Ladders and the Safety Standard for Ladder Towers and Rolling Scaffolds.

In the fire safety field, all standardization work is carried on with the National Fire Protection Association of which the AMIA is an organizational member and is officially represented on the Board of Directors. This association is represented on approximately 37 NFPA technical committees engaged in the development of codes and standards in the fire prevention and fire protection fields. In addition, many member company engineers are members of NFPA technical committees in the name of their company or under a personal membership. The American Mutual Insurance Alliance was founded in 1922.

Formerly: American Mutual Alliance (1956).

\section{AMERICAN NATIONAL STANDARDS INSTITUTE, \\ 1430 Broadway,}

New York, New Yorkk 10018

This is a nonprofit organization whose bylaws provide for membership from national trade, technical, professional, and labor groups; firms from commerce and industry; governmental agencies and departments; consumer groups; and similar organizations and individuals.

This institute, which replaced the United States of American Standards Institute in 1969, was originally organized as the American Engineering Standards Committee (AESC) in 1918 by five engineering societies: the American Institute of Electrical Engineers, American Society of Mechanical Engineers, American Society of Civil Engineers, American Institute of
Mining and Metallurgical Engineers, and the International Organization for Standardization. The AESC's initial purpose was to provide means for coordinating the standards issued by its founders, eliminating confusion and duplication among those standards. Its first act was to invite three Government departments to join on an equal footing with the founder societies. The War Department, the Navy Department, and the Department of Commerce accepted the invitation, and the three representatives from each of these eight groups developed the principles and procedures which basically applied to the work of the American Standards Association through August 1966. Enlarged in 1920 by the addition of trade associations, as well as additional technical and professional societies, the AESC in 1928 was reorganized as the American Standards Association in order to provide a more workable structure. Without significant structural change the association became the American Standards Association, Inc, in 1948. In 1966 the association was reorganized as the United States of America Standards Institute, with a new constitution and bylaws. Its present name was adopted in 1969.

The institute serves as the national clearinghouse for standards and provides the machinery for developing and approving standards which are supported by a national consensus. Article C3 of the American National Standards Institute Constitution states: "In standardization practice a consensus is achieved when substantial agreement is reached by concerned interests according to the judgment of a duly appointed authority. Consensus implies much more than the concept of a simple majority, but not necessarily unanimity."

Technical societies, trade associations, consumer groups, and the like make up the organizational members of the institute. Other classes of members are governmental members, company members, sustaining members (organizations not otherwise eligible for membership but interested in standards development or certification), individual members (persons interested in development of standards or in certification), and honorary members. Five councils, a board, and a committee make up the operating arms of the institute: The Board of Standards Review has the responsibility for the approval of standards. The Executive Standards Council is responsible for standards activities of the institute except for approval or withdrawal of standards as American National Standards. The Organizational Member Council, Company Member Council, and the Consumer Council represent the interests of these groups in the activities of the institute and have an input into the standards program of the organization in that they can recommend standards projects to be developed. The International Standards Council sets administrative and technical policy for the institute's international activities. The Certification Committee administers the authorized certification activities of the institute. Each of these operating arms may establish such boards and committees as are considered necessary to accomplish its programs. 
The Board of Directors is the governing body of the institute. Ex officio members are the president; the immediate past president; three vice-presidents; the director of the National Bureau of Standards or his designated alternate; the chairmen of the seven operating arms of the institute listed in the preceding paragraph; and the chairman of the Government Liaison and Support Committee, one of the three standing committees of the board (along with the Executive Committee and the Finance Committee), whose function is to develop policies and programs designed to improve and strengthen liaison with Federal, state, and local governments. Of the elected directors twelve are nominated by organizational members, twelve are nominated by company members, nine are nominated by the Govcrnment Liaison and Support Committee from among Federal Government members and other representatives of Government organizations qualified for membership, three are nominated by the Consumer Council, and three directors-at-large are nominated by the Board Nominating Committee.

The managing director, who devotes his full time to the affairs of the institute, is its chief administrative officer and also serves as its secretary. Under his direction the staff provides technical and other support to the board, committees, councils, and other operating groups of the institute in carrying out its programs.

As of September 1974 there were nearly 6,000 American National Standards on the organization's books. Of these, approximately two-thirds have resulted from submittals by competent organizations of standards which they have developed through their own procedures, together with evidence as to the existence of consensus in support of such standards. The balance have come through the work of American National Standards Committees. A few-mostly simple standards - have been approved after acceptance by a general conference. Many of the standards on the current list have been revised a number of times. Standards approved by the institute are given the title "American National Standard."

The American National Standards Institute is the United States member of the International Organization for Standardization (ISO). The United States viewpoints to be presented in the technical work of ISO are developed through the interested American National Standards Committees or through a competent committee of another organization or, if none of these is available, through a committee especially organized as a technical advisory group for a particular ISO technical committee. The work of the ISO technical committees results eventually in ISO standards which may be embodied in the national standards of the ISO's member bodies. In addition, the institute is also affiliated with the International Electrotechnical Commission, which is responsible for international standardization in the electrical and electronics fields.

Financial support of the institute comes from the dues paid by the members. An additional source of income is the sale of American National Standards.
In addition to American National Standards and the annual catalog thereof, the institute publishes the ANSI Reporter, a biweekly general newsletter; and Standards Action, a biweekly newsletter that summarizes standards that have been submitted to ANSI for approval as new or revised American National Standards; lists standards that have been approved, reaffirmed, withdrawn, or not approved by the Board of Standards Review; reports information on American National Standards Committees and technical advisory boards, proposals for formation of new ISO and IEC technical committees, and proposed certification programs; and lists newly published standards. These publications are a part of the membcrship serv. ice for all members. Subscriptions are also available to individuals without company affiliations, institutions, libraries, schools, and the like. The institute also holds various regional conferences on topics of interest in the field of standardization.

\section{AMERICAN NUCLEAR SOCIETY, 244. East Ogden Avenue, Hinsdale, Illinois 60521}

This society was founded in 1954. The American Nuclear Society Standards Committee is responsible for ascertaining the need for standards in the nuclear field, for developing or assisting in the development of such standards, for representing the society in activities with other organizations engaging in cooperative or similar activities, and for coordinating all aspects of standards activities and interests within the society.

The over 100 standardization projects are managed by subcommittees of the Standards Committee as follows: ANS-1, Performance of Critical Experiments; ANS-2, Site Evaluation; ANS-3, Reactor Operations; ANS-4, Reactor Dynamics and Control; ANS-5, Energy and Fission-Product Release; ANS-6, Shielding; ANS-8, Fissionable Materials Outside Reactors; ANS-9, Nuclear Terminology and Units; ANS-10, Mathematics and Computation; ANS-11, Radioactive Materials Handling Facility and Specialized Equipment; ANS-13, Fuel Assemblies Criteria; ANS-14, Operation of Pulse Nuclear Reactors; ANS-15, Operation of Research Reactors; ANS-16, Isotopes and Radiation; ANS-18, Environmental Impact Evaluation; ANS-19, Physics of Reactors Design; ANS-20, Systems Engineering; ANS-21, PWR Design Criteria; ANS-22, BWR Design Criteria; ANS-23, GCR Design Criteria; ANS-24, LMFBR Design Criteria; ANS-30, Power Plant Systems; ANS-31, Engineered Safety Features; ANS-32, Reactor Plant Process Systems; ANS-33, Containment; ANS-34, Radioactive Waste Systems; and ANS-35, Fuel Handling and Storage.

Three ANS standards and 12 American National Standards have been published. Some draft and trial use standards are also available. In addition, the American Nuclear Society serves as secretariat for five American National Standards Committees of the Nuclear Technical Advisory Board. 


\section{AMERICAN OIL CHEMISTS' SOCIETY, 508 South Sixth Street. Champaign, Illinois 61820}

This society, founded in 1909, is a scientific organization concerned with basic research on animal, marine and vegetable oils and fats; with their extraction, refining, and use in consumer and industrial products; and with safety, packaging and quality control. The society publishes the Journal of the American Oil Chemists' Society and Lipids, offering original research manuscripts from the aforementioned areas, often attributed to methodology. It also publishes the Official and Tentative Methods of the American Oil Chemists' Society, a two-volume, looseleaf set, annually amended by official Additions and Revisions. This volume is a result of work by various society technical committees. In an effort to offer increased uniformity, this society offers accurately tested and graded natural bleaching earth, activated bleaching earth, diatomaceous earth, refining cups and other materials, all designed for use with specific methodology. The society also maintains a list of sources of commercially available materials, instruments, and other products necessary to application of methodology. In addition, the society certifies referee chemists through its Examination Board and sponsors joint committees with the American Society for Testing and Materials, Inter-Society Color Council, Association of Official Agricultural Chemists, and American Association of Cereal Chemists. Representation is also maintained on committees of the American Association for the Advancement of Science, National Fire Protection Association, National Research Council, American National Standards Committees for ISO/TC 48 and ISO/TC 91, and the Advisory Board, Office of Critical Tables, National Academy of Sciences-National Research Council.

Formerly: Society of Cotton Products Analysts (1922).

\section{AMERICAN OPTOMETRIC ASSOCIATION, 7000 Chippewa Street, \\ St. Louis, Missouri 63119 (Headquarters); 1730 M Street NW. \\ Washington, D.C. 20036 (Washington Office)}

The American Optometric Association (AOA) was founded October 10, 1898. AOA consists of doctors of optometry from throughout the United States, and although national in scope, there are numerous mem. bers from various countries throughout the world. Currently the association has over 17,800 members.

The standardization program activities are approximately 20 percent of $\mathrm{AOA}^{\prime}$ 's total program. Standardization activities are administered primarily by $\mathrm{AOA}^{\text {'s }}$ Professional Development Division (Committee on Research and Development); Education and Manpower Division (Council on Optometric Education); and Community Health Division (Council on Clinical Optometric Care). AOA is a member body of the American National Standards Institute (ANSI). The association and its members participate extensively in various American National Standards committees, establishing standards in various areas, some of which include first quality ophthalmic prescription lenses; requirements for first quality prescription contact lenses; model motorists; data base standards; standards for safe use of lasers; occupational face and eye protection, as well as standards for lighting, color, etc. AOA also works with the National Academy of Sciences Committees in establishing standardization for visual acuity and visual fields testing. AOA participates in International Standards Programs through ANSI as well as through optometric organizations throughout the world. Generally, AOA has been a leader in establishing optometric professional standards and ophthalmic material standards. AOA works with the Food and Drug Administration in establishing standards for soft contact lenses, both directly and through American National Standards Committee Z-80, Subcommittee on Contact Lenses; also with the Department of Transportation in establishing highway safety standards specifically relating to vision, illumination/ visibility of highway signs, driver licensing standards, etc.; Department of Labor in helping to establish standards for vision requirements in construction jobs and other industries; and with the National Institute of Occupational Safety and Health (NIOSH) in establishing eye and face protection standards. AOA has also coordinated work with American ophthalmic lense manufacturers and is active in developing appropriate Federal Government standards relating to eyewear, including Federal Specifications, FF-S-620A, as well as military services standards for optometric clinical performance. Standards are promoted through our various news media--American Optometric Association News and The Journal of the American Optometric Association as well as national optometric news media, state association journals and bulletins to our state association as well as through conferences and seminars.

The Council on Optometric Education (COE) accredits and certifies schools and colleges of optometry throughout the United States and Canada, for the four year professional degree program. $\mathrm{COE}$ is recognized by the National Commission on Accrediting and the United States Office of Education as the accrediting body for the profession of optometry. COE also accredits the one and two year paraprofessional programs at various schools and colleges throughout the United States. The Council on Optometric Education establishes educational standards and has published a manual of accrediting.

The Council on Clinical Optometric Care (CCOC) has established standards for clinical performance and published a manual on clinical standards. CCOC accredits and certifies professional performance as well as facilities with regard to optometric clinics, centers, and clinical service units.

The association also maintains a national registry and certification for paraoptometric personnel. It is anticipated that future certification programs will involve speciality areas of the profession. AOA's Com. 
mittee on Clinical Standards also establishes standards in the area of optometric clinical performance-peer review, utilization review, and evaluation of care, etc. They are also becoming involved in professional standards review activities nationwide. Guidelines and standards are also elaborated in Vision Care in Prepaid Group Practice, a joint publication with the Group Health Association of America, outlining professional standards for optometric care. The association has also evolved Vision Screening Standards for compliance with Title XIX under the Social Security Act which requires all persons under the age of 21 receive a vision screening evaluation.

The scope of our standards is generally national, however, numerous international optometric organizations have also developed and adopted the standards promulgated by AOA. The association coordinates much of its work in setting material standards with American lens, frames and equipment manufacturers, numerous governmental agencies, as well as other eye care organizations.

New projects projected include further development of clinical performance standards as well as the publication of Current Optometric Information and Terminology manual indicating standards of care and performance for all optometric procedures in diagnosis and treatment.

\section{AMERICAN PAPER INSTITUTE, 260 Madison Avenue, New York, New York 10016}

This institute, formed January 1966, is the successor organization of the former American Paper and Pulp Association and its divisions, and the National Paperboard Association. Because of the numerous grades of paper and paperboard and their various uses, there have been no quality standardization programs engaged in by the American Paper Institute or its predecessor organizations. However, standards for testing certain physical characteristics such as bursting strength, tear, brightness, opacity, etc., have been developed for many grades of paper. These specifications are officially published by the Technical Association of the Pulp and Paper Industry, One Dunwoody Park, Atlanta, Georgia 30341. Standard gauge lists for combination paperboard were revised effective January 1969 and adopted by members of the Combination Paperboard Division of the Paperboard Group, API.

Although not directly related to standardization itself, the Dictionary of Paper, third edition (1965), contains over 500 pages of concise descriptions of pulp and other raw papermaking materials, papers, paperboards, paper and properties and papermaking terms. A fourth edition of this dictionary is now in process with a target publication date of 1975 . The contents of this publication afford considerable guidance in the appraisal of paper grades, specifications or standards.

The API is an active member of the American National Standards Paper Committee, P-3, and through this committee maintains contact with respect to international standardization activities. Additionally, the
API works closely with various Federal and state agencies in the development of product specifications, particularly the General Services Administration and the Joint Committee on Printing of Congress.

The API also works closely with the American Society for Testing and Materials (ASTM) in the development of its specifications and standardization activities, as well as in the formulation of safety codes for pulp and paper mills.

Formerly: Pulp, Paper and Paperboard Institute U.S.A. (1965) .

\section{AMERICAN PETROLEUM INSTITUTE, $1801 \mathrm{~K}$ Street NW., Washington, D.C. 20006}

The American Petroleum Institute was founded in 1919 and was the first national petroleum trade association to encompass all branches of the industry: producing, transporting, refining, and marketing.

The institute can and does concern itself with technical matters affecting the petroleum industry whenever there is substantial agreement among its members. Only significant problems which have broad industry application and are not likely to be resolved by some other group or individual, are considered in the institute's standardization program.

From the early years of its first half-century, the American Petroleum Institute has maintained an extensive program which encompasses not only standards for hardware and equipment, but also recommended practices, operating procedures, technical bulletins and even standard reference materials. Worldwide acceptance and use of the over 300 standards formulated by API are attributed to their balanced emphasis on sound engineering, operability, performance and safety considerations.

Authority and responsibility for management and coordination of the institute's standardization program, including relationships with other domestic, national and international standards organizations, is by delegation of the Board of Directors, vested in the API Interdivisional Committee on Standardization. Preparation, publication, revision and maintenance of an individual standard is further delegated to the most appropriate operating division (industry branch) of the institute.

The institute administers a licensing or monogram program within selected divisions for all manufacturers who desire to use the API monogram on equipment and materials fabricated in accordance with published standards. The sole consideration in the issuance of a license is provision by the applicant of reasonable evidence of technical competence, adequate plant facility and financial stability. Application of the monogram constitutes warranty by the manufacturer alone, as to compliance.

API maintains an affirmative attitude toward participation in international standardization and actively participates in the preparation of international standards in areas related to fields of API technical activity. Principle efforts are directed to the International Orga- 
nization for Standardization (ISO), although in some instances API standards themselves are accepted both nationally and internationally.

Active standards committees are estimated to number over 250 with approximately 50 new projects under consideration. Participants are drawn from oil companies, industry supplier and consultant organizations, user groups, and government agencies at all levels, Federal, state, and local. On the order of 5000 voluntary contributors are currently engaged in assessing the institute's standardization programs.

All technical and research data including standards are indexed in the institute's Publications and Materials Guide, issued annually. Projects culminated during the year are announced through publication releases sent to all news media and directly interested parties. The guide is offerd free of charge to anyone having an interest in the institute's publications.

\section{AMERICAN PHARMACEUTICAL ASSOCIATION, \\ 2215 Constitution Avenue NW., Washington, D.C. 20037}

The American Pharmaceutical Association (APhA), founded in 1852, is the national professional society of individual pharmacists in the United States. It concerns itself with matters affecting the professional, technical, legal and scientific aspects of the practice of pharmacy. The primary standardization programs administered by the association pertain to drugs and drug products intended for medicinal use, with approximately 10-15 percent of the total association's program and annual budget being devoted to standardization activities.

The Scientific Division is the organizational staff unit within $\mathrm{APhA}$ that administers the standardization activities. Within the Scientific Division the principal activity is the program of supplementing, revising, and publishing the National Formulary, (NF), and the supplying of samples of authentic specimens of substances of known purity for use in conducting the various tests and assays specified by the NF. Through the Scientific Division, APhA jointly participates with several other organizations in sponsoring and conducting a program, known as the United States Adopted Names Council (USAN), for the establishment of standardized nonproprietary nomenclature for drugs. A relatively small testing laboratory is maintained, the primary program of which pertains to the development of, and standardization of analytical methodology. By virtue of the NF program, and to an extent the USAN program, our organization is involved with the World Health Organization in developing international specifications for drugs and international nomenclature for the naming of drugs. Although to a lesser degree, APhA participates in programs of the Pan-American Health Organization and the Federation Internationale Pharmaceutique. In both the NF and USAN activities, there is considerable involvement with the Federal Government since the Federal Food, Drug, and Cosmetic Act mandates that marketed drugs in the
United States must comply with standards set forth for them in the NF; that the methods of determining such compliance should be those specified in the NF; and that the Secretary of the Department of Health, Education and Welfare is assigned the specific responsibility to ascertain that marketed drugs are in such compliance. Furthermore, the law addresses the subject of the development and recognition of drug names. In all of these activities, major contact is with the Food and Drug Administration. These programs also involve many other agencies within the Government such as the Treasury Department, Alcohol and Tobacco Division; the Social Security Administration, Medicare Division; and the Justice Department, Drug Enforce. ment Administration; etc., but to a relatively limited degree.

Certification Program Activities-The authentic sub. stances which are distributed as standards of reference (NF Reference Standards) are in a sense certified as to their suitability for the intended purpose. Otherwise, it is the responsibility of the drug manufacturer to ensure that their products meet the standards provided and are otherwise in compliance with the specifcations developed.

There are approximately 1,000 separate monographs comprising standards of identity, quality, purity, and strength for individual articles in the official National Formulary and supplements to it. In addition, there are approximately $200 \mathrm{NF}$ Reference Standards currently in distribution. The number of standardized drug names developed through the USAN program is of the order of several thousand. The scope of the standards are national in character by virtue of Federal law. Moreover, each individual state takes note of these standards in the pertinent state drug laws thereby making them a requirement in interstate as well as intrastate commerce. A number of foreign countries such as Canada, have also adopted the National Formulary as a legal standard for drugs marketed, and even in those countries where the NF is not a standard by law, it is frequently looked upon as an unofficial or voluntary standard of reference.

The National Formulary Thirteenth Edition-1970 (NF XIII), along with four supplements to the volume are distributed for APhA by the Mack Publishing Company of Easton, Pennsylvania. Lists of NF Reference Standards are available from the NF office at the APhA address on written request.

\section{AMERICAN PLYWOOD ASSOCIATION, 1119 A Street,} Tacoma, Washington 98401

American Plywood Association (APA) was founded May 16, 1933, as the Douglas Fir Plywood Association (DFPA). The organization is a nonprofit industry trade association engaged in advertising, promotion, quality testing and inspection, product and applied research, and code and standards activities. The association membership consists of plywood mills involved in the manufacture of softwood plywood produced in conformance to Voluntary Product Standard PS 1-66, 
Softwood Plywood, Construction and Industrial. DFPA grade-trademarks have been applied to plywood since 1938, as evidence that the product has been subjected to association quality inspection and testing.

APA's standardization activities are administered by the Technical Services Division, secretariat to the Industry Standards Committee. The plywood industry committee was organized to review and keep current the text of Voluntary Product Standard PS 1.66; and the Division for Product Approval which administers the quality testing, inspection and product certification validation programs for the association. Through cooperation with the Department of Commerce, National Bureau of Standards; the Department of Housing and Urban Development, FHA; Department of Transportation; Department of Defense; and the General Services Administration, APA is involved with the development of their respective standards.

The following are the engineering design standards and use specifications of APA: (1) Plywood Design Standards: Plywood Design Specification-Supplement No. 1, Design of Plywood Curved Panels; Supplement No. 2, Design of Plywood Beams; Supplement No. 3, Design of Plywood Stressed-Skin Panels; and Supplement No. 4, Design of Plywood Sandwich Panels. (2) Plywood Fabrication Standards: Fabrication of Trussed Rafters with Plywood Gussets-GT-8; Fabrication of Plywood Beams-BB-8; Fabrication of Plywood Stressed-Skin Panels-SS-8; Fabrication of Curved Panels-CP-8; Fabrication of Plywood Sandwich Panels-SP-61; and Fabrication of Plywood Folded Plates-FP-62. (3) Specifications: 303 Specialty Siding Specification, and DFPA Special Use Panel Specification. These APA standards are submitted for reference and adoption in building codes and construction standards. In addition, Voluntary Product Standard PS 1-66, a voluntary consensus standard promulgated by the Department of Commerce, is also reproduced and distributed by APA for use by the plywood industry to identify its products.

Currently the Industry Standards Committee is working on a revision to Voluntary Product Standard PS-1 and the Association Products Committee is working on association proprietary product standards.

Certification Program Activities-In order for a member mill to use association grade-trademarks, it must pass initial tests of gluebond quality and maintain a minimum level of gluebond quality in order to continue to apply these grade-trademarks to plywood. When a mill complies with the requirements of the association's quality inspection and testing program, they are issued the appropriate grade-trademarks. The association arranges for the grade-trademarks to be manufactured and maintains ownership of the gradetrademarks issued to a mill. Should a mill fail to meet the requirements of the quality assurance program, the quality supervisor is directed to physically remove the grade-trademarks from the plant. The grade-trademarking service provided to association mills is administered by the Department of Product Approval which utilizes quality supervisors dirccted by regional man. agers who make inspection calls on each mill on a random basis each week, covering all shifts. The necessary laboratory tests on specimens taken from production by the quality supervisor is done at eight strategically located laboratories for testing to check conformance of the specimens with the requirements of Voluntary Product Standard PS-1.

APA is active on an international level as a participating Member of the International Organization for Standardization, Technical Committee ISO/TC 139. Plywood.

\section{AMERICAN PODIATRY ASSOCIATION, 20 Chevy Chase Circle NW., W ashington, D.C. 20015}

The American Podiatry Association was founded in 1912 as a voluntary, nonprofit corporation and is organized under the laws of the District of Columbia.

The objects of the association are to promote the art and science of podiatry and the betterment of public health. The membership is composed of podiatrists who are licensed to practice in one of the states and are members of a component society. Component societies exist in each state, the District of Columbia and Puerto Rico. There is also a component society of podiatrists in Federal service.

The association's Council on Podiatry Education is the accrediting agency for podiatry education is recognized as such by the U.S. Office of Education and the National Commission on Accrediting.

The council maintains standards in accrediting procedures by publishing two documents for each activity of accrediting or approval. These documents are entitled Criteria and Guidelines and Manual of Procedures. The council accredits colleges of podiatric medicine and podiatric assistants' training programs. It approves podiatric residency programs and speciality boards in related fields of education.

The council's criteria and procedures are subject to the approval of the House of Delegates of the American Podiatry Association.

Formerly: National Association of Chiropodists (1958).

\section{AMERICAN PSYCHIATRIC ASSOCIATION, 1700 18th Street NW., Washington, D.C. 20009}

The American Psychiatric Association (APA) is a medical specialty organization, representing over 20,000 members. It was established in 1844 as the Association of Medical Superintendents of American Institutions for the Insane. In 1892 it became the American Medico-Psychological Association, and in 1921 the present name was adopted.

One of the association's objectives as stated in the Constitution is ". . . to advance the standards of all psychiatric services and facilities." The standards program comprises about eight percent of the organization's total activity. Publications include Standards for Psychiatric Facilities (1969) and Standards for Psychiatric Facilities Serving Children and Adolescents (1971). 
APA is a member organization of the Accreditation Council for Psychiatric Facilities and the Accreditation Council for Facilities for the Mentally Retarded of the Joint Commission on Accreditation of Hospitals. It is an active participant in development of standard classification for mental illness and the Diagnostic and Statistical Manual for Mental Disorders (DSM-11), published by the APA, and the manual used throughout much of the world. It serves as consultant to the World Health Organization on the publication, International Classification of Diseases.

lt joins with the AMA Council on Medical Education and the Residency Review Committee for Psychiatry and Neurology in establishing standards for approval of residency training programs in psychiatry and is a member organization of the American Board of Psychiatry and Neurology which gives examinations to certify physicians as qualified in psychiatry.

Standard-setting activities are operated through the APA Council on Medical Education and its Committees on Medical Education, Graduate Education, and Continuing Education; the Council on Mental Health Services and its Task Force on Standards for Psychiatric Facilities, Ad Hoc Committee on Professional Standards Review Organizations; and the Council on Research and Development and its Task Force on Nomenclature and Statistics.

Formerly: Association of Medical Superintendents of American lnstitutes for lnsane (1892); American Medicopsychological Association (1921).

\section{THE AMERICAN PSYCHOANALYTIC ASSOCIATION, \\ One East Fifty-Seventh Street, New York, New York 10022}

The American Psychoanalytic Association was founded in 1911 and is a national, nonprofit, membership organization of medical psychoanalysts. It is the purpose of the organization to study and advance psychoanalysis; to advocate and maintain standards for the training of psychoanalysts and for the practice of psychoanalysis; to foster the integration of psychoanalysis with other branches of medicine and to encour. age research in all fields having to do with the scientific knowledge and welfare of man.

There is a current individual membership of 1,375 active members; 222 associate members; and 293 affiliate members. There are 31 local affiliate psychoanalytic societies in the United States and 21 approved psychoanalytic training institutes. The American Psychoanalytic Association is a Regional Association of the International Psycho-Analytical Association.

The Board on Professional Standards' duties are: to set up standards for the training of physicians in psychoanalysis and standards for approved institutes; to set requirements for character and ethical and professional standards for membership in the association and to receive applications for membership and certify the qualifications of applicants for membership. Subsumed under the Board on Professional Standards are its standing committees all of which are concerned with the setting and maintaining of standards in psychoanalysis. These are: Child Analysis; Institutes; membership; New Training Facilities; Psychoanalytic Education; Research and Special Training. Standards have been published for Training in Psychoanalysis and for Training in Child Psychoanalysis. These standards are complied with by the training institutes which are approved by the association.

\section{AMERICAN PUBLIC HEALTH ASSOCIATION, 1015 18th Street NW. Washington, D.C. 20036}

The American Public Health Association was founded in 1872. A major contribution of this association is the development of standards of procedure, personnel qualifications and practice. lt publishes and continually updates Standard Methods for the Exam. ination of Dairy Products; Standard Methods for the Examination of Water and Wastewater; and Standards for Healthful Housing. It publishes other works where standards are included, for example, Suggested Ordinance and Recommendations Covering Public Swimming Pools. It also publishes standard methods for the Microbiological Examination of Foods and Recommended Methods for the Examination of Ambient Air. APHA is presently developing guidelines for medical experimentation on captive populations.

The APHA has representatives on various boards of the American National Standards Institute (ANSI) and cosponsors their Sectional Committee A40 on Minimum Requirements for Plumbing. APHA's Committee on Professional Education has developed a series of educational qualifications for various kinds of public health workers as well as standards of accreditation for schools of public health. APHA committees also develop publications on such diverse subjects as TB control, radiological health and chronic disease which serve as guides for practitioners, scientists, technolo. gists, administrators and others concerned with public health problems.

\section{AMERICAN ROAD BUILDERS' ASSOCIATION, 525 School Street SW., Washington, D.C. 20024}

The American Road Builders' Association was founded in 1902. The association has, as a major objective, the fostering and encouraging of the full utilization of scientific and educational measures toward the accomplishment of an integrated national highway, airport and urban public transportation system adequate to accomodate the growth and advancement of transportation necessary for the civil economy and the national defense.

Membership in the American Road Builders' Association, working through seven operating divisions, includes Federal, state, county, and city highway engi- 
necrs and administrators as well as consulting engineers. It includes also highway contractors, producers of highway materials, manufacturers and distributors of highway machinery, and educators in civil engineer. ing colleges and universities.

Committees study problems relating to highway legislation; finance, design, construction, maintenance, equipment, and operation. All efforts are constantly directed toward development of improved standards to bring about utilization of new materials and eliminate waste and improper methods, thereby accomplishing greater economy in the highway and airport fields.

Every effort is made to avoid duplication in areas of activity of other associations. The association has cooperated and will continue to cooperate with other associations in joint activities. It has published numerous bulletins dealing with practical application of technical and semitechnical developments.

Formerly: American Road Makers (1910).

\section{AMERICAN SKI TEACHERS' ASSOCIATION OF NATUR TEKNIK, Big Boulder Ski Area, Lake Harmony, Pennsylvania 18624}

ASTAN, founded 1960, has a membership of 348 . It is a group of ccrtified ski instructors united to: bring the best type of people into the ski teaching profession; promote high standards of ski instruction; keep these standards and improve the teaching system; and promote good relations between instructors and ski schools of each ski area. ASTAN maintains a library and placement service; sponsors competitions; and certifies ski instructors. The Board of Examiners Committee gives certification courses. Publications: (1) Newsletter, three/year; (2) Director of Certified Instructors, annual; Skiing for Beginners; and the ASTAN Teaching Manual. Holds annual Instructors Rally, always in April.

Formerly: American Ski Teachers' Association (1970).

\section{AMERICAN SOCIETY FOR ABRASIVE METHODS,}

1049 South Main Street, Plymouth, Michigan $\mathbf{4 8 1 7 0}$

The American Society for Abrasive Methods was founded in 1956. Its purpose is to promote and interpret to business and to the public, the scope and potentialities of abrasives; and to promote and seek to maintain industry-wide standards.

The Society's National Standards Committee is responsible for the formulation and development of standards for abrasives. It cooperates with the American National Standards Institute (ANSI) and serves on American National Standards Committee B74 on Abrasives. The standards are issued by ANSI.

\section{AMERICAN SOCIETY FOR ARTIFICIAL INTERNAL ORGANS, \\ National Office, \\ Box 777 , \\ Boca Raton, Floridla 33432}

The ASAIO was founded in 1954 as an organization to promote the development and safe usage of artificial internal organs. The society includes strong representations from both medical and engineering specialists. The society holds an annual scientific meeting where current advances in all fields of artificial internal organ development are reported. In recent years major interests have focused upon work with artificial kidneys and artificial hearts, but research has been reported in a variety of other fields.

The Standards and Specifications Committee is a standing committee of the society charged with developing voluntary standards for devices within the main scope of interest of the society. At present, four subcommittees are working on standards development in the areas of artificial kidney hemodialyzers, dialysis membranes, intra-aortic balloon augmentation, and membrane oxygenators. A committee for standardization of blood access devices is being formed. In these areas, the ASAIO standards subcommittees are the only ones active on a national scale. The ASAIO is represented on the Medical Devices Technical Advisory Board of the American National Standards Institute (ANSI), and on the International Organization for Standardization ISO/TC 150-SC2, Cardiovascular Devices. Standards developed by the subcommittees are submitted to the national and international organizations for review and dissemination.

\section{AMERICAN SOCIETY FOR MEDICAL TECHNOLOGY, \\ Hermann Professional Building, Suite 1600, Houston, Texas 77025}

The American Society for Medical Technology (ASMT) established in 1932, is a national professional organization composed of approximately 18,000 members engaged in the supervision and performance of clinical laboratory tests. The organization recognizes its major responsibilities as increasing technical knowledge, providing a means for the members to evaluate and improve their performance, and the education of students entering the various levels of clinical laboratory practice. The ultimate goal of the society is the provision of the best possible care to the patient at economically sound levels.

Since ASMT's function is to provide for the total concerns of the individuals practicing within the profession of medical technology, the greater portion of the programs, either directly or indirectly, are involved with standards, their function, updating, and their acceptance. These standards are all national in scope. 
In the area of preparation for the profession, ASMT, in cooperation with the American Society of Clinical Pathologists (ASCP), the American Medical Association, and the U.S. Office of Education determines the accreditation of education programs. This function is carried out through a body called the Board of Schools. Also, certification for individuals who have passed the national examination is carried out by ASMT and ASCP through the Board of Registry.

Continuing education for practitioners is monitored by ASMT through its national program called PACE. State and local affiliate societies cooperate in this program.

Standards for day to day practice are covered in documents such as: (1) ASMT Recommended Minimum Personnel Practices (updated each year); (2) ASMT National Minimum Standards for Clinical Laboratories; and (3) National Committee for Clinical Laboratory Standards (NCCLS) specifications for biology and chemistry reagents or reference materials, controls for equipment, etc. ASMT is very active in the individual committees preparing these specifications. Within ASMT, individuals from the appropriate scientific assemblies evaluate the proposals before the society casts its official vote for acceptance of the standards.

ASMT is also a member of the Medical Device Technical Advisory Board of the American National Standards Institute. International involvement in standards for ASMT is through NCCLS which cooperates, where appropriate, in proposals for technical standards. Other types of joint concerns for ASMT and the international picture are carried out through participation in the International Association of Medical Laboratory Technologists, which in turn, is a member of the World Health Organization. At present, ASMT is working with the Food and Drug Administration in conducting a pilot project for surveillance of products used in clinical laboratories.

Prior to 1972, ASMT was the American Society of Medical Technologists. In 1972, the society officially changed its name to the American Society for Medical Technology.

Formerly: American Society of Clinical Laboratory Technicians (1936).

\section{AMERICAN SOCIETY FOR METALS, Metals Park, Ohio 44073}

This society, founded in 1920, publishes the ASM Metals Handbook, a multiple-volume series. Eight volumes of the eighth edition are now available. These eight volumes are comprised of over 5000 pages of data prepared by technical committees and individual authors. Comprehensive coverage is given to properties, selection, heat treating, cleaning, finishing, machining, forming, forging, casting and welding of metals, and to subjects of a more scientific nature such as metal. lography, crystal structures, and alloy constitutions. In a large measure these handbooks point up recommended practices, or summarize data that will be of value to groups working on standardization. The society maintains representation on the Engineer's Joint Council, and the Joint Committee on Definitions of Terms Relating to the Heat Treatment of Metals. This committee reports to the American Foundrymen's Society, American Society for Metals, American Society for Testing and Materials, and to the Society of Automotive Engineers.

Formerly: American Society for Steel Treating (1934).

\section{THE AMERICAN SOCIETY FOR NONDESTRUCTIVE TESTING, INC., 914. Chicago Avenue, Evanston, Illinois 60202}

The American Society for Nondestructive Testing, Inc. (ASNT), was founded in 1941 as the American Industrial Radium and X-Ray Society, Inc., as a nonprofit, nongovernment organization operating under the charter issued by the Commonwealth of Massachusetts. Subsequent to the changed name in 1945, the society was re-chartered in Illinois. Its primary efforts are in the field of education and spreading the word of the many facets of nondestructive testing and materials evaluation through educational institutions, industry and the membership of the society. It has assisted in the preparation of standards and specifications through its members being involved in the activities of American National Standards Institute and American Society for Testing and Materials. Its only self-produced document that some might consider a standard is SNT-TC-1A, a five-volume set entitled Recommended Practice for Nondestructive Testing Personnel Qualification and Certification. The actual certification of the personnel involved is the responsibility of the employer.

Close liaison is maintained with many governmental bodies through committee activity and membership on pertinent committees.

The society's active work is produced through the established councils, technical and educational, and the many committees and divisions of these councils. These concern themselves with every facet of the methodologies of nondestructive testing and with the preparation of technical programs for conferences, seminars and symposia. The Educational Council works closely with colleges and other educational institutions in the field of curriculum and also assists in the teaching of such courses wherever possible.

The society publishes a journal, Materials Evaluation, on a monthly basis; a Newsletter on a monthly basis; maintains a large number of titles of technical books for sale as well as its own two-volume Non. destructive Testing Handbook. This last item is now undergoing a complete revision and will appear in multi-volumes as prepared and printed. 


\section{AMERICAN SOCIETY FOR QUALITY CONTROL,}

161. West Wisconsin Avenue, Milwaukee, Wisconsin 53203

As the professional organization in the quality control field, ASQC has actively developed and pub. lished standards since its organization in 1946. It assumed cognizance of American War Standards Z1.1 and Z1.2-1941, Guide for Quality Control and Control Chart Method of Analyzing Data, and Z1.3. 1942, Control Chart Method of Controlling Quality During Production, which were revised in 1958 as ASQC Standards B1, B2, B3 (ASA Z1.1, 1.2, 1.3. 1958) and reaffirmed by the American National Standards Institute in 1968. The society, has also published the following standards: Al-1971, Definitions and Symbols for Control Charts (American National Standard 21.5-1971); A2-1972, Definitions and Symbols for Acceptance Sampling by Attributes (American National Standard Z1.6-1971); A3-1971, Glossary of General Terms Used in Quality Control (American National Standard Z1.7-1971); and C1-1968 (American National Standard Z1.8-1971) Specification of General Requirements for a Quality Program. It also has cognizance over American National Standard Z1.4-1971, Sampling Procedures and Tables for Inspection by Attributes, and American National Standard Z1.9-1972, Sampling Procedures and Tables for Inspection by Variables for Percent Defective. ASQC participates in international standardization through its members who are accredited by the American National Standards Institute as delegates to International Organization for Standardization Committee TC 69 and International Electrotechnical Committee TC 56.

The society's Standards Committee is required to keep under observation concepts, symbols, nomenclature, terms, definitions and procedures in use in the quality control field; to select, prepare and recommend those items which the society would find advantageous to standardize; and to provide liaison with national and international standards programs in the quality engineering field.

\section{AMERICAN SOCIETY FOR TESTING AND MATERIALS, 1916 Race Street, Philadelphia, Pennsylvania 19103}

ASTM is a nonprofit corporation formed for the development of standards on the characteristics and performance of materials, products, systems, and services, and the promotion of related knowledge. In ASTM terminology, standards include test methods, definitions, recommended practices, classifications, and specifications. Founded in 1898, ASTM was formally incorporated in 1902, and has an international membership of over 20,000 .

As of July, 1973, over 4900 standard specifications, methods of tests, and definitions were in effect and hundreds of research projects were underway involv- ing some 13,500 of the country's leading engineers, scientists, research workers and educators. All of this activity is of tremendous import to American industry, municipal, state and Federal governments, and other bodies and nations. Its standards and other activities are used throughout the world.

Membership-Of the more than 20,000 regular members of the society, about 2,600 are corporate memberships, and the balance are individuals, universities, technical schools, technical societies and libraries; 15 percent of which is from outside of the United States. Of these members, approximately 13,500 occupy 44,000 berths on the society's 120 main and 1300 subcommittees.

Purpose and Activity - In both phases of activity, standardization and research, the ASTM standing technical committees occupy a most important position. It has been rightly said that these committees are the heart of ASTM. An understanding of their organization and how they function in relation to the parent society is essential. At the outset, it should be stated that the activity is of a cooperative nature, and all members of the committees serve voluntarily. The committees function under definite regulations, governing the personnel and methods of procedure. Each committee is made up of three main classes of membership-producers, users, and general interests. This latter class is comprised of independent authorities who have expert knowledge of the materials to be studied, but who are not concerned directly with their production or use. The producer group may not exceed the combined total of users and general interest groups in any committee. It is recognized that no specification covering the quality and methods of testing a material or product will come into wide usage unless it is satisfactory to both the consumer and producer. The ASTM setup is thus fundamental in its standardization procedure, whereby the producrs and consumers are brought together on an equal footing.

Standardization Procedure-Proposed standards or revisions of existing standards originate in the committee having jurisdiction in that particular field. After detailed study and work involving methods of determining properties of materials, nomenclature, etc., a proposed standard is evolved which is submitted at a meeting of the committee. Actions affecting the proposed standard are subject to a nine-tenths approval by letter ballot vote of the entire committee. Each standard, before adoption by the society, is then submitted to a letter ballot vote of the entire society membership, and a nine-tenths favorable vote of those voting is necessary before adoption.

Research, Knowledge of Materials-Obviously, research and standardization go hand-in-hand. C. B. Dudley, the society's first president and a pioneer in the development of specifications, after enumerating certain requirements of a workable specification for a material, states that "above all it should embody within itself the results of the latest and best studies of the properties of the material which it covers." Early recognition of this fact and its continued recognition through the years undoubtedly has con- 
tributed more basically than any other factor to the wide use and established authority of the society's standards.

Painstaking investigation and study of experience accumulated over years of service are often required before an adequate specification can be prepared. Agreement must be reached on the properties of materials to be specified and the methods of testing them. Due cognizance of manufacturing details, methods of inspection, and marking, should be given.

The society sponsors research in different ways, but primarily through the extensive activities of its many standard and research committees. These are correlated by a Standing Committee on Research. This group also has charge of the research fund from which contributions are made, as the need arises, to further worthy research projects.

An important factor also, is the opportunity afforded technical and research investigators to give results of their work in papers at ASTM meetings. Each year many such contributions containing important data and information on the properties of materials and their testing are published. This activity is a vital factor in the continuing education of engineers and scientists concerned with materials.

Cooperation with Other Groups and the Federal Government-The society recognizes the value and importance of cooperating with other organizations wherever a common interest exists. Accordingly, the society has joined with other national and international bodies in a great many investigative movements. A phase of cooperation which ASTM believes is most important in advancing the knowledge of engineering materials, is the joint sponsorship with other groups of symposia held on important engineering topics. The society has cooperated with such bodies as the American Society of Mechanical Engineers, American Foundrymen's Society, Society of Automo. tive Engineers, American Society of Civil Engineers, Soil Science Society of America, and many others.

Among other societies and activities in which ASTM is officially represented are the following: National Research Council, Metal Properties Council, Textile Research Institute, National Safety Council, International Union of Testing and Research Laboratories for Materials and Structure, Inter-Society Color Council, and others.

The society was one of the five originators of the American Standards Association (now the American National Standards Institute), a clearinghouse for standardization activities. Approximately one-half of the standards recognized as American National Standards were developed by ASTM committees.

ASTM also plays a major role in United States participation in international standardization through the personnel of its technical committees, and the worldwide use of ASTM standards.

Numerous divisions of the Federal Government, including virtually every federal department, cooperate closely with the society and its technical committees, and the assistance rendered by the Federal, state, and municipal governments is invaluable.
Agencies including the General Services Administration, Environmental Protection Agency, Atomic Energy Commission, National Aeronautics and Space Administration, National Science Foundation, Federal Trade Commission, Consumer Product Safety Commission, and Veterans Administration have rendered much service. All of these groups, of course, receive benefits from their work since many ASTM standards are used by the Federal Government; and the society, by publishing various technical contributions from the Government, helps to disseminate knowledge.

Particular mention should be made of the cooperation of the National Bureau of Standards (NBS) and its personnel. The latter is a relatively large group of scientists and engineers of broad training and experience concerned especially with developing factual information on many problems related to materials, and as such bring to the large number of ASTM technical committees on which they are active, an invaluable background. The NBS personnel is the largest "general interest" group in the society.

Service branches of the Federal Government are active in ASTM work, with the Army, Navy and Air Force being represented on committees. They help with various research projects and are vitally concerned with the requirements in ASTM specifications and tests.

Marking Requirements in ASTM Standards-Many of the ASTM specifications require that the product covered shall be marked or identified as to name or brand of the manufacturer, kind of material (in case of different grades or classes), certain testing information (hydrostatic test pressure, in case of pipe), and the ASTM serial designation identifying the specific standard.

Publications - The methods of publishing standards and the very widespread distribution of these publications aid greatly in facilitating their use. For ease of reference, the standards are published in collective form and each is also issued in separate pamphlet form. Predominant in interest is the Book of ASTM Standards. Each of its present 33 parts is published annually in various months of the year. A listing of their titles will give some idea of the tremendous breadth of the society's interest in materials, products, systems, and services. Part 1 on Steel Piping Materials; Part 2 on Ferrous Castings; Part 3 on Steel Sheet, Strip, Bar, Rod, Wire, Chain and Springs; Wrought Iron Bar and Sheet; Metallic Coated Products; Part 4 on Structural Steel, Concrete Reinforcing Steel; Boiler and Pressure Vessel Plate, Steel Rails, Wheels, and Tires; Bearing Steel; Steel Forgings; Ferrous Filler Metal; Ferro-Alloys; Part 5 on Copper and Copper alloys (including Electrical Conductors); Part 6 on Light Metals and Alloys (including Electrical Conductors); Part 7 on Nonferrous Metals and Alloys (including Corrosion Tests); Die Cast Metals; Electrodeposited Metallic Coatings; Metal Powders; Nonferrous Filler Metal; Part 8 on Magnetic Properties; Metallic Materials for Thermostats and for Electrical Resistance, Heating, and Contacts; Materials for Electron Devices and Microelectronics; Part 9 
on Cement; Lime; Gypsum; Part 10 on Concrete and Mineral Aggregates; Part 11 on Bituminous Materials for Highway Construction, Waterproofing, and Roofing; Soils; Skid Resistance; Part 12 on Mortars; Clay and Concrete Pipe and Tile; Masonry Units; AsbestosCement Products; Building Stone; Part 13 on Refractories; Glass, Ceramic Materials; Part 14 on Thermal Insulation, Acoustical Materials; Joint Sealants; Fire Tests; Building Constructions; Part 15 on Paper; Packaging; Cellulose; Casein; Flexible Barrier Materials; Leather; Part 16 on Structural Sandwich Constructions; Wood; Adhesives; Part 17 on Petroleum Prod. ucts-Fuels, Solvents, Engine Tests, Burner Fuel Oils, Lubricating Oils, Cutting Oils, Lubricating Greases, Hydraulic Fluids; Part 18 on Petroleum ProductsMeasurement and Sampling, Liquefied Petroleum Gases, Light Hydrocarbons, Plant Spray Oils, Sulfonates, Crude Petroleum, Petrolatum, Wax, Graphite; Part 19 on Gaseous Fuels; Coal and Coke; Part 20 on Paint, Varnish, Lacquer and Related Products--Materials Specifications and Tests; Naval Stores; Industrial Aromatic Hydrocarbons; Part 21 on Paint, Varnish, Lacquer and Related Products-Tests for Formulated Products and Applied Coatings; Part 22 on Sorp. tive Mineral Materials; Soap; Engine Antifreezes; Wax Polishes; Halogenated Organic Solvents; Part 23 on Industrial Water; Atmospheric Analysis, Part 24 on Textile Materials-Yarns, Fabrics, General Methods; Part 25 on Textile Materials-Fibers, Tire Cords, Felts, Nonwoven Fabrics, Floor Coverings, Zippers; Part 26 on Plastics-General Methods of Testing; Part 28 on Rubber; Carbon Black; Gaskets; Part 29 on Electrical Insulating Materials; Part 30 on General Testing Methods; Fatigue; Statistical Methods; Appearance Tests; Temperature Measurement; Effect of Tem. perature; Part 31 on Metallography; Nondestructive Testing; Radioisotopes and Radiation Effects; Industrial Chemicals; Emission, Absorption and Mass Spectroscopy; Part 32 on Chemical Analysis of Metal; Sampling and Analysis of Metal Bearing Ores; and Part 33, Index.

In addition to these, there are several hundred adjuncts to the Book of ASTM Standards. These are comparison standards that cannot be included in the book and must be made available separately. They include such things as reference photographs for metallic grain size and microstructures, for appearance of cotton yarns, for paint blistering, for inclusions in steel and for magnetic-particle indications of faults in metals. They include actual specimens of mica for grading visual and electrical quality, and sets of aluminum strips on which have been lithographed colors typical of the corrosion products on copper after exposure to gasoline and other fuels. They also include replicas of the color standard to determine the thermal stability of aviation turbine fuels.

A great many of the society's standards are reprinted by industrial companies and are used in textbooks and reference publications. Permission to reprint is frequently given; however, the society has invoked a modest charge for the right to reprint standards when the published material is used for commercial purposes.

Especially notable has been the widespread use of ASTM standards in various building codes such as those recommended by the Building Officials Conference of America Inc., Southern Building Congress, American Insurance Association, International Building Officials Conference, the codes issued by New York City, Chicago, Boston, and others. The Materials Section of the Boiler Code Committee of the American Society of Mechanical Engineers is based on ASTM specifications. There are numerous other related ways in which ASTM specifications are used.

The society's technical magazine, Journal of Testing and Evaluation, is published bimonthly and is effective in promoting the knowledge of the society's activities and stimulating the use of its specifications and tests. In addition, there is a monthly news magazine, ASTM Standardization News, and two quarterlies, Journal of Forensic Science and Tire Science and Technology. ASTM publishes over 30 books on various technical topics each year. Through numerous meetings, the Annual Meeting and Committee Weeks of the Society, and various local and national meetings, the importance of standardization is stressed. Mention should be made of the close cooperation of a great many technical and business journals that, with knowledge of the essential nature of the society's work, include technical articles and new accounts of the progress in the field of engineering materials where ASTM functions.

Formerly: American Section, International Association for Testing Materials (1902).

\section{AMERICAN SOCIETY OF AGRICULTURAL ENGINEERS, 2950 Niles Road, St. Joseph, Michigan 49085}

The American Society of Agricultural Engineers was founded in 1907. ASAE is a technical and professional society for engineers with interest relating to the production and processing of food, feed and fiber. The society has five technical divisions: Power and Machinery, Soil and Water, Electric Power and Processing, Structures and Environment, and Food Engineering. The society's standardization effort, consisting of 10-25 percent of the total program, relates to the development and distribution of officially adopted voluntary standards, recommendations and data. This activity is coordinated by the Assistant Secretary for Technical Activities.

ASAE participates on U.S. Technical Advisory Groups for International Organization for Standardization, ISO/TC 23, Agricultural Tractors and Machinery, and ISO/TC 131, Fluid Power Systems and Components. ASAE standards form the basis of numerous draft proposals for the United States on agricultural tractors and machinery.

ASAE participated heavily in the recent Department of Transportation study concerning the need for regulations on agricultural tractors operated on public 
highways. ASAE, through its members, provides technical support for the development of needed regulations for agriculture under the Department of Labor's Occupational Safety and Health Act. ASAE standards serve as the basis for regulations being proposed to the Occupational Safety and Health Administration by its Agricultural Advisory Committee.

All ASAE standards, recommendations and data are published in the Agricultural Engineers Yearbook. The 1973 edition includes 130 standards. An index and price list is available from ASAE Headquarters on request.

Since ASAE is the principle organization in the United States developing standards for agriculture, ASAE standards are considered national in scope. As a member organization of the American National Standards Institute (ANSI), ASAE has promulgated several standards through ANSI. The Agricultural Engineers Yearbook includes a roster of ASAE committees. Information concerning standardization projects is available from ASAE Headquarters on request.

\section{THE AMERICAN SOCIETY OF ANESTHESIOLOGISTS, 515 Busse Higlıway, Park Rirlge, Illinois 60068}

This society, founded in 1905, is the sponsor of the American National Standards Sectional Committee Z79 on Standards for Anesthesia and Respiratory Equipment. The work of this committee is devoted to: terminology, definition, units of measure, identification, dimensions and tolerances, and methods of test of anesthesia and breathing machine connecting pieces-including breathing tubes, masks and bagsfrom the patient to the machine. The committee has produced Standard Specifications for Endotracheal Tubes Z79.1-1960, and Specifications for Endotracheal Tube Connectors and Adaptors Z79.2-1961. In the final preparation stage, after approval by ballot are standards Tracheal Tubes and Cuffs Z79.1, Oropharyngeal Airways Z79.3, and Anesthetic Reservoir Bags Z79.4. The American Society of Anesthesiologists was host to a plenary meeting in Boston on October 9th and 12th, 1972 of International Organization for Standardization (ISO) Technical Committee 121 which covers the same work as the American National Standards Committee Z79. The ISO draft standards approved on October 12th, 1972 were: Tracheal Tubes, 12l/WG 2 N 67; Anaesthetic Reservoir Bags, 121/WG 2 N 68; Oropharyngeal Airways, 121/WG N 69; Breathing Machines for Medical Use, 121/WG 3 N 96; and Terminology, 121 N $69(=121 /$ WG N 41 -Terms Relating to Anaesthetic Equipment. Subject to small amendments agreed by ISO/TC 121 WG 4 including the title to be Terms Relating to Anaesthesiology, 121/WG $4 \mathrm{~N}$ 51E-Terms Relating to Breathing Machines. Subject to small amendments, 12l/WG 4 N 52-Terms Relating to Modes of Administration of Anaesthetics.

In each case they are almost identical to the American National Standards Z79 drafts.
The American Society of Anesthesiologists has, in addition, a Committee on Mechanical Equipment which maintains liaison with the standardization work of other professional and technical bodies in the medical field.

Formerly: Long Island Society of Anesthetists (1912); New York Society of Anesthetists (1935); American Society of Anesthetists (1935).

\section{AMERICAN SOCIETY OF CINEMATOGRAPHERS, 1782 North Orange Drive, Hollywood, California 90028}

The American Society of Cinematographers (ASC) was founded in 1919. The Research and Educational Committee of this society is engaged in standardization activities on an interdepartmental basis within the motion picture industry.

The versatility and rapid expansion of present day wide screen motion picture production methods necessitate immediate standardization of procedures within the industry for methods, equipment and/or agreements on aperture dimensions. One example of the society's work in this regard is ASC Recommendation No. 13, covering the newly developed Techniscope wide screen production method which is at present followed by all major studios throughout the world. This document sets forth technical facts as well as dimensions for camera aperture and ground glass and/or finder markings.

\section{AMERICAN SOCIETY OF CIVIL ENGINEERS, 345 East 47 th Street,} New York, New York 10017

The ASCE was founded in 1852 for the advancement of the science and profession of engineering. Under certain circumstances it produces national standards, but in general participates through appointed representatives to standards-producing organizations, as well as through review of new standards and codes as they are formulated.

National issues on standards are the concern of the ASCE Committee on Standards and its Task Committees on building codes, metrication, nuclear standards, and performance standards for excavations and foundations.

Presently more than 150 members of ASCE represent the society on over 75 standards and code activities of other organizations, including the American National Standards Institute (ANSI), the American Society for Testing and Materials (ASTM), the American Iron and Steel Institute, the National Sanitation Foundation, the U.S. Chamber of Commerce, the American Institute of Architects, and the National Association of Home Builders. ASCE is also represented on several International Organization for Standardization (ISO) Technical Committees.

In working with these organizations, ASCE prepares, publishes and votes on materials as appropriate to the society, and these usually result in some form 
of published American National Standard or other suitable standards media. The Manuals and Reports on Engineering Practice listed in the General Information Section of the ASCE Register provide some information on ASCE publications related to standards.

Formerly: American Society of Civil Engineers and Architects (1868)

\section{AMERICAN SOCIETY OF ELECTROPLATED PLASTICS, INC., \\ 1000 Vermont Avenue NW., Washington, D.C. 20005}

The American Society of Electroplated Plastics is a nonprofit organization devoted to improving the efficiency of its industry and to promoting the use of electroplated plastics. ASEP was organized in 1966 and incorporated in the State of Pennsylvania in 1967. As the only national association representing the electroplated plastics industry in the U.S., ASEP has a domestic and foreign membership of 65 companies.

The standardization program accounts for roughly 70 percent of ASEP's activities. ASEP's Standards and Guidelines, first promulgated in 1967, has approximately doubled in size as the technology of this new industry has grown. Since the inception of the standardization program, ASEP has worked with the American Society for Testing and Materials in developing specifications, four of which have already received ASTM approval. ASEP standards and guidelines govern such considerations as: parts design; mold design; substrate fabrication requisites; plastic product qualification; test procedures and standards (including standard test panel, adhesion, corrosion, thermal cycling, and appearance); performance capabilities (including substrate, plate construction, and proven applications); handling of molded parts for plating; and industry terms. ASEP's Industry Standards Committee is responsible for coordinating changes to Standards and Guidelines. Registered holders of ASEP's Standards and Guidelines automatically receive new specifications and other changes as they are developed.

No formal international standards agreements exist. However, several overseas firms hold copies of Standards and Guidelines for their information and use.

\section{AMERICAN SOCIETY OF ENOLOGISTS, P.0. Box 411, \\ Davis, California 95616}

The American Society of Enologists is an association of trained enologists, viticulturists and other wine specialists organized in 1950 and incorporated in 1951 in California, as a nonprofit corporation exclusively for scientific and literary purposes in this field. It publishes the American Journal of Enology and Viticulture, a quarterly devoted primarily to original research papers, but also with short abstracts or reviews of books and research papers related to enology.

Under the Technical Projects Committee uniform methods of analysis applicable to wine are studied, collaboratively, and recommended if found satisfactory. Their most recent publication Uniform Methods of Analyses for Wines and Spirits, American Society of Enologists, 1972, lists 11 methods for alcohol, Brix, $\mathrm{pH}$, sulfur dioxide, copper, iron total and volatile acid. Other methods are under study.

Other activities include sponsorship of scholarships and an annual meeting with presentation of research papers and exhibition of apparatus and equipment.

\section{AMERICAN SOCIETY OF HEATING, REFRIGERATING AND AIR-CONDITIONING ENGINEERS, United Engineering Center, 345 East 47 th Street, New York, New York 10017}

ASHRAE, founded in 1894, has contributed standards vital to man's well-being and comfort-in office buildings, factories, school and home construction; in food and beverage processing, storage and distribution; in solar energy utilization; and, more recently, in the nation's space program. The society is organized and operated for the exclusive purpose of advancing the arts and sciences of heating, refrigeration, airconditioning and ventilation, the allied arts and sciences, and related human factors for the benefit of the general public. To fulfill its role, the society shall recognize the effect of its technology on the environment and natural resources to protect the welfare of posterity.

Probably no ASHRAE activity or accomplishment has a more direct influence upon living conditions than its standards. ASHRAE standards are developed to assist industry and public by offering a uniform method of testing equipment for rating purposes, by suggesting safe practices in designing and installing such equipment, by providing other information which may serve to guide the industry. ASHRAE standards have been referred to by national and international agencies, as well as being source documents for the development of American National Standards (ANSI).

The prime responsibility for the development of standards is within the scope of the ASHRAE Standards Committee. This committee is supported by a staff organization administered by the Director of Standards. ASHRAE Standards Project Committees are continually in the process of promulgating new standards, as well as reviewing current standards so that they will reflect technical advances in the areas which they cover. At present the society has 35 standards available. ASHRAE has for many years been a member of the American National Standards Institute (ANSI). The society holds a secretariat for a number of International Organization for Standardization (ISO) technical committees and has taken the lead in submitting several standards for consideration as international standards. The standardization program has grown tremendously since 1940 with the increased cooperation among countries in the standardization field. About one third of the total society 
program is related to the national and international standardization program.

ASHRAE has cooperated with a number of Government agencies, principally with the National Bureau of Standards in supporting technical programs, but there has not been any involvement with Government agencies in the development of specific standards.

Formed by merger of: American Society of Heating and Air-Conditioning Engineers, Inc. and the American Society of Refrigerating Engineers (1959)

\section{AMERICAN SOCIETY OF LUBRICATION ENGINEERS, 838 Busse Highway, Park Ridge, Illinois 60068}

This society was organized in 1944 to encourage the active cooperation of industry and the professions in advancing the knowledge and application of the art of lubrication in all its branches. To support and stimulate the study and development of the theory and practice of the techniques of lubrication, this society develops and promulgates standards on industrial lubricants and lubrication practices. This activity began in 1962. A total of twenty standards have been published to date. These standards are national in scope. A list of standards may be obtained by writing to the above address.

\section{THE AMERICAN SOCIETY OF MECHANICAL ENGINEERS, United Engineering Center, 345 East 47th Street, New York, New York 10017}

The American Society of Mechanical Engineers was incorporated on December 24, 1881.

ASME is a professional society organized to: promote the art and science of mechanical engineering and the allied arts and sciences; encourage original research; foster engineering education; advance the standards of engineering; promote the intercourse of engineers among themselves and with allied technologists; broaden the usefulness of the engineering profession in cooperation with other engineering and technical societies; and promote a high level of ethical practice.

The development of codes and standards is an important part of the society's activity to promote the art and science of mechanical engineering. The ASME Policy Board, Codes and Standards, supervises the standardization activities of the society under the authority delegated to it by the ASME Council which is the governing board of ASME. The Managing Director, Codes and Standards, serves as the Secretary of the Policy Board, Codes and Standards.

The organization participates actively in international standardization through its sponsorship of American National Standards Committees which serve as the USA Technical Advisory Groups for the International Organization for Standardization (ISO). In addition, ASME sponsors several USA Technical Advisory Groups for activities which do not have corresponding American National Standards Committees.

Many branches of the Federal Government are represented on standards committees sponsored by ASME. Among these are: U.S. Department of Aoriculture, U.S. Department of Commerce, U.S. Department of Defense, U.S. Department of Health, Education, and Welfare, U.S. Department of the Interior, U.S. Department of Labor, Atomic Energy Commission, Environmental Protection Agency, Federal Power Commission, General Services Administration, National Aeronautics and Space Administration, Tennessee Valley Authority, Veterans Administration, and the U.S. Postal Service. In addition, liaison is maintained with the U.S. Department of Transportation. ASME operates a certification program in connection with its boiler code activity for boilers, pressure vessels, and nuclear plant components. The society authorizes manufacturers to apply ASME Code Symbol Stamps to their product, indicating compliance with the ASME Boiler Code.

The society currently published 360 standards in all fields of mechanical engineering. The ASME Publications Catalog lists ASME publications as well as its standards.

ASME sponsors the following standards committees: Boiler Code; Performance Test Code; Controls and Safety Devices for Automatically Fired Boilers and Warm Air Furnaces; Decompression Chambers and Transfer Capsules; Codes and Standards Education; Gas Pipeline Committee; Food, Drug and Beverage Equipment Committee; Steam Turbines; Standardization of Therbligs, Process Charts, and Their Symbols; Piston Rings; Diaphragm Actuated Control Valve Terminology; Turbine Water Damage Prevention; Air Pollution Standards; Shielded Ignition Systems for Industrial Engineers; Al3-Scheme for the Identification of Piping Systems; A17-Safety Code for Elevators, Dumbwaiters, Escalators and Moving Walks; A40-National Plumbing Code; A90-Safety Code for Manlifts; A112-Standardization of Plumbing Materials and Equipment; All3-Safety Code for Mechanized Parking Garage Equipment; A120-Power Operated Platforms Used for Exterior Building Maintenance; Bl-Standardization and Unification of Screw Threads; B2-Pipe and Hose Coupling Threads; 4-Allowances and Tolerances for Cylindrical Parts and Limit Gages; B5-Machine Tool, Components, Elements, Performance and Equipment; B15-Safety Code for Mechanical Power-Transmission Apparatus; B16-Standardization of Flanges, Fittings and Valves; B17-Keys and Keyseats; B18-Standardization of Bolts, Nuts, Rivets, Screws, Washers, and Similar Fasteners; B19-Safety Standards for Compressor Systems; B20Safety Code for Conveyors and Related Equipment; B27-Standardization of Retaining Rings, Retaining Clips, and Similar Devices; B29-Transmission Chains and Sprocket Teeth; B30-Safety Code for Cranes, Derricks, Hoists, Jacks and Slings; B31-Code for Pressure Piping; B32-Standardization of Wire Diam- 
eters and Metal Thicknesses; B36-Standardization of Wrought-Iron and Wrought-Steel Tubing and Pipe; B40-Specifications for Pressure and Vacuum Gauges; B46-Classification and Designation of Surface Qualities; B47-Gage Blanks; B55-V-Belts and V-Belt Drives; B56-Safety Standard for Powered Industrial Trucks; B73-Centrifugal Pumps for Chemical Industry Use; B88-Calibration of Measuring Systems for Pressure, Temperature, Fluid Flow and, Liquid Level; B89. Dimensional Metrology; B94-Cutting Tools, Holders, Drivers and Bushings; B95-Terminology for Pressure Relief Devices; B102-Industrial Corundum Bearings; B106-Design of Transmission Shafting; B107-Socket Wrenches and Socket Wrench Drives; B118-Overrunning Clutches; B133-Gas Turbines-Procurement; C85-Terminology for Automatic Control; MH1-Standardization of Pallets; MH5-Standardization of Freight Containers; MH11-Power or Hand Operated Handling Trucks; MH14-Industrial Loading Ramps; N45-Reactor Plants and Their Maintenance; Yl-Abbreviations; Y10-Letter Symbols; Y14-Standards for Drawings and Drafting Practice; Y15-Preferred Practice for the Preparation of Graphs, Charts, and Other Technical Illustrations; Y32-Graphic Symbols and Designations; Z94-Industrial Engineering Terminology; Z228-Incineration; Technical Advisory Groups for ISO/TCl1, Boilers and Pressure Vessels; ISO/TC30, Measurcment of Fluid Flow in Closed Conduits; IEC/TC4, Hydraulic Turbines; and IEC/TC5, Steam Turbines. In addition, ASME has representation on 101 standards writing committees sponsored by other organizations.

The society promotes the use of its standards through press releases to technical magazines and by direct mail publicity to its 66,000 members.

\section{AMERICAN SOCIETY OF PHOTOGRAMMETRY, 105 North Virginia Avenue, Falls Cluurch, Virginia 22046}

Founded in 1934, the American Society of Photogrammetry is primarily concerned with the art, science and technology of measuring and interpreting photographic images. Its scope of interest includes the fields of aerial photography, photogrammetric surveys, photographic interpretation and remote sensing. A monthly journal, Photogrammetric Engineering, is devoted to new developments, equipment, techniques, and applications in these areas.

The society publishes manuals which are generally accepted as standards of reference. These include the Manual of Photogrammetry, the Manual of Photographic Interpretation, and the Manual of Color Aerial Photography. A two-volume Manual of Remote Sensing is now in preparation.

A Committee on Standardization is currently developing the basis for a program of standardization within the society's scope of interest. The Professional Activities Committee is concerned with ethical standards and the certification of professional photogrammetrists. A nomenclature committee contributes to Government programs aimed at the standardization of definitions and terminology.
The socicty is a member of and participates actively in the work of the International Society for Photogrammetry.

\section{AMERICAN SOCIETY OF PLUMBING ENGINEERS, \\ 16161 Ventura Boulevard, Suite 105. \\ Encino, California 91316}

The American Society of Plumbing Engineers (ASPE) is a professional technical society organized to elevate the field of plumbing to professional status. ASPE was incorporated in 1964 as a nonprofit organization. It is the only international organization devoted exclusively to the interests and concerns of plumbing engineering.

Although ASPE does not publish standards, it is engaged in the important work of advising builders, architects and property owners in the value, to them and to their projects, of well conceived, carefully prepared plumbing drawings and clear, concise specifications. The society is actively represented on committees such as the National Standards Plumbing Code Committee of the National Association of Plumbing-Heating-Cooling Contractors, the American National Standards Institute (ANSI), the American National Standards Committee A40; International Association of Plumbing and Mechanical Officials (IAPMO) and the American Society of Sanitary Engineering (ASSE), and on the local level, on numerous code and administrative authorities.

ASPE's code committees: (a) examine all regulatory codes pertaining to the plumbing industry to bring them into sharp focus. Thus, the plumbing engineer can join with governmental authorities to interpret and administer codes so that systems can be designed with a minimum of corrections or revisions during the construction phase of the project, eliminating unnecessary costs; (b) submit proposed revisions or clarifications of codes to code writing authorities in their campaign to simplify, standardize and modernize all codes; and (c) offer advisory services to other organizations or to governmental agencies involved in writing or enacting codes.

\section{AMERICAN SOCIETY OF SAFETY ENGINEERS, 850 Busse Highway, Park Ridge, Illinois 60068}

The society, founded in 1911, is composed of career safety specialists, organized to promote and foster the advancement of the profession and the well-being and professional development of its members.

In 1973 the American Society of Safety Engineers (ASSE) adopted the position that as an organization it would no longer participate in the development of individual technical standards, however, it would continue to develop standards for the profession and/or the professional safety engineer and participate in standards policy bodies. These standards activities 
remain under the supervision of the Vice-President of Professional Affairs.

ASSE promotes the participation of industry, commerce, Government, labor, educational institutions, etc., in the development of technical standards by pointing out to the membership the need for them to urge their individual companies or organizations to become involved in such activities, to assure that any resulting standards are effective and operable. The society uses its limited resources for participation on broader, policy-making committees of these organizations where representation of the profession is appropriate. It also recommends highly qualified specialists to the standards advisory committees being established by Occupational Safety and Health Administration (OSHA).

Absorbed: United Association of Casualty Inspectors (1914).

\section{AMERICAN SOCIETY OF SANITARY ENGINEERING, \\ 960 Illuminating Building, Cleveland, Ohio 44113}

This society was established in 1906 primarily for the purpose of promoting health, welfare and safety of the public through better sanitary principles as related to plumbing. The society has endeavored to develop rules and regulations for the advancement of sanitary science in plumbing, encourage standardization and project the need for practical and scientifically developed plumbing installations. As a help to both manufacturers and local officials, the ASSE established the Seal Program. This seal, displayed on a product, will indicate that the product has been tested and certified for compliance with the standard having the consensus of manufacturers of that class of product and is acceptable to the ASSE. The Standards Committee is presently working to develop standards for products relating to plumbing and sanitation.

Formerly: American Society of Inspectors of Plumbing and Sanitary Engineering.

\section{AMERICAN SOD PRODUCERS' ASSOCIATION, \\ Garmo Inc., Association Building, 9th and Minnesota, Hastings, Nebraska 68901}

The American Sod Producers' Association (ASPA) is the national organization representing the sod industry. It was formally organized in 1967 with 40 charter members as a nonprofit organization under the Statutes of Ohio. Membership consists of sod producers and associated interests such as equipment, seed, and chemical suppliers and landscapers.

ASPA was formed with two broad objectives encompassing the interests of its members in a united effort toward (1) the production of better quality sod more efficiently and economically, and (2) to promote the proper use of sod. In promoting the proper use of sod, a major accomplishment is the advisory assistance that is available in specifying the best adapted sod and its proper installation. In this regard, national guideline specifications were drafted, printed and made available for distribution. Assistance has been provided to various state and Federal agencies as well as architects, landscapers, and a wide variety of professional turfgrass managers with sodding specifications. Copies of the printed specifications are available from the Executive Secretary. In addition, assistance can be provided in writing specifications as well as advising on the proper use of sod.

\section{AMERICAN SOYBEAN ASSOCIATION, P.O. Box 158 Hudson, Iowa 50643}

This association, founded in 1920 , is the nationwide organization of soybean producers and is particularly concerned with standardization of grades for soybeans and soybean products, both for domestic sale and sale into the export markets. Because the United States at present supplies about 90 percent of the soybeans that move into world markets, it is essential that buyers and handlers in other countries understand the standards established for U.S. beans. Therefore, one major activity of the association is in the field of grading standards for soybeans. The association works closely with the Grain Division of the Department of Agriculture on this standards activity.

The association has a direct interest in the standards established for 44 percent protein soybean meal, 50 percent protein soybean meal, soy flour, and soy grits. With a shortage of protein throughout the world, it is important that there be established standards for the new soy protein products, such as extruded and texturized proteins, meat analogues and other commuted new foods. These are new food products and not substitutes for meats and other animal products. Soy oil is the major source of edible vegetable oil throughout the world and, therefore, standards are important for crude, semirefined, and refined grades. Soy oil is well qualified to serve in many other food products such as margarine, shortenings, salad dressings, and cooking and salad oil. Since U.S. soybeans and soybean products are relatively new commodities in the world markets, there is the problem of acquainting buyers with U.S. grading standards, establishing grading standards which are practical from our standpoint and from those of the buyer, and of changing the standards when it is deemed desirable.

\section{AMERICAN SPICE TRADE ASSOCIATION, P.O. Box 1267, 580 Sylvan Avenue, Englewood Cliffs, New Jersey 07632}

This association, founded in 1907, maintains a Quality Control Committee whose function it is to adopt standards of quality for whole spices, seeds, and herbs imported at American ports of entry. Also, through the ASTA's Research Committee, in cooperation with RESEARCH 900, the values of the base 
nutrient composition of spices have been developed. These include not only ash, fat, fiber, moisture, protein, and calories, but the vitamin content as well. In another Research Committee project conducted in cooperation with the Wisconsin Alumni Research Foundation, the content of twenty-one mineral elements in a number of spices has been determined.

The association has developed a publication known as Official Analytical Methods for analyzing spices. These methods contain twelve general methods for analyzing spices, eleven methods for analyzing specific spices, and a method for the determination of ethylene oxide in spices.

\section{AMERICAN VACUUM SOCIETY, 335 East 45th Street,} New York, New York 10017

The American Vacuum Society (AVS) was founded in 1953 as the Committee on Vacuum Techniques, Inc. In 1958, the name was changed to the American Vacuum Society. AVS seeks to advance and disseminate knowledge concerning vacuum science and technology, thin films, vacuum metallurgy and surface science.

The Standards Committee, one of seven standing committees of AVS, administers the standardization activities. There are currently 25 vacuum standards issued by the society which are considered national in scope. The new AVS standards are published in the Journal of Vacuum Science and Technology and eventually will be submitted to the American National Standards Institute (ANSI) for adoption.

The new current projects of the Standards Committee are: procedures for calibrating McLeod gauges; procedures for calibrating equipment used in evaporation processes; and design and fabrication of rugged ionization gauge suitable as transfer standards.

The Standards Committee maintains liaison with the American Society for Testing and Materials and other standards-writing bodies whose interest border on vacuum technology. On an international level, AVS serves as an advisory body to ANSI for representation on the Vacuum Technology Committee, TC/112, of the International Organization for Standardization (ISO).

\section{AMERICAN WATCHMAKERS INSTITUTE INC., P.O. Box 11011, Cincinnati, Ohio 45211.}

Founded in 1960 after a merger of two earlier organizations, the Horological Institute of America and the United Horological Association of America. AWI is a nonprofit corporation dedicated to the advancement of horology. Its more than 4,000 members are watchmakers and others who have acquired a horological background through selling, servicing or collecting horological items. Activities include technical bulletins, a certification program, professional seminars, regional meetings, vocational brochures, technical service, a monthly newsletter, and maintenance of the Packard watch collection. AWI lends slide and film-illustrated scripts to its members.

In general, the activity of the institute is involved in standards of craftsmenship. This is achieved through the dissemination of technical bulletins, and certification examinations-two types: certified watchmaker and master certified watchmakers, and finally, participation in state licensing. Former activities were: Standards Committee participation in the United States of America Standards Institute's (now the American National Standards Institute) program on the Standardization of Corundum Bearings in Horology, a request from the Department of the Army to review standards on chronometers, and a request from the U.S. Bureau of Standards to review railroad time standards. On an international plane, the British Horological Society had requested an opinion from the institute in regard to the proper placement of jewels in a 17 jewel watch.

Finally the institute aims to standardize the technical teaching techniques in the United States through its Education Committee which operates through the schools.

\section{AMERICAN WATER WORKS ASSOCIATION, 6666 West Quincy Avenue, Denver, Colorado 80235}

The American Water Works Association (AWWA) was founded March 29, 1881 to advance the knowledge of the design, construction, operation and management of water utilities in the production and distribution of safe and adequate community water supplies.

AWWA's standards program, the largest national direct participation program of the association, involves approximately 680 committee members. This standards program is administered by the AWWA Standards Council and operates under procedures approved by the AWWA Board of Directors. Early in 1973 the procedures were approved by the American National Standards Institute Board of Standards Review as adequate for the development of a national consensus. The procedures apply to standards and related publications such as books, manuals, handbooks and reports developed by committees of the Standards Council or by committees jointly sponsored with other organizations. A brief report of the Standards Council appears in the AWWA Yearbook. Since AWWA is the major national representative of the water utility industry in the United States, its standards are considered national in scope. The association is publisher of the standards for design and installation, painting, and inspection and repair of steel tanks produced by the Joint Committee on Steel Tanks which is jointly sponsored by AWWA, the American Welding Society, and the New England Water Works Association. In cooperation with committees of the American Public Health Association and the Water Pollution Control Federation, a committee of this association assists in the preparation and periodic revision of the 874-page book, Standard Meth- 
ods for the Examination of Water and Wastewater, now in its 13th edition. The 14th edition is scheduled for publication in late 1974 or early 1975 . Future editions will be published every two years. AWWA holds the Administrative Secretariat for American National Standards Committee B58 on Vertical Turbine Pumps and American National Standards Committee A2I on Cast-Iron Pipe and Fittings. Cosecretariats for American National Standards Committee A21 are the American Gas Association and the New England Water Works Association. The AWWA currently has representatives on 12 standards committees of other organizations.

The AWWA Yearbook contains a complete list of standards committees, including their scopes and membership. Currently there are 68 standards for products and materials and 132 standard test methods for examination of water. The product and material standards are listed in the AWWA Publications Catalog which is published as a part of the AWWA Yearbook, and is available free of charge to anyone who requests it. The water test methods are a part of a larger book entitled Standard Methods for the Examination of Water and Wastewater.

Presently there is no certification program, however, the Standards Committee on Steel Tanks is attempting to develop a self-certification program for manufacturers and formulators of paint systems for steel water storage tanks.

Federal Government activities are part of the standardization program of the association. To this end AWWA cooperates with the Department of Defense Standardization Program Analysis, Federal Supply Class 6810, Chemicals.

There is also an active international program. The association participates in the International Organization for Standardization (ISO) TC5/SC2, Cast Iron and Ductile Iron Pipe; ISO TC 147, Water Quality; and ISO/TC 30/SC7, Water Meters.

\section{AMERICAN WAX IMPORTERS AND REFINERS' ASSOCIATION, 225 West 34th Street, New York, New York 10001}

The association was formed in 1948 for the purpose of establishing and maintaining a cordial and friendly relationship among the members, and by united and cooperative effort to develop, promote and protect the interest of the industry.

It has established specifications, sampling and test methods for carnauba, candelilla and ouricury waxes together with color standards for carnauba wax.

\section{AMERICAN WELDING SOCIETY, $2501 \mathrm{NW}$. 7th Street, Miami, Florida 33125}

The American Welding Society was founded in 1919. The technical committees of this society pre- pare standards such as codes, specifications, recommended practices and technical reports. The standards emanating from these committees represent four broad categories: (1) Welding Fundamentals -including symbols, testing, definitions, filler metals, and safety and health; (2) Welding Processes-including resistance welding; thermal spraying, brazing and soldering; (3) Inspection of Welds, and Qualification of Welders and Procedures; and (4) Industrial Applications of Welding-pertaining to buildings, bridges, ships, storage tanks, automotive, piping and aerospace. The technical committees are composed of approximately 700 experts from the academic community and industry, including producers and consumers, to ensure that the standards reflect the best industrial practices. Symposiums and technical meetings are held to gather information for standards. The society has published more than 70 standards, and cooperates with other organizations in the preparation and review of standards if they include welding.

The society is also involved in the preparation of standards on the international level. As an active member of the International Institute of Welding, the society maintains liaison with the ISO committee on welding. The society sponsors a Technical Advisory Group to ISO/TC44-Welding, which participates through the American National Standards Institute (ANSI) in establishing the USA position for voting on draft international standards. The society acts as technical advisor to the American representation on the IEC Committee on Welding.

The society participates in the ANSI Welding Technical Advisory Board (WTAB) which it helps to organize. The objective of the WTAB is to coordinate welding standards development nationally.

\section{AMERICAN WOOD INSPECTION AGENCY, P.O. Box 5824, \\ Spartanburg, South Carolina 29301}

This organization is a nonprofit, nongovernment corporation organized in 1973 to administrate a quality control program for treating plants manufacturing pressure preserved wood products. The five voting Directors of the corporation are technical people knowledgeable in wood preservation and quality control, and employed in an associated technical capacity. The members of the corporation are the pressure treating companies subscribing to the quality control services of the agency. Members are authorized to mark their products with the AWIA quality mark if the quality of their products, as determined by modern statistical methods, meet or exceed the minimum requirements of the American Wood-Preservers' Association. The agency contracts with various chemical laboratories for the inspection of the preserved wood samples submitted by member treating plants. The results of these inspections are used by the AWIA to rate the quality of the material produced by the treating plants. The AWIA has a quality control manual which sets forth in detail the standard sampling and inspection procedures required for the AWIA quality control program. 
This manual also contains the applicable American Wood-Preservers' Association standards that set forth the minimum treatment requirements for pressure preserved wood.

\section{AMERICAN WOOD-PRESERVERS' ASSOCIATION,}

1625 Eye Street NW.

Washington, D.C. 20006

This association, in its seventieth year, has among its principal objectives the standardization of specifications for wood preservatives and their introduction into the materials to be preserved, and the improvement of materials and methods used in construction with preserved wood. In carrying out its aims, the association has published and keeps current 64 standards covering preservatives, treatment of commodities, analysis methods, conversion tables and other miscellaneous standards. These standards are contained in the AWPA's Book of Standards. The standards are referenced in state and Federal specifications and are widely used throughout the using and producing fields of the industry.

\section{AMERICAN WOOD-PRESERVERS BUREAU, P.O. Box 6085 . 2772 S. Randolph Street, Arlington, Virginia 22206}

AWPB, a nonprofit organization cooperating with the American Wood-Preservers' Association and the American Wood-Preservers Institute, it provides a nationally known Quality Mark that, when affixed to a piece of wood certifies a definite preservative treatment.

The American Wood-Preservers Bureau has issued quality control standards for water-borne and creosote preservatives to assist specifiers and users in obtaining properly pressure-treated products. Each standard stipulates the types and quantities of wood against termites and decay for the end-use applications outlined in each standard.

Standards published are: (1) AWPB Quality Mark Lumber, Timber, Plywood, issued June 1973. The standards include those for Softwood Lumber, Timber and Plywood for Above Ground Use: Pressure Treated with Water-Borne Preservatives (LP-2), Pressure Treated with Light Petroleum Solvent-Penta Solution (LP-3), Pressure Treated with Volatile Solvent (LPG) Penta Solution (LP-4), Pressure Treated with Creosote or Creosote Coal Tar Solutions (LP-5), Pressure Treated with Heavy Petroleum Solvent-Penta Solution (LP.7); and those for Softwood Lumber, Timber and Plywood for Ground Contact Use: Pressure Treated with Water-Borne Preservatives (LP.22), Pressure Treated with Light Petroleum Solvent-Penta Solution (LP-33), Pressure Treated with Volatile Petroleum Solvent (LPG).Penta Solution (LP-44), Pressure Treated with Creosote or Creosote Coal Tar Solutions (LP-55), and Pressure Treated with Heavy Petroleum
Solvent-Penta Solution (LP.77). (2) AWPB FDN, Quality Control Program for Softwood Lumber, Timber and Plywood Pressure Treated with Water-Borne Preservatives for Ground Contact Use in Residential and Light Commercial Foundations, issued February 1972. (3) AWPB Quality Mark Marine Piling, issued July 1971.

\section{ANTI-FRICTION BEARING MANUFACTURERS' ASSOCIATION, 60 East 42nd Street, New York, New York 10017}

The Anti-Friction Bearing Manufacturers' Association was founded in 1933. The Annular Bearing Engineers Committee, Roller Bearing Engineers Committee, and Ball Manufacturers Engineers Committee are sponsored by this association. These engineering committees develop and maintain the AFBMA Standards for Ball and Roller Bearings and Balls, which are published as a set of 13 booklets covering: terminology; boundary dimensions; tolerances; definitions and gaging practices; bearing identification code; packagingrecommended method for domestic and export; shaft and housing fits; mounting accessories; load ratings and fatigue life for ball bearings; balls; load ratings and fatigue life for roller bearings; instrument ball bearings; and rolling bearing vibration and noise.

AFBMA cooperates with the American National Standards Institute and International Organization for Standardization on the development of national and international standards. It also works with Government agencies on the improvement of Federal specifications.

\section{ARCHERY MANUFACTURERS' ORGANIZATION, 618 Chalmers Street, Flint, Michigan 48503}

The Archery Manufacturers' Organization was established in 1950 and it is a private, nonprofit, nongovernmental organization. The primary purpose of the corporation is to improve and promote the sport of archery, improve and promote the business of archery manufacturers; to further the business interests of and promote friendly relationships with its members; to study ways and means of improving business methods; and to establish trade standards and to compile and distribute to its members statistics and information regarding the archery manufacturing industry.

The Standards Committee has provided the industry with a series of carefully planned standards that encompass: bow length, bow weights, arrow spine charts, arrow length, arrow point taper, arrow nock taper, bow string lengths, and bow and arrow nomenclature. The committee serves the organization in an advisory capacity and also as an investigating unit.

Formerly: Archery Manufacturers and Dealers' Association; Archery Manufacturers' Association (1968). 


\section{ARCHITECTURAL PRECAST ASSOCIATION, \\ 825 East 64th Street, \\ Indianapolis, Indiana 46220}

The Architectural Precast Association (APA) was founded in 1966, for manufacturers of precast concrete panels and their suppliers, to: (1) promote the dissemination of educational materials related to the manufacture and use of precast concrete; (2) promote interest in precast concrete throughout the construction industry; and (3) encourage the adoption of the standards and specifications of the association.

APA, with contributions from the Pikes Peak Chapter of The Construction Specifications Institute (CSI), prepared Specifying: Precast Concrete Panels, CSI Specification Series 03410, issued March, 1973 by CSI.

\section{ARCHITECTURAL WOODWORK INSTITUTE, 5055 South Chesterfield Road, Arlington, Virginia 22206}

This institute was formed in 1953 and in 1958 absorbed the Millwork Cost Bureau, which was established in 1914. AWI carries on a sustained program of standardization in the fields of cost accounting, estimating, detailing and billing, and the fabrication of architectural woodwork, sometimes known as special millwork, detail millwork or contract millwork. This is done through the following publications: AWI Cost Accounting Manual (1963); AWI Operational Cost Estimating Book (1960); Quality Standards for Architectural Woodwork (1973); Guide Specification for Architectural Woodwork (1973).

The institute also maintains and offers correspondence course training for estimators and detailers and billers. Likewise, it publishes and distributes to architects and specification writers a series of brochures and technical bulletins to aid and inform them on the proper design-use and specifying of architectural woodwork.

\section{ASBESTOS TEXTILE INSTITUTE, P.O. Box 471, 131 North York Road, Willow Grove, Pennsylvania 19090}

The Asbestos Textile Institute, founded 1944, acts as a clearinghouse for information on asbestos textiles and serves in an advisory capacity to various Government agencies in the preparation and revision of purchase specifications. In addition, it works closely with the American Society for Testing and Materials Subcommittee D13.14 (A-4 on Asbestos) concerning specifications, methods of test and recommended practices for asbestos textiles.

The ATI publishes a Handbook of Asbestos Textiles which sets forth various styles and properties of asbestos textiles and lists the standard grades, weaves and weights of many of the textile products. Included in the handbook is a Glossary of Asbestos Textile
Terms and ASTM Specifications and Methods of Testing for asbestos textiles.

Another pamphlet available from the ATI, prepared under the auspices of the institute's Air Hygiene and Manufacturing Committee, is entitled Measurement of Airborne Asbestos Fiber by the Membrane Filter Method and is concerned with the accurate measurement of airborne asbestos fiber in order to conform with Federal, state or provincial statutory requirements for asbestos threshold limit value.

The institute, jointly with the Quebec Asbestos Mining Association and the Asbestos Cement Products Association, publishes a Manual of Testing Procedures for Chrysotile Asbestos Fibre which provides standard methods for testing the physical and chemical properties of chrysotile asbestos fiber.

\section{THE ASPHALT INSTITUTE, Asphalt Institute Building, College Park, Maryland 20740}

The institute, founded in 1919, has a technical committee structure consisting of an International Technical Committee composed of representatives of institute member companies located in the U.S., Canada and overseas, and of institute engineers, who serve ex officio. This committee coordinates all institute technical committee activities. In addition, committees on asphalt materials, design, and construction technology, as well as ad hoc committees created by the International Technical Committee, exist to handle specific assignments. Other technical committees, either standing or ad hoc, concern themselves with technical matters within the four geographical divisions of the institute.

In addition, the institute maintains a Research and Development Department including well equipped laboratories, at its headquarters building.

The technical committees and the Research and Development Department, as well as other institute engineers, participate in a wide variety of technical society activities concerned with standardization of test procedures and material specifications related to asphaltic products and their use. The institute has published construction specifications for a wide variety of asphalt applications in highway and airfield construction, uses of asphalt in hydraulic structures, asphalt protective coatings for pipe lines, uses of asphalt in recreational areas, and others. It cooperates with the American Society for Testing and Materials, the American Association of State Highway Officials and with state and Federal agencies in laboratory and committee work related to standardization activities.

Formerly: Asphalt Association (1929).

\section{ASPHALT ROOFING MANUFACTURERS' ASSOCIATION, 757 Third Avenue, New York, New York 10017}

The Asphalt Roofing Manufacturers' Association (ARMA) was founded in 1919. The Technical Com- 
mittee of this association cooperates actively in the formulation and improvement of standards and specifications covering asphalt roofing products which are developed by the Federal Government, the American Society for Testing and Materials, and the Underwriters' Laboratories. Through its Simplification Committee, ARMA made studies and analyses designed to show the multiplicity of items produced in the industry and their relative importance from a sales volume standpoint. The purpose of these studies was to enable manufacturers to intelligently accomplish such individual simplification and standardization of their own lines as circumstances seemed to warrant.

Formerly: Asphalt Roofing Industry Bureau (1970).

\section{THE ASSOCIATED COOPERAGE INDUSTRIES OF AMERICA, INC., 818 Olive Street,}

St. Louis, Missouri 63101

This association, founded in 1915 , carries on its standardization work through committees appointed especially for that purpose; namely, the Tight Grade Rules Committee and the Slack Grade Rules Committec. The association maintains strict standards, that are national in scope, to assure the quality of products of the cooperage industry. These standards, frequently revised and kept up-to-date, are incorporated in two booklets: Grade Rules and Specifications, Tight Barrel Staves and Heading, and Grade Rules and Specifications, Slack Barrel Staves, Heading and Hoops.

Transactions throughout the industry are based on these grade rules which in addition, form the basis for Federal specifications for barrels and kegs.

Rules are provided by the association governing inspection service in cases of controversy. The association also maintains standards governing sales and settlements for the use of its members.

The members of this association are constantly cooperating with container users in the development of barrels suitable for their products. These barrels are made from material produced in accordance with the association's standard grades and specifications.

\section{ASSOCIATED LOCIKSMITHS OF AMERICA, INC. C.P.O. 729 , 11 Elmendorf Street, Kingston, New York 12401}

Associated Locksmiths of America (ALA) was founded in December 1955, to encourage and promote the voluntary exchange among locksmiths of technical service data on security products; to elevate the position of the locksmith in the security industry; to establish a uniform code of ethics and to conduct trade promotion activities. ALA held its first meeting and election of officers in July, 1956. About 10 percent of the total program is now involved with standardization.

The Security Standards Committee administers the standardization activity and is now working on standards for security devices in relation to locks. ALA is closely allied with, and active in, the American Society for Testing and Materials' program for voluntary standards in locking devices, Committee F-12 on Security Systems and Equipment. Sevcral years ago, in 1960, ALA was successful in getting industry support to standardize and improve the quality of packaging for key blanks. In 1973 the Security Standards Committee recommended a Standard City Ordinance on Building Security. At present, the organization is working on a recommended standard for state licensing or registration of locksmiths. The Key Blank Boxes, Building Security, and Locksmith License are the three current standards of ALA, that are considered national in scope.

\section{ASSOCIATED MASTER BARBERS AND BEAUTICIANS OF AMERICA, 219 Greenwich Road, P.O. Box 17782, Charlotte, North Carolina 28211}

The Associated Master Barbers and Beauticians of America (AMBBA) was founded in 1924 to provide benefits and professionalize the industry through education and standardization. AMBBA's standardization activities are approximately 20 percent of the entire association program, are administered by the National Educational Council and recommended to the Executive Committee for approval. The standard rules and regulations are written for and apply to barber colleges, individual students and barbers, hairstylists, textbooks, and for judging contestants in contests.

The rules and regulations for standardized schools of the National Educational Council are written and adopted to protect the student and professionalize the industry, through the concept of setting a proper example whereby the student obtains his first impressions. It is understood by all involved that state regulations supersede the standardized rules and regulations of AMBBA. In addition, there is a barber stylist standardized examination and a standardized educational program for the profession. Current projects underway are standardization of advanced educational methods in barber schools as well as for shows and educational seminars.

AMBBA promotes its standards through promotional mailings; personal contact; the monthly magazine, The Professional Men's Hairstylists and Barber's Journal; and barber shows.

Certification Program Activities-Examinations to certify ability to do hair piece work, styling, coloring, relaxing and merchandizing are required for the professional certification of barbers. 


\section{ASSOCIATION FOR EDUCATION OF THE VISUALLY HANDICAPPED, 1604 Spruce Street, Philadelphia, Pennsylvania 19103}

First known as the Instructors of the Blind, and later as the American Association of Instructors of the Blind, the Association for Education of the Visually Handicapped (AEVH) began in 1853 with a national meeting of superintendents of the 16 residential schools for the blind. AEVH was incorporated in Kentucky in 1957 and assumed its current name in 1968. With a membership of 2500, AEVH is the professional organization which serves educators of the visually handicapped throughout the United States and Canada with additional members in several foreign countries. In addition to publishing a professional quarterly, Education of the Visually Handicapped, and a bulletin, Fountainhead, AEVH prints selected papers from each of its biennial conferences. The organization participates actively in training institutes, the development of special standards, the encouragement and report of research in the field, cooperates with national and international agencies and organizations interested in the education of visually handicapped children and youth, and maintains a certification service for teachers and child care workers/houseparents. This certification service, coordinated by a standing committee of the Board of Directors, originated to fill a need of establishing standards for individuals working in the field. Of the current membership, approximately 500 are certified. The standards for each type of certification are reviewed annually and the Board of Directors, upon the recommendation of the Certification Committee, makes changes in line with the changing empluases in the field of education of the visually handicapped.

\section{ASSOCIATION FOR THE ADVANCEMENT OF MEDICAL INSTRUMENTATION, 1500 Wilson Boullevard, Suite 417, Arlington, Virginia 22209}

The Association for the Advancement of Medical Instrumentation (AAMI) founded in 1965 is a professional association; a nonprofit, international organization established with the objective of improving patient care through the application of technology to mediciue. Presently AAMI has a membership of over 3,000 individuals including physicians, engineers, scientists, other health professionals, researchers, educators, Government representatives, and industry officials. In addition, AAMI has over 200 corporations and institutions as members.

AAMI by its charter and bylaws, is a multidisciplinary organization representing all interests and disciplines in the medical instrumentation field. Through the formation of its Standards Committee and Standards Committee Council, its Standards Subcommittees, its professional journal, and other official publications, AAMI strives to promote con- tinuing interdisciplinary communication as a primary objective for all its members and as a vital element in the standards making process.

One of the primary coordination efforts of AAMI is to develop and promulgate medical device standards. This is a significant professional attempt to provide direction in the standards area for developing voluntary consensus safety and performance standards, and includes the active participation and services of individuals from both the private and public sector.

AAMI currently has 13 active standards subcommittees as follows: Cardiac Valve; Catheter; Dialyzer; Electrical Safety; Kidney; Pacemaker; Laser; Ophthalmology; Reliability of Medical Instruments; Sterile Disposables; Ultrasound; Vascular Prostheses; and Neurological Instrumentation.

Several draft standards have already been issued by various of the subcommittees listed above.

\section{ASSOCIATION OF AMERICAN FEED CONTROL OFFICIALS, INC., Box 3160 . \\ College Station, Texas 77840}

The Association of American Feed Control Officials (AAFCO) is a private nonprofit association of State Feed Control Officials maintaining its registered office and a registered agent in the District of Columbia as required by the District of Columbia nonprofit corporation act.

The association was founded in 1905 and includes all officers charged by law with the execution of the state, provincial, dominion and Federal laws in the continent of North America, Hawaii and Puerto Rico regulating the production labeling, distribution, and sale of animal feeds and livestock remedies. It also includes the heads or chiefs of experiment stations, departments of agriculture, bureaus, divisions, sections, laboratories, and employees thereof and research workers charged by law with the examination of animal feeds and livestock remedies.

A uniform bill is provided for the implementation by the various states for consumer protection. The association has advised and will advise in the future control services of many nations concerning their control program.

Many of the states have contracted with the Federal Food and Drug Administration to perform the activities of this agency with regard to animal feeds and drugs used in animal feeds. The Association of American Feed Control Officials publishes an official publication annually with official terms and definitions for feeds and feed ingredients and additives for commercial feeds which is available from the Chief Chemist, Division of Agricultural Chemistry, P.O. Box 16390-A, Baton Rouge, Louisiana 70803. The standards published by this organization are international in scope as outlined above. These standards are adopted universally and used substantially throughout production, labeling, distribution, and sale of animal feeds and livestock remedies.

AAFCO has annual meetings of the Board of Direc- 
tors and the association to provide open discussions regarding uniformity.

\section{ASSOCIATION OF AMERICAN RAILROADS, American Railroads Building, 1920 L Street NW., \\ Washington, D.C. 20036}

This association is the central coordinating and research agency of the American railroad industry. It was established in 1934 as an outgrowth of numerous earlier organizations, many of which dated back to 1867 and were created for the purpose of standardizing various features of railroad service. The association was formed in the interest of adequate and efficient railroad service and to enable the railroads to better contribute to the accomplishment of the purposes of the national transportation policy. The association represents the railroads in appropriate cases before the courts, administrative tribunals, Congressional committees, and other Government bodies. It serves as the joint agency of the railroads concerning such matters as research, operation, railway economics and statistics, accounting and financing, as well as industrywide problems in the data processing field, which may require joint handling in furtherance of the national transportation policy.

For functional purposes, the association is organized by departments which span the fields of law, operations and maintenance, research and testing, railway economics and statistics, finance and accounting, railway information and public affairs, legislation, and management systems and procedures. Those departments which include standardization as a major part of their activities are described in the following paragraphs.

Operations and Maintenance Department,

Operating-'Transportation Division (Washington) :

This general committee (which also serves as General Committee, Operations and Maintenance Department, composed of 16 chief operating officers and one representative of the American Short Line Railroad Association) conducts the activities of this division and supervises the activities of the department. Other work of the Operating-Transportation Division is carried on by sections and standing committees which study and report on the various specialized problems that arise. The efforts of the General Committee and the standing committees are directed toward standardization of various operations and maintenance practices.

The Committee on Compensation is composed of 16 chief transportation officers and a representative of the American Short Line Railroad Association. The efforts of this committee are directed toward the standardization of rates and rules pertaining to mileage allowances for privately owned freight cars, demurrage and storage.

The sections that follow are interested in standardization of the fields indicated.
Communication and Signal Section (Washington):

This section coordinates the principles and practices of American railroads; revises and keeps up to date drawings, specifications, requisites and other miscellaneous information contained in its manuals of recommended practice covering design, construction, maintenance and operation of railway communications and signaling devices; and is developing standards for inductive interference. The C\&S Section has the responsibility for the assignment of radio frequencies to all railroads and the protection of these frequencies.

The section investigates the development of new devices, improvement of existing equipment, and new methods of installation, maintenance, and operation pertinent to the arts of communications and signaling, through its standing committees under the following subject titles: Wire and Cable Lines; Practices and Operation; Electronics; Radio; Instructions and Shop Practice; Designs; Inside Plant; Highway Grade Cross. ing Protection; Transmission and Interlocking, Traffic Control and Block Signaling.

The Communication and Signal Section has representatives on many technical committees, both Government and private.

\section{Intermodal Transportation Section (Washington):}

Development of uniform procedures and practices relating to trailers and containers in the rail-highway transportation field is the objective of this section.

\section{Station and Terminal Committee (Washington):}

This committee assists member roads in the development of important practices and procedures affecting station and terminal operations.

\section{Safety and Special Services Division (Washington):}

This division is charged with responsibility for safety in all areas of railroading. The division is comprised of the following sections, committees or bureaus.

\section{Safety Section (Washington) :}

This section assists member roads in safety programs to promote preventive activities for reducing accidents and personal injuries. It has worked to develop clarification and standardization in railroads' reporting accidents under Federal regulations.

\section{Committee on Operating Rules (Washington):}

The functions of this committee relate to the development of standard rules and practices regarding the operating phase of railroading.

\section{Medical Section (Washington) :}

This section maintains contact with chief medical and surgical officers of member roads to promote 
standards in the medical field and standardization of procedures relating to the health of railroad employees and patrons. It cooperates with state and Federal agencies in formulating standards.

\section{Police and Security Section (Washington) :}

This section handles problems of importance to the railroad industry and attempts, where possible to develop standard practices in matters relating to law enforcement practices, national emergency conditions, trespassing, safety education and training.

\section{Bureau of Explosives (Washingtom):}

This bureau also functions as a part of the Safety and Special Services Division and is an agency for cooperation between shippers, carriers, the Interstate Commerce Commission and the Department of Transportation to promote the safe transportation of hazardous materials. It maintains a chemical laboratory for the study of explosives and dangerous articles and containers. A staff of traveling inspectors insures compliance with the requirements of regulations and specifications.

\section{Engineering Division (Chicago) :}

The several committees of this division are involved with track standards; roadbed; ties; railroad track scales; and all other practices relating to maintenanceof-way matters and establishes standard practices for construction or installation and of maintenance.

\section{Freight Claim Division (Chicago):}

This division publishes a Freight Claim Rule Book, or Manual of Practices, in which are set forth (1) rules and standards prescribed for the investigation, adjustment, and interline apportionment of claims paid; (2) lists of freight claim and prevention officers of member carriers; (3) standard forms used to file claims and furnish statistical information of freight loss and damage; (4) recommended practices in loss and damage prevention work and (5) other information for use in the freight claim offices of member carriers. There are also published and distributed annually, in printed form, interpretations of freight claim rules as handed down by the committees of the division as the result of arbitration procedure.

\section{Freight Loss and Damage Prevention Section (Chicago):}

The Freight Loss and Damage Prevention Section is responsible for all freight loss and damage prevention activities. It maintains close coordination with shippers, shipper organizations, and member roads for the purpose of developing and establishing practical ways and means to reduce loss and damage to freight. The section's activities are directed by a National Freight Loss and Damage Prevention Committee which reports to the General Committee of the Freight Claim Division. Special committees deal with specific phases of freight loss and damage prevention and make recommendations to the National Freight Loss and Damage Prevention Committee.

\section{Freight Loading and Container Section (Chicago):}

The objective of this section is to provide improved packaging or carloading methods for nondangerous commodities moving in rail freight cars. This section conducts surveys with shippers or receivers of freight in order to develop recommended practices for loading and packing of freight.

These activities include performance of tests for the purpose of comparing packaging or loading methods.

To provide interchange of information, the section participates in activities of trade associations or industrial organizations representing manufacturers of shipping containers or commodities moving as freight as well as groups or associations developing standards.

\section{Mechanical Division (Washington):}

Through the activities of its various committees, this division has adopted standards and recommended practices covering materials for cars and locomotives which are incorporated in a manual. This manual, which is revised and supplemented annually, includes specifications for materials. The division also issues periodic revisions of individual manuals relating to specific components.

\section{Economies and Finance Department (Washington):}

This department deals with standardization and simplification of railroad accounting and treasury practices and requirements. This department prepares various publications embracing rules, standard forms, procedures and codes, as well as economic and statistical data covering railroad operations and their financing.

Management Systems Department, Data Systems Division (Washington) :

The objectives are (1) to encourage and facilitate the interchange of information systems and data processing ideas and practices; (2) to stimulate the development and application of data processing and information techniques and establish orderly procedures which will promote their efficient and productive use and simplify the interchange of data; and (3) to provide an organization for prompt consideration and resolution of problems that require concerted action by the railroads.

This division serves as the principal railroad representative to American National Standards Committee X3 and the Transportation Data Coordinating Committee.

Through the Divisions Standards and Coding Com. mittee there is being conducted an examination of the industry's coding and standards need and development of the following: Standard Point Location Code 
(SPLC) ; Standard Route Code; Standard Patron Code; Standard Commodity Codc; Standard Packaging Code; and the Standard Carrier Code.

Researeh and Test Department (Washington) and AAR Researeh Center,

3140 South Federal Street, Chicago, lilinois 60616 :

The objectives of this department, which has charge of technical research on problems affecting carriers, are to increase the profitability of the railroads; to provide cost-effective approaches to safety requirements; and to develop responses to environmental requirements. The principal fields of research are (1) improvements in designs and specifications for equipment, track, and facilities; (2) optimization of design to accommodate dynamic interaction of equipment and tracks; (3) analysis and system studies of railroad operations and maintenance practices; and (4) research on improvements in safety and on environmental problems.

\section{ASSOCIATION OF AMERICAN STATE BOARDS OF EXAMINERS IN VETERINARY MEDICINE, 1680 Teaneck Road, Teaneck, New Jersey 07666}

The Association of American State Boards of Examiners in Veterinary Medicine was estabished in 1957, is a nonprofit, nongovernment organization operating under a State of Illinois charter granted in August 1960. Affiliated members are State Boards of Veterinary Medical Examiners. Individual board appointed members are invited to participate. Thirty-eight of the 44 member states utilize a standard written examination prepared by the Professional Examining Service, labeled National Boards.

The association has close representative liaison with the American Veterinary Medical Association for the purpose of standardizing objective criteria for evaluating graduates of foreign veterinary schools, accrediting programs for the development and training of animal health technicians, and ascertaining the national needs for veterinary services. Through working committees, progress is being made toward further standardization of qualifying practical as well as written examinations. Common dates for examination further this objective.

Standing committees include: Reciprocity, Advisory Law, Advisory Board on Veterinary Specialties, Education, Examination, and Grievance.

Surveys are conducted and reports are prepared and circularized to all 50 states, Puerto Rico and Guam.

The association is a member of licensing National Associations Representing State Licensing Agencies in the Health Field.

Formerly: Association of American Boards of Examiners in Veterinary Medicine (1968).

\section{ASSOCIATION OF BEDDING AND \\ FURNITURE LAW OFFICIALS, c/o Utah Department of Agriculture Room 412, State Capitol Building, Salt Lake City, Utah 84114}

This association provides a national forum for the discussion of all questions relating to the administration of bedding and upholstered furniture laws as carried on by regulatory officials of the states, commonwealths, territories and possessions of the United States, their political subdivisions, the District of Columbia and the Dominion of Canada. The association encourages and promotes the adoption of uniform bedding and upholstered furniture laws, rules, regulations, nomenclature, labeling requirements and enforcement procedures. It secures, devises, tests and adopts standard methods of inspection and sampling of bedding and upholstered furniture and the analyses of filling materials used therein,

Other purposes of the association are to secure, devise, test and adopt standard methods of determining the efficiency of insecticides, fumigants, sterilizing and disinfecting processes and equipment as applied to articles of bedding, upholstered furniture and filling materials used therein; to secure uniformity in the statement of analytical results; to promote, conduct and encourage research in chemistry and allied fields as these relate to analyses of filling materials used in bedding and upholstered furniture.

\section{ASSOCIATION OF EDISON ILLUMINATING COMPANIES, 51 East 42nd Street, New York, New York 10017}

The Association of Edison Illuminating Companies (AEIC) was founded in 1885.

Much of the AEIC's work in standardization is carried on in cooperation with other technical organizations, notably: the American National Standards Institute. The association is officially represented on the following American National Standards Committees: B16, B31, B36, B49, C1, C2, C8, C12, C29, C34, C37, C50 C55, C76, and 05; and on Committees A-I and D22 of the American Society for Testing and Materials.

In consultation with the Insulated Power Cable Engineers Association, the Cable Engineering Section of the Association's Committee on Power Distribution, prepared: specifications for impregnated paper insulated cable-solid, low-pressure gas-filled and oil-filled types (all lead covered), high pressure pipe type; specifications for polyethylene and cross-linked polyethylene, and ethylene propylene rubber insulated shielded cables; a guide for application of maximum insulation temperatures at the conductor for impregnated-paper-insulated cables; and a guide for electrical tests of cable joints $138 \mathrm{kV}$ and above. All were printed by the association. 


\section{ASSOCIATION OF ENGINEERING GEOLOGISTS, \\ P.O. Box 21-4164, Sacramento, California 95821}

The Association of Engineering Geologists was founded in 1957, to promote high ethical and profes. sional standards. There are two committees engaged in standardization activities.

The Building Codes Committee stresses the contribution that can be made by engineering geologists through the intelligent formulation of practical building code provisions. The committee is active on a local level as advisors to county and municipal government groups who are considering code revisions. Code provisions for development of floodplain and tidal marshland are also within the scope of this committee.

The Committee on Engineering Geology Mapping Symbols works on the standardization of Engineering Geology map symbols for utilization by all states and countries.

\section{ASSOCIATION OF HOME APPLIANCE MANUFACTURERS, 20 North Wacker Drive, Chicago, Illinois 60606}

AHAM, a nonprofit association comprised of U.S. manufacturers of over 90 percent of major and portable appliances, was formed in 1966 by merger of the American Home Laundry Manufacturers' Association and the Consumer Products Division of the National Electrical Manufacturers' Association.

AHAM develops voluntary appliance performance standards and makes safety recommendations to Underwriters' Laboratories and American Gas Association, represents the industry in consumer and Government relations, compiles statistics, sponsors certification programs and provides consumer appliance information, educational materials and teaching aids.

AHAM's Engineering, Standards and Safety Board includes engineering executives of member companies who determine policy and direct nine product engineering committees and determine type of contents of standards to be developed with special consideration on product safety.

AHAM helps develop international standards through representation on technical committees of the International Electrotechnical Commission.

Liaison is maintained on standardization with the Federal Government's National Bureau of Standards, General Services Administration, Food and Drug Administration, Federal Trade Commission, and Consumer Product Safety Commission.

AHAM's product certification programs cover key performance characteristics of room air-conditioners, refrigerators/freezers, dehumidifiers, and humidifiers.

AHAM standards are national in scope. Fourteen have been published and 25 are under development in AHAM engineering committees.

Standards use is promoted through publications and press releases, through certification, and by the American National Standards Institute's recognition of AHAM standards as American National Standards.

\section{ASSOCIATION OF IRON AND STEEL ENGINEERS,}

Suite 2350, Three Gateway Center, Pittsburgh, Pennsylvania 15222

This association was founded in 1907 as a means of fostering an exchange of ideas toward the advancement of the iron and steel producing industry. The scope of the AISE now embraces all the various divisions of steel plant engineering, maintenance and operations. Engineering divisions include electrical, mechanical, welding, combustion, operating practice, lubrication, safety, rolling mill, standardization and research. Sixteen district sections are scattered at steel producing centers throughout the country.

The association has developed standards for the steel industry which include such items as motors, surface finish, cranes, wiring, brakes, bearings, mill buildings, etc. In some cases these are detailed standards, in other cases they are recommended practices. A list of current standards is as follows: D-C Mill Motor Standards, A-C Mill Motor Standards, Standard for Machined Surface Finishes, Alloy Steel Chain and Alloy Steel Chain Slings for Overhead Lifting, Specification for Electric Overhead Traveling Cranes for Steel Mill Service, Specification for Design of Ladle Hooks, Crane and Mill Auxiliary Drive Motor Cable Size Wiring Standard, Standard for Desion of Hot Metal Ladles, Brake Standards for Mill Motors, Plain Bearing Recommended Practice, Specifications for Design and Construction of Mill Buildings.

The AISE also sponsors research activities at research institutions for the purpose of developing data for future standards and for the improvement of steel mill operating practice.

Formerly: Association of Iron and Steel Electrical Engineers (1936).

\section{ASSOCIATION OF OFFICIAL ANALYTICAL CIEMISTS,}

Box 540 Benjamin Franklin Station, Washington, D.C. 20044

The association, founded as the Association of Official Agricultural Chemists, is a professional organization of state and federal chemists devoted to developing, testing, and sponsoring standard methods for the analysis of fertilizers, foods, feeds, pesticides, drugs, cosmetics, hazardous substances, and other materials related to agriculture and public health. It was organized in 1884 by the state and federal chemists who were in charge of enforcement of state fertilizer laws, or who, as members of agricultural experiment stations or the U.S. Department of Agriculture, were interested in practical and scientific applications of fertilizers to crops. The form of organization is one in which voting is restricted to official chemists, but discussion is open to all chemists. Four meetings prior to 
1884 had failed to produce a cohcsive and stable organization of both official and commercial chemists. This final organization form was settled upon with the full cooperation and even insistence of commercial chemists. They agreed on the principle that since it was the official chemists who had the responsibility for the enforcement of the laws, they also had the responsibil. ity for the choice of valid methods of analysis for this purpose.

As the regulatory control of other commodities such as foods, feeds, drugs, cosmetics, hazardous substances, and pesticides became a recognized governmental function, the work of the association expanded. It has accepted the responsibility of providing the regulatory and research scientist with accurate and reproducible methods of analysis that arc required for the enforcement of laws and regulations. This is accomplished through adherence to a fundamental constitutional requirement that methods approved by the association be subjected to collaborative study. In this, a number of representative chemists analyze the same samples by the proposed method to demonstrate its accuracy and reproducibility in their hands. At the present time about 600 chemists, designated as "Associate Referees," are studying methods of analysis grouped in about 60 general categories from "Agricultural Liming Materials" to "Waters." Not all of them are official chemists; many are industry chemists, who because of their specialized knowledge and experience, also participate in the development and testing of methods of analysis. The results of the studies of these associate referees form the basis for the actions of the association in its approval or disapproval of methods.

All state chemists including those of universities and experiment stations are members of the association. Federal organizations represented in the association are: Food and Drug Administration, Public Health Service, Department of Agriculture, Department of Defense, Internal Revenue Service, Fish and Wildlife Service, National Bureau of Standards, Atomic Energy Commission, Department of Justice, and Environmental Protection Agency.

The laws enforced by the AOAC members require objective scientific evidence for their successful application. The AOAC attempts to provide for both industry and Government a common meeting ground for discussion, at a scientific level, of methods of analysis that will be used to obtain this evidence. That this has been successful is indicated by the facts that many state laws specify the use of the AOAC methods, where applicable; the Federal definitions and standards of identity for many foods incorporate AOAC methods into their requirements; many Fcderal specifications and private contracts use AOAC methods; and AOAC methods have been quite generally accorded a preferred status in court testimony. Most important of all, the general recognition of AOAC methods removes from the realm of controversy the scientific question of relative validity of methods of analysis. This is settled by the scientists themselves on the basis of the facts developed during their collaborative studies.

Results of 78 years of work by the members of the association are embodied in its primary publication, Official Methods of Analysis of the Association of Official Analytical Chemists, now in its 1lth edition (1970). This publication is a 1000-page laboratory manual which includes 45 chapters, 78 pages of tables, and 51 pages of index. It is an authoritative source of methods of analysis for the regulatory chemist and the agricultural scientist throughout the world. It is supplemented by the bimonthly journal which publishes the transactions of the association, including the annual changes in methods adopted by the association, the reports of the referees, and contributed papers con. taining new methods, new applications and authentic or intcrpretive data.

The association deals with only methods of analysis. Matters involving legislation, definition, administrative policy, and interpretation of laws are dealt with in related official organizations: The Association of Food and Drug Officials of the United States, Association of American Plant Food Control Officials, Association of American Feed Control Officials, and Association of American Pesticide Control Officials. The AOAC maintains formal and informal cooperative arrangements with other scientific societies dealing with methods of analysis to maintain uniformity. Among these are the American Public Health Association (standard methods for the examination of dairy products), American Oil Chemists' Society (fats and oils), American Society of Brewing Chemists (malt beverages), American Society of Enologists (wines), American Association of Cereal Chemists, American Society for Testing and Materials, National Plant Food Institute, and Flavoring Extract Manufacturers' Association. In the international area, cooperation has developed with the Collaborative Pesticide Analytical Committee, Pesticides Analysis Committee of the Ministry of Agriculture in the United Kingdom, the Food and Agriculture Organization of the United Nations, International Dairy Federation and International Organization for Standardization.

\section{ASSOCIATION OF OFFICIAL SEED ANALYSTS, \\ Federal Seed Laboratory, P.O. Box 1705, \\ North Brunswick, New Jersey 08902}

The Association of Official Seed Analysts was founded 1908. The activities of this association in the field of standardization of methods of seed testing are carried out primarily by the following standing committees: (a) Research, (b) Rules, (c) Referee, and (d) Public Service. The principal objective in this field is to develop reliable procedures for testing seeds that will permit duplication of results when the same sam. ple is tested by different stations. Quality factors for which tests are made include: purity of sample, percentage germination, rate of occurrence of noxious weed seeds, varietal purity, and assaying for fungicidal seed treatment. The Research Committee conducts research and reviews literature to make technical information available to the Rules Committee which pre- 
pares a new draft revision of the rules about every fifth year for approval or rejection by the entire association. The Rules Committee also interprets questionable and disputed points of the Rules for Testing Seeds. The Referee Committee circulates samples among the member stations to determine whether stations are testing in accordance with the rules and to point up any weaknesses in the rules. The Public Service Committee encourages association members to publicize the benefits of our work and stimulate interest in seed testing. A publicity kit has been prepared and added to over the years and is circulated for use by member laboratories.

The association works closely with other associations and Government agencies, such as the International Seed Testing Association, United States Department of Agriculture and the Canada Department of Agriculture, in an effort to closely coordinate the rules for testing seeds used by each. Voting membership in the AOSA consists of Federal and state laboratories in the United States and Canada. The Governments of the United States and Canada hold membership in the International Seed Testing Association.

\section{ATOMIC INDUSTRIAL FORUM, 475 Park Avenue South, New York, New York 10016}

The AIF, founded in 1953, is a nonprofit membership association of industry, business research, labor, and educational institutions concerned with the development and utilization of nuclear energy for constructive purposes. The forum's membership includes nearly 600 organizations in the United States and 19 other countries of the free world. The forum's main activity centers on solving the problems facing broad segments of the atomic industry. Its purposes are: to foster and encourage atomic energy development; to provide a forum in which individuals and organizations may cooperate in resolving problems; to promote dissemination of knowledge and understanding of atomic energy: and to foster and encourage atomic energy research and development. Toward this end a major part of the work of the forum is handled by committees supplemented by study or working groups. They do not write standards; however, the forum does sponsor the work of American National Standards Committees N12 and N13. The forum has a staff of 55 and publishes a monthly report to members.

\section{BAKING INDUSTRY SANITATION STANDARDS COMMITTEE, 521 Fifth Avenue, New York, New York 10017}

The Baking Industry Sanitation Standards Committee (BISSC) is a nonprofit organization dedicated to the achieving of sanitation in the baking industry. It was established in 1949 and is supported by those trade associations representing the manufacturers of baking machinery for wholesale and retail uses, and the interested professional sanitarian and engineering organizations. The writing and publication of standards and the registration certification of equipment promoting the sanitary design, construction, and instal. lation of food-processing equipment are the only purposes and functions of this committee.

To date, 35 sanitation standards on various types of baking equipment have been carefully developed, approved and published. Other standards are in the development process.

BISSC is the recognized sanitation standards organization for the baking industry. Government and industry representatives work together in preparing and editing these standards. Task committees are appointed for each specific standard or revision. Final task committee proposals are acted on by the general committee and the BISSC Board of Directors.

Upon application, equipment is certified in accordance with the procedure setforth by the Certification Board. Standards are used by manufacturers and enforcement agencies.

\section{BARRE GRANITE ASSOCIATION, 51 Church Street, Barre, Vermont 05641}

In 1937 this association created the first set of quality standards covering the physical properties of granite and quality standards of workmanship on granite monuments. This action had become necessary due to the wide quality differences prevalent in granite and the difficulty of the public in distinguishing quality. A copyrighted trade name called the Barre Guild was placed on all monuments inspected by the Barre Gran. ite Association, and Certificates of Guarantee were issued on these monuments. Today, nearly 50,000 individual inspections are made each year, and the Barre Guild trademark signifies a standard of quality in the finished monument.

\section{BATTERY COUNCIL INTERNATIONAL, 1801 Murchison Drive, Burlingame, California 94010}

The forerunner of this association, The National Battery Manufacturers' Association was formed in 1924. In 1940 the name was changed to The Association of American Battery Manufacturers. To reflect the fact that an increasing number of members were joining the association from outside of the United States, the name was again changed in January, 1970 to Battery Council International (BCI).

The council collects information of interest to its members and distributes such information through a medium of newsletters approximately once each week.

Through committees, battery standards and specifications are recommended for use by the industry. Committees active in association affairs are as follows: Air and Water Standards, Data Book, Industrial Health, Industrial Relations, Marketing, Materials, Membership, Statistical, Technical, and Traffic.

As their names imply, these committees meet two or more times per year to make recommendations which 
will enable the mcmbcrship to comply with the ccological, industrial health and safety measures, as well as facilitate economical methods of handling shipments. The council publishes a Battery Replacement Data Book which is revised yearly, outlining the types of battery sizes and specifications used in automobiles, including foreign cars as well as domestic.

BCI encourages manufacturers and related battery industries to become members of BCI internationally. These efforts on our part have been gaining results. To further encourage foreign participation in our activities, BCI is holding an International Convention in London, England in 1974.

The council, particularly the Technical, Air and Water, and the Industrial Health Committees cooperate with Government organizations in efforts to help set realistic standards and regulations affecting the industry. These committees have met on several occasions and plan frequent future meetings with Federal agencies interested in related activities.

The Technical Committee is currently holding meetings in order to establish specifications covering plastic containers for storage batteries. This committee has met on several occasions with the General Services Administration in the formulation of Federal Specification W-B-00131J.

\section{BICYCLE MANUFACTURERS' ASSOCIATION OF AMERICA, INC., 110115 th Street NW., Washington, D.C. 20005}

The Bicycle Manufacturers' Association of America (BMA), is a voluntary, private, nonprofit organization, founded in 1916. Its member companies produce some 85 percent of all domestically manufactured bicycles, which in 1972, totaled nearly 9 million. As the trade association for this vital industry, BMA represents the industry in matters of trade and tariff; retains legal counsel; gathers and disseminates sales, wage and hour, and other statistical information; and conducts wide-ranging programs of internal communication and public relations. Principal among these is the bicycle safety education program, which provides publication and distribution of more than 10 million pieces of free safety literature each year, and cooperates in safety education programs with the National Safety Council, Boy and Girl Scouts, police, civic and service organizations, individual schools and state departments of education.

The BMA Safety and Standards Committee, beginning in 1969, developed a broad standard for the manufacture and assembly of bicycles and their various subassemblies, designed to protect the consumer from possible injury and property damage. By January 1971 , all member companies agreed to produce their full line of regular bicycles to the specifications of the standard known as BMA/6, and to submit to its certification program which includes regular and random inspection by an independent testing laboratory. The committee has worked closely with the Consumer Product Safety Commission (and formerly with the Food and Drug
Administration) in the development of a Federal standard for bicycle manufacture.

\section{BIOLOGICAL STAIN COMMISSION, INC., Research and Assay Lalıoratories,}

The University of Rochester Medical Center, Rochester, New York 14642

The commission was incorporated as a nonprofit organization in 1944 and supersedes the (1922) Commission on Standardization of Biological Stains. Its powers are vested in an eleven-membered Board of Trustees, four of whom are officers. Membership in the commission is by invitation and includes approximately 100 members.

The objectives of the commission are the establishment of standard specifications for the identification, purity, performance and labeling of the more important biological stains, in order that they may be relied upon as standard tools in biological and medical research. The commission is national in scope and has the active cooperation of the scientific societies whose interests lie in this field, as well as the interest and cooperation of the manufacturers and distributors of biological stains.

The commission exerts its influence to the above ends through a program of stain certification. Manufacturers and distributors voluntarily submit samples for examination. If the sample meets the commission's specifications, it is approved for marketing as a Certified Biological Stain, and the commission issues certification labels to be affixed to bottles in which it is sold. Certification is on a batch basis, the labels issued by the commission bearing distinctive certification numbers identifying the specific batches with which they are to be used. A sample of each batch is kept on permanent file, and the commission will investigate complaints of any unsatisfactory results obtained with a certified stain.

The commission's standards are given in the appendix of Conn's Biological Stains, 8th edition, 1969, by R. D. Lillie, published under the auspices of the commission by the Williams and Wilkins Co., Baltimore, Md. Fifty-nine stains are currently certified by the commission.

Formerly: Commission on Standardization of Biological Stains.

\section{BITUMINOUS PIPE INSTITUTE, 8 South Michigan Avenue, Chicago, Illinois 60603}

Through the institute's Research and Technical Committee, all member companies' pitch-fibre pipe products have been standardized. Continuous and rigid inspection procedures have been established by the Research and Technical Committee over the years to ensure high levels of manufacturing procedure.

The institute cooperates closely with the American Society for Testing and Materials, National Bureau of Standards, American Society of Sanitary Engineers, Southern Building Code Congress, Western Plumbing 
Officials Association, and all other major standardssetting organizations within the plumbing, sewage, and sanitary engineering fields.

\section{BLUE ANCHOR, INC., 730 Howe Avenue, P.O. Box 15498, Sacramento, California 95813}

Blue Anchor, Inc. was founded in 1901 as the California Fruit Exchange. It is a fresh fruit marketing cooperative handling of the fruit of approximately 1,000 growers organized into 64 local associations and contract shippers. All fruit is subject to the standardization program. Blue Anchor issues standards on all of our deciduous tree fruit and table grape commodities. The Rules and Regulations are updated for each annual season. The standardization policy is set by a Standardization Committee, organized in 1930, and enforced by authorized agents of the Field Department. Although the standards are required for company members only, Blue Anchor works with various Federal and state marketing orders covering pears, plums, peaches, nectarines and grapes.

\section{BOOK MANUFACTURERS' INSTITUTE, 904 Ethan Allen Highway, P.O. Box 368 , Ridgefield, Connecticut 06877}

BMI is a trade association formed in 1933 for book manufacturers and suppliers of book materials and book manufacturing equipment. This institute, together with the Association of American Publishers and the National Association of State Textbook Administrators, provides delegates to the Advisory Commission on Textbook Specifications (ACTS) which meets twice each year. Over the years, ACTS has developed a set of manufacturing standards and specifications which must be met before the purchase of a particular textbook will be considered by most state adoption agencies. This booklet, entitled Manufacturing Standards and Specifications for Textbooks, contains quality standards and specifications for paper, printing, and binding, and provides sample forms which should be used by both the state agencies and the publishers of textbooks. The specifications are distributed through the BMI office.

The institute is the sponsor of the Voluntary Product Standard PS 9-68, Fabrics for Book Covers.

Formerly: Employing Bookbinders of America (1933).

\section{BORDER TERRIER CLUB OF AMERICA, R.R. 1, Box 276,} North Windham, Connecticut 06256

The Border Terrier Club of America was organized in 1949 and is a nonprofit dog club whose objectives are (a) to encourage and promote the breeding of purebred Border Terriers and the dissemination of knowledge regarding Border Terriers: (b) to urge members and breeders to accept the standard of the breed as approved by the American Kennel Club as the only standard of excellence by which Border Terriers shall be judged; (c) to protect and advance the interests of the breed by encouraging sportsmanlike competition at dog shows; (d) to conduct sanctioned and licensed specialty shows under the rules of the American Kennel Club (AKC).

The official standard for the Border Terrier contains a description of the breed which covers the general appearance as well as specific parts of the body, movement, color and the scale of points relating to each.

While there are very few breeders in America, the club has a membership of approximately 100 members. Four Yearbooks containing articles by British and American breeders, judges and members, photographs and pedigrees of every American Champion of record, and the winner of every Obedience Degree since the breed was recognized by the AKC in 1930, have been published by the club. In addition, the official publication of the AKC, Pure-Bred Dogs-The American Kennel Gazette in which a monthly column on the breed appears, is sent to members as well as frequent newsletters.

Annual Specialty Shows are held in conjunction with an all-breed club with the Border Terrier classes being judged by licensed American judges and an occasional breeder-judge from Britain.

\section{BRASS AND BRONZE INGOT INSTITUTE, Room 3500, One North La Salle Street, Chicago, Illinois 60602}

The Metallurgists' Advisory Committee of the institute cooperates with and/or serves on the Standards and Specifications Committee of the American Society for Testing and Materials, the Society of Automotive Engineers, the Copper Development Association, both military and Federal specification bodies, and other specification bodies, in the development of standards and specifications covering ingot brass and bronze. These standards cover the chemical content, the mechanical and physical properties of copper base alloys in the ingot form for use in nonferrous foundries.

The institute further finances, sponsors and directs basic research in such institutions as the Batelle Memorial Institute, and the University of Michigan. Some of these projects are a cooperative effort with the American Foundrymen's Society. The purpose of these research projects is to assist nonferrous foundries throughout the country in the setting of methodology and standards for the production of copper base alloy castings.

Through its Air Pollution Control Committee, the institute cooperates with the U.S. Environmental Protection Agency in the setting up of standards and methods of control of emissions in the brass and bronze ingot industry.

Formerly: Non-Ferrous Ingot Metal Institute. 
THE BRICK INSTITUTE OF AMERICA, 1750 Old Meadlow Road, McLean, Virginia 22101

The Brick Institute of America (BIA), formerly Structural Clay Products Institute (SCPI) was founded in 1934. It is the national authority on brick construction. As BIA is the national association of brick manufacturers, its purpose is to promote the further and propcr use of brick. Approximately 15 percent of staff time and budgets is devoted either directly or indirectly to standards activities. Standards development, review, writing and promulgation are the responsibilities of the Engineering and Research Division. Although BIA does not generally participate in international standards activities, it does, however, maintain an exchange and liaison with similar organizations in other countries. BIA also maintains close liaison with most of the Federal Government agencies writing standards in the construction industry field; i.e., National Bureau of Standards, Housing and Urban Development, Health, Education and Welfare, Department of Defense, Department of Labor, and the Department of Commerce. At this time, BIA is not involved in any certification activities for the brick industry. It does offer independent testing services in the field of masonry for a fee. BIA has two current standards which are: Building Code Requirements for Engineered Brick Masonry, (SCPI) BIA, August 1969, and Standard Specifications for Portland Cement-Lime Mortar for Brick Masonry, BIA M1-72, OctoberNovember 1973 (TN 8A). These standards are national in scope. BIA also actively works with other standards-writing organizations in the development of standards involving or related to Brick Masonry as follows: American Society for Testing and Materials (ASTM) -E-5 on Fire Tests, E-6 on Evaluation of Construction, C-7 on Lime, C-12 on Mortar for Unit Masonry, C-15 on Manufactured Masonry Units, and C.32 on Laboratory Evaluation and Accreditation; American National Standards Institute (ANSI) - A10, Safety Requirements for Construction and Demolition, A41, Building Code Requirements and Good Practice Recommendations for Masonry, A58, Design Loads for Buildings and Other Structures, and A62, Pre-Coordination of Building Components and Systems; International Masonry Industry All-Weather Council-Recommended Practice for Cold Weather Masonry Construction, and Guide Specifications for Cold Weather Masonry Construction.

In addition to these, BIA is presently engaged in research for the development of at least three additional standards: Building Code Requirements for Engineered Hollow Brick Masonry; A Design Standard for Composite (Brick and Block) Masonry, in cooperation with the National Concrete Masonry Association and the American Concrete Institute; and Seismic Design Procedures for Masonry, in cooperation with the National Bureau of Standards, other Federal agencies and other masonry associations.

The Brick Institute of America publishes and distributes its own standards and works with cooperating organizations to publish and distribute cooperative standards. In addition, BIA works closely with the model building code groups toward the adoption of these standards into building codes and regulations. BIA also works with state and local building codes towards the adoption of these standards.

\section{BUILDERS HARDWARE MANUFACTURERS' ASSOCIATION, 60 East 42nd Street, New York, New York 10017}

This association founded in 1926, serves the interests of all builders hardware manufacturers located in the United States. One of its active programs is the development of product standards. Thirteen have been produced and of these six have been approved by the American National Standards Institute (ANSI). They are, to the extent practical for builders hardware products, performance standards.

A certification program for the BHMA Cabinet Hardware Standard No. 201 has been operating since 1968. The testing and administration are performed by an independent third party, the Electrical Testing Laboratories, Inc. The program is open to all manufacturers whether or not they are members of BHMA.

Several proposed Federal specifications contain references to BHMA standards which were approved by ANSI.

Formerly: Hardware Manufacturers' Statistical Association (1961).

\section{BUILDING OFFICIALS AND CODE ADMINISTRATORS INTERNATIONAL, INC., 1313 East 60th Street, Chicago, Illinois 60637}

Founded in 1915, Building Officials and Code Administrators International is a nonprofit municipal service organization vitally involved in the field of building code administration and enforcement in particular, and community development in general. The association's goals encompass two main areas: (a) to serve the public by advocating the use of safe, suitable, modern construction techniques and materials, through its model codes program; and (b) to serve jurisdictions and their code administrators by providing technological know-how and services related to all specialty areas of code administration and enforcement, in addition to a complete model codes maintenance program. Because of the scope of its membership, ideas and experiences are exchanged by code administrators all over the country and the world.

It is governed by building officials and code administrators, its officers, the executive committee and two past presidents. Its programs and activities are carried on by the technical and professional staff under the direction of its Executive Director, appointed by the Executive Committee.

It established performance requirements. Instead of specifying in detail the materials to be used and methods of utilizing them, the BOCA codes state the 
requirements for the performance that materials and assemblies of materials shall produce under given conditions, and establish the evaluation criteria for determining in advance that this performance will be attained. This often results in reduced construction costs and allows ingenuity on the part of the designer.

It cooperates with other organizations in developing standards under the procedures of the American Society for Testing and Materials, American National Standards Institute, National Fire Protection Association, American Standards Institute, Underwriters' Laboratories, Inc., Canadian Standards Association, the American Society of Mechanical Engineers, Portland Cement Association, Gypsum Association, American Plywood Association and many other accredited authoritative agencies which are listed in all of the appendices of the BOCA codes.

BOCA is also represented on numerous committees of the National Fire Protection Association, Chicago High Rise Committee, American Society for Testing and Materials, Council of American Building Officials, American Concrete Institute, American Institute of Architects, American National Standards Institute, National Safety Council, Model Codes Standardization Council, Model Code Research Board, American Society of Civil Engineers, National Conference of States on Building Codes and Standards, Safety Glazing Certification Council and the Chicago Association of Commerce and Industry.

Formerly: Building Officials Conference of America (1970).

\section{BUILDING OWNERS AND MANAGERS ASSOCIATION INTERNATIONAL, 224. South Michigan Avenue, Chicago, Illinois 60604.}

This association is essentially a service organization, and its membership represents a substantial part of the larger commercial office building properties of the U.S., Canada, Australia, and South Africa. In connection with its other activities, this organization devotes time and attention to matters relating to standardization. As long ago as 1915, BOMA International adopted a standard method of floor measurements for the office building industry, and has developed standard methods of rating space. It has also prepared standard methods of accounting and a uniform chart of accounts.

The association makes studies of operating costs, rental conditions, and kindred matters for the purpose of developing standard types of information for the guidance of the industry. It publishes an annual Office Building Experience Exchange Report dealing with economics, and conducts a Building Planning Service applicable to new construction, feasibility, and modernization.

It has cooperated with various sectional committees functioning under the procedures of the American National Standards Institute, acting as cosponsor of proposals for American National Standards on floor measurement in buildings of different types, and being currently represented on American National Standards sectional committees.

Formerly: National Association of Building Owners and Managers (1908); Building Owners and Managers Association International (1968).

\section{CAN MANUFACTURERS' INSTITUTE, 1625 Massachnisetts Avenue NW., W ashington, D.C. 20036}

The Can Manufacturers' Institute (CMI) was established in 1939 as a nonprofit membership corporation. The institute represents U.S. manufacturers of allmetal cans in the standards area, and is primarily concerned with government specifications for cans and legislation affecting cans and can standards.

CMI has a standing Can Standards Committee which seeks to develop standards on sanitary cans for sizes in general demand. Ad hoc subcommittees are created as necessary to study and/or recommend specific standards for full committee action. The institute maintains contact with the National Burcau of Standards and the International Organization for Standardization in the formation of standards.

The standards are published in Recommended CMI Voluntary Industry Can Standards. As of this writing there are 12 published standards, and an additional 4 or 5 are scheduled for publication in 1974.

Conformity to the CMI recommended standards is strictly voluntary, but is encouraged as being for the general benefit of can manufacturers and can users.

\section{CANVAS PRODUCTS ASSOCIATION INTERNATIONAL, 600 Endicott Building, St. Panl, Minnesota 55101}

CPAI, founded in 1912 , is the trade association for the industrial fabric industry. Vertical in structure, its members include fiber producers, weavers, fabric finishers, coaters, laminators and manufacturers of industrial fabric products.

The association's structure includes seventeen divisions, several of which are involved in standardization activities. The Camping Products Manufacturers' Division, in cooperation with the Finishers Division and other fabric suppliers, has developed a model flammability code for materials used in camping tentage. This code, designated CPAI-84, has gained acceptance as a mandatory standard in two states, and the Consumer Product Safety Commission is being asked to consider it as a basis for similar Federal regulations.

The Tarpaulin Division, again with assistance from suppliers, is in the process of revising CPAI-63, its ten year old quality assurance standard for domestic cotton tarpaulins. The revised standard will be expanded to include synthetics and imported materials, and will set strength, water resistance, flame 
resistance, and breathability performance requirements for the various types of tarpaulins.

The Air Structures Division has written a Minimum Performance Standard for Single Wall Air Supported Structures as a guide to manufacturers, prospective users, architects, and regulatory agencies. This standard sets many requirements for the materials, design, construction, and erection of these structures.

In addition, standards in several other areas are being developed by the related divisions. One of these which is nearing completion is an erection standard for large rental tents. Copies of current standards are available from CPAI headquarters.

Formerly: National Canvas Goods Manufacturers' Association (1956).

\section{CARPET AND RUG INSTITUTE, P.O. Box 2048 ,}

Dalton, Georgia 30720

The institute is the national trade association for U.S. manufacturers of carpet and rugs, formed in 1969 through a merger of the American Carpet Institute and the Tufted Textile Manufacturers' Association. Through activities of its technical committee and subcommittees, and in cooperation with Federal Government agencies such as General Services Adminstration, Federal Housing Administration, and the National Bureau of Standards, and private standardssetting organizations such as American Society for Testing and Materials, National Fire Protection Association, and American Association of Textile Chemists and Colorists, the institute develops and proposes standards covering the construction and performance of carpet and rugs for acceptance and promulgation by these agencies or by the industry on a voluntary basis. Current and future activities of CRI committees and subcommittees are published each year in the institute's Directory and Report. Other technical publications include: Carpet Specifier's Handbook and Regulations, and Specifications for Carpet and Rugs.

\section{CAST IRON SOIL PIPE INSTITUTE, 2029 K Street NW., Washington, D.C. 20006}

This institute (CISPI) was founded May, 1949, has developed standards for cast iron soil pipe and fittings which are accepted throughout the United States. The American Society for Testing and Materials (ASTM) A74.72 covers hub and spigot cast iron soil pipe and fittings for extra heavy and service, and is the same as CISPI Standard HS-72. The Hubless Cast Iron Sanitary System is covered by CISPI Standard 301-72. Compression Gaskets are covered by CISPI Standard HSN-72. These standards set forth dimensions and specifications which provide interchangeability between all manufacturer's pipes and fittings. The CISPI standards are national in scope.

The Technical Committee administers CISPI's standardization activities. The Cast Iron Soil Pipe Institute is dedicated to aiding and improving the plumbing industry in the United States. Through a cooperative effort of the soil pipe manufacturers, the institute works to improve the industry's products, achieve a standardization of soil pipe and fittings, and provide a continuous program of program testing, evaluation and development.

\section{CASTER AND FLOOR TRUCK MANUFACTURERS' ASSOCIATION, 1717 Howard Street, Evanston, Illinois 60202}

The Caster and Floor Truck Manufacturers' Associaation (CFTMA) was founded in 1933. Manufacturers in this association produce industrial casters, wheels, and manually operated materials handling equipment.

CFTMA has published a Combined Industrial Wheel Standard, and an Industrial Caster Standard, as well as standards for trailer trucks, platform trucks, and two-wheel hand trucks.

Approximately 50 percent of CFTMA's program is devoted to standardization work. This standardization work is administered by the Standards and Engineering Committee of CFTMA.

CFTMA is actively involved with such Government agencies as the Defense Supply Agency, Department of the Army (Natick Laboratories), and the General Services Administration. CFTMA is also involved with international programs, such as International Organization for Standardization, ISO/TC 4I.

The Caster and Floor Truck Manufacturers Association is currently revising the CFTMA Engineering and Purchasing Planbook, which should be completed by 1974.

\section{CEILINGS AND INTERIOR SYSTEMS CONTRACTORS' ASSOCIATION, 1201 Waukegan Road, Glenview, Illinois 60025}

The Ceilings and Interior Systems Contractors' Association is an international organization consisting of major specialty subcontractors who, as a significant part of their business, sell and install ceiling systems as well as other related products and systems.

Members include contractors from throughout the United States, Canada, Europe, South Africa and Australia. The association is fortunate in having as associate members virtually all major suppliers of ceiling materials and related products and systems.

The Association goals are: to improve contractor net profit and return on invested capital by improving management skills of members; to recruit high quality personnel for careers in the ceiling and interior contracting industry and upgrade the professional skills of personnel at all levels within the industry; to share knowledge among CISCA member firms of all sizes in a spirit of genuine cooperation, confidence, 
and participation; to provide programs for exchanging information among members about the industry and its trends and to develop working alliances with other organizations within the construction contracting industry to deal with common external problems. The association was founded in 1949 and until 1969 was known as the National Acoustical Contractors' Association.

The only CISCA activities relating to standardization are two official specifications of the American Society for Testing and Materials: Standard Specification for Metal Suspension Systems for Acoustical Tile and Lay-in Panel Ceilings (ASTM C 635-69) and Standard Recommended Practice for Installation of Metal Ceiling Suspension Systems for Acoustical Tile and Lay-in Panels (ASTM C 636-69). CISA actively participated in the development of these. The other standard activity has been the Recommended Standards for Seismic Restraint of Direct-Hung Suspended Ceiling Assemblies dated November 15, 1972.

\section{CEMENTED CARBIDE PRODUCERS ASSOCIATION, 2130 Keith Building, Cleveland, Ohio $\mathbf{4 4 1 1 5}$}

This organization was founded on March 2, 1955 and its members are made up of manufacturers of cemented tungsten carbide cutting tools, dies and wear parts.

Standardization activities are a very important part of the association's program and represent approximately 50 percent of its efforts. The standardization programs are conducted through American National Standards Committee B94, TC-1 and deal with dimensional standardization of the products of the industry. The technical activities are handled by the Technical Committee of the association in conjunction with the American Society for Testing and Materials B09:06, Cemented Carbides. This work deals with the physical, metallurgical and chemical aspects of the products of the industry. The association is actively participating in international standards work, working in conjunction with the International Organization for Standardization, ISO/TC 29/WG 9 Turning Tools, ISO/TC 29/WG 19 Wire, Bar and Tube Drawing Dies, ISO/TC 119/WG 4 Sampling and Testing Methods for Hard Metals. The Technical Committee is working with the National Bureau of Standards on certain physical measurements for the products of the industry. There are no certification programs or activities. The association has been responsible for the issuance of 12 dimensional standards and 18 physical, chemical and/or metallurgical standards. The standards developed by the industry are promoted primarily through member companies and announcements in the trade press as and when new standards are available. Copies of all standards can be obtained from the association office.

\section{CHAIN LINK FENCE MANUFACTURERS' INSTITUTE, One Stone Place, Bronxville, New York 10708}

The Chain Link Fence Manfacturers' Institute (CLFMI) was founded in 1960. Although in the past CLFMI has had several fence specifications that were produced with the National Bureau of Standards at their request, we are now actively reviewing the entire specification field with the American Society for Testing and Materials (ASTM). Key representatives of the fencing industry met with the American Society for Testing and Materials in February 1973 to grapple with the problem of setting universal standards for fence specification. CLFMI will join with ASTM in the development of voluntary full-consensus standards that will be adopted nationally. Through this transitional period, and until the publication of the new standards and specifications, CLFMI continues to offer its current standards which are: Specification for Galvanized Steel Chain Link Fence Fabric; Industrial Steel Specifications for Fence-Posts, Gates, and Accessories; Commercial Standard for Industrial Aluminum Alloy Chain Link Fencing; and Standards for China Link Fence Installation.

\section{CHEMICAL SPECIALTIES \\ MANUFACTURERS' ASSOCIATION, 50 East 41st Street, New York, New York 10017}

The Chemical Specialties Manufacturers' Association (CSMA), founded in 1914, is a national trade association representing 400 suppliers, manufacturers and marketers of aerosols, cleaning compounds, disinfectants, insecticides, transportation products, and polishes and floor finishes. All methods and procedures used are either national consensus standards or CSMA tentative standards.

CSMA has a General Standards and Specifications Appraisal Committee which administers all standardization activity. CSMA maintains liaison with international and national organizations through members who are active in the International Organization for Standardization (ISO) and such national consensus standards bodies as American Society for Testing and Materials (ASTM) and American National Standards Institute (ANSI). It also maintains liaison with General Services Administration (GSA) and other agencies through members in areas of specific interest.

CSMA standardization activities are national in scope. Some standards originated and promoted by CSMA are now ASTM, Association of Official Analytical Chemists (AOAC), Society of Automotive Engineers (SAE) or other standards as well. Currently, wherever possible, CSMA specifications are being processed through ASTM for national consensus 
approval. Information on active standards committees and new projects under consideration is available through the CSMA main offices.

From 1914 to 1949 CSMA was known as the National Association of Insecticide and Disinfectant Manufacturers (NAIDM).

\section{THE CHLORINE INSTITUTE, INC., 342 Madison Avenue, New York, New York 10017}

The Chlorine Institute, Inc., founded in 1924, is an international association, concerned with the safe manufacture, shipping and handling of chlorine. Of its total program, approximately one-quarter involves standardization, administered by its Committee on Container Specifications and Safety, and its Product Analysis and Specifications Committee. The institute has developed and adopted some 40 standards. These cover safety, angle and excess flow valves and manway covers for chlorine tank cars, tank trucks and tank barges; valves and fusible plugs for chlorine cylinders and ton containers; piping and equipment for handling chlorine, recommended methods for unloading chlorine tank cars, maintenance of tank car valves, operation of tank trucks and design of stationary storage tanks. These standards are outlined in the institute's list of publications.

The institute cooperates actively with the national standards bodies and various branches of the U.S. Department of Transportation on transportation safety matters, the Army Corp of Engineers on cylinder valve standards, the Environmental Protection Agency on air and water standards and with the Department of Labor's Occupational Safety and Health Administration and the National Institute of Occupational Safety and Health on occupational health and safety standards. The Chlorine Institute is national in scope in both the United States and Canada. Internationally, the institute participates indirectly in other programs through its overseas members and via the Compressed Gas Association.

The standards are promoted through publication of the Chlorine Manual which has gone into four editions, and by a public information program.

\section{COFFEE BREWING CENTER, 1350 Avenue of the Americas, New York, New York 10019}

The Pan-American Coffee Bureau is an instrumentality of the governments of 12 Latin American coffee growing nations. The Coffee Brewing Center (CBC) is a department of the bureau concerned with research and education on coffee. Its work involves standards for production and utilization of coffee, both for the consumer and the food service industry.

Coffee Laboratory - The laboratory serves as the basis for analytical work for brewing and equipment evaluation awards, provides direct service to industry in such areas as grind analysis, roast color measurement, bulk density, etc., and develops methods for analyzing coffee, some of which are widely used and becoming more or less standard for the industry.

Standards Development-Liaison is maintained with other technical and trade associations toward the development of standards for coffeemakers and related systems as they apply to both the food service and consumer fields. The work underway at the present time involves: (1) filter paper standard sizes for coffeemakers; (2) coffee grind standards; (3) cup size standards for home coffeemakers.

Equipment Evaluation Program-The Coffee Brewing Center has established a coffee brewing equipment evoluation service and seal of approval program that covers all types of coffee brewing equipmentinstitutional, home type, and vending.

The seal of approval is awarded to that equipment submitted by manufacturers for laboratory analysis, and found capable of brewing coffee according to CBS standards. The award is given only to individual designs or models and not necessarily to the entire range of a manufacturer's equipment. Brewing instrutions furnished with the equipment must also comply with the CBC's recommended procedures.

The Library-An extensive file of literature available to industry, students, writers and others interested in learning more about coffee.

\section{COLLEGE OF AMERICAN PATHOLOGISTS, Standards Committee, 230 North Michigan Avenue, Chicago, Illinois 60601}

The Standards Committee of the College of American Pathologists (CAP) is concerned with standards useful in all phases of laboratory medicine, including anatomic and clinical pathology. These include: (1) national proficiency survey programs, now administered by a separate Surveys Committee; these go to about 8000 laboratories; (2) inspection and accreditation programs for clinical laboratories-administered by a separate CAP Committee; (3) batch certification of cyanmethemoglobin standards for the National Academy of Sciences-National Research Council; (4) distribution of pure primary standard solutions whose content we have verified; (5) standards for laboratory test reports and sample handling; (6) standards for medical usefulness needs and screening tests; and (7) product evaluation of laboratory products.

International program-The committee actively collaborates with the International Commission for Standardization in Hematology in the fields of cyanmethemoglobin standards and blood coagulation and with the commission on World Standards of the World Association of Pathology Societies.

Federal involvement-The committee and its individual members collaborate actively with the National Bureau of Standards, Food and Drug Administration, the Center for Disease Control as consultants and committee members.

Standards issued-A list of standard solutions marketed may be obtained thorugh the CAP office. 
They are national in scope. Standards in other fields are ordinarily channelled through the National Committee for Clinical Laboratory Standards. Numerous publications are found in indexed literature.

Active committees-The active committees are named above. New projects include revision of medical usefulness standards; microbiology standards; normal values; quality assurance program for clinical laboratories; laboratory reports systems and delivery of reports. An extensive subcommittee and a resource committee are supportive.

Promoting the use of standards-This is conducted through direct mailing to the membership; articles in indexed literature; the CAP publication, pathologists; and the trade magazines.

\section{THE COLOR ASSOCIATION OF THE UNITED STATES, INC., 200 Marlison Avenue, New York, New York 10016}

The Color Association of the United States, Inc. (CAUS) is a nonprofit organization established in 1915, with members in all fields from around the world. Its major function is color forecasting with its scope of activities including: $(a)$ seasonal color forecasts applicable to industry in the advertising, automotive, cosmetic, dyestuff and colorants, fiber, paper products, and plastics areas-these seasonal color forecasts include color cards for textiles, women's and children's wear, accessories, hosiery and socks, men's wear, men's socks, and home furnishings, which are issued twice a year; $(b)$ general color information, market research and color consultations; and (c) Standard Color Cards. Other than the Standard Color Card, which is in its 9th edition, CAUS cooperates with the Government and industry as a service to industry. Some of the standard color cards that are developed in association with the United States Government are with the Department of Defense, for thread, buttons, tapes, and embroidery yarns; and for the branches and agencies, arms and services. All standard colors are listed by color name and cable number; CAUS does not issue a catalog of color standards.

On an international level, this association maintains a membership in Intercolor, International Color Forecasts; and in Intersociety Color Council, which has international activities. Our standards are national and international in scope.

Formerly: Textile Color Card Association of the United States (1954).

\section{COMMISSION ON ACCREDITATION OF REHABILITATION FACILITIES, 6510 North Lincoln Avenue, Chicago, Illinois 60645}

The commission, established in 1966, is a national private, nonprofit organization setting standards for the operation of rehabilitation facilities. A resource compendium of standards is available from commission headquarters. A facility's compliance with the standards is assessed in an objective on-site survey out of which accreditation may be awarded. Approximately 700 standards have been developed, covering nine basic aspects of a facility's operations, including purposes; organization and administration; services; personnel; records and reports; fiscal management, physical facilities; community relations; and program evaluation. A periodic newsletter, entitled the Carf Report, is distributed at no charge to persons who wish to be kept apprised of the organization's activities. Partial funding is provided by the Rehabilitation Services Administration of the Department of Health, Education and Welfare.

\section{COMPOSITE CAN AND TUBE INSTITUTE, 1725 Eye Street NW., Washington, D.C. 20006}

The Composite Can and Tube Institute was founded in 1933 as a nonprofit organization to foster the collective interests of the composite can and tube industry. In addition to technical activities, CCTI holds national, area and committee meetings; prepares and circulates bulletins containing items of general interest; surveys labor fringes and hourly rates in the industry; sponsors statistical, plant safety, traffic and environmental control programs; and is active in many fields customarily included in association efforts such as public relations and preparation of various industry directories.

Approximately 10 percent of the total institute pro. gram is devoted to standards. This portion of the program is administered by the Technical Committee made up of technically oriented persons divided about equally between those representing companies producing composite tubes and cores and those producing composite cans. The Composite Can Committee also oversees certain of these activities on occasion.

CCTI does not participate in international programs nor with Federal government standardization activities, except when requests are received for specific information. CCTI has no certification program activities.

Presently, CCTI publishes standard testing procedures to provide uniform methods for both manufacturers and users to measure and test the physical characteristics of composite cans, tubes and cores. Further, the institute has developed and published recommended industry standards covering dimensions for certain high volume types of composite cans to accommodate customers' closing and handling equipment. Finally, CCTI has published guidelines as sources of information for manufacturers and users of industry products. CCTI has published 26 standard testing procedures and is in the process of preparing four new and revising six standard testing procedures. It has published 17 recommended industry standards, has no new recommended industry standards under consideration, but is in the process of revising three. 
CCTI has published three guidelincs, and has no new ones nor any revisions under consideration. Scope of the work is national. As standard testing procedures, recommended industry standards and guidelincs are published or revised, they are publicized in the trade press.

Formerly: National Fibre Can and Tube Association (1970).

\section{COMPRESSED GAS ASSOCIATION, INC., 500 Fifth Avenue, New York, New York 10036}

Founded in 1913, CGA's major purpose is to provide, develop, and coordinate technical activities in the compressed gas industries, including end-uses of products, in the interest of safety and efficiency, and to the end that they may serve, to the fullest extent, the best interest of the public and industry. CGA is active primarily in the fields of safety and technical specifications pertaining to the compressed gas and related product and service industries. This includes the medical fields of anesthesia and respiration.

Specific standardization activities: The Association collaborates with national organizations such as the National Fire Protection Association, the National Liquefied Petroleum Gas Association, the American Society for Testing and Materials, the American National Standards Institute, Association of American Railroads, and the American Society of Anesthesiologists, to develop far-reaching specifications and standards of safety to benefit industry and the public.

CGA compiles information and publishes material such as the Handbook of Compressed Gases and many pamphlets which contain a description of the most widely used gases and give in detail the safest recognized methods, many developed by CGA, for handling and storing gases.

CGA conducts national and regional technical meetings and seminars to discuss practices, standards, and problems related to the broad spectrum of the compressed gas industries.

It submits recommendations to appropriate Government agencies, to improve safety standards and methods of handling, transporting, and storing gases. CGA acts as advisor to authorities, some of which are regulatory such as the U.S. Department of Transportation, the U.S. Interstate Commerce Commission, U.S. Coast Guard, U.S. Food and Drug Administration, Canada's Board of Transport Commissioners and Department of Transport, and state, provincial, municipal, and local agencies concerned with the safe handling of compressed gases. In addition there is some activity on an international level withparticipahandling of compressed gases. In addition there is some activity on an international level with participation in committees of the United Nations and the International Organization for Standardization (ISO).

CGA's standards are national in scope. News reports are published in Compressions, CGA's newsletter at approximately monthly intervals.
Formerly: Compressed Gas Manufacturers' Association (1949)

\section{COMPUTER AND BUSINESS EQUIPMENT MANUFACTURERS' ASSOCIATION, 1828 L Street NW., Suite 1200, Washington, D.C. 20036}

CBEMA was organized in 1916 as the Office Equipment Manufacturers' Institute, reorganized in 1961 as the Business Equipment Manufacturers' Association, and in 1972 adopted its present name.

CBEMA is a nonprofit organization that provides its members a forum for industry consultation and united action; a means for communicating facts and views of the industry to Government, to other industries and the public. CBEMA does not publish standards in its own name but does participate actively with national standards bodies. CBEMA is an organizational member of the American National Standards Institute (ANSI) and serves as the secretariat of two standards committees operated under ANSI procedures: X3, Computers and Information Processing and X4, Office Machines and Supplies. Through its Environment and Safety Committee, CBEMA represents its members to other American National Standards Committees, including B11, Safety Standards for Machine Tools; C101, Leakage Current for Appliances; D20, Model Motorist Data Base; P3, Pulp and Paper; X9, Banking; Y14, Drafting; and Y32, Graphic Symbols. It also participates in the Underwriters' Laboratories Industry Advisory Conference, Office Appliance and Data Processing Equipment sections.

CBEMA devotes approximately 25 percent of its total program to standardization activities. CBEMA's Standards Department, headed by the Director of Standards, administers the standardization activities. The standards are promoted through publicity in association communications and the technical and trade press; distribution by member companies; reference to, and incorporation of, standards in member company public and internal technical publications; and through implementation of standards in member company products. Active standards committees and projects are listed in CBEMA annual and periodic activity reports.

International Standards Participation-Through American National Standards Committees X3 and X4, CBEMA participates in the corresponding International Organizatin for Standardization (ISO) Technical Committees 97 and 95 respectively, providing direct support to ANSI as Secretariat for TC 97 and a number of Subcommittees of each. Through the Underwriters' Laboratories and the U.S. National Committees for each, CBEMA supports International Electrotechnical Commission Technical Committees: 61. Safety of Household Electrical Appliances; 65, Industrial Process Measurement and Control; and the newly formed TC 74, Safety of Office Machines and Data Processing Equipment. CBEMA also maintains active liaison and cooperation with the standards pro- 
grams of the European Computer Manufacturers' Association (ECMA) and with national industry standards bodies of Japan and the European countries.

Federal Government Standards Relations - CBEMA cooperates with the Federal Information Processing Standards (FIPS) program by direct liaison and exchange of documents between $\mathrm{X} 3$ and $\mathrm{X} 4$ and the National Bureau of Standards, and by providing membership, upon invitation, on industry advisory committees to the FIPS Program. The National Bureau of Standards, General Services Administration and Department of Defense are organizational members of $\mathrm{X} 3$ and X4. Additionally, staff members of these agencies are members of $\mathrm{X} 3$ and $\mathrm{X} 4$ technical subcommittees, together with others from the Departments of Agriculture, Commerce, Health, Education and Welfare, Interior, Labor, Transportation, Treasury, and the U.S. Postal Service, National Communications Service, National Aeronautics and Space Administration, Civil Service Commission, Federal Reserve System and Library of Congress. CBEMA also represents the industry views to, and cooperates with, the standards program of the Occupational Safety and Health Administration, Department of Labor and related activities of the Department of Health, Education and Welfare.

The total number of standards issued are: by $\mathrm{X} 3$, as American National Standards-33, with 12 additional standards in final stages of approval; by X4, as American National Standards-16, with five others nearing completion.

\section{CONCRETE REINFORCING STEEL INSTITUTE, \\ 180 North La Salle Street, Chicago, Illinois 60601}

The CRSI was organized in 1924 and has operated continuously as a national trade association. It consists of and represents mill producers, fabricators, and suppliers of reinforcing hars. Associated members include producers and suppliers of other products used in concrete construction and fabricating equipment manufacturing. The purpose of CRSI is to increase the use of reinforcing bars through research, education, promotion, improved efficiency for lower final costs through better design, improved materials, and construction techniques.

Reducing cost through standardization has been a continuing activity of CRSI for 50 years and involves up to five percent of CRSI efforts. Beginning with Steel Reinforcing Bars--R26-30, CRSI has sponsored development, through the procedures of the National Bureau of Standards, of Simplified Practice Recommendation R53-63-Steel Spirals for Reinforced Concrete Columns (withdrawn 7-2-72); Simplified Practice Recommendation R265-63-Forms for TwoWay Concrete Joist Floor and Roof Construction (withdrawn 5-15-73) ; Product Standard PS 16-69Types and Sizes of Forms for One-Way Concrete Joist Construction; and Product Standard PS7-66-Wire Bar Supports for Reinforced Concrete Construction (withdrawn 2-19-74). Current standard activities are conducted by the CRSI Engineering Practice Committee and subcommittees on bar supports, placing reinforcing bars, concrete joist construction, detailing reinforced concrete, and splicing reinforcing steel.

\section{CONSTRUCTION INDUSTRY MANUFACTURERS' ASSOCIATION, \\ 111 East Wisconsin Avenue, Milwaukee, Wisconsin 53202}

CIMA is a U.S. based association of more than 170 firms that manufacture construction equipment and related components and supplies. The membership also includes leading construction industry publications. CIMA can trace its history back to 1921 when it was known as the Highway Industries Association. It was incorporated under its present name in 1949.

CIMA acts as a clearinghouse for the construction equipment manufacturing industry in the areas of safety, health and environmental performance standards for construction machines. The term "performance standards" refers to performance criteria for machine safety, protective devices, noise characteristics, etc., as opposed to engineering standards which dictate design.

The main leadership for this task is provided by a Performance Standards Committee of the CIMA Board of Directors composed of 12 industry executives who work with ClMA's Technical and Safety Services staff. This board committee is assisted by a large 150-man panel of specially named and highly qualified performance standards representatives from each participating member company. These technical representatives are organized within product-line committees consisting of eight machinery segment groups covering the following product areas: crawler tractors, rubber tired loaders and dozers, motor graders, off-highway trucks, scrapers, crane carriers, asphalt and crushing equipment, and rollers and compactors.

An important fact to note is that CIMA does not write these performance standards itself since it believes these standards should represent a consensus of all interested parties. Accordingly, this task is turned over to nationally recognized standards-writing bodies such as the Society of Automotive Engineers.

CIMA is dedicated to avoid duplicating standards work being pursued by other national or international organizations. As a result, it has "listening post" committees providing input and output to and from other trade associations and technical societies working on problems such as engine emissions, dust and solids' pollution of air, vibration, visibility and many others.

CIMA is also active in the broad area of "commercial" standards that cover product maintenance, usage, certification, test, inspection, etc. Certain productoriented groups within CIMA known as Bureaus write and publish commercial standards which, in practice become guidelines for bodies such as the American National Standards Institute in development of con- 
sensus standards. CIMA's PCSA Bureau, formerly the Power Crane \& Shovel Association, has published three commercial standards: No. 1, Mobile Power Crane \& Excavator Standards (1968); No. 2, Mobile Hydraulic Crane Standards (1969); No. 3, Mobile Hydraulic Excavator Standards (1969). PCSA's Technical Committee works actively with national and international organizations.

Formerly: Construction Industries Association.

\section{THE CONSTRUCTION SPECIFICATIONS INSTITUTE,}

1150 17th Street NW., Suite 300, Washington, D.C. 20036

The institute founded in 1948 , is a nationwide technical society dedicated to improving and coordinating all aspects of construction specifications and communications. From its founding goal of improving specification writing practices, the institute has provided leadership for standardization in specifications and industry communications and a common forum for all members of the construction team to meet, discuss, and formulate industry direction in construction practices.

CSI is a horizontally structured organization encompassing all segments of the construction industry including architects, engineers, contractors, material suppliers, students, educators and others. In 1973, the institute had a membership of over 11,000 and 122 chapters throughout the 50 States.

CSI publishes a monthly magazine The Construction Specifier, which is distributed to members as a member service. The institute also publishes technical documents dealing with specific portions of construction specifications. The institute is involved through The Construction Sciences Research Foundation in research work in the construction industry and has developed a comprehensive and complete product information retrieval system and an automated computerized system for specification text manipulation adaptable to all types of master specification programs.

\section{CONTRACTOR'S PUMP BUREAU,} 13975 Connecticut Avenue, Suite 310 , Silver Spring, Maryland 20906

The Contractor's Pump Bureau (CPB) was founded 1937. The organization is made up of 13 major manufacturers of pumps for the contracting industry. The standards program is the primary purpose of the organization and is administered directly by the Board of Directors.

Standards currently issued are the 14th Revision, dated January 17, 1970 for the following types of contractors pumps: self-priming centrifugal, diaphragm pumps, submersible pumps and trash pumps. These standards are national in scope.

Currently the Board of Directors is reviewing standards for submersible and trash pumps. Promotion for the use of standards is through advertising in industry publications.

\section{CONVEYOR EQUIPMENT \\ MANUFACTURERS' ASSOCIATION, \\ 1000 Vermont Avenue NW., Washington, D.C. 20005}

CEMA was organized in 1933 and incorporated in 1935. Among the association's purposes is, standardization of design, manufacture, and application on a voluntary basis and in such manner as will not impede development of conveying machinery and component parts or lessen competition. Standardization activities are administered by the CEMA Product Sections and CEMA Engineering Conference. Currently there are 14. CEMA standards.

CEMA works with the Federation Europeenne de la Manutention (FEM) to enhance exchange of information with European conveyor manufacturers and participates in FEM conferences on an observer basis. CEMA is a member of the American National Standards Institute and several CEMA standards have been adopted as American National Standards. CEMA also works with other organizations, such as the American Society of Mechanical Engineers, and with such Federal Government organizations as the Occupational Safety and Health Administration, Office of Standards and the Bureau of Mines wherever possible.

Formerly: Association of Conveyor and Material Preparation Equipment Manufacturers (1935); Conveyor Association (1945).

\section{COOLING TOWER INSTITUTE, INC., 3003 Yale Street, Suite 107. Houston, Texas 77018}

The institute, organized in 1950, is an international self-governing, nonprofit technical association of cooling tower manufacturers, owners, and suppliers of related chemicals and equipment. Its standards program is planned around the development of a series of individual standards which, taken together, constitute a specification for a CTI Code Tower.

Published CTI Standards are: STD-103, Redwood Lumber Specifications: Recommended grades, grading rules, and allowable design stresses for redwood lumber; ATP-105, Acceptance Test Procedure: Methods and instrumentation for determining water cooling capability of mechanical draft towers; NCL-109, Nomenclature: Terms and definitions describing cooling tower components, design and performance; STD. 111, Gear Speed Reducers: Rating practice and operating considerations for use with propeller type fans; WMS-112, Pressure Preservative Treatment of Lumber: Minimum retentions and penetrations in application of AWPA treatment standards; STD-114, Douglas Fir Lumber: Grades, recommended stress, nonframework grades and grading rules in applica- 
tion of WCLA grades; STD-115, Southern Pine Lumber: Grades, recommended stress, nonframework grades and grading rules in application of SPIB grades; STD-119, Timber Fastener Specifications: Recommended material, manufacturing limitations, design requirements and allowable loads for timber fasteners; STD-127, Asbestos Cement Materials: Establishes grades and dimensions of incombustible asbestos cement materials for industrial field assembled water cooling towers when used for casings, splash bar fill, evaporative surface fill, air inlet louvers and corner roll; STD-201, Certification Standard for Commercial Water Cooling Towers: Sets forth procedure whereby CTI may certify that a line of towers will perform in accordance with the manufacturer's published ratings.

CTI has been working closely with the Environmental Protection Agency in an effort to control therman and chemical pollution.

\section{COPPER DEVELOPMENT ASSOCIATION INC., 405 Lexington Avenue, New York, New York 1001.7}

The Copper Development Association Inc. was established in 1963. It is the long-range engineering development and market development arm of the U. S. copper and brass industry. Its primary efforts are in the development of new markets for copper and copper alloys; major emphasis is directed at creating new concepts, building prototypes and proving commercial feasibility for these new applications for copper, brass and bronze. In addition, CDA provides extensive technical support to users of copper and copper alloys. As part of its technical support work, CDA carries out standardization activities for brass mill and foundry products. CDA publishes the Stand. ards Handbook, for the U. S. copper and brass industry, in seven parts covering: tolerances; alloy data, both wrought and cast; terminology; engineering data; sources; and a specifications cross index. Standards constitute less than 10 percent of CDA's total activities.

CDA participates in international standards programs through the U. S. A. National Committee for Copper and Copper Alloys and is the Secretariat. In this way, it is helping in the development of International Organization for Standardization (ISO) standards and Pan American standards, via Pan American Standards Commission (COPANT). CDA is involved in Federal Government standardization activities primarily through the review of Federal and military standards submitted to it for that purpose. CDA is not involved in certification programs.

The 7-part CDA Standards Handbook is national in scope and is available free of charge. A Standards Advisory Committee within the association provides guidance for all CDA's standards publications and for CDA activity in U. S. voluntary standards organizations.

Supersedes: Copper and Brass Research Association.

\section{THE CORDAGE INSTITUTE, 2300 Calvert Street NW. Washington, D.C. 20008}

The Cordage Institute was founded on June 17 , 1920. The membership of the Cordage Institute is composed of substantially all of the rope and twine manufacturers in the United States, with some Canadian manufacturers and Cordemex of Mexico as special members. The objectives of the institute are voluntarily and without pecuniary profit to: promote the interests of the industry and improve its services to the public; compile and distribute information throughout the membership and to interested members of the public; and to cooperate in the handling of problems common to the industry.

The institute's standardization program receives substantial attention, is the subject of many mailings to the members of the institute, and has a prominent place on the agenda of the institute's meetings. The standardization activities are carried on by its Tech. nical Committee. This program is under the policy direction and supervision of the Executive Committee of the institute. The Technical Committee has developed or participated in developing specifications for hard fiber and synthetic rope and twine with Government agencies since 1924. Close working relationships on standards have been maintained with the U.S. Army, U.S. Navy, the Maritime Administration, the Coast Guard, the General Services Administration, and others. Most recently relationships have been with: the Defense Supply Agency (Defense Industrial Supply Center) in regard to military specifications for natural and synthetic fiber ropes; U.S. Naval Ship and Engineering Center in regard to military specifications; and with the U.S. Army Natick Laboratory also in regard to military specifications.

The list of the seven principal Cordage Institute publications, each of which contains many individual standards, is: Quality Control-Minimum Standards; Specifications for Synthetic Ropes; Standard Test Methods for Stranded and Plaited Synthetic Fiber Ropes; Bend Tests Made on Natural and Synthetic Fiber Ropes; Fiber Rope Slings_Load Ratings and Safe Practices; The Cordage Industry Product Catalog; and The Safe Use of Rope-A User's Guide to the Safe Application of Fiber Ropes. These are all national in scope and considered advisory to Mexican and Canadian members as well as to U.S. members.

The Technical Committee has also worked with private organizations such as the following on specifications and standards: American Merchant Marine Association (towing hawsers on ocean-going vessels); American Society of Mechanical Engineers (sling specifications); National Ski Area Association (rope tow and rescue rope specifications); New York City Fire Department (rescue ropes); and public utility companies (specifications and test methods).

The following is a list of active standards committees and new projects under consideration: the Technical Committee is actively pursuing standards development. The current projects include: revision of the 
Product Catalog; review of testing procedures for hardness, ultraviolet degradation, acid degradation and breaking; development of a list of expert witnesses and testing laboratories; preliminary review of subject of permanent elongation and elasticity; preparation of sample specifications on working loads; conducting of determination of testing speeds for polyethylene rope; and completion of polypropylene specifications for use by the utility industry, and procedures for testing electrical leakage.

In international programs, the institute and its Technical Committee have participated in the activities of Technical Committee 38-Textiles, of the International Organization for Standardization (ISO) and in the work of the American Society for Testing and Materials with the ISO. The standards work of the institute has special international significance because of the special membership by Canadian manufacturers and Cordemex of Mexico.

\section{CORN REFINERS ASSOCIATION, INC., and its research division, CORN INDUSTRIES RESEARCH FOUNDATION,}

1001 Connecticut Avenue NW., Washington, D.C. 20036

The association, formerly Corn Industries Research Foundation, Inc., was incorporated February 9, 1932. Governed by a Board of Directors, two from each of the 11 corporate members, the association conducts industrywide programs of research, technical service, and public information. Its varied activities include the development of standardized procedures, terminology, instrumentation, methods of measurement, and the like on behalf of industry members and the consumers of industry products.

An Analytical Procedures Committee develops the Standard Analytical Methods of the member companies of Corn Industries Research Foundation on a continuing basis. Members of this committee serve as associate referees for various Association of Official Analytical Chemists (AOAC) product categories. A reference volume, Critical Data Tables, compiled by the Scientific Committee, is available from the association at cost.

The Applied Development Committee and its subcommittees gives attention to broad technical service problems. It recently cooperated with the Food Chemicals Codex in developing monographs for modified starches. On a continuing basis, it assists the Department of Defense in the development of military specifications. Cooperative work is now underway with the United States Pharamacopeia on monographs for industry products as well as with the Joint Expert Committee of the Food and Agricultural Organization of the United Nations/World Health Organization (FAO/WHO). The association has also worked for over ten years with the FAO/WHO Codex Alimentarius Commission, the International Organization for Standardization, and the International Commission for
Uniform Methods of Sugar Analysis, in the development of international standards.

The Raw Materials Committee works with the Grain Division of the United States Department of Agriculture on grain standards.

Formerly: American Manufacturers' Association of Products from Corn (1923) ; Associated Corn Products Manufacturers (1932); Corn Industries Research Foundation (1966).

\section{COTTON WAREHOUSE ASSOCIATION OF AMERICA, \\ 1707 L Street NW., Suite 540, Washington, D.C. 20036}

The Cotton Warehouse Association of America (CWAA) was formed in 1969. The new association resulted as a merger of the National Cotton Compress and Cotton Warehouse Association (founded in 1937) and the American Cotton Compress and Warehouse Association. The association's regular members consist of cotton compress and cotton warehouse owners and operators in the cotton belt states from the Carolinas to California. Associate membership is available to industry-related businesses such as insurance companies, banks, equipment dealers, manufacturers, steamship and truck lines.

CWAA has Special Committees on Bale Preparation, Insurance and Standards, and Research and Engineering. For a number of years, the Research and Engineering Committee worked closely with U.S. manufacturers of cotton bale ties and buckles, with a view to improving their quality, strength and reliability. The resulting standards, which have been widely used by manufacturers since 1956, cover width of ties, thickness of ties, minimum elongation of ties under stress, flatness of ties, weight and minimum tensile breaking strength of both ties and buckles.

\section{COUNCIL OF NATIONAL LIBRARY ASSOCIATIONS, \\ Chairman, American National Standards Committee Z39, c/o School of Library Science, The University of North Carolina, Chapel Hill, North Carolina 27514}

This association includes in its membership 13 major library associations in the United States. Nearly all of these associations are concerned with standardization in various aspects of librarianship.

CNLA's principal concern with standardization is as the Secretariat, since 1950, of the American National Standards Committee Z39 on Library Work, Documentation and Related Publishing Practices. The work of this committee has been assigned to subcommittees having the following titles: Program; Machine Input Records; Bibliographic References; Transliteration; Library Statistics; Proof Corrections; Arrangement of Periodicals; Trade Catalogs and Directories; Binding; 
Standard Book Numbers; Book Publishing Statistics; Library Materials Price Indexes; Report Literature Format; Thesaurus Rules and Conventions; Identification Codes; Publicity and Promotion; Standard Account Numbers; Music Industry Code; Technical Report Numbering; Bibliographic Entries for Microfiche Headers; Journal Article Citations; Advertising Microform Publications; and Standard Order Form.

In recent years the American National Standards Committee Z39, representing the American National Standards Institute (ANSI), has reviewed and formulated the position on draft International Organization for Standardization (ISO) standards in the following areas: Bibliographic References for Patents, Contents Pages in Serials, Abstracts, Bibliographic Information Interchange-Format for Magnetic Tape Recording, Transliteration of Yiddish International Library Statis. tics and International List of Periodical Title Abbreviations. The committee holds the Secretariat for ISO/ TC46 Subcommittee 2, Conversion of Languages, and the Secretariat for Working Group 1, Character Sets for Documentation and Bibliographic Use, of the newly organized TC 46 Subcommittee 4 on Automation in Documentation.

Fifteen Z39 American National Standards have been approved and published (they are available from the American National Standards Institute); Z39.11967, Periodicals: Format and Arrangement; Z39.2. 1971, Bibliographic Information Interchange on Magneitc Tape; Z39.4-1968, Basic Criteria for Indexes; Z39.5-1969, Abbreviation of Titles of Periodicals; Z39.6-1965, Trade Catalogs; Z39.7-1968, Library Statistics; Z39.8-1968, Compiling Book Publishing Statistics; Z39.9-1971, Identification Number for Serial Publications; Z39.10-1971, Directories of Libraries and Information Centers; Z39.11-1972, System for the Romanization of Japanese; Z39.12-1972, System for the Romanization of Arabic; Z39.13-1971, Advertising of Books; Z39.14-1971, Writing Abstracts; Z39.15-1971, Title Leaves of A Book and; Z39.161972, Preparation of Scientific Papers for Written or Oral Presentation.

\section{CRANE MANUFACTURERS' ASSOCIATION OF AMERICA, INC. 1326 Freeport Road, Pittshurgh, Pennsylvania $\mathbf{1 5 2 3 8}$}

The Crane Manufacturers' Association of America (CMAA), formerly the Electric Overhead Crane Institute, is the organization of leading electric overhead traveling crane manufacturers of the United States for the purpose of promoting standardization and providing a basis for uniform quality and performance.

The current standards of CMAA are: Specifications for Electric Overhead Traveling Cranes, specification number 70; Crane Operator's Manual; and Specifications for top running and Underhung Single Girder Electric Overhead Traveling Cranes, specification number 74. CMAA is represented on the American
National Standards Committee B30, Safety Code for Cranes, Derricks and Hoists.

\section{CRAYON, WATER COLOR AND CRAFT INSTITUTE, Eden Hill Road, Newtown, Connecticut 06470}

The Crayon, Water Color and Craft Institute (CWCCI), Inc. was founded in 1936. It is an association of manufacturers of children's art materials which conducts a wide range of activities.

Standardization activities represent approximately 20 percent of the total program. CWCCI's Certification Committee is responsible for the standardization activities.

Since 1943, the institute has worked with the National Bureau of Standards in the development and updating of commercial and more recently Voluntary Product Standards for the products within the scope of the institute. The two current standards are: CS130-60, Color Materials for Art Education in Schools and PS30-70, School Chalk. It is presently planned to replace CS130-60 with five separate standards. School chalk was the first to be issued. Standards for school paste and paints and inks for use in schools are in process. Standards for crayons and for modeling clay will be initiated upon the comple. tion of the two pending standards.

The Certified Products Bureau of the institute, initiated in 1940, insures the safety and quality of the products of subscribers to the bureau. Certified products are identified by a CP or AP Seal, both registered trademarks. The CP Seal insures both nontoxicity and specific quality requirements; the AP Seal insures nontoxicity only. Nonmember manufacturers may subscribe and be authorized to use the CP and AP Seals of the bureau if they meet the rigid requirements. The products covered by the seals are crayons, chalk, finger paints, modeling clay, liquid and powdered tempera, semimoist water colors, block printing ink, school paste and related school art products.

\section{DFA OF CALIFORNIA, 303 Brokaw Road, P.O. Box 270A, Santa Clara, California 95052}

Since 1909 this trade association has established grade standards, for dried fruits and tree nuts, that are considered national in scope. These standards comply with both the domestic and foreign need to know that goods shipped comply with contract descriptions. The standards of this type defy explicit definition since the goods are inspected according to the buyer's specifications and his acceptance of the merchandise. Certificates issued as a result of this type of inspection have achieved worldwide acceptance and establish a prime focal evidence of a "delivery" by the shipper. 
This organization has for many years participated in the establishment of written specifications defining defects and certain quality standards as set forth in U.S.D.A. grades and industry specifications. It also acts as the research agency in developing such standards as may be required for new products developed in the dried fruit industry.

DFA of California cooperates with foreign governments and submits food additives petitions used in the dried fruit and tree nut industries.

Services rendered by this association now include prune, walnut, and fig inspections as required by Federal or state marketing orders governing these products, and under private contract, inspections of the majority of dricd apples and cut fruits produced in California.

Formerly: Dried Fruit Association of California.

\section{DAIRY AND FOOD INDUSTRIES SUPPLY ASSOCIATION, 5530 Wisconsin Avenue, Washington, D.C. 20015}

This Association (DFISA) was founded in 1912 to represent the manufacturers of supplies and equipment for the dairy industry. It has today expanded into the supplier organization for the board spectrum of the food industry. The principal activity of the Association is to sponsor and stage a biennial trade show, the largest in the food field, with 200,000 square feet of floor space and 15,000 registered viewers. The 3-A Sanitary Standards program is cosponsored by DFISA and other dairy processor trade associations in the industry. The Association houses the secretary of the program and coordinates the work of thirty specific task committees which develop the substance of the standard. In a staff of seventeen, the standards work occupies the time of three staff people. The standards activity is implemented within the Association by the DFISA Technical Committee, and "satellite" task committees.

The 3-A program involves participation by representatives from the U.S. Public Health Service, the U.S. Department of Agriculture and state and local regulatory health offices. In addition to 3-A standards for specific equipment, the program develops a category of accepted practices which provides for a method instead of for a single piece of equipment. To date there are approximately 37 standards, of which five are not yet in print. The standards are national in scope and are voluntary for the industry. They are, however, frequently adopted for regulatory enforcement at the local level. The standards are published officially in the Journal of Milk and Food Technology, the official publication of the International Association of Milk, Food and Environmental Sanitarians. Current activity is reflected in tentative $3-A$ sanitary standards for blenders, colloid mills, dry product bins and conveyors, dry product hopper trucks, sanitary tubing, and farm tanks.

A parallel activity is represented by the E-3-A Sanitary Standards which are developed for equipment used in the processing of liquid eggs. This is cosponsored by DFISA and the Poultry and Egg Institute of America. The program was initiated in 1968, and 12 standards have been issued. Current activity is concentrated on egg breakers, egg washers, and HTST pasteurization for liquid eggs.

The 3-A program for dairy equipment is the result of cooperation among dairy processors, the users of equipment; dairy industrial suppliers and equippers, the manufacturers and sellers of dairy equipment; and public health officials and sanitarians, the regulatory officials under whose jurisdiction the equipment is installed and used.

Voluntarily supported by the national trade associations in the dairy processing industry, the program has resulted in the adoption of a total of 37 Standards and Practices for dairy equipment. Equipment complying with the standards may carry the $3-\mathrm{A}$ Symbol, provided its manufacturer received authorization to do so from the 3-A Symbol Council.

Generally speaking, the 3-A Standards and Practices are acceptable in public health jurisdictions in nearly every town, city and state in the United States. The 3-A Sanitary Standards and Practices are cited in the recommended Grade "A" Pasteurized Milk Ordinance of the U.S. Public Health Service.

\section{DATA PROCESSING MANAGEMENT ASSOCIATION, 505 Busse Highway, Park Ridge, Illinois 60068}

This is an organization both national and international in scope, founded in 1951, and composed of 25,000 data processing and systems personnel engaged in the use and management of computers and related equipment. The standardization activities comprise about 10 percent of the total program. DPMA assists in the development of standards in the data processing field through its membership and active participation on the American National Standards Committee X3 on Computers and Information Processing. Through this membership and through DPMA's official monthly publication, "Data Management," the association encourages and publicizes efforts toward the development of standards in data processing equipment, terminology, data codes, analysis, documentation and computer programming languages.

DPMA solicits review and comment by its members on proposed standards. These are discussed at meetings of X3 where the DPMA delegate is empowered to register DPMA's vote.

The certification program outlined in Certificate in Data Processing (CDP), consists of certification by examination of individuals recognized to be knowledgeable in data processing management. The CDP program is intended to aid in the establishment of recognized professional standards within the data processing industry.

Formerly: National Machine Accountants' Associa. tion (1965) 


\section{DIAMOND WALNUT GROWERS, INC., \\ 1050 South Diamond Street, P.O. Box 1727, Stockton, California 95201}

Diamond Walnut Growers, Inc. (DWGI) was founded in 1912 under the name California Walnut Growers Association. It is a nonprofit cooperative association owned by approximately 3,850 walnut growers who produce more than 50 percent of the walnuts grown in the State of California. (The name of the cooperative was changed in 1956.)

The Evaluation Committee of the Board of Directors established 9 domestic, 5 Canadian, 15 foreign, and 70 special customer standards for shelled wal. nuts with all statements of maximum restraints and definitions concerning size, color, and defective kernels from United States Standards for Shelled Walnuts (Juglans regia), 23 F.R. 10354, January 25, 1959, and Department of Agriculture, Consumer and Marketing Service Walnut Color Chart of 1967, except where superseded by the Code of Federal Regulations, Title 21, Section 128.10, March 30, 1972, or other applicable sections.

The committee established four color and five size standards for inshell walnuts with all statements of tolerance and definitions concerning size, color, and grade defects from United States Standards for Grades of Walnuts (Juglans regia) in the Shell, 29 F.R. 12865, September 12, 1964, as amended September 1, 1968, 33 F.R. 10840.

All standards are national in scope and DWGI markets under the Agricultural Marketing Agreement Act of 1937, as amended, with administration by the Walnut Control Board in San Mateo. DWGI's involvement with other governmental agencies also includes the Department of Agriculture, Fruit and Vegetable Division, Food and Drug Administration, Economic Research Service, Foreign Agricultural Service, and the Department of Commerce.

The standards are promoted through 88 domestic and 33 foreign brokers. DWGI employes a Quality Control Department and the services of the Dried Fruit Association of California to certify products during processing and at time of shipment. A complete listing of standards is available through the Stockton headquarters of Diamond Walnut Growers, Inc.

\section{DIAMOND WHEEL MANUFACTURERS' INSTITUTE, 2130 Keith Building, Cleveland, Ohio 44115}

The Diamond Wheel Manufacturers' Institute was founded in 1963. The DWMI is national in scope and its members are all located within the continental United States. They manufacture from basic raw materials, grinding wheels and blades in which the abrasive used is diamonds-either natural or manufactured.

The percentage of standardization to the total program is about 30 percent and the standards program is administered by the Standards and Safety Committee. The industry is actively engaged in international standardization through International Organization for Standardization, ISO/TC $29 / \mathrm{WG} 5$. There is no activity of a standards nature in conjunction with the Federal Government, nor is there a certification program. Currently there are four standards issued under the auspices of the industry: American National Standard B74.1, Identification Code for Diamond Wheel Shapes; American National Standard, B74.3, Standard Specifications for Shapes and Sizes of Diamond Grinding Wheels, Hand Hones, and Mounted Wheels; American National Standard B74.16, Checking the Size of Diamond Abrasive Grain; and American National Standard B74.17, Test for Bulk Density of Diamond Abrasive Grain. All of the foregoing standards are national in scope, since they have been promulgated through the American National Standards Institute.

\section{DISTILLED SPIRITS COUNCIL OF THE UNITED STATES, INC., 538 Pennsylvania Building, Washington, D.C. 20004}

In March, 1973, three independent trade associations of the distilling industry, i.e., (1) Distilled Spirits Institute, (2) The Bourbon Institute and (3) Licensed Beverage Industries, were consolidated into a new association, Distilled Spirits Council of the United States, Inc. (DISCUS). Each of the three will retain its respective identity as an operating division of DISCUS.

One of the primary functions of this council, through its standing committees composed of technical experts from member companies, is the continuing development and maintenance of categorical standards pertinent to the industry. Ongoing studies, as needs are foreseen or dictated by developments in the regulatory and/or private sectors, are initiated and pursued through standards formulation, frequently in cooperation with appropriate Federal agencies. Typical projects include plant safety standards and metric size standards, both domestic and international. Other studies, with standards as a goal, involve the transportation and storage of hazardous materials, filtration processes and containers.

\section{DOOR OPERATOR AND REMOTE CONTROLS MANUFACTURERS' ASSOCIATION, 110 North Wacker Drive, Chicago, Illinois 60606}

This association, frequently referred to as DORCMA, was established in 1959 as a national trade association comprised of manufacturers of vehicular door operators-residential, commercial or industrialand/or remote controls for the operation of the same. Remote controls for automatic door operators generally are of the radio type. Only one standard has been developed by the association's Technical Committee, this being a Minimum Standard for Heavy Duty 
Industrial and Commcrcial Draw Bar Type Electrically Powered Door Operators, and national in scope. It bears no other identification, has not been promoted by the association but is available upon request.

The association has cooperated with Underwriters' Laboratories in its development of UL 325 Standard for Safety for Door, Drapery, Gate and Window Operators and Systems. It also has cooperated with the Federal Communications Commission regarding the rulcs and equipment authorization procedures of RF devices. Standardization activities comprise a very small percentage of the association's activities. No new standardization projects currently are under consideration.

\section{DRY COLOR MANUFACTURERS' ASSOCIATION, \\ 561 Franklin Avenue, Nutley, New Jersey 07110}

The Dry Color Manufacturers' Association, founded in 1925, is a nonprofit organization. It is composed of 33 United States producers of dry, flushed and dispersed inorganic and organic pigments.

The association has an Ecology Committee, comprised of four subcommittees: Air and Water Pollution, Heavy Metals, Rhodamine Dyes and Pigments, and Toxicity. These committees are working actively with Government agencies such as Occupational Safety and Health Administration and Environmental Protection Agency to establish standards for safe working conditions in handling chemicals, dyes and pigments.

Traces of various metallic impurities are commonly found in most industrial chemical products, including organic pigments. The concentration range of their occurrence is a matter of increasing concern.

A survey has been made by the Organic Pigments Subcommittee of the Dry Color Manufacturers' Association of the trace metal content of a wide range of organic pigments. Data were collected from 17 organic pigment manufacturers comprising 376 samples representing 140 organic pigment structures. This report gives the result of this survey and discusses the significance of the findings. The metals surveyed included arsenic, lead, mercury, barium (soluble), cadmium, antimony and selenium. The selection of metals was based on those listed in American National Standard Z 66.1-1964 and Federal and local laws and regulations, but not including the regulations for certified colors covered by the Food and Drug Administration.

\section{EASTERN BIRD BANDING ASSOCIATION, INC., 58A Fairfield Lane, Jameslurg, New Jersey 08831}

The association was founded in April 1923. EBBA provides consultation services to professional and amateur ornithologists who are active, and licensed by the Fish and Wildlife Service, to engage in banding and marking activities of birds protected by the Bird Treaty Acts. Additionally, EBBA publishes an attractive, quarterly magazine dealing with bird banding and related activities, and research data, new methods and field techniques. Approximately 900 members are located in the Eastern United States and other states as well as foreign countries. Standardization of field methods is of great importance to our scope of activities which further aids work done by appropriate governmental agencies in the collection of field data and statistics of bird populations, bird migration, breeding studies, and similar projects involving marking and banding of birds as a means of gathering these data. Persons permitted to tag birds in this way, are licensed by the U.S. Department of the Interior's Fish and Wildlife Service. Information on licensing should be obtained from the Bird Banding Laboratory, Office of Migratory Bird Management, Laurel, Maryland 20810.

\section{EDISON ELECTRIC INSTITUTE, 90 Park Avenue, New York, New York 10016}

This institute founded in 1933, is the national trade association of the investor-owned electric light and power companies. The major part of its standardization activities is carried out through representation on some 70 standards committees of the American National Standards Institute. Most of these are concerned with standards for electric utility equipment and customers' appliances and also codes involving industry practices, such as the National Electrical Safety Code. The institute also carries on a certain amount of standardization relative to electric utility equipment with other industry associations such as the National Electrical Manufacturers' Association. Institute representatives also are active in standardization activities of the American Society for Testing and Materials and the National Fire Protection Association.

In some cases certain committees of the institute issue specifications intended particularly for use of the member companies as an aid in preparing their own specifications for purchase of material. The Transmission and Distribution Committee has issued a number of these, covering various items of line hardware and timber products. Other committees have issued several specifications relating to metering and safety equipment. The titles of these various specifications are shown in EEI Publications and Service Materials, available from the institute.

\section{ELASTIC FABRIC MANUFACTURERS' COUNCIL OF NORTHERN TEXTILE ASSOCIATION, 211 Congress Street, Boston, Massachusetts 02110}

The Elastic Fabric Manufacturers' Council became part of Northern Textile Association in 1970 and represents over three quarters of the elastic fabrics industry of the United States. 
The EFMC's Technical Committee is actively engaged in the establishment, review, revision and promulgation of standard test methods, performance standards and specifications for standard types of knitted, woven and braided elastic fabrics and nonelastic braided trimming. Current standards include: Woven Waistband Elastic Minimum Performance Standard/A Performance Standard for Webbing Used in Men's and Boys' Underwear and Pajamas; Methods of Testing Wide Elastic Fabrics-Tension and Stretch, NTA-EC-1-71.

In addition to counseling engineering societies such as the American Society for Testing and Materials and Federal agencies, the EFMC's Technical Committee is a source for interlaboratory testing of test methods, review of product characteristics and the development of suggested tolerances and specifications.

Formerly: Elastic Fabric Manufacturers' Institute (1970).

\section{ELECTRICAL APPARATUS SERVICE ASSOCIATION, INC., 7710 Carondelet Avenue, St. Louis, Missouri 63105}

The Electrical Apparatus Service Association (EASA), founded in 1933, is a trade association of companies engaged in the repair of electrical apparatus. Most of the 1900 members are in the U.S., Canada, or Mexico, and recently EASA added members in Europe, Asia, Australia, Central America and Africa.

This association originally developed the following standards: (1) Electric Motor and Generator Rebuilding Standards-for integral horse power motors and electrical machinery and equipment one to one thousand KVA; (2) Transformer Rebuilding Standards-applying only to transformers completely rewound; (3) Rewinding Standards for Single Phase Induction Motors-for ratings up to and including 10 H.P., 300 volts, Class A insulation; (4) Rewinding Standards for Three Phase Induction Motors-for ratings up to and including 200 H.P., 600 volts, Class A insulation and (5) Hand Power Tool Rebuilding Standards. These standards have recently undergone extensive revision by the Engineer's Advisory Committee and were incorporated into one standard. It covers rebuilding, reconditioning, and rewinding of $\mathrm{AC}$ rotating apparatus, DC rotating apparatus, liquid filled distribution transformers, air-cooled distribution transformers, hand power tools, hermetic motors, testing, and safety.

Formerly: National Industrial Service Association (1960).

\section{ELECTRICAL GENERATING SYSTEMS MARKETING ASSOCIATION, Tribune Tower, 435 N. Michigan, Chicago, Illinois 60611}

The Electrical Generating Systems and Marketing Association (EGSMA), founded in 1963, is an interna- tional industry organization representing manufacturers and distributors involved with the generation, transmission, storage and control of electrical energy not directly supplied by the public utility companies.

Under policy direction of its Board of Directors and operating through its various committees and staff, the association is to: maintain a cooperative standards program for developing and promulgating standards and specifications to serve the industry and its customers; provide an effective liaison between the industry and its customers, both civilian and military, for the interchange of information and ideas; and assist its customers in obtaining the most advanced and reliable products and scientific developments from the industry.

Formerly: Engine Generator Set Manufacturers' Association (1971).

\section{ELECTRICAL TESTING LABORATORIES, INC., 2 East End Avenue, New York, New York 10021}

Electrical Testing Laboratories, Inc. (ETL) was founded in 1896. It is an employee-owned, independent testing, inspection and certification agency. Operating as a multidisciplined organization, its divisions are acoustical, chemical, photometric, electrical/ electronic, automotive/mechanical, air-conditioning, manufactured housing and carpet certification.

Somewhat in excess of 50 percent of ETL's activity is in the field of product certification where its Certification Services Development group writes standard methods for the operation of safety and/or performance label, listing and certification programs. These methods called Procedural Guides cover all aspects of certification from initial certification, through follow-up inspections, quality control audit and decertification, including label and listing removal requirements. These standards, national in scope, are published by affected industries and/or ETL. Procedural guides are presently published on: appliances; air-handling and conditioning equipment; luminaires; medical devices; electrical cable; fluorescent ballasts and starters; lamps; architectural glass and aluminum; builders hardware; mobile homes; recreational vehicles; industrialized housing and carpeting. ETL's airconditioning activities are international.

ETL's certification programs are recognized and employed by Federal Government agencies, such as General Services Administration (GSA); Department of Housing and Urban Development, Federal Housing Administration (HUD/FHA); and Occupational Safety and Health Administration (OSHA). Carpet certification procedures to HUD/FHA Minimum Property Standard, Use of Materials UM 44c, were prepared under contract by ETL.

ETL makes available its procedural guides and certified directories to all interested parties. Originally known as the Lamp Test Bureau (1896-1904), ETL operated as the exclusive testing, research and standards-writing arm of the Association of Edison Illuminating Companies until 1942. 


\section{ELECTRONIC INDUSTRIES ASSOCIATION, 2001 Eye Street NW., Washington, D.C. 20006}

The Electronic Industries Association (EIA) was founded in 1924. "EIA Engineering Standards are designed to serve the public interest by climinating misunderstandings between manufacturers and purchasers, facilitating interchangeability and improvement of products, and assisting the purchaser in selecting and obtaining with minimum delay the proper product for his particular need. Existence of such standards shall not in any respect preclude any member or nonmember of EIA from manufacturing or selling products not conforming to such standards. Standards are proposed or adopted by EIA without regard to whether their proposal or adoption may in any way involve patents on articles, materials, or processes. By such action, EIA does not assume any liability to any patent owner, nor does it assume any obligation whatever to parties adopting EIA Standards." The preceding statements are the policy of EIA, reflecting the basic objectives of all EIA standardization programs.

In all cases, specific requirements and restraints expressed below must govern in the development of EIA Standards. All standardization programs must be shown to serve a legitimate public interest objective and that objective should be specifically stated in the context of the standard. To assure this, the program should relate to the achievement of one or more of the following objectives: (1) promotion of interchangeability or improvement of products; (2) elimination of misunderstandings or confusion between manufacturers and buyers with respect to the products; (3) providing assistance to the purchaser in selecting and obtaining with minimum delay a suitable product for his particular need; or (4) serving a declared governmental or public interest.

Formerly: Radio Manufacturers' Association (1950); Radio-Electronics-Television Manufacturers' Association (1957).

Absorbed: Magnetic Recording Industry Association (1965).

\section{ENTOMOLOGICAL SOCIETY OF AMERICA, 4603 Calvert Road,} College Park, Maryland 20740

The Entomological Society was established in 1953 by the consolidation of the American Association of Economic Entomologists (1889-1952) and the former Entomological Society of America (1906-1952). The society is a professional, scientific, nonprofit organization, operating under articles of confederation dated July 23, 1954 in Washington, D.C. The boundaries that encompass Mexico, the United States and Canada comprise the geographical limits of the society. However, membership is available to entomologists in all parts of the world.

The following Standing Committees provide reports that may relate to standardization activities on:
Common Names of Insects; Insecticide Terminology; Insecticide Reference Standards; Insect Survey and Losses; Professional Training, Standards and Status; and Special Committee on Insecticide Resistance.

The reports of these committees are published annually in the March issue of the Bulletin of the Entomological Society of America. Lists prepared by these committees are coordinated with the American National Standards Institute. Lists are used on a national basis for the purpose of standardizing the use of common names of principal insect pests, common names of insecticides, methods for determining insect loss and damage, and insecticide resistance.

\section{ESSENTIAL OIL ASSOCIATION OF U.S.A., INC., 60 East 42nd Street, New York, New York 10017}

This association, founded in 1927, serves the interest of processors, importers and dealers in essential oils and synthetic chemicals.

Aromatic and flavor materials range from the synthetic chemical compounds emerging from a modern research laboratory to the oil extracted from natural materials. There are several hundred natural materials that are processed into essential oils such as flowers, spices, herbs, citrus products, fruits, leaves, roots, wood, gums and animal products. The processing of these materials include distillation, extraction with a volatile solvent, maceration and enfleurage (cold fat absorption). These natural oils contain a multitude of chemical compounds, such as alcohols, esters, aldehydes, detones, phenols, Iactones, terpenes, and sesqui-terpenes. They are reasonably uniform in composition and identifiable by such physical characteristics as specific gravity, refractive index, optical rotation, solubility in alcohol and other solvents.

Identification of these constituents in essential oils has led to the synthesis of many of them to duplicate nature's chemistry. Modern research has produced a number of new synthetic aromatic chemicals similar in structure and odor to the constituents of the natural oils and structures not found in nature, as far as we know, as well as some that have entirely new odor characteristics. In all, there are perhaps 3,000 or more synthetic materials which have become important ingredients in the development of finished perfume or flavor compounds.

The Scientific Section of the EOA, over the past 35 years, has developed some 300 specifications with 20 test methods to aid in their determination. These are incorporated in the internationally accepted volume, EOA Standards and Specifications. This work has enchanced not only the professional stature of the industry, but has upgraded the increasing number of new products. This service to large-scale users fills a need which has not been covered previously by the official monographs of the United States Pharmacopeia (USP) and the National Formulary (NF).

The Instrumental Analysis Committee evaluates new spectroscopic developments, as well as the more 
recently introduced Gas Liquid Chromatography, in analytical techniques as an aid to research and quality control.

\section{EXPANDED SHALE CLAY AND SLATE INSTITUTE, \\ 1041 National Press Building, Washington, D.C. 20004}

The ESCSI is a nonprofit technical organization supported by producers of expanded shale, clay and slate using the rotary kiln process. The lightweight aggregate produced by its members conforms with all of the requirements of Standard Specification for Lightweight Aggregates for Structural Concrete, American Society for Testing and Materials, ASTM C 330-69, and in addition, meets stipulated minimum institute standards of performance in concrete.

The major objectives of the ESCSI are to: improve and extend the uses of expanded shale aggregate through research and development; disseminate the authentic data developed to the architectural and engineering professions and to the construction industry; cooperate and collaborate with other technical organizations interested and active in the field of concrete; and maintain standards for uniformly high quality of product among the membership. These objectives are pursued primarily under the auspices of its Technical Direction Committee, and the Asphalt Applications, Masonry, Production, Special Uses, Structural Design, and Structural Properties Committees.

The institute is active in many allied technical organizations engaged in promulgating building codes, methods of test, recommended practices, specifications and standards for structural lightweight concrete, lightweight concrete masonry, and/or lightweight aggregates.

Technical and promotional literature, prepared and published by the institute, is available without charge in limited quantity from its members or headquarters office. Included in its series, Lightweight Concrete Information Sheet, are two pertinent items: No. 10 -Concrete Masonry Guide Specifications; and No. 11 -Guide Specifications for Structural Lightweight Concrete.

Formerly: Founded as Expanded Shale Institute (1952), changed in 1955 to current name.

\section{EXPANSION ANCHOR MANUFACTURERS INSTITUTE, 331 Madison Avenue, New York, New York 10017}

Founded in 1972, EAMI is a nonprofit organization comprised of the major USA manufacturers of expansion anchors for the construction industry. Its purposes are to further the development of the expansion anchor industry, to promote the safe and effective application of expansion anchors, to encourage research and to cooperate with organizations engaged in such work.
A Technical Committee comprised of engineering representatives of all EAMI member companies is continuously involved in the development of standards. The committee cooperates with Government and private organizations that are concerned with the safe. effective and economical employment of expansion anchors.

Examples of cooperative programs of standards development are a Research Standard for Testing Anchors in Concrete for the International Conference of Building Officials (ICBO) and proposed Standard Methods of Test for Strength of Anchors in Concrete and Masonry Elements by the American Society for Testing and Materials (ASTM). Similar standards activities are planned in conjunction with the General Services Administration (GSA), the Housing and Urban Development, Federal Housing Administration, and other Federal agencies.

\section{EXPANSION JOINT MANUFACTURERS' ASSOCIATION, \\ 331 Madison Avenue, \\ New York, New York 10017}

This association was formed in April 1955 to foster and study the problems peculiar to expansion joints. The association operating through its Technical Com. mittee is continuously engaged in the improvement of its standards which were developed in the interest of public safety and for guidance in design and determination of service capacities and quality of Bellows Expansion Joints. Copies of the standards may be obtained by writing to the secretary.

\section{FACING TILE INSTITUTE, 500 12th Street SW., Suite 810 Washington, D.C. 20024}

This institute, founded in 1934, is composed of manufacturers of ceramic glazed structural facing tile, natural finish tile, and glazed brick. The institute has engaged in the standardization of shapes, colors, and installation techniques and has recently updated its specifications.

The institute maintains liaison with the Structural Clay Products Research Institute, and Mason Contractors Association of America. There is a continuous program of testing and certification of all members' products covering surface appearance and finish conducted by Pittsburgh Testing Laboratories.

Formerly: Glazed Brick and Tile Institute.

\section{FACTORY MUTUAL ENGINEERING AND RESEARCH,}

\section{Boston-Providence Turnpike,} Norwood, Massachusetts 02062

The Factory Mutual Engineering and Research is a wholly owned associate of the Factory Mutual System which was founded in 1835. With district offices in 17 
major industrial centers of the Unitcd States and Canada, this organization provides property and production loss-prevention enginccring service to industrial organizations insured in the four companies of the Factory Mutual Systcm. Standards developed by this organization from loss experience, engineering background, basic research, applied research, and industrial-scale fire tests, form the basis for its services. These numerous standards, including such subjects as installing automatic sprinklers, safeguards for flammable liquids, gases, dusts, industrial ovens and dryers, and protection of buildings against wind damage, are available to the public in data book form.

An important group within the organization is the research staff who, in addition to conducting the test portion of loss-prevention standards development, approves equipment and materials and services conccrned with property damage limitation. Items meeting their performance standards are listed in the Factory Mutual publication entitled Approval Guide. Most such items are marked by the manufacturers with a special identifying symbol to show that they are so approved.

Through memberships and committee representations, assistance is given to the standardization activities of other national scope organizations dealing with materials, equipment, and methods for industrial property and production loss-prevention. Included are such organizations as the American National Standards Institute, National Fire Protection Association, and American Society for Testing and Materials.

Factory Mutual System was formerly: Associated Factory Mutual Fire Insurance Companies.

\section{FAMILY CAMPING FEDERATION OF AMERICA,}

Bradford Woods, Martinsville, Indiana 4.6151

The Family Camping Federation of America (FCFA) is a nonprofit organization founded in 1960 for family camping leaders dedicated to the total interest and needs presenting all segments of the industry. FCFA's standards were adopted to give direction in the establishment and operation of family campgrounds, and serve as a basis for camporound accreditation.

The adopted Family Camporound Standards presently represent the concensus of opinion of both professional and lay authorities and are the culmination of over eight years of work. FCFA has 81 standards catagorized into the following four types: (1) Mandatory-considered to be absolutely essential to give assurance of campground quality; (2) Desirable (design standards) - considered to be highly desirable; (3) Sanitation and (4) Administration, all of which are voluntary. In addition to these, the campground must comply with all applicable codes and regulations governing the installation, construction and operation of a family campground. The federation is affiliated with the American Camping Association, works closely with several government agencies and consults on an international basis.

Formerly: Family Camping Federation.

\section{FARM AND INDUSTRIAL EQUIPMENT INSTITUTE, 410 North Michigan Avenue, Chicago, Illinois 60611}

The Farm and Industrial Equipment Institute (FIEI), founded in 1893, is a nonprofit association of manufacturers of farm and industrial equipment, representing over 90 percent of the North American business.

Its principal purpose is to serve as a coordinating body for many matters where joint industry action is desirable to better serve its customers. FIEI is instrumental in originating and coordinating activities concerned with education, engineering standards, traffic and transportation, conservation, research, statistics, safety codes and legislation, and all such matters which are of common interest to the industry. This work is carried out through 42 standing committees and through 13 affiliated organizations and councils, each with their own committees.

A substantial percentage of FIEI activities involve proposals for standardization relating to performance and interchangeability. They are developed by FIEI engineering committees and approved by the FIEI Engineering Policy Committee before being submitted to the American Society of Agricultural Engineers, the Society of Automotive Engineers and the American National Standards Institute for adoption as voluntary standards and publication by these professional societies to promote their use.

FIEI also works with numerous international groups for the harmonization of regulations in the interest of world trade, including the International Organization for Standardization (ISO), the Organization for Economic Cooperation and Development (OECD), the European Committee of Association of Manufacturers of Agricultural Machinery (CEMA), and others. FIEI representatives attend international meetings in other countries many times a year, and cosponsored with the American National Standards Institute an international seminar for ISO TC-23.

FIEI is involved with government standardization activities: on the federal level with the U. S. Department of Agriculture, the Department of Transportation, Department of Labor, Office of Special Housing Assistance, Environmental Protection Agency, and the Department of Commerce; and on the state level in connection with certification and regulatory activities.

FIEI engineering committees and councils involved in standards-proposals activities are listed in the FIEI Organization and Membership Roster which is available upon request from the Farm and Industrial Equipment Institute.

Formerly: National Association of Agricultural Implement and Vehicle Manufacturers; National Association of Farm Equipment Manufacturers (1933); Farm Equipment Institute (1965). 


\section{FEDERATION OF SOCIETIES FOR PAINT TECHNOLOGY, 121 South Broad Street, Philadelphia, Pennsylvania 19107}

The federation founded in 1922, is the technical society of the decorative and protective coatings industry and allied lines such as printing inks, etc. Members of the federation are chemists, chemical engineers, and supervisory production personnel of the industry. The federation is composed of 25 local organizations, 22 of which are in the United States, two in Canada, and one in England.

The objectives of the federation are as follows: (1) to develop or provide practical and technical facts, data, and standards fundamental to the manufacture and use of paints, varnishes, lacquers, related protective coatings, and printing inks; (2) to promote the investigation and interchange of ideas among its members and to promote research and application of the sciences in the manufacture and use of paints, varnishes, lacquers, related protective coatings, and printing inks; (3) to arrange for the collection and dissemination of information pertinent to the industries served by the federation and for the presentation, discussion, and publication of papers and other contributions; (4) to encourage the establishment of constituent clubs and to coordinate their activities with those of the federation; (5) to cooperate with the National Paint, Varnish, and Lacquer Association and other organizations in a manner consistent with the provisions of these bylaws; and (6) to perform a public service by the constant improvement of products and elimination of wasteful methods in manufacture.

Formerly: Federation of Paint and Varnish Production Clubs (1960).

\section{FELT MANUFACTURERS' COUNCIL OF NORTHERN TEXTILE ASSOCIATION, 211 Congress Street, Boston, Massachusetts 02110}

The Felt Council (FMC) became part of Northern Textile Association in 1961 and represents over 80 percent of the pressed felt industry of the United States.

The FMC's Technical Committee is actively engaged in the establishment, review, revision and promulgation of physical and chemical specification requirements for standard types of wool felt in both roll and sheet form. The currently active specification is as follows: Wool Felt Standard Specification, FS14$68 / 71$.

In addition to counseling Federal agencies and engineering societies such as the American Society for Testing and Materials and Society of Automotive Engineers on their wool felt specifications, the FMC's Technical Committee is a source for new technical information and papers covering additional wool felt performance characteristics which have not yet reached specification requirement status.

Absorbed: Felt Association of New York City.

\section{THE FERTILIZER INSTITUTE, 1015 18th Street NW., W ashington, D.C. 20036}

This organization, founded in 1970, supports standardization through simplification and uniformity of Federal and state fertilizer regulatory laws as well as of chemical analytical methods. It also is heavily involved in the safety standards activities at state and Federal levels. The institute provides this support through its staff and qualified committeemen from the industry.

The objective of such standardization is to increase the accuracy and precision of the chemical analysis of fertilizers, and by means of education and safety practices to prevent accidents and injury.

Further, the institute supports the enactment of state uniform fertilizer laws as recommended by the Association of American Plant Food Control Officials. Also, the institute supports further standardization of reporting and publication forms used in the various states to record the consumption of fertilizers by material and grade on an annual, seminannual, quarterly or monthly basis by state and county statistics at least annually.

\section{FIBRE BOX ASSOCIATION, 224 South Michigan Avenue, Chicago, Illinois 60604}

The Fibre Box Association, incorporated in 1940 as a nonprofit organization, is a trade association representing manufacturers of corrugated and solid fibreboard. Its membership throughout the country produces approximately 85 percent of the fibreboard boxes manufactured. Its aims are to promote the industry's general welfare; to represent the members before appropriate Government, transportation, industrial or other agencies; to compile and disseminate statistical information; and to develop data useful to its members in marketing their products.

The association is a member of the International Corrugated Case Association and participates in pertinent activities of the American National Standards Institute and the International Organization for Standardization. It is quite active in an advisory capacity with Federal Government bodies preparing standards and specifications involving corrugated and solid fibreboard. The principal agencies are the General Services Administration and the U.S. Army Natick Laboratories.

In conjunction with the Packaging Machinery Manfacturers Institute it has issued four joint voluntary standards and one recommended practices bulletin. These are referenced in the FBA Handbook, available from member companies.

A second bulletin involving adhesives, prepared jointly with two other associations, will be issued shortly. Copies of the standards and bulletins are disseminated, upon request, to general industry. Announcements of new standards or bulletins appear in trade journals. 


\section{FINE HARDWOODS-AMERICAN WALNUT ASSOCIATION,}

666 North Lake Shore Drive, Chicago, Illinois 60611

FH-AWA was founded in 1914 and merged with Fine Hardwoods Association on April 1, 1971. This association cooperates in the development of grade rules for walnut lumber which are published by the National Hardwood Lumber Association. It also cooper. ates with the Hardwood Plywood Manufacturers Association in its Rules for Measurement and Inspection of Veneers and Plywood. These grade rules are in general use both in the United States and foreign countries.

\section{FINNISH PLYWOOD DEVELOPMENT ASSOCIATION, \\ 210 East Broad Street,}

Falls Church, Virginia 22046

This Association represents member mills manufacturing birch plywood used in various interior and exterior applications. The Technical Division of the Association is responsible for conducting research and testing.

The Association is a member of the American Concrete Institute, American National Standards Institute, American Society for Testing and Materials, Building Officials and Code Administrators International, International Conference of Building Officials, and the Southern Building Code Congress.

In addition, the Association works cooperatively with the American National Standards Institute, as well as the International Organization for Standardization, and offers assistance in the development of other product standards or specifications which affect the use of birch and other hardwood plywoods used in structural applications.

\section{FIR AND HEMLOCK DOOR ASSOCIATION, Yeon Building, \\ Portland, Oregon 97204}

The Fir and Hemlock Door Association (FHDA) was founded in September of 1965. Its primary purpose is to foster and protect the interests of consumers in the use of fir and hemlock panel doors.

Standardization activities occupy approximately 60-70 percent of the total program efforts. These activities are administered by the officers and a Commercial Standards Committee. FHDA has cooperated with the U. S. Department of Commerce, National Bureau of Standards and other Government and private agencies in a revision of CS 73-61 before publishing Industry Standard FHDA/4.72, which is a current industry standard.

FHDA represents the major and majority of fir and hemlock panel door manufacturers and its industry standards are uscd nationally as the principal specification and use document.

The active group concerned with standards continues to be the Commercial Standards Committee, appointed annually. Current considerations are related to studying standardization of glass sizes to accommodate a change to safety glass use.

Standards information is publicized and promoted in releases, mailings to the trade and product publications prepared and distributed by Western Wood Products Association, the management arm of FHDA.

\section{FLAT GLASS MARKETING ASSOCIATION, 1325 Topeka, Topeka, Kansas 66612}

The Flat Glass Marketing Association (FGMA) was founded in 1949. This association has recently published a revised edition of their Glazing Manual. By virtue of its ever increasing popularity throughout the United States, the new manual has gained recognition and is now being widely distributed in numerous foreign countries. Broadening design concepts, new construction methods and accelerated building material developments made the republication imperative.

The new manual was prepared by the FGMA Glazing Manual Committee. Its purpose is to set forth in one volume the recommended basic procedures for glazing. The scope, however, has been enlarged to encompass plastic installation as well as the new suspended glazing system. The format of the manual has been improved, consolidating the information and making the technical data more readily accessible.

It is the aim of this manual to be of particular use to the architect in specifying glazing methods, materials and procedures; to the contractor in supplying the recommended materials; and to the glazier in achieving quality performance.

Formerly: Flat Glass Jobbers' Association (1969).

\section{FLUID CONTROLS INSTITUTE, 12 Bank Street, Summit, New Jersey 07901}

This institute founded in 1921 is a nonprofit association of manufacturers of fluid control devices such as control valves, regulators, solenoid valves, steam traps, check valves, strainers and separators, and space heating specialities. FCI is engaged in formulating voluntary standards and practices with respect to terminology, design, function, capacity, efficiency, construction, materials, manufacture, and testing of fluid control devices through the sections engaged in various fields of activity.

The institute has Standardization and Standards Planning Committees chaired by appointees drawn from representatives of member companies. The product oriented sections also have standardization chairmen responsible for guidance of standards activi- 
ties until the work has progressed to adoption of individual standards by the institute.

The institute is a member body of the American National Standards Institute. FCI has liaison representative monitoring work being carried on by International Organization for Standardization and International Electrotechnical Commission in the area of international standards, and Instrument Society of America, National Fluid Power Association and Scientific Apparatus Makers' Association on domestic standards.

Fluid Controls Institute has published 17 standards available from the institute office.

Formerly: National Association of Steam and Fluid Specialty Manufacturers (1941); National Steam Specialty Club (1956).

\section{FOOD PROCESSING MACHINERY AND SUPPLIES ASSOCIATION, 7758 Wisconsin Avenue NW. Washington, D.C. 20014.}

The Food Processing Machinery and Supplies Association (FPM\&SA), formerly the Canning Machinery and Supplies Association, was founded in 1885. Its main program is the development and presentation of the annual National Exposition for Food Processors. Although standardization activities currently are minimal, the Technical and Sanitation Committee is responsible for the administration of any activities in cooperation with associations dealing with the establishment of standards for materials used in the production, preparation, processing and packaging of foods and other products which are packaged in glass, metal, fibre and/or plastic. FPM\&SA has cooperated with the National Canners' Association and the Can Manufacturers' Institute in the standardization of sizes of tin cans and with the Glass Container Association of America in developing standard sizes of glass containers.

\section{FORGING INDUSTRY ASSOCIATION, 55 Pulblic Square, Cleveland, Ohio 44113}

The Forging Industry Association (FIA) began in 1913 as the American Drop Forging Association, and underwent several changes in organization and name until adopting the present FIA structure in 1965. Forging Industry Association, an Ohio corporation not-for-profit, currently represents about 70 percent of the manufacturers of impression die forgings in the United States and Canada.

The association is the cosponsor, along with the National Safety Council, of the American National Standard B24.1-1971 Safety Requirements for Forging. FIA is also represented on the American National Standards Committee Bll, which is concerned with machine tools and related equipment.

A booklet entitled Tolerances for Impression Die Forgings dated 1963, has been developed and printed by FIA. Additionally, the association is represented with the International Organization for Standardization on Technical Committee 17.

\section{FRICTION MATERIALS STANDARDS INSTITUTE, INC., \\ Bergen Mall Office Center, East 210 Route 4, \\ Paramus, New Jersey 07652}

The Friction Materials Standards Institute, Inc. (FMSI) was founded in 1949 to promote distribution of relevant information pertaining to automotive brake linings, brake shoes and clutch facings to the friction materials industry. FMSI has 11 regional members outside the United States.

Standardization activities of the institute comprise 25 percent of the total program. These activities are administered by the Data Book and Technical Committee and the Quality Control Subcommittee. The institute issues catalogs using a standard numbering system for all current automotive brake linings, brake shoes, and clutch facings. The copyrighted numbering system is authorized for use by the institute, to its members and to customers of its members. In that manner, FMSI's standard numbering system is worldwide in scope. FMSI publishes the Automotive Data Book and Brake Shoe Identification Catalog annually. The institute's involvement with the Government is through its promotion of the standardization of test equipment, test procedures and test evaluation for the National Highway Traffic Safety Administration (NHTSA).

Formerly: Brake Lining Manufacturers' Association.

\section{GAS APPLIANCE MANUFACTURERS' ASSOCIATION, \\ 1901 North Fort Myer Drive, Arlington, Virginia 22209}

This association, which was founded in 1936, represents manufacturers of all types of domestic, commercial, and industrial gas equipment, appliances, and accessories. It works through the national standards promulgation procedures of other groups and organizations rather than developing its own standards. In this manner, a high quality of manufacturers' input has been provided to assist committees and subcommittees comprised of consumers, energy suppliers, and other general interest groups in the development and constant maintenence of approximately 75 different standards for gas appliances and equipment which have been recognized as American National Standards by the American National Standards Institute.

This high quality manufacturers' input on standards-related matters has also been provided through GAMA to many other organizations concerned with the development and maintenance of national standards, such as the American Society for Testing and 
Materials, American Society of Mechanical Engineers, National Fire Protection Association, National LP.Gas Association, and American Gas Association.

Gas appliance and equipment manufacturers' input is also frequently provided to many Government agencies such as the Department of Commerce, Consumer Product Safety Commission, Federal Housing Administration, and General Services Administration.

A Committee Personnel List is available from GAMA, showing the membership of American National Standards Committees Z21 (domestic and commercial gas appliances and equipment), Z83 (industrial gas equipment) and Z223 (national fuel gas code).

\section{GEMOLOGICAL INSTITUTE OF AMERICA, 11940 San Vicente Boulevard, Los Angeles, California 90049}

As a school for the purpose of training jewelers, this institute teaches diamond appraising and coloredstone evaluation, using standard grading systems developed for this purpose. Several of the systems employed are modifications of those long used in the jewelry industry, but the institute's appraising system developed for diamonds is based on a grading system for diamond cutting, which was possibly the first ever developed. Prices are set against grading standards on each of the important gemstones. In addition, the institute maintains gem testing and research laboratories in Los Angeles and New York City, as well as a gemological library consisting of 2,000 volumes.

\section{GLASS CONTAINER MANUFACTURERS' INSTITUTE, INC., $1800 \mathrm{~K}$ Street NW., Washington, D.C. 20006}

The Glass Container Manufacturers' Institute, Inc. was established in 1945 and represents the manufacturers of glass containers and closures producing approximately 90 percent of the United States output. The basic objective of the institute is to promote the continued growth and acceptance of glass containers as desirable, competitive packages for beverages, foods and other commodities.

The institute has a Technical Committee augmented by specific subcommittees and task groups. Technical staff meets regularly in this committee with qualified specialists from each of the participating firms to review and investigate the unique technical problems developing within the industry. A current standardization activity is the initiation, through the consensus route with the National Bureau of Standards of the Department of Commerce, of a Voluntary Product Standard for Carbonated Soft Drink Bottles (TS-214). This will cover the major considerations in the manufacture and control of containers for carbonated soft drinks. Resolution of this consensus standardization activity is anticipated within the year.

\section{GLASS TEMPERING ASSOCIATION, 1325 Topeka, \\ Topeka, Kansas 66612}

The Glass Tempering Association was founded in 1958, is a nonprofit organization. Its primary efforts are in developing specifications, standards and testing procedures for a variety of tempered glass products.

The association has technical committees involved in Standards and Engineering, Appliance Specifications, Construction Specifications, Spandrel Specifications and Consumer Safety Glazing Legislation. These committees meet two to three times a year to review their respective standards, and their work is compiled in the Engineering and Standards Manual published by the association.

\section{GRAPIIIC COMMUNICATIONS COMPUTER ASSOCIATION, \\ Graphic Communications Center, 1730 North Lynn Street, Arlington, Virginia 22209}

The Graphic Communications Computer Association, a separate international membership organization within Printing Industries of America, Inc., was founded in 1966 to assist the graphic communications industry and member firms in particular in the effective use of computer systems. 1ts primary functions include research on the application of computer technologies to the processes of printing and publishing, educational programs and seminars for industry exchange of information on computer use, and identifcation and development of areas of standardization to assist dissemination of information through publishing.

Its Composition Committee, composed of representation from state, Federal, and Canadian government agencies (including U.S. Government Printing Office) and private industry, continues to promote and partici. pate in the development of standard approaches to information file identification and typographic specification to maximize the application of generalized, hardware, independent approaches to composition system design. It has represented the printing and publishing industry in American National Standards committee efforts to expand bit structures to encompass the full range of symbols required in text processing and computer assisted typographic composition. It represents its parent organization on American National Standards Committee X-3, Computers and Information Processing.

Formerly: PIA Computer Scction.

\section{GRAY AND DUCTILE IRON FOUNDERS' SOCIETY, \\ Cast Metals Federation Building, 20611 Center Ridge Road, Rocky River (Cleveland), Ohio 44116}

The society, founded 1928 , is a trade association in the ferrous foundry industry serving producers of 
gray iron, ductile iron and white iron castings. The society does not establish standards, but provides active support and data to the various standards organizations, especially the American Society for Testing and Materials. The society promulgates updated summaries of established specifications. In addition to providing technical services to members and customers, the society provides full staff services in marketing, cost accounting and financial management. The society's Gray and Ductile Iron Castings Handbook, published in 1971, is a complete (680 pages) reference for users of Gray, ductile, white and alloy iron castings.

Formerly: Gray Iron Institute (1935); Gray Iron Founders' Society (1946).

\section{GRINDING WHEEL INSTITUTE, 2130 Keith Building, Cleveland, Ohio 44115}

The Grinding Wheel Institute was founded in 1914. The standardization activities of this institute are carried on by the Standards and the Safety Committees. The work of the Standards Committee deals primarily with simplification matters. It initiated the program for simplification of sizes of grinding wheels. The Standards Committee's activities also include assistance in the development of American National Standards covering the products of the industry. As they are finalized, they are submitted to the American National Standards Institute for approval.

This institute was joint sponsor with the International Association of Governmental Labor Officials in the development of the American National Standard Safety Code for the Use, Care, and Protection of Abrasive Wheels, which was approved and issued as American National Standard B7.1-1970. The institute is also represented on three American National Standards Committees-Small Tools and Machine Tool Elements, Safety Code for Exhaust Systems and the Mechanical Standards Board of the American National Standards Institute.

Formerly: Grinding Wheel Manufacturers' Association (1948).

\section{GUMMED INDUSTRIES ASSOCIATION, INC., THE, 380 North Broadway, Jericho, New York 11753}

This association, founded in 1920, represents domestic manufacturers of water-activated gummed paper products and, through associate memberships, these manufacturers' raw material suppliers. The GIA publishes standard test procedures and also has cooperated with the National Bureau of Standards, in the establishment of Simplified Practice Recommendation R 114-63, Gummed Kraft Paper Sealing Tape; and with the General Services Administration in the preparation of Federal Specification PPP.T-45C, Tape, Gummed, Paper, Reinforced and Plain, For Sealing and Securing. The association is also currently developing voluntary product performance standards which, together with other data, are expected to be issued as an American National Standards by the American National Standards Institute.

\section{GYPSUM ASSOCIATION, 201 North Wells Street, Chicago, Illinois 60606}

The Gypsum Association was organized in 1930 and is engaged in promoting the use of gypsum and gypsum products. Technical research programs are continually conducted in fire, sound and structural testing of gypsum products and related accessories. Contributions are made to building codes through education in the application and uses of gypsum products, and to the life-safety aspects of fire protection by providing advisory services in the interests of the industry and users of its products.

The association actively participates on several American Society for Testing and Materials, National Fire Protection Association, and American National Standards Committees, as well as participation in the work of major model code groups, such as American Insurance Association, Building Officials and Code Administrators International, International Conference of Building Officials, Southern Building Code Congress and National Academy of Code Officials. Membership is also maintained in the National Association of Housing and Redevelopment Officials and parallel interests are maintained with major contractor groups, such as International Association of Wall and Ceiling Contractors and Gypsum Drywall Contractors International.

The association is organized into anumber of committees. These are Building Code, Manufacturing and Mining, Materials Handling, Promotional, Safety, Technical and Traffic. There are representatives from each committee that hold membership in related national societies and committees.

Contributions are made to Federal standards published by the Department of Housing and Urban Development; the Department of Health, Education and Welfare; Building Research Advisory Board; General Services Administration; Occupational Safety and Health Administration; Environmental Protection Administration; Bureau of Mines; National Bureau of Standards and the military services of the Department of Defense.

Educational and general interest publications, movies, slide programs are developed and offered to the public. Recommended practices and a variety of guides are published.

\section{GYPSUM ROOF DECK FOUNDATION, 5820 North Nagle Avenue, Chicago, Illinois 60646}

This is a national trade association, founded in 1959 , and the only association in this industry. Its constituent members are building contractors active in the promotion, sales and installation of poured-inplace gypsum roof decks. 
Members also include suppliers to the industry. The association has developed and published the following: Standard Installation Practices For The Gypsum Roof Deck Industry, Design Data, Poured Gypsum Roof Deck, and How To Inspect A Gypsum Roof Deck.

This association also published and is concerned with the development of the American National Standard A 59, Specifications For Reinforced Gypsum Concrete; the American Society For Testing and Materials Specifications, C 317, C 318, C 472, and C 473; and the Gypsum Association's Blue Sheet on Testing Samples of Gypsum Concrete.

\section{IIACK AND BAND SAW MANUFACTURERS' ASSOCIATION, 1803 South Busse Road, Mount Prospect, Illinois 60056}

The purpose of the Hack Band Saw Manufacturers' Association (HBSMA) is to promote the common business of the industry and seek general improvements of the products for the industry.

This association has had standardization as the main objective since its founding in the 1920's as the Hack Saw Association. At that time, the association's main purpose was to standardize the many thousands of sizes of hack saw blades then on the market. With the advent of band saws, the association's name was changed and its scope enlarged to include the standardization of band saws. Standardization activities consist of 30 percent of the total program, with the Standardization Committee administering those activities. The two current standards: Hack Saw Blades, American National Standard B121.1; and Band Saw Blades, American National Standard B122.1, are constantly being reviewed and updated by the commit. tee. The changes needed in existing standards are detected by means of popularity indices and nonstandards reports - the first issued annually and the second quarterly. New blades and new applications make this continual "watch-dogging" imperative, for thus the manufacturers remain flexible enough to fit their customer's needs and by standardization, the number of "specials" needed cuts costs for everyone involved. Current projects consist of cooperation with machine manufacturers for band saw length standardization, and for friction sawing sizes.

HBSMA is the Secretariat of the International Organization for Standardization, ISO/TC 29-WG15 on Band Saws.

Formed by merger of: Hack Saw Association; Metal Cutting Band (1959).

\section{HARDWOOD DIMENSION MANUFACTURERS' ASSOCIATION, 3813 Hillshoro Road, Nashville, Tennessee 37215}

The Hardwood Dimension Manufacturers' Association was founded in December 1929 to write grading rules and standards for the industry; conduct and stimulate trade promotion activities; and to encourage educational plant tours and seminars that promote free exchange of manufacturing techniques and ideas in the industry and among its members.

Committees of this association cooperate with all lumber manufacturing associations for both hardwood and softwood, and furniture manufacturing and other wood using industries in bringing about standardization programs on grading rules for hardwood dimension parts. In this connection the association, under the administration of the Grade Rules Committee, published the Rules for Measurement and Inspection of Hardwood Dimension Parts, Rules for Measurement and Inspection of Hardwood Interior Trim and Moldings, and Rules for Measurement and Inspection of Hardwood Stair Treads and Risers. These rules are listed in the catalog of the National Lumber Manufacturers Association (National Forest Products Association), and since they are the only grading rules or standards for the industry, are considered national in scope.

In order to assure purchasers that the various types of products covered by these grading rules and standards are in accordance with the quality and grade covered by the standards, the producers of this industry may either individually, or in cooperation with the association, issue guarantee certificates of classification (HDMA Certificate of Origin) for specific shipments, or grade and trademark, or each piece or bundle as conforming to the HDMA grading rules.

\section{HARDWOOD PLYWOOD MANUFACTURERS' ASSOCIATION, \\ P.O. Box 6246, \\ Arlington, Virginia 22206}

The Hardwood Plywood Manufacturers' Association (HPMA) was founded in 1921. HPMA is the national trade association for hardwood plywood manufactur. ers and prefinishers of hardwood plywood, with an office and laboratory in Arlington, Virginia. Field inspectors operate out of Arlington, Virginia; Portland, Oregon; and Los Angeles, California.

Fifty percent of HPMA's total program is in the area of standardization, including inspection, testing, and certifying to standards. The Technical Committee for these activities is under the guidance of the Technical Director. HPMA issued HPMA-LF-71, Interim Industry Standard for Laminated Hardwood Block Flooring; HP.SG.71, Structural Design Guide For Hardwood Plywood; CB-SG-73, Design Guide for Wood Composition Board Panels; and GP-RUD-73, Recommended Use Document For Two-Ply Panels For Gussets. HPMA has inspection, testing, and certifying programs for hardwood plywood, prefinished hardwood plywood, wood composition board panels, laminated hardwood block flooring and two-ply gusset plates. HPMA initiated the writing of the U.S. Department of Commerce's Product Standard, PS 51-71, Hardwood and Decorative Plywood. HPMA cooperates with all Government agencies that write Federal and military 
specifications which affect hardwood plywood and flooring. It reviewed the Department of Housing and Urban Development's Minimum Property Standards for One- and Two-Family Dwellings, Multi-Family Dwellings, and Care-Type Housing with reference to its products.

HPMA's standards are used internationally by its foreign members, Canada and Panama. HPMA has been active internationally through representation at the following meetings and conferences: the United Nations Food and Agriculture Organization meetings in Rome, the 2nd Asian Plywood Conference in Tokyo, and the 3rd Asian Plywood Conference in Seoul, Korea.

Formerly: Hardwood Plywood Institute (1964).

\section{HOIST MANUFACTURERS' INSTITUTE, 1326 Freeport Road, Pittslourgh, Pennsylvania 15238}

The Hoist Manufacturers' Institute (HMI) was founded in 1967 as a trade association of U.S.A. manufacturers of manual and electrically operated overhead handling hoists. Approximately 60 percent of the institute's time is expended on engineering standards. The Engineering Committee administers HMI's standards activities with approval of the Board of Directors. They consist of four specifications on overhead handling hoists: HMI 100-Standard Specifications for Electric Wire Rope Hoists; HMI 200Standard Specifications for Hand Operated Chain Hoists; HMI 300-Standard Specifications for Manually Lever Operated Chain Hoists; HMI 400-Standard Specifications for Electric Chain Hoists; plus the American National Standard B30.16, Safety Code for Overhead (Handling) Hoists. These standards are considered national in scope.

The institute cooperates with the Naval Construction Battalion Center, Defense Supply Agency and Naval Ship Engineering Center, by commenting on their military specifications. On an international level, the organization is represented on pertinent U.S.A. committees in presenting U.S.A. viewpoints in international standards.

Formerly: Hoist Manufacturers' Association.

\section{HOME VENTILATING INSTITUTE, 230 North Michigan Avenue, Chicago, Illinois 60601}

A voluntary organization for manufacturer selfregulation, founded in 1955, the Home Ventilating Institute (HVI) conducts a program for certified performance standards for residential vented range hoods and wall and ceiling exhaust fans.

HVI certified ratings for air delivery were introduced in 1960 and for sound emission in 1971. All ratings are based on independent tests at Texas A \& M University., Products bearing the HVI label must be so certified.
Ratings are related to air change standards for kitchens, bathrooms and other rooms.

The HVI label is cited by the Department of Housing and Urban Development, Federal Housing Administration (HUD/FHA) as evidence of compliance with test requirements of the Minimum Property Standards which require that all ventilating equipment be tested and rated according to HVI procedures. The National Medallion Homes Standards cites HVI standards.

HVI is recognized as a quality control agency by the International Conference of Building Officials and the Building Officials and Code Administrators International.

Standards are being developed for powered attic space ventilators.

The HVI cooperates with the Canadian Standards Association and the International Electrotechnical Commission in development of proposed standards.

The HVI standards are supported in continuing press articles and HVI's guide and annual directory of ratings.

\section{ILLUMINATING ENGINEERING SOCIETY, United Engineering Center, 345 East 47 th Street, New York, New York 10017}

Standardization work of this society, which was founded in 1905, is carried on by over 80 technical committees and subcommittees that study and report to its Board of Directors on lighting of all areas such as: airports and aircraft, farms, industrial plants, institutions, offices, public conveyances, residences, schools, service stations and parking areas, sports and recreational areas, stores, streets and highways, theaters and television studios. The society's committees are also concerned with light sources, lighting and air-conditioning, lighting education programs, lighting progress, lighting maintenance, light control and equipment design, nomenclature, quality and quantity of light, searchlighting and testing procedures for illumination characteristics. Standards, specifications, and reports on the above subjects are published in the quarterly Lighting Design and Application journal. Six of these reports became American National Standards after processing through the channels of the American National Standards Institute.

Through an active research program the society is able to feed to the technical committees data that are used in developing reports and standards.

The society is also active in related matters through representation on committees of other professional organizations, some of which are the International Commission on Illumination, National Research Council, Inter-Society Color Council, Society of Motion Picture and Television Engineers, American Association for the Advancement of Science, American National Standards Institute, and U.S. Institute for Theatre Teclınology. 
INDIANA LIMESTONE INSTITUTE OF

AMERICA, INC.

Stone City National Bank Building, Suite 400,

Bedford, Indiana 4.7421

The Indiana Limestone Institute of America (ILIA) was founded in 1928. The institute serves the construction industry, the archilectural profession and the limestone industry as a coordinating agency for the dissemination of accurate, unbiased information on limestone standards, recommended practices, grades, colors, finishes, and all technical data required for specifying, detailing, fabricating and erecting Indiana limestone. The institute is supported by quarriers, fabricators and associates of Indiana limestone build. ing stone.

ILIA devotes 20 percent of its activities to its standardization program and its Technical Committee is responsible for those activities. The Indiana Limestone Handbook, the only ILIA standard, is the national standard for the industry. In addition, Government agencies include reference to ILIA, as the standard source for information on Indiana limestone, in their standards and specifications.

Absorbed: National Association for Indiana Lime. stone.

\section{INDUSTRIAL DIAMOND ASSOCIATION OF AMERICA, INC., \\ 53 East Main Street, Moorestown, New Jersey 08057}

This association (IDAA), established in 1945, is involved with standards for industrial diamonds. With the American Society of Manufacturing Engineers, it cosponsors American National Standards Institute (ANSI) Project B-67, Industrial Diamonds and Accessories for Their Use. Through this project, an American National Standard for Diamond Dressing Tools has been developed and approved. Through cosponsorship with the Grinding Wheel Institute, the association also cosponsors ANSI Project B-74.1, Identification Code for Diamond Wheel Shapes. Other American National Standards to which the association has cooperated include B-74.16, Checking the Size of Diamond Abrasive Grain, and B-74.17, Test For Bulk Density of Diamond Abrasive Grain. Other standardization projects are being studied by various committees with a view to presenting them to ANSI for approval.

In cooperation with the National Bureau of Standards, the association developed a separate Commerical Standard for grading of diamond powder, approved September 1963 and known as CS261-63, Grading of Diamond Powder in Sub-Sieve Sizes. It is currently cooperating with NBS in reviewing this standard.

IDAA's Toolmakers Industry Committee is currently revising and updating the Handbook-Diamond Tool Shanks, as compiled and published by the association in 1954.

\section{INDUSTRIAL FASTENERS' INSTITUTE, 1505 East Ohio Building, Cleveland, Ohio 44114}

The Industrial Fasteners' Institute (IFI) is an association of leading North American manufacturers of bolts, nuts, screws, rivets, and all types of special industrial fasteners. IFI member companies combine technical know-how to advance fastener technology and application engineering. The institute works cooperatively with national and international technical organizations, developing fastener standards and technical practices.

Users of fasteners in all industries benefit from advances made by IFI members in fastener design, manufacture and application, assuring users of maximum engineering efficiency and reliability, at minimum cost of assembly. There are more than 500,000 standard and 3,000,000 special sizes, kinds, and shapes of fasteners and engineering components.

In addition to maintaining its own standardswriting program, IFI has historically published the Fastener Standards Book. The fifth edition of Fastener Standards Book represents the fifth major presentation since the initial publication in 1941. During this 29-year period, copies have been distributed to major manufacturing and construction interests throughout the world. A major reference book for users of mechanical fasteners, this edition is the only single collection of all pertinent standards documents of all types of general purpose commercial industrial fasteners. The standards book is considered a "bible" for design engineers and production managers in all industries.

A principal development since publication of the fourth edition was the passage in 1966 of The National Traffic and Motor Vehicle Safety Act. That act has focused attention on the need for careful selection of fasteners for all safety critical applications, and for use of handling, storage, initial installation and subsequent maintenance procedures which preserve the integrity of the fastener as originally manufactured. For any safety critical applications, the user should consider whether fasteners manufactured to commercial standard and acceptable quality levels are adequate for such application. With respect to the selection and handling of replacement fasteners, the institute urges all users to employ the same degree of care as with the original product, so that the quality of the assembly is in no way diminished.

Formerly: American Institute of Bolt, Nut and Rivet Manufacturers.

\section{INDUSTRIAL MANAGEMENT SOCIETY, 570 Northwest Highway, Suite 4, Des Plaines, Illinois 60016}

Through the Occupational-Rating Research Group, this society, which was founded in 1934, developed an occupational-rating plan for hourly and salaried occupations, which is a standard devised by the 
society for standardizing and evaluating occupations. This standard is being widely used at the present time throughout the country. The use and adoption of the plan as set forth in this standard serve to establish more uniform classifications of grading occupations among various manufacturers concerned. The society also maintains a rental library of industrial engineering training and work simplification films. These films depict "before and after" phases of method improvements made on actual jobs in some of America's leading companies. All films are award winners from an annual competition sponsored by the society. Also developed and recently published is a new standard for evaluating office jobs.

\section{INDUSTRIAL MEDICAL ASSOCIATION, 150 N. Wacker Drive, Chicago, Illinois 60606}

The Industrial Medical Association (IMA), established in 1915, is a professional organization for all physicians concerned with the relationship between health and work, and the work environment. Its purposes are to further the education and to advance the knowledge and skills of its members. The association also promotes interest, stimulates research, and disseminates information directed toward improvement and conservation of the health of employees. It endeavors to represent the interests of its members in cooperating with industry, labor, government, and other medical organizations on matters pertaining to the health of people who work. The association seeks to unite into an active and dynamic organization all physicians fully or partially engaged in the practice of occupational medicine and surgery.

In pursuit of these purposes and objectives, individual physicians engaged in the practice of occupational medicine and surgery are encouraged to develop skills and competence to carry out the following characteristic functions of this special field: (1) To aid in the placement of job applicants by ascertaining their physical, mental, and emotional capabilities for work which they can perform with an acceptable degree of efficiency without hazard to themselves or others; (2) To guide and assist all employees in achieving and maintaining optimal health so that they may perform effectively and with satisfaction until retirement; (3) to reduce the incidence, and thereby the cost to both employee and employer, of illnesses and accidents through the development of effective health programs; (4) To provide for the diagnosis and treatment of occupational injuries and illnesses and, where indicated or necessary, of nonoccupational disorders; (5) to promote maximal rehabilitation of all sick and injured employees; (6) to aid in the effective administration of employee benefits concerned with health and disability; (7) to cooperate with those charged with establishing product safety and consumer protection; (8) to cooperate with the health professions and with voluntary and governmental agencies concerned with community health and welfare; (9) to explore, with health planning organizations and the private sector of medical practice, means of integrating occupational medicine into the delivery of total health care; and (10) to aid in the assessment of the work and community environment and the control of hazards to health.

IMA contributes to the development of standards through representation in the following American National Standards Committees: N12, N13, S3, Z4, Z16, Z37, Z49, Z66, Z87, Z88, Z89, Z117, Z136 and Z137. In addition IMA is represented on the Safety Technical Advisory Board of the American National Standards Institute.

Formerly: American Association of Industrial Physicians and Surgeons (1951).

\section{INDUSTRIAL SAFETY EQUIPMENT ASSOCIATION, 2425 Wilson Boulevard,} Arlington, Virginia 22201

The ISEA was founded in 1927 as a trade association for the manufacturers of personal protective equipment and those manufacturers of unit-type first aid kits and machinery guarding devices. The association does not promulgate and publish its own standards but over a great many years has worked through the procedures of the American National Standards Institute (ANSI) and the National Fire Protective Association. Membership has been represented on many standards committees directly or indirectly concerned with safety and fire protection.

Liaison has been maintained for a long period with the Federal Government in coordinating Federal specifications, military standards and specifications, and most recently with the Occupational Safety and Health Administration and the National Institute of Occupational Safety and Health.

Activities in the standards field of the ISEA is centered in its Product Group structure. Under the ISEA umbrella there are 13 separate Product Groups, each dealing with a specific product classification. They are: Air and Oxygen; Eye Protection; Gas Masks; Head Protection; Hearing Protection; Machinery Guards; Portable Hazard and Measuring Instruments; Respirators; Safety Belts and Nets; Safety Footwear; Safety Glass; Safety Wearing Apparel; and Unit First Aid.

In addition to the above, an active Certification Committee is the fountainhead of the association's activities with outside certifying bodies. Present activities are direct liaison with National Institute of Occupational Safety and Health Testing and Certification Laboratories in Morgantown, West Virginia and the Bureau of Mines.

The following American National Standards and Committees, through ANSI, have been of principal interest to ISEA, and in which the membership have been among the principal architects: A10.11, Safety Nets: A10.14, Safety Belts and Lanyards; B11, Series of Safety and Machine Tools; L18, Protective Occupational Clothing; Z41, Safety Shoes; Z49, Welding Safety; Z87, Eye and Face Devices; Z88, Series on 
Respiratory Devices; Z89, Series on Head Protection Devices; Z90, Road-User Helmets; and Z137, Hearing Protectors.

\section{THE INDUSTRIAL TRUCK ASSOCIATION, 1326 Freeport Road, Pittshurgh, Pennsylvania 15238}

The Industrial Truck Association was established in 1924. This association, through its Engineering Committee and with the approval of its Board of Directors, has developed a Manual of Recommended Practices which are used to advance safety and efficiency in the desion, manufacture, and use of industrial trucks.

The association cooperates with the American National Standards Institute, Inc. in working with the various American National Standards committees, as well as with the National Fire Protection Association, affecting powered industrial trucks.

Formerly: Electric Industrial Truck Association (1951).

\section{INDUSTRY SERVICE BUREAUS, 331 Marlison Avenue, New York, New York 10017}

\section{Aircraft Locknut Manufacturers' Association}

This national organization, organized in 1952, works closely with the military and civilian branches of the Government in the development of aircraft locknut specifications, standards, and methods of cataloging.

\section{Electric Fuse Manufacturers' Guild}

This nationaI organization, founded in 1932, develops and submits to the appropriate Government offices suggestions for the improvement of military and Federal specifications and standards covering electric fuses. It also cooperates with the National Bureau of Standards in matters relating to the performance and specifications of different types of electric fuses. In addition, the guild cooperates with the Underwriters' Laboratories concerning labels and materials from which electric fuses are made. It works on International Electrotechnical Commission standards.

\section{Hand Tools Institute}

The institute represents the USA manufacturers of mechanics' hand service tools and works closely with the General Services Administration and other Government departments in matters relating to hand service tools specifications, standards, and cataloging. It is the leading hand tool association promoting safe use of hand tools and was founded in 1935. The institute also publishes a safety standards booklet entitled Proper Care and Safe Use of Striking and Struck TooIs.

\section{Socket Screw Products Bureau}

The bureau, founded in 1934, works closely with the civilian and military branches of the Government in matters relating to socket screw and set screw cataloging, specifications, and standards.
Tapping Screw Service Bureau

Through its Standards Committee, this organization cooperates with the Society of Automotive Engineers and the American National Standards Institute in the development of suggested dimensional and size standards for tapping screws. The bureau also cooperates with the military and civilian branches of the Government in the development of tapping screw spec. ifications and standards. It was organized in 1950.

\section{United States Cap Screw Service Burcau}

This bureau (USCSSB) cooperates with the U.S. Bureau of Customs in matters relating to the proper nomenclature and classification of industry products for customs purposes. It also cooperates with other Government agencies in the improvement of military and Federal specifications and standards for cap screws. Suggested improvements in cap screw standards also are developed by USCSSB's Standards Committee, which works in close cooperation with the American National Standards Institute and the Society of Automotive Engineers.

\section{United States Machine Screw Service Bureau}

The Standards Committee of this organization considers the dimensional standards of the products of the industry and cooperates with the American National Standards Institute and the Society of Automotive Engineers in the development of proposed additions to, and changes in existing standards in industry products. It was organized in 1928.

\section{United States Wood Screw Service Bureau}

The Standards Committee of this organization develops proposed standards, dimensions and sizes of wood screws. It works in close cooperation with the American National Standards Institute and with Government agencies in matters pertaining to military and Federal specifications and standards for wood screws. It was established in 1928.

\section{INSTITUTE OF ELECTRICAL AND ELECTRONICS ENGINEERS, Standards Operations, 345 East $47_{\text {th }}$ Street, New York, New York 10017}

The Institute of Electrical and Electronics Engineers (IEEE) was formed by a merger, in 1963, of the American Institute of Electrical Engineers (AIEE), founded in 1884, and the Institute of Radio Engineers, founded in 1912 .

Standards activities within the institute are entrusted to the Standards Board which is responsible for final approval of IEEE standards and for representing the IEEE in matters relating to units and standards. The Standards Board is responsible for authorization and coordination of standards projects within the institute. The work of preparing IEEE 
standards is carried out within the Technical Committees of the 31 groups and societies within the institute. There are presently about 400 IEEE standards covering electrical and electronics equipment, test methods, units, symbols, definitions, and rating methods. In addition, there are about 250 projects underway for the development of new standards. About 10,000 of the institute's 160,000 members are active in the institute's standards programs.

The institute was a founder of the American National Standards Institute (ANSI) and it is represented on the majority of its technical advisory boards. It holds secretariats or cosecretariats of 17 American National Standards Committees, and it has 203 representatives on American National Standards Committees. It is the policy of the institute to submit its current standards to ANSI for approval as American National Standards. When IEEE standards fall within the scope of existing American National Standards Committees, IEEE sub. mits its standards to ANSI via these committees.

The institute is also a member body of the National Fire Protection Association (NFPA) and participates in a number of NFPA standards projects that fall within IEEE's technical concern. Close cooperation with U. S. Government activities has been traditional since 1901, when the institute urged the U.S. Congress to establish a national standardizing body in Washington, D.C. National Bureau of Standards (NBS) representatives participate at all levels of IEEE standards-making activities, as members of working groups, technical committees, delegates to American National Standards Committees, chairmen of American National Standards Committees under IEEE secretar. iat, on ANSI Technical Advisory Boards, and as members of the IEEE Standards Board. IEEE works closely with the Department of Defense (DoD). Several IEEE standards have been developed jointly with one or more DoD activities and have been accepted by the military as replacements for previous military standards. IEEE shares an American National Standards Committee secretariat with the U.S. Navy, and many representatives of the DoD participate actively in IEEE standards development.

While the major portion of IEEE membership is within the United States, the institute is transnational in character, and its standards activities are neither limited to U.S. members, nor are its standards generated for the exclusive use of the United States engineering community. A substantial number of Canadian members participate actively throughout the broad standards program of the institute, and a number of IEEE standards have been approved as Canadian standards by the Canadian Standards Association. It is the policy of IEEE to encourage its members from nations other than the United States to offer IEEE standards for approval as national standards of their countries. The Standards Board of the institute has for many years included members from other nations as well as from the United States.

To publicize its standards, the IEEE Standards Office publishes complete lists of its standards at regular intervals. Newly published standards are listed in Spectrum, the monthly magazine distributed to all institute members, and standards of special interest to groups and societies within IEEE are publicized in their newsletters. Sets of standards on units and symbols, rotating machinery, nuclear engineering, and audio and electroacoustics are available in special binders, and leaflets showing the contents of these sets are available.

\section{INSTITUTE OF ENVIRONMENTAL SCIENCES, \\ 940 East Northwest Highway, Mt. Prospect, Illinois 60057}

This institute (IES), founded in 1957, is devoted to the development and promotion of standards, specifications, research, simulation techniques, testing tech. niques, and the development of design criteria for equipment operation.

IES's Standards Committee considers and investigates all matters relating to units and standards pertaining to, or applicable in, environmental engineering, coordinates the work of the technical committees with respect to the making and reviewing of standards, and represents the institute in its work with other standardization bodies in matters relating to standards and units. The committee also appoints representatives to serve on standardizing committees sponsored by the institute, and on delegations for standardizing purposes which work under the sponsorship of other societies and technical organizations. As a representative of the institute, the Standards Committee gives final approval to standards in the organization's name, reports all new and revised standards, and seeks the guidance and approval of its department upon all policy questions, including that of undertaking the preparation of standards in new fields.

The Institute of Environmental Sciences has members on several American National Standards Committees such as S2 Mechanical Shock and Vibration, and is sponsor of the Z84 committee which is responsible for compiling a glossary of environmental terms. In addition, the institute cooperates with many other national technical organizations in matters regarding environmental standards, testing and engineering. Members have joined in cosponsoring meetings or group efforts with such organizations as the American Society for Testing and Materials, American Institute of Aeronautics and Astronautics, American Society for Quality Control, Institute of Electrical and Electronics Engineers, Department of Defense Shock and Vibration Information Center, and the Army Materiel Command. Globally, the institute sponsors a representative to the International Electrotechnical Commission concerned with international standardization of environmental test methods.

The Institute of Environmental Sciences absorbed the American Association for Contamination Control (AACC) on October 19, 1973. The former AACC members will make up two new divisions of IES: viz. the Industrial Contamination Control Division and the Biosciences Division. 
AACC's standardization program comprises approximately 25 percent of its total activities. The six technical committees that are involved in the program are Codes and Standards; Bio-Sciences; Design, Construction and Operation of Clean Rooms; Nuclear Energy; Particle Monitoring; and Garments and Laundry. On an international level, AACC is a member of the International Committee of Contamination Control Societies. The Government agencies with which it collaborates on standards activities are the Atomic Energy Commission, Army Chemical Corps, National Aeronautics and Space Administration and the United States Air Force. The AACC has four current standards: High Efficiency Particulate Air Filters, Laminer Flow Clean Air Devices, Testing and Certification of Clean Rooms, and High Efficiency Gas Phase Absorber Cells, that are considered national in scope. Currently the Bio-Science Committee is developing a biological contamination standard.

The standardization activities of the former AACC will continue as activities of IES.

IES formed by merger of: Institute of Environmental Engineers (founded 1955) and Society of Environmental Engineers; absorbed the American Association for Contamination Control (October 19, 1973).

\section{INSTITUTE OF HIGH FIDELITY, 516 Fifth Avenue, New York, New York 10036}

This institute, established in 1954, is an industry organization whose Standards Group formulates methods of measurement applicable to home electronic entertainment devices such as amplifiers, FM and AM tuners, etc. The intent of the standards has been to set ux methods of measurement to include all the allowances that should be made for the peculiarities of different units. Implicit in this approach is freedom from a restrictive philosophy and preservation of a forward looking attitude of a progressive industry.

The IHF Standard Methods of Measurement for Audio Amplifiers was published first in 1958 as Number IHFM A-200 and revised to IHF A-201 in 1966. It covers measurement methods of amplifiers, both small signal and power, for transient and steady state, and the method of publishing these results. Block diagrams and tutorial material are included to make the methods explicit and complete. The standard pertains to single and multichannel amplifiers. It was updated late 1973.

The IHFM Standard Methods of Measurement for Tuners was published in 1958. It covers AM and FM tuner measurements beginning with definition of terms, operating conditions, requirements and characteristics of testing apparatus, and test procedures. The committee is currently working on updating and broadening this standard to cover multiplex measurements.

Upon completion of the tuner standard, the committee plans to develop methods of measurements for tape equipment, loudspeakers, phonograph pickups, record players, and headphones.

Formerly: Institute of High Fidelity Manufacturers.

\section{INSTITUTE OF PRINTED CIRCUITS, 1717 Howard Street. Evanston, Illinois 60202}

Members of this international trade association include producers and users of printed circuit boards. Membership also includes key suppliers of raw materials and production equipment. There is also a provision for technical liaison membership for qualified experts from Government agencies.

One of the major functions of the IPC is to develop comprehensive specifications and standards. To date the IPC has produced approximately 21 separate standards, and are currently working on approximately 30 new standards.

In summary, the IPC has published recommended dimensional tolerances for commercial and military applications. In addition, a standard for acceptability of printed circuit boards has been published, as well as a standard for repairability. Detailed standards for flexible flat cables, flexible circuitry, and for multilayer printed wiring boards have been developed by the IPC.

In addition to developing IPC standards for domestic use, the IPC is active in the International Electrotechnical Commission which formulates international standards for electronic components.

\section{INSTITUTE OF SCRAP IRON AND STEEL, 1729 H Street NW., W ashington, D.C. 20006}

The Institute of Scrap Iron and Steel (ISIS) was founded in 1928. For many years, the institute has endeavored to establish with the cooperation of Government and interested parties, specifications for the iron and steel scrap grades prepared by its member companies and others in the industry to meet the needs of consumers. These specifications had their origin in trade practices and consumer requirements dating back to the nation's first use of scrap in the steel and foundry industries.

Formal codification of these specifications came in 1926 under the direction of U. S. Department of Commerce Simplified Practice Recommendation R58-26. Revisions occurred in 1928, 1936, 1953, 1959, and 1961. The Simplified Practice Recommendation was withdrawn on May 15, 1973. It was superseded by the current Specifications for Iron and Steel Scrap which were promulgated by ISIS's Marketing and Specifications Committee in October 1971. In 1973, these specifications were reprinted and include an ISIS code number for each grade of iron and steel scrap. The specifications cover basic open hearth, blast furnace, electric furnace and foundry, cast iron and special grades of iron and steel scrap, and give recognized classifications for each grade. Offgrade material and scrap containing residual material are defined and 
the degree of cleanliness described. Provisions are made for deviations from the designated classifications.

\section{INSTITUTE OF TRAFFIC ENGINEERS, Suite 905, 1815 North Fort Myer Drive, Arlington, Virginia 22209}

The Institute of Traffic Engineers (ITE) was founded in 1930.

The institute's principal contribution to the development of standards is through cooperative efforts with other groups such as the National Advisory Committee on Uniform Traffic Control Devices. Council on Uniform Traffic Control Devices for Canada, National Committee on Uniform Traffic Laws and Ordinances and the American National Standards Institute.

In addition to cooperative endeavors toward standards in the field of highway transportation and traffic safety, the institute has developed and published a number of standards and specifications which have been approved as American National Standards of the American National Standards Institute. These cover such subjects as: Adjustable Face Pedestrian Signal Heads; Adjustable Face Vehicular Traffic Control Signal Heads; A Model Performance Specification for the Purchase of Reflective Pavement Marking Paint; A Standard for Flashing and Steady-Burn Barricade Warning Lights; Pre-timed, Fixed-cycle Traffic Signal Controllers; and Traffic Signal Lamps. ITE also publishes recommended practices and technical reports for the safety and efficient movement of goods and people.

Approved standards appear in the institute's journal, Traffic Engineering and in the Traffic Engineering Handbook.

\section{INSTRUMENT SOCIETY OF AMERICA, 400 Stanwix Street, Pittsburgh, Pennsylvania 15222}

This society is a nonprofit, technical, scientific, and educational organization of individuals interested in the theory, design, manufacture, and use of instruments. Areas of technical activity include measurement, data acquisition, processing, display, telemetry, and automatic control in both industrial and laboratory applications. Publications of information reports, recommended practices, and standards have been an integral part of society operations since the organization was formed in 1946. Technical progress in instrumentation is also presented at conferences and symposia and through ISA periodicals, proceedings, and miscellaneous publications.

ISA maintains Standards and Practices Committees in the broad areas of measurement devices, control devices, symbology, computer hardware and software, and safety. Examples of the work of these committees in each area include documents on: thermocouples, flowmeters, transducers, rotameters; face-to-face dimensions, manifold designs, pneumatic circuits, annunciators, dynamic response testing; instrumention flow sheets and specification forms, panel tubing; mercury handling, instrumentment purging, intrinsically safe circuits, computer hardware testing, computer programs, control valve sizing, and control valve capacity test procedures. Through 1972, ISA has published 40 standards and recommended practices. The society is a member of the American National Standards Institute and contributes to ANSI Technical Advisory Boards and Committees for measurement and automatic control, medical devices, orifice flanges, pressure gages, instrument calibration, metrology, electrical measuring and reference instruments, automatic control terminology, nuclear instruments, and computer components.

Internationally, ISA serves on the U.S. National Committee for the International Electrotechnical Commission (IEC) and the U.S. Technical Advisory Group for IEC TC 65. Through its Fund for International Standards Travel, ISA also supports attendance of U.S. representatives to standards meetings abroad.

Formerly: American Society of Instrument Engineers (1939); American Society for Measurement Control (1944).

\section{INSULATED POWER CABLE ENGINEERS' ASSOCIATION,}

192 Washington Street, Belmont, Massachusetts

IPCEA is noncommercial in its structure. It derives standards and technical information and makes them available to those interested in electrical cables. It publishes standards jointly with National Electrical Manufacturers' Association and collaborates with other organizations in the same field such as the Association of Edison Illuminating Companies, American Society for Testing and Materials, Institute of Electrical and Electronics Engineers, National Electrical Code, Underwriters' Laboratories, and the Rural Electrification Administration, U.S. Department of Agriculture, etc., when they request assistance in developing their own specifications and technical data.

The membership of the association consists of engineers from the technical staffs of the leading American and Canadian manufacturers of wire and cable used for the transmission and distribution of electrical energy. Membership is individual, not by company; and is limited to engineers who are on the technical staff, not marketing sections, of concerns engaged in the manufacture of electrical cable and are qualified by technical training.

The activities of this association are concerned with matters relating to bare, covered, and insulated conductors including preparation of engineering recommendations and standards, and consultation and collaboration with other technical organizations and agencies in the preparation and publication of engineering standards and technical papers for bare and insulated wire and cable. Copies of lists of these publications may be obtained from the secretary. 
INTER-SOCIETY COLOR COUNCIL, c/o Department of Chemistry,

Rensselaer Polytechnic Institute,

Troy, New York 12181

The Inter-Society Color Council (ISCC) was founded in 1933 to stimulate and coordinate work leading to the standardization, description, and specification of color, and to promote the practical application of the results of such work to color problems arising in science, art, and industry. Its current membership consists of 29 delegates from national societies and individual members, all with a common interest in color.

The ISCC is not a standardizing body, but many of the results of its work are incorporated by its member bodies into standards which they issue or sponsor. This work is carried out by subcommittees of the ISCC Problems Committee, to which problems are submitted by the member bodies.

Examples of standardization activities in which the ISCC has participated include the ISCC-NBS Method of Designating Colors and a Dictionary of Color Names (National Bureau of Standards Circular 553, 1955) ; designations of filters for theatrical lighting; a Comparative List of Color Terms (1949, under revision 1973) : Color Aptitude Test (available through the Federation of Societies for Paint Technology); and recommendations for illuminating and viewing conditions in the colorimetry of reflecting materials (1964); standard methods for mounting textile samples for colorimetric measurement (1968); standard practice for visual examination of small color differences (1972); determination of the strength of colorants (1972); and the determination of sets of maximally different nonfluorescent colors (1965). Current activities of Problems Subcommittees are summarized in the Annual Report Issue (usually May/June each year) of the ISCC Newsletter.

\section{INTERNATIONAL ASSOCIATION OF ELECTRICAL INSPECTORS, 802 Busse Highway, Park Rirlge, Illinois 60068}

The International Association of Electrical Inspectors (IAEI) was founded in 1928.

The scope of this organization is to cooperate in the formulation of standards for the safe installation and use of electrical materials, devices and appliances. IAEI also promotes the uniform understanding and application of the National Electrical Code, and other electrical codes and standards.

IAEI promotes cooperation between inspectors, the electrical industry, and the public. The association also collects and disseminate information relative to the safe use of electricity. About 75 percent of its meeting and publication program are devoted to the work of standardization. The Board of Directors reviews and administers the standardization activities. Liaison in electrical code work exists with its members in Canada and Japan, where there is special interest in electrical codes.

IAEI maintains liaison with the Federal Government in many standardization activities, particularly for the use and application of the National Electrical Code. Its standardization interests are mainly with the activities of the Department of Housing and Urban Development, the Consumer Product Safety Commission, as well as with the Occupational Safety and Health Administration (OSHA), of the Department of Labor.

IAEI maintains an educational and certification program for certain of our members who qualify for certification. The association is concerned and involved in establishing qualified certification programs in various states for recognition of our electrical inspector members on state levels in the form of licenses for electrical inspectors often called certification.

The association does not issue any standards.

\section{INTERNATIONAL ASSOCIATION OF MILK, FOOD AND ENVIRONMENTAL SANITARIANS, P.O. Box 701, Ames, Iowa 50010}

In the 1920's two trade associations and one professional association formulated uniform standards for fittings used on milk pipe lines. The trade groups are now known as Milk Industry Foundation, and Dairy and Food Industries Supply Association; the professional group is now known as International Association of Milk, Food and Environmental Sanitarians. The standards for fittings and equipment evolved in those early days became popularly known as " 3 -A" standards. Since 1944, every major dairy processing group, suppliers and equippers, and the U. S. Public Health Service have taken part in the development of these standards but the results are still referred to as 3.A Sanitary Standards.

Standards are formulated by the 3-A Sanitary Standards Committees which meet together once or twice a year. They are: (1) The Committee on Sanitary Procedures of International Association of Milk, Food and Environmental Sanitarians; (2) the Sanitary Standards Subcommittee of the Dairy Industry Committee, representing the following associations of processors: American Butter Institute, American Dry Milk Institute, Evaporated Milk Association, International Association of Ice Cream Manufacturers, Milk Industry Foundation, and National Cheese Institute; and also representing the association of equippers and suppliers: Dairy and Food Industries Supply Association; (3) representatives of the Milk Sanitation Branch, U. S. Public Health Service, Department of Health, Education and Welfare. Invited to a regular meeting of all the committees, moreover, are representatives of all manufacturers of record (regardless of association affiliation), of equipment of the type or types under consideration. 
INTERNATIONAL ASSOCIATION OF PLUMBING AND MECHANICAL OFFICIALS, 5032 Alhambra Avenue, Los Angeles, California 90032

IAPMO was established in 1926 by and for inspection officials for cities, counties and states with the goal of bringing about uniformity in plumbing codes and interpretation of the various sections of the codes.

IAPMO promulgates and sponsors the Uniform Plumbing Code that is used in over 2,500 jurisdictions in the United States and is the mandatory code for 10 states. The Uniform Plumbing Code protects more people in the United States than any other plumbing code. IAPMO also cosponsors the Uniform Mechanical Code with the International Conference of Building Officials. IAPMO presently writes installation standards for conventional plumbing products and maintains existing IAPMO product standards. As a policy the association shall not write any new material standards for conventional plumbing. Another division of the association promulgates both installation and material standards for plumbing in the mobile home and recreational vehicle industry. The association first accepted this responsibility over 20 years ago. These standardization activities are administered by the IAPMO Standards Committee and IAPMO Trailer Standards Committee. The Government agencies with which IAPMO is involved are the Department of Housing and Urban Development, the Department of Labor, and the National Bureau of Standards. Currently there are 55 standards issued by the organization, with 25 percent of the total IAPMO program being devoted to standardization.

Certification activities-IAPMO produces a monthly updated conventional plumbing product listing directory for jurisdictions to use as a guide for approval. The directory certifies that products have been tested to comply or exceed the requirements of applicable standards and the Uniform Plumbing Code. Over 10,000 products are listed. Certification must be updated and renewed each year and manufacturers are subject to reinspection during the year of listing. As in standards, the mobile home and recreational division monthly updates a listing directory for enforcement officials in this vital area of the plumbing industry.

Formerly: Los Angeles Area Plumbing Inspector Association (1926) ; Plumbing Inspectors' Association of Southern California (1929); Plumbing Inspectors' Association of California (1930) ; Pacific Coast Plumbing Inspectors' Association (1934); Western Plumbing Officials Association (1945) ; International Association of Plumbing and Mechanical Officials (1967).

\section{INTERNATIONAL ASSOCIATION OF WALL AND CEILING CONTRACTORS, 1775 Church Street NW., Washington, D.C. 20036}

The association no longer publishes standard specifications but, because it is a member of and participates in committees of the American Society for Testing and Materials and the American National Standards Institute, the association endorses specifications published by those two organizations.

The association has joint committees with four international unions: United Brotherhood of Carpenters and Joiners of America; International Brotherhood of Painters and Allied Trades; Operative Plasterers and Cement Masons International Association; and the Wood, Wire and Metal Lathers International Union to establish standards for apprenticeship for drywall, drywall taping, plastering, and lathing. It also has established a Manufacturers' Liaison Committee to improve communications between the association and manufacturers and associations of the industry.

The association has an active Technical Committee which participates in joint meetings with technical committees of the Gypsum Association, Metal Lath Association, Perlite Institute, Portland Cement Association, and others. This Technical Committee is divided into 9 subsections, each working with its respective field within the wall and ceiling industry.

Formerly: Contracting Plasters' International Association (1956); Contracting Plasters and Lathers' International Association (1970).

\section{INTERNATIONAL CITY MANAGEMENT ASSOCIATION, \\ 1140 Connecticut Avenue NW. Washington, D.C. 20036}

The International City Management Association (ICMA), founded in 1914, has long had an interest in standardization as part of its work in increasing the proficiency of municipal administrators and strengthening the quality of urban government through professional management. Early efforts involved measurement units for certain public works activities together with correlative manuals and other publications.

The most recent effort, began in December 1972, is a productivity measurement/enhancement program undertaken jointly by ICMA and the Urban Institute for the National Commission on Productivity, the U.S. Department of Housing and Urban Development, the National Science Foundation, and the City of St. Petersburg, Florida, and Nashville/Davidson County, Tennessee. A major part of this project is to review existing municipal codes and establish standards of performance which can serve as the basis for national transferable norms through which crossnational performance measures may be obtained for municipal services. Services currently under study include police, fire, solid waste and waste water management, parks and recreation, local transportation systems, and library systems.

Formerly: International City Managers' Association (1969). 


\section{INTERNATIONAL CONFERENCE OF BUILDING OFFICIALS, \\ 5360 South Workman Mill Road, Whittier, California 90601}

The International Conference of Building Officials publishes the Uniform Building Code, Uniform Mechanical Code and a Uniform Fire Code covering minimum requirements for safe construction in buildings or structures. The objective is to furnish a complete set of codes for state, city and county administrative authorities and to insure a maximum amount of safety to life from fire, structural and exit hazards.

The codes are developed and maintained through national public hearings attended by state, city and county officials, as well as representatives from the entire construction industry. The codes are changed each year and new editions are published on a threeyear cycle. The jurisdictions which adopt these documents constitute a total population of over 50 million, extending from Michigan in the east to the Pacific Ocean, including the states of Alaska and Hawaii.

The organization is also involved in the development of standards for acceptance of new products through research activities. Hearings are held each month to review data submitted in support of new materials or products which are not now covered in the modern model building codes. Recommendations are issued to the member jurisdictions in order that manufacturers may obtain uniform recognition of their new products.

In addition to the codes, the International Conference of Building Officials is involved in the development of standards for educational programs and publish the following documents which are used in universities and short courses available across the country: Building Department Administration; A Training Manual in Field Inspection of Buildings and Structures; Plan Review Manual; and Dwelling Construction Under the Uniform Building Code.

\section{INTERNATIONAL DISTRICT HEATING ASSOCIATION, 5940 Baum Square, Pittsburgh, Pennsylvania 15206}

The International District Heating Association (IDHA) was founded in 1909 for the purpose of advancing the science, standards and knowledge of district heating; and for the exchange of information relating to the management and operation of district heating systems. Its scope now includes district cooling.

Standing and technical committees investigate and report on industry statistics, problems, new developments, etc. for the membership. Publications include a quarterly technical magazine, District Heating, a Handbook, Rate Reference Book, and Proceedings of papers and reports presented at annual meetings.

It does not publish standards of its own, but uses those of the American National Standards Institute; and is represented on pertinent committees of that body: B31.1, Power Piping and B87.1, Decimalized Inch.

Formerly: National District Heating Association.

\section{INTERNATIONAL MOBILE AIR CONDITIONING ASSOCIATION, INC., 6116 North Central Expressway, Dallas, Texas 75206}

Founded 1958, IMACA serves system manufacturers, parts and service suppliers, distributors and dealers in mobile air conditioning applications including: auto, heavy truck, recreational vehicle, farm and offhighway vehicle, boat, aircraft, bus and railroad. Its program includes sales promotion, public relations, engineering standards, product certification, annual trade show, monthly magazine, annual directory, technical papers and legislative activities. The Engineering Committee administers the standards program now consisting of 17 standards in print under the IMACA name. Sixteen of these are for automotive and one for recreational vehicle application. IMACA standards have been sumbitted to the American National Standards Institute for approval as American National Standards. Certification for automotive application is available in four modes: CFM, Btu, component parts, or a combination of all. There are three new standards underway for heavy truck $\mathrm{A} / \mathrm{C}$ parts, and one new standard underway for rebuilt automotive A/C parts. IMACA Standard 200 is in use by General Services Administration. All standards are national in scope. The use of standards is promoted through national trade, press, publicity and the IMACA monthly magazine.

Formerly: Automotive Air Conditioning Association (1970).

\section{INTERNATIONAL MUNICIPAL SIGNAL ASSOCIATION, 4034. Woodhaven, P.O. Box 20549,} Houston, Texas 77025

The International Municipal Signal Association (IMSA), organized in 1896, is a nonprofit, technical and educational association. Its active membership consists of approximately 3000 persons in the United States, Canada and the free countries of the world who are directly engaged in the engineering, construction, maintenance and operation of electrical, electronic and graphic communication systems used in the public safety services such as fire and police alarm, traffic controls, radio communication, street lighting, signs and markings, and related systems.

Its major objectives are: (1) to unite those interested in those fields for the purpose of improving the 
efficiency of public safety services; (2) to collect and disseminate educational material and to develop and conduct educational and training programs for the benefit of association members and the industry; (3) to cooperate in the formulation of standards for materials and the safe installation, operation and maintenance of such systems; (4) to promote closer cooperation between all members of the industry and encourage free and open consideration of all engineering concepts and opinions; and (5) to cooperate fully with other organizations with similar objectives.

The standing committees of IMSA are responsible for the development of standards and manuals, in their specific areas, for use by the members and industry. The IMSA Wire and Cable Specifications, containing some 29 standards for various types of signal and communications wire and cable, has been accepted nationally for many years and is recognized by the Department of Transportation, Bureau of Pub. lic Roads. In cooperation with manufacturers of wire and cable, these specifications are periodically revised and updated by the Association's Cable Committee.

IMSA members represent the association on sectional committees of the National Fire Protection Association and assisted in the development of NFPA's Pamphlet 73, Municipal Fire Alarm Systems, which is accepted and recognized as the national standard. The Federal Communications Commission recognizes IMSA's Radio Committee as the representative frequency coordinating body for the Fire Radio Service and, accepts and considers the committee's petitions, comments, and testimony in their rulemaking decisions. The association publishes two comprehensive reference and training manuals, The IMSA Traffic Control Manual and The IMSA Fire Alarm Manual, which describe in detail the accepted practices and procedures for the proper installation, maintenance and operation of traffic control and fire alarm systems. These standards and manuals are promoted in the association's bimonthly publication, the IMSA Signal Magazine.

\section{INTERNATIONAL NONWOVENS AND DISPOSABLES ASSOCIATION, 10 East 40 Street. New York, New York 10016}

INDA is an international, nonprofit trade association founded in June, 1968 to represent the nonwoven fabrics and disposable soft goods industries. The association does not develop standards, but does work with other national technical organizations in this area. In June, 1971, INDA published its first set of recommended tests (DART) applicable to nonwoven fabrics and disposable soft goods. The first ten DART cover the properties of absorption, abrasion resistance, bursting strength, optical properties, permeability, repellency, tear, tensile/elongation, thickness and weight. Since then, recommended tests for flammability have been added. The DART, for the most part, designate and recommend the use of proven methods published by established standards organizations such as the American Society for Testing and Materials, the Technical Association of the Pulp and Paper Industry, the American Association of Textile Chemists and Colorists, the American National Standards Institute and others. Where necessary, certain modifications and adaptations of the published methods were made to make them specifically applicable to the products of this industry. The work in this area is the responsibility of INDA's Test Methods Subcommittee. Work is currently underway to find objective means for measuring softness, hand and drape. The associa. tion is currently involved in a research project to determine the degree of electrostatic hazards in hospital operating rooms when flammable anesthetics are in use. The study is being conducted by an independent research firm under the joint sponsorship of INDA, Sterile Disposable Devices Committee of the Health Industries Association and the Medical-Surgical Manufacturers Association. INDA publicizes the availabil. ity of its recommended tests in its various publications including its international Directory for the Nonwoven Fabrics and Disposable Soft Goods Industries.

Formerly: The Disposables Association (1972).

\section{THE INTERNATIONAL SOCIETY FOR TERRAIN-VEHICLE SYSTEMS, 711 Hudson Street, Hoboken, New Jersey 07030}

The society, a private, nonprofit organization composed of about 300 members from 28 countries, was founded in Turin, Italy, in January 1962. Its purpose is to provide an international forum to effect the achievement and advancement of knowledge of the mechanics of terrain-vehicle systems and soil working machinery in all environments. Technical papers, reviews, comments, and discussions in the field of terramechanics are presented at periodic regional meet. ings and at an international conference held once every three to four years. The information is published quarterly by the society in the Journal of Terramechanics.

In April 1965 the society formed the Standardization Committee whose purpose was to formulate a glossary of terrain-vehicle terms that would be used as standards for the society. The committee has grouped terms into eight categories. Standards for three categories have been published in the journal as follows: Terrain Geometry, Vehicle Physical Characteristics, and Vehicle Performance Characteristics. Standards for two categories have been finalized and will be published in forthcoming issues of the journal as follows: Soil Test Devices Associated with SoilVehicle Tests and Terıain Characteristics Associated with Soils. The committee is presently working on standards for the remaining three categories as fol. lows: Standards for Terrain Characteristics Associated with Vegetation, Standard Symbols, and Standard Test Procedures. 
INVESTMENT CASTING INSTITUTE, 1717 Howard Street. Evanston, Illinois 60202

The Investment Casting Institute was founded in 1953, for the purpose of providing an organization through which programs could be initiated to accelerate the growth of technology, as well as the market, for investment castings.

Approximately 25 percent of ICl's total program is devoted to standardization work which is administered by the ICI Engineering Committee.

The Investment Casting Institute has been actively involved with the British Investment Casters Technical Association, as well as the Aerospace Material Specifications Division of the Society of Automotive Engineers, and the American Society for Testing and Materials.

The ICI has published the Investment Casting Handbook, which is their only current publication.

\section{JEWELERS VIGILANCE COMMITTEE, 156 East 52nd Street,} New York, New York 10022

Jewelers Vigilance Committee is a national organization supported by the jewelry industry at large, specializing in marking, labeling, and other descriptive terminology and related trade practice problems. It has engaged in standardization activities as a major part of its work since its creation in 1913. Particular emphasis has been in the areas of the precious metals, especially in regard to their consumer uses; precious and nonprecious stones used in jewelry; and watches. It was instrumental in the drafting and publication of Commercial Standards for Marking Jewelry and Novelties of Silver (1944); Marking of Articles made Wholly or in Part of Platinum (1938); Marking Articles made of Karat Gold (1938) ; Marking Articles made of Silver in Conjunction with Gold (1935); and Marking of Gold Filled and Rolled Gold Plate Articles Other Than Watch Cases (1934).

The standardization work of the Jewelers Vigilance Committee also contributed significantly to the Federal Trade Commission's success in developing trade practice rules for the jewelry industry (1957), for the metallic watch band industry (1962), and guides for the watch industry (1968).

Currently a standardization study involves possible revision of the National Gold and Silver Stamping Act (15 U. S. C. 294, et. seq.) dealing with marking requirements of gold and silver as well as revision of the above commercial standards where necessary.

Absorbed: American Jewelers Protective Association (1943).

\section{JOINT INDUSTRIAL COUNCIL, 7901 Westpark Drive, McLean, Virginia 22101}

The Joint Industrial Council (JIC) was organized in 1962 through the cooperative efforts of the National
Machine Tool Builders' Association and the large users of machine tools and the suppliers of accessory equipment to the industry. The prime purpose of the organization is to provide direction, coordination and continuity of effort in the development and advancement of standards which will encourage the safe and reliable application of controls to machines and equipment used in industrial applications.

The entire efforts of the organization are devoted to writing standards and the National Machine Tool Builders' Association serves as secretariat for the organization, handling all administration.

Committees are formed to write or to rewrite standards for the application of electrical, electronic, hydraulic and pneumatic devices to machine tools. Currently, there are four standards in existence, one for each of the above types of equipment.

The standards, which are entirely voluntary in nature, are used to a great extent by the builders and users of the industrial equipment covered. In some areas they are supplementary to existing codes and in other areas they are the only standards which pertain to the particular equipment.

The standards are promoted through notices in the pertinent trade journals and through the continued use on the part of the user industries.

The current JIC supersedes the former Joint Industry Conference which had been formed by the automotive companies in Detroit in 1947.

\section{JUVENILE PRODUCTS MANUFACTURERS' ASSOCIATION, 59 East Main Street, Moorestown, New Jersey 08057}

The Juvenile Products Manufacturers' Association (JPMA) is a national trade association of corporations, firms, or individuals engaged in the manufacture of juvenile products. Most of the regular members manufacture products which can be broadly defined as juvenile furniture, as opposed to being toy manufacturers.

The JPMA was founded and incorporated as a nonprofit association in the state of New York in 1962. It serves as spokesman for the industry representing it in national, regional and community affairs.

The industry's activities for the development of juvenile product safety performance standards includes twelve individual subcommittees actively working on new standards or improvements to existing standards. Each subcommittee deals with a particular major product category and is composed of manufacturers of that product. In the present program are subcommittees for: Car Seats, High Chairs, Dressing Tables, Full Size Cribs, Crib Mattresses, Armheld Carriers, Portable Cribs, Swings, Walkers, Rigid Frame Back Carriers, Carriages and Strollers, and Play Yards. 


\section{LAW ENFORCEMENT ASSOCIATION ON PROFESSIONAL STANDARDS, EDUCATION AND ETHICAL PRACTICE, 8001 Natural Bridge Road, St. Louis, Missouri 63121}

The Law Enforcement Association on Professional Standards, Education and Ethical Practice, established in 1971, is a professional, nongovernmental, educational organization of college graduates in police service, education, research, and allied specialties. Known as LEAPS, it has members in 25 states and concerns itself with police professional matters, including the upgrading of police service, setting minimum standards for practice and developing a standard code of ethical practice. LEAPS has adopted a policy of support for use of the metric system. A Committee on Standards serves in the area of professional practice.

\section{LEAD INDUSTRIES ASSOCIATION, 292 Madison Avenue, New York, New York 10017}

This organization has available recommended specifications for lead roofing and flashing, sheet lead membranes for decorative pools and planters, leadasbestos anti-vibration pads, lead plumbing and other lead applications. In addition to its own work on standardization and simplification, this association has representatives who serve on committees of the American National Standards Institute and the American Society for Testing and Materials. It also cooperates with various agencies of the Federal Gov. ernment in the development of specifications covering lead products.

\section{LIBRARY BINDING INSTITUTE, 160 State Street, Boston, Massachuset ts 02109}

The Library Binding Institute (LBI) founded in 1935, is a trade association of library book binders. Approximately 30 percent of the program is devoted to standardization activities which are administered by the Technology Committee. The Standard for Library Binding, 1971 is national in scope and has become the basis for the vast amount of library rebinding of worn volumes, of periodicals, and the prebinding of new volumes in bindings which will withstand the rigors of normal library usage.

LBI certifies library book binders capable of producing quality work that meets the institute's standards and passes its In Plant Quality Control Program.

\section{LINEN SUPPLY ASSOCIATION OF AMERICA, \\ P.O. Box 2427, \\ 975 Arthur Godfrey Road, Miami Beach, Florida 33140}

The linen supply industry is classified as Standard lndustrial Classification (SIC) 7213 (1972 edition).
Linen supply companies are in the business of renting clean laundered items to millions of customers in commerce, industry and the professions.

The Linen Supply Association of America (LSAA), founded in 1913, is the industry's trade association. Member firms represent over 90 percent of the linen supply industry in the United States by sales volume.

Standards activities of LSAA include: accounting standards - setting up uniform accounting data for comparison and control; marketing information including standardized lists of customers by SIC code category; definitions and standards for textile rental items rented by member firms; textile standardization programs working in cooperation with manufacturing mills and member companies; sanitation standardization programs in conjunction with member companies and the National Sanitation Foundation; standards for washing and dry cleaning cleanliness through washing and dry cleaning test bundle reports measuring washing and dry cleaning efficiency.

\section{MTM ASSOCIATION FOR STANDARDS AND RESEARCH, 9-10 Saddle River Road, Fair Lawn, New Jersey 07410}

The MTM Association for Standards and Research, established in 1951 is a 501 (c) 3, nonprofit, nongovernment association. Its primary efforts are in the field of research and training in a technique called methods-time-measurement (MTM). It is basically devoted to the art and science of MTM in the area of "man at work." The purposes of the association are set forth in the Articles of Incorporation and are: (1) to conduct, stimulate, and coordinate basic and applied research, of both members and nonmembers, in the field of methods-time-measurement (MTM); (2) to compile, and make available to the public, information pertaining to the development and application of MTM; (3) to establish standards and by all other possible means to sustain the high quality of work done by all organizations and individuals in the use of MTM including all phases of MTM training and application techniques; (4) to increase acceptance for the proper use of MTM: and (5) to sponsor, assist, and support the formation and activities of MTM associations in other countries in cooperation with the International MTM Directorate, Inc. which is the official international body for the cooperation and coordination in the field of MTM.

The MTM Association for Standards and Research is composed of a wide variety of memberships including academicians, individual members, and corporate memberships that include various branches of the Government, insurance companies, manufacturing facilities, banks, educational institutions, consultant companies, the Association for the Blind, etc.

The activities of the MTM Association for Standards and Research are conducted primarily through the association staff and its volunteer committees. The present committees as approved by the Board of 
Dircctors are as follows: Training and Qualifications Committee; Mcmbership Committee; Conference Committee; Public Relations Committee; Administration and Policy Planning Committee; Rcsearch Committee; Member Services Committee; and Finance Committee.

The association's standards activities are for a methodology for deriving a time to perform a given manual task. Projects in progress include standardization data for clerical operations, work under the microscope, and work in maintenance areas.

\section{MAGAZINE PUBLISHERS' ASSOCIATION see \\ AMERICAN ASSOCIATION OF ADVERTISING AGENCIES}

\section{MAGNETIC MATERIALS PRODUCERS' ASSOCIATION, 1717 Howard Street, Evanston, Illinois 60202}

The Magnetic Materials Producers' Association (MMPA) is a national trade association, which was formed in 1959.

Manufacturers in this association compound and process basic magnetic materials. Their primary objective is to promote the progress and development of the magnetic materials industry, through standardization programs, and other activities as may be necessary.

The Standards and Engineering Committee of MMPA administers all standardization programs, which totals approximately 50 percent of all the programs of MMPA. This association has published two standards: Permanent Magnet Guidelines; MMPA Standard No. 0100-72-Standard Specifications for Permanent Magnet Materials. This standard has been accepted by the military departments of the Government, in lieu of Federal Specification QQ-M-60.

The Standard and Engineering Committee is also conducting work on standard methods for magnetic testing, magnetization, stabilization, and measurement guidelines.

Formerly: Permanent Magnet Producers' Association.

\section{MALLEABLE FOUNDERS' SOCIETY, 20611 Center Ridge Road, Rocky River, Ohio 44116}

This society (MFS), is concerned mainly with technical research and advisory services, assisting its members to maintain standard grades of products, and developing new applications and uses for malleable castings. MFS in the past cooperated with the National Bureau of Standards in the establishment of Simplified Practice Recommendation R79 for malleable foundry refractories (withdrawn $2 / 15 / 71$ ). In carrying on this work, it has sponsored the adoption of the present standard specifications for malleable castings of the American Society for Testing and Materials (ASTM), as well as those of other technical organizations.

The society is represented on the ASTM Committec on Malleable Iron Castings. MFS assists in the development of Federal and military specifications in its field.

\section{MANUFACTURERS' STANDARDIZATION SOCIETY OF THE VALVE AND FITTINGS INDUSTRY, 1815 North Ft. Myer Drive, Arlington, Virginia 22209}

This society, with its predecessor, the Committee of Manufacturers on Standardization of Pipe Fittings and Valves, has been in continuous existence for over 50 years.

The method of carrying on standardization work by the society is by means of committees selected from the engineering departments of representative manufacturers that are directly engaged in the manufacture of valves and fittings.

At present, the society has about 25 committees working on subjects covering threaded and flanged fittings and valves (ferrous and nonferrous), marking and terminology, material, cast and malleable iron fittings, unions and union fittings, water works, weld. ing fittings, butterfly valves, pipe hangers, quality standards, nuclear, valve actuators, etc.

The society has now in force approximately 25 standard practices which it has developed and adopted. These are for finishes for contact faces of connecting-end flanges of ferrous valves and fittings; spot-facing standard; standard marking system for valves, fittings, flanges, and unions; 125-lb. bronze gate valves; specification for stainless-steel castings for valves, flanges, and pipe fittings; 150-lb. corrosionresistant cast flanges, flanged valves, and flanged fittings; stainless-steel butt-welding fittings; steel pipeline flanges; quality standards for steel castings for valves, flanges, and fittings; pipe hangers and supports, connecting flange joint between tapping sleeves and tapping valves; hydrostatic testing of steel valves; high test wrought welding fittings; high pressure flanges and threaded stubs for use with lens gaskets; pressure temperature ratings for steel butt-welding end valves; butterfly valves; ball valves; cast iron gate, swing check and plug valves; silver brazing joints; and malleable iron thread and pipe unions.

In addition, the society serves as joint sponsor with the American Society of Mechanical Engineers and the Mechanical Contractors' Association of America for the Standards Committee on Pipe Flanges and Fittings, which resulted in the approval of 32 standards by the American National Standards Institute. It is also officially represented on 11 additional American National Standards Committees working on the following projects: scheme for the identification of piping systems; specifications for cast iron pipe and 
fittings; National Plumbing Code; dimensional standardization of plumbing equipment; standardization and unification of screw threads; pipe thread; code for pressure piping; standardization of dimensions and materials of wrought iron and wrought steel pipe and tubing; classification and designation of surface qualities.

The society maintains unofficial representation on committees of the American Society of Mechanical Engineers, American Welding Society, National Board of Boiler and Pressure Vessel Inspectors, National Fire Protection Association, American Petroleum Institute and the American Water Works Association.

Through its various committees, the society cooperates with a number of Federal agencies in formulating and revising numerous Government specifications on valves and fittings for both military and civilian use.

\section{MANUFACTURING CHEMISTS' ASSOCIATION, 1825 Connecticut Avenue NW., W ashington, D.C. 20009}

This association, founded in 1872, is one of the oldest and most diversified chemical trade organizations in the Western Hemisphere. It represents U.S. and Canadian manufacturers of basic chemicals who sell to others a substantial portion of the chemicals which they produce.

Early activities included the establishment of recommended strengths of acids with tables of physical properties; recommended specifications for laboratory apparatus, graduates, and thermometers; publication of a table of the elements with chemical and physical data; and short historical sketches of the discovery of the different elements. Assistance to the Congress of the United States in tariff legislation affecting the chemical industry, development of transportation regulations in cooperation with the Bureau of Explosives and Interstate Commerce Commission, and other technical work related to chemicals, were not only part of MCA's early activities but are continuing on a current basis.

\section{Environmental Management}

The association has long taken a prominent part in both technical and legislative phases of environmental management and pollution abatement.

Safety and Health-One of the most widely known activities of MCA is its program of chemical plant safety administered by the Safety and Fire Protection Committee. For its work in this field, the association has received awards from the American Society of Association Executives, and the National Safety Council, four times in succession. Safety activities include an annual presentation to the two member companies showing the greatest improvement in plant safety over a five year period, and annual awards to individual plants of member firms having worked a calendar year without an industrial injury.

The committee periodically sponsors safety workshops for plant supervisors. A major contribution is the publication of 100 manuals known as Chemical Safety Data Sheets and 20 Safety Guides which set forth properties and essential information for safe handling, storing, shipping, waste disposal, and other matters pertaining to potentially hazardous substances. These are distributed worldwide. A sound-and-color film, Safety in the Chemical Laboratory, has been produced and a 234-page book, Guide for Safety in the Chemical Laboratory, has been published. The most recent project has been the publication, on an intercommittee basis, of highway transportation emergency guides known as MCA Chem-Cards, and of Cargo Information Cards for Water Transportation covering barge shipments of certain hazardous chemicals.

The Occupational Health Committee advises regarding health hazards to workers in the chemical industry and to consumers of the industry's products, and assists member companies in the establishment or revision of health services. Its activities include sponsorship of workshops for industry safety engineers, industrial hygienists, toxicologists and medical officers regarding implementation of the Occupational Safety and Health Act.

The Food, Drug, and Cosmetic Chemicals Committee deals with technical and legislative matters related to chemicals in foodstuffs, pharmaceuticals, and cosmetics. This committee, in cooperation with the Public Relations Department, prepared the association's booklet Food Additives: What They Are/ How They Are Used.

Air-W ater-Solid W astes-The Water Resources Committee originated in 1936, and Air Quality Committee in 1949, with the Solid Wastes Management Committee having been organized in 1969. MCA has supported many measures designed to aid the public and continually provides guidance to governmental legislative bodies as well as to industry.

These environmental engineering committees inform the chemical industry concerning events and trends bearing on pollution and its prevention, abatement. and control; assist member companies in planning for effective management of environmental problems; and promote the development and exchange of noncompetitive technical information. Fundamental guidelines are contained in MCA's policy statements on environmental management, principles for air pollution control, principles for water pollution control, and the chemical industry and environmental health.

Precautionary Labeling-The Labels and Precautionary Information Committee was organized in 1944 to guide chemical shippers on adequate labeling and to assist governmental agencies in drafting regulations and laws governing the uniform labeling of potentially hazardous materials. Manual L-1, Guide to Precautionary Labeling of Hazardous Chemicals, is 
widely used by industry and regulatory agencies, and has served as a basis for drafting regulations.

Transportation and Packaging

For over 65 years, through its Transportation and Distribution, Chemical Packaging, and Transportation Equipment Committees, the association has carried on research and development work which has contributed substantially to the present safe methods of shipping hazardous chemicals. The work includes the development of new and specialized containers, equipment, handling methods, and procedures for the safe transporting of the multiplicity of chemical products made by the industry. Recommendations are presented to regulatory groups of Federal, state, and municipal governments and to rail and motor carrier classification bodies. MCA periodically sponsors technical symposia on the transportation and packaging of chemicals, both independently and in cooperation with other national organizations. Publications in this field include manuals of recommended practice for the handling of chemicals in tank cars, tank trucks, portable tanks, drums, and other containers.

\section{Chemtrec}

The association's Chemical Transportation Emergency Center, known as CHEMTREC, is a voluntary project of the chemical manufacturing industry. It was established as a public service for the purpose of providing immediate advice for those at the scene of emergencies when chemicals are involved in accidents on highways, railroads and waterways. Prompt contact is then made with the shipper of the chemicals involved for more detailed assistance and appropriate follow-up. CHEMTREC operates around the clock, seven days a week, to receive direct dial, toll-free calls through a single telephone number from any point in the continental United States. Shippers of chemicals, principally MCA member companies, are notified through preestablished telephone contacts, providing 24-hour accessibility. As circumstances warrant, other concerned trade associations with emergency-handling programs covering specific products are contacted and kept informed, as are appropriate Government agencies and regulatory bodies.

Other committees with standardization activities include the Engineering Advisory (voluntary standardization of process equipment), and the Nuclear Committees.

\section{Technical Publications}

MCA publishes several hundred different pieces of technical and informational literature, as well as films and filmstrips, pertinent to the chemical industry. Approximately 1,000 copies of each new technical publication are issued free to state and Federal officials, health departments, technical and medical school libraries, and others. A publications list is available on request.

\section{MAPLE FLOORING MANUFACTURERS' ASSOCIATION, 424. Washington Avenue, Oshkosh, Wisconsin 54901}

One of the prime objects of this association is to establish and enforce uniform grades and standards of products; to constantly improve methods of manu. facture; and to make the association trademark a symbol of excellence in methods and materials. Through its Grades Committee, this association has established grading rules for hard maple, beech and birch flooring. For the protection of the specifier and consumer, the association requires its members and encourages other hardwood flooring manufacturers to properly and clearly identify species of their flooring product. The letters MFMA on maple, beech, or birch flooring signify that the flooring is standardized and guaranteed by the association to be in accordance with the current established grading rules.

This association has opened its membership to Associate Members made up of qualified flooring contractors to further improve quality of installations.

This association has also adopted specifications for heavy duty and for gymnasium-type floor finishing products for maple, beech and birch floors. For this project, the association employs the services of a commercial testing laboratory. The specifications are revised every three years for the purpose of improving performance characteristics of the heavy duty and gymnasium floor finishes. Products which have met these specifications and have been certified to the association, will receive its written approval. A list of MFMA endorsed and approved finishes is published at intervals during the 3-year period. The association reserves the right of withdrawal of its approval on substantial evidence of depreciating quality of the product.

\section{MARBLE INSTITUTE OF AMERICA, 1984 Chain Bridge Road, McLean, Virginia 22101}

The institute is an organization composed of quarriers, importers, wholesalers, finishers and contractors of marble, formed to establish standards for marble and the quality of workmanship related to its use.

This institute has accumulated a vast amount of information from the domestic and foreign marble producing and finishing centers of the world, and is in a position to give to architects, engineers, builders, and others interested in marble, authentic information regarding the available marbles of the world.

Through the American National Standards Institute, the institute has helped to produce the following American National Standards: Standard Specifications for Interior Building Marble (A94.1-1961); Standard Specifications for Thin Exterior Marble Veneer (A94.2-1961); and Thin Exterior Marble In Curtain Or Panel Walls (A94.3-1961). 
The institute has also published a 178-page Marble Design Manual with contents organized to conform with the Uniform System For Construction Specification.

\section{MARKING DEVICE ASSOCIATION, 1611 Chicago Avenue, Evanston, Illinois 60201}

This association prepares standards for various kinds of metal marking tools and dies. Included are standards for size and depth of marking characters, styles of symbol stamps, stock sizes for steel letters and figures, and stock sizes for various stamp blanks. Other standards in use by members of the organization include those for bores and keyway sizes for roll dies, roller die blanks, and type and type holders for interchangeable steel type.

The association also develops standard terminology for all kinds of marking devices, including metal marking tools and dies, rubber stamps, seals, stencils, and marking inks.

Formerly: International Stamp Manufacturers' Association.

\section{THE MATERIAL HANDLING INSTITUTE, INC. 1326 Freeport Roarl, Pittshurgh, Pennsylvania $\mathbf{1 5 2 3 8}$}

The Material Handling Institute, Inc. was founded in 1945 as the horizontal trade association representing manufacturers of industrial material handling equipment, which is used in plants, plant-yards, piers, terminals and warehouses.

Approximately 10 percent of the activities are devoted to standardization. These activities are administered by the Automatic Identification Manufacturers Section; Below/Hook Lifters Section; Controlled Mechanical Storage Systems Section; Conveyor Section; Industrial Metal Containers Section; and the Loading Ramp Manufacturers Section. Although MHI does not issue standards, the product sections mentioned do issue standards with an average of about two per section. The scope of standards are national except as they find their way into international standards through an international standards organization. MHI cooperates through the American National Standards Institute in domestic and international standards activities. The institute is involved in the development of industry commentary on military specifications of the: Naval Supply Systems Command; Army Mobility Command; Naval Construction Battalion Center; and the Naval Engineering Center.

Absorbed: Association of Lift and Portable Elevator Manufacturers.

\author{
MECHANICAL CONTRACTORS' \\ ASSOCIATION OF AMERICA, INC., \\ 5530 Wisconsin Avenue NW., \\ Suite 750 , \\ Washington, D.C. 20015
}

The association is joint sponsor with the American Society of Mechanical Engineers and the Manufacturers Standardization Society of the Valve and Fittings Industry for American National Standards Committee Bl6 on Pipe Flanges and Fittings functioning under the procedures of the American National Standards Institute (ANSI). In addition, it is represented on numerous American National Standards Committees dealing with the following subjects: code for pipe threading; code for pressure piping; standardization of dimensions and materials of wrought iron and wrought steel pipe and tubing; standards for drawings and drafting room practice; approval and installation requirements for gas-burning appliances; graphical symbols and abbreviations for use on drawings; scheme for identification of piping systems, and safety in construction.

Two departments of this association are actively engaged in standardization activities; they are the National Certified Pipe Welding Bureau and the National Environmental Balancing Bureau. The National Certified Pipe Welding Bureau provides the means for members of the bureau to develop under its auspices standardized procedures for pipe welding which are used as the basis of a program for testing pipefitter welders. The National Environmental Balancing Bureau (NEBB) is a nonprofit organization to solve the construction industry's problems with systems controlling environmental systems in buildings and in related systems involving liquid flow. NEBB also establishes industry standards, procedures and specifications in the environmental balancing field. It has established educational programs with colleges and universities in local chapter areas. NEBB provides certification for firms that meet the organization's requirements which include meeting the required standards for work performance and supervision.

Formerly: Heating, Piping and Air Conditioning Contractors' National Association; Heating and Piping Contractors' National Association; National Association of Master Steam and Hot Water Fitters.

\section{MECHANICAL POWER TRANSMISSION ASSOCIATION,}

1717 Howard Street, Evanston, Illinois 60202

The Mechanical Power Transmission Association (MPTA) is a national trade association, which was founded in 1933. MPTA is concerned with the development of standards and other programs concerning v-belt drive systems and devices, variable speed drives, and transmission products including belt drives. 
MP'TA has maintained effective liaison with the following other associations: Rubber Manufacturers' Association (RMA), American Society of Mechanical Engineers, American National Standards Institute, International Organization for Standardization, and many others.

The Standards and Engineering Committee of MPTA administers all standardization activities, which amount to approximately 50 percent of MP'TA's program.

There are seven MPTA standards, of which five were developed in liaison with RMA. They are the: Welded Steel Conveyor Pulley Standard; Specifications for Drives Using Variable Speed V-Belts; Standard Specifications for Drives Using Narrow V-Belts (3V, $5 \mathrm{~V}$, and $8 \mathrm{~V}$ Cross Sections) ; Specifications for Drives Using Classical Multiple V-Belts (A, B, C, D and E Cross Sections) ; Specifications for Drives Using Single V-Belts (2L, 3L, 4L and 5L Cross Sections); Specifications for Drives Using Synchronous Belts (XL, LH, XH and XXH Belt Sections); and the most recent, Standard Specifications for Welded Steel Wing Pulleys.

Formerly: Multiple V-Belt Drive and Mechanical Power Transmission Association.

\section{METAL BUILDING MANUFACTURERS' ASSOCIATION, 2130 Keith Building, Cleveland, Ohio 44115}

The standardization work of the association is carried on by the Technical Committee. The work of this committee consists of preparation of recommendations concerning such projects as methods used in application of design loads, recommended minimum thicknesses of steel to be used in manufacturing metal buildings in order to assure proper service, and other general recommendations for use by model code bodies in preparing or revising these codes in order to have properly constructed metal buildings. The Technical Committee of the association works in conjunction with the American Iron and Steel Institute, model code bodies, and other code committees in order to assure users of metal buildings that proper installations are made.

The association has published Metal Building Systems Manual (revised in 1971). This document includes sections on recommended design practices, recommended guide specifications, and nomenclature covering metal building systems.

\section{METAL COOKWARE MANUFACTURERS' ASSOCIATION, P.O. Box D, Fontana, Wisconsin $\mathbf{5 3 1 2 5}$}

The Metal Cookware Manufacturers' Association (MCMA) was founded in May, 1922, as the Aluminum Wares Association. In 1963, when many of its member companies were expanding and diversifying by making cookware from other materials, it was decided to change the name to the Metal Cookware Manufacturcrs' Association. 'Today, membership totals 21 companies. This represents a significant majority of the total metal cookware production in the United States.

The standards activity of the Metal Cookware Manufacturers' Association is an important part of its program and represents 10 to 15 percent of MCMA's total activity. The standards program is conducted through a regular established Standards Committee composed of technical representatives of member companies. At present, membership of this committee totals nine (9) persons.

Standards Committee-The committee is an active group meeting approximately three (3) times per year to constantly review the standards that have been accepted to be sure that they are current and up-todate. MCMA is reviewing all standards today in the light of the various programs on product safety. The one project MCMA is working on at present has to do with the types of phenolic materials used for cooking utensil handles. In addition, the association is considering what will be necessary and essential in connection with changes to the international metric system.

The Standards Manual as prepared by this association has been available to member companies who have contributed to the formulation of these standards.

The standards which have been developed by MCMA are of a voluntary nature and serve as a guideline. MCMA does not have a formal certification program.

\section{METAL CUTTING TOOL INSTITUTE, 331 Madison Avenue, New York, New York 10017}

One purpose of the institute is to promote standardization of sizes, dimensions and tolerances of rotary type, multiple point, metal cutting tools, such as twist drills, reamers, taps, milling cutters, and gear generating tools, and to simplify these in cooperation with the American National Standards Institute (ANSI), American Society of Mechanical Engineers and other national and international bodies, with a view to eliminating waste and reducing costs. In this regard, the institute actively participates in technical and advisory committees of major national standardizing bodies.

Results of such activity are reflected in widely promulgated American National Standards on twist drills, reamers, taps, and milling cutters. These standards form the basis of Federal specifications and individual company standards, as well as reflecting current United States industry practice in the formulation of International Organization for Standardization (ISO) standards.

The institute publishes Metal Cutting Tool Hand- 
book and such pamphlets as Metal Cutting Tool Nomenclature, Drilling Today's Materials, Drilled Holes for Tapping, Tolerances for Twist Drills and Reamers, Milling Cutters and End Mills, and Standards and Dimensions for Taps and Dies.

\section{METAL LADDER MANUFACTURERS' ASSOCIATION, P.O. Box 580, \\ Greenville, Pennsylvania 16125}

One of the most important activities of this association is to participate in the development and promulgation of safety standards pertaining to the products manufactured by its members. Specifically, the MLMA has developed, and will continue to develop, revised versions of its safety standard entitled Safety Code for Portable Metal and Fiberglass Ladders.

In addition, members of the association are actively engaged in the work of the following American National Standards Committees developing safety codes: (a) The A14 Committee which is working on revisions to American National Standard A14.2-1972, Safety Code for Portable Metal Ladders. (b) The American National Standards Committee A92 working on American National Standard A92.1, Standard Safety Code for Mobile Scaffolds, Ladder Towers and Telescopic Work Platforms. (c) The American National Standards Committee Al0 which is working on revisions to the Construction Code and its various subsections. This committee is developing a revision to American National Standard A10.8, Standard Safety Code for Building Construction Safety Requirements for Temporary Scaffolding. (d) The American National Standards Committee A14.5 which is developing a Safety Standard for Portable Fiberglass Ladders.

\section{METAL POWDER INDUSTRIES FEDERATION, P.O. Box 2054, Princeton, New Jersey 08540}

The Metal Powder Industries Federation (MPIF) was founded in 1945 to serve technical and trade interests of metal powder producing and consuming industries.

The Standards Board and three standards committees administer the standardization activities of MPIF. Standardization is one of the major activities of the federation and the various trade associations operating within its structure which is made up of the Metal Powder Producers' Association, Powder Metallurgy Parts Association, In-Plant Powder Metallurgy Association, Powder Metallurgy Equipment Association, and Refractory and Reactive Metals Association.

About 110 standards ( 80 material standards and 30 test standards) have been issued in the field of powder metallurgy and magnetic cores. Basically they deal with ferrous and nonferrous $\mathrm{P} / \mathrm{M}$ materials and industry practices. These standards are considered national in scope. Involvement with the Federal Government consists of reviewing the Federal specifications issued by the General Services Administration involving $\mathrm{P} / \mathrm{M}$ products. The Federal specifications are reviewed by the Standards Board. On an international level, MPIF participates on International Organization for Standardization Technical Committee 119, on Metal Powder and Metal Powder Products.

Formerly: Metal Powder Association (1957).

\section{METAL TUBE PACKAGING COUNCIL OF NORTH AMERICA. 1414 Avenue of the Americas, New York, New York 10019}

The Metal Tube Packaging Council of North America, established in 1914 as the Collapsible Tube Association, is a trade association. The current name of the organization was adopted in 1966. Its primary purpose is to provide information on metal tubes to marketers in North America. It is the only organization of its kind, representing all manufacturers of collapsible metal tubes in North America. At the present time it distributes a publication to a private list, six times per year.

The Standards Committee administers the standardization activities for the council. The six current Collapsible Tube Standards are for: Nomenclature; Neck and Orifice Sizes-American Standard Thread and Modified Buttress Thread Forms; Thermoset Cap Sizes, American Standard Form; Thermoplastic Cap Sizes; and Standard Length, Wall and Shoulder Sizes. These standards are available without cost from the executive office.

\section{MILK BOTTLE CRATE MANUFACTURERS' COUNCIL, 2130 Keith Building,} Cleveland, Ohio $\mathbf{4 4 1 1 5}$

\section{The standardization and simplification activities of this association are carried on by the Simplification and Standardization Committee. Its work has been confined to simplification matters dealing with devel- opment of minimum pocket sizes and minimum dimensions of the crate in order to insure proper interstacking of milk bottle crates. \\ MILL MUTUAL FIRE PREVENTION BUREAU, 2 North Riverside Plaza, Chicago, Illinois 60606}

The Mill Mutual Fire Prevention Bureau was offcially established on January 2, 1911 in Oxford, Michigan. Its primary objective is to provide technical data to agri processing plants for the reduction of loss to property by fire or wind and to personnel by injury within the plant. It has been largely responsible for the development of standards in reducing fire hazards in grain handling and grain processing plants. These standards cover such areas as dust control, design of cyclone collectors, standards for mechanical drives, 
electrical codes, control of insect and fumigation, etc. all of which aid to the prevention of fire within the agri plant.

In addition to the standards and pamphlets, considerable time is devoted to plant protection and this is acquired through standards involving local and central station fire alarm systems, nonstandard sprinkler installations, installation of portable fire extinguishers, etc. While most of this material is prepared for insureds of subscribing members of the Mill Mutual Fire Prevention Bureau, it is also made available to others, and is frequently sought after by companies in foreign countries.

An LPE Bulletin, Loss Prevention Engineering is prepared to advise the public of the various materials made available. There are some 25 pamphlets listed in this bulletin, all directed toward safe practices in agri plants.

Engineering members of the Mill Mutual Fire Prevention Bureau are actively engaged on National Fire Protection Association committees and committees of the National Safety Council. In addition to this the engineers of the bureau maintain Registered Professional Engineers and many are members of organizations such as the American Society of Mechanical Engineers, Institute of Electrical and Electronics Engineers, Society of Fire Protection Engineers, and International Association of Electrical Inspectors.

A close alliance is held with various trade associations in the field of flour milling, animal feeds, grain elevator operations and poultry raising. As problems arise in these particular areas, research is done by the Engineering Department and material is made avail. able to these fields to assist in the reduction of loss of property or life.

\section{MOBILE HOMES MANUFACTURERS' ASSOCIATION, P.0. Box 201, 14650 Lee Road, Chantilly, Virginia 22021}

This trade association (MHMA), founded in 1935, represents the manufacturers and suppliers of factorybuilt housing, a $\$ 4$ billion industry that built 80 percent of all homes sold for less than $\$ 20,000$ in 1972. It cooperates with committees of the American National Standards Institute (ANSI) and the National Fire Protection Association (NFPA) in the constant review and updating of the Mobile Home Standard (NFPA 501B and American National Standard A119.1) covering the installation of the plumbing, heating and electrical systems as well as the construction of the body, frame, running gear, and chassis of the mobile home. It works with them in the establishment of their Standard for Mobile Home Parks (NFPA 501A and American National Standard A177.1). The association is working to secure national adoption of the Mobile Home Standard; by mid-1973, 36 states had enacted it into law. Members of MHMA are required to build to the standard and certify their compliance to it by placing an oval blue and silver seal near the front door. Inspectors representing MHMA's Standards Division monitor the compliance of its members by inspecting their plants on an unannounced and frequent basis.

The combined membership of MHMA and the Trailer Coach Association represented 66 percent of all 1972 mobile home production, and a total of 84 percent of the 576,000 homes shipped to U.S. dealers in 1972 went into states where compliance is mandatory.

Both manufacturers and suppliers are represented on the ongoing MHMA Standards Committee which has five subcommittees dealing with electrical systems, plumbing, heating, construction and windows.

Formerly: Trailer Coach Manufacturers' Association.

\section{MONORAIL MANUFACTURERS' ASSOCIATION, 1326 Freeport Road, Pittshurgh, Pennsylvania 15238}

Monorail Manufacturers' Association Specifications For Underhung Cranes and Monorail Systems apply to underhung cranes operating on the lower flange of a track section, and to a single track monorail system including all curves, switches, transfer devices, trolleys, lift and drop section, and associated equipment. The specifications include both power-driven and hand-operated equipment. Provisions of this specification do not encompass all of the safety precautions and safeguards applicable to monorail systems primarily used for transportation of personnel. The association was founded in 1933.

\section{MO-SAI INSTITUTE INC., P.0. Box 5398, East Pasadena, California 91107}

Mo-Sai Institute, Inc., was founded in 1940. A nonprofit organization, the institute was organized to standardize, improve and promote the use of precast architectural concrete. Standardization is administered by the Technical Committee. While not participating in international standardization programs, institute members in Canada and Japan have promulgated the group's standards in those areas.

Institute standards are frequently included, by reference, in specifications of the General Services Administration, U. S. Army Corps of Engineers, and U. S. Navy. Certification activities are principally undertaken through participating in programs of American Society for Testing and Materials, American Concrete Institute and Prestressed Concrete Institute. Current standards are contained in one publication, Standard Specifications of Mo-Sai Institute. Standards are national in scope and are promoted through market development activities of member companies. 


\section{MOTOR VEHICLE MANUFACTURERS' ASSOCIATION OF TIE UNITED STATES, INC., New Center Building, Detroit, Michigan 48202}

The Motor Vehicle Manufacturers' Association of the United States was founded in 1913 as the National Automobile Chamber of Commerce. Practically all engineering standardization work arising in the industry represented by this organization is conducted through the Society of Automotive Engineers financed in substantial part by grant from the association. The association cooperated with the National Conference on Street and Highway Safety in the preparation and promulgation of state and city traffic ordinances. This work continues under the National Committee on Uniform Traffic Laws and Ordinances.

In addition, this association is a member of the American National Standards Institute in connection with standards related to motor vehicles and their use. It is a participant in international standards programs of International Organization for Standardization and International Special Committee on Radio Interference (CISPR) and the Economic Commission for Europe (ECE) Working Party 29.

The association also cooperates with the Technical Committee of the Bureau Permanent International des Constructeurs d'Automobiles in international standards work.

Formerly: Automobile Manufacturers' Association, Inc. (1972).

\section{NATIONAL ACADEMY OF SCIENCES- NATIONAL ACADEMY OF ENGINEERING- INSTITUTE OF MEDICINE- NATIONAL RESEARCH COUNCIL, 2101 Constitution Avenue NW., Washington, D.C. 20418}

The National Academy of Sciences is a private, nonprofit organization dedicated to the furtherance of science and its use for the general welfare, and required by its Congressional Charter of 1863 to act as an official adviser to the Federal Government, upon request, in all matters of science and technology. Its members, now numbering about 1000 , are elected in recognition of their distinguished and continuing achievements in original research. The National Academy of Engineering was established in 1964 under the charter of the NAS. The Institute of Medicine was chartered by the NAS in 1970. The National Research Council was established by the academy in 1916 to enable the broad community of U.S. scien. tists and engineers to associate their efforts with the limited membership of the academy in service to science and the nation. The members of the Research Council are drawn from academic, industrial, and government organizations throughout the country. Representatives of more than 100 scientific and technical societies, designated members of Government sci- entific agencies, and members-at-large receive their appointments from the president of the academy.

The primary purpose of these organizations is to bring together the most competent scientists and engineers of the country in appropriate groups to deal with scientific problems and to exchange information in furtherance of research.

No laboratories are maintained, but the NAS.NAEIOM-NRC seeks to stimulate and support the work of individual scientists and to coordinate investigations dealing with broad problems in research, both nationally and internationally. This is carried out through a wide variety of means, including conferences, technical committees, surveys, collection and collation of scientific and technical data, the sponsorship of scientific publications and research organizations, and the administration of public and private funds for research projects and fellowships. It provides unique means for organizing attacks on scientific problems which involve many specialized fields and for obtaining disinterested and objective assessments of problems for groups representing dissimilar or con. flicting interests.

Since the activities of the Academy-Research Council are directed largely toward stimulating and facilitating scientific research, rather than its conduct or direction, the program in the field of standardization is necessarily quite limited. However, there have been some calls to undertake such assionments. Current standardization activities are listed below.

Assembly of Behavioral and Social Sciences-The Committee on Vision is currently active in cooperation with the Z80 Committee of the American National Standards Institute (ANSI) in its attempt to promote standardized methods for the testing of ophthalmic lenses, particularly for impact resistant lenses. The committee is also active on a continuing basis on setting of standards for induction into or retirement from the Armed Forces based upon visual function. An additional concern is the setting of vis. ual standards required for the performance of specialized military occupations such as flying. The committee works internationally with North Atlantic Treaty Organization (NATO) in setting performance standards for visual function of NATO pilots, standardized painting of propeller tips to avoid accidents among ground crew, and standardized lighting of runways. Finally, the committee is concerned with standardized lighting of buoys, marking of navigation channels in costal regions, harbors, and rivers.

The Committee on Hearing, Bioacoustics, and Biomechanics has published reports setting noise exposure standards beyond which noise levels human hearing would be jeopardized. These standards have frequently been adopted by ANSI. The committee cooperates with the International Organization for Standardization in setting of similar noise exposure standards on an international basis. The committee has cooperated with the International Civil Aviation Organization in setting restrictions on the flight of commercial supersonic transports that would result in the production of sonic booms. The committee is 
currently cooperating with the Department of Transportation, the Federal Aviation Agency, and the Environmental Protection Agency, in developing guidelines for state and local governments to follow for the control of transportation noise, and with the Environmental Protection Agency in setting similar guidelines to control other sources of environmental noise. The committee also is active on setting of standards for induction into or retirement from the Armed Forces based upon auditory function. An additional concern is the setting of auditory standards required for the performance of specialized military occupations such as flying.

Assembly of Life Sciences-The Committee on Animal Nutrition has prepared a series of reports dealing with the nutrient requirements of various domestic animals.

The Institute of Laboratory Animal Resources (ILAR) was founded in 1952. Through the efforts of an Advisory Council, Executive Committee and varied committees, ILAR serves as a coordinating agency to disseminate information, survey existing and required resources, establish standards, promote education, hold conferences, and upgrade laboratory animal resources. ILAR strives to keep the laboratory animal community currently informed through its quarterly publication, ILAR News, and has published approximately 100 other publications on the following subjects: Proceedings of Symposia and Workshops; Surveys of Laboratory Animal Use; Standards and Guidelines for the Breeding, Care, and Management of Laboratory Animals; Animal Procurement Specifications; Abstracts on Animal Models for Biomedical Research; and other miscellaneous publications in the laboratory animal field.

Food and Nutrition Board-The board prepares Recommended Dietary Allowances as a guide to the maintenance of complete healthful nutrition. Its Food Chemicals Codex establishes standards of identity and purity for the chemicals used as intentional additives in food. The Food Protection Committee of the board considers standards that affect food processing, production and storage.

Chemistry and Chemical Technology-Through its Advisory Center on Toxicology, the division advises on tolerances for industrial substances that might constitute a hazard for personnel. The Numerical Data Advisory Board studies problems relating to standards for compiling and disseminating critically evaluated numerical data. The Committee on Symbols, Units, and Terminology, operating jointly under this division and the Divisions of Engineering and Physical Sciences, coordinates for the United States national and international interest in symbols, units, and terminology in all areas of the physical sciences. It also functions on behalf of the American National Standards Institute as USA Committee for International Organization for Standardization Technical Committee 12 in its interdisciplinary program on quantities, units, and symbols.

Earth Sciences-A Committee on Seismology advises Government agencies on the World-Wide Net- work of Standardized Seismograph Stations. An Ocean Affairs Board gives broad support to the marine sciences and advises several Government agencies on oceanographic problems. The Committee on Remote Sensing Programs for Earth Resource Surveys advises the Government on remote sensing programs for earth resource surveys and environmental monitoring.

Engineering-There are many units in the division whose activities are closely related to establishing standards or codes; but it is the intent of the division that actual formulation of standards be avoided. Rather, units are expected to help supply scientific and technical data on properties and performance to assist responsible standards-writing groups.

Highway Research Board does not set standards but its authoritative publications are routinely used as standards by numerous agencies. Examples include traffic control warrants, definitions, new testing procedures and design details. Similar data leading to standardization by other organizations are developed continuously in the activities of Highway Research Board standing committees and contractors performing research under the Highway Research Board administered NCHRP program.

Ship Research Committee-This committee is a standing committee of the Maritime Transportation Research Board. Its activities cover the fields of materials, design, fabrication, and inspection as related to merchant ship hulls.

Advisory Board on Military Personnel SuppliesThis board and its several committees provide scientific and technical advisory services to the U.S. Army Natick Laboratories on matters of military clothing, food, and shelter.

Building Research Advisory Board-BRAB advisory services are used by Federal agencies as scientific and technical input to the development of standards and other requirements for housing and building construction. BRAB also operates the BRAB Federal Construction Council, a voluntary correlating group of some nine Federal construction agencies with major building construction responsibilities. The deliberations of this council lead also to certain standards or accepted practices in materials, methods, and designs employed in a great volume of Federal building activities. A special program of the council deals with the creation of recommended Federal guide specifications for building construction.

Physical Sciences-Several committees of the division concern themselves with standardization activities as part of their overall program. Among these are the following: the Committee on Symbols, Units, and Terminology cooperates with U.S. activities and international scientific unions and commissions in coordinating the recommendations and views of major United States scientific and technical activities concerned with standardization of symbols, units and terminology in the physical sciences; the Committee on Line Spectra of the Elements surveys the field and directs attention to significant problems for investigation, encourages group attack on related aspects of major problems, and compiles data on atomic spectra. 
The Committee on Nuclear Science has several subcommittees and panels which form research conferences and review articles, monographs and special reports, and make available data and recommended standards, constants, and procedures for benefit of other scientific groups, Government, and industry. A number of technical panels, organized to conform with divisional activities of the National Bureau of Standards, advise and assist the Director of the Bureau in evaluation and planning.

The Academy-Research Council has published or has been responsible for the publication of many individual reports or series of reports dealing with some aspect of standardization. Among these are International Critical Tables of Numerical Data; Physics, Chemistry, and Technology ( 7 volumes and index); Data on Chemicals for Ceramic Use; Tables of Chemical Kinetics, Homogeneous Reactions (with supplement); Method of Coding Chemicals for Correlation and Classification; Specifications and Criteria for Biochemical Compounds; A Glossary of Terms in Nuclear Science and Technology; Principles and Procedures for Evaluating the Safety of International Chemical Additives in Foods; Status Report on Standardization of Radionuclides in the United States; and Measurements and Standards of Radioactivity.

A listing of publications in print is available from the Printing and Publishing Office.

\section{NATIONAL ACCREDITATION COUNCIL, 79 Madison Avenue, New York, New York 10016}

Founded in 1967, the council (NAC) seeks to improve the quality of specialized services in its field. It (1) develops and updates standards for the management and services of agencies and schools for the blind and visually handicapped and (2) administers a voluntary system through which organizations found to be in substantial compliance with the standards are given the public recognition of accreditation. The decision to grant, withhold, or defer accreditation is made by the Commission on Accreditation. The Commission on Standards initiates plans and proposals for development of new standards and revision of existing standards and reviews all standards before they are promulgated.

Development and application of the standards have been encouraged and funded in part by the Rehabilitation Services Administration, Social and Rehabilitation Service, and by the Office of Education, both of the U. S. Department of Health, Education and Welfare.

Present standards cover 13 administrative and program areas encompassing hundreds of standards. Standards are listed in The COMSTAC Report and in three self-study and evaluation guides.

NAC is the only nationally recognized standardsetting, accrediting organization for specialized services to the blind and visually handicapped. As projects for new standards are developed they are reported in the Annual Report. NAC promotes the use of the standards through mailings, meetings and cooperation with other organizations in the field.

\section{NATIONAL ASSOCIATION OF ARCHITECTURAL METAL MANUFACTURERS, 1033 South Boulevard, Oak Park, Illinois 60302}

NAAMM, a nationwide association of fabricators of hollow, architectural, residential, miscellaneous, and ornamental metal products, was founded in 1939. Its objectives are to: promote mutual interests and cooperation among the members of the industry; promote educational and inspirational activities within the industry; compile and disseminate statistics and other information pertaining to the industry; furnish technical information to architects and engineers about the industry; maintain and improve the technical standards of the industry; conduct studies and surveys to increase the use of and markets for the products of the industry; promote and assist in the development of new products for the industry; promote other activities materially beneficial to the industry which are appropriate to trade associations generally.

NAAMM and its Architectural Metal Products Division, Metal Bar Grating Division, and Hollow Metal Manufacturers Association, a division of NAAMM have developed standards and specifications for many of the products of the industry - standards and specifications universally accepted and used by architects, specification writers, and Government agencies. They are quality standards and specifications that have given specifying authorities confidence in the products of the industry.

The following technical publications contain NAAMM's recommended practices and specifications and standards: Metal Stairs Manual; Metal Bar Grating Manual; Metal Product Outline Manual; Metal Finishes Manual; Specifications for Custom Hollow Metal Doors and Frames-NAAMM Standard CHM-1-74; and Fire-Rated Custom Metal Doors and Frames, and Glossary of Architectural Metal Terms Manual.

Formerly: National Association of Ornamental Metal Manufacturers;

Absorbed: National Steel Door and Frame Association (1962).

\section{NATIONAL ASSOCIATION OF BEDDING MANUFACTURERS, 1150 17th Street NW., Suite 200, \\ W ashington, D.C. 20036}

The National Association of Bedding Manufacturers (NABM) founded in 1915, is national in scope and represents manufacturers of mattresses, bedsprings, and dual purpose sleep equipment as well as suppliers of machinery, raw and finished materials, components and other supplies and services necessary to the manufacture of bedding.

NABM, virtually throughout the entire span of its 
existence, has been aware of the importance and mutual benefits of standardization to both industry members and the consuming public.

Various committees and members of NABM are involved on a continuing basis with a number of Government agencies and related trade groups in a cooperative effort of reviewing, developing, updating and revising industry and Government standards as they apply to bedding products as the occasion warrants.

Recent examples of this work are the conclusion in 1972 of a project in cooperation with the American Hotel \& Motel Association to develop test equipment and procedures for evaluating performance characteristics of mattresses and boxsprings and a current project with the National Bureau of Standards to revise Simplified Practice Recommendation R2-62, Bedding Products and Components. This standard, first issued in 1922 as R-2, is the oldest active standard in the National Bureau of Standards' inventory and has been revised and reissued in 1930, 1932 , 1954, 1957 and 1962.

Standards and specifications pertaining to bedding products are initially distributed to members of NABM and related trade groups with the association's recommendations as to their applicability and use. A substantial distribution of additional copies is made in response to subsequent requests from interested parties.

\section{NATIONAL ASSOCIATION OF BLUE SHIELD PLANS, \\ 211 East Chicago Avenue, Chicago, Illinois 60611}

The National Association of Blue Shield Plans (NABSP), established in 1946, serves and represents 71 locally organized and operated nonprofit health care prepayment plans which together serve over 80 million Americans.

A primary objective of NABSP is provision by its member plans of high quality service to subscribers, beneficiaries and physicians. This is often accomplished by establishment of performance objectives for various aspects of plan operations and includes standardization of data definitions and accounting procedurcs. Member plans are required to report information describing scope of operation, financial condition and experience on a routine basis.

Blue Shield Plans serve as fiscal agents for Federal Medicare (Bureau of Health Insurance), Medicaid (Medical Services Administration) programs, and CHAMPUS (Department of Defense) programs.

NABSP coordinates the provision of health care prepayment services for multistate purchasers through local Blue Shield Plans, including the world's largest privately underwritten contract, the Federal Employees Health Benefit Program (Civil Service Commission).

Adherence to standards promulgated by the association is encouraged or formally required when necessary by action of the Conference of Plans which amends or extends existing NABSP Standards of
Membership. These rcquirements must be met by organizations desiring to qualify for membership in NABSP. Association staff, at the direction of the NABSP Board of Directors, administer the various standards.

Illustrative of the NABSP activities are standardized programs in medical service nomenclature and coding, service utilization review and measurement, physician charge and plan allowance data, benefit description, accounting procedures and data processing systems.

Formerly: Associated Medical Care Plans (1946), Blue Shield Medical Care Plans (1950), National Association of Blue Shield Plans (1960).

\section{NATIONAL ASSOCIATION OF BROADCASTERS, 1771 N Street NW., Washington, D.C. 20036}

The National Association of Broadcasters whose membership includes over 5000 AM, FM, and TV stations was formed over 50 years ago as a trade association to represent the commercial broadcasting industry.

The NAB Recording and Reproducing Committees have established standards for recording and reproducing in which more than 100 of the nation's authorities on various phases of recording participated. The standards program is a continuing effort which first started in 1941. The standards pertain to the recording and reproducing of disc, cartridge tape, reel-to-reel magnetic tape and cassette, as well as methods of measurement. They include standard playback curves, response limits and criteria for establishing test records and tapes. The standards also contain mechanical dimensions for records, reel flanges and hubs, and cassettes. A glossary of terms in included. These are professional standards promulgated primarily for the broadcasting industry.

Formerly: National Association of Radio and Television Broadcasters (1951-1957).

\section{NATIONAL ASSOCIATION OF CORROSION ENGINEERS, P.O. Box 1499 . Houston, Texas 77001}

NACE is a nonprofit technical society which was incorporated in the State of Texas in 1943. This organization is the only technical society in the United States that is devoted entirely to matters concerning the prevention and control of corrosion and the protection of materials. Through its Technical Practices Committees, NACE is engaged in preparing standards to promote the use of the best technical practices to reduce the cost of corrosion and to increase the safety of industrial, public and private installations where corrosion damage could create hazards. NACE has cooperated with the Federal Government in developing industry-oriented standards for the Office of Pipeline Safety and the Office of Hazard- 
ous Materials in the Department of Transportation. The association has an Accreditation Program whereby members of the association can become accredited as Corrosion Specialists, Corrosion Specialists in Training, Senior Corrosion Technologists and Corrosion Technicians. All the standards that have been issued by NACE are listed in a NACE publication brochure that is available from the association. The standards developed by NACE are national in scope in that they are pertinent to industries or segments of industries and are of interest to that industry or segment of industry throughout the country. Active standards committees are structured under the Technical Practices Committees which are composed of eight group committees primarily oriented on industrial basis. These group committees are then subdivided into forty-two unit committees, under which standardwriting task groups can be formed. Annual directories of these committees are issued by NACE Headquarters and are available at no cost.

\section{NATIONAL ASSOCIATION OF COUNTY ENGINEERS, 308 Jacolyn Drive NW. Cedar Rapids, Iowa $\mathbf{5 2 4 0 5}$}

The National Association of County Engineers (NACE) is the only organization of its type, founded in 1956, and is an affiliate of the National Association of Counties (NACO). The predominate objective is to identify the various technical and management problems common to most counties, and document their practical solutions. The original objective was to emphasize the relations, actions and methods of management, and a number of committees produced guide manuals delineating the better practices in use throughout the country. The work was financed by the Federal Highway Administration and Highway Users Federation for Safety and Mobility - as it still is today. In recent years, numerous committees produced a second generation of Action Guide Manuals which emphasizes standards for both modern county engineering management and procedures for simplified engineering and technical analysis. With the use of these "how-to-do-it" guides, the professional considerations are more readily identified, and the universally accepted engineering solutions can be applied. These literally "best sellers" published 17 volumes and sold in sets only, include: (1) Organization-PersonnelPurchasing; (2) Cost Records; (3) Advance Road Programs; (4) Comprehensive County Planning; (5) Planning County Road Systems; (6) Refuse Disposal; (7) County Traffic Operations; (8) Maintenance Management; (9) Public Support; (10) Spot Safety Improvements; (11) Administration of Bridge Inspection; (12) Soil Erosion and Water Pollution Prevention; (13) Aerial Photography; (14) Drainage; (15) Travel Generation; (16) Subsurface Soils Exploration; and 17 Summary Volume.

The officers, (Board of Directors) elected by the 1200 international members, appoint the Research Program Planning Committee, which directs all research work through a professional staff at the NACO office in Washington, D. C.

The NACE Board of Directors has been summoned to consult formally and informally with several of the Federal departments, congressional committees, individual Senators and Congressmen; the Highway Research Board, various state departments and state associations. The NACE input has helped to develop National policy and Federal legislation.

NACE has conducted workshops on manual subjects throughout the country, and holds a Management Research Conference each year, and meets annually with the NACO meeting each summer.

\section{THE NATIONAL ASSOCIATION OF ELEVATOR CONTRACTORS, 4321 Hartwick Road, Suite 306, College Park, Maryland 20740}

The National Association of Elevator Contractors, founded in 1949, is a nonprofit, nongovernment corporation; is made up of independent elevator contractors and their suppliers.

Some 30 percent of the association's activities are devoted to the development, promulgation and education of the industry of the American National Standard Safety Code for Elevators, Dumbwaiters, Escalators and Moving Walks (American National Standard A17.1-1971). Committees serve on the Executive Committee and the Standards Committee of the A17.1 Safety Code.

Classes for members and nonmembers are conducted annually in Code Understanding. Working with the Building Officials and Code Administrators and the National Association of Elevator Safety Authorities classes are conducted leading to the certification of Elevator Safety Inspectors. All educational activities are conducted by the Executive Director of NAEC.

\section{NATIONAL ASSOCIATION OF FOOD CHAINS, 1725 Eye Street NW., Washington, D.C. 20006}

Standardization activities of this association include work in the following areas: (1) standard invoices; (2) standardization of pallets; (3) cooperation in funding and developing the universal product code and symbol for the grocery industry; (4) research on the shape and type of containers used to transport food products; and (5) study of modularization of shipping containers for grocery products.

NAFC is working with supplier associations in the produce, meat and dry groceries areas in encouraging the use of standard invoice forms. The utilization of these forms is aimed at reducing the processing time in handling supplier invoices.

As a trade association, NAFC played a vital part in the adoption of the 48 in by 40 in four-way hardwood 
pallet as the standard pallet for the food industry, and the suggested alternative size which is 32 in by 40 in Increased unitization of shipments with standard pallets has substantially reduced the cost of moving food products for the manufacturer or the consumer.

NAFC is also working with produce suppliers to make nonbulger pack produce containers available as standard containers. These nonbulge pack containers are aimed at delivering produce to the consumer with less damage than the bulge pack container.

Because of the difficulty in palletization of square cases, NAFC is encouraging the adoption of case shapes more conclusive to palletization. Standard item codes for all food products is also an area of NAFC activity.

\section{NATIONAL ASSOCIATION OF FOOD EQUIPMENT MANUFACTURERS, III East Wacker Drive, Chicago, Illinois 60601}

The association is concerned with equipment standards and practices in the field of commercial food preparation and service. Standardization activities include research and educational programs in foodservice layout, refrigeration, dishwashing and dishhandling. The Advisory and Emergency Feeding Committee works in cooperation with Government and civil defense agencies concerned with mass feeding in times of emergency. It maintains close liaison, for cooperative effort in standardization, with Food Facilities Engineering Society, National Sanitation Foundation and other industry groups.

\section{NATIONAL ASSOCIATION OF FURNITURE MANUFACTURERS, INC., 8401 Connecticut Avenue NW., Suite 911 , \\ W ashington, D.C. 20015}

Two associations, The National Association of Furniture Manufacturers, and the Southern Furniture Manufacturers Association have established a Joint Industry Upholstery Fabric Committee. This committee consists of 11 leading furniture manufacturers combined with technical experts from a dozen fabric mills and representatives from such retail organizations as Sears Roebuck and J. C. Penney.

Representatives of the committee have met with the National Bureau of Standards (NBS) for the purpose of developing wearability standards for upholstery fabrics that will enable us to distinguish their wearability characteristics into such catagories as heavy duty, medium, light wear, and decorator fabrics.

We submitted our proposed standards and test procedures to NBS and subsequently presented them to the American National Standards Institute (ANSI) and the American Society for Testing and Materials (ASTM) for review.

\section{NATIONAL ASSOCIATION OF GLUE MANUFACTURERS, 2805 Patterson Plank Road, Box 850 \\ North Bergen, New Jersey 07047}

The National Association of Glue Manufacturers (NAGM) was founded in 1922. Standardization and simplificatinn activities of this association are carried on by the Technical Committee which is charged with the duty of establishing standard grades and methods for testing animal glue products manufactured by its members. The following publications are available from the association: Animal Glue in Industry and Standard Methods for the Sampling and Testing of Animal Glues. These Standard Methods are considered national in scope.

NAGM through its Technical Committee, has established a cooperative testing program in which its members and certain outside laboratories are invited to participate. The purpose of the testing program is to establish certain standards which will result in more uniform testing. This is achieved by the distribution of samples of animal glues to the member and nonmember participating laboratories. The samples are subjected to a series of tests established by the Technical Committee and the results forwarded to the association's headquarters where they are tabulated, identified by number only and sent to the association's members as a specific report. Each participating member is informed of its identification number in the report and is therefore in a position to compare the results.

Through its members, the NAGM is represented on the Technical Association of the Pulp and Paper Industry, Gummed Industries Association, American Society for Testing and Materials, and Adhesives Manufacturers' Association of America.

\section{NATIONAL ASSOCIATION OF HOSIERY MANUFACTURERS, 516 Charlottetown Mall, Charlotte, North Carolina 28204}

Among the principal activities of this association (NAHM) is technical research leading to standards concerning sizing systems and terminology for various types of hosiery. Two such standards developed under the auspices of the U.S. Department of Commerce, National Bureau of Standards, were Commercial Standard CS46-65, Hosiery Lengths and Sizes Excluding Women's and Commercial Standard CS234-61, Measurements for Stretch Socks and Anklets, for which NAHM was the proponent.

In addition to the above, the association in recent years, through extensive research and testing, developed a simple method for use in describing women's pantyhose in order to provide wearers with properfitting garments. The end result is a recommendation, widely followed throughout the industry, that all 
pantyhose be described in terms of height and weight of the wearer for whom they are produced.

Absorbed: Southern Hosiery Manufacturers' Asso. ciation (1956).

\section{NATIONAL ASSOCIATION OF HOSPITAL PURCHASING MANAGEMENT, 1340 North Astor Street, Suite 1201, Chicago, Illinois 60610}

The National Association of Hospital Purchasing Management (NAHPM) was founded in 1957, and chartered by the State of Illinois as a nonprofit professional organization of hospital purchasing directors. The primary efforts of the NAHPM are (1) to foster an increased knowledge of and proficiency in purchasing management; (2) to conduct and participate in educational programs and activities concerning purchasing management; (3) to provide media for the interchange of ideas and dissemination of material relative to hospital purchasing management, by bringing about closer cooperation, developing curricula and supporting materials for use by educational institutions, to cooperate with hospitals and other patient care institutions and agencies; (4) to establish principles relative to hospital purchasing management to establish standards of performance for individuals and institutions in the various areas of hospital purchasing management through certification and educational conferences and research in hospital purchasing management.

The Professional Development Committee has established guidelines for the certification of hospital purchasing managers.

Formerly: National Association of Hospital Purchasing Agents (1968).

\section{NATIONAL ASSOCIATION OF INDUSTRIAL PARKS, Suite 1110 - 1800 North Kent Street, Arlington, Virginia 22209}

The National Association of Industrial Parks (NAIP) was founded in 1967. Membership is open to developers of industrial and office parks and others interested in industrial real estate who are admitted as associate members. The purpose of NAIP is to stimulate growth of the industry; to help improve prospects and profits of its members; and to foster the establishment and maintenance of standards for the operation of industrial parks. The following criteria was established to help fulfill the purpose of NAIP: The assembly of land under one continuing control, to provide facilities for business and industry consistent with a master plan and restrictions, resulting in the creation of a physical environment achieving the following objectives: Consistency with community goals; sufficient business and industrial operations; human scale and values; compatibility with natural environment; achieving and sustaining highest land values.

The standards for NAIP consist of those for: paved streets, adequate utility systems for multiple industrial users, setback or percentage coverage requirements, landscaping, offstreet parking, and architectural control through approval of appearance, siting, building materials, and signs.

\section{NATIONAL ASSOCIATION OF METAL NAME PLATE MANUFACTURERS, INC., 1000 Vermont Avenue NW., Washington, D.C. 20005}

This association, originally known as the Metal Etching and Fabricating Association, was incorporated in July 1951 as a nonprofit organization. The name was changed to National Association of Metal Name Plate Manufacturers, Inc., (NAME) in 1968. The term "name plate" refers to any metal plate that has been etched, embossed, stamped, engraved or imprinted and which is fastened to another object for purposes of identification, instruction, or decoration. NAME's membership accounts for approximately twothirds of the total business volume of the name plate manufacturing industry in the United States.

Standards represent a relatively small but highly significant portion of the association's activities. In 1969 NAME published Metal Name Plate Industry Standards and Practices. This book is the only set of standards in existence for the industry in the U.S. Among the subject areas covered by NAME stand. ards are: nomenclature, finishes, fabrication tolerances, materials, fastening methods, inspection, reject procedure, delivery, and equipment preparation. Copies have been distributed throughout the industry and to customers of the industry in both private and public sectors for their information and use in writing specifications. Although no formal international standards exist, numerous copies of NAME's standards and practices book have been sent on request to overseas companies. The Book of Standards Committee of NAME's Board of Directors is responsible for compiling and coordinating changes to Metal Name Plate Industry Standards and Practices.

\section{NATIONAL ASSOCIATION OF MOTOR BUS OWNERS, \\ 1025 Connecticut Avenue NW., W ashington, D.C. 20036}

The association, founded in 1926, is the national trade association for the intercity motor bus industry with membership of some 450 bus operating companies, 21 state and regional bus associations, and about 75 bus manufacturers, suppliers, and others with an interest in bus transportation. Although the association has issued no standards of its own, it is actively concerned in the development of standards and requirements in matters affecting motor carrier and motor vehicle safety and occupational safety and health. Included are operation, maintenance, and inspection of vehicles, safety-related parts and accessories such as brakes, tires, lights, windows, seats, etc., control of noise and pollutant emissions, and accident 
reporting. Such activities involve both active cooperation with Government agencies involved, particularly those in the U.S. Department of Transportation, and participation in the work of voluntary groups, such as those sponsored by the American National Standards Institute. In connection with standardization of vehicle sizes and weights, the association works primarily with Federal and state legislative groups.

Similarily, the association works with the Interstate Commerce Commission and other interested Government agencies, and industry groups in connection with standards and requirements relative to such matters as accounting, reporting of financial and operating data, certification of operating authorities, and vehicle registration.

Association committees and staff representatives are primarily responsible for its standardization activities. Included are committees on (1) Safety, (2) Vehicle Safety Standards, (3) Maintenance and Inspection, and (4) Accounting.

Formerly: Motor Bus Division of American Automobile Association; National Motor Bus Division of American Automobile Association; National Association of Motor Bus Operators (1960).

\section{NATIONAL ASSOCIATION OF PIPE COATING APPLICATORS, 2504 Flournoy-Lucas Roarl, Shreveport, Louisiana 71108}

On October 22, 1964 fourteen men assembled in New Orleans, Lousiana to discuss action to be taken for the betterment of the plant pipe coating industry. From this meeting, the association which has come to be known as NAPCA, was formed.

The National Association of Pipe Coating Applicators seeks to: promote the general welfare of the plant pipe coating application industry; stimulate the use of plant applied pipe coating and related materials; standardize and improve specifications and materials; aid consumers and manufacturers in their coating material research; cooperate with other industries and organizations; disseminate information to the members of the plant applied pipe coating application industry, its customers and the public.

NAPCA has issued 19 standards, specification and suggested procedures (recommended practices) for the industry; these are published under the series title NAPCA Bulletins, and have the cover title of National Association of Pipe Coating Applicators Specifications and Plant Coatings Guide.

NAPCA further encourages high standards of workmanship and business ethics in this industry.

\section{NATIONAL ASSOCIATION OF PLASTIC FABRICATORS, 4.720 Montgomery Lane, Washington, D.C. 20014}

This association (NAPF), founded in 1956, is composed of suppliers of materials and machinery and manufacturers of decorative plastic laminated prod. ucts for residential and commercial uses. The association has published Quality Specifications QS 1-1965 which detail the manufacturing requirements for countertops, work surfaces, wall paneling, partitions and cabinet doors made of decorative plastic laminate. Product Standards A-1-70, A-2-71, and C-1-70 supersede some sections of QS 1-1965. A special panel of the Technical Committee is currently engaged in a program to develop performance standards that are related to the products end use. These will supersede the existing prescription type standards.

The development of performance standards is viewed as a prelude to the introduction of an industry certification program. The NAPF is national in scope and its standards are distributed to Federal agencies, architects, builders, trade journals, standards publications, and to all allied industries.

The association's membership is international. In addition to individual companies, the Laminated Plastic Fabricators' Association of England, and the Laminated Plastic Fabricators' Association of New Zealand are extended memberships. Technical information and fabricating technological data is exchanged regularly.

\section{NATIONAL ASSOCIATION OF PLUMBING-HEATING-COOLING CONTRACTORS, 1016 20th Street NW., Washington, D.C. 20036}

National Association of Plumbing-Heating-Cooling Contractors (NAPHCC) was founded June 29, 1883. The objects and purposes of the association are: for the advancement and encouragement of better methods and practices in the fields of plumbing, hydronic heating, and hydronic cooling; for the advancement of sanitation and sanitary laws and for the advancement of techniques in air-conditioning-be it heating or cooling-leading to better protection of the health and welfare of the public; for the improvement of plumbing appliances and fixtures and of heating and cooling equipment and parts; for the education of the members of the industry in the arts of plumbing, hydronic heating and hydronic cooling and the best method of conducting such business; for the establishment of harmonious and equitable relations between contractors, journeymen, and other employ. ees and between manufacturers and jobbers in supplies used in the plumbing, heating, cooling, gas-fitting and drainage business; for the education of the apprentice in the arts of plumbing, hydronic heating, and hydronic cooling and the establishment of a continuing apprenticeship system.

The Technical Committee administers the standardization activities of the organization. In recent years, NAPHCC became involved with the Federal Government concerning the Department of Health, Education and Welfare's (HUD) acceptance of the National Standard Plumbing Code which was developed and published by NAPHCC and is now cosponsored by 
the American Society of Plumbing Engineers. HUD approved the code in early 1973.

Formerly: National Association of Master Plumbers (1883); and National Association of PlumbingHeating-Cooling Contractors (1962).

\section{NATIONAL ASSOCIATION OF PURCHASING MANAGEMENT, INC., 11 Park Place, New York, New York 10007}

This association (NAPM), has approximately 115 affiliated local purchasing associations in this country, representing 18,000 purchasing officials, both public and private. Representing a body of corporate consumers, including purchasing agents of industrial concerns, private and public utilities, and governmental and institutional buyers, this association takes an active part in standardization and simplification programs of value to its members.

In the early years of this association, it was extremely active in the formulation of national standards and simplified practices. While this association and its members are still vitally interested in standardization, the emphasis has shifted from formulation to promulgation of standards through company standardization programs.

The NAPM Professional Development Planning Committee has sponsored an educational program which, although it does not come strictly within the purview of standardization, does cover subjects which are either directly or indirectly related to the broad field of standardization and simplification. In an effort to advance further sound principles of purchasing and to elevate the purchasing profession, this committee's professional development program includes, among other things, the publication of a series of handbooks for the guidance and use of the entire membership of the association.

Formerly: National Association of Purchasing Agents (1968).

\section{NATIONAL ASSOCIATION OF RECYCLING INDUSTRIES, INC., 330 Madison Avenue, New York, New York 10017}

The National Association of Secondary Material Industries (NASMI) founded in 1913, represents the nation's recycling industries. Members of the association have as their prime functions the collection, processing, importing, exporting, smelting, refining, and the conversion of new raw materials from scrap metals, waste paper, and waste textiles along with and the manufacture of products from recycled materials.

The association is the source of four sets of standards which are internationally recognized and accepted. These are: NF-73, covering delivery and quality standards for trading in all nonferrous scrap metals, (copper, brass, nickel, stainless steel, aluminum, lead, tin, zinc, precious and exotic metals); PS-72, delivery and quality classifications for trading in paper stock; WS-63, for wool stock; and CS-65, covering the trade in cotton and synthetic fibers. These standards and classifications are under continuous review by standing committees in each of the association's commodity divisions: the Metal Dealers Division, Secondary Metal Institute; Foreign Trade Division, Paper Stock Institute of America; Paper Stock Consumer Division and the Textile Division.

Formerly: National Association of Secondary Material Industries, Inc. National Association of Waste Material Dealers (1960).

\section{NATIONAL ASSOCIATION OF RELAY MANUFACTURERS, P.O. Box 1649, Scottsdale, Arizona 85252}

The National Association of Relay Manufacturers (NARM) was founded in 1947. The purpose of NARM is to promote the standardization of terminology and test procedures in the manufacture and use of relays. To implement this purpose, the association has standing committees which coordinate the activities of NARM members with relay users and Government agencies in establishing specifications for relays.

In April of each year NARM cosponsors a National Relay Conference at Oklahoma State University. The purpose is to provide engineers and specialists concerned with relays, the opportunity to present results of their technical investigations to representatives of prominent relay manufacturers and users and to those persons affiliated with institutions of higher learning who are interested in this area.

NARM has sponsored the publication, Engineers' Relay Handbook which contains the material of previously published specifications relating to terminology and test procedures. It is an all-encompassing engineering reference source covering all relays from electromechanical to hybrid and solid state. NARM also publishes the booklet, Definitions of Relay Terms.

NARM cooperates with other organizations such as Electronic Industries Association (EIA) and is presently engaged in writing standards for reed switches, solid state relays and mercury displacement relays. Other specifications developed by NARM are primarily for relay manufacturers, such as specifications for low carbon and silicon steels, and EMI iron for use in magnetic circuits for relays.

\section{NATIONAL ASSOCIATION OF WIPING CLOTH MANUFACTURERS, 189 West Madison Street, Chicago, Illinois 60602}

This association (NAWCM) was established in April 1932 and contains 175 members. This organization has adopted specifications for the sale of wiping cloths which cover the process of sterilization and 
grading. In addition, it also has adopted an official label, the presence of which on a bale or carton of industrial wipers represents a guarantee that the contents of the bale or carton conform to the specifications. The wording of the label reads as follows: "The wiping cloths contained in this bale or package have been produced and packed according to specifications of the National Association of Wiping Cloth Manufacturers." Each member of the association issues an affidavit certifying that he, as a manufacturer of the particular bale or package of wiping cloths, has complied with all rules and regulations of the state and city health departments. The manufacturer also certifies that the wipers contained in a given shipment are correct in weight, and that he has complied with all of the recommendations promulgated by NAWCM.

Concerning enforcement of specifications, labels and affidavits, the association relies chiefly upon the integrity of its members, each of whom pledges himself to comply with association standards in the sale of any bale or carton of wiping cloths carrying or accompanied by the association label or affidavit. A Complaints Committee investigates any alleged failure to conform. Violation of the pledge is punishable by expulsion from the association, with attendant loss of the privilege of using the association label and affidavit. During recent years several committees of the association have cooperated with technical committees of the Navy Department and General Services Administration in preparation of specifications for purchase of wiping cloths for Federal agencies.

Formerly: Sanitary Institute of America.

\section{NATIONAL ASSOCIATION ON STANDARD MEDICAL VOCABULARY, 2802 Mermaid Avenue, Brooklyn, New York 11224}

The National Association on Standard Medical Vocabulary is a nonprofit organization for the betterment of the medical and allied terminologies. It was founded by Jakob Edward Schmidt, grammatolatorphilologist-author of Charlestown, Indiana in 1960. The organization has grown to include over 7,000 educators, scientists and philosophers and is totally dedicated to the standardization of modern American medical vocabulary. Assistance is given to the editors and publishers of directories, dictionaries, and compendia dealing with medical terminology.

\section{NATIONAL AUDIO-VISUAL ASSOCIATION, INC., 3150 Spring Street, Fairfax, Virginia 22030}

The National Audio-Visual Association, Inc. (NAVA), founded in 1939, is the national trade association of the commercial audio-visual industry including nonbroadcast television. The membership consists of dealers selling A.V equipment and mate- rials, film rental libraries, manufacturers of A-V equipment, producers of films and other A.V materials, publishers, independent manufacturers' representatives and $\mathrm{A} \cdot \mathrm{V}$ professional services members. In addition, the association has a substantial number of associate members who are interested in audio-visuals but are not commercially connected with the A-V industry.

NAVA is a cosponsor of PH7, Instructional Audio. Visual System Standards, of the Photographic Standards Board of the American National Standards Institute. For the past several years the association has worked exclusively with this committee in standards making activities, under the guidance and direction of the association's Technical Standards Committee.

The association has no standards of its own at the present. Work will begin soon on the standardization of lapse time counters on audio cassette recorders.

Formerly: National Association of Visual Educa. tion Dealers (1947).

\section{NATIONAL AUTOMATIC MERCHANDISING ASSOCIATION, \\ 7 South Dearborn Street, Chicago, Illinois 60603}

This is the national trade association representing vending and foodservice management companies, vending machine manufacturers and the suppliers of vendible products and component parts. NAMA was founded in 1936.

NAMA has sponsored since 1957, an Automatic Merchandising Health-Industry Council whose mem. bers and observers represent the U. S. Public Health Service, Armed Forces, national public health associations, university public health consultants and members of the vending/foodservice management industry.

The Health-Industry Council develops and recommends to NAMA standards for the evaluation and certification of vending machines, certification program controls, research projects and educational materials.

Two standards developed by the council are used by public health consultants retained by NAMA at Michigan State University and Indiana University, to evaluate and certify vending machines. They are the NAMA Vending Machine Evaluation Manual and the NAMA Standard for Coin-Operated Special Dispensers.

The standards contain all machine design and construction requirements of the U.S. Public Health Service's Vending of Food and Beverages (1957, amended 1965) together with additional sanitary and safety requirements recommended by the HealthIndustry Council.

The NAMA standards and certification activities are recognized nationally by public health and military agencies and are cited in a number of Federal and local vending sanitation regulations.

NAMA publishes listings of certified vending machines, administrative controls, research studies and educational materials which concern public health and safety. 


\section{NATIONAL AUTOMATIC SPRINKLER AND FIRE CONTROL ASSOCIATION, 277 Park Avenue, New York, New York 10017}

The primary objective of this association (NAS and FCA), is the advancement of the art of automatic control of fire through automatic sprinklers, and the conservation of life and property from fire. This organization is a national trade association of automatic sprinkler manufacturers and installers. It was founded in 1914.

The association cooperates with national technical bodies in the preparation of standards and fire protection sections of building codes and ordinances. It has 64 representatives on 54 important National Fire Protection Association committees. These committees set standards for design, installation, inspection, and maintenance of automatic sprinklers. The association cooperates in the desion, installation and maintenance of standpipes and hose systems and of private underground systems supplying water for fire extinguishment, including the character and adequacy of water supplies and the selection, installation, and maintenance of valves, hydrants, monitor nozzles, hose and accessory equipments, as well as the supervision of valves controlling water supply for fire protection.

The association concerns itself with the design and construction of hose houses and fire department procedure in fighting fires in buildings equipped with automatic sprinklers. In this respect, it publishes regular editions of a News Bulletin and an internal Industry Bulletin. To further that end, the association engages in a program of lectures to state fire schools and fire chiefs' associations.

It cooperates with the American Insurance Association, Insurance Services Office, Underwriters' Laboratories (UL), and Factory Mutual Engineering and Research relative to the formulation of standards, specifications and regulations for fire apparatus and their use.

The association is officially represented on sectional committees functioning under the procedure of the American National Standards Institute (ANSI) engaged in the development and revision of the following subjects: code for pressure piping, pipe threads, and pipe flanges and fittings.

The NAS and FCA is a member of the Southern Building Code Congress, the International Conference of Building Officials and Code Administrators International. One of the objectives of the association is to maintain consistency between codes and standards and coordinate the industry's activities in the model code field with those in the standard making bodies, including National Fire Protection Association, American Society for Testing and Materials, American National Standards Institute, Underwriters' Laboratories, Factory Mutual System and other standard making organizations, which from time-to-time, affect the automatic sprinkler industry.
NATIONAL AUTOMOBILE THEFT BUREAU, 30 East 42nd Street, New York, New York 10017

This bureau, founded in 1912, is a service organization supported by more than 4.50 insurance companies, writing automobile fire and theft insurance. Although its primary purpose is to locate stolen cars, it is also a leader in the promotion of auto theft prevention activities. The bureau, designated by the International Association of Chiefs of Police as its clearing house on automobile theft information, maintains a nationwide stolen vehicle file. This information is made available on a 24 hour a day, 7 days a week basis to law enforcement agencies by teletype, telephone, message switching and direct entry into regional law enforcement banks.

The bureau cooperates with all automobile manufacturers in the adoption of a standard vehicle identification number as well as in a standard method of stamping and affixing such numbers.

In addition, it prints and distributes to law enforcement agencies a Motor Vehicle Identification Manual, a Commercial Vehicle Identification Manual, and Manual for the Investigation of Automobile Fires.

The services of the bureau are for the benefit, not only of insurance companies and law enforcement agencies, but of the entire motoring public.

\section{NATIONAL BOARD OF BOILER AND PRESSURE VESSEL INSPECTORS, 1155 North High Street, Columbus, Ohio $\mathbf{4 3 2 0 1}$}

The board, founded in 1919, confines its membership to persons charged with enforcement of the boiler and pressure vessel laws in various states, municipalities in the United States with over 1,000,000 population, and the Canadian provinces. The board operates in the following areas of standardization: (a) boiler and pressure vessel law enforcement; (b) uniform boiler laws and rules throughout the jurisdiction of its members; (c) uniform qualifications for boiler and pressure vessel inspectors, including identical examinations conducted simultaneously throughout the United States and Canada; (d) uniform stamping of boilers and pressure vessels that are inspected during construction by such boiler and pressure inspectors who hold valid National Board commissions; and (e) uniform relieving capacity ratings of safety valves and pressure relief valves for boiler and unfired pressure vessel service.

All states, municipalities and Canadian provinces that have boiler and pressure vessel laws, recognize the National Board inspector's commission and National Board stamping on boilers and pressure vessels as meeting their safety law requirements for new construction. Transfer of such objects between states is implemented by National Board stamping. Relieving capacities of safety valves and pressure relief 
valves as certified by the National Board of Boiler and Pressure Vessel Inspectors, is used by the various state, municipal and provincial jurisdictions to determine adequate volumetric relicf of the pressurized medium in event of runaway conditions.

When requested by the States, Canadian Provinces, or the ASME Boiler and Pressure Vessel Committee, the board makes shop surveys, reviews, evaluates, audits, investigates and makes unannounced shop visits.

The National Board publications are: National Board Inspection Code, 1971; National Board Boiler Blowoff Equipment, 1968; Relieving Capacities of Safety Valves and Relief Valves, 1970; and the National Board Information Booklet.

The board works with the American Society of Mechanical Engineers, Boiler and Pressure Vessel Code; the U.S. Department of Labor, Occupational Safety and Health Administration (OSHA); the U.S. Coast Guard and the Atomic Energy Commission (AEC) in the development of safety standards, codes and uniform safety inspections.

\section{NATIONAL BUILDERS' HARDWARE ASSOCIATION, 1815 North Fort Myer Drive, Rosslyn, Virginia 22209}

This association, founded in 1934, serves the interests of 500 builders' hardware and/or door distributors in the United States and Canada and selected overseas locations. One of its active programs is the promotion of standardization of hardware locations and installation. Twelve location standards have been promulgated through the American National Standards Institute and numbered American National Standards A115.1 through A115.12.

As the only national trade association for builders' hardware and/or the door distribution industry, the scope of standards is national.

Standards are promoted through Doors and Hardware, the industry trade journal (circulation 10,000) and through voluntary self-compliance among industry manufacturers and distributors. New standards, including locations for tubular deadlocks, are in process.

Formerly: National Contract Hardward Association (1954).

\section{NATIONAL CABLE TELEVISION ASSOCIATION, INC. 918 Sixteenth Street NW. W ashington, D.C. 20006}

The National Cable Television Association (NCTA) has since 1952, represented the increasingly complex interests of the growing cable television industry before Congress and Federal agencies, in courts of law, and before state regulatory agencies in dialogues with other industries and groups. Through the news media we have successfully conveyed the industry's message to the general public.
Our greatest service to members and to industry is in the strength of our unified voice.

The Engineering Department administers NCTA's standardization activities. Current standards issued by NCTA are our NCTA Engineering Standards which cover the areas of Visual Carrier Level, Amplifier Distortion, Graphic Symbols, the Standards Numbering System, and Norse Level in Cable Systems. The active standards committees and new projects are: C-TAC (Cable Television Advisory Committee); EIA/CTSC (Cable Television Systems Communications) ; NEC (National Electric Code); and the JCIC (Joint Committee on Inter-Society Coordination). We promote the use of our standards through our Bulletin, Expos, and training centers. Internationally, NCTA participates in subcommittees of the International Electrotechnical Commission, and with the Government, is involved with the Federal Communications Commission.

Formerly: National Community Television Association (1969).

\section{NA'TIONAL CANNERS' ASSOCIATION, 113320 th Street NW. Washington, D.C. 20036}

NCA was founded in 1907, by commercial packers of food products in hermetically sealed containers, sterilized by heat.

This organization maintains a liaison with the National Conference on Weights and Measures for the purpose of developing constructive and uniform laws and regulations on the state level. In addition, to develop improvements in the products, processes, quality control measures, spoilage prevention and sanitation techniques used in the canning industry, the association maintains research laboratories in Berkeley, California; Seattle, Washington; and Washington, D.C.

NCA is an active participant in a program of developing an international standard of food cans. This activity is under the auspices of the International Organization for Standardization (ISO) with the secretariat residing in the British Standards Institution. The American National Standards Institute (ANSI) has designated NCA as the delegate to the ISO Technical Committee, ISO/TC 52-Hermetically Sealed Food Containers.

Formed by merger of: Atlantic State Canners' Association and the Western Packers' Association (1907).

\section{NATIONAL CARGO BUREAU, INC., One World Trade Center, New York, New York 10048}

National Cargo Bureau, Inc. (NCB) was founded in 1952. It is dedicated to the safe loading, stowing, securing and unloading of cargo and cargo containers on all vessels, and for the design, strength, safety and suitability of cargo handling gear and cargo containers, including the security and integrity of containers. 
The bureau is a nonprofit organization whose membership is comprised mainly of persons who are promi. nently identified with steamship management or marine insurance underwriting organizations.

Internationally, the bureau participates in activities of the Intergovernmental Maritime Consultative Organization (IMCO) by being active on the IMCO Maritime Safety Committee, the Subcommittee on Containers and Cargoes (formerly the Bulk Cargoes Subcommittee) and the Subcommittee on the Carriage of Dangerous Goods. This subcommittee recently completed its work in revising the international regulations for the carriage of bulk grain.

NCB is authorized to assist the U.S. Coast Guard in administering the provisions of the Dangerous Cargo Act and the applicable regulations in Title 46, of the Code of Federal Regulations, Shipping, with respect to: inspection of vessels for suitability for loading dangerous cargo; examination of stowage of dangerous cargo; making recommendations as to stowage requirements of dangerous cargo; and issuance of certificate of loading setting forth that the stowage of dangerous cargo is in accordance with the regulations.

The bureau is also authorized by the U.S. Coast Guard to certify the loading of bulk grain cargoes and to approve grain loading plans in accordance with current regulations. The bureau is officially recognized by the Coast Guard and the Department of Labor as a cargo gear certification agency. National Cargo Bureau is national in scope and has offices in all principal seaports in the United States.

Absorbed: Bureau of Inspection of Board of Underwriters of New York; Board of Marine Underwriters of San Francisco (1952).

\section{NATIONAL CLAY PIPE INSTITUTE, 350 West Terra Cotta Avenue, Crystal Lake, Illinois 60014}

The National Clay Pipe Institute (NCPI) is a national nonprofit organization incorporated in 1944. The association members are vitrified clay pipe manufacturers throughout the United States, as well as associate member companies in several foreign countries. The NCPI renders engineering advisory services to design engineers, Government officials and others. It conducts scientific research, national advertising and public relations programs on behalf of the indus. try. The institute maintains a research laboratory located at Crystal Lake, Illinois. Research programs are occasionally conducted at various independent research laboratories and universities.

The institute publishes a textbook Clay Pipe Engineering Manual for engineers, city and state officials and architects. Also, the institute publishes various additional technical brochures of an educational nature relating to the use of vitrified clay pipe in sanitary sewer systems. The institute also produces colored $16 \mathrm{~mm}$ films showing the details of clay pipe manufacturing, recommended methods of sewer construction and related subjects. These films are available for industry and public use.
NCPI is active in the American Society for Testing and Materials, the American National Standards Institute and the American Association of State Highway Officials. It also assists in the development of Federal specifications.

Formerly: National Clay Pipe Manufacturers.

\section{THE NATIONAL CLAY POT MANUFACTURERS, P.O. Box 384. Jackson, Missouri 63755}

The National Clay Pot Manufacturers, Incorporated, was established in 1956 to "act to stimulate professional and public interest in the uses and advan. tages of clay flower pots and in the modern techniques employed in their manufacture and productuion." The organization was incorporated as a Missouri not-forprofit corporation. One of the activities of the organization is the standardization of sizes and shapes of clay flower pots manufactured in the United States. Being a small organization, the group acts as a committee of the whole to effect standardization of sizes and shapes of clay flower pots manufactured in this country. The activities of the association have resulted in greater standards than have ever been known by the manufacturers of red clay flower pots.

\section{NATIONAL COMMITTEE ON UNIFORM TRAFFIC LAWS AND ORDINANCES, 1776 Massachusetts Avenue NW, Suite 430, \\ W ashington, D.C. 20036}

The committee, established in 1926, maintains the Uniform Vehicle Code and Model Traffic Ordinance as standards for quality and uniformity among state and local motor vehicle and traffic laws. It also publishes documents showing differences among state laws and encourages adoption of these standards. In areas of emerging or experimental interest, the committee prepares model state laws.

The National Committee cooperates in efforts to achieve international agreement of traffic laws and is involved with the U.S. Department of Transportation's highway safety program.

Organized in 1947 to continue work begun in 1925 , the committee has over 130 members including legislators, police officers, traffic engineers, highway officials, motor vehicle administrators, governors' highway safety representatives, judges, prosecutors, city attorneys, educators, physicians, mayors, county officials and attorneys general, insurance companies, motor clubs, safety councils, manufacturers, dealers, trade associations, unions, national transportation associations and other individuals and groups inter. ested in achieving sound, uniform motor vehicle laws and regulations.

Formerly: National Conference on Street and Highway Safety (1947). 
NATIONAL CONCRETE MASONRY

ASSOCIATION,

1800 North Kent Street,

P.O. Box 9185,

Rosslyn Station,

Arlington, Virginia 22209

The National Concrete Masonry Association, established in 1920 , is a nonprofit trade association representing concrete masonry manufacturers throughout the United States, Canada and 21 other countries. Its functions are to encourage the development of the art and science of manufacturing concrete masonry, to create a standard of excellence in manufacture, to develop criteria for the proper use of concrete masonry products, to encourage such use, and facilitate the acquirement and interchange of practical knowledge among its members and related industries and organizations.

The standardization activities of the association are developed by the Technical and Specifications Review Committees and are subject to approval by the Board of Directors. In addition, the association maintains continuing liaison and participation in the standardization and specification activities of the major national code bodies in the U.S., the American Society for Testing and Materials and the American Concrete Institute. Liaison and product specification assistance is also conducted on a regular basis with agencies of the Federal Government including the National Bureau of Standards, Departments of Housing and Urban Development, Defense, Commerce, Agriculture, Health, Education and Welfare, and with the Corps of Engineers, Veterans Administration, General Services Administration, National Aeronautics and Space Administration and the Federal Aviation Administration.

The National Concrete Masonry Association is the only national organization representing the interests of the concrete masonry industry.

Absorbed: Autoclave Building Products Association.

\section{NATIONAL COTTONSEED PRODUCTS ASSOCIATION, 2400 Poplar Avenue, P.O. Box 12023, \\ Memphis, Tennessee 38112}

This association maintains, for members, trading rules which contain standards of quality, weight and measurement of all cottonseed products, and general terms and conditions applicable to buyers and sellers who are association members, both domestic and foreign. In addition to defining product grade and quality, the association's rules provide for adjustments, packaging, performance of contracts, weighing, sampling and inspection service, chemical analysis and arbitration of differences.

The association has a chemists' committee composed of qualified oil chemists, which must approve methods of chemical analysis before they are incorporated into the trading rules. A committee on seed grading cooperates with the U. S. Department of Agriculture in providing methods for the evaluations of cottonseed.

The research committee regularly reviews research on cottonseed and cottonseed products and recommends lines of work for support by the association; a research fellowship is maintained at the New Orleans Laboratory of the Agriculture Research Service and grants are made to several universities and other research agencies.

The association works with the Association of American Feed Control Officials to standardize regulations governing the labeling and marketing of cottonseed cake and meal.

Trading rules activity may involve as much as ten percent of the association's program of work. A Trading Rules book is published annually. The trading rules also cover sunflower seed and peanut oil at the refining level. Special rules are used in exports of cottonseed oil. No other international standard activity is undertaken.

The association certifies official chemists, weighers and inspectors.

The scope of activities for the members of this association covers may common problem areas such as transportation, insurance, product promotion and raw material development.

Members of all committees are included in the Rules book. Copies may be obtained from the association for a nominal charge.

Founded in 1897 as the Interstate Cottonseed Crushers' Association, the organization was reorganized and adopted its present name in 1929.

\section{NATIONAL CRUSHED STONE ASSOCIATION, 1415 Elliot Place NW., Washington, D.C. 20007}

This association cooperates with national technical organizations in standardizing specifications, methods of test, and recommended practices involving the use of crushed stone. It is represented on technical committees of the American Society for Testing and Materials dealing with concrete and concrete aggregates, road and paving materials, and mortars for unit masonry. The association actively participates in the technical committee work primarily concerned with the development of recommended practices of the American Concrete Institute, the American Railway Engineering Association, and the Highway Research Board of the National Research Council.

Through a joint committee composed of representatives of the National Sand and Gravel Association, the National Slag Association, and this association, a simplification program was initiated under the auspices of the National Bureau of Standards which resulted in the establishment of Simplified Practice Recommendations R147-42 (withdrawn 10-23-72), on wire diameters for mineral aggregate production screens and R163-48 on coarse aggregate (crushed stone, gravel, and slag) sizes. In continuation of the cooperative 
effort of the three mineral aggregates associations, a Joint Technical Committee of representatives of the technical staffs of these associations has been formed for the purpose of coordinating and combining the technical work on problems of mutual interest.

\section{THE NATIONAL EASTER SEAL SOCIETY FOR CRIPPLED CHILDREN AND ADULTS, 2023 West Ogden Avenue, Chicago, Illinois 60612}

The National Easter Seal Society, founded in 1956, is a federation of separately incorporated affiliates united in a common cause: serving the needs of America's handicapped. Together, this network of 2,000 state and local affiliates, chapters and committees in all States, Puerto Rico and Washington, D.C., has achieved worldwide recognition as the oldest and largest voluntary agency providing services to handicapped children and adults. These services relate to the individual as well as the environment in which the handicapped person functions.

The National Easter Seal Society, in cooperation with the President's Committee on Employment of the Physically Handicapped, works toward the elimination of architectural barriers across the nation by: (1) increasing public awareness of the opportunities denied the handicapped for participation in community life because of architectural barriers; (2) stimulating community action to provide accessibility in public buildings, transportation and housing to the disabled; and (3) assuring the elimination of architectural barriers by influencing legislation, building codes and regulations.

As pioneers in a movement to make the United States a more humane society, the National Easter Seal Society for Crippled Children and Adults, in the late 1950's, initiated the establishment of the Steering Committee to develop standards for accessibility for the handicapped. Representatives of more than 50 organizations concerned with design and building construction were brought together for the purpose of determining such standards. Today, the committee's end product, the American National Standard Specifications for Making Buildings and Facilities Accessible to, and Usable by, the Physically Handicapped, is the basis for Public Law $90-480$ and its counterpart in 48 states as well as for the building codes adopted by numerous municipalities across the country.

The National Easter Seal Society through its liaison with the American Institute of Architects, channels information to the American National Standards Institute (ANSI) for continuous review of standards (American National Standard Al17-1961 R1971). Also, in cooperation with the President's Committee on Employment of the Handicapped, the Easter Seal Society, the U. S. Department of Housing and Urban Affairs and the U. S. Department of Transportation, the Easter Seal Society promotes the development of standards in housing and transportation to assure accessibility for the handicapped population of the United States.
Formerly: National Society for Crippled Children and Adults (1967).

\section{NATIONAL EDUCATION ASSOCIATION, 1201 16th Street NW., Washington, D.C. 20036}

The National Education Association (NEA) of the United States, a private, nonprofit, nongovernmental organization, was founded August 26, 1857 under the name The National Teachers' Association. The name was changed to the National Education Association of the United States on November 6, 1886. NEA is a professional organization of approximately 1.4 million educators; 52 state-level and 9000 local associations are affiliates.

The purpose of NEA is to elevate the character and advance the interests of the profession of teaching and to promote the cause of popular education in the United States.

Approximately 7 percent of the total program is devoted to standardization activities. The basic aim of NEA is professional excellence. This goal is to develop principles and procedures that lead to the improvement of instruction, professional development, and self-governance for the profession and for teachers.

NEA is a member of the World Confederation of Organizations of the Teaching Profession.

\section{NATIONAL ELECTRICAL CONTRACTORS' ASSOCIATION, 7315 Wisconsin Avenue, Washington, D.C. 20014}

The Nationai Electrical Contractors' Association (NECA) which was founded in 1901, is the nationwide trade association representing the electrical contracting industry. Standards activities are under the guidance of the association's Codes and Standards Committee.

The National Electrical Code is a stabilizing force in the electrical construction industry. It sets the basic standards for electrical equipment and materials and the methods of their installation. One of the first projects of NECA after its formation in 1901 was to secure the electrical contractors right to a voice in the formulating of the electrical code rules. Today, more than 70 years later, electrical contractors, through NECA, have representation on the Correlating Committee and all of the code making panels of the National Electrical Code Committee which is responsible for the development, revision and promotion of the National Electrical Code. NECA also represents electrical contractors on the group responsible for the development of the National Electrical Safety Code, which is concerned with outside construction.

The development of electrical material and equipment standards and their inspection and approval are of important concern to electrical contractors. Electrical contractors are represented on related committees of the American National Standards Institute through NECA representation on such committees. 
Adequate and clear electrical specifications and drawings facilitate both the estimating and installation of electrical installations. Through NECA participation on related American National Standards Committees and in the activities of other associations such as the Construction Specifications Institute, the electrical contractor's views are represented.

The promotion of better wiring standards requires technical standards whether the application is residential, commercial or industrial. Developing standards of adequacy is the function of the NECA Technical Service which maintains competent representation on interindustry and other standards agencies. A NECA Standard of Installation which defines good workmanship has been developed for inclusion in specifications for electrical installations. It is also used as an authoritative guide to determine the "neat and workmanlike manner" requirements of the National Electrical Code.

The prevention and reduction of accidents to electrical workers has always been important to electrical contractors. The recent Federal legislation on occupational safety and health has made it a necessity. NECA provides continuing information to its members on OSHA requirements and developments and represents the electrical contractors' viewpoints to the Federal Agencies.

\section{NATIONAL ELECTRICAL MANUFACTURERS' ASSOCIATION, 155 East 44th Street, New York, New York 10017}

This is a trade association of manufacturers of almost every kind of equipment and apparatus used for the generation, transmission, distribution and utilization of electric power. The membership of NEMA comprises over 500 of the major electrical manufacturing companies in the country. The membership is limited by its constitution to corporations, firms and individuals actively engaged in the manufacture for sale in the open market of products included with the product scope of one or more of the 80 NEMA product subdivisions. It may therefore be considered an aggregation of product sections, each representing a group of manufacturers of certain classes of products, such as motors and generators, steam turbines, transformers, wire and cable, switchgear, industrial control, and building equipment products. Sections with related interests are organized into seven divisions.

NEMA has published over 200 separate standards publications for electrical apparatus and equipment in the following classifications: illuminating equipment, signalling and communication equipment, industrial apparatus, building equipment and supplies, insulating materials, insulated wire and cable, generation, transmission and distribution equipment.

A considerable amount of NEMA standardization activity is in cooperation with other organizations engaged in standardization. Standards of interest to NEMA are developed in cooperation with other industries or other branches of the electrical industry, through such agencies as the American Society for Testing and Materials, Edison Electric Institute, National Fire Protection Association, Underwriters' Laboratories, the Institute of Electrical and Electronics Engineers, and other associations, laboratories or Government bodies.

Many electrical product standards originating within NEMA or initiated by other organizations are of such national significance as to make desirable their adoption as American National Standards under the procedure established by the American National Standards Institute (ANSI) which provides participation by and consideration of the views of all interested groups. NEMA supports ANSI through participation in its standardizing activities. It has representation on many standards committees and sponsors several of them. It addition, it is represented on ANSI Technical Advisory Board and the Organizational Member Council.

NEMA participates in the International Electrotechnical Commission (IEC), the international body for the development and approval of recommendations for electrical standards, by means of representation on the U.S. National Committee of the IEC; by its representatives on the American National Standards Committees which act as advisory groups to the U.S. National Committee on the technical provisions of IEC proposals; and by the presence of its representatives at meetings of IEC Technical Committees. Through the U.S. National Committee on Participation in the International Commission on Rules for the Approval of Electrical Equipment (CEE), NEMA provides an observer to the CEE, a European safety organization.

In addition to products standards, NEMA is vitally concerned with and participates in the development of safety standards affecting electrical equipment. There are two principal codes dealing with electrical safety: the National Electrical Code (American National Standard Cl) developed by the National Fire Protection Association and dealing with installations in and around buildings, and the National Electrical Safety Code (American National Standard C2) sponsored by the National Bureau of Standards and dealing with power houses, substations, overhead and underground lines. NEMA cooperates with other branches of the industry in an effort to secure acceptance throughout the country of nationally recognized standards for safe construction and installation. Its members also cooperate in an advisory capacity with the Underwriters' Laboratories in the development of standards for electrical safety.

NEMA, upon invitation, furnishes the military and other governmental standardizing bodies information and recommendations for use in the preparation of their initial drafts or revisions of various Federal and military specifications affecting products within its scope.

Formed by merger of: Electric Power Club; Associated Manufacturers of Electrical Supplies. 


\section{NATIONAL ELEVATOR INDUSTRY, INC., 600 Third Avenue, \\ New York, New York 10016}

The National Elevator Industry (NEII) was founded in 1934. Two committees of this organization are concerned with the development of standards and codes. The Standards Committee is concerned with the development of elevator engineering standards and the Central Code Committee is concerned with all phases of safety codes that pertain to elevators, dumbwaiters, escalators and moving walks.

The Standards Committee has formulated standard layouts for the industry. These layouts give standard car sizes and hoistway and machine room dimensions for various types of elevators.

The Central Code Committee is concerned with the preparations, interpretation, revision and adoption of all safety codes for elevators, dumbwaiters, escalators and moving walks. This committee, working through regional subcommittees throughout the country, takes an active part in securing the adoption of new state and city elevator safety codes, the revision of existing codes, and securing uniform interpretation of code rules conforming to the American National Standard A17.1 Safety Code for Elevators. Working in conjunction with the American Standards Association (ASA, and now the American National Standards InstituteANSI) A17 Sectional Committee, NEII assisted in the development and subsequent revision of ASA A17.1 American Standard Safety Code for Elevators, Dumb. waiters and Escalators and in its publication by the American Society of Mechanical Engineers in 1925 as an American Standard, and of the ASA Al7.2 American Standard Practice for the Inspection of Elevators first approved by ASA and published by ASME in 1945.

Formerly: National Elevator Manufacturing Industry $(1969)$.

\section{NATIONAL ENVIRONMENTAL HEALTH ASSOCIATION, 1600 Pennsylvania, Denver, Colorado 80203}

The National Environmental Health Association (NEHA), founded in 1937, is a nonprofit nongovernmental organization working toward raising educational employment and performance standards for the profession. Until 1969, it was known as the National Association of Sanitarians. It is composed of 47 state associations with a coordinating national office in Denver, Colorado. This office publishes the Journal of Environmental Health, a bimonthly, which is distributed to members, subscribers, and institutions, as well as to individuals in 57 countries. The association is very active in the field of education and has a National Accreditation Council which has developed an accreditation program for environmental health curricula in four-year colleges and universities. Similar guidelines and sample curricula have been set up for two-year programs. NEHA is also actively sponsoring a national registration program for sanitarians in conjunction with the Professional Examination Service of New York. The association is in the process of developing standards for a national certification program for food service owners and operators. This new program will include a textbeok, a self-inspection manual and a movie. Annually, the association sponsors an educational conference where members come to hear nationally recognized speakers and participate in the activities and reports of over 45 committees. Listings of committees and committee members can be found in the November/December issue of the Journal of Environmental Health.

\section{NATIONAL ENVIRONMENTAL SYSTEMS CONTRACTORS' ASSOCIATION, 1501 Wilson Boulevard, Arlington, Virginia 22209}

In 1968 the National Warm Air Heating and Air Conditioning Association merged with the Airconditioning and Refrigeration Contractors of America to form the National Environmental Systems Contractors' Association (NESCA).

The main purpose of NESCA is to provide impor. tant and useful services to firms, corporations or individuals who design, install, service or repair heating, air-conditioning, and refrigeration systems. A major function of this association is the development of standards for the desion and installation of warm air heating and air-conditioning systems. Standards are published in practical manual form. Many of the manuals have been adopted as standards of design and installation by the Federal Housing Administration. These manuals are regularly updated by a committee of contractors and engineer-representatives of manufacturers.

NESCA's Manpower Committee recently established, in conjunction with the Department of Labor, the National Apprenticeship Standards for Environmental Control Systems Craftsmen (Refrigeration and Air Conditioning Technician). The standards have been approved and registered by the Bureau of Apprenticeship and Training, Manpower Administration, U.S. Department of Labor. The standards are designed as a guideline for establishing local apprentice programs for the training of installation craftsmen for the heating and air-conditioning industry. This program is only available to contractors who are members of NESCA. As a point of information, NESCA's Manpower Committee works only in behalf of those contractors who operate within the merit shop or open shop segment of our industry. Thus, these standards pertain only to the merit shop contractors and in no way affect NESCA contractors who are signatory with any union. 


\section{NATIONAL FEDERATION OF LICENSED PRACTICAL NURSES, INC., 250 West 57th Street, New York, New York 10023}

The National Federation of Licensed Practical Nurses was founded in 1949 as a nonprofit corporation designed to: represent licensed practical nurses in the health field; establish policy and standards for practical nursing; develop and promote continuing education for licensed practical nurses; insure the public that good standards of nursing would be observed; and to cooperate with allied health groups in working to improve health care for the people.

The membership of the National Federation is composed of licensed practical nurses in 40 constituent state associations, and individual members in 10 states.

The Education Committee works cooperatively with the National Licensed Practical Nurses Education Foundation, the education and research arm of NFLPN, in developing guidelines for continuing education and serves as an information resource for licensed practical nurses and allied health groups.

The NFLPN supports the National League for Nursing (NLN) as the recognized agency for accreditation of practical nursing programs. NLN uses the NFLPN Statement of Functions and Qualifications of the Licensed Practical Nurse as one of the criteria for accreditation.

NFLPN works cooperatively with NLN and supports its efforts in the improvement of curriculum, development of faculty and research in practical nursing and development of practical nursing programs. NFLPN contributes to the development of standards for practical nursing through representation on the Steering Committee of the NLN.

\section{NATIONAL FEDERATION OF STATE HIGH SCHOOLS ASSOCIATIONS, 400 Leslie Street,} Elgin, Illinois 60120

The National Federation, which now represents over 22,000 high schools and nearly $10,000,000$ secondary school students, was organized in 1921 primarily to secure proper adherence to the eligibility rules of the various state high school associations during interstate competition. Definite standards for sanctioning domestic athletic events have been estab. lished and are enforced by the National Federation.

Playing rules are written by committees of secondary school personnel and are published and distributed by the National Federation for domestic competition in 14 interscholastic sports; for boys: baseball, basketball, football, gymnastics, soccer, swimming and diving, track and field, volleyball and wrestling; for girls: basketball, gymnastics, swimming and diving, track and field and volleyball. Sixty-six rules related publications are published by the National Federation (nearly all on an annual basis), including 26 rule books and 14 rule examinations.
Of primary concern in writing athletic rules for high school competition is adapting the playing rules to the abilities of secondary school athletes. Standards of safety are regularly scrutinized and revised for this purpose and are incorporated in the rule publications. In addition, the National Operating Committee for Safety in Athletic Equipment was formed in 1970 by the National Federation and other athletic organizations.

The various state high school associations which use the National Federation rule codes are responsible for their enforcement. The National Federation provides national interpretations of the rules.

Statements of general standards and policy are contained in the official handbook of the National Federation of State High School Associations. The current rule publication list is obtainable from the National Federation headquarters.

Formerly: National Federation of State High School Athletic Associations (1970).

\section{NATIONAL FIRE PROTECTION ASSOCIATION, 470 Atlantic Avenue, Boston, Massachusetts 02210}

This association is a nonprofit, technical and educational organization to promote the science and improve the methods of fire protection. Organized in 1896, the association now enjoys a membership which includes 180 national and regional organizations, and approximately 28,500 individuals, firms, and corporations.

One of the main functions of NFPA is in the standards making field under which codes, standards, and recommended practices are developed as guides to engineered protection for reducing loss of life and property by fire. The other principal function is to educate the public in fire prevention to reduce mancaused fires.

The standards activity is handled by 162 committees and sectional committees whose membership is comprised of approximately 2,100 individuals representing qualified international, national and regional organizations, NFPA sections or technical committees, and individuals especially qualified to serve on the basis of their personal knowledge of the subjects. In addition, committees may have liaison or advisory members, and corresponding members, the latter group being composed chiefly of individuals who live outside the North American continent who are in a position to assist in the committee work only through correspondence.

Fire safety has broad applications and the standards formulated and adopted by the association cover a wide range of subjects. The standards are combined and published yearly as National Fire Codes, the volumes of which are identified as follows: Volume 1, Flammable Liquids; Volume 2, Gases; Volume 3, Combustible Solids, Dusts and Explosives; Volume 4, Building Construction and Facilities; Volume 5, Elec- 
trical (including the National Electrical Code) ; Volume 6, Sprinklers, Fire Pumps and Water Tanks; Volume 7, Alarms and Special Extinguishing Systems; Volume 8, Portable and Manual Fire Control Equipment; Volume 9, Occupancy Standards and Process Hazards; Volume 10, Transportation. The total number of standards published in these volumes is 226 . The total number of pages in the National Fire Codes (in their most recent editions) is 9,500 pages.

These codes and standards are nationally recognized and widely adopted by the Federal, state and local governments. A number of the standards issued by NFPA are subsequently submitted to and approved by the American National Standards Institute. Typical of these standards are the National Electrical Code, the Life Safety Code, and a series of codes on Dust Explosion Hazards.

Being an international organization with members in more than 80 countries, NFPA is involved in many international programs. In their standards making field, the NFPA participates in the International Organization for Standardization and the Canadian Electrical Code Committee.

Many agencies of the Federal Government serve on the technical committees of the association and many agencies use NFPA technical committee documents for various purposes. These agencies include the Departments of Labor, Health, Education, and Welfare, National Bureau of Standards, General Services Administration, Housing and Urban Development and the Veterans Administration.

\section{NATIONAL FLAXSEED PROCESSORS' ASSOCIATION, Box 24.6, Littleton, North Carolina 27850}

This association, consisting of flaxseed processors producing linseed oil and meal, contributes to the development of national standards for flaxseed and flaxseed products. The association itself, and through its members, cooperates in the development of test methods and specifications which are ultimately approved and issued by Government agencies and organizations such as the American Society for Testing and Materials and the American Oil Chemists' Society. Publications to date include Trading Rules Governing Purchase and Sale of Linseed Oil and Lin. seed Meal.

\section{NATIONAL FLUID POWER ASSOCIATION, INC., P.O. Box 49 , Thiensville, Wisconsin 53092}

This association, founded in 1953, sponsors standards for the fluid power industry in the United States. It also sponsors the American National Standards Committee B93, Fluid Power Systems and Components, through which NFPA and other fluid power standards are processed to become American National Standards. In addition, NFPA serves as the secretariat (designated by the American National Standards Institute-ANSI) for Technical Committee 131, Fluid Power Systems and Components, of the International Organization for Standardization (ISO).

National in scope, the association sponsors some 50 current fluid power standards, issued separately and in a comprehensive 900-page publication of all NFPA, ANSI, and ISO fluid power standards.

The association's standards program is administered by the NFPA Technical Board, under the direction of which are organized 25 separate sections or committees, and some 150 project groups. NFPA standards cover dimensions, specifications, methods of testing or rating, terminology, symbols, and procedures for systems as well as individual components, including fluid power cylinders, valves, pumps, motors, sealing devices, conductors, fittings, filters, fluids, servovalves, accumulators, and pneumatic logic devices.

A certification program is underway for pressure and fatigue rating of fluid power components.

An index listing of all NFPA and ANSI fluid power standards is available from the association upon request.

Standards activities account for half of the total association programs.

\section{NATIONAL FOREST PRODUCTS ASSOCIATION, \\ 1619 Massachusetts Avenue NW., Washington, D.C. 20036}

This association is national in scope, and was originally founded in 1902 under the name National Lumber Manufacturers' Association. In 1965, the present name was adopted.

NFPA represents the interest of more than 1200 producers of forest products, particularly in the areas of Federal regulations and policies that affect the forest products industry. This association is a federation of 24 affiliated wood associations.

Most of the participation in standardization activities is carried on by the NFPA Technical Services Division. This association prepares and distributes various standards for the use of lumber and wood products. Prominent among these are the National Design Specification for Stress-Grade Lumber and Its Fastenings, Wood Structural Design Data booklet, Maximum Spans for Joists and Rafters in Residential Construction, Wood Construction Data Series, and Technical Report Series. NFPA is directly involved with the four major model building codes groups, the Model Code Standardization Committee, in the development and revision of various codes to provide practical, economical code requirements for the building community and enforcing jurisdictions.

This association is not involved to a significant extent in international programs, except for a repre. sentation on a few American National Standards Committees developing international standards. 
NFPA provides technical input to various Federal construction standards, such as the following: HUD. FHA Minimum Property Standards; DoD Tri-Services Military Family Housing Specifications; DoD Construction Criteria Manual; General Services Administration Construction Specifications; and Health, Education and Welfare Construction Standards.

Many other miscellaneous Government and military construction standards are reviewed by NFPA and its federated associations. In addition, this association is active with the National Conference of States on Building Codes and Standards, the Model Code Standardization Council, the One and Two Family Dwelling Code and other similar groups.

NFPA is represented on the American National Standards Z34 Certification Committee, and is active in various standards committees, code and Government organizations that are considering new certification accreditation procedures.

The various regional and species associations that are federated with NFPA prepare and publish grading rules adapted to their respective species which are then used for the grading of lumber. These associations also develop a variety of product standards.

The association has continually engaged in the development of lumber standards by participating with various committees of the American Society for Testing and Materials, and the American National Standards Institute, including those which develop standard methods for fire endurance test, for building construction and methods for testing building construction.

\section{THE NATIONAL FORMULARY, 2215 Constitution Avenue NW., Washington, D.C. 20037}

The National Formulary (NF), established in 1888, is a book of drug standards which since 1906 has been recognized as an official drug compendium in the Federal food and drug law, as well as the drug laws of individiaul states. As such, the standards prescribed therein are subject to enforcement by Federal and state drug officials (i.e., the Food and Drug Administration).

The entire NF program is devoted to standardization activities. The criteria for establishing standards and specifications, and the procedures followed in qualifying an article for admission to the NF, are formulated by the NF Board, which is elected by the Board of Trustees of the American Pharmaceutical Association (APhA). The association is the national professional society of individual pharmacists, and it publishes the NF as a service to the public health and welfare. Acting within the guidelines established by the NF Board, the NF Committee on Admissions recommends articles for $\mathrm{NF}$ recognition, and the $\mathrm{NF}$ Committee on Specifications assists in developing standards, specifications, test procedures, and assays.

The NF is a compendium of standards designed to promote the safety, effectiveness, quality, and purity of drugs and drug dosage forms selected on the basis of therapeutic value. Such standards include the drug names, definitions, descriptions, and specificationsincluding test procedures and assays for the determination of compliance with the standards. NF standards and specifications are developed and established in such a manner to ensure adequate and appropriate characteristics of quality, strength, purity, and identity of the articles to which the respective standards apply.

For this purpose there are approximately 1,000 separate monographs comprising standards of identity, quality, purity, and strength for individual articles in the currently official National Formulary and supplements to it. Many of the NF test or assay procedures require the use of a special reference substance. There are approximatly $250 \mathrm{NF}$ Reference Standards currently in distribution. The authentic substances which are distributed as standards of reference (NF Reference Standards) are in a sense certified as to their suitability for the intended purpose. Otherwise, it is the responsibility of the drug manufacturer to ensure that their products meet the standards provided and are otherwise in compliance with the specifications developed.

The scope of the standards are national in character by virtue of Federal law. Moreover, each individual state takes note of these standards in the pertinent state drug laws thereby making them a requirement in interstate as well as intrastate commerce. A number of foreign countries, such as Canada, have also adopted the National Formulary as a legal standard for drugs marketed, and even in those countries where the NF is not a standard by law, it is frequently looked upon as an unofficial or voluntary standard of reference.

The organization is involved with the World Health Organization in developing international specifications for drugs and international nomenclature for the naming of drugs. It also participates to a lesser degree in programs of the Pan-American Health Organization and the Federation Internationale Pharmaceutique.

There is considerable involvement with the Federal Government since the Federal Food, Drug, and Cosmetic Act specifically provides that marketed drugs in the United States must comply with standards set forth for them in the NF, that the methods of determining such compliance should be those specified in the NF, and that the Secretary of the Department of Health, Education and Welfare (HEW) is assigned the specific responsibility to ascertain that marketed drugs are in such compliance. Furthermore, through APhA, NF jointly participates with several other organizations in sponsoring and conducting a program for the establishment of standardized nonproprietary nomenclature for drugs known as the United States Adopted Names Council (USAN). In all of these activities, the overwhelming contact is with the Food and Drug Administration and its various bureaus, and offices. However, these programs also involve many other agencies within the Government, such as the Treasury Department (Alcohol and Tobacco Divi- 
sion), the Social Security Administration (Medicare Division), the Justice Department (Drug Enforcement Administration), etc.

The NF has long been a leader in efforts to utilize the metric system to standardize weights and measures in the United States. The metric system was introduced into the second edition of the NF in 1896, and since 1960 all units of weights and measures in the NF have been given only in the metric system.

The principal scope of current activities provides for the establishment of new monographs or standards for the National Formulary; proposals of the NF Board are issued from the $\mathrm{NF}$ office on a regular basis, for public review.

New editions are issued at five year intervals, with supplements being issued at periodic intervals between revisions. The National Formulary Thirteenth Edition-1970, (NF XIII), distributed for the APhA by the Mack Publishing Company of Easton, Pennsylvania, along with five supplements to the volume which have been issued to date, constitute the latest listing of NF standards. Lists of NF reference standards are available from the office on written request.

\section{NATIONAL, HARDWOOD LUMBER ASSOCIATION, Suite 1450, 332 Sonth Michigan Avenue, Chicago, Illinois 60605}

One of the principal functions of this organization (NHLA) since its formation in 1898 has been the maintenance of standards for the grading of hardwood lumber, and an inspection staff for the official application of the standards. The 1,500 member firms are located almost entirely in the United States and Canada, but there is a scattering of members in other countries of the world.

The association issues biennially a new edition of the Rules for the Measurement and Inspection of Hardwood Lumber, Cypress, and Thin Lumber. NHLA's grade rules are recognized as standard throughout the world.

The association maintains qualified inspectors in the principal hardwood markets and producing districts of the United States and Canada who are authorized to issue certificates of inspection of hardwood lumber and cypress, the correctness of the grades and measurements shown on the certificate being guaranteed by the financial resources of the association. This official inspection service is available to the members and nonmembers on government contracts, including Federal, state or local. Extensive use of this service has been made by the U. S. Defense Supply Agency.

A full-time school is maintained in Memphis, Tennessee, by the association for the training of men to be proficient hardwood inspectors. The course of four months is open to members and nonmembers and their employees up to 50 in number.

\section{NATIONAL INDUSTRIAL LEATHER ASSOCIATION, P.O. Box 1485, Pompano Beach, Florida 33061}

The association, through its Engineering and Technical Committees representing its different divisions, has developed dimensional standards covering leather belting, mechanical leather packings, certain textile leathers, etc. These same committees have also prepared standard procedures for testing such physical characteristics of various industrial leather products as the bond strength of cement used in the fabrication of leather belting, porosity of leather packings, etc.

Through the work of the association, horsepower rating tables and correction factors have been developed for flat leather belting, which have been adopted by the entire industry. The association and its committees have cooperated in the preparation of Federal specifications covering various industrial leather products. NILA is on the American National Standards Sectional Committee B93 in the development of recommended practices pertaining to sealing devices.

Formerly: American Leather Belting Association (1926).

\section{NATIONAL INSTITUTE OF INFANT SERVICES, \\ Diaper Service Accreditation Conncil, 2017 Walnut Street, Philadelphia, Pennsylvania 19103}

The institute is a result of a merger in 1971 of two national associations, the Diaper Service Industry Association, and the National Institute of Diaper Services, organizations that had been in existence since 1938. The main purpose was to conduct research into the requirements of diaper processing to meet the sensitivity of infant skin. An independent accredited medical laboratory under the supervision of a clinical pathologist conducted microbiological and patch test studies on infants to establish standards. The laboratory then devised testing procedures by which random sample diapers can be tested routinely against the prescribed standards. A diaper service must meet these standards in order to establish qualification and maintain membership.

Standards are raised from time to time as new knowledge is revealed by the continuing research program. The diaper test now includes five major areas: (1) a sanitary score, awarded on the basis of microorganisms found on the sample, either by direct plating or by subculture; if any pathogenic organisms are found, the sample is not acceptable. Nonpathogenic organisms are permissable only up to 100 colonies; (2) a $\mathrm{pH}$ test by the colorimetric procedure, to show that the sample meets the acceptable range of 4.5 to 6.5 ; (3) evidence of impregnation of the sample with an EPA-approved bacteriostat using the PetrocciClarke agar plate test method against Staphylococcus 
aureus (ATCC 6538) after 24-hour incubation; (4) a softness test with freedom from stiffness or pilling; and (5) an absorbency test so that water added drop by drop enters the fabric immediately.

The institute sponsors an autonomous professional Diaper Service Accreditation Council which has promulgated standards for plant sanitation, customer service, and marketing practice, and which is empowered to accredit diaper service applicants who go through self-evaluation and inspection by an independent site committee for evaluation against the standards. Accredited members must maintain all standards as they may be changed in annual review by the council.

\section{NATIONAL INSTITUTE OF OILSEED PRODUCTS, \\ 111 Sutter Street,}

\section{San Francisco, California 94104}

The National Institute of Oilseed Products (NIOP) was founded in 1934 as a nonprofit organization devoted to promoting the vegetable oils and vegetable oil products industry.

NIOP keeps its members and those in the industry informed regarding the uses of vegetable oils and their products, and the economic conditions affecting their manufacture, distribution and sale.

NIOP maintains and publishes annually, uniform trading rules containing standard terms and conditions for which the products may be traded. These rules cover product grade and quality specifications, quantity specifications, sampling and chemical analysis procedures, adjustments, and settlement of disputes by arbitration.

The Sampling and Analysis Committee makes periodic recommendations to the governing board for revisions in the rules pertaining to sampling and analytical procedures and requirements.

The Rules Committee cooperates with the International Association of Seed Crushers (Europe), Philippine Coconut Oil Producers' Association, Philippine Copra Exporters' Association, and the U.S. Department of Agriculture in efforts to improve product quality and establish higher standards of trade practices, which are then incorporated in the rules.

The Chemists' Certification Program requires annual successful completion by approved chemists in the American Oil Chemists' Society Smalley Check Sample Series.

Rules books are circulated to each member and to other.interested parties.

\section{NATIONAL KNITWEAR MANUFACTURERS' ASSOCIATION, 350 Fifth Avenue, New York, New York 10001}

The National Knitwear Manufacturers Association, founded in 1866, is comprised of manufacturers of knit underwear, nightwear and allied products such as sportshirts.
The association's pioneering in the field of standardization dates back to 1920. At that time it began work on the collection of data, looking toward the standardization of methods of measuring, measurements and tolerances for knit underwear in the interest of the consumer, as well as the jobber, manufacturer and retailer. To facilitate this work, the association detailed one of its employees to the National Bureau of Standards where for over seven years he collected and tabulated essential data.

Over the years the NKMA has continued its work in this field in close cooperation with the U.S. Department of Commerce in developing, establishing and promoting commercial standards of measurements and size conformity, and looks forward to a continuation of this cooperation.

Formerly: National Association of Knit Goods Manufacturers (1934); Underwear Institute (1968); and National Knitwear Manufacturers' Institute (1970).

\section{NATIONAL LEAGUE FOR NURSING, INC., 10 Columbus Circle, New York, New York 10019}

The National League for Nursing (NLN), formed in 1893 and under its present name since 1952, was founded to improve nursing education and service through a coalition of nurses; allied health providers; consumers; schools and agencies. NLN fosters community planning for comprehensive health care. Nationally, NLN accredits all types of nursing education programs, and community health nursing services with the American Public Health Association (APHA).

The NLN standardization activities are administered by the following four education departments: Practical Nursing Programs; Diploma Programs; Baccalaureate and Higher Degree Programs; Associate Degree Programs; and the Home Health Agencies and Community Health Services, each of which has a council. The councils are responsible for the formulation of criteria for accreditation. Criteria committees of the council revise the criteria which is approved by the councils. Accreditation activities based on the criteria represent 50 percent of the entire NLN program.

The National Commission on Accreditation approved NLN for associate degree baccalaureate and masters programs. NLN is approved as the accrediting agency for nursing education programs by the United States Office of Education. The home health agencies accreditation is conducted in cooperation with the APHA.

Formerly: American Society of Superintendents of Training Schools for Nurses (1893); National League of Nursing Education (1912); National League for Nursing, Inc.--Incorporated the former National Organization of Public Health Nursing and the Association of Collegiate Schools of Nursing (1952). 


\section{NATIONAL LIME ASSOCIATION, 5010 Wisconsin Avenue NW., Washington, D.C. 20016}

The National Lime Association was founded in 1902. In order to assist lime consumers in the most efficient utilization of quick and hydrated lime, this association has developed, through association-sponsored research in concert with its Technical Committee, construction guide specifications, materials specifications, and general recommendations in the mortar, plaster, stucco, highway, and water purification and pollution abatement fields. In addition, the association is engaged in committee work with the American Society for Testing and Materials, American National Standards Institute, American Road Builders' Association, American Water Works Association, Highway Research Board, American Concrete Paving Association, and the American Public Works Association in standards work that involves lime.

Some of the activity is reflected in educationpromotional literature and movies published by the association. A few examples are: Water Supply and Treatment; Exterior Masonry Construction; Chemical Lime Facts; Chemical Treatment of Sewage and Industrial Wastes; Lime Handling, Application, and Storage in Treatment Processes; Lime Stabilization Construction Manual; Flexible Pavement Design Guide; Lime Plant Safety Manual; Specifications for Lime and Its Uses in Plastering, Stucco, Unit Masonry, and Concrete; and Lime Stabilization of Clay Soils for Better Roads, a 271/2 minute, $16 \mathrm{~mm}$. movie and Dallas-Ft. Worth Airfield Stabilization, 18 minute, $16 \mathrm{~mm}$ movie.

Formed by merger of: National Agricultural Limestone Institute and National Crushed Limestone Institute (founded 1955).

\section{NATIONAL LUBRICATING GREASE INSTITUTE, \\ 4635 Wyandlotte Street, Kansas City, Missouri 64112}

The institute, founded in 1933 , is a technical society whose objectives are the development of better lubricating greases for the consumer and better grease lubricating engineering service to the industry.

These objectives are fulfilled by committee actions. Committee members are appointed from member firms who prepare and solicit technical papers to be presented at the annual meeting. Dissemination of these data is by presentation at the annual meeting and subsequent publication in the "NLGI Spokesman," the institute's monthly technical journal.

The Technical Committee of this institute is charged with developing data pertinent to the manufacture, standardization, and application of products of the industry. This committee and individual members of the institute cooperate with committees of technical organizations in matters relating to standards and specifications.
The Technical Committee cooperates with the Lubrication Committee of the American Petroleum Institute, and with various technical committees of the Society of Automotive Engineers, American National Standards Institute, American Society for Testing and Materials, Anti-Friction Bearing Manufacturers Association, American Association of Railroads, American Pctroleum Institute, American Society of Lubrication Engineers, and others.

The institute offers cooperation to interested departments of the United States Government, including the Departments of Defense, Army, Navy, Air Force; Department of Commerce, National Bureau of Standards; Federal Trade Commission; and the Interstate Commerce Commission.

\section{NATIONAL MACHINE TOOL BUILDERS' ASSOCIATION, 7901 Westpark Drive, McLean, Virginia 22101}

The National Machine Tool Builders' Association (NMTBA) organized in 1902, is comprised of companies producing about 90 percent of the U.S. machine tool industry's total output. NMTBA's principal objectives are: (1) to be an effective spokesman for the industry in promoting a better understanding of the machine tool industry by the Government, the public, and all other interested groups; (2) to provide educational, technical, economic, and informational services to its members; (3) to encourage higher technical and safety standards, and to promote technological advancements and improvements in the design, engineering, manufacturing and selling of machine tools. To achieve these goals, the association cooperates with other business and industry groups in the United States and with its counterpart associations throughout the world.

Various technical committees guide the association efforts in standardization work. While the NMTBA formerly wrote an electrical standard, its committces now publish technical documents which are primarily informative in nature. In order to obtain the broadest industry representation in promulgating standards, the association now sponsors machine tool oriented committees of the American National Standards Institute and similar standardizing organizations; cooperates with standardization committees of other trade associations; serves as secretariat of the Joint Industrial Council; and supports representation on committees of the International Organization for Standardization and the International Electrotechnical Commission.

Fundamentally serving to guide the standardizing activities affecting the machine tool industry, the association keeps its membership informed through an engineering newsletter and the manufacturing public informed through press releases published in the trade journals and publications of other trade associations and technical societies. 


\section{NATIONAL MICROFILM ASSOCIATION, 8728 Colesville Road, Suite 1101, Silver Spring, Maryland 20910}

Founded in 1945, the National Microfilm Association has had a continuing interest and involvement in standards in its role as an information forum for vendors and users of micrographic systems. The NMA Standards Board supcrvises the activities of some 17 standards committees engaged in the development of industry standards or recommended practices. Periodic reports on these committees and their activities can be found in the standards column of The Journal of Micrographics. Once a new standard has been approved by the Standards Board and by the membership of NMA as an industry standard, it is then sub. mitted to the American National Standards Committee on Photographic Reproduction of Documents, PH5, of which NMA is the sponsor/secretariat. In this capacity, NMA coordinates the development and approval of new American National Standards in the field of micrographics and also publishes them. NMA also participates in the work of the International Organization for Standardization when requested by the American National Standards Institute (ANSI), the official U.S. representative to ISO.

Current NMA Standards are: Quality for Computer Output Microfilm, MS1-1971; Format and Coding for Computer Output Microfilm, MS2-1971; Facsimile Transmission of Microfilmed Documents, MS3-1972 and American National Standard C16.451973; Flowchart Symbols and Their Usages in Micrographics, MS4-1972; Microfiche of Documents, MS5-1972; Glossary of Micrographics, MS100-1971; and Recommended Practice for Inspection and Quality Control of First Generation Silver Halide Microfilm, MS104-1972. The NMA Publications List provides up-to-date information of standards published by NMA.

\section{NATIONAL MINERAL WOOL INSULATION ASSOCIATION, INC. 211 East 51 Street, \\ New York, New York 10022}

A nonprofit organization formed in 1933 to render service to its members and to the building industry to promote the welfare and development of mineral wool insulation products designed for installation in buildings utilized for human occupancy. Members of its Technical Committee assist, to the extent legally permissible, in the development of standards and specifications, national in scope, referring to mineral wool insulation products. Active membership is maintained in the American Society for Tcsting and Materials; American Society of Heating, Refrigerating and AirConditioning Engineers; and the model building code organizations. The association leads the insulation industry in matters relating to the overall thermal performance of buildings to the conservation of energy. When so invited, it cooperates with and advises such Government agencies as the General Services Administration in the establishment of Fedcral specifications for appropriate mineral wool products and with the Federal Housing Administration and other governmental bodics, both Federal, state and local, in the establishment of thermal performance standards that will contribute to the conservation of energy. The association also advises and consults with related industry trade associations, utilities and othcr energy suppliers, and professional organizations regarding standards, research, applications and other matters related to the industry.

Formerly: National Rock and Slag Association; National Mineral Wool Association.

\section{NATIONAL MODEL RAILROAD ASSOCIATION, \\ P.O. Box 1328, Station C, Canton, Ohio 44708}

This service organization was established in Milwaukee, Wisconsin, in 1935 to advance the hobby of scale model railroading through the development, adoption and regulation of standards, promote cooperation and understanding betwcen producers and users of hobby materials, and increase opportunities for fellowship among model railroaders.

Membership comprises about 25,000 persons active in the field, primarily in the United States but also throughout the world, including members and firms in the trade as well as individual practicing hobbyists. The association is subdivided into 15 geographic regions, one in the British Isles and the balance in the United States and Canada. Management is directed by nine elected nonpaid officers, who also serve with the 15 Regional Presidents as members of the governing Board of Trustees, and all services other than membership record-keeping and mailings are performed by a volunteer staff.

$A$ basic function of the NMRA and the primary reason for its founding is that of establishing and maintaining design standards for the manufacture of components for use in the hobby. These are intended to insure interchange between items produced by various sources and to improve performance. Initial specifications were adopted in 1936 and have been followed continuously by producers of scale railroad models and parts since that time, including refinements as the state of the art progressed.

Typical NMRA standards define track and wheel relationships, electrical power specifications, and clearance dimensions between rolling stock and trackside structures. An additional class of specifications, known as NMRA recommended practices, covers desirable characteristics other than those necessary for physical interchange and is intended to enable manufacturers to improve their product in a manner most suited to the user's needs. A General Engineering Committee is charged with responsibility for development of standards and recommended practices, and a separate Conformance-Inspection Committee checks manufactured products for compliance. Items meeting 
the standards specifications are granted an NMRA Conformance Warrant which may be used in advertising as long as continued compliance is indicated by repeat inspections.

\section{NATIONAL MUNICIPAL LEAGUE, 47 East 68th Street,} New York, New York 10021

The National Municipal League (NML) was founded in 1894. The model laws that are devised, published, and distributed by this organization are intended to serve as standards and to stimulate uniformity in state, county, and city legislation. They include a model bond law, budget law, city charter (which provides the council-manager form of government), model county charter, election administration system, model real property tax collection law, registration system, model state constitution and others.

\section{NATIONAL OAK FLOORING MANUFACTURERS' ASSOCIATION, 814 Sterick Building, Memphis, Tennessee $\mathbf{3 8 1 0 3}$}

Standardization and simplification activities of this association are carried on by its Grading, Milling and Inspection Committee, which has been functioning for more than 40 years.

The association has adopted official rules on oak, birch, beech, hard maple, and pecan flooring, which cover in detail the grades and sizes of quartered and plain sawn stock. It cooperated with the Federal Gov. ernment in the formulation of the Federal specification for hardwood flooring (Lumber and Timber: Hardwood, MM-L-736C), which includes references to the grading rules of this association for oak, birch, beech, and hard maple flooring.

Until last year the National Bureau of Standards published Commercial Standard CS56-60 covering grading rules for white and red oak flooring established through cooperation of the association, but the standard was withdrawn when the Bureau learned that the standard was seldom referred to since hardwood flooring was customarily sold subject to the Official Flooring Grading Rules of the association.

This association maintains a rigid supervision of species, manufacturing, kiln-drying, bundling, and all other features pertaining to oak, birch, beech, and hard maple so that its sizes and grades will be maintained. The use of the association's registered trademark "NOFMA" has been granted to all of its members whose stock of oak flooring has been found to comply with the association's official grading rules. It also maintains a reinspection service available for the retail dealers who purchase products of member companies, so that, in the event there is doubt concerning the quality of stock bought, a reinspcction may be had and the matter settled immediately.

Formerly: Oak Flooring Manufacturers of United States; Southern Oak Flooring Industries.

\section{NATIONAL PAPER BOX ASSOCIATION, 231 Kings Highway East, Haddonfield, New Jersey 08033}

This association, founded in 1918 and which represents the rigid paper box industry, has developed specifications for box-covering papers which include standards for fade resistance, surface or color rub, put-up, sample books, and billing terminology. The Specifications Committee of the association is promoting acceptance of these standards to paper mills, distributors, and box manufacturers. Further work is being done by the committee on paperboard, adhesives, and paper boxes.

Formerly: National Paper Box Manufacturers' Association (1969).

\section{NATIONAL PARTICLEBOARD ASSOCIATION, 2306 Perkins Place, Silver Spring, Maryland 20910}

This association consists of manufacturers of wood particleboard and medium density fiberboard who participate in the development of standards through NPA's Technical Committee. NPA has promulgated five industry standards. These are NPA 1-73, Standard for Particleboard for Mobile Home Decking; NPA 2-72, Standard for Particleboard Decking for FactoryBuilt Housing; NPA 3-73, Specification for Particleboard Floor Underlayment Coated with Wax-Polymer Type Hot Melt Coatings; NPA CO1-73, Specification for Wax Polymer Type Hot Melt Coatings for Particleboard; and NPA 4-73, Standard for Medium Density Fiberboard. In addition, the association sponsored Commercial Standard CS236-66 for Mat-Formed Wood Particleboard and assisted the General Services Administration in the preparation of Federal Specification LLL-B-800a, Building Board (Particleboard) Hard Pressed, Vegetable Fiber.

\section{NATIONAL PRINTING INK RESEARCH INSTITUTE Lehigh University, Bethlelıem, Pennsylvania 18015}

The institute was established at Lehigh University in 1946. It was founded to engage in scientific research on printing inks, on the equipment and techniques involved in their production, and on the printing surfaces to which they are applied. Recognizing the printing ink industry's need for such information, one of the projects undertaken by NPIRI was a compilation of a set of standard test methods. Such a series of tests is an essential basis for interchange of technical information, for ink research, for scientific control of ink production, and thus for the resulting advances in ink technology.

The material in the manual, consisting of 44 tests, has been divided into seven main sections: Sampling and Preparation, Qualitative Chemical Tests, Quantitative Chemical Tests, Physical Tests, Performance Tests, Resistance Tests, and Tests for Related Mate- 
rials. The last section covers materials such as paper, rollers and blankets, printing plates and fountain solutions, which do not enter into ink production but contact the ink and influence its behavior during use. An evaluating procedure is carried out on each recommended method both by the institute and by individual companies cooperating with the institute. It is intended that this group of test methods grow with time in the directions indicated by the needs of the industry.

\section{NATIONAL RETAIL MERCHANTS' ASSOCIATION, 100 West Thirty-First Street, New York, New York 10001}

This association (NRMA) takes an active part in the formulation of standards and specifications relative to retail store organization, retail systems, retail trade terminology, business practices, and specifications for commodities used in the trade. In carrying forth this work, the association cooperates actively with the American National Standards Institute (ANSI) and other technical and trade organizations and the Government.

NRMA initiated programs for the establishment of several Simplified Practice Recommendations under the auspices of the National Bureau of Standards, U.S. Department of Commerce (NBS). The association formerly cooperated with NBS in the revision of several Simplified Practice Recommendations, and cooperates actively with NBS in the establishment of standard sizing of all apparel. Currently, a member of NRMA's Technical Committee is represented on a special NBS task force on sizing for the International Organization for Standardization (ISO).

NRMA is a member body of ANSI and participates actively in the work of several American National Standards Committees. The association is sponsor of the American National Standards Committee L22, whose standards relate to the end use of all textiles.

Formerly: National Retail Dry Goods Association (1958).

\section{NATIONAL RIFLE ASSOCIATION OF AMERICA,}

1600 Rhode Island Avenue NW., Washington, D.C. 20036

The National Rifle Association of America (NRA), established in 1871, is a nonprofit membership organization, with more than one million individual members and some 10,000 affiliated local clubs and state organizations. Because some of its major programs include the supervision of marksmanship instruction and competition and of safety education involving firearms, much of NRA standardization efforts are in these fields.

The NRA prepares and provides standard construction plans for a large variety of shooting ranges for different guns and events. Some of these must meet standards established for international competition.
Paper targets used in training and competition are standardized. These standards are researched and established by various specialized program committees and then channelled through NRA's Competition Rules and Programs Committee.

Educational standards, with standardized aids, are provided for the safety programs.

Reports are included in annually revised competitive rule books, in annual meeting reports, and special shooting range literature and program outlines and manuals.

\section{NATIONAL ROOFING CONTRACTORS' ASSOCIATION, 1515 North Harlem Avenue, Oak Park, Illinois 60302}

The National Roofing Contractors' Association (NRCA) was founded in 1886. NRCA now represents over 1,000 members and the majority of roofing dollar volume done in the country each year. NRCA has six technically oriented active committees: the Air Pollution Task Force, the Performance Standards Evaluation Committee, the Roofing Manual Task Force, the Technical Assistance Program Task Force, the Technical and Research Committee, and the Urethane Roofing Committee.

Through the NRCA Roofing Manual, the association provides to the roofing industry recommended procedures, practices and evaluative comments on roofing specifications, construction details and roofing materials. In addition, NRCA has issued position papers on built-up roof test cut procedure, temporary roof deck coverings, venting lightweight insulating concrete roof fills, and the roofing guarantee. NRCA has participated in a study on the movement of built-up roofing membranes in cooperation with the University of Illinois. NRCA has been an information source and advisory counsel to the center of building technology at the National Bureau of Standards. Technical Conferences are sponsored cooperatively by the National Bureau of Standards (NBS) and NRCA every other year at NBS Headquarters in Gaithersburg, Maryland.

NRCA has also developed roofing industry safety standards through standards-setting procedures of the American National Standards Institute. Additionally, NRCA is active in its participation on the American Society for Testing and Materials Committees, setting standards for the testing of roofing materials.

Numerous technical works and reports are on file at the NRCA Headquarters and collected items are available upon request.

\section{NATIONAL SAFETY COUNCIL, 425 North Michigan Avenue, Chicago, Illinois 60611}

The mission of the National Safety Council, which was founded in 1913, is: to determine and evaluate methods and procedures that (a) prevent accidents and (b) mitigate injury and economic loss resulting 
from accidents; and to provide leadership to expedite the adoption and use of those methods and procedures that best serve the public interest.

While the National Safety Council recognizes the vast need for standards that are relevant to all of the safety disciplines, the council does not develop standards. Instead, the council relies on and provides significant manpower for the devclopment of standards via existing nationally recognized standards-producing organizations. To achieve this end, the council is heavily represented in the activities of the American National Standards Institute (ANSI), the American Society for Testing and Materials (ASTM), and the National Fire Protection Association (NFPA).

With respect to ANSI, the council is currently represented on its Board of Directors; Special Committees of the Board; the Consumer Council and its Consumer Product Safety Committee, Certification Committee, and Consumer Education Committee; Organizational Member Council; Executive Standards Council and its Technical Advisory Boards concerned with Highway Traffic, Safety, Construction, and Nuclear Energy. The council is currently sponsor and provides the secretariat for 22 American National Standards involving 72 documents and has representation on 101 American National Standards Committees involving 282 documents.

With respect to ASTM, the council is currently represented on its E 17 Committee on Skid Resistance; E 34. Committee on Toxic Materials and Harmful Physical or Biological Agents; and F 15 Committee on Consumer Product Safety.

With respect to NFPA, the council is currently represented on 22 subcommittees of NFPA standards committees.

Historically, the council has played a major role in the development of standards that pertain to occupational safety and health and more recently is becoming heavily involved in the development of consumer product safety standards, both through nationally recognized standards-producing organizations. The council enthusiastically promotes and consistently seeks public support for the adoption and use of those consensus standards that fall within the scope of the National Safety Council's mission.

\section{NATIONAL SAND AND GRAVEL ASSOCIATION, 900 Spring Street, Silver Spring, Maryland 20910}

The standardization work of this association falls into two categories: the committees of the association that deal with specifications for various uses; representatives of the association that are active in the standardization work of pertinent technical organizations such as the American Society for Testing and Materials, the American Concrete Institute, the American Railway Engineering Association and others. It also cooperates with the National Crushed Stone Association and the National Slag Association through the Joint Technical Committee of mineral aggregates associations in the development of standards and coordination of technical problems of mutual interest.

This association, jointly with the National Ready Mixed Concrete Association, maintains research facilities in College Park, Maryland. This Joint Research Laboratory conducts research pertinent to industry problems, and particularly those dealing with standardization of specifications and test methods. The policies of the laboratory are governed by a Joint Research Committee representative of the two associations.

\section{NATIONAL SANITATION FOUNDATION, 3475 Plymouth Roarl, Ann Arbor, Michigan 48105}

The National Sanitation Foundation (NSF) was chartered in 1944 in the State of Michigan as a noncommercial, nonprofit standards, research and educational organization seeking solutions to problems affecting man's environment. It is dedicated to the prevention of illness and improvement of quality living through a better environment. NSF sponsors or conducts objective research and educational programs seeking a quality environment. These studies provide an authoritative basis for the establishment of minimum sanitation standards for equipment, products and devices that are generally acceptable to health authorities. The standards development and certification program activities represent about 50 percent of the total efforts of NSF. The standards and certification program is extended throughout the United States and Canada, and provides services to about $50 \mathrm{com}$ panies in eight countries of Europe and Japan, whose products are exported to the United States.

The standards and research efforts of NSF involve a number of Federal agencies, including U. S. Public Health Service, Food and Drug Administration, Environmental Protection Administration, Department of Housing and Urban Development and the various branches of the Armed Services and the Veterans Administration, as well as local and state official agencies. The foundation has published 47 standards and four criteria, under which testing and certification services are currently extended to over $1600 \mathrm{manu}$ facturers who use the NSF Seal on over 25,000 items of equipment or products covered by the above standards. The foundation publishes a list of the available standards distributed by NSF as well as an annual food equipment listing, a plastics listing covering potable water and drain-waste-vent products, a listing of water treatment equipment used in swimming pool applications and a listing of special categories of equipment or products including film badges, plumbing components for mobile homes and recreational vehicles, thermoplastic refuse bags and containers and wastew ater treatment service.

NSF standards under development include autoclaves, flow rate controllers and indicators, foam cups and containers, life support equipment used in hos- 
pitals, mobile patient care equipment, retail food store refrigerators, respiratory equipment and plastics for food service equipment.

\section{NATIONAL SASH AND DOOR JOBBERS' ASSOCIATION,}

\section{North Wacker Drive,} Chicago, Illinois 60606

This association, formed in 1964 by the merger of two regional jobber associations, Northern and Southern, has been active in the support and development of Commercial Standards related to window and door products. In cooperation with the National Woodwork Manufacturers' Association (NWMA), NSDJA since 1953 helped prepare and further Commcrcial Standards relating to double hung, casement, awning, and single hung wood window units which have now been incorporated into NWMA's Industry Standard 2.

NSDJA initiated and developed Voluntary Product Standard PS 32-70 for wood interior hinged door units. NSDJA is also active in promoting standards for the use of safety glazing materials in hazardous locations.

In addition, the association is interested in various standards relating to the softwood plywood industry and, representing distributors, assists in the coordination of problems connected with plywood Voluntary Product Standards.

Formed by merger of: Northern Sash and Door Jobbers'Association (1935); and Southern Sash and Door Jobbers' Association (1935).

\section{NATIONAL SCALE MEN'S ASSOCIATION, 1928 South Grand Avenue, Santa Ana, California 92705}

This organization is composed of approximately 1200 technical men engaged in the design, production, sale, installation, maintenance, testing, and operation of weighing machines.

It has organized 11 committees which are assigned to study and develop certain phases of the scale industry, including the development of standards and specifications covering railway and industrial track scales; highway vehicle scales; built-in, self-contained, and portable scales; counter scales; grain scales, automatic and hand-operated scales; automatic indicating and recording railway and industrial scales, automtic indicating and recording scales other than large capacity, electronic and hydraulic scales of Iarge and small capacity; pits and foundations; weighing practices, scales used for transportation and labor charges; weighing practices, scales used for purposes of barter; corrosion prevention; construction materials; and welding and heat treatment.

The association has adopted specifications for overhauling and repair of heavy-capacity scales; light industrial service track-scales; railway track-scale test weight cars; standard code of rules relating to maintenance and transportation of track-scale test weight cars; and a definition of a standard test of a railway track scale.

The standards and codes which have been adopted by the association have recieved the indorsement of the National Conference on Weights and Measures and the American Railway Engineering Association.

Formed by merger of: National Association of Scale Experts and Amcrican Scale Men's Association (1916).

\section{NATIONAL SCHOOL SUPPLY AND EQUIPMENT ASSOCIATION 1500 Wilson Boulevard, Arlington, Virginia 22209}

This association, founded in 1916, is composed of manufacturers and distributors of school equipment, supplies and instructional materials. Standards produced by the association include Recommended Standards for Design of Interior Folding and Telescopic Seating, which establishes uniform standard criteria for the design manufacture, and installation of interior folding and telescopic seating normally used in school gymnasiums, and Testing Procedures for Measuring Sound Transmission Loss Through Movable Walls and Folding Partitions. This standard establishes a uniform set of practices for the installation of the test specimen, the conduct of the test, and the certification of the results when operable walls are tested for sound transmission loss in accordance with American Society for Testing and Materials E90, Tentative Recommended Practice for Laboratory Measurement of Airborne Sound Transmission Loss of Building Floors and Walls.

The association has also produced a Suggested Purchasing Specification for a Select Group of School Paper Products and is currently developing safety standards for heavy duty playground equipment in cooperation with the Division of Childrens Hazards, Bureau of Product Safety, Department of Health, Education and Welfare.

Formerly: National School Service Institute (1958).

\section{NATIONAL SILO ASSOCIATION, P.O. Box 247, 209 Franklin Street, Cedar Falls, Iowa 50613}

The National Silo Association (NSA) was established 61 years ago. The organization has over 100 members with the safety and standards committee and program activities making up at least 50 percent of the total program.

NSA is international in scope in that it now has an international division as well as a Canadian division.

NSA recently completed an industrywide survey which will be used in updating our standards for the industry. The updating and printing of these standards should be completed by the end of 1973 .

With the need for a safety program in each of the manufacturer's plants and with the work the crews are doing on the farms, and with the requirements to 
meet Occupational Safety and Health Administration (OSHA) standards, NSA has developed an operator's safety manual as well as recommended to OSHA its adoption as standard specification standards for the silo industry. The nature and extent of NSA's involvement and activities with OSHA is quite extensive.

The National Silo Association has and will continue to cooperate with the American Concrete Institute, American Society of Agricultural Engineers or any other technical associations in developing safety standards for the industry.

Formerly: National Association of Silo Manufacturers (1956).

\section{NATIONAL SLAG ASSOCIATION, 300 South Washington Street, Alexandria, Virginia 22314}

The association, founded in 1918 cooperates actively with specification-writing organizations at the national and state levels in formulating and revising aggregate specifications and in development of standards covering test procedures. This cooperative program is carried out mainly through representation on technical committees of such national organizations as the American National Standards Institute, American Society for Testing and Materials, American Concrete Institute, Association of Asphalt Paving Technologists, Highway Research Board, American Railway Engineering Association, American Society of Civil Engineers, American Public Works Association, and the Industrial Hygiene Foundation. Standardization of aggregates is further promoted by research dealing with aggregates and their end-use products, conducted in the association's laboratory located in Youngstown, Ohio. Much of the research thus conducted is planned and programmed by the association's Technical Committee. This committee is composed of technical representatives from the various member companies.

\section{NATIONAL SOCIETY FOR THE PREVENTION OF BLINDNESS, INC. 79 Madison Avenue, New York, New York 10016}

The National Society for the Prevention of Blindness, Inc., founded in 1908, is the oldest voluntary health agency nationally engaged in the prevention of blindness through a comprehensive program of community service, public and professional education, and research. With advice and guidance of professional scientific advisory committees, the society has developed standards for vision screening of preschool and school age children, for eye safety programs in schools and industry, for glaucoma screening and for services providing low vision aids to the partially sighted.

Publications, films, posters, charts and advisory service are available on request. The society is supported entirely by contributions, memorial gifts, bequests and legacies, which are deductible for purposes of income taxes.
Formerly: National Committee for the Prevention of Blindness (1927):

Formed by Merger of: New York State Committee for the Prevention of Blindness combined with, American Association for the Conservation of Vision (1918).

\section{NATIONAL SOFT DRINK ASSOCIATION, 1101,16 th Street NW. Washington, D.C. 20036}

The National Soft Drink Association (NSDA) was founded in 1919 as the American Bottlers of Carbonated Beverages. It assumed its current name in 1967. Its purposes are to provide the manufacturers of soft drinks throughout the United States and others interested in the welfare of the industry a forum to discuss matters of common interest, provide a medium for improving soft drink plant operating procedures, conduct research on problems relating to the industry, provide informational and educational services in the interest of the consumer and to increase the prestige of the industry and its products in the American economy. The association throughout the years has been instrumental in being a party to voluntary standards or guidelines which were designed for the betterment of the consumer and the industry generally. For example, NSDA has established a standard for bottlers' sugar, recommended a standard concerning the com. position of solutions used for washing beverage bottles, and standards for methods of controlling water, sugar, carbon dioxide, bottle washing solutions and sanitation. Most recently, the association has adopted a voluntary bottle specifications guideline which relates to the bottles used for carbonated beverages. Currently, the association is involved as a coproponent with the National Bureau of Standards seeking to develop a consensus standard for the manufacturing of carbonated beverage bottles. The industry is also seeking to reach voluntary guidelines in the area of secondary packaging and pre-mix and post-mix tanks. NSDA has participated over the years with the Food and Drug Administration regarding standards of identity for products manufactured by the industry. There are no certification programs within the industry or any enforcement procedures for them, since all of the programs are voluntary. All of the association's stand. ards are promoted through association publications and memoranda and are national in scope.

Formerly: American Bottler's Protective Association (1967).

\section{NATIONAL SOYBEAN PROCESSORS' ASSOCIATION, 1730 Pennsylvania Avenue NW., Washington, D.C. 20006}

The National Soybean Processors' Association was established in 1930. Standardization of quantity and grades of soybean oil and soybean meal, and development of standard trading rules constitute the important activities of this association. Upon the 
recommendations of its Soybean Oil Trading Rules Committee, the association adopted standard specifications for crude domestic soybean oil covering quality, grade and methods of analysis. Standard specifications for crude, degummed, and once-refined soybean oil have been developed for export use. In addition, its Meal Trading Rules Committee serves a similar purpose in providing standards and trading rules for soybean meals.

\section{THE NATIONAL SWIMMING POOL. INSTITUTE, 2000 K Street NW., Washington, D.C. 20006}

The National Swimming Pool Institute (NSPI), was founded in 1956. NSPI is a national trade association comprised of approximately 1,750 swimming pool builders, pool equipment manufacturers and suppliers, architects, engineers, public officials and others allied with the growing pool industry. Only those companies maintaining high ethical standards are accepted for membership in the institute. The purpose of NSPI is to set guidelines for pool builders and to work toward better pool building and the maintenance of higl ethical standards.

NSPI has issued many publications including the care and maintenance guides and handbooks; types of pools; materials; organization and business management; case studies; and two standards for residential and public pools. The NSPI standard for public and residential pools are the most complete, comprehensive, and up to date standards published in the swimming pool industry. In order that NSPI's standards include knowledge and information of other groups, it has liaison representatives and direct participation by the American Public Health Association, National Safety Council, Underwriters' Laboratories, National Sanitation Foundation, National Electrical Code, International Association of Plumbers and Mechanical Officials, Consumer Product Safety Commission, and the Young Mens' Christian Association of the United States. The standardization activities are administered by the Technical Council and involve 34 percent of NSPI's total program. The following includes NSPI's active standards committees: Publications Committee, Advisory Liaison Committee, Dimensional \& Structural Design Committee, Accessary Equipment Committee, Chemical Treatment \& Process Committee, Circulation Systems Committee, Pool Operator \& Service Committee. A new project is the review of Public Pool Standards, and the continual investigation into all standard activities to make sure that they are up to date as the need arises.

Certification programs activities: The Pool Registry Program requires participating pool builders and installers to provide pools which meet or exceed the NSPI minimum industry standards for design and construction. The pool company registers each pool by placing a permanent plaque in the deck of the pool and forwarding the registry form to NSPI's independ. ent registry agent. Under the program pools are divided into five classes determined by the dimensions of the diving hopper. Diving boards are similarly rated so that a pool-to-diving board safe match can be effected.

NSPI cooperates with the Government in standardization activities by providing information and assistance to the Consumer Product Safety Commission, Environmental Protection Agency, Department of Health, Education and Welfare, Department of Housing and Urban Development, Department of Commerce, and the Federal Trade Commission; and maintains liaison with other international swimming pool organizations.

\section{NATIONAL TERRAZZO AND MOSAIC ASSOCIATION, INC., 716 Church Street, Alexandria, Virginia 22314}

The National Terrazzo and Mosaic Association, Inc. (NTMA) was founded in 1923. NTMA is a full service trade association. The standardization and technical services comprise about 60 percent of the program. The standardization activities are administered by the Technical Committee and the Quality Control Committee. The association's standards are accepted by virtually all Government agencies. NTMA's current Technical Data Book contains 25 separate complete standard national specifications for the installation of all types of terrazzo, both cemen. titious and resinous.

The Research and Development Committee is presently developing new application and grinding techniques.

NTMA's standards are promoted to the architectural industry by regional technical representatives and through paid space advertising.

\section{NATIONAL WATER WELL ASSOCIATION, 88 East Broad Street, Columbus, Ohio 43215}

The National Water Well Association (NWWA), founded in 1948, is an organization of water well drilling contractors, manufacturers, wholesale suppliers and professional geologists, hydrologists and engineers interested in the problems of locating, developing and utilizing underground water supplies. Objectives of the association include the promotion of scientific development and the advancement of the science of ground water hydrology.

The association's Specification Committee has cooperated with the American Waterworks Association in developing a standard for deep wells. This committee through the National Water Well Association Research Facility is now under contract to the United States Environmental Protection Agency (EPA) for the development of well construction specifications for all types of wells and geologic conditions. These specifications will be promulgated by EPA to all state and local governments.

The association offers a voluntary Certification Pro- 
gram for water well drilling contractors and pump construction contractors throughout the United States. One general and 12 specific examinations are given for certification achievement. Standards and certification are promoted through NWWA's industry trade journal, the Water Well Journal.

\section{NATIONAL WHOLESALE HARDWARE ASSOCIATION, 1900 Arch Street, Philadelphia, Pennsylvania 19103}

The National Wholesale Hardware Association (NWHA) was established in 1894, for wholesalers of hardware products.

NWHA has a comprehensive standardized forms program and as a result has issued Standardization of Forms and Information Flow Used in Ordering, Shipping, and Billing of Merchandise Within the Hardgoods Industry. NWHA, the American Hardware Manufacturers' Association, the National Builders Hardware Association, the National Industrial Distributors' Association and the Southern Industrial Distributors' Association strongly recommend the adoption of the included standardized forms by companies throughout the hardgoods industry. All segments of the industry will benefit from the program of standardization of forms and information flow, because clerical personnel will know where to look for specific data; fewer interpretation errors will develop; related paper work can be pulled together more easily; cross checking becomes faster and more accurate; unnecessary delays in the movement of goods can be greatly reduced and costly follow up procedures can be eliminated.

The standardization booklet, which includes a glossary of terms, the distributor's purchase order to vendor's back order acknowledgment, vendor's packing copy to accompany shipment, vendor's invoice to distributor, distributor's check voucher, use of bill of lading, vendor's shipment and item identification, and exhibits of forms, is available from NWHA.

\section{NATIONAL WOODEN PALLET AND CONTAINER ASSOCIATION, 1619 Massachusetts Avenue NW., Washington, D.C. 20036}

This association, founded in 1947, consists of manufacturers and distributors of pallets, pallet containers, boxes, crates, shook, and skids. The association pub. lishes standard specifications covering the construction of hardwood, softwood, and plywood pallets. These standards provide minimum requirements for a series of nine quality grades covering various wooden pallets.

Formed by merger of: National Wooden Box Association and National Wood Pallet Manufacturers' Association (1947). National Wooden Box Association was formed (1964); National Wooden Box Council.
NATIONAL WOODWORK MANUFACTURERS' ASSOCIATION,

400 West Madison Street, Chicago, Illinois 60606

This association has taken an active interest in the standardization of commodities in its industry. It was sponsor of the following standards published by the National Bureau of Standards: Commercial standard CS120-58 for Ponderosa Pine Doors; CS171-58 for Hardwood Veneered Flush Doors; CSI63-64 for Ponderosa Pine Windows, Sash, and Screens; CS190-64 for Double-Hung Wood Window Units; C.S204-64 for Wood Awning Window Units; CS205-64 for Wood Casement Window Units; CS208-57 for Wood Door and Window Frames; CS262.63 for Preservative Treatment for Millwork: CS264-64 and 265-64 for Horizontal Wood Window Units; and CS266-64 for Single Hung Wood Window Units. These standards have been revised and issued as industry standards. They are available from the association.

Formerly: National Door Manufacturers' Association (1950).

\section{NATURAL GAS PROCESSORS ASSOCIATION, \\ 1812 First Place, 5th and Boston, Tulsa, Oklahoma 74103}

This association, formerly the Natural Gasoline Association of America was founded in 1921 to develop standard tests and specifications for casinghead gasoline. Specifications, particularly for vapor pressure, were established that are still referred to in casinghead contracts written today. Later, tests to determine the gasoline content of natural gas were developed.

Following work on natural gasoline tests, interest was directed toward the field of LP-gas (propane and butane) and natural gas. Vapor pressure composition specifications and approved loading techniques have been developed for LP-gas. Analytical procedures and contaminant tests have been developed for both LP-gas and natural gas.

Most recent work has been in the field of cryogenic gas processing, LNG, and synthetic gas processing. The development of new standards in these fields have been assigned within various sections of the Technical Committee.

Many of the tests and specifications developed by NGPA have been accepted and published by the American Society for Testing and Materials. Standards not available through ASTM are listed in a periodically updated publication folder available from the association offices.

NGPA developed standards are accepted nationally and, in many cases, internationally for natural gas processing operations and for contractual purposes. The standardization program is a major part of the association work, representing one-fourth to one-third of the total NGPA program. 


\section{NORTH AMERICAN WHOLESALE LUMBER ASSOCIATION, \\ 180 Madison Avenue, New York, New York 10016}

The National American Wholesale Lumber Association, which was founded in 1893 , changed its name to the North American Wholesale Lumber Association in 1972. One of the objects of this association is to aid and more efficiently distribute all lumber and forest products (1) through standardization of grades and sizes, and (2) through the elimination of unfair practices and trade abuses, in cooperation with proper Government agencies and officials. This association's activities in standardization are carried on in cooperation with the American Lumber Standards Committee on which it maintains official representation in the development of American Lumber Standards. The association endorses the principle of grade-marking all lumber and will appoint special committees when occasion requires, to consult and cooperate with grademarking committees of lumber manufacturers' associations for the grade-marking of lumber of various species.

\section{NORTHEASTERN LUMBER MANUFACTURERS' ASSOCIATION, 13 South Street, Glens Falls, New York 12801}

NELMA was founded in 1933 as a private, nonprofit, nongovernmental organization. It is incorporated in the State of Delaware. The association's purpose is the promotion of the welfare and the advancement of the interests of the northeastern lumber producer.

NELMA is the American Lumber Standards Committee Board of Review's rules writing agency for the northeast. Also, it is an approved grading agency. The development of the Standard NELMA Grading Rules for Northeastern Lumber is the responsibility of the association's Grading Committee.

\section{NORTHERN HARDWOOD \& PINE MANUFACTURERS' ASSOCIATION, INC., Suite 501 Northern Building, Green Bay, Wisconsin $\mathbf{5 4 . 3 0 1}$}

NH\&PMA was established in 1905 as a nonprofit association to promote the use of Northern woods. One of its objectives is to establish and maintain uniform standard grades for lumber and logs.

NH\&PMA derives its authority to write and maintain Official Grading Rules for Softwood and Aspen Lumber from Voluntary Product Standard 20-70. The Product Standard promulgated by the U.S. Department of Commerce established a common basis for uniform industrywide inspections and grademarking for each piece of lumber which is produced and sold.

As an authorized grade rules writing agency represented on the American Lumber Standards Committee, the NH\&PMA is committed to the formulation and maintenance of uniform grading rules in the interest of standards for quality, sizes and nomenclature for both manufacturer and consumer alike.

Additionally, the association maintains an inspection staff and offers the services of supervision of lumber inspectors, reinspection of shipments and certification of shipments.

The association publishes the Official Rules for Eastern White Pine, Norway Pine, Jack Pine, Eastern Spruce, Balsam Fir, Eastern Hemlock, Tamarack and Aspen. Another publication of the association is the Official Grading Rules for Northern Hardwood and Softwood Logs and Tie Cuts.

\section{OPTICAL MANUFACTURERS' ASSOCIATION, 1730 North Lynn Street, Arlington, Virginia 22209}

The association has prepared and makes available Standards and Specifications for Marking and Stamping Optical Frames and Mountings Made in Whole or in Part of Gold, that are based upon the National Stamping Act, Commercial Standards CS 47-34 and CS $67-38$ promulgated by the National Bureau of Standards, and pertinent rulings of the Federal Trade Commission. The association has worked out methods of marking temple lengths and measuring frame and lens sizes, and has adopted screw standards for ophthalmic frames. The association is an active member of the American National Standards Committee Z80 that is concerned with standards for ophthalmic frames, lenses, contact lenses and sunglasses.

\section{OPTICAL SOCIETY OF AMERICA, 2100 Pennsylvania Avenue NW., Washington, D.C. 20037}

The Optical Society of America was founded in 1916 to increase and diffuse the knowledge of optics in all its branches, pure and applied; to promote the mutual interests of investigators of optical problems, of designers, manufacturers, and users of optical instruments and apparatus of all kinds; and to encourage cooperation among them.

The standardization and specification work of this society is handled largely by technical committees which have published reports in the society's journal on visual sensitometry; colorimetry; photometry; standard wavelengths; nomenclature and standards; photographic standards of intensity; geometrical, physiological, and physical optics; photochemistry and photography, radiometry; and spectrophotometry. The latest and most elaborate of these technical reports appeared as a book, The Science of Color, published in 1953 by Thomas V. Crowell Co., for the Colorimetry Committee of the Optical Society of America, and in 1963 by the Optical Society of America.

In addition, the society cooperates with other technical organizations in standardization and specifications within the various branches of optics. The society cooperates actively with the International 
Commission for Optics and the International Commission on Illumination. It cooperates extensively with the American National Standards Institute (ANSI), serving as sponsor for the American National Standards Sectional Committee on Optics, and having representatives on the ANSI Photographic Standards Board and on seven American National Standards sectional committees in photography, motion pictures, safety glass, and ophthalmic lenses. The society also maintains representation on boards or committees of the American Institute of Physics, the National Research Council, the American Association for the Advancement of Science, and the Inter-Society Color Council.

\section{OUTDOOR POWER EQUIPMENT INSTITUTE, INC., $1725 \mathrm{~K}$ Street NW., Suite 903.905, Washington, D.C. 20006}

The Outdoor Power Equipment Institute (OPEI) was founded in 1952. Although OPEI does not independently develop product or safety standards for the industry, it has undertaken sponsorship for the development of recommended safety specifications for power mowers under the American National Standards Institute. In the future OPEI anticipates development of safety specifications applicable to other outdoor powered equipment. Any such standards will also be issued as American National Standards.

Formerly: Lawn Mower Institute.

\section{PACKAGING MACHINERY MANUFACTURERS' INSTITUTE, 2000 K Street NW. Washington, D.C. 20006}

PMMI is a voluntary nonprofit association, founded in 1932, of U.S. companies manufacturing packaging machinery and packaging-related converting machinery. The institute seeks to solve the common problems of the packaging machinery industry; and toward this goal, PMMI provides information and services to member companies, users of packaging and converting machinery, the Government and the general public.

Standardization work plays a small but important role in the institute's activities. Industry standards are dealt with under the guidance of the Product Safety and Technical Information Committees. PMMI is a member of the American National Standards Institute (ANSI) and supports its work with the International Organization for Standardization.

Working closely with the Occupational Safety and Health Administration, PMMI has published a safety standard for the Care, Use and Construction of Packaging Machinery which is currently under ANSI review.

PMMI also cooperates with other related associations such as the Fibre Box Association and the Adhesives Manufacturers' Association of America in promoting recommended practices on the storage, maintenance and application of adhesives used in conjunction with automatic packaging machinery.

PMMI makes active use of the packaging industry's trade press to inform machinery users of the institute's work in the standards area.

\section{PAINTING AND DECORATING CONTRACTORS OF AMERICA, 7223 Lee Highway, Falls Church, Virginia 22046}

The Painting and Decorating Contractors of America (PDCA) was founded as a national organization in 1884. One of the stated objects of this organization is its efforts to protect members and the general public by endeavoring to maintain high standards of workmanship and safety in the painting, decorating, drywall, wallcovering and coating industries.

The association maintains a National Apprenticeship and Training Committee. This committee, in conjunction with the International Brotherhood of Painters and Allied Trades, and the Gypsum Drywall Contractors International Association, prepares and distributes complete courses of training for all painting, decorating, wallcovering and drywall apprentices throughout the nation, as well as material for journeyman retraining. This joint apprenticeship committee prepares standards of training which are approved by and filed with the Bureau of Apprenticeship and Training, U.S. Department of Labor.

PDCA maintains a National Safety Committee. This committee, in conjunction with the Bortherhood of Painters and Allied Trades, has prepared a booklet of safety in the painting, decorating and drywall industry. PDCA is a member of the National Safety Council and is a member of the American National Standards Institute (ANSI). PDCA has membership on the various committees of ANSI and helps with the preparation of standards for submission to the Occupational Safety and Health Administration for approval as safety standards for the construction industry and the painting and decorating industry.

All of the committees are listed in the annual yearbook which is published in July of each year. The monthly publication, PDCA 73, promotes use of various standard materials provided by these committees through this association.

\section{PAPER STATIONERY AND TABLET MANUFACTURERS' ASSOCIATION, INC., 444. Madison Avenue, Suite 2301, \\ New York, New York 10022}

The Paper Stationery and Tablet Manufacturers' Association was founded in 1933 and incorporated in 1934 as a nonprofit, business supported organization. The association represents converters of paper, paperboard and related materials for production of writing paper and envelopes for personal correspondence, and writing papers for educational uses. 
Standardization activities in the association are handled through the Standards Research Committee. Standards research has been conducted since 1938. The most recent publication on voluntary recommended standards for most commonly accepted sizes and specifications for tablets and related products was published in 1964. At present, this is the only standards publication available to the public.

The association does not set standards for the industry. It only recommends sizes and specifications for a variety of writing tablets based on industry practice and experience. Some additional standards research has been done on envelope sizes and length to width ratios, but this data has never been published.

The association is national in scope and recommended voluntary standards are available to nonassociation members, Government agencies and an interested general public.

The Standards Research Committee currently is embarking on a study of the impact of making a transition to a metric system of measurement.

\section{PAPERBOARD PACKAGING COUNCIL, $1800 \mathrm{~K}$ Streel NW. Washington, D.C. 20006}

The Paperboard Packaging Council (PPC) is a nonprofit national trade association representing companies in the production and conversion of paperboard into folding cartons and packages. The Paperboard Packaging Council was established in July 1967, from the merger of several preexisting groups such as the Folding Paper Box Association and The Institute for Better Packaging.

The council's functions include several areas such as marketing information and statistics, industrial relations and safety, technical and production, and Government relations.

The development of industry standards represents a relatively small percentage of the council's ongoing activities, and efforts in this direction come under the Technical and Production Committee, and/or special ad hoc groups established for these purposes.

PPC was the proponent and contributed toward the development of the U.S. Department of Commerce Simplified Practice Recommendations R258-56, OnePound Eastern Flat Margarine Carton and R261-58 (both withdrawn October 2, 1973); and R252-60, Standard Sizes of Pint, Quart, and Half-Gallon Rectangular Ice Cream Cartons and Molds. The council issues Guidelines and Standards for the Paperboard Packaging Industry, as a set of voluntary industry standards and specifications recommended for the guidance of both users and suppliers of folding paper cartoons. Recently the council, in conjunction with the Federal Government developed a new bacon carton. PPC also cooperates with the Government in reviewing and commenting on Federal specifications. Currently, the council is involved in standards for printing nutritional labeling and Universal Product Code symbols on fluid milk cartons.

\section{PERLITE INSTITUTE, 45 West 45th Street, New York, New York 10036}

As a national and international, nonprofit trade association, this institute sponsors research leading to standardization of specifications and methods of testing perlite and perlite products. The institute collects data, initiates and correlates research, and develops specifications and test methods. It cooperates closely with technical and engineering societies, other trade associations, and Government agencies interested in standards.

The institute publishes test methods and related standards containing test methods for evaluating quality of expanded perlite, and American Society for Testing and Materials Specifications applicable to perlite. It also publishes standards for perlite products used in the building, industrial, and horticultural industries.

\section{PHARMACEUTICAL MANUFACTURERS' ASSOCIATION, 1155 Fifteenth Street NW., W ashington, D.C. 20005}

This association was created in 1958 by a merger of the drug manufacturers formerly belonging to the American Drug Manufacturers' Association and the American Pharmaceutical Manufacturers'Association. Scientists of member firms constitute committees which work with the United States Pharmacopoeia and the National Formulary in developing methods of analysis and standards for drugs used by the medical and allied professions. These association committees also cooperate with the Food and Drug Administration, the National Institutes of Health, the Bureau of Narcotics and Dangerous Drugs, and other agencies of the Federal Government.

Among other things, the association encourages high standards of potency, quality, and purity for pharmaceutical and biological products intended for use by the medical and allied professions in the cure, mitigation, treatment, prevention or diagnosis of disease; it assists appropriate scientific and Government agencies in the establishment of scientific and tcchnical standards for such products. It encourages research in the development of new and better medicinal products and better facilities and methods for their pharmacological and clinical evaluation. It urges efficiency, safety, and better methods in the manufacture, maintenance, packaging, and transportation of medicinal products. It promotes the enactment of uniform and reasonable drug legislation for the protection of public health, and cooperates with regulatory agencies in the rcasonable enforcement of such legislation. It disseminates information on Government regulations and policies and on other subjects of interest to the pharmaceutical industry, and encourages and promotes the development of scientific and technological skills useful in the discovery, 
evaluation, and production of pharmaceutical and biological products for the cure, mitigation, treatment, prevention, or diagnosis of disease. It cooperates in all lawful ways with professional associations in the health field, other industries, and government authorities in the advancement of medical science, the improvement of public health and the advancement of the pharmaceutical industry.

\section{PHARMACOPEIA OF THE UNITED STATES SEE UNITED STATES PHARMACOPEIA}

\section{PHOTO CHEMICAL MACHINING INSTITUTE, 1717 Howard Street, Evanston, Illinois 60202}

The Photo Chemical Machining Institute (PCMI) was founded in 1968 for companies producing metal parts by photo chemical machining.

PCMI has published three standards including: PCMI-D-300, Standards for Dimensional Tolerances and PCMI-T-100, Terms and Definitions. Both of these standards are published in a booklet entitled: What Is The Photo Chemical Machining Process and What Can It Do For You?

PCMI has published a third standard for metal specifications for use in chemical machining. It is the PCMI-A-200, entitled Guidelines for Specifying Metals and Alloys for Photo Chemical Machining. This specification is included in the 200 page PCMI publication entitled: Guide to Alloy Selection. This guide contains 34 specifications of the American Society for Testing and Materials on such topics as copper, nickel, stainless, aluminum, magnesium, cold rolled carbon steel strips, titanium, and many others. The purpose of this guide is to provide, in one reference volume, a compendium of all alloy specifications that are utilized in photo chemical machining.

\section{PHOTOGRAPHIC SOCIETY OF AMERICA, 2005 Walnut Street,} Philadelphia, Pennsylvania 19103

The society, founded in 1933, is a nonprofit organization, international in scope, and devoted to the advancement of photography in all its manifestations. The broad interests of PSA members encompass a wealth of experience in the uses of all types of photographic materials, the technology of their applications, and the characteristics and processes of their manufacture. Through its Uniform Practices Advisory Committee, PSA organizes the multidiscipline viewpoints of its membership to assist in the formulation of society uniform practices and in the contribution to national standardization. The society is affiliated with the American National Standards Institute (ANSI) and has representatives on all of the PH sectional committees on photography as well as membership on the Photographic Technical Advisory Board. The representatives selected by this society to represent its photographic standards interest, are chosen on the basis of their competence as users, their technical knowledge in the field, and their genuine interest. Each representative is charged with the responsibility of interpreting the feelings and attitudes of the society primarily from the consumer's viewpoint in resolving the important questions of standardization before casting his ballot. To assist their representatives, as well as to provide input to the ANSI Consumer Council, PSA is currently organizing a consumer advisory committee to direct the consumer needs in standards documents as well as for the assessment of uniform performance specifications.

The PSA Uniform Practices Advisory Committee also formulates the practices and the requirements for: judging and exhibition, nondiscriminatory entry, safe handling, and other rules which contribute to the success of international photographic salons, film festivals, and amateur photographic and camera club events on a worldwide basis. Through this function, the PSA has established itself as the de facto body in the formulation of international regulations for the exhibition of photographic materials.

Formerly: Associated Camera Clubs of America.

\section{PIPE FABRICATION INSTITUTE, 1326 Freeport Road, Pittsburgh, Pennsylvania $\mathbf{1 5 2 3 8}$}

The Pipe Fabrication Institute was founded in 1913. The standardization program of this institute functions through its engineering and metallurgical committees. The standards and technical bulletins emanating from these committees cover the design, fabrication and erection of industrial and high pressure-high temperature piping to meet the most exacting requirements of power plant-both nuclear and fossil, chemical, petroleum, and process piping. Through its members, the institute is officially represented on various code bodies and national engineer. ing societies.

\section{PIPE LINE CONTRACTORS ASSOCIATION, 2800 Republic National Bank Building, Dallas, Texas 75201}

This association was organized in the fall of 1947 to serve as a medium for the exchange of information among contractors engaged in the main-line pipe line construction industry. Its purposes are: (l) to make membership in the association a reasonable assurance to the public of the skill, integrity, and responsibility of its members; (2) to maintain the standards of the pipe line contracting business at the level necessitated by its quasi-professional character and to establish members of the association in the public mind as contractors to fulfill obligations in good faith; (3) to promote more cordial and cooperative relations among pipe line contractors and between those with whom they deal or have contact; (4) to encourage efficiency among pipe line contractors and their employees; (5) to seek correction of injurious, discriminatory or unfair business methods practiced 
by or against pipe line contractors; and (6) to eliminate, as far as possible, the occurrence of injury or death to pipe line contracting employees.

Representatives of the association serve on a joint committee which has published a Standard for Welding Pipe Lines and Related Facilities. Representatives of the association also work with other committees of the American Petroleum Institute and the American Gas Association in an effort to prepare a recommended form of contract and specifications for pipe line construction work.

\section{PLUMBING AND DRAINAGE INSTITUTE, 5342 Boulevard Place, Indianapolis, Indiana $\mathbf{4 6 2 0 8}$}

The Plumbing and Drainage Institute (PDI) is an association of manufacturers of plumbing and drainage products, incorporated in 1954 under the General Not-for-Profit Corporation Act of the State of Illinois. Its objectives are: (1) to contribute its combined talents and resources to promote advancement of plumbing engineering and the plumbing industry in general through publicity, public relations, research and standardization of product requirements; (2) to prepare, edit and publish standards related to plumbing products performance and application; (3) to provide certified testing, rating and installation procedures for grease interceptors and water hammer arresters.

The standards-writing activity is delegated to an Engineering Committee whose members represent various organizations. Standards currently published by the institute are: (1) Grease Interceptors, PDI Standard G.101; (2) Water Hammer Arresters, PDI WH-201-1965 (revised 1971). (This standard also issued by the American Society of Sanitary Engineering as ASSE \# 1010, March 1967.)

The following standards, published by the American Society of Mechanical Engineers, were prepared and edited by Panels 6-21 and 26 composed of the PDI's Engineering Committee, for American National Standards Project A112: American National Standard A112.6.1-1972, Supports for Off the Floor Plumbing Fixtures for Public Use; American National Standard A112.21.1-1968, Floor Drains; American National Standard A112.21.2-1971, Roof Drains; American National Standard A112.26.1-1969, Water Hammer Arresters. Several other American National Standards are in process for issue at a later date.

The standards referred to above are national in scope in that they are extensively used by architects, engineers, contractors, and Government agencies such as General Service Administration, Department of the Army, Coast Guard and Veterans Administration.

Certification testing equipment is maintained in an independent laboratory by the institute for testing water hammer arresters. The test laboratory issues test certificates to manufacturers whose products have passed PDI WH-201 tests. The institute, by agreement, furnishes certification seals which are placed on the product as evidence that the product installed has met the PDI performance specification.

Formerly: Plumbing and Drainage Manufacturers' Association (1949).

\section{POLYURETHANE MANUFACTURERS' ASSOCIATION, 600 South Michigan Avenue, Chicago, Illinois 60605}

The Polyurethane Manufacturers' Association established in 1972 is a private, nonprofit trade association consisting of those companies involved in the manufacture of solid polyurethane thermosetting elastomers and their related chemical and equipment suppliers.

The purpose of the association is to promote and maintain an organization for the mutual advancement and welfare of its members and the polyurethane industry.

As part of their goal, the Polyurethane Manufacturers' Association has established a Standards Committee whose purpose is to select and standardize physical test procedures suitable for use with solid polyurethane elastomers, and to promote and disseminate these recommended practices throughout the industry. The program, which the Standards Committee will undertake to accomplish this goal, consists of two phases: (1) evaluation and selection of existing specifications suitable for use with solid polyurethanes; and (2) to modify or institute new test procedures in a form suitable for use as an educational tool.

The specifications when completed will be issued in booklet form by the Polyurethane Manufacturers' Association.

\section{POWDER ACTUATED TOOL MANUFACTURERS' INSTITU'TE, INC., 331 Madison Avenue, New York, New York 10017}

Founded in 1952, PATMI is a nonprofit organization comprised of all the major USA manufacturers of powder actuated fastening systems. Its purposes are to further the development of the powder actuated fastening systems industry, to encourage the safe use and effective application of powder actuated fastening systems, to encourage research, and to cooperate with organizations engaged in such work.

The institute cooperates with Government and private organizations that are concerned with the use of powder actuated fastening systems and promotes the education of users and others in the safe and useful employment of those systems.

A Technical Committee comprised of engineering representatives of all PATMI member companies is continuously involved in the development of standards. Its direction and participation was a major factor in the preparation of American National Standard Al0.3-1972 for Powder Actuated Fastening Systems. Through cooperation with the U.S. Department of Labor, the PATMI Technical Committee's 
safety standard recommendations were incorporated by reference in the Construction Safety Act of 1969 and the Occupational Safety and Health Act of 1970.

A representative of PATMI serves on the International Organization for Standardization, ISO/TC 29 Subcommittee developing an international standard for power loads used in powder actuated fastening systems.

The PATMI Technical Committee has prepared standardization data for the General Services Administration (GSA) for powder actuated fasteners and will soon embark on similar updated GSA specification standards for powder actuated tools and power loads. Similar efforts by PATMI members for building construction standards are now underway with the American Society for Testing and Materials (ASTM) and with the Federal Housing Administration of the Department of Housing and Urban Development.

\section{PRESSURE SENSITIVE TAPE COUNCIL, 1201 W aukegan Roarl, Glenview, Illinois 60025}

The Pressure Sensitive Tape Council (PSTC), founded in 1953, is an organization of manufacturers of self sticking tapes with the objectives of increasing knowledge about their use and the understanding of their characteristics.

The PSTC's Technical Committee has developed a series of recommended test procedures for determining the various characteristics of pressure sensitive tape such as adhesion, tensile strength, thickness, etc. In addition, it has available laboratory test apparatus for the testing of pressure sensitive materials. The council publishes an annual directory of all American tape products indicating their principal use and characteristics. It also maintains liaison with Government agencies interested in pressure sensitive tapes.

The council has recently adopted a metric conversion program. It works closely with other trade associations in Europe and Japan.

\section{PRINTING INDUSTRIES OF AMERICA, INC., 1730 North Lynn Street, Arlington, Virginia 22209}

Printing Industries of America, Inc. the world's largest trade association representing the graphic arts industry, was founded in 1887 as a federation of national, state, and regional associations. It performs a primary role in industrial relations, management development, public relations and government affairs for its industry. By its own efforts and through cooperation with other organizations, including the American National Standards Institute, it has maintained a continuing interest in the development of standards for promoting technological progress and production efficiencies.

Recent activities have included a secretariat role in American National Standards Committee B65, resulting in Safety Specifications for Controls and Signaling Devices for Printing Presses; participation with the
Technical Association of the Pulp and Paper Industry in production; operating communication standards for magazine paper mills, printers and publishers: publication of Virgin Vinyl Standards for Loose Leaf Binders through its Binding Industries of America Section; development of Standard Specifications for Preparation of Computer Prepared Second and Third Class Postage Mailing Labels, through its Magazine Printers Section; preparation of standards for printing plate gauges, sizes, tolerances, and packaging, through its National Association of Grained Plate Manufacturers Section; participation with Magazine Publishers Association and others in the development of standard specifications for advertising reproduction material for magazine web offset printing; and others through its Graphic Communications Computer Association and International Business Forms Sections.

Absorbed: Lithographers and Printers' National Association (1964).

Formerly: United Typothetae of America (1945); Printing Industry of America, Inc. (1965).

\section{PROJECT MANAGEMENT INSTITUTE, P.O. Box 43, \\ Drexel Hill, Pennsylvania 19026}

The Project Management Institute (PMI) was founded in October 1969 as a nonprofit organization devoted exclusively to the field of project management. PMI's objectives are to: foster recognition of the need for professionalism in project management; provide a forum for the free exchange of project man. agement problems, solutions and applications; coordinate industrial and academic research efforts; develop common terminology and techniques to improve communications; provide interface between users and suppliers of hardware and software systems; and to provide guidelines for instruction and career development in the field of project management.

Currently, standardization efforts represent perhaps 10-15 percent of the institute's efforts. The functions are performed through the Professional Liaison Committee which can call on and coordinate with the Technology, Research Policy and Education Committees. The institute participates in national activities through the American National Standards Committee XK 36.3 and internationally, through liaison with an appointed observer to Internet. PMI currently does not deal with the Federal Government directly; a number of members are Federal employees in agencies involved with project management.

\section{PULVERIZED LIMESTONE ASSOCIATION, c/o Pfizer Inc., 640 Nortll 13th Street, Easton, Pennsylvania 18042}

The Pulverized Limestone Association was founded in 1954. This association is composed of companies engaged in manufacturing and selling pulverized limestone products of a minimum fineness of 97 percent, passing through a 325 mesh screen. One of 
the objects of this organization is to develop high and uniform standards that can be usefully adapted by manufacturers and users of pulverized limestone. As part of this, it is also active in developing the best and most useful method of testing significant properties of pulverized limestone.

The association sponsors research projects for the use of pulverized limestone in the manufacture of paper, plastics, rubber, paints, floor coverings and other useful applications as an inert filler material.

\section{RACK MANUFACTURERS' INSTITUTE, 1326 Freeport Road, Pittshurgh, Pennsylvania 15238}

The RMI consists of 27 firms located throughout the United States which are engaged in the design and manufacture for sale of industrial steel storage racks.

RMI has been active in several areas over the years, notably in standardization and fire protection of high rack storage areas. Its published standards and nomenclature include: Standard Nomenclature for Pallet Stacking Frames, Nomenclature for Drive-in and Drive-thru Pallet Racks, Nomenclature for Pallet Racks, Nomenclature for Cantilever Racks, and, most recently, an Interim Specification for the Design, Testing and Utilization of Industrial Steel Storage Racks. This specification was promulgated in the interest of improved uniformity of rack performance and enhanced public safety and supersedes the RMI's Minimum Engineering Standards published in 1964. RMI is currently engaged in a comprehensive seismic analysis study with results to be released later this year (1973).

The previously mentioned interim specification is currently under review by the American National Standards Institute for acceptance as an American National Standard.

\section{RADIO TECHNICAL COMMISSION FOR AERONAUTICS, \\ 1717 H Street NW., Suite 655, Washington, D.C. 20006}

The Radio Technical Commission for Aeronautics (RTCA) was formed in 1935. RTCA is a medium through which the aviation community, industry and Government, can discuss and resolve common technical problems in an atmosphere of confidence. Through this process RTCA has become an organization that is universally recognized for its proven accomplishments in the advancement of aeronautics. It is an organization which enjoys confidence and respect, both nationally and internationally. RTCA's scope of activities is in the field of aviation electronics and telecommunications, and in other closely allied fields. Some examples of areas of interest are: determination of common operational requirements; stateof-the-art developments and applications; minimum operational characteristics for airborne systems; minimum performance standards and test procedures; environmental test procedures for electronic/electrical instruments; operational and technical characteristics of systems; aeronautical frequency spectrum utilization; and other problems associated with air traffic control, navigation, communications, and efficient utilization of airports and airspace. RTCA provides leadership and guidance to industry and Government by pinpointing common problems and requirements, and by recommending solutions and applications within the state-of-the-art. This includes monitoring other activities and effectively following-up on approved project studies. RTCA engages in studies of common problems and the development of coordinated technical solutions; provides open forums for the exchange of views; and operates as an information source, particularly with respect to common problems and requirements, developments, and potential applications within the state-of-the-art.

The work to accomplish RTCA's mission takes place through each of its major elements: the Assembly, the Executive Committee, the Technical Advisers, the Special Committees, and the Secretariat. The general membership of RTCA is known as the assembly, and membership in the assembly is open to any United States organization identified with some phase of RTCA activities. It comprises over 100 Government and industry organizations. The Federal Government members include: the Department of State, Department of the Army, Department of the Navy, Department of the Air Force, U. S. Marine Corps, Department of Commerce, Federal Aviation Administration, Fed. eral Communications Commission, National Aeronautics and Space Administration, and the U. S. Coast Guard. International associate status is available to foreign organizations. Membership is not open to individuals. The affairs of RTCA are managed by its Executive Committee. Every assembly member is represented on the Executive Committee by a member thereof who is appointed by the organization or membership group he represents. Technical advisers are appointed for a period of one year by the chairman. They act in the capacity of expert consultants to RTCA. Special committees are authorized by the Executive Committee. The memberships of special committees are drawn principally from the RTCA Assembly. The secretariat of RTCA, under the director, Technical Services, arranges technical forums, briefings and committee meetings, maintains technical liaison, publishes RTCA documents, and operates as a technical information source for RTCA members.

RTCA devotes approximately 75 percent of its total program to its standardization activities. It has completed numerous studies on complex questions which are of tremendous practical importance to aviation. Included among these in recent years are: Universal Air-Ground Digital Communications System Standards; Minimum Operational Characteristics for Airborne Systems; a New Guidance System for Approach and Landing; and Minimum Performance Standards for Emergency Locator Transmitters. A complete list of current reports is available on request from the secretariat. Currently, special committees are in the 
process of developing reports on the following subjects: U.S. National Aviation Standard for the VHF/ UHF Air-Ground Communications-Voice and Data; VORTAC Improvements; Planning for $50 \mathrm{kHz}$ VOR/ ILS Channeling; Environmental Conditions and Test Procedures for Airborne Electronic/Electrical Equipment and Instruments; Altitude Encoders for use with Aircraft Radar Transponder Beacons; Airborne Doppler Radars; and Airborne LORAN A and C Equipments. A complete list of current Special Committees is contained in the Activities Report, available on request from the secretariat.

RTCA has benefited from extensive international participation in special committee activities. Special committees also have developed and are producing internationally-coordinated standards on airborne equipment. This international coordination effort is underway with the European Organization for Civil Aviation Electronics (an activity of the European Civil Aviation Conference), and others, to meet the international standardization needs of both manufacturers and users of electronic equipment. Certain RTCA internationally-coordinated standards are recognized in connection with the Standards and Recommended Practices (SARPS) of the International Civil Aviation Organization, (ICAO).

\section{THE RAILWAY TIE ASSOCIATION, 314 North Broarlway, St. Louis, Missouri 63102}

The Railway Tie Association was founded in 1919 as the National Association of Railroad Tie Producers, and changed to its current name in St. Louis, on June 3, 1937. RTA is national in scope, with a membership of virtually all of the producers, pressuretreaters, and marketers of wood railroad cross ties, as well as most of the railroad users of wood cross ties represented by purchasing officers and maintenanceof-way officers. Perhaps 15 percent of the total program is consigned to the standardization program. The standardization activities of the Railway Tie Association are administered by the Executive Committee and by the Committee on Research and Product Development.

The organization's participation in international programs is somewhat limited, but through RTA's Canadian membership, there exists a free exchange in matters pertaining to wood cross tie specifications.

RTA cooperates freely with Government agencies on cross tie specifications. Recently, RTA provided counsel for the proposed revision of the cross tie Federal Specification MM-T-371, to the U. S. Army Mobility Equipment, Research and Development Center, Fort Belvoir, Virginia. The association has one current standard: Specifications for Cross Ties and Switch Ties of the Railway Tie Association.

The Railway Tie Association's active standards committee is the Committee on Research and Product Development. This committee is presently working with the Association of American Railroads Research Center and the Chicago and Northwestern Railway on a research test track at Des Plaines, Illinois. RTA's standards are promoted through Cross Ties, the monthly magazine of the association.

\section{RED CEDAR SHINGLE AND HANDSPLIT SHAKE BUREAU, 5510 White Building, Seattle, Washington 98101}

At the request of this bureau, a general conference of representative manufacturers, distributors, and users of red cedar shingles was called in 1931 under the auspices of the National Bureau of Standards, following which there was adopted a Commercial Standard for this commodity. At the request of interested groups, the standard was later revised to include California redwood and tidewater red cypress shingles, and issued as Commercial Standard CS31-33 for Wood Shingles. This standard, which was revised in 1938 and 1952, covers No. 1 grade shingles, and was accepted and approved for publication by the National Bureau of Standards.

In order that interest might be increased in the manufacture, sale, and use of high-grade shingles, and consumers protected on the basis of quality, the Red Cedar Shingle and Handsplit Shake Bureau inaugurated a certification program. In accordance with this program, the bureau developed a quality label which manufacturers place on bundles of No. 1 grade red cedar shingles with a statement of guarantee that the shingles meet all the quality requirements of the Commercial Standard. In addition, the bureau maintains a corps of trained inspectors who visit the plants at frequent, unannounced intervals to check on the quality of shingles. Failure on the part of producers to comply with the requirements of the Commercial Standard results in loss of the right to use the labels until satisfactory adjustment has been made. Labels are also issued and placed on bundles of shingles for No. 2 and No. 3 grades which are indicated in plain figures on the labels, and carry statements that the singles are guaranteed to meet all quality requirements of the respective grades, as shown in current grading and packing rules of the Red Cedar Shingle and Handsplit Shake Bureau.

In 1955, at the request of this bureau, similar standards were drawn up for machine-grooved red cedar shakes and rebutted-rejointed red cedar shingles, designated as CS199-55. These two products are derived from red cedar shingles, and are used for exterior walls of buildings. A similar grademarking and certification program is followed as in the case of red cedar shingles, described above.

Formed by merger of: Red Cedar Shingle Bureau and Handsplit Cedar Shake Association (1963).

\section{REDWOOD INSPECTION SERVICE, 617 Montgomery Street, San Francisco, Califormia 94111}

In 1961, the Redwood Inspection Service was incorporated as a nonprofit organization for the pri- 
mary purpose of establishing uniform grades of redwood lumber, preparation and distribution of cducational information and publications, consultation with Government agencies concerning grades and grading of redwood lumber, and supervision of grades and grading of redwood and other species of lumber.

The service is the rules-promulgating agency for the redwood lumber industry. Its membership includes some 85 percent of the redwood production, the number of members varying between 30 and 40 . The rules are developed by a Grading Committee and approved by an 11-member Board of Directors. Prior to publication, the rules are submitted for approval by the American Lumber Standards Committee (ALSC), a quasi-public organization established under the Voluntary Product Standards program of the U. S. Department of Commerce.

The service has in this manner adopted standard specifications for grades, sizes, patterns, and grademarks for redwood lumber; planing mill products; special purpose uses for redwood lumber including tank stock, stadium seat stock, foundation sills, structural grades, structural glue laminating grades, and miscellaneous products including railroad ties, cooling tower material, shingles, and shakes.

It has also adopted official grademarks signifying that products so marked have been graded in accordance with standard specifications of the Redwood Inspection Service. These grademarks are applied by qualified graders of member companies or by cooperating grading agencies operating within requirements established by the American Lumber Standards Committee.

The service cooperates with other lumber organizations and with the American Lumber Standards Com. mittee in keeping current the American Lumber Standards set forth in the U. S. Department of Commerce Product Standard 20-70. The service's grading rules for redwood lumber are in accordance with these standards and approved by ALSC.

\section{THE REFRACTORIES INSTITUTE, 1102 One Oliver Plaza, Pittshurgh, Pennsylvania 15222}

The Refractories Institute, founded in 1951, is a nonprofit association of refractories manufacturers. This association cooperates with national technical associations regarding test methods for refractories. A manual has been published entitled Recommended Equipment and Procedure for the Palletized Loading and Shipment of Refractory Products, 1970.

\section{RESILIENT TILE INSTITUTE, 26 Washington Street, East Orange, New Jersey 07017}

For many years, this institute has prepared specifications for certain materials and methods in the resilient flooring field, and has worked with the Government in the preparation of similar Federal specifications.
Following are the specifications currently published by this institute: (a) Tile Specifications-Asphalt Tile, Vinyl Asbestos Tile, Self-Adhering Vinyl Asbestos Tile; (b) Adhesives, Cleaners and Polish Specifications -Adhesives (Cut Back), Adhesives (Emulsion), Cleaners, Floor Polish (Water Emulsion) ; (c) Installation Specifications--Installation of Vinyl Asbestos and Asphalt Tile for Floors, Installation of Vinyl Asbestos Tile as a Wall Covering; and (d) Maintenance Recommendations-Maintenance of Asphalt and Vinyl Asbestos Tile, No-Wax Maintenance of Vinyl Asbestos and Asphalt Tile in Commercial Buildings, Floor Protection Devices for Hospitals, Floor Protection Devices for Schools.

\section{RESISTANCE WELDER MANUFACTURERS' ASSOCIATION, 1900 Arch Street. Philadelphia, Pennsylvania 19103}

The Resistance Welder Manufacturers' Association was founded in 1931. The development of standards and specifications of this association is through its Technical Committee, assisted and advised by various subcommittees. RWMA has developed specifications for resistance welding machine: spot, press, portable, seam, upset butt, flashbutt, etc.

Standard classification of resistance welding electrode alloys has been developed, stating the minimum permissible physical and electrical qualities. Trade names and numbers are identified and classified.

Standards have been developed for spot welding electrode holders, welding electrodes (spot and seam); together with recommended electrode alloys for spot welding of similar and dissimilar metal combinations.

Standard nomenclature and definitions on resistance welding equipment and techniques have been developed. Cooperation of RWMA has assisted in development of National Electric Manufacturers' Association standards on resistance welding controls.

\section{RICE MILLERS' ASSOCIATION, 1048 Pennsylvania Building, 42513 th Street NW., Washington, D.C. 20004}

The Rice Millers' Association was founded in 1899. The association establishes standard contract terms and conditions for trade in rice and rice products. It prescribes standard forms of sales contracts for use in rice trade in the United States, Puerto Rico, and export markets. The association has adopted and uses grade and quality standards for rice of the U. S. Department of Agriculture.

\section{RUBBER MANUFACTURERS' ASSOCIATION, 1901 Pennsylvania Avenue NW. Washington, D.C. 20006}

The Rubber Manufacturers' Association was founded in 1915. The Technical Committees of this organization's several product groups collaborate with Federal, 
state and municipal agencies, domestic and foreign associations, and individual commercial users in the development of new or improved domestic and international standards and specifications for all kinds of rubber and rubber-like products. Emphasis is placed on the practicality of physical requirements endeavoring to achieve a simplification and minimization of sizes and types which will derive the greatest potential economic benefit to producers, wholesalers, retailers, and consumers through lowered processing, distribution, and inventory costs. The most efficient use of labor and raw materials is also an objective.

Typical products covered by these standardization activities include motor vehicle and agricultural tires; transmission, conveyor and elevator belts; suction, discharge, air, steam, gasoline and fire hose of both rubber and plastic; roll coverings and protective linings; molded and extruded rubber products; sheet rubber, mats and matting; O-rings and shaft seals; protective and fabric-upper footwear; druggists' sundries; surgical, hospital, and industrial rubber gloves, tubing, sheeting, and other items; sponge rubber and foam latex matresses, pillows, cushions and furniture upholstery; carpet and rug underlays; rubber and plastic heels, soling materials, and other shoe products; natural-rubber-type descriptions, and standard samples.

Formerly: New England Rubber Club (1909); Rubber Club of America (1917); Rubber Association of America (1929).

\section{THE RUBBER RECLAIMERS ASSOCIATION, INC., 63 Radnor Avenue, Naugatuck, Connecticut 06770}

The association, founded in 1930, publishes standard recipes and procedures for testing reclaimed rubber for use in rubber compounds. It also issues specifications for scrap rubber as related to acceptable grades and conditions for delivery to reclaimers.

\section{SALT INSTITUTE, \\ 206 North Washington Street, Suite 300, Alexandria, Virginia 22314}

The organization was founded in 1914 as the Salt Producers Association. In 1963, the corporate name was changed to Salt Institute. The institute's activities include research, information services, Government relations, member services, and field services to users of salt. It is a nonprofit trade association supported by the world's major salt producers.

Approximately 20 percent of the institute's total program concerns standardization. The Technical Director administers the standardization activities. The Technical Director is a U. S. Representative of Sub-Committee 5 of the International Organization for Standardization, Technical Committee 47. The institute serves as the national as well as the international standards representative for the salt industry. The institute cooperates with the following Federal Government agencies in standardization activities: General Services Administration, National Bureau of Standards, and the Department of the Army; and the National Academy of Sciences. In addition to working with the Federal Government in standardization activities, the institute also works with various trade associations that produce consensus standards such as: the American Water Works Association, the American Society for Testing and Materials, and the U. S. Pharmacopeia.

\section{SCAFFOLDING AND SHORING INSTITUTE, 2130 Keith Building, Cleveland, Ohio 44115}

This institute, founded in 1960, includes manufacturers of scaffolding and shoring. SSI establishes recommended criteria and inspection procedures for the proper and safe use of scaffolding and shoring to support formwork in concrete construction. Its standardization activities have involved attempts to obtain standardization of safety requirements in various state, city, and Federal codes. The institute has prepared and distributed Recommended Safety Rules for Scaffolding and Steel Frame Shoring, Single Post Shores, and Horizontal Shoring Beams.

Other publications are recommended erection procedures for scaffolding, vertical shoring, and horizontal shoring beams. The institute also prepared a booklet entitled "Recommended Safety Requirements for Shoring Concert Formwork" (Rev. Dec. 1971).

Formerly: Steel Scaffolding and Shoring Institute.

\section{SCIENTIFIC APPARATUS MAKERS' ASSOCIATION, \\ 1140 Connecticut Avenue NW., Washington, D.C. 20036}

This national trade association, founded in 1918, represents over 200 leading manufacturers and distributors of scientific instruments and laboratory apparatus. It is organized into seven product-oriented sections: analytical instruments, laboratory apparatus, measurement and test instruments, nuclear instruments, optical, process measurement and control, and scientific laboratory furniture and equipment. Each section has an active standardization program pursued through a standards committee. Section standards activities are coordinated by an overall SAMA Standardization Committee operating with a full-time SAMA Standards Executive. All standards are formulated, processed, approved and published in accordance with a SAMA Standards Manual.

A total of 28 SAMA standards have been published. These have been widely distributed through member companies and related organizations, and their availability is published from time to time in the trade and technical publications. Where appropriate SAMA standards have been and are being advanced through the American National Standards Institute (ANSI) to become American National Standards. 
The association sponsors and provides the secretariat for American National Standards Committee C100, Electrical Reference Instruments, and American National Standards Committee C39, Electrical and Electronic Instruments, as well as 5 subcommittees of C39. SAMA was instrumental in the recent establish ment of ANSI technical advisory boards for Measurement and Control Instruments (MACTAB), and Medical Devices (MEDTAB).

SAMA cooperates and supports closely the related standards making activities of: Instrument Society of America, American Society for Testing and Materials, Institute of Electrical and Electronic Engineers, National Conference of Standards Laboratories, National Committee on Clinical Laboratory Standards, Underwriters' Laboratories, National Fire Protection Agency, American Petroleum Institute, Association for Advancement of Medical Instrumentation, and others. It maintains active liaison and support of Government agencies involved in standards and specifications, including: National Bureau of Standards, General Services Administration, Department of Defense, Environmental Protection Agency, and the Occupational Safety and Health Administration.

Over the past 13 years SAMA has become increas. ingly active in international standards working with the pertinent committees and working groups of the International Organization for Standardization (ISO), the International Electrotechnical Commission (IEC); and more recently the International Organization for Legal Metrology (OIML). The association supports U.S. delegates to several committes and working groups and sponsors working group and committee secretariats.

Absorbed: Association of Nuclear Instrument Manufacturers (1917).

\section{SHEET METAL, AND AIR CONDITIONING CONTRACTORS' NATIONAL ASSOCIATION, 1611 North Kent Street, Arlington, Virginia 22209}

The Sheet Metal and Air Conditioning Contractors' National Association, known as SMACNA, was established in 1944 as a nonprofit, incorporated, trade association dedicated to the advancement of the sheet metal, heating, ventilating, air-conditioning, industrial sheet metal and roofing industries. Extensive activities and services are carried out in four departments: technical, labor relations, legislative affairs, and business management. Although some standards are developed for labor relations and safety practices, the majority of the organization's standards are produced by its Technical Services Department which employs engineering and other technical staff who work in conjunction with technical committees appointed mainly from the membership. SMACNA's technical standards fall in two general subject areas: duct construction and architectural sheet metal.

SMACNA's technical documents have national acceptance across the building and construction industry and the organization is the recognized authority on duct construction detail and is a recognized authority on architectural metal detail. Current publications are: Architectural Sheet Metal Manual, Architectural Sheet Metal Specifications, Air Handling Specifications, Low Velocity Duct Construction Standards, High Velocity Duct Construction Standards, Fibrous Glass Duct Construction Standards, Balancing and Adjustment of Air Handling Systems, Fire Damper Guide for Air Handling Systems, Ducted Electric Heat Guide for Air Handling Systems, Duct Liner Application Standard, Pressure Sensitive Tape Standards for Fibrous Glass Duct, Residential Heating and Air-Conditioning System Installation Standards (SMACNANESCA), Thermoplastic Duct (PVC) Construction Manual and Special Study Report on Fire Protection for Ceiling Outlets.

Publications are currently being developed for design of duct systems, flexible duct standards and industrial duct construction.

Formerly: Sheet Metal Contractors' National Association (1956).

\section{SNELL MEMORIAL FOUNDATION, INC. 761 Laurel Drive, Sacramento, California 95825}

The Snell Memorial Foundation, Inc. is a nonprofit California corporation organized October 10, 1957. Its primary purpose is to carry out research in brain trauma and protective headgear, and to develop and utilize advanced techniques for related critical measurements. Much of its work has been carried out under National Institutes of Health research grants.

It promulgated in 1959 the first standard for road users' crash helmets in the United States, and has established itself internationally as a pioneer and leader in developing increasingly higher standards for this usage. Its 1970 standard is generally recognized as carrying the most stringent safety performance requirements for road users' protective headgear in the world today. It also has established 1973 standards of safety performance criteria for skiier, bicyclist and equestrian protective helmets.

The foundation's standards are not minimum standards. Rather, they represent the upper levels of protective criteria which the manufacturing art is capable of meeting, and as that capability increases, the level of the standard is raised. Since 1959, the foundation has approved manufacturers' products meeting these and other criteria for certification under contractual agreements providing, among other matters, for ongoing random sample testing of helmets taken from dealers' shelves. Through its certification program, the foundation is able to keep in the forefront of improvements in the state of the manufacturing art, both as to methodology and materials, and to obtain data useful in its research program and development of more sophisticated test procedures.

The foundation is secretariat for the American National Standards Committee Z90 for road users' protective headgear; its research personnel serve as United States representatives on the International 
Organization for Standardization (ISO) committees for road user and industrial protective headgear; and it has cooperated closely with research commands of the U.S. Armed Forces, with state and local law enforcement agencies, and with the Federal Trade Commission. Nearing completion is a four-year study of the adequacy of industrial protective helmets. The foundation has published 13 papers. Copies of its standards are available from the foundation.

\section{THE SOAP AND DETERGENT ASSOCIATION 475 Park Avenue South, New York, New York 10016}

This association, which was founded in 1926, is a national trade group representing manufacturers of well over 90 percent of the soap and detergents produced in the United States and their raw material suppliers. Through its Technical and Materials Division, it conducts research to determine the effect of industry product constituents in water and sewage treatment processes, on aquatic life and water resources, and on consumer safety.

The association has acted as the coordinating agency in developing a test procedure and standards for determining the biodegradability of alkyl benzene sulfonate and linear alkylate sulfonate. Participating in the Joint Government/Industry Task Force on Eutrophication, the association helped develop an accepted standard algal assay procedure, which is now available from the U. S. Environmental Protection Agency. Subcommittees of the Technical and Materials Division are working with the Consumer Product Safety Commission toward the development of protocols under the Federal Hazardous Substances Act, which would establish the level of hazard of various constitutents in consumer products.

The Technical and Materials Division has a continuing program to review and evaluate existing procedures and to develop new methods and standards to meet current needs.

Formerly: Association of American Soap and Glycerine Producers.

\section{SOCIETY FOR INFORMATION DISPLAY, 654. North Sepulveda Boulevard, Los Angeles, California 90049}

The Society for Information Display, organized in 1962, is a private, nonprofit, nongovernment organization. Its primary efforts are in the field of computer derived dynamic information display. The standardization program is approximately 5 percent of the total program and is administered by the Definitions and Standards Committee. This committee is involved in international programs to the extent that the committees of the Institute of Electrical and Electronics Engineers (IEEE), Electronic Industries Association (EIA) and American National Standards Institute (ANSI), in which it is active, are involved. These committees are American National Standards Com- mittee X-3, IEEE/Electron Devices and EIA/6.16. No standards have been issued as yet but several are in preparation as a result of joint activities with the other organizations. These standards are concerned with light emitting diodes (IEEE), industrial cathode ray tubes (EIA), and fonts for alphanumeric dot characters (IEEE/ANSI), and are all national in scope.

\section{SOCIETY FOR TECHNICAL COMMUNICATION, INC., Suite 421, 1010 Vermont Avenue NW., W ashington, D.C. 20005}

The Society for Technical Communication (STC) was established in 1958 through a series of mergers of local and regional groups which had been formed throughout the country by persons concerned with the preparation and dissemination of technical communication. It is a nonprofit, educational membership organization whose purpose is to advance the theory and practice of technical communication in all media. It has chapters in the United States and Canada and members in foreign countries.

Activities include chapter programs, an annual international technical communication conference, publication of a journal, and standards and reference material used in technical documentation, manuals, reports, and writings. The STC Standards Council is interested primarily in two broad categories of standards: (1) guidelines which bear directly upon the profession of technical communication, (2) data and procedural standards which govern science, engineering, and the art that must be applied, interpreted or referenced in technical communication. STC has liaison with the American National Standards Institute, the Metric Association and others concerned with publication of technical information.

Formed by merger of: Association of Technical Writers and Editors; Society of Technical Writers (1957).

\section{SOCIETY OF ALLIED WEIGHT ENGINEERS, INC., Box 60024, Terminal Annex, Los Angeles, California 90054}

The Society of Aeronautical Weight Engineers was organized in 1939 in Los Angeles, California, and was incorporated as a nonprofit organization April 2, 1941. The society is now international. Effective January 1 , 1973, the society name was changed to the Society of Allied Weight Engineers, Inc.

The purpose of SAWE is (a) to promote recognition of weight control as a specialized branch of engineering; (b) to exchange weight information for mutual benefit; (c) to combine efforts to reduce the weight of purchased equipment; (d) to promote a better understanding among weight engineers; and (e) to promote and enhance the professional status of 
weight engineers and to encourage study of mass properties and weight engineering problems.

SAWE has contributed its services to the accomplishment of: standardization of mass property forms; standardization of mass property procedure; standardization of method of determining trapped residuals; development of detail weight statement; development of mass properties data for higher learning; development of accessory weight data; sponsorship of exchange of weight data; exchange between airline members of information concerning weight reduction on airline equipment; the collection of standard weights of raw stock and hardware together with engineering data into the "SAWE Weight Handbook."

\section{SOCIETY OF AUTOMO'TIVE ENGINEERS, 400 Connmonwealth Drive, Pittshurgh, Pennsylvania 15096}

Standardization has been an important activity of this society from its very beginning. It now carries on technical standardization work for the motor vehicle, aircraft, airline, space vehicles, farm tractor, earthmoving, and roadbuilding machinery, and other manufacturing industries using internal combustion engines. With the exception of aerospace, safety and environmental standards, which are published in looseleaf form, the basic standards of the society are published annually in the SAE Handbook. The society's standardization work is under the general direction of the SAE Technical Board which organizes such technical committees as may be necessary to carry on the work. The society's standards and technical committee activities also include active advisory cooperation with the Armed Forces and numerous other Federal and state government agencies. SAE is active in international standardization and sponsors several U. S. Technical Advisory Groups for International Organization for Standardization projects under the auspices of the American National Standards Institute. In addition, many SAE standards have found international usage by being voluntarily adopted by foreign industry or government. SAE standards are national in scope and are used widely throughout the international vehicle technical community.

The SAE standardization activity began in 1902 with the adoption of standards by the National Association of Automobile Manufacturers. In 1903, the Association of Licensed Automobile Manufacturers (ALAM) was organized by manufacturers licensed under the Selden Patent. In 1910, the society took over from the Mechanical Branch of the ALAM its work of preparing technical data and appointed the first standards committee in the automotive industry. During the years immediately following, other industries began to use internal combustion engines more widely, and it became evident that the SAE was the logical body in which to centralize all such activities. In 1917, the American Society of Aeronautics Engineers and the Society of Tractor Engineers merged with the SAE and soon thereafter the National Association of Engine and Boat Manufacturers and the
National Gas Engine Association merged their engineering and standardization work in the SAE, and the Society of Automobile Engineers then became the Society of Automotive Engineers, Inc. In 1926, the society initiated standardization in automotive production engineering, and in 1931 adopted the first standardization in the motor transport field.

In cooperation with the American Petroleum Institure, SAE sustains the Coordinating Research Council. This council was set up in 1942 to conduct cooperative research and similar work aimed at mating fuels and lubricants to power plants.

All standards, specifications, and reports developed by the society are made available for industry, the Government, or other usage on a voluntary basis. Currently there are approximately 3,000 standards and specifications covering the on-highway, off-highway and aerospace fields. Frequent checks are made to determine usefulness of each document. Unused documents are canceled. SAE interfaces in some way with every agency of the Government that is concerned with the design, manufacture or regulation of the vehicle. In most instances, SAE provides the means by which industry and government personnel can come together as individuals to discuss common technical problems and to work out feasible solutions to these problems. Because of the Government's interest in regulatory activities relating to the transportation equipment, and as a large volume purchaser of vehicles of all types, Government agencies have long drawn upon SAE and its cooperative engineering program for information and assistance. SAE standards are recognized in government publications as methods for measuring or testing for establishing minimum technical requirements in areas where government regulatory control has been established.

\section{SOCIETY OF DIE CASTING ENGINEERS, 16007 West 8 Mile Road, Detroit, Michigan 48235}

Established in 1954, the society is a nonprofit organization, incorporated in the State of Michigan in 1955. It exists to serve the interests of its members and others working in the die casting industry and associated industries. The society has a Technical Council with subcommittees working in several fields including safety, machinery, alloys, process, dimensions, metrication, quality, die design and coatings.

The society collaborates with other, older-established societies in the cast metals field in the estab. lishment of consensus standards in the above areas. It also provides guidance for research workers in cast metals, but does no research work itself.

\section{THE SOCIETY OF MANUFACTURING ENGINEERS, 20501 Ford Road, Dearborn, Michigan 48128}

SME was founded in 1932 as the American Society of Tool Engineers. From 1960 to 1969 it was known 
as the American Society of Tool and Manufacturing Engineers and in 1970 it became the Society of Manufacturing Engineers.

The change in name reflects the evolution of the manufacturing engineering profession, and the growth and increased sophistication of a technical society that has gained an international reputation for being the most knowledgeable and progressive voice in this field.

SME's function is to follow and assess the trends and developments in manufacturing; then to interpret, publish, and distribute the information. It provides a common ground and focal point from which manufacturing engineers and corporate managers can share ideas, information and accomplishments.

Engineering standards are of great concern to the manufacturing community and hence a vital part of this organization. Those standards activities sponsored by this society, and those which this society has representation on, are coordinated by the Technical Divisions of SME. SME has worked closely with the National Bureau of Standards, the American National Standards Institute, and the American Society for Testing and Materials in establishing standards in various fields. Standards which this society currently fosters include: Decimalized Measure, Industrial Diamond Dressing Tools, Safety Codes for the Care, Use, and Protection of Power Driven Brushing Tools, Tooling Nomenclature, Scales for Use in Decimal Inch Measure. These are the nationally sponsored standards of SME. In addition to this there are over 200 senior chapters of the SME, and each of these chapters has a standing committee devoted to the reviews and implementation of standards. Each committee reviews the standards in their particular area or field of expertise and initiates action or offers comment where necessary.

Formerly: American Society of Tool and Manufacturing Engineers.

\section{SOCIETY OF MOTION PICTURE AND TELEVISION ENGINEERS 862 Scarsdale Avenue, Scarsdale, New York 10583}

The Society of Motion Picture and Television Engineers is a nonprofit organization concerned with the engineering aspects of motion pictures, television, instrumentation, high-speed photography, and the allied arts and sciences. Founded in 1916 to develop technical standards for motion picture engineering, it has expanded to include television and the areas mentioned above. As secretariat of two American National Standards Committees, PH22 Motion Pictures and C98 Combined Visual-Aural Magnetic Recording for Television, SMPTE is responsible for generating and maintaining standards for these disciplines.

The society fulfills its objectives, as well as the standards program, by: (a) presenting technical papers at monthly meetings held by its 13 chapters; (b) arranging semiannual week-long technical conferences with technical papers sessions and equipment exhibits; (c) publishing a monthly technical journal; and (d) manufacturing and distributing technical test film for motion pictures and television.

Formerly: Society of Motion Picture Engineers (1950).

\section{TIE SOCIETY OF NAVAL ARCHITECTS AND MARINE EINGINEERS 74. Trinity Place,} New York, New York 10006

This society, in cooperation with other interested organizations such as the American National Standards Institute and the International Organization for Standardization, takes an active part in the establishment of standards, guidelines and codes relating to the design, construction, maintenance and operation of merchant marime ships, yachts, boats, offshore and ocean bottom structures, hydrofoils, surface effect ships and submersibles.

SNAME, founded in 1893, administers an extensive and active Technical and Research (T\&R) Program involving over 900 volunteer members covering all aspects of the above technologies, in cooperation with the Government including its regulatory agencies, scientific and research laboratories, academic institutions and the marine industry. It thus assists in the development of internationally recognized codes and standards on such subjects as shipboard vibration measurements, ship equipment shop and installation tests, ship sea trial acceptance tests, selection of high strength and alloy steels, allowable stresses in ships, guides to allowable abrasive blasting, coating systems and deck coverings, shipboard cranes, life support systems, centralized control and automation, shipboard nuclear power plant safety and others.

\section{SOCIETY OF THE PLASTICS INDUSTRY INC., 250 Park Avenue, New York, New York 10017}

This is a trade and technical society of over 1200 companies in all branches of the plastics industry interested in quality standards, research, uniform accounting, traffic rates, wage rate surveys, tariffs, codes, public relations, informative labeling, safety, fire prevention, food packaging, etc. It was founded in 1937.

SPI runs a number of industry conferences each year and sponsors the National Plastics Exposition every three years, usually in Chicago.

The companies making up the membership of this society are: injection, compression, and transfer molders; laminators; extruders; fabricators; calenderers; printers; embossers; reinforced plastics processors; raw material suppliers; machinery and equipment manufacturers; tool, die, and mold makers; research, development, and testing laboratories.

The society's members are located throughout the United States, Canada, and 28 other countries. Branch offices are maintained in Chicago at 3150 Des Plaines Ave., Des Plains, Illinois 60018 and Los Angeles at 611 South Catalina Street. 
For years SPI has worked closely with the U.S. Department of Commerce through the National Bureau of Standards toward the development of Commercial Standards and Voluntary Product Standards for plastic products. The cooperative efforts of companies in the plastics industry, the society, and the National Bureau of Standards have proved highly successful. As a result, these industry standards represent the largest number of voluntary standards prepared by any trade association through the Department of Commerce.

Voluntary standards have been published by the Department of Commerce on the following plastics products: TFE-Fluorocarbon (Polytetrafluorethylene) Resin Molded Basic Shapes; Polyvinyl Chloride (PVC) Plastic Pipe; Polyethylene (PE) Plastic Lipe; Acrylonitrile-Butadiene-Styrene (ABS) Plastic Pipe; TFE-Fluorocarbon (Polytetrafluoroethylene) Resin Electrical Insulating Tubing; TFE-Fluorocarbon (Polytetrafluoroethylene) Resin Sheet; TFE-Fluorocarbon (Polytetrafluoroethylene) Resin Flexible Hose (Wire Braid Reinforced), Vinyl-Metal Laminates; Polyethylene Sheeting (Construction, Industrial \& Agricultural Applications); Vinyl Plastic Weatherstrip; Styrene Rubber Plastic Sewer and Drain Pipe and Fittings; Rigid Unplasticized Polyvinyl Chloride Pipe; Flexible Polyethylene Plastic Pipe; Polyethylene Film; Gel-Coated Glass-Fiber Reinforced Polyester Resin Shower Receptors; Gel-Coated Glass-Fiber Reinforced Resin Bathtubs; Rigid ABS Plastic Pipe (IPS Dimensions) ; Glass-Fiber Reinforced Polyester Corrugated Structural Plastics Panels; Melamine Dinnerware (Alpha-Cellulose-Filled) for Household Use; Vinyl Chloride Plastics Garden Hose; Solvent Welded (SWP Size) Cellulose-Acetate Butyrate Pipe; Rigid Polyvinyl Chloride Sheets; General Purpose Vinyl Plastic Film; Heavy-Duty Alpha-Cellulose Filled Melamine Tableware; Polystyrene Plastic Wall Tiles, and Adhesives for their Application.

In addition, SPI committees are continually working on the preparation of other standards for plastics products for submission to the American Society for Testing and Materials and the American National Standards Institute (ANSI). SPI financially supports ANSI acting as secretariat to International Organization for Standardization, ISO TC-61 and participates fully in its activities.

\section{SOUTHERN BUILDING CODE CONGRESS, INTERNATIONAL}

3617 Eighth Avenue, South, Birmingham, Alabama 35222

The Southern Building Code Congress established in 1945, is a private, nonprofit, quasi-legislative organization, dedicated to the codification of minimum construction standards in a family of documents. Each code promulgated outlines standards which insure adequate safety to life, public health and welfare without adding unnecessarily to the costs of proposed structures. The codes produced by SBCC are as follows: Southern Standard Building Code; Southern Standard Plumbing Code; Southern Stand. ard Gas Code; Southern Standard Housing Code; and the Southern Standard Mechanical Code.

The congress has established a mechanism by which building code regulations are developed through the due process necessary for laws, regardless of whether they regulate human behavior or building activity.

As new technologies evolve, additions, subtractions and alterations to the contents of the codes become necessary. Each year, carefully written and edited changes are proposed by code officials, inspectors, architects, engineers, builders and associates from industry, manufacturer-producers and testing and research institutes. These proposed changes, substantiated by extensive documentation, are reviewed for clarity and content and then are printed in the October edition of Southern Building magazine, the monthly publication of the SBCC. In late October the Annual Research Conference of the SBCC is held.

The codes produced by the SBCC may be adopted by any city, county or state where adoption by reference is permitted. This adoption method merely requires passage of an enabling ordinance and the filing of three public record copies of each adopted code with the clerk of the respective Government agency. The ordinance should refer to the code by title, edition, name of the publisher and date.

The ordinance should include provisions to repeal all other conflicting ordinances and regulations and should establish or update fire districts as outlined on a map, also to be filed with the clerk. Once the enabling ordinance is adopted by the governing body, the clerk certifies its adoption and causes the ordinance to be published in a local newspaper. Publication of such an ordinance of adoption by reference should be done in conformity with state laws. A suggested wording of an ordinance of adoption can be furnished upon request.

Most Government agencies using the Southern Standard Codes have adopted them by the method outlined.

\section{SOUTHERN HARDWOOD LUMBER MANUFACTURERS' ASSOCIATION, Sterick Building, Memphis, Tennessee 38103}

The Southern Hardwood Lumber Manufacturers' Association was founded in 1935. Southern hardwoods are graded under the rules of the National Hardwood Lumber Association, as are all hardwoods manufactured in the United States and Canada. This organization cooperates with the National Hardwood Lumber Association in grade standardization of hardwood lumber; also with Government agencies and all lumber associations in the development of American Lumber Standards fostered by the Department of Commerce.

Formerly: Southern Hardwood Producers Inc. 


\section{SOUTHERN PINE INSPECTION BUREAU \\ P.O. Box 846, \\ Pensacola, Florida 32594}

This bureau is an autonomous nonprofit agency and is the recognized organization in the southern pine industry for the formulation and maintenance of grading standards. Since 1940, the Southern Pine Inspection Bureau has carried on a standardization program in developing grading rules for southern pine lumber carried on for more than 25 years previously by the Southern Pine Association. These rules are in conform. ity with American Lumber Standards as set forth in the current edition of Voluntary Product Standard PS 20-70, published by the National Bureau of Standards.

The Southern Pine Inspection Bureau took an active part in the formulation of these national standards and has direct representation on the American Lumber Standards Committee. This bureau also is officially represented on the Technical Committee on Timber of the American Society for Testing and Materials with reference to the preparation of standard specifications for timber and timber products.

The bureau's functions are to maintain standards of size and definite grade classifications, as reflected in its published grading and inspection rules, for the benefit of the lumber-using public and of the industry, and to provide competent and adequate inspection facilities. These inspection facilities are universally regarded as fair and impartial, and are used not only as a means of adjudicating disputes as to grades between buyers and sellers but also for the certification of southern pine lumber before shipment from the mill. The grading and manufacture of subscribers to the bureau are under the supervision of bureau quality supervisors and those mills which prove their efficiency in grading and agree to maintain the established standards of size and grade are licensed to grademark their lumber with a bureau mark symbolizing such supervision and efficiency.

\section{SPECIAL LIBRARIES ASSOCIATION, 235 Park Avenue South, New York, New York 10003}

Special Libraries Association, founded in 1909, is an international organization of 8,000 professional librarians and information experts. Special libraries serve industry, business, Government, research, educational and technical institutions-all organizations, both public and private, requiring or providing specialized information. The association encourages and promotes the utilization of knowledge through the collection, organization, and dissemination of information for the general welfare and the advancement of mankind.

The association has published a 20 page brochure entitled Objectives for Special Libraries. It sets forth standards for objectives, staff, collection, services, physical facilities, and budget for special libraries. A companion brochure, Profiles of Special Libraries, describes desirable practices in six different prototype libraries. Special Library Sketchbook describes actual operations of 12 special libraries.

SLA commits approximately 1-2 percent of its total program to standardization activities. The organization participates in the work of a number of American National Standards Sectional Committees: Z39 Library Work and Documentation; Z85 Library Equipment and Supplies; PH5 Photographic Reproduction of Documents. It is also represented on the ALA Library Technology Program Advisory Committee which develops standards for library binding, equipment, and supplies. The SLA Standards Committee provides overall guidance in this area. SLA is a member of International Federation of Library Associations (IFLA) and International Federation for Documentation (FID). A triennial salary survey is undertaken and published in Special Libraries, the official journal.

\section{SPECIALTY WIRE ASSOCIATION, 1625 Eye Street NW., Washington, D.C. 20006}

The Specialty Wire Association (SWA) was organized in 1937 as a nonprofit trade association made up of companies who manufacture from steel rod all forms of steel and alloy steel wire for industrial uses. Typical commodities are spring wire, stapling wire, rope wire and tire bead wire.

The technical program of the association was begun in 1944 to provide manufacturers and purchasers of fine and specialty wire with technical information relating primarily to the production and standards of performance of such wires. The purpose of the program is to make it easier for the buyer to specify the kind of wire that is wanted, and for the buyer and manufacturer to arrive at a mutual understanding of the specifications a given wire is to have. This program is conducted by SWA's Technical Advisory Committee, made up of technical representatives of specialty wire manufacturers.

The Technical Committee has published two Standards Manuals, Volume I covering round wire and Volume II covering flat and shaped wires. These two volumes contain recommended standards for over 160 steel wire commodities.

\section{SPORTING ARMS AND AMMUNITION MANUFACTURERS' INSTITUTE, 420 Lexington Avenue, New York, New York 10017}

The Sporting Arms and Ammunition Manufacturers' Institute was founded in 1926 (succeeding an organization active during and immediately following World War I known as the Society of American Manufacturers of Small Arms and Ammunition). The purpose of SAAMI is to serve the mutual interests of the U.S. sporting firearms and ammunition industry with emphasis on activities to assure safe use of these products by sportsmen and others having a lawful need for them. In terms of manpower and hours devoted by representatives of member companies who 
serve on SAAMl's several committees, study groups and task forces, most of the institute's program is devoted to product safety and standardization.

Product standards and product safety activities are administered by the SAAMI Technical Committee under general direction of SAAMI's Executive and Policies and Practices Committees. A Product Safety Subcommittee and two task forces, one for ammunition and a second for firearms, are engaged in product standards development; they are responsive to the Technical Committee. A key SAAMI staff member is its Director of Product Safety.

The SAAMI Technical Committee is actively reviewing current industry test methods, procedures, and recommended manufacturing safety practices. At the committee's initiative, there have been adopted two voluntary industry standards recognized as SAAMI standards. Their titles are: SAAMI Standard for Rim Fire Ammunition-Velocity and Pressure; SAAMI Standard for Rim Fire Dimensions-Ammunition-Firearms Chambers and Bores. These particular standards were submitted for the review procedure prescribed by the American National Standards Institute (ANSI) and offered for recognition as American National Standards. The Technical Committee is reviewing other data with respect to firearms for possible consideration and adoption as industry standards. Should a new industry standard be adopted, it would be submitted to the procedure of review/recognition/ adoption as American National Standards.

The SAAMI Technical Committee establishes definitive proof loads recommended for factory testing of U.S. made sporting firearms, thus assuring greater safety to the users of such arms. This committee also maintains liaison with the Department of Defense in relation to manufacturing, testing and performance specifications of commercial ammunition purchased by the Government.

The scope of SAAMI is national. Through common usage, SAAMI data sheets dealing with recommended maximum cartridge-minimum chamber dimensions are international in scope. SAAMI is the only trade association in the United States actively engaged in sporting arms and ammunition product standards development and promulgation. At this time there is no certification program.

SAAMI membership includes ten (out of twelve) principal U. S. and Canadian producers of sporting frrearms; the four major North American makers of sporting ammunition; all four commercial producers of smokeless propellants in the United States and Canada. Thus, SAAMI standards and the practices, procedures and recommendations set forth in the SAAMI Technical Committee Manual are recognized throughout American and Canadian industry.

\section{SPORTS CAR CLUB OF AMERICA, INCORPORATED, \\ Post Office Box 22476. \\ Denver, Colorado 80222}

This is a nonprofit organization with approximately 23,000 members, founded in 1944 and incorporated in the State of Connecticut. The club sanctions national and regional races and three major professional racing series listed on the International Calendar. It also sanctions rallies (precision driving tests over a given route at an exact speed), gymkhanas (intricate driving maneuvers in a cleared area), concours d'elegance (rating cars by a correlation of age, condition and equipment of the vehicle), and numerous international events and world championship races.

SCCA has developed safety standards for competitions, and standards and procedures for speed events for automobiles which may take part in events, for issuance of competition licenses, and for the organization and conduct of its events. These standards and procedures are set forth in its publications: Production Car Specifications; General Competition Rules; and Rally and Solo Rules.

In addition, SCCA sponsors American National Standards Sectional Committee Z90, Vehicular Head Protection. This committee is concerned with safety requirements for head protection for automobile drivers engaged in high hazard activities or occupations, as well as crash helmets for motorcyclists. American National Standard Z90.1-1971, developed by this committee, was recently issued.

\section{SOUTHERN CYPRESS MANUFACTURERS' ASSOCIATION, 1614. Berwick Road, Jacksonville, Florida 32207}

This association has formulated and adopted stand. ard specifications for grades of tidewater red cypress which are in conformity with the American Lumber Standard, Voluntary Product Standard PS 20-70.

Recognizing the need for uniform marking and authoritative supervision of the marking of standard grades of red cypress lumber, this association has adopted standard grademarks. The insignia "SCMA" is the property of the Southern Cypress Manufacturers' Association. Only licensed inspectors of this association or competent inspectors or manufacturers authorized by the association to officially grademark cypress, are permitted to place this mark on lumber. Lumber bearing this symbol is officially grademarked. The appearance of official marks on planing mill products such as flooring, ceiling, bevel siding, drop siding, etc., indicate an official grademark for the particular product of the planing mill.

\section{SPRING MANUFACTURERS' INSTITUTE, 24. Stearns Street, P.O. Box 959, Bristol, Connecticut 06010}

The Spring Manufacturers' Institute (SMI) is an organization of the manufacturers of precision mechanical springs dedicated to the advancement of the spring industry. In 1933 representatives of spring firms met in Buffalo, New York, and organized the Spring Manufacturers' Association. Forty spring manufacturers were listed as charter members. Through 
the years, the scope of the organization's activities gradually broadened. An indication of the increasing technical nature of the organization was its name change in 1961 to the Spring Manufacturers' Institute. Today, the institute has more than 190 members, approximately 150 parent firms and the balance, branch plants. SMI keeps spring makers abreast of the newest developments in materials, equipment, manufacturing procedures, management methods through technical sessions, and through publication of Springs, Magazine, organ of the industry.

SMI maintains realistic spring standards in keeping with current technological requirements and works with material and equipment suppliers to improve industry capabilities. SMI develops valuable materials such as the SMI Spring Design Calculator and the SMI Handbook of Spring Design, a basic manual developed by SMI for use in designing springs. Included are standards for compression, extension, torsion, flat and hot wound springs; data on wire spring materials, tolerances, etc.; and a glossary of spring terms.

In October of 1972, representatives of SMI Standards Committee met with representatives of the German Spring Manufacturers Association in Chicago and again in Germany in April, 1973 to develop what is hoped will become a universal glossary of spring symbols or signs. The SMI Standards Committee is one of the most active and productive of all SMI committees. Since the first edition of the SMI Standards Manual published in 1949, revisions have been made in 1959, 1962, 1964 and 1968. In 1970 a companion publication was issued, a Design Handbook, to round out the service potential of the manual. Now the manual and handbook are combined into a single publication with the information contained in the two books revised and consolidated in a manner to make its use easier. For the first time the manual contains information on hot wound springs and a metric-U.S. units conversion table.

Considerable progress has been made in gaining industrywide acceptance of these spring standards and efforts are continuing in standardizing the nomenclature, design techniques, and tolerances for the spring industry.

\section{SPRINKLER IRRIGATION ASSOCIATION, 13975 Connecticut Avenue, Suite 310, Silver Spring, Maryland 20906}

The Sprinkler Irrigation Association, founded in 1949 , is a national trade organization whose membership is made up of manufacturers and distributors of sprinkler irrigation equipment, designers and installers of sprinkler irrigation systems for turf and agriculture, engineers and university and government personnel interested in and active in the field.

The organization is active in the field of setting standards and specifications both on its own initiative and through close cooperation with allied organizations such as the American Society of Agricultural
Engineers. Standards and specifications are drawn up through two levels of groups functioning within the organization: commodity divisions and special committees. Commodity groups, organized along lines of manufactured products, can set standards for their particular phase of the industry and are set up in the following categories: quick couplings and fittings; tubing and pipe; sprinklers; pump and power units; mechanical move; and center pivot. Committees active in the area of standards and specifications are the Standards and Specifications Committee and the Turf Committee.

Currently under review are new standards for installation of turf irrigation systems. Recently submitted to the National Electrical Code Committee were final recommendations of the Center Pivot Commodity Division for the adoption of new code requirements for electrically driven center pivot systems.

\section{STANDARDS ENGINEERS SOCIETY, 2617 East Hennepin Avenue, Minneapolis, Minnesota 55413}

This is a professional technical society of standards engineers founded in 1947, incorporated in 1956, and currently consisting of some 1000 individual members organized in 20 local sections throughout the United States and Canada. The objectives of this association are: (1) to provide a forum for the interchange of information on standardization and standardization methods. This forum is provided by meetings at the local and national level; and by the publications of the society-a bimonthly magazine, Standards Engineering and an annual Proceedings; (2) to further standardization as a means of enhancing general welfare; (3) to promote knowledge and use of approved standards; (4) to encourage additions to the literature of standardization; and (5) to stimulate education in standardization at the collegiate level. The society recognizes accomplishments in standards work by appropriate awards and by a membership structure which includes the grade of Fellow and Honorary Life Fellow.

\section{STEATITE MANUFACTURERS' ASSOCIATION, 331 Madison Avenue, New York, New York 10017}

This association was formed in 1956 by manufacturers of Steatite, which is a generic term for kiln fired ceramic compositions composed chiefly of various magnesium silicate crystals.

Standardization work of the Steatite Manufacturers' Association is published in standards, which includes general test methods, inspection sampling, loss factor tests, resistance to thermal and other technical explanations.

Copies of the standards may be obtained by writing to the secretary. 
STEEL BAR MILLS ASSOCIATION, 1125 West Lake Street, Room 208, Oak Park, Illinois 60301

This association, founded as a voluntary trade association in 1911, and named the Rail Steel Bar Association, became the Steel Bar Mills Association (SBMA) in 1968. SBMA is involved with the solution of operational problems in electric furnace steelmaking and rolling of bar products to accepted standards from billet, rail and axle steel.

Standards activities, primarily in the development of bar standards in billet, rail and axle steel, are undertaken in a dual cooperative basis with the American Society for Testing and Matcrials and other standards groups.

The Association Technical Committee, the Association Permanent Rail Steel Committee and the Product Quality Committee of the Plant Operations Division, maintain ongoing work in standards. Cooperation with Canadian standards activity is part of the work of SBMA as well as frequent and continuing activity with the National Bureau of Standards.

SBMA does not issue standards but sponsors American Society for Testing and Materials Standards in A616, A617 Rail and Axle Steel Concrete Reinforcing Bars and a Standard Specification for Hot Rolled Steel Fence Posts (respectively). Additional counsel and committee activity with ASTM are also undertaken by the association.

\section{STEEL DECK INSTITUTE, 9836 West Roosevelt Road, P.O. Box 270, Westchester, Illinois 60153}

Organized in 1939 by manufacturers of steel roof deck, the institute insures uniform industry standards for the engineering design, manufacture, and field usage of steel roof deck throughout the United States. Through its institute, members of the industry strive to maintain a high-quality product, promote good building regulations, disseminate information relative to the proper use of steel roof deck and engage in research programs to improve performance.

The institute's Technical Committee, appointed from the staff of its membership, studies technical problems, analyzes and evaluates existing and new methods to assure safe construction, and initiates research projects, such as fire resistance tests at nationally recognized laboratories. A major testing program having the objective of developing reliable, unbiased standard performance values for steel decking used as a horizontal diaphragm was completed in 1972, at West Virginia University. A publication, Tentative Recommendations for the Design of Steel Deck Diaphragms, resulted from this research effort.

The institute's primary publication is the Steel Roof Deck Design Manual, which incorporates Basic Design Specifications, Standard Load Tables, Code of Recom- mended Standard Practice, and Recommendations for Field Storage and Erection.

Formerly: Metal Roof Deck Technical Institute.

\section{STEEL DOOR INSTITUTE, c/o Thomas Associates, Inc., 2130 Keith Building, Cleveland, Ohio 44115}

The Steel Door Institute was founded in 1954 and is an organization of manufacturers of swing type steel doors and frames used in commercial, industrial and residential construction, both single and multifamily.

The standardization program of the institute represents approximately 50 percent of its total program. The standardization activity is administered by the institute's Technical Committee. The Technical Committee is involved in international programs indirectly through the Underwriters' Laboratories and the American Society for Testing and Materials. Close and extensive liaison is maintained with Federal agencies which include General Services Administration; Corps of Engineers, Departments of the Army and Air Force; Department of Housing and Urban Development, Federal Housing Administration; Veterans Administration; United States Postal Service; and Department of Health, Education and Welfare. The institute issues standards in the form of technical data sheets and American National Standards. The technical data series represents 14 separate publications and the American National Standard series represents two publications. The standards activity is national in scope.

\section{STEEL FOUNDERS' SOCIETY OF AMERICA, Cast Metals Federation Building, 20611 Center Ridge Road, Rocky River, Ohio 44116}

The Steel Founders' Society of America was established in 1902. The society has issued a Recom. mended Minimum Standard for Commercial Carbon Steel Castings, and tentative specifications for steel foundry raw materials covering: (1) Western Bentonite, (2) Gelatinized Cereal Binder, (3) Zircon Sand and Flour, (4) Washed and Dried Sand, (5) Crude Sand, (6) Forsterite and/or Olivine Aggregate and Flour, (7) Cast Steel Abrasives, (8) Malleable Iron Abrasives, (9) Moldable Exothermic Pad Materials, and (10) Exothermic Materials for Molded Exothermic Sleeves. The Specifications Committee has other raw material specifications in process. The society is represented on specification committees of other organizations, and cooperates particularly with technical committees of the American Society for Testing and Materials in the development of standards and methods of test for steel and steel castings, metallography, radiographic and magnetic particle testing, and other matters of interest.

Absorbed: Alloy Casting Institute (1970). 
STEEL JOIST INSTITUTE,

2001 Jefferson Davis Highway,

Suite 707,

Arlington, Virginia 22202

This institute is a nonprofit organization of manufacturers actively engaged in the fabrication and distribution of open web steel joists. It was organized in 1928 to place the industry on a sound engineering basis. Its objectives are to establish and standardize methods of design and construction for open web steel joists, to provide test and research data for public dissemination, to assist in the development of appropriate building code regulations, and to publish information relative to the proper use of steel joists in the interest of safety and the public welfare.

The institute's first standard specification was adopted in 1928 and its first load table was adopted the following year. Its current Standard Specifications and Load Tables for Open Web, Longspan and Deep Longspan Steel Joists, comprising J- and H-Series, LJand LH-Series and DLJ- and DLH-Series, have become recognized industry standards.

\section{STEEL SHIPPING CONTAINER INSTITUTE, 2204 Morris Avenue, Union, New Jersey 07083}

Steel Shipping Container Institute, Inc. (SSCI) was founded in February 1944 as a national trade organization representing manufacturers of steel drums and pails. SSCI maintains liaison activities with customer groups, reviews testing procedures and specifications with regulatory agencies, is actively involved in environmental problems, and has contact with legislative representatives of the Federal and state governments.

SSCI is deeply involved with the Office of Hazardous Materials, Department of Transportation and the U. S. Army Natick Laboratories. In conjunction with the Department of Transportation, Office of Hazardous Materials, Bureau of Explosives, Uniform Freight Classification Committee, National Motor Freight Classification Committee, Manufacturing Chemists' Association, Petroleum Packaging Committee, and National Paint and Coatings Association, we have developed 95 percent of all of the standards presently existing in our industry. They are available in printed form from the American National Standards Institute. As the industry representative, SSCI regularly participates in development of the United Nation's program for the development of international packaging regulations as part of the U. S. Delegation. These standardization activities consist of approximately 10 percent of the total program with the Technical Project Chairman Committee administering the activities.

\section{STEEL STRUCTURES PAINTING COUNCIL, 4400 Fifth Avenue, Pittshurgh, Pennsylvania 15213}

This council was established in 1950 to fill a vital need for impartial research, specifications and information on the protection of steel by paints and coatings. Many organizations, recognizing the work of the council, have become supporting members, and have made available personnel, funds, or facilities to further the council program.

At the time of its organization, the council stated these objectives: (1) to determine and outline the best methods that have been developed up to the present time for cleaning and painting steel; (2) to issue specifications covering practical and economical methods of surface preparation and painting of steel structures; (3) to provide long-range research programs involving field and laboratory work and to evaluate various methods and coatings and costs thereof, to prevent or reduce corrosion on steel structures; and (4) to issue periodic recommendations for further improving the effectiveness and economy of the protection of steel structures.

The SSPC has issued the Steel Structures Painting Manual, which has won international acceptance among leading steel and paint manufacturers as well as contractors and companies fabricating and using steel. Volume 1, Good Painting Practice, is an encyclopedia-type manual providing industry with a comprehensive guide for the cleaning and painting of steel structures. Volume 2, Systems and Specifications, contains all of the specifications issued by the council, including surface preparation, pretreatment, paint application, paints and paint systems.

The council also carries out a long-range research and testing program.

\section{STEEL WINDOW INSTITUTE, c/o Thomas Associates, Inc., 2130 Keith Building, Cleveland, Ohio 44115}

The Steel Window Institute was founded in 1920. It is a trade association composed of a majority of American steel window manufacturers. Through research and interchange of ideas among its members, better products and services are developed and made available to the building trade.

The standardization and simplification presented in SWI recommendations are the answers to maximum economy. However, the creative abilities and productive facilities of the institute manufacturers are also geared to the exacting customer demands of modern architecture and construction.

Surveys are conducted to determine the relative popularity of types and sizes, and recommendations by the institute are circulated to members, nonmembers, architects, and Government agencies. 
Recommended Specifications for Steel Windows, 1973, is available from the institute.

Formerly: Metal Window Institute.

\section{STUCCO MANUFACTURERS' ASSOCIATION, 14006 Ventura Boulevardl, Suite 204, \\ Sherman Oaks, California 91403}

The Stucco Manufacturers' Association was organized in 1957 to promote use of colored stucco finish coats in building construction. A staff administered public relations program is aimed at increasing the industry's service to contractors, architects, and the general public.

Standardization activities are not the function of standing committees, but grow out of group action on an "as needed" basis. The current publication, Exterior Colored Stucco Specification Guide, relates primarily to application procedures. Although the association is national in scope, it recognizes that standards may vary among geographic areas because of different climatic conditions, skilled manpower pool, and availability of materials.

\section{SUMP PUMP MANUFACTURERS' ASSOCIATION, \\ 221 North LaSalle Street, Chicago, Illinois 60601}

The Sump Pump Manufacturers' Association is a national trade organization representing the manufacturers of domestic sump pumps, together with component and accessory suppliers. Originally founded in 1956, the association became inactive in 1962 . It was reactivated in 1968 under new management and with broader objectives.

Its objectives and activities include: (1) development and promulgation of quality standards, spelling out design and performance criteria for sump pumps used in homes; (2) implementation of a certification and labeling program for all products which conform to these standards; (3) development and dissemination of statistical information designed to describe market size and activity; (4) promotion of improved provisions in building codes on the use of sump pumps; and (5) educational efforts designed to encourage proper and safe installation, maintenance, and use of domestic sump pumps.

The Domestic Sump Pump Standards are national in scope, and are designed to supply the purchaser and/or user with accurate performance data and to assist in the determination of proper application and selection of this equipment. They provide a uniform method of testing and rating, and include a specification system covering basic materials of construction for all major components. They also detail minimum specifications for motors, nameplate data, service cords and control switches.
TANNERS' COUNCIL OF AMERICA, 411 Fifth Avenue, New York, New York 10016

The Tanners' Council of America is the trade association of the leather industry of the United States and its membership includes virtually all tanners and finishers of leather. The council was organized in 1917 through the amalgamation of various regional as well as national groups concerned with the processing, finishing and marketing of hides, skins and leather. The council's activities cover the full range of trade association functions including statistical compilation and standardization in various areas such as leather colors, raw material and technical specifications.

Color-Official standards for seasonal leather, footwear and accessory colors are developed and circulated by the council to the tanning, shoe and other leather product industries. These standards are prepared by the Color Bureau of the Tanners' Council with the advice and assistance of shoe manufacturers and retailers. A semiannual Official Leather Color Book is made available by the council to all interested trades. Master standards are preserved by the council for reference and duplication.

Raw Material Trim-The technical laboratory of the Tanners' Council initiated a new standard method for commercial trim of domestic cattlehides. This was approved as economically sound and desirable by an overwhelming majority of tanners and suppliers. It was submitted to the National Bureau of Standards, U. S. Department of Commerce, as a proposed voluntary industry standard and was officially published April 4, 1965, as Commercial Standard, CS268-65, Hide Trim Pattern for Domestic Cattlehides (amended 1966).

Raw Material Technical Standards-The Research Laboratory of the Tanners' Council has developed standards generally accepted in the hide and leather industries for degree of cure and weight differentials between fleshed, brined and green hides. These standards are available on request to all interested persons. The council's Hide Bureau has defined the characteristics of various commercial hide selections and the applicable weight designations for such selections.

Leather Weight Designations-The council has developed and maintained a standardized system for designation of leather weight or thickness. Since the thickness of leather is a highly important characteristic in the design and production of shoes and other leather products, standardized weight designations were long needed. Extensive investigation of trade practice enables the council to establish a limited number of standards which would meet the requirements of the tanning and leather-consuming industries. These have been officially circulated and made available throughout the world.

Formed by merger of: National Association of Tanners; Morocco Manufacturers National Assocation; Patent and Enamelled Leather Manufacturers' Association. 


\section{TECHNICAL ASSOCIATION OF THE PULP AND PAPER INDUSTRY, One Dunwoody Park, Atlanta, Georgia 30341}

The Technical Association of the Pulp and Paper Industry (TAPPI) was founded in 1915. The objectives of the association are to promote investigation, research and interchange of ideas among its members in the field of pulp and paper manufacture and use; to arrange for the presentation and publication of paper; and to provide testing procedures and stand. ards fundamental to pulp and paper manufacture and use. The association is divided into eleven divisions dealing with problems relating to pulp manufacture, paper and board manufacture, paper-synthetics, corrugated containers, coating and graphic arts, engineer. ing, research and development, testing, environmental, management sciences, and finishing. Under these divisions are a number of committees engaged in projects coming within the scope of activities of each division.

Testing procedures include official standards, provisional methods and useful methods. These are prepared by the active technical committees and approved by a Standards Committee and the members of the association in accordance with prescribed rules and regulations. The Testing Division, whose primary function it is to develop standards and testing procedures, is divided into the following committees: adhesives, chemical methods, fillers and pigments, optical methods, packaging materials, paper, paperboard, paper shipping sack, physical methods, precision, pulp, pulping and papermaking chemicals, and wax. There are several other testing committees in other divisions, notably the Fiberboard Shipping Container Testing Committee. The Standards Committee, having the administrative responsibility for the approval system, reports to the President after final approval of the standards. The standardization program is from 10-15 percent of TAPPI's entire program. Currently there are 285 standards issued by TAPPI which are considered national is scope. New standards are announced in the monthly journal, Tappi.

The association cooperates with the American Society for Testing and Materials by having membership representatives on ASTM technical committees. It cooperates with the Intersociety Color Council in developing color standards and with the American National Standards Institute in promoting American National and International Standards. TAPPI holds the secretariat of American National Standards Committee P3 and works closely with the International Organization for Standardization, ISO/TC6 on pulp, paper and related products.

\section{TELEPHONE GROUP,}

\section{American Telephone and Telegraph Company, 195 Broadway, New York, New York 10007}

This group which functions under the auspices of the American National Standards Institute (ANSI) consists of the American Telephone and Telegraph Company and the United States Independent Telephone Association and their member and associated companies. The group is represented on the ANSI Board of Directors and on the ANSI Executive Standards Council and Organizational Member Council. It is also represented on the following ANSI Technical Advisory Boards: Construction, Electrical and Electronics, Graphic, Information Systems, Mechanical, Miscellaneous, and Safety. In addition, it has well over 100 individuals serving on standards committees concerned with projects in the following fields: abbreviations and symbols, automotive, civil engineering and construction, drawings, electrical engineering, materials handling, mechanical engineering, national electrical code, office machines, equipment and supplies, petroleum products, photography, safety, vibrations and mechanical shock, and wood. The group is also represented on committees of such organizations as the Institute of Electrical and Electronics Engineers in the preparation and revision of American National Standards sponsored by these organizations.

Additional standardization work is carried on through representatives on committees of various engineering societies, such as the Radio Technical Commission for Marine Services and international organizations such as the International Electrotech. nical Commission and the International Organization for Standardization. Cooperative work is handled with numerous committees of the Electrical Section and the Communications Section of the Association of American Railroads engaged in the formulation of recommendations and specifications dealing with various phases of communications for railroads.

\section{THE TEST BORING ASSOCIATION, INC.} 271 North Avenue,

\section{New Rochelle, New York 10801}

The Test Boring Association, Inc., whose name was changed in 1967, was organized in 1941 to promote and further the interests of contractors and others engaged in test boring and core drilling, and to engage in any and all lawful activities which will enhance the progress of the test boring and core drilling industry.

In furtherance of its objectives, the association developed and has available, a Recommended Standard Boring Specification for Cased Borings.

Formerly: Test Boring and Core Drilling Contractors Association; Test Boring Contractors' Association (1969).

\section{THERMAL INSULATION MANUFACTURERS' ASSOCIATION, INC. 7 Kirby Plaza,}

\section{Mt. Kisco, New York 10549}

The association is a nonprofit trade association representing manufacturers of insulation for thermal industrial uses. Its purpose is to cooperate with other industries, technical societies, research organizations, and Government agencies in all matters that will 
disseminate accurate information regarding inorganic insulation. The association has been called on regularly to counsel in the preparation of Federal specifications, military specifications, guide specifications, etc.

By virtue of participation in the activities of American Society for Testing and Materials Committee C 16 on Insulation, the association has aided constructively in preparing test methods and product standards relating to thermal insulating products.

It maintains active participation in the American Society of Heating, Refrigerating and Air-Conditioning Engineers, the National Fire Protection Association, and the Building Research Institute, and cooperates with other organizations that are interested in industrial insulation products.

Formerly: National Insulation Manufacturers' Association (1941).

\section{THE THREAD INSTITUTE, INC. 1133 Avenue of the Americas, New York, New York 10036}

The Thread Institute, founded in 1933, is a national trade association for thread manufacturers, converters, and jobbers. The Technical Committee which meets as needed to deal with the problems of standardization, is responsible for the institute's standards and as such has several ad hoc subcommittees for cotton, silk, nylon, polyester, and corespun threads.

Cooperation exists between the U. S. Army Natick Laboratories and the institute in development programs for the specifications: VT 276, Cotton; VT 280 , Cotton Gimp, Buttonhole; VT 291, Linen; VT 295, Nylon; VT 285, Polyester; VT 301, Silk; MIL-T43548, Thread Polyester; Cotton Covered; MIL-T. 43624, Polyester, Spun; MIL-T-43636, Nylon,
Non-Melting; MIL-T-83193, Nylon, Spun Staple, High Temperature.

The institute also maintains liaison with threadoriented committees of the American Society for Testing and Materials through representatives of The Thread Institute member firms. Furthermore, there is participation in the Annual Conference on Weights and Measures.

Formerly: Cotton Thread Institute (1945).

TILE COUNCIL OF AMERICA INC., P.O. Box 326,

Princeton, New Jersey;

Architectural Services Office, 1707 N Street NW.

Washington, D.C. 20036

The Tile Council of America, Inc., organized in 1946 , is a trade association of 20 ceramic tile manufacturers dedicated to expansion of the ceramic tile industry in the United States through advertising, promotion and research on tile installation methods and materials.

The standards activities, conducted by the Architectural Services and Research Divisions, are national in scope. Close contact is maintained with Government agencies and other national organizations to assist with development and interpretation of standards and specification for installation of ceramic tile.

Tile Council annually publishes the Handbook for Ceramic Tile Installation, which is a guide specification for architects and specifiers covering all generally accepted ceramic tile installation methods and referencing installation and material standards applicable to the methods.

Current Standards Published by Tile Council of America, Inc., are listed below:
ANSI A108.1-1967

ANSI A108.2-1967

ANSI A108.3-1967

ANSI A108.4-1968

ANSI A108.5-1967

ANSI A108.6-1969

ANSI A108.7-1967

ANSI Al18.1-1967

ANSI A118.2-1967

ANSI A118.3-1969

ANSI A118.4-1973

ANSI A136.1-1967

ANSI A137.1-1967

TCA-8701

\section{Tile Council of America Inc., Standards}

Glazed Ceramic Wall Tile Installed With Portland Cement Mortar

Ceramic Mosaic Tile Installed With Portland Cement Mortar

Quarry and Paver Tile Installed With Portland Cement Mortar

Ceramic Tile Installed With Water-Resistant Organic Adhesives

Ceramic Tile Installed With Dry-Set Portland Cement Mortar

Ceramic Tile Installed With Chemical Resistant, Water Cleanable Tile-Setting and Grouting Epoxy

Electrically Conductive Ceramic Tile Installed With

Conductive Dry-Set Portland Cement Mortar

Dry-Set Portland Cement Mortar

Conductive Dry-Set Portland Cement Mortar

Chemical Resistant, Water Cleanable Tile-Setting and Grouting Epoxy

Latex-Portland Cement Mortar

Organic Adhesives for Installation of Ceramic Tile

Ceramic Tile

Ceramic Tile Panels for Bath Tub Recess Surrounds 
TIN RESEARCH INSTITUTE, INC., 483 West Sixth Avenue, Columbus, Ohio 43201

The Tin Research Institute was founded in 1949. Work of the Tin Research Institute is directed to develop the use of tin and is based on scientific and technical study of the metal, its alloys and compounds, and of industrial processes which use tin or may provide future markets.

Members of the institute participate widely in the development of standards and specifications for tin ingots, tinplate, tin alloys, bearings, solders, pewter and tin and tin alloy coatings. Membership is held in committees of the International Organization for Standardization (ISO), American Society for Testing and Materials, Institute of Printed Circuits, American Welding Society, American Pewter Guild, and coordination committees for Federal specifications.

\section{TIRE AND RIM ASSOCIATION, 3200 West Market Street, Akron, Ohio 44313}

This association, founded in 1903, is the technical standardizing body of the tire, rim and related parts manufacturers of the United States. TRA's program is entirely devoted to standardization activities and its standards are national in scope. Among the standards established are tire loads, tire inflations, tire dimen. sions, recommended rims, dual spacings, rim dimensions, valve and valve hole dimensions for tire and rim equipment used on passenger cars, bicycles, motorcycles, motor scooters, trucks, buses, recreational vehicles, trailers, earthmovers, road graders, agricultural tractors and implements, industrial vehicles, mobile homes, and aircraft. Current standards are listed in TRA's Yearbook.

The association cooperates in establishing standards for international use and as such participates in the International Organization for Standardization, ISO/ TC-31. TRA, through the Rubber Manufacturers' Association, has also provided technical advice to the Government.

\section{TRAFFIC AUDIT BUREAU, 708 Third Avenue, \\ New York, New York 10017}

This bureau, founded in 1933, consists of advertisers, advertising agencies, and operators of outdoor advertising plants. Its purposes are to establish standard practices with respect to the circulation evaluation and visibility of outdoor advertising; to supervise and direct practices in connection with the collection, recording and authentication of traffic and other data related to outdoor advertising; to prepare and issue standardized factual statements of the circulation values of outdoor advertising plants; and to perform other acts and services which will further the joint interests of advertisers, advertising agencies, operators of outdoor advertising plants, and the public.

\section{TRANSPORTATION DATA COORDINATING COMMITTEE, \\ 1101 Seventeenth Street NW., Washington, D.C. 20036}

The Transportation Data Coordinating Committee (TDCC), established in 1968, is a nonprofit organization, incorporated in the District of Columbia. It was founded by leading shippers, carriers, and others interested in the need for standardization of transportation data, codes, formats, and systems that will permit computer-to-computer data exchange between parties involved in transportation, distribution, and trade activities. It has been responsible for the selection and promotion of standard codes and data elements for transportation data transmission.

TDCC has seven major technical task forces and eight subcommittees that deal with primary information fields that govern the movement and payment of cargo. These include commodity coding, geographic coding, customer coding, carrier coding, packaging coding, tariffs, and data formats for advanced systems.

The National Transportation Forum and Exhibit is sponsored annually by the TDCC and features both national and international programs for electronic data interchange between shippers, carriers, banks, and Government. TDCC is a public organization, with membership open to those interested in modernizing transportation administrative systems by employing the latest computer and communications technology.

\section{TRUCK BODY AND EQUIPMENT ASSOCIATION, INC., \\ 5530 Wisconsin Aventue, Suite 1220, \\ Washington, D.C. 20015}

Originally chartered in 1947 as the NationaI Truck Body Manufacturers' Association, this nonprofit organization had a three fold objective: (1) to enable its members to unite in effort to encourage and promote the best interests of manufacturers of commercial truck bodies; (2) bring to the attention of proper authorities the material needs and demands of the industry; and (3) develop practices and methods designed to aid the industry and promote the public interest. As the association added distributors of truck bodies and equipment to its membership, a new name was chosen to be more representative of the growing organization and consequently in 1949, the National Truck Body Manufacturers and Distributors' Association was founded. The organization continued to grow in numbers, prestige and various directions of activities. Finally in 1952, the Board of Directors chose a new name to match the organization's progressive image and attitude, and Truck Body and Equipment Association, Inc., or simply TBEA, was born.

Today this association continues to represent over 750 manufacturers, distributors, and suppliers of truck bodies, equipment and related accessories 
throughout the United States and several foreign countries. It has still as its goal, the advancement of the truck body and related equipment industry in each and every endeavor.

The success of TBEA's service to the industry program depends completely on the diligent efforts and cooperation of its standing and special committees, plus that of its 22 industry divisions-the members of which volunteer to donate their time and efforts for the betterment of the industry.

Because TBEA's membership is comprised of various segments of the industry, each with specific types of equipment, organizational makeup, or problems peculiar to their own products or distribution methods, a system of industry divisions were developed to cope with their individual needs. These divisions include two types: those inclusive of distribution trade areas, and those devoted to product types. These divisions include: Ambulance Manufacturers Division, Automotive Electrical Components Division, Beverage Body Manufacturers Division, Chesapeake Regional Division, Elevating Tailgate Division, Fire Apparatus Manufacturers Division, Hydraulic Hoist Division, Hydraulic Hoist and Dump Body Division, Metropolitan New York Regional Division, MichiganOhio Regional Division, Northern California Regional Division, Pacific Northwest Regional Division, Rear Loading Refuse Body Manufacturers Division, Refrigerated Transport Division, School Bus Manufacturers Institute, Service Body Institute, Southern California Regional Division, Southwestern Regional Division, Tri-State Regional Division, Truck Tank Manufacturers Division, Utility Body Dealers Division and the Van Body Division. Each of these specialized divisions retains its group identity but operates within the framework of the overall association. Each division has an engineering committee that is responsible for the research and development in standardization activities.

The following technical papers are typical examples: Glossary of Terms-Hydraulic Hoist, Dump Bodies, Elevating Tailgates; Glossary of Terms-Truck Van Bodies and Components; Truck Van Body Facts; Hopper Capacity Rating for Rear Loading Refuse Bodies; Hydraulic Hoist and Dump Body Classification Chart: Hydraulic Conversion Hoist Classification Chart; Static Load Test Code for School Bus Body Structure; Standard Code for Testing and Rating Automotive Bus Hot Water Heating and Ventilating Equipment; and the School Bus Accident Reporting Form.

Various committees work with Federal and state governmental agencies and issue industry papers including: Excise Tax Guide; OSHA Guide for Applying Safety and Health Standards, Handbook for FMVSS Final and Intermediate Manufacturers, Responsibilities of Truck Chassis Dealers to the Motor Vehicle Safety Act of 1966, "Mini Guide" to Federal Motor Vehicle Safety Standards, Motor Vehicle Safety Standards Guide, Lighting Diagrams Published in Conformance with Motor Vehicle Safety Standard No. 108, A Layman's Guide to Basic Law Under the
National Labor Relations Act; OSHA Standards for Motor Vehicles, and the Occupational Safety and Health Guide.

The association also publishes monthly newsletters in the field of finance, labor, labor safety standards, legislation, excise taxes, and motor vehicle safety.

\section{THE TRUCK TRAILER MANUFACTURERS' ASSOCIATION, 2430 Pennsylvania Avenue NW., Washington, D.C. 20037}

The Truck Trailer Manufacturers' Association (TTMA) was organized in 1940.

TTMA means, essentially, people working together through their industry association to best serve not only the industry's but the nation's transportation needs-building trailers and supplying components. The association was formed to establish confidence between various manufacturers of truck trailers and their suppliers to bring a greater awareness and a mutual understanding of the problems confronting all manufacturers. One of its main purposes is to conduct programs and activities which will further interest and benefit the trailer manufacturers and also to provide a means of cooperating with the agencies of the Federal Government in any appropriate manner which will best serve the nation and member interests.

The TTMA Engineering Committee and the Tank Conference Engineering Committee of the Truck Trailer Manufacturers' Association are made up of some of the industry's most authoritative engineers. These committees, through research and working together, have contributed greatly to the technological advancement of trailer, tank, and container manufacturing. Many technical bulletins and recommended practices have been prepared covering such subjects as brakes, electrical systems, couplers, wheels, tires, refrigeration, and others.

Acting in concert with other organizations, the Truck Trailer Manufacturers' Association took the lead in making available a Standard Industry Procedure for Determining Heat Transfer of Refrigerated Truck Trailers. This standard was developed at the National Bureau of Standards with assistance from the U. S. Department of Agriculture and the association. This is known in the industry as the Heat Sink Test Method (USDA \#433 of September 1960) and is available from TTMA.

Recognizing the need for a standard simplified in-plant test method, an extensive survey was made in February 1969 by the Engineering Committee of the Truck Trailer Manufacturers Association to determine the various types of in-plant testing being conducted by trailer manufacturers. In addition, the survey included the degree of correlation that had been found between these simplified test methods and the Heat Sink Test Method. From this survey there was developed a Research Report entitled, Thermal Testing of Commercial Transport Equipment and a companion TTMA Recommended Practice RP 38-73- 
Method for Rating Heat Transmission of Refrigerated Vehicles which establishes a test method for determining rates of heat transmission and air leakage of refrigerated trailers and containers which can readily be conducted within the plant facility of a manufacturer.

The Truck Trailer Manufacturers' Association represents the producers of over 90 percent of the truck trailers, tank trailers, and containers built annually in the United States. Additionally, over 100 major material and component suppliers to the industry are associate members. Its membership is also international in scope having members located in South America, Canada, South Africa, and The Netherlands.

The industry works closely with such organizations as the American National Standards Institute, the United States Coast Guard, the Maritime Administration, the International Organization for Standardization, and the Department of Transportation.

\section{TRUSS PLATE INSTITUTE, INC. 919-18th Street NW., Suite 205, Washington, D.C. 20006}

Founded in 1961, the Truss Plate Institute was formed by manufacturers actively engaged in the production and distribution of metal connector plates for the trussed rafter industry for the purpose of maintaining the industry on a sound engineering basis by establishing methods of design and construction for wood trussed rafters using metal connector plates, to provide test and research data for public dissemination, to assist in the development of proper building code regulations, and to disseminate information relative to the proper use of wood trussed rafters in the interest of safety and public welfare.

A private, nonprofit organization, the Truss Plate Institute publishes design criteria, span tables and a quality control guide for metal plate connected wood trussed rafters.

\section{TUBULAR EXCHANGER MANUFACTURERS' ASSOCIATION, 331 Marlison Avenue, New York, New York 10017}

The association, founded in 1939 , represents manufacturers of tubular exchanger equipment. The standardization activities of TEMA are carried on by its Technical Committee. The standards, presently consisting of 11 sections, cover various clarifications and expansions on material, thermal physical properties of fluids and other general information relating to the various classes of exchangers. Copies of the standards of the Tubular Exchanger Manufacturers' Association may be obtained from the secretary.

\section{ULTRASONIC INDUSTRY ASSOCIATION, INC., 271 North Avenue, New Rochelle, New York 10801}

The Ultrasonic Manufacturers' Association, Inc. (UIA), whose name was changed in 1973 to Ultra. sonic Industry Association, Inc., was organized in 1955 to promote by every lawful means the growth of the industry on a sound and lasting basis. Formation of the association was motivated by the vast potential of ultrasonics for commercial, industrial, defense, and medical applications.

The first achievement by UIA was the development of definitions covering basic industry terminology designed to promote a common language and thus facilitate understanding between manufacturers and users. The second achievement was the development of a standard rating covering ultrasonic electric generators.

UIA cooperates in the development of standards with the American National Standards Institute and is represented on the American National Standards Sectional Committees S1 on Acoustics and S3 on Bioacoustics. Other organizations with which UIA cooperates include the Institute of Electrical and Electronics Engineers, National Safety Foundation, Acoustical Society of America, National Electrical Manufacturers' Association, and American Society for Testing and Materials. In addition, UIA provides assistance when requested, to various Government agencies such as the Departments of the Navy and Air Force, and maintains standardizing liaison with other Government agencies such as the Federal Communications Commission.

\section{UNDER WRITERS' LABORATORIES, INC., 207 East Ohio Street, Chicago, Illinois 60611}

This independent organization, devoted to testing for public safety, was established to maintain and operate laboratories for the examination and testing for safety of devices, systems, and materials. Founded in 1894, the enterprise is operated for service, not for profit. It is chartered as a nonprofit corporation without capital stock, under the laws of the State of Delaware.

Testing laboratories are maintained at Chicago, Illinois; Melville, L.I., New York; Northbrook, Illinois; Santa Clara, California; and Tampa, Florida.

of equal importance with the examination and testwork of Underwriters' Laboratories (UL), is its inspection and followup program in the factories where listed devices are manufactured. Representatives charged with the responsibility for making these periodic inspections are located in approximately 150 cities throughout the United States and 46 cities outside of the United States.

The formal objectives of Underwriters' Laboratories 
are to conduct scientific investigations, studies, experiments, and tests to determine the relation of various materials, devices, constructions, and methods to life, fire, and casualty hazards, and to ascertain, define, and publish standards, classifications, and specifications for materials, devices, constructions, and methods affecting such hazards, and other information tending to reduce and prevent loss of life and property from fire, crime, and casualty.

UL's Listing and Inspection Service is applicable to those products which have been evaluated with respect to all reasonably foreseeable hazards to life and property, and where such hazards have been safeguarded to an acceptable degree.

UL's Classification and Inspection Service is applicable to those products which have been evaluated with respect to specific hazards only, or with respect to performance under specified conditions.

UL's Certificate and Inspection Service is applicable to products comprising field-installed systems at a specific location, or to specific quantities of certain products where it is impractical to apply the listing mark or classification marking to the individual product.

In addition, UL has a recognition and inspection program which is applicable to those products which have been evaluated only for use as components of end-product equipment listed, classified, or certificated by UL.

Also, UL conducts fact-finding and research projects which are conducted on a contract basis for manufacturers, trade associations, governmental agencies, and others in the interest of public safety.

The majority of insurance underwriters in the United States, and many Federal, state, and municipal authorities, plant operators, architects, building owners and users either accept or require listing or classification by Underwriters' Laboratories as a condition of their recognition of devices, systems, and materials having a bearing upon life and fire hazards, and upon theft and accident prevention.

It should, however, be noted that findings of Underwriters' Laboratories in any case represent its independent opinion arrived at in accordance with its aims and purposes. Underwriters' Laboratories does not guarantee that its findings will be accepted or recognized in any individual case. Such assurances can be obtained only from the authority having jurisdiction of the particular technical area or Government unit.

It should be noted as well that products listed or classified are not necessarily equivalent in quality or merit.

In the event of a disagreement between Underwriters' Laboratories and any of its clients with respect to an engineering or technical matter involving the method of measurement used in the tests applied by Underwriters' Laboratories, the results of the tests so used, or the interpretation of these results, the question at issue may be submitted to the National Bureau of Standards, acting as a referee, provided that in the opinion of the Bureau the impor- tance of the case justifies its acceptance by the Bureau and that parties to the submission agree in writing to accept and abide by the fiuding of the Bureau.

Underwriters' Laboratories is divided into several engineering departments, each dealing with distinct and separate subjects as follows: electrical; heating, air-conditioning, and refrigeration; casualty and chemical hazards; burglary protection and signaling; fire protection; and marine. Each of these departments has prepared standards providing specifications and requirements for construction and performance under test and actual use of systems, materials, and appliances of numerous classes submitted to the laboratories.

Underwriters' Laboratories has issued more than 305 of these standards for safety based on sound engineering principles, actual experience, and an appreciation of the problems of manufacturing, installation, and utility. These standards for safety are the result of years of research and collaboration by laboratories' engineers, manufacturers, consumers, and recognized specialists in many fields, including the members of the five UL Engineering Councils and its Consumer Advisory Council.

Where no specific published standard exists, UL has selected appropriate requirements from its published standards and has applied them in evaluating over 4,000 generic product categories shown in UL's ten product directories. These requirements constitute UL's unpublished standards for safety, known as desk standards. Prospective submitters may, upon presentation of essential product submittal information, obtain information as to the requirements of those standards to be used by UL in evaluating a specific product submittal.

UL does not require that there be a specifically designated published safety standard in order for it to examine and test a product to determine that the design adequately safeguards the hazards expected in connection with the product's use. Rather, UL evaluates the design by application of appropriate requirements selected from published standards of UL, and by application of newly-developed requirements to cover uses and conditions for which specific requirements do not exist.

When provided with product description and other essential product submittal information, UL will, upon request, furnish to prospective submitters a statement of requirements for products not previously covered by a published or proposed standard.

The requirements of a UL standard for safety are so stated that if correctly applied, there is no discrimina. tion between the products of two or more manufacturer-submitters. They are published so that others may know the basis for laboratories' opinions, and the standards must necessarily justify the opinions. A catalog listing all available UL standards for safety is published twice each year. Many of the laboratories" standards are recognized as American National Standards by the American National Standards Institute.

The standards are an important tool of Underwrit- 
ers' Laboratories in its established policy of stating the facts concerning products investigated, and its opinion concerning these facts.

A manufacturer whose product passes the laboratories' requirements and for which factory inspection service is to be established, is provided with a "Procedure" prepared by laboratories' engineers as part of the work under the application. This procedure describes and illustrates the product in detail, particularly as to the construction or performance of the features tested. It becomes the manufacturer's guide for future production, and is used by representatives of Underwriters' Laboratories in reexamination and periodic check testing of the product. The laboratories' factory inspection service of listed, classified, recognized, and certificated products is intended to supplement and check the manufacturer's own regular inspections to insure compliance of the factory output with requirements established for the product.

Manufacturers, regularly employing UL's Inspection Service, are freely consulted in all matters concerning standards of performance and inspection in their respective industries.

Underwriters' Laboratories publishes (lists) the names of the companies who have demonstrated the ability to provide a product conforming to the established requirements. Listing signifies that production samples of the product have been found to comply with the requirements, and that the manufacturer is authorized to use the laboratories' listing mark (or classification marking, recognition marking, or certificate) on the listed (or classified, recognized, certificated) products which comply with the requirements.

The listing, classification, recognition, or certification of the product is contingent upon the establishment of the laboratories' inspection service. Under the inspection service, the manufacturer attaches labels, markers or other authorized evidences of listing (classification, recognition, or certification) to such of his products as are found by him to be in compliance with UL requirements.

Should examination and tests by the laboratories' representative disclose features not in compliance with the requirements, the manufacturer is required either to correct such items or to remove the UL identification from the product.

Approximately 2 billion UL labels are delivered annually to manufacturer-subscribers to UL's listing and inspection service.

A number of Federal specifications covering material or appliances of classes, which are under supervision of 'Underwriters' Laboratories, recognize the laboratories' identifying marks as evidence of compliance with the applicable requirements of such Federal specifications.

In its work in standardization, Underwriters' Laboratories cooperates with many organizations including the American National Standards Institute and National Fire Protection Association. Its employ. ees have about 500 assignments on committees of these and other groups. Among these are many American National Standards committees.
Underwriters' Laboratories also cooperates with the American Society for Testing and Materials through representation on technical committees dealing with the development of standards and methods of test for such items as gypsum, electrical insulating materials, rubber products, bituminous waterproofing and roofing materials, and petroleum products and lubricants.

\section{UNITED LIGHTNING PROTECTION ASSOCIATION, INC., 34. May Street, \\ Webster, New York 14580}

Established in 1935, this association provides reliable educational materials on the hazards of lightning and what constitutes proper lightning protection. Its members must conform to the highest standards of lightning protection systems, engineering, installation and service to maintain membership.

Members of the association serve on numerous committees and in other key roles in helping to establish various standards and codes such as the Lightning Protection Code of the National Fire Protection Association, and the Lightning Protection Installation Requirements Code of Underwriters' Laboratories. The association is consulted frequently by building supply manufacturers, insurance firms, safety groups, and power companies to advise on potential hazards and what constitutes proper lightning protection.

\section{UNITED STATES COUNCIL OF THE INTERNATIONAL CHAMBER OF COMMERCE,}

1212 Avenue of the Americas, New York, New York 10036

The International Chamber of Commerce, founded in 1919 and with headquarters in Paris and national committees in 45 countries, promotes standardization in most phases of world commerce. These include banking and trading procedures, definitions of trade terms, sizes of pallets and containers, markings for dangerous goods, extent and validity of distribution statistics, etc. It also issues codes of fair play and recommendations for uniformly high levels of commer. cial practice. Full information and all publications are available from its United States Council.

Formerly: United States Associates of the International Chamber of Commerce (1949).

\section{UNITED STATES GOLF ASSOCIATION, Golf House,}

Far Hills, New Jersey 07931

This association, founded in 1894, has developed standards for golf balls and golf clubs. In its current booklet, Rules of Golf, this association's specifications concerning the style and make of clubs, and the size, weight, and velocity of golf balls, are included. These specifications are applicable to equipment and balls used in connection with tournaments conducted by this association or under its rules. 


\section{U. S. PHARMACOPEIA, PHARMACOPEIA OF THE UNITED STATES OF AMERICA, UNITED STATES PHARMACOPEIAL CONVENTION,}

12601 Twinlbrook Parkway, Rockville, Maryland 20852

This convention is a nonprofit corporation which meets every five years to reorganize the revision program of the Pharmacopeia of the United States of Annerica, established in 1820. It is made up mainly of representatives of the medical and pharmacy colleges of the United States, of the state and national medical and pharmaceutical associations, the national trade associations, and the departments of the Federal Gov. ernment most concerned with standards for medicinal preparations. The convention elects, for five year terms, officers, a Board of Trustees, and a Committee of Revision consisting of 60 members, each of whom is qualified in a special branch of medicine, pharmacy, or the allied sciences. The convention is financed through the sale of the Pharmacopeia and USP Reference Standards. The committee members receive only modest honoraria for a vast amount of voluntary work.

The primary object of the convention is to produce at intervals of five years, a new revision of the Pharmacopeia by the Committee of Revision serving under the direction of a salaried, permanent staff. The revision program includes: (a) selection of those drugs held in high esteem as representing the soundest practice of medicine; $(b)$ the establishment of standards of strength, quality, and purity for the selected drugs; and (c) the provision of tests, assays, and material standards of reference (Z50) required to demonstrate compliance with the specifications set forth. Supplements of the Pharmacopeia are provided as required.

The standards given in the Pharmacopeia are recog. nized by Congress in the Federal Food, Drug, and Cosmetic Act for the purpose of regulating the quality of drugs moving in interstate commerce and by the state legislatures in corresponding statutes for enforcement by state agencies.

The U.S. Pharmacopeia is also recognized as official in Canada, and it is one of the premier pharmacopeias of the world. Approximately 10 percent of the books and 20 percent of the USP Reference Standards are purchased from outside the U.S.

\section{UNITED STATES TESTING COMPANY, INC., 1415 Park Avenue, Hoboken, New Jersey 07030}

This independent commercial laboratory, established in 1880 , plays an important role, generally on a fee basis, in assisting Government agencies, manufacturers, and trade associations in establishing national standards. The United States Testing Company also develops test procedures including instrumentation. The company is also active in conducting testing for certification and labeling in order to assure that the products meet the specified standards.
The company is also known as Nationwide Consumer Testing Institute, Inc.

The products include consumer appliances, toys, home entertainment equipment, garden and lawn equipment, recrcational goods, textiles, chemicals, cosmetics, drugs, paint, construction materials, plastics, paper metals, and foods.

Various staff members serve voluntarily on commit. tees of standards making organizations such as the American Society for Testing and Materials and American National Standards Institute.

\section{VACUUM CLEANER MANUFACTURERS' ASSOCIATION 1615 Collamer Street Cleveland, Ohio $\mathbf{4 4 1 1 0}$}

On October 21, 1913, eleven companies in the vacuum cleaner industry organized what is now one of the oldest, most highly regarded trade associations in the country, the Vacuum Cleaner Manufacturers' Assoiation (VCMA). Initially, its purpose was to provide a central headquarters for voluntary reports on production and sales and information generally helpful to the member companies.

Since that time, it has expanded its scope to include national affairs, education, traffic, foreign competition and technical standards.

The Technical Standards Committee is composed of engineers from member companies, who formulate or assist other organizations to formulate standards of safety and performance for floor care appliances. This committee has currently published a Guideline for a Consumer Floor Care Products Safety Standards. It is currently very active in assisting to formulate standards with the American Society for Testing and Materials, Committee Fll, Vacuum Cleaners.

The committee also provides representation on technical committees of the International Electrotechnical Commission in the formulation of international standards, and supplies a liaison representative to work with the Canadian Standards Association.

\section{VARIABLE RESISTIVE COMPONENTS INS'TITUTE, 1717 Howard Street, Evanston, Illinois 60202}

The Variable Resistive Components Institute, formerly the Precision Potentiometer Manufacturers Association, was founded in 1960. Manufacturers in this trade association produce precision potentiometers and trimmers. A standard nomenclature for wirewound and high resolution potentiometers is available from PPMA. In addition, incoming inspection standards are available covering wirewound precision potentiometers. A similar standard is presently being developed for high resolution precision potentiometers. 


\section{VEHICLE EQUIPMENT SAFETY COMMISSION, \\ 1030 15th Street NW., Suite 536, \\ Washington, D.C. 20005}

Congress passed the Beamer Resolution in 1958 (Public Law 85-684), which granted approval to the states to enter into compacts in the interest of highway traffic safety. In 1961, the Vehicle Equipment Safety Compact was drafted under the aegis of the Western Governors' Conference and the Council of State Governments. The first state joined the compact in 1962. Presently, 42 states and the District of Columbia are signatories. The compact has as its basic purposes the achievement of greater uniformity of laws, rules and regulations, regulating vehicle equipment, expediting the widespread use of new and improved safety equipment on vehicles, and retaining jurisdiction and enforcement of rules, regulations, and laws in the hands of the states.

The National Traffic and Motor Vehicle Safety Act of 1966 (Public Law 89-563) names the Vehicle Equipment Safety Commission specifically as consultant to the Department of Transportation in the promulgation of Federal Motor Vehicle Standards.

There are currently ten standards as follows: Regulation V.1, Minimum Performance Requirements and Uniform Test Procedures for New Tires for Passenger Cars and Station Wagons; Regulation V.2, Minimum Performance Requirements and Uniform Test Procedures for Retreaded Tires for Passenger Cars and Station Wagons; Regulation V-3 Minimum Requirements and Uniform Test Procedures for Motor Vehicle Brake Linings; Regulation V-4, Safety Glazing Materials for Glazing Motor Vehicles Operating on Land Highways; Regulation V-5, Minimum Requirements for Motor Vehicle Connecting Devices and Towing Methods; Regulation VESC-6, Minimum Requirements for School Bus Construction and Equipment; Regulation VESC-7, Safe Operating Condition of Tires Including Tire Tread Depth Requirement (Passenger Car Type Tires); Regulation VESC-8, Minimum Requirements for Motorcyclists' Eye Protection; Regulation VESC-9, Safe Operating Condition of Truck and Bus Type Tires; Regulation VESC-10, Minimum Requirements for Type II School Bus Construction and Equipment.

The commission presently has three (3) additional committees in the process of developing new standards: one is the minimum thickness and strength of brake drums or rotors and how this can be checked without removing a major component of the vehicle suspension; one is the minimum performance and equipment requirements of motorcycles and motor driven cycles; and the third is the minimum performance and equipment requirement on special vehicles, altered or reconstructed, four or more wheels.

Each of our standards are constantly monitored, reviewed and revised when necessary.

\section{WATER CONDITIONING FOUNDATION, 1780 Maple Street, P.O. Box 194, Northfield, Illinois 60093}

The Water Conditioning Foundation was established in 1948 as a trade association of water conditioning equipment manufacturers and suppliers to the water conditioning industry. In behalf of the industry, the foundation conducts a national public relations program, and serves as the industry's liaison with the public, private, and Government sectors. The foundation currently has two equipment standards, S-100 for Household, Commercial and Portable Exchange Water Softeners, and S-200 for Household and Commercial Water Filters. The testing program against both standards is conducted by an independent testing laboratory, and certification is made through the foundation following laboratory validation. These standards have national application, and the voluntary testing program is open to all manufacturers of water softeners and water filters. Both standards have a revision date effective 1973. In addition to intra-industry promotion of the use of the equipment validation program, the foundation uses its public relations channels to inform consumers of the integrity of certified equipment. S-100 and S.200 have been developed through consultation with the National Bureau of Standards, U.S. Department of Commerce; Federal Housing Administration; and other Government agencies, as well as quasi-public and private organizations concerned with equipment standards. The foundation is currently developing standards for reverse osmosis and chemical feeding equipment.

\section{WATER POLLUTION CONTROL FEDERATION, \\ 3900 Wisconsin Avenue NW., Washington, D.C. 20016}

The federation was established in 1928 as a nonprofit, technical membership organization. Its objectives are to advance the fundamental and practical knowledge of all aspects of water pollution control by the dissemination of technical knowledge through publications, technical conferences, improvement of the professional status of those working in the field, promotion of public understanding and participation, and encouragement of the adoption and implementation of sound regulations aimed toward effective water pollution control.

A principal activity of this organization is the publication of the monthly technical journal of the Water Pollution Control Federation. This journal, with 23,000 readers all over the world, is the acknowledged reference for technical information in the field. The federation is also publisher of an annual yearbook, and a series of Manuals of Practice including the following subjects: Safety in Wastewater Works, Regulation of Sewer Use, Units of Expression for Wastes and Waste 
Treatment, Sewer Maintenance, Sewage Treatment Plant Design, Desion and Construction of Sanitary and Storm Sewers, Uniform System of Accounts for Wastewater Utilities, and Operation for Wastewater Plants.

In addition, the federation is one of the three sponsoring organizations for the continuing production of Standard Methods for the Examination of Water and Wastewater, which is updated on a continuing basis but revised and published each five years. This publication is the standard in the analytical field in matters concerning water and wastewater.

Formerly: Federation of Sewage Works Associations (1949); Federation of Sewage and Industrial Wastes Associations (1959).

\section{WATER SYSTEMS COUNCIL, 221 North LaSalle Street, Chicago, Illinois 60601}

The council, founded in 1932, represents and serves the leading manufacturers of domestic and farm water systems equipment. Approximately 85 percent of all such production is represented by the membership of the council.

The Testing and Rating Standards adopted by the council have been established in the public interest, and are designed to supply the purchaser and/or user automatic, electric water systems with accurate performance data and to assist in the determination of proper application and selection of this equipment. Any manufacturer of electric water systems may indicate adherence to these standards by stating in the specifications and product description: "Tested and rated in accordance with Water Systems Council standards." member manufacturers of the council may also affix their performance certified by manufacturer seal to products bearing their name or brand name, or incorporate the seal design in the description of any product to indicate adherence to these testing and rating standards and procedures. The standards cover: (1) shallow well water system pumps; (2) deep well water system pumps; (3) deep well submersible water system pumps; (4) pump motor standards; (5) submersible pump motor standards; and (6) hydropneumatic tank volume standards.

Formerly: National Association of Domestic and Farm Pump Manufacturers.

\section{WELDING RESEARCH COUNCIL, 345 East 47th Street, Room 801, New York, New York 10017}

The Welding Research Council, organized in 1935 by the Engineering Foundation, is a realistic, flexible mechanism set up by interested engineering societies and trade associations to accomplish certain objectives. These objectives simply stated are: (1) to conduct needed cooperative research in welding and closely allied fields; (2) to disseminate research information;
(3) to promote welding research in the universities; and (4) to provide a means for cooperation, interchange of ideas, and information with similar agencies abroad.

The council disseminates the results of its own research work and that of many other affiliated organizations through its five regular publications, namely: Welding Research, Reports of Progress, Welding Research News, Bulletins, Welding Research Abroad.

In addition to the regular publications of the council, pamphlets, books, and special reports are issued from time to time. All of these publications, which represent some $\$ 3$ million worth of research annually, are made available to subscribers and research workers, as well as code-making bodies.

The council is currently administering work in the following areas: interpretive reports, weldability, pressure, vessel research, resistance welding, structural steel, aluminum alloys, welding processes, high alloys, and reactive and refractory metals.

In addition to the major engineering societies, the council works closely with more than a dozen Government departments, and such leading trade associations as the American Iron and Steel Institute, American Petroleum Institute, American Institute of Steel Construction, American Gas Association, Edison Electric Institute, Aluminum Association, Resistance Welding Manufacturers' Association, and others.

\section{WEST COAST LUMBER INSPECTION BUREAU, 6980 SW. Varns Road, P.O. Box 23145, Portland, Oregon 97223}

The West Coast Lumber Inspection Bureau (WCLIB) is an industry owned, nonprofit corporation that provides lumber quality control services at its approximate cost. WCLIB serves the area west of the summit region of the Cascade Mountains in the States of Washington and Oregon, and the entire State of California. Its services are available to any producer, user, distributor, or dealer handling West Coast lumber products.

The bureau was founded in 1911 as a part of the old West Coast Lumbermen's Association.

The bureau is one of the three major rules writing agencies in the United States. The others are the Western Wood Products Association and Southern Pine Inspection Bureau. These three agencies are responsible for the principal part of all the quality control programs for softwood lumber production in the United States. WCLIB supervises or grades four and one-half to six billion feet of lumber per year which is the bulk of all production west of the Cascades.

The main objectives of the bureau are to maintain uniform standards of lumber grading and manufacture, to promote the use of grade stamped lumber as an assurance to the buyer, seller and consumer that the interests of each are fully protected, and to assist in the efficient use of West Coast lumber products. 
The American Lumber Standards Committee is the licensing agent for all of the twelve grading agencies and six rules writing agencies in the United States.

Bureau activities include the publication and distribution of West Coast Grading Rules, supervision of the grading manufacturing practices of subscriber plants, grade stamping of West Coast lumber with official Bureau stamps, certificate inspection of lumber shipments, reinspection of lumber in dispute at destination and assistance to specification agencies, buyers and consumers of West Coast products.

\section{WESTERN WOOD MOULDING AND MILLWORK PRODUCERS, P.O. Box 25278, Portland, Oregon 97225}

Founded August 9, 1963, Western Wood Moulding and Millwork Producers is a multiservice manufacturer's trade association within which standards programs account for 5 to 10 percent of the total budget. Standards are initiated through a standing committee and administered by the association staff.

The most important standard is the WP/Series Moulding Patterns catalog of accurate, full scale renderings of the most popular wood moulding profiles used nationwide. This may be used as a standard basis for all U. S. moulding producers. Work has been initiated to pave the way for conversion of wood mouldings to metric sizes within five years. Within the current catalog are grading rules for standard mouldings and finger joint and priming standards.

Recently produced standards include Industry Standard WM 1.73 for Wood Interior Door Jambs and Frames and WM72-2I, Vinyl Wrapped Interior Moulding and Millwork Products Standard. The Federal Housing Administration's approval is being pursued for the latter standard.

In addition, the American Society for Testing and Materials, ASTM D-3110-Standard Specification for Adhesives Used in Non-Structural Glued Lumber Products was formulated by Western Wood Moulding.

The association is a certified testing agency under the provisions of the U.S. Department of Commerce Commercial Standard CS 262-63, Water-Repellent Preservative Non-Pressure Treatment for Millwork.

All standards issued by the association are intended for national use.

Formerly: Western Wood Moulding Producers (1968).

\section{WESTERN WOOD PRODUCTS ASSOCIATION 1500 Yeon Building, Portland, Oregon 97204}

This association combines the membership of the former Western Pine Association and West Coast Lumbermen's Association and has members throughout the 12 contiguous Western States. Its members process Douglas Fir, Larch, Ponderosa Pine, Sugar Pine, Idaho White Pine, Lodgepole Pine, White Fir, Engelmann
Spruce, Sitka Spruce, Mountain Hemlock, Western Hemlock, Western Red Cedar, Incense Cedar, Red Alder and Aspen.

The association writes grading rules in conformity with Voluntary Product Standard PS 20-70, published by the U.S. Department of Commerce for all softwood lumber, except Redwood and Sitka Spruce, produced in the western states. In addition, the association supervises grading by its members using grading rules written by other lumber inspection bureaus.

Use of the association's official grade, trade and species marks, indicates that the lumber was graded under association supervision by either a member or a grading rule subscriber. These marks are protected and can be placed on lumber only by a Western Wood Products Association quality supervisor or by an operator whose grading practices are given regular and periodic quality supervision by the association. Each grade stamp carries a mill number or name so that the shipper can be identified.

The association's inspection certificates financially guarantee the grade and tally of certified shipments.

\section{WESTERN WOODEN BOX ASSOCIATION, 430 Sherman Avenue, Suite 206, Palo Alto, California 94306}

The Western Wooden Box Association (WWBA) was established in 1929. WWBA represents the manufacturers and distributors of sawn wooden boxes, crates, lugs, veneer components, pallets and loading material for interstate and export shipment of western fresh fruit, vegetables and melons.

In California, where most of the box shook manufactured by the industry is used, the majority of such containers are covered by standards set up under the California Agricultural Code and Western Wooden Box Tariff No. 1. In arriving at the standards so set by law, cooperation between the wooden box industry, the fresh fruit and vegetable industries, the Uniform Classification Committee representing American Railroads, Transcontinental Freight Bureau, and the Bureau of Fruit and Vegetable Standardization (a division of the California Department of Agriculture) is maintained.

The wooden box industry itself has manufacturing standards as set forth in the Standard Grade Rules for Box Shook and Western Wooden Box Tariff No. 1. Whereas the standards set up under the State of California Agricultural Code specify inside dimensions of containers, the standard grading rules provide a yardstick for quality of shook and official specifications used in the manufacture of containers.

In addition, Freight Container Tariff No. 1-H provides mandatory standards for minimum thickness and other container specifications for use in movement of perishable fresh produce via rail interstate. Truck movement of sawn wooden nailed containers, although not covered by container tariffs, for the most part are covered by specifications of inside measurements as set forth in the California Agricultural Code and Western Wooden Box Tariff No. I. 
Formerly: Pacific Division of National Wooden Box Association.

\section{WHEY PRODUCTS INSTITUTE, 130 North Franklin Street, Chicago, Illinois 60606}

The Whey Products Institute (WPI), a national trade association of whey processors, was founded in 1971. WPI's purposes are to stimulate and conduct research and to collect and disseminate information for the education of the public and users as to the character, quality, convenience, economy, use and functions of whey products and products derived from whey, to promote the utilization of such products, and to collect and disseminate such statistics and information as will further such purposes.

WPI's standardization activities consist of $60-75$ percent of the total program. The Standards/Research Committee administers the standards program. The current standards are in the areas of: product definition/nomenclature; specifications and grade classification; and sanitation. These standards are accepted as national in scope by the industry. WPI's activities outside the organization consist of cooperation with the Food and Drug Administration and the Department of Agriculture and on an international level, WPI contributes towards the Codex Alimentarius.

\section{WINE INSTITU'TE, 717 Market Street, San Francisco, California 94103}

This institute, founded in 1934, devotes its efforts in standardization primarily towards advocating the adoption of wine and brandy quality standards as established by Federal and state agencies. This institute's committees make studies and recommendations in connection with standards of identity and quality for wine and brandy. The recommendations are then placed before official agencies for consideration in connection with the establishment of new standards or the revision of existing standards.

\section{WIRE REINFORCEMENT INSTITUTE, 7900 Westpark Drive, McLean, Virginia 22101}

WRI, the Wire Reinforcement Institute, is a volun. tary, incorporated association of United States and Canadian manufacturers of steel welded wire fabric. It was founded in Washington, D.C. in 1930, and was organized to increase the sale and use of welded wire fabric by dissemination of information about the product and its applications, and through scientific and market research. It provides technical service in the public interest and cooperates with Government agencies on all levels, in any program affecting the wire fabric industry.

Engineering Service-Research is conducted to develop basic information from which to gain a better understanding of welded wire fabric so that it can be used more effectively and its market can be expanded. This research is in these areas: (1) physical properties, (2) design methods and practices, and (3) behavior of fabric in construction applications.

Consulting Service-Upon request, consulting services are rendered to Government agencies as well as to consulting engineers, architects, contractors, and builders. These contacts provide an opportunity to educate the specifiers and constructors regarding the best design and construction procedures, and at the same time, direct these practices to fit in with manufacturing limitations.

\section{WOOD AND SYNTHETIC FLOORING INSTITUTE, 1201 Waukegan Road, Glenview, Illinois 60025}

WSFI was originally formed as the Wood Flooring Institute in 1954; synthetics were added in 1970. The institute is principally comprised of more than 40 flooring contractors throughout the United States. Standards have been published for all types of floors and floor surfaces. A set of 14 standards is available from WSFI Headquarters in Glenview, Illinois.

Currently the institute is developing programs for better estimating of flooring installations and investigating fire safety synthetic surfaces.

The institute operates a continuing program of updating specifications and is the only major representative of the flooring industry in the United States.

\section{ZINC INSTITUTE, 292 Madison Avenue, New York, New York 10017}

The Zinc Institute was founded in 1918. The activities of this institute in the field of standardization are confined to specifications and standards in connection with the finished products of the zinc industry. The institute is a member of the American Society for Testing and Materials (ASTM), and cooperates with those committees dealing with corrosion of iron and steel, on specifications for nonferrous metals and alloys, and on corrosion of nonferrous metals and alloys. It has cooperated in the preparation of ASTM specifications covering slab zinc (spelter), rolled zinc, and zinc base alloy die castings. In addition, it concerns itself in all ASTM specifications relating to zinc-coated steel and iron articles such as fencing, wire, sheets, pipe, hardware, etc., as well as methods of test in connection therewith.

It cooperates also with the Standardization Division, Federal Supply Service, General Services Administration, in the preparation and revision of Federal specifications covering slab zinc (spelter); zinc plates, sheets and strip; zinc anodes for cathodic protection; zinc base alloys for die castings; and zinc dust-zinc oxide primer paint (for galvanized- zinc-coated- or zinc surfaces). In conjunction with the promotion activities of the institute and its efforts to improve 
the quality of zinc-coated (galvanized) roofing sheets, the institute licenses steel manufacturers without charge to stamp the American Zinc Institute's seal of quality mark on all galvanized sheets, which conform to rigid specifications as to quality and which carry a full 2-ounce coating.

Formerly: American Zine Institute (1968).

\section{State Governments}

\author{
ARIZONA, STATE OF, \\ Manager, Purchasing Office, \\ Finance Division, \\ Department of Administration, \\ The Capitol Building, \\ 1700 West Washington, \\ Ploenix, Arizona 85007
}

The State of Arizona Purchasing Office, Division of Finance, Department of Administration, is responsible for administering the standardization activities for the State as applies to procurement of supplies, materials and equipment.

The standards program was implemented in 1968 when a central State purchasing office was authorized by legislative appropriation.

Currently standards issued by this office approximate 150 items. These standards are those reviewed and adopted from the National Association of State Purchasing Officials and National Institute of Governmental Purchasing organizations information exchange circulars.

The Manager of the State Purchasing Office is Chairman of the State Standards Committee. The committee is comprised of department administrators representing approximately seven larger agencies and institutions of the State on a rotating basis and dependent on the commodity under review.

The standards are promoted by (1) informing State agencies of the existence and adherence to State specifications as formulated or adopted by the standards committee; (2) review of all State agency requests by central purchasing for deviations and changes to State specifications and standards.

\section{COLORADO, STATE OF \\ State Purchasing Director, Division of Purchasing, Department of Administration, Suite 232 - State Services Building, Denver, Colorado 80203}

Effective March 26, 1973 a State Purchasing Director was assigned to administer the standardization program for the State of Colorado.

The program is being developed to encompass those standards considered effective and applicable over a long period of time. It is a program of statewide scope for which implementation is anticipated in the near future. The program will include a full time standards committee. The use of standards, upon implementation of the new program, will be promoted by selling the program to using agencies and by appropriate contracts and awards to substantiate the standards established.

\section{CONNECTICUT, STATE OF, Director, \\ Purchasing Division, \\ Department of Finance and Control, \\ P.O. Box 1141, 460 Silver Street, Middletown, Connecticut 06457}

The prime function of the State of Connecticut Standards Division is to supervise, study, and review all commodity standards and specifications submitted to the Standardization Committee for their consideration and adoption.

To assist in this important function, approximately 300 qualified personnel, representing 30 Advisory Committees, are currently serving on these committees, some of which were originally organized in June, 1952.

Representatives of industry, other states, cities, towns, national purchasing groups and branches of the Federal Government have continued to express interest in the division's unique approach to the development of specifications and standards. This division strives to establish specifications developed in full cooperation with State agencies and responsible industry representation. The Standards Division promulated and/or revised 161 specifications, acceptable brands lists, and standards during 1971-1972 which controlled the quality of approximately $\$ 30$ million of commodities purchased for using State agencies. The specifications are designated to provide optimum value and quality to satisfy the needs of the using agencies.

Approximately 350 documents, including acceptable brands lists, Connecticut standards, and specifications have been established to serve all phases of State procurement.

\section{FLORIDA, STATE OF, Director,}

Division of Purchasing, Bureau of Standards, Department of General Services, William D. Bloxham Building, Tallahassee, Florida 32304

The State of Florida Division of Purchasing implemented a standardization program in 1968 . Under the Director of the Division of Purchasing, this program was designed to standardize the many high-volume common items purchased by various State agencies. Standardization is accomplished first by preparing 
specifications which reflect minimum requirements consistent with the present state of the art offered by manufacturers and secondly, by inspection and test of a quality standard product (pre-bid sample). Random samples are tested, using the same inspection and test criteria to assure product integrity throughout the term of a contract.

The Division of Purchasing has published 2050 standards covering a wide variety of items. When completed, these standards are promulgated with copies being sent to the National Bureau of Standards, General Services Administration, National Association of State Purchasing Officials, National Association of Purchasing Management, National Institute of Gov. ernmental Purchasing, and the American Society for Testing and Materials. Presently the American Society for Testing and Materials, using State of Florida specifications as a foundation, is working with the paper industry to establish industry standards on unwatermarked, cut size, office papers.

\section{GEORGIA, STATE OF,} Director,

Purchasing and Supplies Division, Department of Administrative Services, 116 Mitchell Street SW., Atlanta, Georgia 30334

The standardization activities of the State of Georgia are administered by the Purchasing and Supplies Division of the Department of Administrative Serv. ices. Formal specifications development and a program of standardization of purchased materials began in April 1972, with the implementation of the Contract Section of the division. Currently about 60 statewide standard contracts are in effect and the program aims toward staffing for development of standard specifications covering one-half of the State's materials needs by the end of 1975 . These standards and the associated purchasing contracts are promoted for utilization by all city and county purchasing functions in the State, also.

\section{ILLINOIS, STATE OF, State Purchasing Agent, Procurement Division, Department of General Services, 801 State Office Building, Springfield, Hlinois 62706}

The Procurement Division of the Department of General Services, formerly known as the Purchases and Supplies Section of the Department of Finance, is responsible for purchasing commodities and equipment, and formulating specifications for all State agencies except for the universities.

State purchasing agents of this division (buyers) write specifications for various commodity and equipment items. There are currently over 90 standard specifications for commodities and products for the
State of Illinois. In the case of highly sophisticated equipment, the purchasing agents work with the engineers associated with the agency using such items. Agents may also meet with manufacturers to discuss new specifications or the need to update old ones. Specifications established by this office are sent to all appropriate State agencies.

\section{KANSAS, STATE OF, Director, Division of Purchases, Department of Administration, State Office Building, Topeka, Kansas 66612}

The standardization program, as it relates to commodities used by the agencies of Kansas government, is under the jurisdiction of the Division of Purchases. In July, 1953, Kansas by statutory authority created a centralized Purchasing Division under which specifica. tions and standards are developed. This is a continuing process including constant revisions and additions.

Standards are on file in the office of Director of Purchases, State Office Building, Topeka, Kansas. The basic specifications and standards are written and indexed by employees of the Division of Purchases with help from the using agencies. A Standards Committee at the University of Kansas Medical Center assists with hospital and medical standards and specifications. Other areas are supplied by ad hoc committees, set up as needed in specific instances. The only standing committee is the Medical Center Committee.

Use of standards by the agencies of State government is a statutory authority of the Director of Purchases, and their use is a cooperative requirement of his office.

\section{KENTUCKY, COMMONWEALTH OF, Chief, Specification and Inspection, Division of Purchases, Department of Finance, New Capitol Annex, Frankfort, Kentucky 40601}

The Specification and Inspection Section, of the Division of Purchases, within the Executive Department for Finance and Administration, was activated in 1956, but without continuous activity since. Its purpose is to assist commodity buyers, and construction and renovation buyers, by maintenance of the standards and specifications of the: General Services Administration, American Society for Testing and Materials, and several laboratory reporting services. The division's ongoing committee efforts exist in such areas as: vehicles, janitorial maintenance products, furniture and others, with the purpose of establishing written standard specifications which will be of benefit to all State agencies.

The Specification Section also conducts some 
inspections of sites and shipments to determine that the service or product is in compliance with established contracts.

\section{MARYLAND, STATE OF, Chief of the Purchasing Bureau, Department of General Services, 301 West Preston Street, Baltimore, Maryland 21201}

The Purchasing Bureau of the Maryland State Department of General Services initiated a standardization program in June 1973.

At this time the staff consists of two standards technicians and to date the program activity is directed at furniture standardization.

The bureau's intent is to establish standards for all significant items that are widely used by the State and to develop specifications for these items. The scope of its long-range program encompasses cataloging standards and specifications and also includes certification activities.

\section{MICHIGAN, STATE OF, Standards Executive, \\ Purchasing Division, Standards Section, Department of Management and Budget, Mason Building, Lansing, Michigaul 48913}

The Standards Unit is primarily responsible for developing and establishing standard specifications, and arranging for laboratory tests at state-owned facilities and commercial laboratories. Specifications have been developed for a large number of commodities, thereby establishing a much better understanding between the buyer and the seller, regarding the item being purchased. This is absolutely necessary for good competitive bidding. Several hundred specifications have been prepared and are in use, but many more are needed. The specifications are continually revised in order to keep them up to date.

The standards engineer, buyers and agency representatives work together in developing standards. This "committee" approach has been particularly effective for the purchase of food, pharmaceuticals, vehicles, computers, clothing and textiles, paper, laundry equipment, furniture, paint, traffic control devices, and radio equipment. The Purchasing Division is responsible for the inspection of all purchases in cooperation with the receiving agencies. Major responsibility for inspection must rest with agency personnel in the field where commodities are received.

The Standards Unit arranges for inspection and grading of numerous items prior to shipment, to insure that quality products are received. All meat items are processed under Institutional Meat Purchase Specifications (IMPS) and are selected and inspected by the United States Department of Agriculture (USDA) before shipment to the using agencies.
Poultry purchases are also inspected by USDA. Practically all canned fruits, vegetables, and juices are graded by USDA, and a certificate furnished with each shipment. Butter and cheese are graded by the Federal-State Inspection and Grading Service. Coal is purchased on definite specifications. It is sampled and tested during the entire shipping season to determine whether the coal meets the Btu content requirements on which it was purchased.

\section{MINNESOTA, STATE OF, Director of Procurement, Standards and Engineering Unit, Procurement Division, Department of Administration, Saint Paul, Minnesota 55101}

The Standards Unit was organized in 1953, and is now called the Standards and Engineering Unit (SEU). This unit is responsible for developing and promulgating procedures, standards, and specifications, for a wide range of commodities and services procured by the State of Minnesota's Procurement Division. SEU is also responsible for general quality control, inspection, and laboratory testing. The Commissioner of Administration issued and authorized the formation of a State Standardization Committee in June of 1962.

The State of Minnesota has issued approximately 450 specifications and standards, (general and detail). The specifications and standards are listed in MN. 1, Minnesota Master Index of Standard Specifications, Standards, Acceptable Brands Lists, Procedures, and Miscellaneous Procurement Division Publications and Documents.

At the present time, there are nineteen active Standards Advisory Committees which are responsible in the following areas: Group 23, Vehicles, 2310Passenger Vehicles, and 2320-Trucks; Groups 35 and 79, Laundry and Dry Cleaning Equipment and Supplies; Groups 36 and 75, Reproduction Equipment, Supplies, and Paper; Group 41, Refrigeration and Air Conditioning Equipment and Supplies; Groups 45, 47, and 48, Plumbing Supplies and Equipment; Groups 58 and 67, Audio-Visual Equipment; Group 65, Drugs; Group 66, Microscopes; Group 68, Chemicals and Chemical Prod.-Herbicides, Insecticides, etc.; Group 71, Furniture, other than Library); Groups 71 and 76, Library Furniture; Group 74, Office Machines and Related Equipment, (Typewriters, Manual and Electric) ; Group 75, Office Supplies; Group 77, Musical Instruments; Group 78, Recreational and Athletic Equipment; Group 79, Cleaning Equipment and Supplies, (Housekeeping); Groups 79, 81, 85, Paper Products-Towels, Tissue, (other than Reproduction Paper) ; Groups 83, and 84, Clothing and Textiles; and Group 89, Food.

SEU has a Procurement Newsletter which is used as a vehicle for promoting the use of standards. Cer. tification is through lab and field testing to State and Federal specifications, and standards. 
MISSOURI, STATE OF,

Director,

Contracting and Procurement Division,

Office of Administration,

Jefferson City, Missouri 65101

Centralized Procurement was established by the Missouri Legislature in the mid 1930's with the establishment of the State Purchasing Agent's Office. In January, 1973, the Division of Contracting and Procurement was reorganized from the former State Purchasing Agent's Office and placed within the Office of Administration.

The Division of Contracting and Procurement is a Merit System organization of the State government of Missouri charged by Chapter 34 of the Revised Statutes of the State of Missouri with the responsibility for procurement of supplies and services for all but a few statutorily and constitutionally exempt agencies of State government. The major activity of the division is a Buyer Section consisting of 10 professional buyers responsible for specific commodities and services required by the various State institutions.

The following standards, which are statewide in scope, are furnished to bidders and referred to in Invitations to Bid on items covered by the standard specifications: Missouri Meat Specifications, Missouri Mattress Specifications, Missouri Bronze and Iron Specifications, Missouri Steamfitters Supplies, Missouri Intermediate Automobiles Specifications and Missouri Paint Specifications.

\section{MONTANA, STATE OF, Chief, \\ State Purchasing Bureau, Department of Administration, State Capitol Building, Helena, Montana 59601}

The State of Montana is developing a standards program at this time and has set up specifications and acceptable brands lists which have been used as a basis to award state contracts.

Each buyer is responsible for the completeness of specifications used in calls for bids and in some cases a brand item or guaranteed equal can be bid.

There is one specifications analyst who works in conjunction with the Chief of Purchasing and all buyers and representatives from State departments, to arrive at specifications which will apply to all departments and be broad enough to allow competitive bidding.

The department does not have a testing lab, therefore, use is made of the Department of Highways' lab and University facilities for the testing of some items. Each receiving agency is responsible for quality and control and for checking items when they arrive, to determine whether or not the item is as specified in the bidding process.
NEW JERSEY, STATE OF,

Director,

Standards and Specifications Section,

Division of Purchase and Property,

State House,

Trenton, New Jersey 08625

The Standards and Specifications Section was initiated in 1956 and has the responsibility for establishing standards and specifications of all materials purchased to these specifications. This section also performs evaluations, inspections, testing of materials, and the resolving of complaints.

The objective is to assure that all vendors doing business with the State of New Jersey Purchase Bureau adhere to all prepared product and service specifications. It is also the purpose to effect economies wherever possible by means of the most efficient use of the materials purchased and to recommend the purchase of as few articles as possible for the same type of use.

The section maintains active membership in the American Society for Testing and Materials, National Association of State Purchasing Officials, and National Institute of Governmental Purchasing.

\section{NEW YORK, STATE OF, Director, \\ Division of Standards and Quality Control, Office of General Services, South Mall Tower, \\ Albany, New York 12223}

This Division of New York's Office of General Services (OGS) is responsible for establishing standards and specifications for equipment procured by the Division of Purchasing for all State agencies and departments of the State of New York including the State University. Activated in 1954 with four specification writers, the Division of Standards and Quality Control has since been expanded to include an Engineering Specifications Bureau, an Inspection Bureau and Chemical, Physical, Electrical-Electronic and Light Reflectance Laboratories. Specifications are developed by the Specifications Bureau unilaterally or in cooperation with committees chaired by the specification engineers and consisting of respresentatives of major State agencies which are users of the product under consideration, after consultation with industry. These are continuing committees which meet, to review and revise the applicable specification at least once a year or more often if the situation warrants. Items such as athletic equipment, grounds maintenance equipment, paint and wall covering materials, office furniture and equipment and others are now under committee study and review. Some consideration is given to the development of qualified products or acceptable brands lists but this method of specifying is not currently emphasized. Term contracts issued against OGS standards and specifications 
are mandatory for State agencies and none but contract items may be purchased without specific OGS approval.

\section{NORTH CAROLINA, STATE OF, State Purchasing Officer, Standards and Engineering Section, Purchase and Contract Division, Department of Administration, 116 West Jones Street, Raleigh, North Carolina 27603}

The duty to establish and enforce specifications is assigned to the Purchase and Contract Division and to the State Standardization Committee. The Standardization Committee was first established in July, 1959. Its duty is to review, adopt, establish and/or modify standard specifications wherever feasible applying to articles purchased or leased. This committee consists of the Secretary of the Department of Administration, who serves as chairman, and six members appointed by the Governor. Standard specifications as adopted by this committee are applicable to the purchase of items made under both indefinite quantity term contracts and under definite quantity contracts.

The Standards and Engineering Section implements the statutory duties of the Standardization Committee, under the administrative directions of the State Purchasing Officer. Advisory committees, composed of regular state employees and other individuals with specialized knowledge in specific commodities or classes of commodities, formulate proposed standard specifications for presentation to and adoption by the Standardization Committee.

The Standards and Engineering Section maintains a quality control program by testing, evaluating and inspecting deliveries made to the various agencies. The staff of the section includes consultants in the mechanical, electronic, chemical and industrial engineering fields. They are available to State agencies, institutions, public school systems, community colleges and technical institutions as consultants in the selection, use and maintenance of equipment and supplies. There are approximately 125 current standards issued by this office, with the active standards committees numbering 19. Standard specifications are distributed to using agencies and vendors as they are developed.

\section{OREGON, STATE OF, Administrator, \\ Specification Section, Procurement Division, Department of General Services, 1225 Ferry Street SE., Salem, Oregon 97310}

The Specification Section was established in 1951, as a support function for the Procurement Division. Responsibilities of the section include formulation and issuance of standard specifications, qualified products lists and purchase specifications for use by State purchasing agents, State agencies and authorized political subdivisions. Approximately 90 standard specifications and 30 qualified products lists are presently in existence. They are supplied upon request, and as referenced on distribution sheets issued by State purchasing agents. The Specification Section also provides assistance to State purchasing agents as required on any specification problems. A small laboratory is available for technical product testing (particularly paint). A Booklet of State Standard Bid Paragraphs is maintained for standardization of bid wording and format (particularly contract-type bids); and a State Commodity Code system is maintained to facilitate control of purchasing agent commodity assignments, etc. The following committees are activiated as needed to assist the Specification Section in developing and revising specifications: Fine Printing Paper Committee, Motor Vehicle Committee, Office Equipment Committee and Furniture Committee.

\section{PENNSYLVANIA, COMMONWEALTH OF, Secretary of Property and Supplies, Department of Property and Supplies, Room 602, North Office Building, Harrisburg, Pennsylvania $\mathbf{1 7 1 2 5}$}

The Bureau of Standards in the Department of Property and Supplies, established October 1, 1929, has the responsibility for the standardization program in the Commonwealth of Pennsylvania. Among other functions they are responsible for establishing standards and specifications for all materials, except certain highway materials, supplies, equipment and services purchased by the Commonwealth. In addition, the bureau conducts a field inspection program and tests through the use of laboratory facilities delivered materials for conformance to these established specifications. It also offers technological and advisory services to all State agencies.

One of the major responsibilities of the bureau is to review purchase requisitions prior to going out on bid, and also, perform bid evaluations and make recommendations for the award on bids.

The bureau has published over 700 Commonwealth specifications which are periocially reviewed, updated and listed in an Index to Commonwealth Specifications which is published yearly with monthly updates. The index and accumulative supplements are forwarded to all using agencies, National Institute of Governmental Purchasing, National Association of State Purchasing Officials, Canada, various states, and school districts upon request.

Standards Committees are actively working on environmental sanitation services specifications; standards and specifications for a safe school bus for the Pennsylvania school districts; participating in the revision of the Pennsylvania Motor Vehicle Code; developing uniform standard definitions, classifications, and recommend procedure for requisitioning fertilizers and herbicides, and closed circuit and mobile communications systems.

The bureau maintains membership and actively participates in the National Institute of Governmental 
Purchasing, Technical Association of the Pulp and Paper Industry, American Society for Testing and Materials, American Association of Textile Chemists and Colorists, American National Standards Institute, National Association of State Purchasing Officials and the American Chemical Society.

\section{RHODE ISLAND, STATE OF, State Purchasing Agent, Division of Purchases, \\ Department of Administration, 289 Promenade Street, Providence, Rhode Island 02908}

The State Purchasing Agent, head of the Division of Purchases operates a centralized organization for the purchase of supplies and equipment and is the contracting authority for services and construction for all State agencies as outlined in: 37-2-2, 37-2-3, GL 1956.

The Standards Section was established to implement the duties of the State Purchasing Agent. The principal duty of the Standards Section is to be concerned with the development of standard specifications and acceptable brand lists, and as necessary, their amendments or revisions.

A Standard Specification Preparation Manual was prepared as a guide for development of the commodity standardization program within the State government. The Standard Specification Manual provides for the appointment of Advisory Committees to assist in the development of technological data necessary for the preparation of standard specifications and acceptable brands lists. To date we have 16 active committees meeting regularly. The Standards Section has developed catalogs for the following: food, footwear, clothing, furniture, office supplies and lumber, and are presently working on cataloging hardware, electrical supplies and plumbing supplies. Standard specifications and acceptable brands lists are on file for numerous items.

\section{TENNESSEE, STATE OF, Director, \\ Purchasing Division, Department of Gemeral Services, C2-202 Central Services Building, Nashville, Tennessee 37219}

The Department of General Services was created by a legislative act in 1972. The purpose of the act was to place certain staff functions of the State government under the administrative control of a single department. The department is composed of eight divisions which perform the following functions.

Administrative Division-This division is composed of the Commissioner, Deputy Commissioner, departmental fiscal officer, personnel officer, systems analyst, and sufficient clerical staff, to coordinate and supervise the activities of the divisions in the department.

Purchasing Division-The Director of this centralized purchasing agency receives its authority and oper- ating guidelines from the State purchasing statutes. The same statutes also created a Board of Standards that is composed of the State Comptroller, the Commissioner of Finance and Administration, and the Commissioner of General Services. It is the duty of this board to examine and approve standard specifications for all materials, supplies, and equipment purchased for the use of State government and to examine and approve the rules and regulations governing the operation of this division as provided by the State purchasing statutes.

The Department of General Services, Purchasing Division, is charged not only with the centralized procurement responsibility but also with the supply management responsibility which includes the exercise of procurement controls over the operating departments and agencies. The statutes governing State purchasing have defined and extended the purchasing function to encompass the total supply concept. In carrying through the responsibilities, the purchasing division is involved directly with many details-specifications, standardization, value analysis, inventory control, market analysis, vendor performance, evaluation of offers, compliance with the law, disposition or disposal of surplus property, inspection of receipts, and the delegation of authority.

Purchasing represents material management with the overall objective of maintaining costs at economic levels and reducing them wherever possible.

\section{TEXAS, STATE OF, Executive Director, Texas State Board of Control, P.O. Box 13047, Capitol Station, Austin, Texas 78711}

The State Board of Control has, among other functions, the responsibility for establishing specifications and standards for materials, supplies and equipment purchased for agencies of the State. The program was initiated in 1957 and as a result 362 specifications have been developed, 85 of which have acceptable products listings. The board enlists the cooperation of other State agencies, manufacturers, and national standards and testing organizations in the establishment, maintenance, and revision of its specifications. The board encourages and fosters the use of the standard specifications in order that the most efficient purchase of products may be continuously accomplished.

\section{UTAH, STATE OF, Purchasing Agent, Division of Purchasing, Department of Finance, State Capital Building, Salt Lake City, Utah 84114}

The Department of Finance, is responsible for the purchasing/standardization activities for the State of 
Utah. The standardization program for the State of Utah was formed in 1941. The Director of Finance appoints with the approval of the Governor, the Purchasing Agent.

The Director of Finance exercises the powers and performs the duties relating to the purchase of all supplies, materials, equipment and services required in the administration of any department of the State, the administration of a central purchasing and store system for the departments of the State and the exercise of inventory control over all departments.

The Purchasing Standardization Committee seeks the advice, assistance and cooperation of all State departments as to their particular requirements in the preparation or revision of any standard or specification adopted by it and ascertains the precise requirements of each department. Each specification adopted for any commodity must satisfy the requirements of the majority of the departments having use for the commodity. After its adoption each standard or specification, until revised or rescinded, is the control in the purchase of every commodity to which it applies; provided however, that the State Purchasing Agent with the approval of the Governor may purchase commodities not complying with such specifications or standards when required to meet the particular needs of any department.

The Director of Finance is the chairman of the Purchasing Standardization Committee. In the absence of the Director, the State's Purchasing Agent serves as chairman. The committee meets upon the call of the Governor or of its chairman or any seven members upon two days notice to each of the members thereof. Seven members constitute a quorum for the transaction of business. The committee meets as often as necessary but at least once every six months.

The State of Utah in preparing specifications uses a brand name and model number on acceptable brands where standards are not available. Each buyer is responsible for the specifications being accurate and nonrestrictive. The words "or approved equal" follow the brand name in all instances.

The Purchasing Division has a specification analyst who works with the Purchasing Agent and all buyers where specifications are for bidding annual contracts. $\mathrm{He}$ also works with the various State departments when requested.

Since the State does not have a testing laboratory, Division of Purchasing utilizes the State Highway Department laboratory and University of Utah facilities when required.

The State Purchasing Agent makes the final decision as to whether or not the specifications have been met by the various companies submitting bids.

The standards and specifications for the State are filed with the National Association of State Purchasing Officials (NASPO) Standards Committee. NASPO maintains a collection of state specifications and standards which are available through the Council of State Governments, the NASPO Secretariat.

\section{VIRGINIA, COMMONWEALTH OF, Director, \\ Department of Purchases and Supply, Post Office Box 1199, \\ Richmond, Virginia 23209}

Section 2.1-279 of the Code of Virginia relating to this department reads as follows: "So far as practicable. all materials, equipment and supplies, purchased by or for the officers, departments, agencies or institutions of the State, shall be standardized by the Director, and no variation shall be allowed from any established standard without the written approval of the Director. Such standards shall be determined upon the needs of all using agencies, so far as their needs are in common, and for groups of using agencies or single using agencies so far as their needs differ. When changes or alterations in equipment are necessary in order to permit the application of any standard, such changes and alterations shall be made as rapidly as possible."

The Department of Purchases and Supply attempts to carry out this directive, for the most part, through the establishment of various statewide purchase contracts. For instance, the department has standardized on such contract products as carpet, metal office furniture, paint, floor maintenance supplies, and xerographic toner. These standards are usually expressed in specifications or approved brands lists and are based on tests conducted by various State agencies and/or consultations with major manufacturers.

\section{WEST VIRGINIA, STATE OF, Director,}

Purchasing Division,

Department of Finance and Administration, State Capitol Building,

Charleston, West Virginia 25305

All procurement activity in the State of West Virginia is centralized in the Purchasing Division of the Department of Finance and Administration. This division not only has the responsibility for procurement of all material used by the State but also for classification of all commodities and adopting and formulating a schedule of standard specifications. Such standards and specifications are mandatory after the time of their publication for use by all units of State government.

The responsibility for all standardization activities of the State of West Virginia rests with the Director of Purchasing. To assist the Director of Purchasing, the legislature created one staff position of Specification Analyst.

The standardization activities of the State of West Virginia commenced July 1, 1973. The first standard specification promulgated was for canned foods and staple groceries. In the near future more activity is expected in all areas where the State buys large quantities of goods. 
WISCONSIN, STATE OF,

Director,

Bureau of Purchases and Services,

Department of Administration,

1 West Wilson Street,

Madison, Wisconsin $\mathbf{5 3 7 0 2}$

The State Bureau of Purchases and Services, Wis. consin Department of Administration, is responsible for standardization in public purchasing and public printing for the State. The principal activity is vested in the Standards and Value Analysis Unit, State Purchasing Section, a unit which has been formally in existence since 1962, but traces its genesis to the passage of the State central purchasing law in 1929. The supervisor and staff chair standing and ad hoc standards committees comprised of using agency representatives. Nearly half (48 percent) of the State's approximate $\$ 120$ million purchases for fiscal 1972-73 were made under the standards program. The basic listing of standardization is the Index of Scheduled Procurement Operational Bulletins. Promotion of the use of standards is found in s. $16.72(2)$, Wis. Stats. The State Printing Section also has a standards program following the purchasing format but somewhat limited by the inherent variables of printing.

The Wisconsin State Purchasing Standards and Value Analysis Unit, under the State Bureau of Purchases and Services, has the responsibility of reducing the variety of materials, equipment, supplies and contractual services purchased and for the selection of the quality level most consistent with State agency needs on a statewide basis. Expressing these requirements in written specifications and standards which are acceptable to the agencies and to the market in which they must be procured, provides basic combinations for centralized large volume contracting. Standards committees are formed and convened to assist in this process. The separate committees are composed of State purchasing and agency personnel who are knowledgeable in the commodity or service being standardized. The committees are advisory to State purchasing and meet as often as is necessary to keep standardized specifications and policies current. In the selection and development of standard specifications consideration is given for the maximum availability and competition of that commodity or service in the market place. Whenever possible, specifications recognized by industry and national standards are adopted for State use.

\section{WYOMING, STATE OF, \\ Purchasing Administrator, \\ Purchasing and Property Control Division, Department of Ardministration and Fiscal Control, \\ Cheyenne, Wyoming 82002}

The Purchasing and Property Control (PPC) Division of the State of Wyoming is the procurement office for the necessary purchase of merchandise. This division also sets standards for equipment and supplies.
The division started a standardization program in the fall of 1971. Items standardized at this date are: office furniture, typewriters, duplicating paper, janitorial supplies, letterheads, envelopes, and miscellaneous forms. Standardized items are kept on inventory at the Central Services warehouse. The agencies within the State of Wyoming requisition the standardized merchandise from the office of Purchasing and Property Control. PPC assigns a stock room number to the requisition and fills the order. The order is delivered to the agency by our delivery service.

PPC is forming a standardized guide on adding machines and electronic calculators. The program is in cooperation with administrators of the various agencies.

PPC also has a policy and procedures manual to assist in promoting the items listed as standard.

\section{Federal Government}

\section{AGRICULTURE, DEPARTMENT OF, Fourteenth Street and \\ Independence Avenue SW., W ashington, D.C. 20250}

\author{
Office of Automated Data Systems, \\ Departmental Information Processing Standards, \\ Rural Electrification Administration, \\ Agricultural Marketing Service, \\ Packers and Stockyards Administration, \\ Scales and Weighing Branch, \\ Animal and Plant Health Inspection Service
}

Departmental Information Processing Standards, Office of Automated Data Systems, U.S. Department of Agriculture

The Office of Automated Data Systems (OADS) is responsible for establishing and managing a departmental computer network. The office also manages the total ADP resources of the Department. Standards relating to the management and operation of all departmental ADP activities are administered by OADS through the Departmental Information Processing Standards (DIPS) Program. This standardization activity, formally initiated in September, 1972, will coordinate development, implementation and maintenance of ADP, data and data communications related standards.

The DIPS will be promulgated in a DIPS Manual. The manual will include standards and informational material to support operations of the computer network and other ADP activities. Standards relating to computer center management, project management, hardware, software, applications development, data and security of computer resources are contained in the DIPS Manual. Applicable Federal and external standards are also incorporated in the departmental standards. Procedures, guidelines and other informational material which implement the standards will be assembled in a second manual.

ADP Systems Division of OADS has primary responsibility for the DIPS Program. In the develop- 
ment of standards, USDA agency participation is sought to ensure that the standards satisfy all agency requirements to the maximum extent possible. Task groups and committees representing Department agencies are available to assist in the development and review of proposed standards.

The objectives of the DIPS Program are to create, implement and maintain ADP, data and data communications standards, guidelines and procedures needed by agencies of the Department and departmental computer network as a basis for managerial control; improve hardware and software systems, enhance the effectiveness of application development and provide a basis for measurement of information processing performance with the Department.

\section{Rural Electrification Administration, U.S. Department of Agriculture}

The Rural Electrification Administration (REA) is active in the preparation of engineering standards and specifications for materials and equipment and for the design and construction of electric and telephone facilities to serve rural areas. The electric standards include overhead and underground distribution lines, overhead transmission lines, substations and generating plants. The telephone standards include overhead and underground telephone lines, station equipment and central office equipment.

Standards and specifications of national standardizing groups are utilized to the maximum practicable extent. Where they are not adequate or where they do not exist, REA prepares standards and specifications to be used by its borrowers which construct and operate rural electric and telephone systems. Standards and specifications are also prepared where it appears that such specifications and standards will result in reduced costs, improved materials and equipment, or the more effective use of engineering services. Standards and guides are also prepared which relate to the management and operation of rural electric and telephone systems.

REA standards are utilized by approximately 1,000 rural electric systems and 800 rural telephone systems in 47 states to which loan funds have been made available. The standards are also utilized by other organizations in this country and abroad.

Information on REA standards and copies of most standards are available upon request to the Rural Electrification Administration, U. S. Department of Agriculture, Washington, D. C. 20250. Several REA publications which include specifications, standard construction drawings and contract forms are available from the Superintendent of Documents, U.S. Government Printing Office, Washington, D. C. 20402.

\section{Agricultural Marketing Service, U.S. Department of Agriculture}

U.S. grade standards for food and farm products are developed by standardization staffs within the seven commodity divisions of the Agricultural Marketing Service, with the assistance of the statistical staff. Pres- ent legislative authority for standardization work is provided by the U.S. Cotton Standards Act, 1923; The Tobacco Inspection Act, 1935; The Naval Stores Act, 1923; United States Grain Standards Act, 1916, revised 1968; and the Agricultural Marketing Act, 1946. The standards are contained in Code of Federal Regulations 7, parts 0 to 209. The first USDA grade standards were those established for cotton in 1909, under a provision of the USDA appropriation act for 1908-9.

The purpose of the standards is to identify the degrees of quality in food and farm products, and thereby aid in marketing by establishing the usability or value of these products.

In general, the standards cover the fresh or raw agricultural products, such as wheat, and not products such as flour into which the raw product may be processed. Exceptions are the grade standards estab. lished for canned, frozen, and dried fruits and vegetables, butter, certain types of cheese, and a few other processed products such as jams and peanut butter. Grade standards are developed or revised on request or as needed, in accordance with changes in produc. tion, processing, or marketing practices and the public is invited to comment on proposed standards or revisions. Use of the grade standards, for the most part, is voluntary.

Grading, inspection, or classing services, to certify the quality of products according to the U.S. grade standards, are provided by USDA to producers, packers, wholesalers or others, on request, and usually for a fee to cover the cost of the service. Under the SmithDoxey Act, classing of cotton by grade is provided free to producers who request it. Under the U.S. Grain Standards Act, grain exported by grade must be officially inspected and a fee is charged for this inspection. The Tobacco Inspection Act provides for free and mandatory inspection of tobacco based on official grades, after a referendum in which two-thirds of the growers supplying an auction market vote approval. Tobacco may also be inspected on a voluntary, fee-forservice basis.

There are current U.S. grade standards for 389 food and farm products, listed in Agriculture Handbook No. 341, USDA Standards for Food and Farm Products, April 1973. A standardization committee, made up of standardization specialists from each of the commodity divisions meets quarterly to discuss common problems and methods of handling new projects. One current project involves incorporating more accurate statistical sampling methods into the standards.

Use of the standards is promoted through individual and group meetings with members of the various agricultural industries, marketing and food procurement agencies, consumer and educational groups, and through publications and other news media.

\section{Packers and Stockyards Administration, Scales and Weighing Branch, \\ U.S. Department of Agriculture}

The Packers and Stockyards Administration has jurisdiction over livestock scales, monorail scales, and live poultry scales in commerce. Such scales are gen- 
erally located at public stockyards, meat packing plants, or poultry processing plants subject to the provisions of the Packers and Stockyards Act, 1921, as amended and are required by regulation to be tested at least semiannually according to prescribed procedures. Codes of specifications, tolerances, other technical requirements, and testing procedures for such scales have been formally adopted through publication in the Federal Register (9 CFR 201.71), et seq. These codes correspond with minor exceptions to National Bureau of Standards Handbook 44, Fourth Edition, Specifications, Tolerances, and Other Technical Requirements for Commercial Weighing and Measuring Devices, as adopted by the National Conference on Weights and Measures. When necessary, due to action by the National Conference, these codes are anended or new codes promulgated to promote uniformity of interpretation and enforcement.

Aninal and Plant Mealth Inspection Service (APHIS), U.S. Department of Agriculture (USDA)

The Animal and Plant Health Inspection Service was established to implement several Acts that include the following areas of standards: Import-Export of Animals and Animal Products, Animal Welfare, Veterinary Biologics, and Meat and Poultry Inspection. Each of the following is the responsible regulatory group for the aforementioned.

Import-Export Staff, Veterinary Services, APHIS-USDA, 820-A, Federal Center Building, Hyattsville, Maryland 20782

Legislative authority: (1) 21 USC 113, May 21, 1884, an act to prevent the exportation of diseased cattle. (2) 21 USC 101-07, August 30, 1890, an act to suspend importation of livestock for a limited time when necessary to protect animals in the U. S. from contagious diseases and to set up quarantine of imported animals when necessary; also to provide for inspection of animals imported and those intended for export. (3) 46 USC 466a, March 3, 1891, an act specifying that all vessels transporting animals to foreign countries provide humane accommodations with specific reference to space, ventilation, pens, food and water supplies. (4) 21 USC 112, 113, 120, 121 February 2, 1903, an act authorizing regulation of exportation and transportation of livestock from any place in the U.S. where communicable livestock diseases exist to any other part of the U.S. or to foreign countries; and to take proper measures to prevent the introduction into the U.S. of communicable diseases of animals.

Regulatory reference: 9 CFR, I-D, Parts 91-97, Exportation and Importation of Animals (Including Poultry) and Animal Products.

Effective date: Original authority for these standards was effective in 1884. Since that time, additional statutes, regulations, and standards have been developed as deemed necessary by the Congress and by the Department.

Scope of Program: The staff establishes standards for pretesting animals for export and provides inspection of the animals at specific ocean, air, and border ports. Standards are established for resting export animals in proper facilities before loading and for proper accommodations on transport vessels. Import standards are set for inspection and quarantine of animals and poultry to be brought into the U.S. and for permits to accompany animals and animal semen imported from specified countries. The staff provides inspection of aircraft and other conveyances for import animals. They establish standards for unloading, cleaning, and disinfecting conveyances and containers for import animals; and they maintain sanitary control of animal by-products, hay and straw.

Enforcement of standards: Export standards are enforced at specified ports of export. Import standards are enforced at U.S. Import Centers at Clifton, New Jersey, Miami, Florida, and Honolulu, Hawaii.

Specific standards requirements for the export and import of animals and animal products are available upon request from the Import-Export Staff.

Certification activities: Animals intended for export to a foreign country must be accompanied by a certificate of health issued by an accredited veterinarian certifying that the animals have been inspected and tested according to established standards. Animals offered for importation must be accompanied by a certificate, issued by a veterinary officer of the country of origin, specifying that the animals meet established standards. Special certification requirements apply to dogs for handling livestock, animals and animal semen from Canada, Mexico, Central America and the West Indies.

\section{Animal Care Staff, Veterinary Services, APHIS-USDA, 701-A, Federal Center Building, Hyattsville, Maryland 20782 .}

Legislative Authority: Public Law 89-544 amended by P.L. 91-579, 7 USC 2131 et seq., the Animal Welfare Act of 1970.

Regulatory reference: 9 CFR, I-A Parts 1, 2, and 3, Animals and Animal Products; Animal and Plant Health Inspection Service, USDA; Animal Welfare.

Effective dates: Under P.L. 89-544, regulations and standards became effective February 24, 1967. Under P.L. 91-579, additional regulations and standards became effective December 24, 1971.

Scope of program: Regulations and standards under the Animal Welfare Act regulate licensed animal dealers, licensed or registered animal exhibitors, and registered research institutions. Animals covered by regulations and standards are: dogs, cats, nonhuman primates, guinea pigs, hamsters, rabbits, and other warmblooded animals that have been designated by the Secretary of Agriculture. Currently excepted from regulations and standards are: birds, horses, ponies, farm animals, rats and mice, fish and aquatic animals, and all other coldblooded animals. Responsibility as established by the Act is "To regulate the transportation, purchase, sale, housing, care, handling and treatment of such animals by persons or organizations engaged in using them for research or experimental 
purposes or for exhibition purposes or holding them for sale as pets or in transporting, buying, or selling them for any such purpose of use."

Separate divisions or subparts of the standards have been established for the following groups of animals: (a) dogs and cats; (b) guinea pigs and hamsters; (c) rabbits; (d) nonhuman primates; and (e) other warmblooded animals designated by the Secretary of Agriculture. Each subpart of the standard covers facilities, general; facilities, indoor; facilities, outdoor; primary enclosures; feeding; watering; sanitation; employees; separation of specific types of animals; veterinary care; handling; vehicles and primary enclosures used to transport animals; food and water requirements in transit; care in transit.

Enforcement: The Act, regulations, and standards are enforced by a field force of veterinarians covering the entire United States, divided into 5 regions and 18 area offices, coordinated by the Animal Welfare Staff as listed in Item 2.

Certification activities: The Animal Welfare Act directs the Department of Agriculture to establish minimum standards for all regulated animals covering the specified aspects of humane handling, care, treatment, and transportation. The Act specifies that: "In promulgating and enforcing standards ... the Secretary is authorized and directed to consult experts, including outside consultants where indicated." The Act also specifies that: "The Secretary shall consult and cooperate with other Federal . . . instrumentalities concerned with the welfare of animals used for research, experimentation or exhibition when establishing standards..."

These directives on establishing minimum standards are carried out by convening separate work conferences with representatives of the scientific community, animal welfare groups, animal dealers, animal exhibitors, and Government officials. Biologies Staff, Veterinary Services, APHIS-USDA,
828.A, Federal Center Building, Hyattsville, Maryland 20782.

Legislative authority: 37 Stat. 832-833, 21 USC 151158, the Virus-Serum-Toxin Act, passed by the Congress March 4, 1913.

Regulatory reference: 9 CFR, I.E, Parts 101-117, 122 and 123, Animals and Animal Products; Animal and Plant Health Inspection Service, USDA, and Viruses, Serums, Toxins, and Analogous Products; Organisms and Vectors.

Effective date: The Act was effective July 1, 1913; individual standards have been issued and revised continually since that time.

Scope of program: Regulations and standards under the Act regulate licensed manufacturers engaged in interstate sale of veterinary biologics and inspectors who bring such products into the United States under permit. The purpose of the activity is to make sure biological products used in the diagnosis, prevention, and treatment of animal diseases meet Department standards for purity, safety, potency, and efficacy. Currently, 41 licensees and 2 importers sell approximately
10 billion doses annually-mostly vaccines used by veterinarians and livestock and poultry producers to immunize against diseases.

Currently about 70 standard requirements are in effect for producing and testing 208 generic products licensed for production under the Act. A complete list of standards is available from the Biologics Staff. There are six new standard requirements under consideration at this time. Information about these proposals may also be obtained by writing to the Biologics Staff.

Enforcement of standards: The Act, regulations, and standards are enforced by a field force of veterinarians covering the entire United States, divided into 5 regions and 18 area officers. Enforcement is coordinated by Veterinary Services headquarters. Inspectors visit plants to see that production standards are followed and selective check tests are conducted on biologics at the APHIS laboratory, Ames, Iowa.

Certification activities: The Virus-Serum-Toxin Act directs the Department of Agriculture to license manufacturers and to set regulations affecting the manufacture of any virus, serum, toxin, or analogous product intended for use in the treatment of domestic animals to ensure that the materials are not worthless, contaminated, dangerous, or harmful. The Department maintains laboratories at Ames, Iowa, to evaluate current methods of testing the qualities of these materials and to develop new test methods. Since relatively few man. ufacturers are involved, they can be consulted individually to plan and review changes in standards.

\section{Meat and Poultry Inspection Staff, APHIS,}

316-E, Administration Building,

U.S. Department of Agriculture, W ashington, D.C. 20250

Legislative authority: (1) 21 USC 71-96, March 4, 1907, The Meat Inspection Act, as amended in 1967, to authorize the examination of animals, meat, meat-food products, used in interstate or foreign commerce, and inspection of slaughter and packing establishments. (2) 21 USC 451-469, August 28, 1957, The Poultry Products Inspection Act, as amended in 1968, to provide for the compulsory inspection of poultry and poultry products for wholesomeness at processing plants.

Regulatory reference: 9 CFR, III-A and C, Parts 301-335, and 381, Mandatory Meat Inspection and Mandatory Poultry Products Inspection.

Effective date: The two statutes providing legislative authority were effective in 1907 and 1957, respectively. Individual standards and regulations have been issued continually since that time.

Scope of program: Standards have been developed to cover the ingredients, methods of processing, and labeling of meat and poultry food products; the materials and design of plant facilities and equipment; sanitary practices: the disposition of diseased animals; and inspection methods.

Committees: Standards are developed by appropriate staffs within the program in consultation with the National Meat and Poultry Inspection Advisory Committee, meeting quarterly in Washington, D.C. 
Current standards are contained in the appropriate sections of the Code of Federal Regulations.

Enforcement: Standards are enforced by APHIS inspectors in some 6,000 plants in the U.S. and in 1,059 certified plants in foreign countries.

\section{ATOMIC ENERGY COMMISSION, ${ }^{1}$ Washington, D.C. 20545}

Two organizations within the AEC have major responsibilities in the administration of standardization activities. These organizations are the Directorate of Regulatory Standards and the Division of Reactor Research and Development.

The Directorate of Regulatory Standards develops and issues guides, regulations, criteria and codes for: the design, siting, construction and operation of nuclear facilities; the production, transportation, protection and disposition of nuclear materials and by-products; and health and environmentally-related aspects of the above activities.

The Directorate coordinates its activity with its sister organizations under the Director of Regulation to develop standards which will ensure timely licensing of nuclear facilities as well as their safe operation. In promulgating its standards, the Directorate also works closely with the American National Standards Institute (ANSI), the Institute of Electrical and Electronic Engineers (IEEE), the American Society for Testing and Materials (ASTM), the American Society of Mechanical Engineers (ASME) and other standards groups.

At its present rate of production, the Directorate issues almost 150 standards per year. These may be found in: 10 Code of Federal Regulations (CFR) Parts $20,21,30,31,32,40,50,55,70,71,73$ and 100; 14 CFR Part 103; 46 CFR Part 146; and 49 CFR Parts $170-179$ and 397.

The Division of Reactor Research and Development formerly Reactor Development and Technology (RDT), through its contractor organizations, develops and publishes RDT Standards for application to priority AEC reactor development programs. These standards are made available to the nuclear industry and can be used as a basis for developing industry-wide standards for commercial nuclear applications.

The RDT standards office at the Oak Ridge National Laboratory (ORNL) publishes a bimonthly Index of RDT Standards. The index and copies of standards are available from ORNL.

Standards include requirements for material, process, component, instrumentation and quality assurance for application to liquid metal fast breeder reactors and light water reactors. Published standards number 279 and over 200 are in preparation.

${ }^{1}$ The Atomic Energy Commission has been reorganized and its functions divided into two new groups: the U.S. Energy and Research Development Administration, and the U.S. Nuclear Regulatory Commission.
COMMERCE, DEPARTMENT OF,

W ashington, D.C. 20230

Office of the Assistant Secretary for Science and Technology, Office of Product Standards, Maritime Administration, National Bureau of Standards,

National Oceanic and Atmospheric Administration, Office of Telecommunications

Office of Product Standards, Office of the Assistant Secretary for Science and Technology,

U.S. Department of Conmerce

The Office of Product Standards (OPS) was established by directive of the Assistant Secretary for Science and Technology on May 24, 1967, under the name of Office of Standards Review (subsequently, it became the Office of Standards Policy), as a constituent operating unit of the Department of Commerce.

OPS exists to strengthen the ability of the Department to contribute to the solution of national policy issues concerning the types of industrial or consumer product standards to be established; the responsibilities of the various agencies of the Federal Government in developing or aiding in the development of standards; the forms of participation in standards-setting activities by Government, industry, the scientific community, and the general public; the means of participation by the United States in international standards activities; the legal, economic, and other aspects of assuring adherence to or compliance with standards; and other problems relating to the development and use of standards.

OPS provides staff assistance to the Assistant Secretary for Science and Technology in the formulation of policies dealing with standards activities, and the coordination of Commerce standards programs and policies with those of other Federal departments and agencies, trade and professional associations, and individuals. This includes participation by the U.S. Government in the activities of international organizations or conferences concerned with the formulation or adoption of international standards and cooperation with the Executive Office of the President and with other Federal agencies to assure that their interests, and the interests of groups for which they are responsible, are given proper consideration.

\section{Office of Ship Construction, Division of Ship Design, Maritime Administration, U.S. Department of Commerce, Washington, D.C. 20235}

The Standard Specifications for Merchant Ship Construction have been prepared by the technical staff, naval architects and marine engineers, of the Office of Ship Construction in the Maritime Administration for the purpose of providing guidance to the maritime industry in the preparation of detail ship specifications 
for constructing ships. Various segments of the industry, such as ship owners, shipbuilders, design agents and manufacturers of major machinery and equipment have over the years reviewed these specifications and the present document reflects their input. The specifications are complete in all aspects of required contract work and accomplish the following pertinent objectives: establish levels of quality as a bench mark for Construction Differential Subsidy; identify current requirements of regulatory bodies; reflect latest technological developments; indicate measures of standard. ization to encourage mass production techniques; and include standard text to reflect legal aspects of contract work.

The development of guidance specifications for ship construction was first authorized on May 20, 1960 by the Federal Maritime Board. The first two formal editions were issued in November 1965 and March 1968 under the title Standard Specification for Cargo Ship Construction which applied mainly to general cargo ships. The latest edition entitled Standard Specifications for Merchant Ship Construction was issued December 1972 with broadened applicability to include other types of merchant ships such as container, Lighter Aboard Ship (Barge Carrying Ship) (LASH), Ore-Bulk-Oil (Supertanker) (OBO) and tanker vessels. It is intended to further update these standard specifications periodically to reflect continuing technological developments and pertinent results of research and development investigations. Future editions may also include applicable text for LNG, tugbarge combinations and other specialized designs as well as other forms of propulsion machinery (diesel, gas-turbine, nuclear, etc.) in addition to the steam turbine already in the current text.

Distribution of the standard specifications is handled by the National Technical Information Service, U.S. Department of Commerce, Springfield, Virginia, 22151 (refer to Publication No. COM-7211469). Publicity concerning the availability of future editions will be provided through announcements by the National Technical Information Service, notices from the MarAd Office of Public Affairs, publications in the Federal Register and news releases to technical magazines.

\section{National Bureau of Standards, U.S. Department of Commerce, Washington, D.C. 20234}

Institute for Applied Technology, Standards Development Services Section, Law Enforcement Standards Laboratory, Standards Information Services

Institute for Conputer Sciences and Technology, Office of ADP Standards Management Office of Engineering Standards Services,
Institute for Applied Technology, National Bureau of Standards

The Standards Development Services Section assists producers, distributors, users and consumers, and agencies of the Federal, state, and local governments in the establishment of standards for products; and administers the Department of Commerce's voluntary product standards program as is set forth in Part 10 of Title 15, Code of Federal Regulations, Procedures for the Development of Voluntary Product Standards.

The Department's voluntary product standards program supplements the activities of the private standardizing bodies by providing a mechanism for the development and publication of voluntary standards that are needed but are not being effectively developed by the private bodies. Standards published by this activity were previously called Simplified Practice Recommendations (SPR) and Commercial Standards (CS). As of December 1965, all publications including revisions of SPR's and CS's are called Voluntary Product Standards (VPS). Subsequent to the publication of a VPS it is submitted to the American National Standards Institute (ANSI) for listing as an American National Standard.

There is no governmental regulation or control involved in the adoption and use of a Voluntary Product Standard. The documents are offered for sale by the Superintendent of Documents, U.S. Government Printing Office, Washington D.C. A price list of the current standards and other information concerning this activity can be obtained by writing to the Standards Development Services Section.

\section{Law Enforcement Standards Laboratory, Institute for Applied Technology, National Bureau of Standards}

The Law Enforcement Standards Laboratory (LESL) was established at the National Bureau of Standards (NBS) in January 1971 by an interagency agreement with the National Institute of Law Enforcement and Criminal Justice (NILECJ), Law Enforcement Assistance Administration (LEAA), U. S. Department of Justice, in accordance with Title 1 , Section 402(b) of the Omnibus Crime Control and Safe Streets Act of 1968, P.L. 90-351.

In accordance with priorities established by NILECJ, LESL (1) conducts state-of-the-art surveys; (2) performs laboratory testing and evaluation of commercially available equipment; (3) develops test methods; and (4) develops several series of documents including national voluntary equipment standards, user guidelines, and miscellaneous reports.

The standards developed by LESL are performance oriented insofar as possible. They are not consensus standards, but are subjected to extensive technical and editorial review within NBS as well as by other Government agencies, manufacturers, users and independent experts. The standards are given a final review by NILECJ and are then promulgated by them. They are widely distributed to law enforcement agencies and made available to others through the National Technical Information Service of the Department of Commerce and the National Criminal Justice Reference Service of LEAA. 
As of this date, standards have been developed for: (1) the Ballistic Resistance of Police Body Armor; (2) Hearing Protectors for Use on Firing Ranges; (3) Magnetic Switches for Burglar Alarm Systems; (4) Mechanically Actuated Switches for Burglar Alarm Systems; (5) Walk-Through Metal Detectors for Use in Weapon Detection; and (6) Mobile Antennas. Many additional standards are under development in the areas of protective equipment, communications equipment, security systems, weapons, emergency equipment, investigative aids, vehicles and clothing.

While the great bulk of LESL's effort is in behalf of LEAA, some work is also done to develop standards for other Government agencies. A standard for Evidential Breath Alcohol Testers has been developed for the National Highway Traffic Safety Administration (NHTSA) and a small continuing program has been established to develop additional standards and perform related tasks of interest to the Research Institute and to the Office of Alcohol Countermeasures of NHTSA.

\section{Standards Information Services, \\ Institute for Applied Technology, National Bureau of Standards}

The Standards Information Services Section of the National Bureau of Standards (NBS-SIS) maintains the largest reference collection of engineering and related standards, specifications, test methods, codes and recommended practices in the United States. Established in 1965 as the Standards Communication Center, NBS-SIS has expanded its original holdings of several thousand standards to an extensive reference collection of over 200,000 standards issued by U.S. trade, professional and technical associations, Federal and state governmental organizations, foreign national, and international and regional standardizing bodies.

Referral Services-NBS-SIS serves primarily as a referral activity by identifying sources of standards, and directing inquirers to the respective standardsissuing organizations to obtain copies of standards. By means of computer-produced Key-Word-In-Context (KWIC) Indexes, NBS-SIS answers more than 4,000 inquiries each year.

The Standards Collection-The NBS-SIS reference collection, located in Room B151, Building 225 at the NBS site in Gaithersburg. Maryland about 25 miles northwest of Washington, D. C., is open to the public Monday through Friday from 8:30 A.M. to 5:00 P.M. Of the 200,000 standards now housed in this collection, over 23,000 are industry and national standards issued by more than 400 U.S. technical societies, professional organizations and trade associations; 6,000 standards of 35 state purchasing offices; 8,500 standards and specifications of Federal civilian agencies; 163,000 foreign national standards of some 57 countries; and 3,000 standards of international and regional standardization groups. The resources of the collection also include over 100 technical reference books, directories, encyclopedias, guides and manuals; over 125 periodicals and newsletters; and many articles, reports, pamphlets, and handbooks on standardization.

Publications-NBS-SIS compiles computer-produced indexes designed to assist all who are interested in information on standards. Among these Indexes are National Bureau of Standards Special Publication 329, An Index of U.S. Voluntary Engineering Standards issued in March 1971 listing titles of standards published through 1969, and Supplement No. 1, issued in December 1972, listing titles issued in 1970 and 1971. These two indexes together list the titles of more than 23,000 standards issued by over 380 U.S. private organizations. Supplement No. 2 is in preparation and, when published in mid-1974, will cover the years 1972-1973. NBS Special Publication 352, World Index of Plastics Standards appeared in December 1971. Technical Note 762, Tabulation of Voluntary Standards and Certification Programs for Consumer Products was issued in March 1973. NBS Special Publication 375, An Index of State Specifications and Standards appeared in September 1973 while NBS Special Publication 390, An Index of International Standards appeared in March 1974. Compila. tion has already begun on an index of foreign Englishlanguage standards. All of these publications are available from the Superintendent of Documents, Government Printing Office, Washington, D. C. 20406.

Form of Requests-Requests for information may be made by personal visit, telephone (Area code 301: 921-2587), or a letter addressed to: Standards Information Services, Building 225, Room B.162, National Bureau of Standards, Washington, D. C. 20234.

Since NBS-SIS conducts its search by using key word indexes, all requests should be as specific as possible, and include all words and terms necessary to identify a standard, e.g. X-ray machines rather than medical electronic equipment.

A brochure describing the office and services, and lists of the organizations whose standards are represented in the collection, are available upon request to NBS-SIS.

\section{Office of ADP Standards Management, Institute for Computer Sciences and Technology, National Bureau of Standards}

The Office of ADP Standards Management provides overall policy guidance, long range planning and detail management of the data processing standards mission of the National Bureau of Standards. This mission is carried out in accordance with the legislative authorities of Public Law 89-306, dated October 30 , 1965 and Executive Order 11717, dated May 9, 1973.

The Institute for Computer Sciences and Technology (formerly the Center for Computer Sciences and Technology) was organized in November 1965.

The primary mission of the Institute is to provide agencies and the Administrator of General Services with scientific and technological advisory services relating to automatic data processing (ADP) and related systems, and to make appropriate recommendations to the Secretary of Commerce, who on behalf 
of the President, establishes uniform Federal automatic data processing standards.

The Office of ADP Standards Management also monitors Federal participation on related voluntary jidustry standards organizations. Management direction is provided so that government participants are cognizant of overall government objectives and are therefore able to adequately represent government requirements in the development of voluntary standards.

Adherence to standards adopted as Federal ADP standards is through validation testing against fixed criteria. Tests are developed in accordance with the specifications of the standards and products are measured against these specifications.

Federal ADP standards are promulgated by NBS as Federal Information Processing Standards Publications (FIPS PUBS). FIPS PUBS are available by subject title from the Government Printing Office for a nominal charge. There are 28 FIPS PUBS of which 21 are mandatory standards, two are guidelines and four provide general information concerning the FIPS program. The List of Publications in the Federal Information Processing Standards Series (LP-58) provides a complete index and abstract of the current standards. The activities and committees in which the FIPS program is involved are described in FIPS PUB 12-1, FIPS Index.

The principal method used in implementing the FIPS is through the issuance of Federal Property Management Regulations by the General Services Administration. These regulations make the FIPS applicable to the procurement of ADP products and services.

Marine Environmental Metrology, National Oceanographic Instrumentation Center, National Ocean Survey,

National Oceanic and Atmospheric Administration,

U.S. Department of Commerce, Rockville, Maryland 20852

The Marine Environmental Metrology program at the National Oceanographic Instrumentation Center (NOIC) is active in providing specialized operational standards and techniques required to assure that marine instruments give meaningful and quality data, traceable to recognized defining standards at the national and international levels. The program maintains a liaison with the National Bureau of Standards and other nationally known measurement experts and funds for their services when expertise is required in relationship to a primary level of measurement.

A large portion of the standards development is generated from the products of it's calibration and testing services to the scientific community. It involves the creation of calibration procedures, measurement techniques, and test methods as well as the in-house or contractural development of laboratory and field physical transfer standards. The program has developed 19 calibration procedures for oceanographic and marine meteorlogical instruments, available through NOIC's Documentation Group, that are being used and evaluated for eventual voluntary acceptance by the scientific, academic, and industrial community.

The program conducts an interlaboratory calibration effort with various activities involved in marine instrumentation, their development, testing, and calibration. It continuously evaluates the measurement performances of the participating laboratories and provides methods for reducing data variances. Also, it offers a mechanism to exchange measurement ideas, evaluate and promote acceptances of calibration procedures, techniques, and equipment and provide standard test specifications for inclusion to any marine instrument purchases.

\section{Office of Telecommunications, \\ U.S. Department of Commerce, 1325 G Street NW. \\ Washington, D.C. 20005}

The Office of Telecommunications as authorized by Section 2(12) and (13), 15 U.S.C. (12) and (13) and by procedures of 15 C.F.R. (200) as applicable is active in standardization related to telecommunications. Operating under the authority of the National Bureau of Standards, units of the Office have been engaged in standardization for transmission of radio waves since about 1911. The Office of Telecommunications was established as a primary operating unit in 1970.

The principal activities of the Office are investigating conditions affecting the transmission of radio waves and compiling and distributing information regarding the transmission of radio waves. Standards are established by: cooperation with other governmental agencies and with private organizations; by invention and development of devices and testing methods to serve the needs of Government agencies, scientific institutions and industrial enterprises; and by providing scientific and technical advisory services to Government agencies.

The Office chairs the Standards Working Group of the Technical Subcommittee of the Interdepartment Radio Advisory Committee which provides standards required for managing government use of radio frequencies. The Office serves on the Federal Telecommunication Standards Committee of the National Communication System to develop telecommunication standards for the interoperability of government data communication systems and for computer-communication interfaces. The Office also works with other Federal agencies in the development of standards and standards policy for other areas of voice, data, and radio wave transmission and has under consideration projects for broadband (video, data, facsimile, and voice) networks.

\section{CONSUMER PRODUCT SAFETY COMMISSION, W ashington, D.C. 20207}

The Consumer Product Safety Commission, an independent Federal regulatory agency, was officially 
activated on May 14, 1973, to implement the Consumer Product Safety Act., PL 92-573. The Commission's primary goal is to substantially reduce injuries associated with consumer products. The Act granted broad authority to issue and enforce safety standards for more than 10,000 consumer products. The administration of four acts previously handled by other agencies was transferred to the Commission; they include the Flammable Fabrics Act, the Federal Hazardous Substances Act, the Poison Prevention Packaging Act, and the Refrigerator Door Safety Act.

Under the requirements of the Consumer Product Safety Act, the Commission may adopt standards issued by qualified agencies or organizations, or issue standards independently. The Commission may ban hazardous substances presenting an unreasonable risk of injury. The development of standards by other agencies is encouraged and the Consumer Product Safety Commission participates in the development of international product safety standards. The Office of Standards Coordination and Appraisal serves as the focal point for standards development within the Consumer Product Safety Commission; the Bureau of Compliance is responsible for standards enforcement.

Product certification is specifically mentioned by the Act. Manufacturers or private labelers must issue certificates stating that their product meets a specified standard. The Commission may prescribe testing and labeling.

To date (August 1, 1973), the Commission has issued an amended Standard for the Flammability of Mattresses. Some proposed regulations currently under consideration include bicycles and baby cribs. Proposed and final standards issued by the Commis sion are published in the Federal Register upon approval. Final regulations will be published in Title 16, Chapter 2 of the Code of Federal Regulations. The Office of Standards Coordination and Appraisal may be contacted for a complete list of standards issued by the Consumer Product Safety Commission.

\section{DEFENSE, DEPARTMENT OF, \\ Office of the Assistant Secretary of Defense for Installations and Logistics, Pentagon, Washington, D.C. 20301}

The Defense Standardization Program under the aegis of the Office of the Secretary of Defense is managed by the Defense Materiel Specifications and Standards Board.

The Defense Standardization Program was established in 1953 under the authority of Title 10, U.S. Code, Sections 2451-2456. The statute has been implemented by DoD Directive 4120.3 and the associated DoD Standardization Manual 4120.3-M providing policies, procedures and instructions for direct use by the military departments and DoD agencies. The current program is a continuation of work started in
1916-1921 through the cooperative efforts of the War and Navy Departments via the Army-Navy Aeronautical Standards Board.

The Defense Materiel Specifications and Standards Board was established under the provisions of the revised DoD Directive 4120.3, dated 6 June 1973. The Standards Board is comprised of flag rank personnel, one engineering and one logistic member from the Office of the Secretary of Defense and corresponding members from each of the military departments. In addition, the Defense Supply Agency provides one logistic member. The chairman of the nine member Standards Board is appointed by the Assistant Secretary for Installations and Logistics with the concurrence of the Director, Defense Research and Engineering.

The Defense Standardization Program spans the range of materials, parts and equipments as well as the engineering practices and processes used in the development, test and evaluation, production and logistic support of the material used by the military services. The intent of the program is to control the proliferation of items and practices through the development and use of specifications, engineering standards, handbooks and engineering drawings; thereby achieving greater economy and effectiveness of resources through better reliability and maintainability and lower costs over the entire life cycle.

The Standards Board will be augmented by panels of experts from the military departments and DoD agencies to provide expertise necessary to cope with the engineering, scientific and industry related problems. The panels will have cognizance over the studies, plans and implementation of efforts devoted to the areas under the scope of their respective charters.

In addition to the 25,000 active military series specifications and more than 10,000 military standards listed in the Department of Defense Index of Specifications and Standards which is available from the Superintendent of Documents, Government Printing Office, there are additional quantities of documents which have been retired from active use but are still available (at a fee) through our archival service. Current military specifications and standards are furnished without charge. The entire DoD Standardization Program represents the integration of actions accomplished by the commodity structure of the DoD components. The Standardization Directory, SD-1, which is available from the Naval Publications and Forms Center, 5801 Tabor Avenue, Philadelphia, Pennsylvania 19120, lists the addresses and scopes of interest of the 68 offices in the Department of Defense to which various standards functions have been assigned.

It is $\mathrm{DoD}_{0}$ policy to cooperate with the standards organizations operating in the other Government departments and agencies as well as those in the private sector. There are procedures in the Defense Standardization Manual for adopting industry standards so as to avoid the preparation of duplicative or overlapping military documents. The DoD Index of 
Specifications and Standards lists those industry documents which have been adopted.

The Department of Defense has the largest and most comprehensive standardization program in the world-governmental or nongovernmental. The specifications and standards developed by the program are widely used in both domestic and international standards. In fact, many of its specifications and standards constitute the standard to which industry builds for commercial purposes. The procedures of the program have been widely copied by individual industrial firms and industry standardizing organizations as the basis for their own standardization programs.

\section{ENVIRONMENTAL PROTECTION AGENCY, 401 M Street SW. Washington, D.C. 20460}

The Environmental Protection Agency (EPA) was created to permit coordinated and effective governmental action to assure protection of the environment by the systematic abatement and control of pollution through proper integration of a variety of research, monitoring, standards-setting, and enforcement activities. Legislative authority for establishing standards is found in the Clean Air Act, as amended; the Federal Water Pollution Control Act, as amended; the Refuse Act; the Federal Insecticide, Fungicide, and Rodenticide Act, as amended; and the Federal Food, Drug, and Cosmetic Act, as amended. Title 40 CFR provides the procedures for implementing this legislative authority.

EPA's Offices of Air and Water Programs and Hazardous Materials Control exercise primary responsibility for developing air and water quality standards, criteria of solid waste standards, noise emission, and radiation protection standards. Before an environmental standard is finalized, however, the heads of state and local governments are consulted through the Advisory Commission on Intergovernmental Relations and public comment is solicited. In most cases, once a standard is set, states and other jurisdictions are required to submit by a certain date implementation plans for meeting these standards or face the alternative of having EPA write and impose its own plan. Both the standards and resulting implementation plans are published by EPA in the Federal Register.

\section{FEDERAL COMMUNICATIONS COMMISSION, Office of Chief Engineer, 1919 M Street W ashington, D.C. 20554}

The Federal Communications Commission was created under the Communications Act of 1934 (47 U S C 151) to regulate interstate and foreign commerce in communications by wire and radio in the public interest. The Commission's jurisdiction extends to all interstate and foreign communications by wire and radio and all interstate and foreign transmission of energy by radio which originates and/or is received within the United States. (47 U S C 152(a)). "Transmission of energy by radio" or "radio transmission of energy" includes both such transmission and all instrumentalities, facilities and services incidental to such transmission. $47 \mathrm{U} \mathrm{S} \mathrm{C}$ $153(\mathrm{~d}))$.

Under the authority of the Communications Act, the Commission has enacted mandatory rules and regulations in the public interest. Among those rules and regulations are technical performance standards for certain radio equipment and operations. In addition to these mandatory technical standards, the radio communications industry also works diligently to adopt voluntary technical standards.

The industry group, known as the Electronic Indus. tries Association (EIA), sponsors the work of many technical committees. The standards adopted by EIA are generally recognized by consensus; and manufacturers of radio transmitting equipment generally comply with the standards. Often these voluntary standards, after appropriate procedures, form the basis for mandatory rules adopted by the Federal Communications Commission.

The technical committees of EIA maintain close liaison with the Office of the Chief Engineer of the Federal Communications Commission. Technical personnel of the Commission are often invited to serve on various groups within the industry organization. The Federal Communications Commission has encouraged this kind of industry-government cooperation so that voluntary standards adopted by the industry will harmonize with Commission rules and policies.

The American National Standards Institute (ANSI) is a domestic association comprised of EIA and similar associations for other industries. ANSI represents United States industries in the International Electrotechnical Commission (IEC). ANSI and its foreign industry counterparts meet and negotiate within the IEC on international voluntary standards. The standards proposed by ANSI in these negotiations are those recommended by one or more of its member organizations. Any agreements reached within the IEC are private and do not have treaty status, even though some of ANSl's foreign counterparts may be government controlled. From the international standpoint, thus, these industry standards are still voluntary even though a nation may make them mandatory within its own jurisdiction.

\section{GENERAL SERVICES ADMINISTRATION, Fedleral Supply Service, Office of Standards and Quality Control, 18 th and $F$ Streets, Washington, D.C. 20406}

The General Services Administration which was created by the Federal Property and Administrative Services Act of 1949 (63 Stat. 377) as amended, provides for the Government an economical and efficient 
system for the management of its property and records.

The GSA Standardization Program covers: (a) development and maintenance of Federal specifications and standards; (b) standardization of commodities procured by the Government; (c) coordination of governmental standardization activities; and (d) development and maintenance of the Federal Catalog System. The assigned agency plan is used in the development of Federal specifications and standards. The Federal Standardization Handbook (4l CFR 101-29) guides agency participation in the program.

There are now over 6,000 Federal specifications and standards and approximately 100 associated Qualified Products Lists which support those Federal specifications requiring qualification testing prior to procurement. These documents, which are mandatory for use by all Federal agencies, are listed in the Index of Federal Specifications and Standards (4l CFR 10129.1).

Working in close consonance is the GSA Quality Assurance Program which handles the inspection and testing of supplies procured under GSA contracts. Through the 10 regional Quality Control Divisions and the six regional laboratories, this program provides assurance that material supplied is in compliance with contract specifications, is obtained through inspection at origin and destination, and through the Quality Approved Manufacturer Program, which is a method of reduced Government inspection which makes maximum use of the quality control systems of suppliers who have excellent quality control and past performance records. In addition, the regional Quality Control Divisions are engaged in preaward engineering evaluations of bidders' capabilities to comply with quality control and delivery terms of the contract; assistance to contractors in establishing adequate quality control systems and planning and scheduling production, as well as maintaining a continuing liaison with them to insure that their quality control systems remain effective; surveillance of depot stocks to update shelf-life material and conduct quality audits; and the investigation of complaints.

\section{HEALTH, EDUCATION AND WELFARE, DEPARTMENT OF}

\author{
Food and Drug Administration, \\ Bureau of Foods, \\ Bureau of Drugs, \\ Bureau of Veterinary Medicine, \\ Bureau of Radiological Health, \\ Bureau of Biologics
}

National Institute for Occupational Safety and Health, Office of Research and and Standards Development, Testing and Certification Laboratory, Associate Director for Washington Operations

Food and Drug Administratiou,

Department of Health, Education and Welfare, Rockville, Maryland 20852 Bureau of Foods

The standard setting activities of the Bureau of Foods result in the promulgation of substantive regu- lations which have the force and effect of law. All regulations issued are authorized by the Federal Food, Drug, and Cosmetic Act, Title 21 of the United States Code (21 USC). In the developmental stages, they are published in the Federal Register for comment, and when adopted, are codified in Title 21 of the Code of Federal Regulations (21 CFR).

Section 401 of the Act (21 USC 341) requires the establishment of standards of identity, quality and fill of container when such action will promote honesty and fair dealing in the interest of consumers. Any interested persons, or the Commissioner of Food and Drugs, may propose a new standard or an amendment to an existing one. Proposals are published in the Federal Register and comments invited. Based on comments received and other information, the Commissioner publishes an order ruling on the proposal. Persons adversely affected by the order have 30 days to object and request a hearing. Noncontested orders become effective on a specific date which is not less than 30 days after the ruling is published. Food standards now cover 20 different classes of foods (21 CFR, Parts 10 through 53) and number approximately 480 . Most of these are standards of identity which specify the basic composition of the food. Fourteen standards prescribe minimum levels of quality and 17 standards specify minimum fill of container for particular foods. The Division of Food Technology in the Office of Technology, Bureau of Foods, is the action unit for food standards activities.

Food Additives and GRAS Substances-Section 409 of the Act (21 USC 348) authorizes the issuance of regulations prescribing the conditions under which a food additive may be safely used. The standardization activity in regard to food additive regulations includes research and development to accomplish scientific evaluation of claims and data submitted by industry in support of their petitions; the development, validation and application of those regulatory analytical methods necessary to enforce compliance with regulations; and the accomplishment of periodic reviews of previously approved food additives in terms of current information. In addition, it includes all activities concerned with ensuring the safety of all substances previously classified generally recognized as safe (GRAS, through review and evaluation of the toxicological literature, manufacturers' use patterns, consequent consumer risk patterns, and toxicological testing. Approximately 265 food additive regulations have been issued and codified in 21 CFR, Part 121.

Color Additives-Section 706 (21 USC 376) of the Act authorizes the issuance of regulations prescribing the conditions under which color additives (as defined in Section 201(t) (1) of the Act (2l USC 32l(t) (1)) may be safely used. The standardization activities in regard to color additives includes all scientific and regulatory activities necessary to assure the safety of color additives in human foods. Among these activities are the review and evaluation of petitions for regulations covering new color additives, review of the safety of previously approved color additives in light of new toxicological knowledge and testing procedures, 
review of all synthetic and natural color additives to assure their conformance to safety and purity requirements and to assure they are used only within specified limits. In addition, samples from each batch of color manufactured must be submitted to FDA to determine compliance with specifications unless the color is specifically exempted from certification. If specifications are met, a certificate is issued and the color is said to be certified. The manufacturer pays for the certification service. In FY 1973, 5,373,565 pounds of color additives were certified.

Color Additive regulations are codified at $21 \mathrm{CFR}$, Parts 8 and 9. Since July 12, 1960, regulations prescribing the specifications and conditions for safe usage have been issued for 46 color additives. These specifications are mandatory and must be met before the color additive may be used in foods, drugs, or cosmetics.

The Division of Food and Color Additives in the Office of Compliance, Bureau of Foods, is the action unit for food additive, color additive and GRAS review activities.

\section{Bureau of Drugs}

The Food, Drug, and Cosmetic Act provides that all batches of insulin and antibiotics for human use are subject to certification by the Food and Drug Administration to insure that such drugs have the characteristics of strength, quality, and purity to adequately insure safety and efficacy of use. Regulations appearing in the Code of Federal Regulations, Title 21 (Parts 141 through 164) prescribe standards and tests and methods of assay for insulin and antibiotic drugs.

In 1972, the Food and Drug Administration developed procedures for reviewing the safety and efficacy of over-the-counter (OTC) drugs. In order to accomplish this review of OTC drugs within a reasonable period of time, the FDA is utilizing expert medical advisory panels to evaluate existing medical data regarding these drugs. OTC drug monographs (standards) will be developed by FDA as conclusions are reached for each therapeutic class. The first monograph of approximately 25 therapeutic categories is nearing completion and a number of categories are under review by the expert panelists. These monographs will appear in 21 CFR Part 130 (Subpart D). In 1973, the FDA established procedures for developing standards for in vitro diagnostic products for use in the collection, preparation, and examination of specimens taken from the human body. These standards, some of which are currently under development, will describe the performance requirements necessary to assure accuracy and reliability of results, specific labeling requirements necessary for the proper use of a particular class, and procedures for testing the product to assure its satisfactory performance. General requirements for in vitro diagnostic products appear in 21 CFR Part 167.

\section{Bureau of Veterinary Medicine}

The Bureau of Veterinary Medicine is charged with responsibility under section 409 (c) of the Food, Drug, and Cosmetic Act with the preparation for publication of regulations regarding the addition of food additives to animal feed and/or pet foods prescribing their specifications and safe conditions of use. Publication of regulations is required by the Food Additive Amendment of 1958. Regulations are established in 21 CFR Part 121, Subpart C and are based upon an evaluation of data submitted in petitions filed by interested persons.

The Bureau is also charged with the responsibility for the preparing for publication of regulations by the New Animal Drug Amendments of 1968 regarding the specifications and safe and effective conditions for use of new animal drugs in dosage forms and in animal feeds under the provisions of Section 512(i) of the Act. Regulations are established in Title 21, Parts 135 and 135a through 135g. In addition, Section $512(\mathrm{n})$ of the Act requires publication of certification requirements and tests and methods of assay for new animal drugs containing any kind of penicillin, streptomycin, chlortetracycline, chloramphenicol or bacitracin or any derivatives thereof. Certifieation monographs are published in Subchapter C of Title 21. New animal drug and certification monographs are based upon evaluation of new animal drug applications containing the necessary supporting data filed by interested persons.

\section{Bureau of Radiological Health}

The radiation responsibilities assigned to the FDA include: (1) determination of permissible levels of radioactivity in foods and drugs and the establishment and promulgation of suitable regulations, (2) maintenance of a program of radiation monitoring of such products, (3) performance of research and training on identification, evaluation, and decontamination of radioactivity in foods and drugs, and (4) approval of radioactive drugs used in diagnosis and treatment, and related inspection and enforcement activities, and (5) an electronic product radiation control program which includes the development and administration of performance standards to control the emission of radiation from electronic products and the undertaking by public and private organizations of research and investigation into the effects and control of such radiation emissions.

This last program was inaugurated in 1969 under the Radiation Control for Health and Safety Act of 1968 (P.L. 90-602; 42 U.S.C. 263(b) et seq.) and is administered by the Bureau of Radiological Health.

Standards issued under this authority are codified as regulations in 21 CFR Part 278, Subpart C. There are currently three standards in effect: for television receivers (21 CFR 278.210), cold cathode gas discharge tubes (21 CFR 278.211), and microwave ovens (21 CFR 78.212). A fourth standard for diagnostic x-ray equipment (21 CFR 278.213) becomes effective August 1, 1974.

Manufacturers of products or components for which there are standards in effect are required to certify that their products or components meet the applicable standards. Use of the standards by industry 
is mandatory; however, the Bureau promotes compliance by frequent conferences with the affected industries. In addition, in June of 1969, a Technical Electronic Product Radiation Safety Standards Committee was formed as required by the Radiation Control for Health and Safety Act of 1968. The committee advises the HEW Secretary on all performance standards proposed to be established for products that may expose consumers to radiation hazards. This committee has 15 members of which five each are selected from industry, Government, and the general public. Consultation with the committee prior to the promulgation of any standard under the Act is mandatory.

Standards now in the process of development include standards for: laser products, cabinet x-ray systems, ultrasonic therapy, and microwave diathermy systems.

\section{Bureau of Biologics}

The Bureau of Biologics administers the biological control provisions of the Public Health Service Act (42 USC 262), as well as relevant portions of the Federal Food, Drug, and Cosmetic Act (21 USC 301 et. seq.). Products subject to these provisions include bacterial and viral vaccines, toxoids, antitoxins, blood and blood derivatives and allergenic products, and other similar products applicable to the prevention, treatment or cure of diseases or injuries of man.

The control of biological products is primarily through a process of licensing each manufacturer for each product upon a demonstration that the product complies with the written standards for such product. In addition to preparing standards specific for a particular product, general standards applicable to all products, as well as interpretative and precedural standards are published in the Federal Register and are incorporated into Title 21 Code of Federal Regulations, Part 273.

The Bureau also provides physical standard preparations to evaluate the safety and potency of the products. The U.S. standard and reference preparations are developed and maintained by the Bureau for use in the performance of tests prescribed in regulations. Where international preparations exist, the U.S. preparations are adjusted to have at least the equivalent activity of the corresponding international preparations. There is no authorization to provide such preparations to other laboratories unless they are to be used for work directly related to the control or development of biological products.

Office of Research and Standlards Development, National Institute for Occupational Safety and Health, Department of Health, Education, and Welfare, 5600 Fishers Lane,

Rockville, Maryland 20852

Under section 20(a) (3) of the Occupational Safety and Health Act of 1970 (P.L. 91-596), the National Institute for Occupational Safety and Health
(NIOSH) develops criteria dealing with toxic substances which describe exposure levels that are safe for various periods of employment, including but not limited to exposure levels at which no employee will suffer impaired health or functional capacities or diminished life expectancy as a result of his work experience. Such criteria are to be developed to enable the Secretary of Labor to meet his responsibilities for promulgating standards under the Act and are released by NIOSH in the form of a criteria document. The criteria document also contains recommendations, as appropriate, for medical control and surveillance procedures; for personal protective clothing and devices; for placarding and labeling occupationally hazardous work areas; and for educating the worker in the hazards and the control of the hazards. Criteria documents have been or will soon be released for asbestos, beryllium, carbon monoxide, hot environments, noise, ultraviolet radiation, organic lead, inorganic mercury, coke oven emissions, benzene, tricholoroethylene, toluene, cadmium and its compounds, chromic acid, fibrous glass, silica glass, tetraethyl lead, tetramethyl lead, sulfuric acid, sulfur dioxide, arsenic and its compounds, parathion, cotton dust, and arsine. The subjects of future ceriteria documents may be identified on the NIOSH Priority List for Criteria Development for Toxic Substances and Physical Agents.

Testing and Certification Laboratory,

National Institute for Occupational Safety and Health, Department of Health, Education, and Welfare, 944 Chestnut Ridge Road, Morgantown, West Virginia 26505

The Testing and Certification Laboratory was established in 1972 by the National Institute for Occupational Safety and Health (NIOSH) under the provisions of the Occupational Safety and Health Act of 1970 (P.L. 91-596), to insure that devices used for evaluation and control of occupational hazards meet minimum standards required to protect the health and safety of workers. The responsibilities of the laboratory include: (1) development of performance specifications for each device; (2) publication of these specifications and certification procedures in the Federal Register; (3) initial approval testing of such devices; (4) surveys of sampling and equipment manufacturers' establishments to insure continuous operation of a satisfactory quality control program; and (5) periodic testing of certified items procured on the open market. Specifications and certification procedures for the following devices are contained in the associated section of the Code of Federal Regulations: respiratory protective devices, 30 CFR, Part 11; coal mine dust personal sampler units, 30 CFR, Part 74; direct reading gas and vapor detector tube systems, 42 CFR, Part 84; and personal protective devices, 42 CFR, Part 83. Development of additional approval regulations for other protective devices or industrial hygiene instruments will be based on research performed by NIOSH. 
Associate Director for Washington Operations,

National Institute for Occupational Safety and Health, Department of Health, Education, and Welfare, 5600 Fishers Lane,

Rockville, Maryland 20852

On the authority of section 101 of the Federal Coal Mine Health and Safety Act of 1969 (P.L. 91-173), the National Institute for Occupational Safety and Health establishes mandatory coal mine health standards for the Secretary of Health, Education, and Welfare with consideration for the advice of the Secretaries of Labor and Interior, the appropriate representatives of the coal mine operators and miners, and other interested persons, organizations, and governments. These health standards are transmitted to the Secretary of the Interior for publication in the Federal Register as proposed amendments to Title 30, Code of Federal Regulations. In 1971, standards were proposed for airborne respirable chest concentrations, airborne contaminants, noise, surface bathing facilities, change rooms, sanitary toilet facilities, and drinking water. Development and revision of standards are based upon research, demonstrations, experiments, and technical feasibility. Additional information may be obtained from an annual publication, the Federal Coal Mine Health Program.

\section{Housing and Urban Development, Department of}

Housing Production and Mortgage Credit Office, Federal Housing Administration,

U.S. Department of Housing and Urban Development, Washington, D.C. 204.11

The HPMC office of HUD writes, updates, revises and clarifies construction and design standards for HUD-associated residential construction. This activity grew out of the National Housing Act of 1934. The Code of Federal Regulations reference is Title 24-Housing and Urban Development.

The standards as originally established in 1935 were intended to provide the minimum essentials for a property to be considered economically sound security for Federal Housing Administration mortgage insurance purposes. In 1940 the FHA issued Minimum Requirements for Rental Housing covering multifamily units; while Property Standards and Minimum Construction Requirements for Dwellings applicable to single-family dwellings was published in 1942. These were reissued after World War II under the titles: Minimum Property Requirements for Properties of Three or More Living Units and Minimum Property Requirements for Properties of One or Two Living Units. The second document was issued under 50 separate publications for various geographic areas. This diversification created many problems, so with the aid of an advisory committee of construction industry leaders, architects, engineers and planners, the standards were combined into one book applicable nationwide. The new standards, MPS for One- and Two-Living Units, was published in 1958. Similarly the multifamily standards were revised with the aid of an industry advisory committee. The new standards, MPS for Multifamily Housing, was published in 1963.

Besides these two standards, HPMC has criteria for nursing homes, swimming pools, housing for the elderly, mobile home parks, community water supply systems, community sewerage disposal systems, as well as guidelines for urban renewal rehabilitation, planned unit development with a homes association, insulating houses from aircraft noise, and land-use intensity. HPMC issues structural engineering bulletins for individual structural systems and use of materials bulletins for proprietary materials not covered by our standards.

HPMC encourages industry policing and selfcertification for those materials covered by product standards and Federal specifications. It also requires third party certification in conformance with ANSI Z34.1-47R59 for lumber, plywood, windows, exterior flush doors, plastic bathtubs, etc.

Currently the HPMC office of HUD is working on a new and improved system of housing standards. Three books of mandatory standards and one guide manual are in preparation. They are: MPS for Oneand Two-Family Dwellings, MPS for Multifamily Housing, MPS for Care-Type Housing, and a Manual of Acceptable Practices.

The new documents will be more dependent on nationally recognized standards of the building industry and on performance language with fewer specification-type details. They will be available from the Superintendent of Documents, Government Printing Office, Washington, D.C. 20402.

\section{INTERDEPARTMENTAL SCREW THREAD COMMITTEE, c/o Committee Chairman, National Bureau of Standards, Washington, D.C. 20234}

This Committee (ISTC) replaces the National Screw Thread Commission which was established by an act of Congress in 1918. The ISTC is responsible for: (1) recommending to appropriate activities research and development efforts relating to screw threads; (2) developing standards for inch and metric screw threads; (3) participating in the development of standards for gages, dies, taps, and other items associated with the manufacture and use of interchangeable threaded parts employed by Government agencies; and (4) providing advisory services on science, technology, and standards of practice as these relate to screw threads.

Standards approved by the ISTC are published in National Bureau of Standards Handbook H28, ScrewThread Standards for Federal Services, Part I, 1969, Part II, 1957, Reprinted December 1966 with corrections, and Part III 1957, Reprinted December 1966 with corrections. Handbook H28 is mandatory for the Department of Defense and is referenced in most Federal Government contracts. 
The membership of the ISTC consists of representation from the National Bureau of Standards, U. S. Department of Commerce; the Departments of Defense, Army, Navy, and Air Force; Atomic Energy Commission; Federal Aviation Administration; National Aeronautics and Space Administration and industry. The industry members are chosen from the American National Standards Sectional Committee $\mathrm{BI}$ so as to be representative of both manufacturers and users of threaded products. The ISTC works closely with the American National Standards Sectional Committee Bl which is concerned with the standardization and unification of screw threads and is the industry counterpart of the ISTC.

\section{INTERIOR, DEPARTMENT OF THE}

Bonneville Power Administration,

Geological Survey, Office of Water Data Coordination, Mining Enforcement and Safety Administration

Bonneville Power Administration,
U.S. Department of the Interior, U.S. Department of the Interior
Portland, Oregon 97208

The standards activities of the Bonneville Power Administration (BPA) are accomplished through participation in committees and working groups of the American National Standards Institute, Institute of Electrical and Electronics Engineers, and International Electrotechnical Commission and other such established standards organizations. BPA writes specifications for electrical apparatus, equipment maintenance, and design standards for internal use only.

\section{Office of Water Data Coordination, Geological Survey, \\ U.S. Department of the Interior, National Center, \\ Reston, Virginia 22092}

The Geological Survey, as part of its implementation of Office of Management and Budget Circular A-67, has designated its Office of Water Data Coordination (OWDC) to identify methods used to acquire water data and to recommend methods for use by Federal agencies. The OWDC accomplishes this with the advice and guidance of an advisory committee composed of representatives of Federal agencies involved in the acquisition and/or use of water data.

This activity is an outgrowth of the efforts of an interagency work group, which was designated by the Federal Advisory Committee on Water Data in 1970 in an effort to obtain better coordination and quality control of water data acquired by Federal agencies. The work group issued in December 1972 the report Recommended Methods for Water-Data Acquisition which lists recommended methods in six categories. With this as a base, an ad hoc subcommittee of the Federal Advisory Committee on Water Data formulated the current procedure for the continued identification and recommendation of water-data acquisition methodologies. The identification of meth- ods is accomplished through working groups which are responsible for specific areas of concern, such as ground-water quantitative methods, biologic and bacteriologic quality of surface and ground water, soil moisture, etc. The methods identified by the work groups, together with their recommendations, are reviewed by the Coordinating Council and then issued as a chapter, or a part thereof, in a looseleaf handbook. The work groups are responsible for the continued review of methodologies in their area of concern.

Close liaison is maintained with the American Society for Testing and Materials, the International Organization for Standardization and the standardization activities of organizations such as the Ameriacn Water Works Association, Water Pollution Control Federation, and American Public Health Association. In addition, close working ties have been established with nonfederal organizations at regional, state, and local levels.

\section{Mining Enforcement and Safety Administration, U.S. Department of the Interior, Washiugton, D.C. 20240}

Functions of the Mining Enforcement and Safety Administration (MESA) were removed from the Bureau of Mines effective July 16, 1973. The legislative authority for MESA's standardization activities are found in the Federal Coal Mine Health and Safety Act of 1969-PL 91-173; Federal Metal and Nonmetallic Mine Safety Act of 1966-PL 89-577; and the Title 30 of the Code of Federal Regulations.

PL 91-173-The Secretary of the Interior is authorized to develop and promulgate mandatory safety standards for the protection of life and the prevention of injuries in coal mines and to promulgate the health standards transmitted to him by the Secretary of Health, Education, and Welfare. PL 91-173 provides that the Secretary of the Interior is authorized to certify mine employees whose duties under this Act require certification when the mining laws of any state do not provide for such certification.

$P L$ 89-577-The Secretary of the Interior is authorized to develop and promulgate health and safety standards for the purpose of protecting the life, the promotion of health and safety, and the prevention of accidents in metal and nonmetal mines. PL 89-577 provides that the Secretary of the Interior is authorized to establish advisory committees to assist him in the development of health and safety standards for mines subject to this Act. New projects are being considered and developed on a continuing basis.

To date, 4,000 standards have been issued as a result of both Acts. The standards are developed and published in the Federal Register on a continuing basis, therefore any listing provided is complete and current only on the date of issue. Violations of mandatory standards are cited during inspections of the mines. Compliance with madatory standards is required. 


\section{JOINT COMMITTEE ON PRINTING, Congress of the United States, S-151, U.S. Capitol, Washington, D.C. 20510}

The Joint Committee on Printing, created by act of August 3, 1846 (9 Stat. 114), is responsible for establishing specification standards for papers used in public printing and binding. These standardization activities are administered by a Committee on Paper Specifications and its Technical Subcommittee, under the chairmanship of a Joint Committee staff member and including representatives of the U.S. Government Printing Office; General Services Administration; National Bureau of Standards, Department of Commerce; and Departments of the Army, Navy and Air Force.

Government Paper Specification Standards include approximately 85 individual specifications for writing and printing papers, together with testing and color standards, all of which are mandatory for use by the departments of the Government in the preparation of procurement documents for paper stocks and in specifying paper stocks to be used in printing, binding, or duplicating unless otherwise authorized by the Joint Committee on Printing.

\section{JUSTICE, DEPARTMENT OF}

\begin{abstract}
Law Enforcement Assistance Administration; National Institute of Law Enforcenent and Criminal Justice Equipment Systems Improvement Program, Standards and Guidelines Group
\end{abstract}

\section{See: Law Enforcement Standards Laboratory under Commerce, Department of, National Bureau of Standards, LESL}

\section{LABOR, DEPARTMENT OF}

\section{Occupational Safety and Health Administration, U.S. Department of Labor, Washington, D.C. 20210}

The Occupational Safety and Health Act, PL 91.596 was enacted December 29, 1970 and went into effect April 28, 1971. This law was passed to assure safe and healthful working conditions, so far as possible, for every working man and woman in the Nation. Two main functions within the mission of OSHA are to develop and promulgate occupational safety and health standards and to issue regulations necessary for assuring compliance with its standards and regulations. The Office of Standards has the main responsibility in carrying out these functions.

The Occupational Safety and Health Administration (OSHA) adopted its initial standards on May 29, 1971 and they consisted of national consensus standards, and the Federal standards that were already in effect under other Department of Labor administered laws. When the Office of Standards determines a need, on the basis of information submitted by interested parties, scientific data from the field, or experience gained under other health and safety laws, the Office of Standards will develop new standards, revoke or modify existing standards using one of two procedures available. All regular proposals to promulgate, modify or revoke an Occupational Safety and Health standard using the $6(\mathrm{~b})$ procedure must be published following the APA requirements in the Federal Register to afford interested parties an opportunity to comment before the standard becomes effective or is revoked. A temporary emergency standards procedure $(6(\mathrm{c})$ procedure) may be used to promulgate standards where the APA procedures are waived. Such a temporary emergency standard must be replaced by a 6 (b) standard within 6 months.

In developing new standards or modifying standards, the Office of Standards determines whether there is a need for the establishment of a standards advisory committee to assist them in the standardssetting function. Once it is determined there is a need for a committee, one is appointed which consists of 5 to 15 members and is composed of representatives of management, labor, state and Federal governments and the public. Advisory committee meetings are opened to the public and a transcript is made available for public review. The Office of Standards presently has committees working on occupational noise standards, heat stress, construction standards, agricultural standards and carcinogen standards.

The present reprint of OSHA standards contains subject indexes which were published fully in the Federal Register. The OSHA standards are contained in the Federal Register, Title 29 of the Code of Federal Regulations: (1) General Industry, Part 1910, reprinted October 18, 1972; (2) Maritime, Parts 1915-1918, reprinted October 19, 1972; and (3) Construction, Part 1926, reprinted December 15, 1972.

The OSHA Standards have required certain pieces of equipment or installations to be approved. Such approvals must be obtained from nationally recognized testing laboratories or from the enforcing authority. OSHA's Office of Standards plans to begin an accreditation program in FY74 to recognized testing laboratories interested in listing or approving equipment as required in OSHA standards. The Office of Standards also accredits qualified private agencies for the certification of certain equipment such as shore based cranes and ship's gear in the marine cargo handling industry.

The Office of Standards has been effective in helping employers and employees understand the language used in the Act, and in its standards promulgation procedures, and its standards by providing interpretations of OSHA's standards to all interested parties upon request. The Office of Standards has entered into an agreement with the Government Printing Office to provide a subscription service of OSHA, National Institute for Occupational Safety and Health (HEW) and Occupational Safety Health Review Commission Standards, regulations and interpretations to enable employers and employees to keep up-to-date on these activities. 


\section{NATIONAL AERONAUTICS AND SPACE ADMINISTRATION}

NASA Headquarters; Office of Safety and Reliability and Quality Assurance,

Goddard Space Flight Center Data Systems Requirements Committee,

George C. Marshall Space Flight Center,

Lyndon B. Johnson Space Center;

Safety, Reliability, and Quality Assurance Office

\author{
Office of Safety and Reliability and Quality Assurance, \\ NASA Headquarters, \\ National Acronauties and Space Administration, \\ Washington, D.C. 20546
}

NASA Headquarters, Office of Safety and Reliability and Quality Assurance, has initiated standards applicable to line certification of Class A microcircuits as specified in MIL-M-38510. NASA participates in the Defense Standardization Program for Federal Supply Classes 5961 and 5962. NASA activity is in consonance with Title 10, USC Chapter 145 and Department of Defense (DoD) Directive 4120.3. Four NASA documents have been issued and are available from the Government Printing Office: NHB 5300.4(3C), May 1971 edition-Line Certification Requirements for Microcircuits; NHB 5300.4(3D), May 1971 editionTest Methods and Procedures for Microcircuit Line Certification; NHB 5300.4(3E), October 1971 edition -Radiographic Inspection for Microcircuits; and NHB 5300.4.(3F), June 1972 edition-Qualified Products Lists Requirements for Microcircuits.

Current activity is underway to update the above to include other types beyond the presently covered monolithic types. Use of the above and related DoD standards are required by a NASA management issuance.

Goddard Spaee Flight Center Data Systems Requirements Committee,

NASA/Goddard Space Flight Center,

National Aeronautics and Spaee Administration, Greenbelt, Maryland 20771

The Data Systems Requirements Committee (DSRC) is responsible for the establishment, publication, and review of Goddard Space Flight Center (GSFC) Aerospace Data Systems Standards which apply to all projects using the GSFC Spaceflight Tracking and Data Network (STDN) and/or the GSFC Mission Operations, Data Handling and Processing Facilities. They govern interfaces between major parts of aerospace data systems; i.e., between the flight and ground systems of telemetry, command, tracking, communication, timing, and data handling and processing. The primary purposes of the standards are to maximize multiproject use of standard data systems and to specify minimum performance levels available to those who use such systems. Conformance to the Aerospace Data Systems Standards is required of the projects. Likewise, STDN and the Mission Operations, Data Handling and Processing Facilities are obligated to provide support in conformance with the Aerospace Data Systems Stand- ards. Flight operations with nonstandard systems are not permitted unless specific waivers are granted by the Data Systems Requirements Committee or the Director, GSFC.

The DSRC was established in 1960 and has issued and updated 9 standards. The current Aerospace Data Systems Standards are: Pulse Code Modulation Telemetry Standard; Pulse Amplitude Modulation Telemetry Standard; Tone Command Standard; Tone Digital Command Standard; PCM/FSK Command Data System Standard; Radio Frequency and Modulation Standard for Space-to-Ground Telemetry; Spacecraft Clock Systems Standard; Spacecraft Minitrack Signal Source Standard; and, Magnetic Tape Track Standard.

Gcorge C. Marshall Space Flight Center,

National Aeronautics and Spaee Administration, Huntsville, Alabama 35812

The standards developed by the Marshall Space Flight Center, National Aeronautics and Space Administration (NASA) are for internal application, including industrial firms which have contracts in support of Center missions.

Although these standards have been developed for internal application, they are available for use elsewhere if desired. The standards are issued in the Marshall Management Instruction Manual (MMI) 8070.2, Specifications and Standards for Space Systems and Related Equipment, and available from the Marshall Space Flight Center.

\section{Safety, Reliability, and Quality Assurance Office, Lyndon B. Johnson Space Center, \\ National Aeronauties and Space Administration, Houston, Texas 77058}

The Safety, Reliability, and Quality Assurance (SR\&QA) Office of the Lyndon B. Johnson Space Center (JSC) administers the Center's Manned Spacecraft Criteria and Standards Program to provide the process whereby operational, design and safety experience can be brought to the attention of personnel involved with the various disciplines required to accomplish manned space flight.

These standards are in the form of JSC technical policy statements of principles, philosophies, or criteria for manned spacecraft, space flight equip. ment, and space experiments. Some standards present detailed requirements for the design of a particular kind of hardware. Other standards present general techniques and procedures to be employed for manufacture, assembly, servicing, checkout, test or other operations associated with manned space flight.

Proposed standards are reviewed by specialists in the pertinent technical discipline, and submitted to a management review board. The board is composed of management personnel with expertise in the various technical disciplines. Upon recommendation of the board the standards are approved by the JSC Director.

Approved standards are included in JSCM 8080, Manned Spacecraft Criteria and Standards. All JSC 
organizational elements are responsible for applying these standards to JSC and JSC contractor design and procedural activities. Compliance audits and periodic review of the currency of standards are performed by SR\&QA. An approved waiver is required for any departure from a standard, whether the departure is based on state of the art advancement, or other considerations.

\section{NATIONAL CONFERENCE OF STANDARDS LABORATORIES, c/o Secretariat, \\ National Bureau of Standards, Washington, D.C. 20234}

NCSL is a continuing, nonprofit laboratory-oriented organization to promote cooperative efforts toward solving the common problems faced by standards laboratories in their organization and operation. It was established in 1961 under the sponsorship of the National Bureau of Standards. Its membership consists of academic, scientific, industrial, commercial, or governmental laboratories concerned with the measurement of physical quantities, the calibration of standards and instruments, and the development of standards of practice. It provides liaison with technical societies, trade associations and educational institutions interested in these activities.

NCSL pursues its goals through joint voluntary action by: (1) Holding conferences, workshops, seminars, and meetings for presentation of papers and discussions pertaining to technical and managerial problems, operating practices, and policies for standards laboratories. (2) Collecting and disseminating information about current practices for the organization, operation, and evaluation of measurement standards and calibration laboratories. (3) Formulating voluntary standards of practice for the guidance of members, studying the calibration needs of science and industry, conducting measurement agreement comparisons, publishing a Directory of Standards Laboratories and available services.

\section{NATIONAL CONFERENCE ON WEIGHTS AND MEASURES, \\ c/o Conference Executive Secretary, National Bureau of Standards, Department of Commerce, Washington, D.C. 20234}

The Conference, sponsored by the National Bureau of Standards (NBS), is composed primarily of state, county, and city weights and measures officials, who constitute the active membership. It includes also, as advisory members, representatives of the Federal Government who are concerned in any way with regulatory weights and measures officers or their official activities, or who are interested in the objectives and activities of the Conference. A third membership category, associate members, comprises representatives of manufacturers of commercial weighing and measuring devices, business, industry, railroad, and industrial weighing and scale departments, consumers, and other interested in the objectives and work of the Conference.

The Conference meets annually to consider various problems arising in connection with weights and measures administration; to promote efficiency and uniformity in laws, rules, specifications, tolerances, and methods of supervision and test; and to coordinate activities of state and local weights and measures officials.

In the development of codes and specifications, tolerances, and regulations for commercial weighing and measuring devices, the National Bureau of Standards cooperates closely with the Conference Committee on Specifications and Tolerances. As necessity arises, these codes are modified, and new codes are formulated, thus keeping the entire group in line with changing conditions of the trade and with the developments of the equipment industry.

The Conference codes are published by the National Bureau of Standards and generally are offi. cially promulgated by the states as published. The reports of the proceedings of each annual meeting of the Conference also are published by NBS.

The Conference has adopted a Model State Law on Weights and Measures, Model State Packaging and Labeling Regulation, and several other model regulations, and from time to time endorses standard methods of test for commercial apparatus.

The Conference has been effective in bringing about a gratifying degree of uniformity and mutual cooperation among the states in the matter of weights and measures supervision.

\section{TRANSPORTA'TION, DEPAR'TMENT OF, 400 Seventh Street SW., W ashington, D.C. 20590}

\author{
United States Coast Guard, \\ Office of Boating Safety, \\ Office of Merchant Marine Safety, \\ Federal Aviation Administration, \\ Federal Highway Adninistration, \\ Engineering and Traffic Operations, \\ Federal Railroad Administration, \\ National Highway Traffic Safety Administration
}

Office of Boating Safety,

United States Coast Guard,

U.S. Department of Transportation

The Boating Standards Division of the Office of Boating Safety has the primary responsibility for issuing and administering standards relating to recreational boating safety.

The Coast Guard's authority to issue standards in this area was somewhat limited under the Motorboat Act of 1940 and the Federal Boating Act of 1958. However in August 1971, the Federal Boat Safety Act of 1971 was signed into law. This Act gave the Coast Guard authority to issue regulations to: (1) establish minimum safety standards for boats and associated equipment, and (2) require the installation, carriage, or use of associated equipment on boats. 
This law also made the manufacturer directly responsible for his product meeting safety standards and being free from safety-related defects. Regulations issued under this act require manufacturers of boats and associated equipment to certify compliance of their products with applicable safety standards. Further, defect notification procedures have been established for noncompliance and those defects which create a substantial risk of personal injury to the boating public.

To date, several standards have been issued governing safe loading, safe powering, and flotation of boats as well as requirements for personal flotation devices. These standards may be found in Subchapter S, Boating Safety of Title 33, Code of Federal Regulations. Major project areas now under consideration include: fire and explosion of fuel, steering and control systems, environmental systems, and special watercraft.

\section{Office of Merchant Marine Safety, United States Coast Guard, U.S. Department of Transportation}

The U.S. Coast Guard's Office of Merchant Marine Safety is responsible for commercial vessel plan review, a construction inspection program for passenger vessels, and an equipment approval system for associated equipment.

The Merchant Marine Safety Program of vessel review and inspection has the objective of minimizing lives lost, property damage, and personal injury in marine transportation through prevention. Vessel plans are reviewed by Coast Guard technical personnel and accepted or rejected as being in compliance with broad-based safety standards established by the Coast Guard. Vessels, under construction and periodically thereafter, are inspected for continued compliance. The program deals primarily with making the vessel on which passage has been purchased capable of a safe passage.

The associated equipment approval system is designed to ensure compliance with certain performance requirements established by the Coast Guard. The objective is to establish a means by which the consumer may rely on the piece of equipment, lifesaving devices, fire extinguisher, etc., when it is needed. The approval aids in the enforcement of water safety by the regulatory body (Coast Guard) since the equipment must meet certain basic minimum requirements. The intent is to maximize the probability of survival and rescue of the consumer in the event abandonment of the vessel becomes necessary.

The Legislative authority and statutory citations for the plan review and inspection program are Title 52 (RS 4399-4500) which provides for a Federal agency to have the authority for administration of the laws, rules and regulations governing the inspection and navigation of merchant vessels, Title 46 USC 369 (plans and specifications for construction or alteration of passenger vessels; examination and approval by the
Commandant of the Coast Guard) and the 1960 International Convention for Safety of Life at Sea, a treaty to which the United States is signatory. These statutes give general authorization to the Coast Guard for plan review, inspection and equipment approval for certain watercraft.

The Legislative authority for the associated equipment approval system is the Motorboat Act of 1940 , and the Federal Boat Safety Act of 1971 under which the Coast Guard is concerned with the administration and enforcement of laws, rules and regulation over motor boats, Title 46 USC 481 RS 4488 (Regulations for vessels subject to Coast Guard). Title 46 USC 489 RS 4491 (Use of instruments for security of life to be approved) and the 1960 International Convention for the Safety of Life at Sea.

Regulations for plan review and inspection: 46 CFR Subparts 70-80 inclusive (Rules and Regulations for Passenger Vessels); and 46 CFR Subparts 175187 inclusive (Rules and Regulations for Small Passenger Vessels).

Regulations for associated equipment approvals: 46 CFR Subparts 160-164 inclusive (Specifications); and 46 CFR Subpart 24.26 inclusive (Rules and Regulations for Uninspected Vessels).

The Coast Guard promotes this program by membership in the following societies: American Society for Testing Materials, American Society of Mechanical Engineers, National Fire Protection Association, American Boat and Yacht Council, International Organization for Standards, and the Intergovern. mental Maritime Consultative Organization.

\section{Federal Aviation Administration, U.S. Department of Transportation, Washington, D.C. 20591}

Federal Aviation Administration (FAA) standards are either regulatory or nonregulatory in nature. Those in the later category are found in the various numbered parts of the Federal Aviation Regulations and as such are subject to revision in accordance with the administrative rule-making procedures in which the public participates. Regulatory amendments and notices of proposed rule-making are published in the Federal Register.

The nonregulatory standards, generally contained in FAA Advisory Circulars, serve principally as a means of providing safety information to the public with respect to aircraft operations or of a related aeronautical interest. Nonregulatory circulars also provide the public with guidelines in meeting regula. tory requirements. The FAA periodically publishes a revised Advisory Circular Checklist and Status of Regulations which lists current advisory circulars and Federal Aviation Regulations. Most of the circulars may be obtained free of charge. The regulations, which are organized by volume, may be purchased from the U.S. Government Printing Office.

Regulations and standards are developed and administered by various services and offices within FAA. The Flight Standards Service is responsible for 
most of the regulatory material which includes the certification, operation and maintenance of aircraft, engines, propellers and aircraft equipment; licensing of airmen; operational procedures; and the certification of schools, repair stations, and parachute lofts. The Air Traffic Service is responsible for regulations and standards governing airspace utilization, air traffic control and procedures, and for the establishment and installation of navigational facilities. The Airports Service is responsible for regulations and standards concerning airport certification and airport grants; the Office of Aviation Medicine, for airmen aeromedical standards; the Office of Environmental Quality, for aircraft noise standards; and the Office of Air Transportation Security, for airport and air carrier security requirements.

The Federal Aviation Administration was created under Title VI of the Federal Aviation Act of 1958 to provide for the regulation and promotion of civil aviation in such a manner as to best foster its development and safety, and to provide for the safe and efficient use of the airspace by both civil and military aircraft, and for other purposes. The Federal Aviation Regulations are promulgated under Title 14 of the Code of Federal Regulations. The first regulations and civil aviation safety standards originated with the passage of the Air Commerce Act of 1926.

\section{Engineering and Traffic Operations, \\ Federal Highway Administration, \\ U.S. Department of Transportation}

The Federal Highway Administration (FHWA), working in full concert with an official organization of the highway departments of several states, and the American Association of State Highway and Transportation Officials (AASHTO), prepares FHWA standards and implements AASHTO standards pursuant to the authority of $23 \mathrm{U} \mathrm{S} \mathrm{C} \mathrm{109.} \mathrm{The} \mathrm{standards}$ promulated for Federal-aid highways are listed in FHWA Policy and Procedure Memorandum (PPM) 40-2, and in title 23, Code of Federal Regulations. Standards for federally owned highways follow the Federal-aid standards, although Federal agencies for which FHWA supervises direct Federal highway construction may alter the standards for their particular highway purpose.

The committee within AASHTO which has overall responsibility for the development of standards is the Standing Committee on Engineering Policies. This committee not only produces standards in its own right but utilizes various operating subcommittees for much of the developmental work. Standards are maintained in current status by periodic review and updating on a time cycle varying from 2 to 10 years, depending upon the rapidity of change in the state of the art and rate of obsolescence for the particular aspect of highway design and construction covered by the standard.

New subjects for which standards are currently under consideration include (1) highway drainage; (2) highway noise evaluation and attenuation measures; (3) location and design of bikeways; and (4) barriers for motorists' protection against roadside hazards.

The cooperative state-Federal standards program has resulted in a remarkable uniformity, nationwide, in the geometric design, safety and signing standards for the several classes of highways and their appurtenances.

\section{The Federal Railroad Administration, U.S. Department of Transportation}

The Federal Railroad Administration (FRA) was created pursuant to Section 3(e)(1) of the Department of Transportation Act of 1966. This Act transferred to the FRA the railroad safety activities of the Bureau of Railroad Safety and Service of the Interstate Commerce Commission, including the administration and enforcement of the Safety Appliance Acts, 45 U S C 1-16; the Locomotive Inspection Act, 45 U S C 22-34; the Accident Reports Act, 45 U S C 38-43; the Hours of Service Act, 45 U S C 61-64 and the Signal Inspection Act, 49 U S C 26. In addition, the Federal Railroad Safety Act of 1970, Pub. L. 91-458 (80 Stat. 971), authorized the FRA, through a delegation from the Secretary of Transportation (49 C F R 1.49(0)), to promote safety in all areas of railroad operations by prescribing appropriate regulations supplementing the existing rail safety statutes and regulations. The regulations promulgated under this legislative authority are found in Title 49, Subtitle B, Chapter II of the Code of Federal Regulations. The rule-making activity of the FRA is intended to promote uniformity in rail safety regulations applicable to all common carriers engaged in the general railroad system of transportation.

In the development of specifications, tolerances and standards the FRA follows those rule-making procedures set out in $49 \mathrm{C} \mathrm{F} \mathrm{R} \mathrm{211,} \mathrm{including} \mathrm{the} \mathrm{provision}$ of an opportunity for comment by private individuals, the industry and labor. Existing regulations prescribe standards and procedures with respect to track safety, reporting and classification of accidents, hours of service, locomotive inspection, safety appliances, power brakes, signal systems and the installation, inspection, maintenance, and repair of systems, devices and appliances.

Further regulations in the areas of operating rules, telegraphic reporting of accidents, freight car standards, marking of rear-end of trains to enhance visibility, passenger train speeds over $110 \mathrm{~m} . \mathrm{p.h}$. and certification of state agencies for participation in surveillance and investigation activities are being developed as part of the FRA's ongoing program to enhance the safe operation of the nation's railroads. Inquiries concerning proposed rule-making activities may be addressed to the Associate Administrator, Office of Safety, Federal Railroad Administration, 400 Seventh Street SW., Washington, D.C. 20590.

\section{National Highway Traffic Safety Administration} U.S. Department of Transportation

The National Highway Traffic Safety Administration carries out programs relating to the safety 
performance of motor vehicles and related equipment under the National Traffic and Motor Vehicle Safety Act of 1966. The Associate Administrator, Motor Vehicle Programs, is responsible for implementing the motor vehicle safety programs to reduce the occurrence of highway crashes, reduce the severity of injuries in such crashes, and improve survivability and injury recovery by better post-crash measures. Safety standards and regulations are issued which prescribe safety features and levels of safety-related performance for motor vehicles and motor vehicle equipment. The first of these standards was issued in 1966. Total number of standards issued is now 43, plus 11 regulations. These standards appear in Chapter $\mathrm{V}$ of Title 49 of the Code of Federal Regulations. A complete technical document of the Federal Motor Vehicle Safety Standards and Regulations is published and updated by the U.S. Government Printing Office.

Manufacturers are required to furnish certification of conformity. The Administration conducts an intensive testing program to determine whether vehicles and equipment comply with applicable standards. It also investigates reports of safety-related defects not covered by a standard, and can require a manufacturer of motor vehicles or motor vehicle equipment to take certain actions as to such defects.

The Administration cooperates with the National Motor Vehicle Safety Advisory Council, which is made up of public and industry representatives, and consults with them on vehicle safety standards.

\section{TREASURY, DEPARTMENT OF THE}

\author{
Bureau of Customs, \\ Bureau of the Mint, \\ Bureau of Alcohol, Tobacco and Firearms \\ Bureau of Customs, \\ U.S. Department of the Treasury, \\ $2100 \mathrm{~K}$ Street $\mathbf{N W}$. \\ Washington, D.C. 20229
}

In 1941 U.S. Customs authorized the use by the molasses trade of a direct-pressure type mercury gage, such as the Pneumercator, for measuring molasses in tanks.

This authorization was contingent on having the gage certified to show corrections, if any, to the scale readings at various points.

Until January 1,1960 this calibration was performed by the National Bureau of Standards. On or about that date NBS discontinued this service, and thereafter the U.S. Customs Service Laboratory at Baltimore, Maryland, assumed the responsibility.

At the present time the Laboratory certifies fewer than 10 Pneumercator gages per year. Calibration is performed on receipt of the unit accompanied by an open purchase order. The fee includes charges for labor, handling, and overhead. It varies per gage, depending upon the number of units submitted at one time, from $\$ 250$ to $\$ 300$.

Customs has no active standards committees or new projects underway or under consideration.

\author{
Bureau of the Mint, \\ U.S. Department of the Treasury, \\ 15th and Pennsylvania Avenue NW. \\ Washington, D.C. 20220
}

The Bureau of the Mint, Department of the Treasury, develops and administers the technical standards for the United States coinage. Nominal diameter and weight standards are established by statute (31 U.S.C. 317 and 391). Deviations allowed in the weight of minor coins are established by 31 U.S.C. 350 . Thickness standards, and other tolerances are developed by the Office of Technology, Office of the Director.

These standards are only imposed internally on the coin manufacturing processes. However, their importance in the development of coin handling and coin operated equipment so commonly found throughout the nation warrants their publication upon request. Written inquiries should be directed to the Director of the Mint, and to the Attention of Office of Technology.

\section{The Bureau of Alcohol, Tobacco and Firearms, U.S. Department of the Treasury, 1111 Constitution Avenue, Washington, D.C. 20226}

The Bureau of Alcohol, Tobacco and Firearms (ATF) is the agency with primary responsibility for enforcement of Federal laws relating to the production, storage and taxation of alcohol and tobacco products, firearms and explosives.

Standards have been established by the Bureau's Scientific Services Division, which apply to hydrometers, thermometers and William's test tubes supplied to the Bureau for testing the alcoholic content of beverages. Although these standards are not usually published, they are supplied to bidders for manufacturing contracts.

In cooperation with various industry segments, ATF prescribes and enforces standards of identity for alcoholic beverages. These standards are established by regulations applicable to all such beverages produced in or imported into the United States. Standards for the various classes of wines are published at 27 CFR Part 4; those for distilled spirits are published at 27 CFR Part 5.

The Scientific Services Division sets specifications for ethyl alcohol, denatured alcohol, proprietory solvents and special industrial solvents. These are incorporated as Federal Specifications O-E-760B issued by the General Services Administration. Through regulations issued by ATF at 26 CFR Parts 211 and 212, these standards are applicable to the production of these products in the United States.

The standards of identity for small cigars, as defined in 26 U.S.C. 5702 and in regulations issued by ATF at 26 CFR Part 270, are further established by laboratory test procedures set up by the Scientific Services Division. These analytical tests are utilized to enforce these standards for small cigars, as differ- 
entiated from cigarettes, upon all such products consumed within the United States.

Additionally, the Bureau sets specifications relating to construction of storerooms for explosive materials. These specifications are published in 26 CFR Part 181.

\section{VETERANS ADMINISTRATION, Department of Medicine and Surgery, Washington, D.C. 20420}

The standardization activities of the Veterans Administration (VA) are administered by the Safety, Occupational Health and Fire Protection Division and have been in effect for many years. The Division establishes VA standards relative to safety, occupational health and fire protection, as supplements to adopted national standards. Currently there are fourteen VA standards: Carpet Safety Requirements, Automatic Fire Extinguishing Protection, Air Conditioning Systems, Magnetic Door Locks, Liquid Oxygen Walker Units, Trash Containers, Exit Through ICU or CCU, Storage, Preparation and Consumption of Food and Beverages by Employees in Places of Work, Food Service Equipment and Facilities, Lasers, Pipetting in Hospital Laboratories, Needle/Syringe Handling Procedures, Electron Microscopes, and Microwave Ovens.

There are three new standards projects under consideration: Noise, Bathtubs, and Laboratory Safety Equipment-Safety Showers and Eyewashes. The VA Policy Manual MP-3, Part III lists the current standards.

\section{Index}

\subsection{Association Index By Subject Heading Areas}

This is a listing of associations by subject heading areas. Under each of the subject areas the organizations are listed in alphabetical order, being classified in the broad sense of the word. The subject terms are considered generic in scope but relevant to the (1) field and/or subject, including existing subclasses (e.g., Engineering-electrical, civil, mechanical, mining, and aeronautical, etc.) or type of organization including their industry, technology, trade, or profession; (2) concern, cause, interest, or activity of the group; and (3) applicable products, materials, systems, services, or related aspects and applications. Subject fields are sometimes grouped into one subject heading area and in some instances, such as under the terms Agriculture (subject area 2), and Food, of Food and Drug (4); and Engineering (15), and Industrial (Technical and Trade) (18), the classifications are intended as a further breakdown even though there is a subject overlap. Subclassification is determined by the reader either by consideration of the organization's name, or by reading the summary content of the specific organization. Obviously, an organization may appear under more than one sub. ject area.

\section{List of Subject Heading Areas}

Business, Commercial and Management

Agricultural

Transportation

Food and Drug

Mandates, Codes and Legal Involvements

Scientific

Educational and Cultural

Health and Medical

Safety

Hobbies, Crafts, and Pets

Athletic, Sports and Recreation

Consumerism

Environmental

Communication

Engineering

Construction and Materials

Automatic Data Processing (ADP)

Industrial (Technical and Trade)

Textiles and Fabrics, and Clothing

Sanitation

Public Interest

Energy

Packaging and Paper

Instrumentation, and Measurement and Weighing Devices

\section{BUSINESS, COMMERCIAL AND MANAGEMENT ( 1 )}

American Bankers' Association

American Council of Independent Laboratories, Inc.

American Dental Trade Association

American Hotel and Motel Association

American Insurance Association

American Mutual Insurance Alliance

American Wax Importers and Refiners' Association

Archery Manufacturers' Organization

Architectural Woodwork Institute

Building Owners and Managers' Association International

Computer and Business Equipment Manufacturers' Association

Data Processing Management Association

Electrical Testing Laboratories, Inc.

Factory Mutual Engineering and Research

Industrial Management Society

International City Management Association

Linen Supply Association of America

National Association of Blue Shield Plans

National Association of County Engineers

National Association of Hospital Purchasing Management

National Association of Industrial Parks

National Association of Purchasing Management, Inc.

National Institute of Infant Services

National Municipal League

National Retail Merchants' Association

National Wholesale Hardware Association

Paper Stationery and Tablet Manufacturing Association, Inc.

Pipe Line Contractors' Association

Project Management Institute

Rice Millers' Association

Society of Allied Weight Engineers. Inc.

Traffic Audit Bureau, Inc.

Transportation Data Coordinating Committee

United States Council of the International Chamber of Commerce

United States Testing Company, Inc. 


\section{Federal Government}

Agriculture, Department of

Animal and Plant Health Inspection Service

Commerce, Department of

Maritime Administration

General Services Administration

\section{AGRICULTURAL (2)}

American Association of Nurserymen

American Feed Manufacturers' Association

American Society of Agricultural Engineers

American Sod Producers' Association

American Soybean Association

Association of American Fced Control Officials, Inc.

Association of Official Analytical Chemists

Association of Official Seed Analysts

Blue Anchor, Inc.

Corn Refiners' Association, Inc.

Cotton Warehouse Association of America

Dairy and Food Industries Supply Association

Diamond Walnut Growers, Inc.

Farm and Industrial Equipment Institute

Fertilizer Institute

International Society for Terrain-Vehicle Systems

Mill Mutual Fire Prevention Bureau

National Academy of Sciences-National Academy of

Engineering-Institute of Medicine-National Research Council

National Silo Association

National Soybean Processors' Association

Perlite Institute

Rice Millers' Association

Sprinkler Irrigation Association

\section{Federal Government}

Agriculture, Department of

Agricultural Marketing Service

Animal and Plant Health Inspection Service

Departmental Information Processing Standards

Packers and Stockyards Administration. Scales and Weighing Branch

Rural Electrification Administration

Treasury, Department of

Bureau of Alcohol, Tobacco and Firearms

\section{TRANSPORTATION (3)}

(Including highways and airports since they accomodate transportation; velicles, conveyors and urban transportation systems; and traffic operations.)

Aerospace Industries Association

Air Transport Association

American Association of Motor Vehicle Administrators

American Association of State Highway and Transportation Officials

American Automobile Association

American Boat and Yacht Council, Inc.

American Bureau of Shipping

American Feed Manufacturers' Association

American National Standards Institute

American Road Builders' Association

American Society for Testing and Materials

Association of American Railroads

Chlorine Institute, Inc.

Farm and Industrial Equipment Institute

Friction Materials Standards Institute, Inc.
Industrial Truck Association

Institute of Traffic Engineers

International City Management Association

Manufacturing Chemists' Association

Motor Vehicle Manufacturers' Association of the Unitcd States, Inc.

National Academy of Sciences-National Academy of

Engineering-Institute of Medicine-National Research Council

National Association of County Engineers

National Association of Elevator Contractors

National Association of Motor Bus Owners

National Cottonseed Products Association

National Elevator lndustry, Inc.

National Fire Protection Association

Railway Tie Association

Refractories Institute

Society of Automotive Engineers

Sports Car Club of America, Inc.

Transportation Data Coordinating Committee

Truck Body and Equipment Association, Inc.

Truck Trailer Manufacturers' Association

Vehicle Equipment Safety Commission

\section{Federal Government}

Commerce, Department of

Maritime Administration

Transportation, Department of

Engineering and Traffic Operations, Federal Highway Administration

Federal Aviation Administration

Federal Railroad Administration

National Highway Traffic Safety Administration

United States Coast Guard

Office of Boating Safety

Office of Merchant Marine Safety

\section{FOOD AND DRUG (4)}

(Including food equipment, supplies, services, processing, production and storage; spitits and beverages.)

American Association of Cereal Chemists

American Association of Clinical Chemists

American Association of Medical Milk Commissions, Inc. and Certified Milk Producers of America, Inc.

American Dry Milk Institute

American Medical Association

American Oil Chemists' Society

American Pharmaceutical Association

American Society of Agricultural Engineers

American Society of Enologists

American Soybean Association

American Spice Trade Association

Association of American Feed Control Officials, Inc.

Association of Official Analytical Chemists

Association of Official Seed Analysts

Blue Anchor, Inc.

Coffee Brewing Center

Corn Refiners'Association, Inc.

DFA of California

Dairy and Food Industries Supply Association

Diamond Walnut Growers, Inc.

Distilled Spirits Council of the United States, Inc.

Food Processing Maclinery and Supplies Association

National Academy of Sciences-National Academy of Engineering-Institute of Medicine-National Research Council

National Association of Food Equipment Manufacturers

National Environmental Health Association

National Formulary

National Institute of Oilseed Products 
National Soybean Processors' Association

Pharmaceutical Manufacturers' Association

Rice Millers' Association

Salt Institute

U.S. Pharmacopeia, Pharmacopeia of the United States of

America, United States Pharmacopeial Convention

Whey Products lnstitute

Wine Institute

\section{Federal Government}

Agriculture, Department of

Agricultural Marketing Service

Animal and Plant Health Inspection Service

Health, Education and Welfare, Department of

Food and Drug Administration

Veterans Administration

\section{MANDATES, CODES AND LEGAL INVOLVEMENTS (5)}

(Including mandatory regulations, codes, ordinances, and laws; any organization that develops standards appearing in building codes; and nonmandatory codes, i.e., the building codes that do not have legal standing unless they are adopted by reference or inclusion, in an act of state, county, or by municipal governments. Also included are organizations that have any involvement, contribution or support, of regulatory activities even though the organization is a voluntary standards development group.)

American Association of Motor Vehicle Administrators American Automobile Association

American Feed Manufacturers' Association

American Insurance Association

American Road Builders' Association

American Society for Testing and Materials

American Society of AgricuItural Engineers

American Society of Plumbing Engineers

Association of American Railroads

Association of Bedding and Furniture Law Officials

Association of Official Analytical Chemists

Brick Institute of America

Building Officials and Code Administrators International, Inc.

Canvas Products Association International

Carpet and Rug Institute

Dairy and Food Industries Supply Association

Farm and Industrial Equipment Institute

Fertilizer Institute

Glass Tempering Association

International Association of Plumbing and Mechanical Officials

International City Management Association

lnternational Conference of Building Officials

Jewelers Vigilance Committee

Law Enforcement Association on Professional Standards,

Education and Ethical Practice

Motor Vehicle Manufacturers' Association of the United

States, Inc.

National Association of Elevator Contractors

National Automatic Sprinkler and Fire Control Association

National Automobile Theft Bureau

National Board of Boiler and Pressure Vessel lnspectors

National Canners Association

NationaI Cargo Bureau, Inc.

National Committee on Uniform Traffic Laws and Ordinances

National Electrical Contractors' Association

National Electrical Manufacturers' Association

National Elevator Industry, Inc.

National Fire Protection Association

National Forest Products Association

National Formulary

National Municipal League
Pharmaceutical Manufacturers' Association

Scaffolding and Shoring Institute

Southern Building Code Congress

Steel Joist Institute

Truss Plate Institutc, Inc.

U.S. Pharmacopeia, Pharmacopeia of the United States of

America, United States Pharmacopeial Convention

Vehicle Equipment Safety Commission

Western Wooden Box Association

\section{Federal Government}

Agriculture, Department of

Agricultural Marketing Service

Animal and Plant HeaIth Inspections Service

Packers and Stockyards Administration, Scales and Weighing Branch

Atomic Energy Commission

Commerce, Department of

National Bureau of Standards

Law Enforcement Standards Laboratory

Consumer Product Safety Commission

Environmental Protection Agency

Federal Communications Commission

Health, Education and Welfare, Department of

Food and Drug Administration

Interior, Department of

Mining Enforcement and Safety Administration

Joint Committee on Printing, Congress of the United States

Labor, Department of

Occupational Safety and Health Administration

National Conference on Weights and Measures, NBS

Transportation, Department of

Federal Aviation Administration

Federal Railroad Administration

National Highway Traffic Safety Administration

Office of Merchant Marine Safety, United States Coast Guard

Treasury, Department of

Bureau of Alcohol, Tobacco and Firearms

\section{SCIENTIFIC (6)}

American Association of Bioanalysts

American Association of Cereal Chemists

American Association of Clinical Chemists

Amcrican Association of Textile Chemists and Colorists

American Ceramic Society, Inc.

American Crystallographic Association

American Leather Chemists' Association

American National Standards Institute

American Nuclear Society

American Oil Chemists' Society

American Society for Medical Technology

American Vacuum Society

Association of Official Analytical Chemists

Atomic Industrial Forum

Biological Stain Commission

Electrical Testing Laboratories, Inc.

Entomological Society of America

Essential Oil Association of U.S.A., Inc.

Felt Manufacturers' Council of Northern Textile Association

Fertilizer Institute

Instrument Society of America

Manufacturing Chemists' Association

National Academy of Sciences-National Academy of

Engineering-lnstitute of Medicine--National Research

Council

Salt Institute

Scientific Apparatus Makers' Association

Snell Memorial Foundation. Inc.

Society of the Plastics Industry

Tile Council of America, Inc. 


\section{Federal Government}

Atomic Energy Commission

Commerce, Department of

National Oceanic and Atmospheric Administration, Marine Environmental Metrology

Environmental Protection Agency

\section{EDUCATIONAL AND CULTURAL (7)}

(Including organizations with educational programs for the trade or profession as well as educational programs as a service to the user; school related equipment and supplies; and information services.)

Accrediting Bureau of Medical Laboratory Schools American Association for Health, Physical Education, and Recreation

American Association of Poison Control Centers

American Association of Psychiatric Services for Children American Automobile Association

American Board for Certification in Orthotics and Prosthetics, Inc.

American Boards of Examiners in Speech Pathology and

Audiology, American Speech and Hearing Association

American Ceramic Society, Inc.

American College of Surgeons

American Concrete Pipe Association

American Home Economics Association

American Hospital Association

American Industrial Hygiene Association

American Library Association

American Medical Association

American Mining Conoress

American National Standards Institute

American Optometric Association

American Podiatry Association

American Psychiatric Association

American Psychoanalytic Association

American Ski Teachers' Association of Natur Teknik

American Society for Medical Technology

American Society for Nondestructive Testing, Inc.

American Watchmakers' Institute Inc.

Architectural Precast Association

Architectural Woodwork Institute

Associated Master Barbers and Beauticians of America

Association for Education of the Visually Handicapped

Association of American State Boards of Examiners in

Veterinary Medicine

Association of Home Appliance Manufacturers

Book Manufacturers' Institute

Coffee Brewing Center

Construction Industry Manufacturers' Association

Council of National Library Associations

Entomological Society of America

Farm and Industrial Equipment Institute

Gemological Institute of America

Gypsum Association

Illuminating Engineering Society

Industrial Management Society

Instrument Society of America

International Conference of Building Officials

International Municipal Signal Association

Law Enforcement Association on Professional Standards,

Education and Ethical Practice

National Accreditation Council

National Association of Food Equipment Manufacturers

National Association of Hospital Purchasing Management

National Association of Plumbing-Heating-Cooling Contractors

National Association of Purchasing Management, Inc.

National Association on Standard Medical Vocabulary

National Education Association

National Environmental Health Association
National Federation of Licensed Practical Nurses National Fire Protection Association

National League for Nursing, lnc.

National Machine Tool Builders' Association

National School Supply and Equipment Association

National Society for the Prevention of Blindness, lnc.

National Swimming Pool Institute

Painting and Decorating Contractors of America

Project Management Institute

Redwood Inspection Service

Society for Technical Communication, lnc.

Special Libraries Association

Standards Engineers Society

Sump Pump Manufacturers' Association

United Lightning Protection Association, Inc.

United States Golf Association

Vacuum Cleaner Manufacturers' Association

\section{Federal Government}

Commerce, Department of

National Bureau of Standards

Standards Information Services

Interior, Department of

Office of Water Data Coordination, Geological Survey

\section{HEALTH AND MEDICAL (8)}

Accrediting Bureau of Medical Laboratory Schools

American Association for Health, Physical Education, and Recreation

American Association for Rehabilitation Therapy, Inc.

American Association of Bioanalysts

American Association of Poison Control Centers

American Association of Psychiatric Services for Children

American Board for Certification in Orthotics and Prosthetics, Inc.

American Boards of Examiners in Speech Pathology and Audiology, American Speech and Hearing Association

American College of Surgeons

American Conference of Governmental Industrial Hygienists

American Dental Association

American Dental Trade Association

American Electroencephalographic Society

American Foundrymen's Society

American Hospital Association

American Industrial Hygiene Association

American Lung Association

American Medical Association

American National Standards Institute

American Optometric Association

American Podiatry Association

American Psychiatric Association

American Psychoanalytic Association

American Public Health Association

American Society for Artificial Internal Organs

American Society for Medical Technology

American Society of Anesthesiologists

American Welding Society

Association for the Advancement of Medical Instrumentation

Association of American State Boards of Examiners in

Veterinary Medicine

Association of Official Analytical Chemists

Biological Stain Commission

College of American Pathologists

Commission on Accreditation of Rehabilitation Facilities

Compressed Gas Association, Inc.

Dairy and Food Industries Supply Association

Industrial Medical Association

International Nonwovens and Disposables Association

Manufacturing Chemists' Association

National Academy of Sciences-National Academy of

Engineering-Institute of Medicine-National Research Council 
National Association of Blue Shield Plans

National Association of Hospital Purchasing Management

National Automatic Merchandising Association

National Environmental Health Association

National Federation of Licensed Practical Nurses

National Formulary

National League for Nursing, Inc.

National Society for the Prevention of Blindness, Inc.

National Swimming Pool Institute

Optical Manufacturers' Association

Optical Society of America

Pharmaceutical Manufacturers' Association

U.S. Pharmacopeia, Pharmacopeia of the United States of America, United States Pharmacopeial Convention

\section{Federal Government}

Agriculture, Department of

Animal and Plant Health Inspection Service

Atomic Energy Commission

Health, Education and Welfare, Department of

Food and Drug Administration

National Institute for Occupational Safety and Health

Interior, Department of

Mining Enforcement and Safety Administration

Labor, Department of

Occupational Safety and Health Administration

Transportation, Department of

Federal Aviation Administration

Veterans Administration

\section{SAFETY (9)}

Acoustical Society of America (Biological Safety)

Air-Conditioning and Refrigeration Institute

American Association of Motor Vehicle Administrators

American Association of Poison Control Centers

American Association of State Highway and Transportation Officials

American Automobile Association

American Boat and Yacht Council, Inc.

American Bureau of Shipping

American Concrete Pipe Association

American Conference of Governmental Industrial Hygienists

American Defense Preparedness Association

American Foundrymen's Society

American Institute of Steel Construction, Inc.

American Insurance Association

American Mining Congress

American Mutual Insurance Alliance

American National Standards Institute

American Nuclear Society

American Oil Chemists' Society

American Paper Institute

American Petroleum Institute

American Society of Agricultural Engineers

American Society of Mechanical Engineers

American Society of Safety Engineers

American Water Works Association

American Welding Society

Associated Locksmiths of America, Inc.

Association for the Advancement of Medical Instrumentation

Association of American Railroads

Association of Home Appliance Manufacturers

Association of Iron and Steel Engineers

Battery Council International

Bicycle Manufacturers' Association of America, Inc.

Building Officials and Code Administrators International, Inc.

Canvas Products Association International

Chlorine Institute, Inc.

Composite Can and Tube Institute

Compressed Gas Association, Inc.

Computer and Business Equipment Manufacturers' Association

Construction Industry Manufacturers' Association

Cordage Institute
Crane Manufacturers' Association of America, Inc.

Diamond Wheel Manufacturers' Institute

Distilled Spirits Council of the United States, Inc.

Dry Color Manufacturers' Association

Electrical Apparatus Service Association, Inc.

Electrical Testing Laboratories, Inc.

Factory Mutual Engineering and Research

Farm and Industrial Equipment Institute

Fertilizer Institute

Fir and Hemlock Door Association

Forging Industry Association

Glass Tempering Association

Grinding Wheel Institute

Gypsum Association

Hoist Manufacturers' Institute

Industrial Safety Equipment Association

Industrial Truck Association

Institute of Traffic Engineers

Instrument Society of America

International Association of Electrical Inspectors

International Association of Plumbing and Mechanical Officials

International Conference of Building Officials

International Municipal Signal Association

International Nonwovens and Disposables Association

Joint Industrial Council

Juvenile Products Manufacturers' Association

Manufacturing Chemists' Association

Mechanical Contractors' Association of America, Inc.

Metal Ladder Manufacturers' Association

Mill Mutual Fire Prevention Bureau

National Association of Corrosion Engineers

National Association of County Engineers

National Association of Elevator Contractors

National Association of Motor Bus Owners

National Automatic Merchandising Association

National Automatic Sprinkler and Fire Control Association

National Board of Boiler and Pressure Vessel Inspectors

National Cargo Bureau, Inc.

National Committee on Uniform Traffic Laws and Ordinances

National Electrical Contractors' Association

National Elevator Industry, Inc.

National Federation of State High Schools Associations

National Fire Protection Association

National Lime Association

National Machine Tool Builders' Association

National Rifle Association of America

National Roofing Contractors' Association

National Safety Council

National Sash and Door Jobbers' Association

National Silo Association

National Society for the Prevention of Blindness, Inc.

National Swimming Pool Institute

Optical Society of America

Outdoor Power Equipment Institute, Inc.

Packaging Machinery Manufacturers' Institute

Painting and Decorating Contractors of America

Paperboard Packaging Council

Powder Actuated Tool Manufacturers' Institute, Inc.

Rack Manufacturers' Institute

Scaffolding and Shoring Institute

Snell Memorial Foundation, Inc.

Soap and Detergent Association

Society of Die Casting Engineers

Society of the Plastics Industry

Southern Building Code Congress

Sporting Arms and Ammunition Manufacturers' Institute

Sports Car Club of America, Inc.

Steel Deck Institute

Truck Body and Equipment Association, Inc.

Truss Plate Institute, Inc.

Underwriters' Laboratories, Inc.

United Lightning Protection Association, Inc.

Vehicle Equipment Safety Commission

Water Pollution Control Federation

Wood and Synthetic Flooring Institute 


\section{Federal Government}

Atomic Energy Commission

Commerce, Department of

National Bureau of Standards

Law Enforcement Standards Laboratory

Consumer Product Safety Commission

Health, Education and Welfare, Department of

Food and Drug Administration

National Institute for Occupational Safety and Health

Interior, Department of

Mining Enforcement and Safety Administration

Labor, Department of

Occupational Safety and Health Administration

National Aeronautics and Space Administration

Transportation, Department of

Engineering and Traffic Operations, Federal Highway Administration

Federal Aviation Administration

Federal Railroad Administration

National Highway Traffic Safety Administration

United States Coast Guard

Office of Boating Safety

Office of Merchant Marine Safety

Veterans Administration

\section{HOBbIES, CRAFTS, AND PETS (10)}

American Watchmakers' Institute Inc.

Border Terricr Club of America

Crayon, Water Color and Craft Institute

Institute of High Fidelity

National Model Railroad Association

Photographic Society of America

Sports Car Club of America, Inc.

\section{ATHLETIC, SPORTS AND RECREATION (11)}

Amatcur Athletic Union of the United States, Inc

American Amateur Baseball Congress, Inc.

American Association for Health, Physical Education, and Recreation

American Boat and Yacht Council, Inc.

American Bowling Congress

American Fishing Tackle Manufacturers' Association

American Ski Teachers' Association of Natur Teknik

Archery Manufacturers' Organization

Eastern Bird Banding Association

Family Camping Federation of Amcrica

International City Management Association

National Fedcration of State High Schools Associations

National Rifle Association of America

Sporting Arms and Ammunition Manufacturers' Institute United States Golf Association

\section{Federal Government}

Transportation, Department of

Office of Boating Safety, United States Coast Guard

\section{CONSUMERISM (12)}

(Including associations concerned with popular consumer products, usually those sold over the counter, uscd inor-around the home, but excluding food and drug products; recreational boating; and including consumer services.)
American Association of Medical Milk Commissions, Inc. and Certified Milk Producers of America, Inc.

American Bankers Association

American Boat and Yacht Council, Tnc.

American Footwear Industries Association

American Home Economics Association

American Hotel and Motel Association

American Ladder Institute

American National Standards Institute

American Society for Testing and Materials

American Wax Importers and Refiners' Association

Association of Bedding and Furniture Law Officials

Association of Home Appliance Manufacturers

Barre Granite Association

Battery Council International

Bicycle Manufacturers' Association of America, Inc.

Book Manufacturers' Institute

Can Manufacturcrs' Institutc

Canvas Products Association International

Carpet and Rug Institute

Coffce Brewing Center

Crayon, Water Color and Craft Institute

Fir and Hemlock Door Association

Glass Container Manufacturers' Institute, Inc.

Institute of High Fidelity

Jewelers Vigilance Committee

Manufacturing Chemists' Association

National Association of Bedding Manufacturers

National Association of Furniture Manufacturers, Inc.

National Association of Hosiery Manufacturers

National Canners' Association

National Clay Pot Manufacturers

National Institute of Infant Services

National Lubricating Greasc Institute

National Model Railroad Association

National Safety Council

National Soft Drink Association

Optical Manufacturers' Association

Outdoor Power Equipment Institute Inc.

Paper Stationery and Tablet Manufacturers' Association Inc.

Pressure Sensitive Tape Council

Soap and Detergent Association

Society of Automotive Engineers

Thread Institute, Inc.

Tire and Rim Association

Vacuum Cleaner Manufacturers' Association

Wood and Synthetic Flooring Institute

\section{Federal Government}

Commerce, Department of

National Bureau of Standards

Office of Engineering Standards Services

Consumer Product Safety Commission

Transportation, Department of

Office of Boating Safety, United States Coast Guard

\section{ENVIRONMENTAL (13)}

(Including pollution, in or outdoor conditions, controls, and prevention; and any aspect of the ecological cycle.)

Acoustical and Insulating Materials Association Acoustical Society of America Air Pollution Control Association

American Foundrymen's Society

American Mining Congress

American National Standards Institute

American Nuclear Society

American Society for Testing and Materials

American Society of Mechanical Engineers

Anti-Friction Bearing Manufacturers' Association

Association of Engineering Geologists 
Battery Council International

Chlorine Institute, Inc.

Construction Industry Manufacturers' Association

Cooling Tower Institute, Inc.

Dry Color Manufacturers' Association

International City Management Association

Manufacturing Chemists' Association

National Academy of Sciences-National Academy of

Engineering-Institute of Medicine--National Research Council

National Association of County Engineers

National Association of Motor Bus Owners

National Association of Recycling Industries, Inc.

National Cable Television Association, Inc.

National Lime Association

National Sanitation Foundation

National School Supply and Equipment Association

National Water Well Association

Rubber Reclaimers Association, Inc.

Soap and Detergent Association

Water Pollution Control Federation

\section{Federal Government}

Atomic Energy Commssion

Environmental Protection Agency

Health, Education and Welfare, Department of

National Institute for Occupational Safety and Health

Housing and Urban Development, Department of

Interior, Department of

Office of Water Data Coordination, Geological Survey

Labor, Department of

Occupational Safety and Health Administration

Transportation, Department of

Engineering and Traffic Operations, Federal Highway Administration

Federal Aviation Administration

Veterans Administration

\section{COMMUNICATION (14)}

Air Transport Association

American Bankers' Association

American National Standards Institute

Association of American Railroads

Graphic Communications Computer Association

International Municipal Signal Association.

National Association of Broadcasters

National Audio-Visual Association, Inc.

National Cable Television Association, Inc.

Printing Industries of America Inc.

Radio Technical Commission for Aeronautics

Society for Technical Communication, Inc.

Society of Motion Picture and Television Engineers

Special Libraries Association

Telephone Group

Traffic Audit Bureau, Inc.

Transportation Data Coordinating Committee

\section{Federal Government}

Agriculture, Department of

Rural Electrification Administration

Commerce, Department of

National Bureau of Standards

Law Enforcement Standards Laboratory

Office of Telecommunications

Federal Communications Commission

National Aeronautics and Space Administration
ENGINEERING（15)

(lncluding the following subclasses: Electrical and Electronics, Civil, Mechanical, Mining and Metallurgical, Chemicals, Aeronautical, Structural, Steam Power, Hydraulic, Petroleum Product, etc. Some of these associations are by character also typed as trade or technical organizations.)

Acoustical Society of America

Aerospace Industries Association

Air Transport Association

American Association of Petroleum Geologists

American Association of State Highway and Transportation Officials

American Automobile Association

American Boiler Manufacturers' Association

American Bureau of Shipping

American Chain Association

American Concrete Institute

American Concrete Paving Association

American Defense Preparedness Association

American Die Casting Institute

American Gear Manufacturers' Association

American Home Lighting Institute

American Institute of Architects

American Institute of Chemical Engineers

American Institute of Mining, Metallurgical, and Petroleum Engineers

American Mining Congress

American National Standards Institute

American Nuclear Society

American Road Builders' Association

American Socicty for Metals

American Society for Nondestructive Testing, Inc.

American Society for Quality Control

American Society for Testing and Materials

American Society of Civil Engineers

American Society of Heating, Refrigerating and Air-Conditioning Engineers

American Society of Lubrication Engineers

American Society of Mechanical Engineers

American Society of Photogrammetry

American Society of Plumbing Engineers

American Society of Safety Engineers

American Society of Sanitary Engineering

American Vacuum Society

American Water Works Association

American Welding Society

Anti.Friction Bearing Manufacturers' Association

Asphalt Institute

Association of Edison Illuminating Companies

Association of Engineering Geologists

Association of Home Appliance Manufacturers

Association of Iron and Steel Engineers

Brass and Bronze Ingot Institute

Caster and Floor Truck Manufacturers' Association

Construction Industry Manufacturers' Association

Conveyors Equipment Manufacturers' Association

Copper Development Association Inc.

Crane Manufacturers' Association of America, Inc.

Diamond Wheel Manufacturers' Institute

Electrical Apparatus Service Association, Inc.

Electrical Generating Systems Marketing Association

Electrical Testing Laboratories, Inc.

Electronic Industries Association

Expansion Joint Manufacturers' Association

Factory Mutual Engineering and Research

Farm and Industrial Equipment Institute

Fluid Controls Institute

Friction Materials Standards Institute, Inc.

Grinding Wheel Institute

Home Ventilating Institute

Illuminating Engineering Society

Industrial Truck Association

Industry Service Bureaus 
Institute of Electrical and Electronics Engineers

Institute of Environmental Sciences

Institute of High Fidelity

Institute of Traffic Engineers

Insulated Power Cable Engineers' Association

International Association of Electrical Inspectors

International District Heating Association

International Mobile Air Conditioning Association, Inc.

International Society for Terrain.Vehicle Systems

Manufacturers Standardization Society of the Valve and

Fittings Industry

Mechanical Contractors' Association of America, Inc.

Mechanical Power Transmission Association

Metal Building Manufacturers' Association

Metal Cutting Tool Institute

Mobile Homes Manufacturers' Association

Monorail Manufacturers' Association

Motor Vehicle Manufacturers' Association of the United States, Inc.

National Academy of Sciences-National Academy of

Engineering-Institute of Medicine-National Research Council

National Association of Corrosion Engineers

National Association of County Engineers

National Association of Elevator Contractors

National Association of Motor Bus Owners

National Association of Relay Manufacturers

National Board of Boiler and Pressure Vessel Inspectors

National Cable Television Association, Inc.

National Clay Pipe Institute

National Elevator Industry, Inc.

National Environmental Systems Contractors Association

National Fluid Power Association, Inc.

National Machine Tool Builders' Association

National Water Well Association

Outdoor Power Equipment Institute, Inc.

Packaging Machinery Manufacturers' Institute

Pipe Fabrication Institute

Pipe Line Contractors' Association

Plumbing and Drainage Institute

Powder Actuated Tool Manufacturers' Institute, Inc.

Rack Manufacturers' Institute

Radio Technical Commission for Aeronautics

Society for Information Display

Society of Allied Weight Engineers, Inc.

Society of Automotive Engineers

Society of Manufacturing Engineers

Society of Motion Picture and Television Engineers

Society of Naval Architects and Marine Engineers

Standards Engineers Society

Steel Deck Institute

Steel Founders' Society of America

Steel Joist Institute

Telephone Group

Test Boring Association, Inc

Truck Body and Equipment Association, Inc.

Truck Trailer Manufacturers' Association

Truss Plate Institute, Inc.

Ultrasonic Manufacturers' Association, Inc

Underwriters' Laboratories, Inc.

United Lightning Protection Association, Inc.

Vehicle Equipment Safety Commission

Water Systems Council

Welding Research Council

\section{Federal Government}

A griculture, Department of

Rural Electrification Administration

Commerce, Department of

Maritime Administration

National Bureau of Standards

Office of Engineering Standards Services

Office of Telecommunications

Defense, Department of
Federal Communications Commission

Housing and Urban Development, Department of Interdepartmental Screw Thread Committee, NBS Interior, Department of

Bonneville Power Administration

Mining Enforcement and Safety Administration

National Aeronautics and Space Administration

Transportation, Department of

Engineering and Traffic Operations, Federal Highway Administration

National Highway Traffic Safety Administration

\section{CONSTRUCTION AND MATERIALS (16)}

(Including materials such as wire fabrics and those to be processed; associations that represent architects, contractors, manufacturers, inspectors and inspection services and grading of materials; products that are utilized in building structures as well as in any type of construction and construction applications; and tools and equipment used in construction.)

Acoustical and Insulating Materials Association

American Concrete Institute

American Hardboard Association

American Home Lighting Institute

American Hot Dip Galvanizers Association

American Institute of Architects

American Institute of Steel Construction, Inc.

American Institute of Timber Construction

American Iron and Steel Institute

American Lumber Standards Committee

American National Standards Institute

American Plywood Association

American Society for Testing and Materials

American Society of Heating, Refrigerating \& Air-Conditioning Engineers

American Society of Plumbing Engineers

American Welding Society

American Wood Preservers' Association

American Wood Preservers' Bureau

Architectural Precast Association

Architectural Woodwork Institute

Asbestos Textile Institute

Asphalt Institute

Asphalt Roofing Manufacturers' Association

Association of Iron and Steel Engineers

Brick Institute of America

Building Officials and Code Administrators International, Inc. Ceilings and Interior Systems Contractors' Association

Chain Link Fence Manufacturers' Institute

Concrete Reinforcing Steel Institute

Construction Industry Manufacturers' Association

Construction Specifications Institute

Expanded Shale Clay and Slate Institute

Facing Tile Institute

Fine Hardwoods-American Walnut Association

Finnish Plywood Development Association

Fir and Hemlock Door Association

Flat Glass Marketing Association

Gypsum Association

Gypsum Roof Deck Foundation

Hardwood Dimension Manufacturers' Association

Hardwood Plywood Manufacturers' Association

Illuminating Engineering Society

Indiana Limestone Institute of America, Inc.

International Association of Plumbing and Mechanical Officials

International Association of Wall and Ceiling Contractors

International Conference of Building Officials

International District Heating Association

Lead Industries Association

Maple Flooring Manufacturers' Association

Marble Institute of America

Mechanical Contractors' Association of America, Inc. 
Metal Building Manufacturers' Association

Mo-Sai Institute Inc.

National Academy of Sciences-National Academy of

Engineering-lnstitute of Medicine-National Research Council

National Concrete Masonry Association

National Crushed Stone Association

National Electrical Contractors' Association

National Elevator Industry, Inc.

National Environmental Systems Contractors' Association

National Fire Protection Association

National Forest Products Association

National Hardwood Lumber Association

National Mineral Wool Insulation Association, Inc.

National Oak Flooring Manufacturers' Association

National Particleboard Association

National Roofing Contractors' Association

National Sand and Gravel Association

National Slag Association

National Terrazzo and Mosaic Association, Inc.

National Woodwork Manufacturers' Association

North American Lumber Association

Northeastern Lumber Manufacturers' Association

Northern Hardwood and Pine Manufacturers' Association, Inc.

Perlite Institute

Pipe Line Contractors' Association

Powder Actuated Tool Manufacturers' lnstitute, Inc.

Red Cedar Shingle and Handsplit Shake Bureau

Redwood Inspection Service

Resilient Tile Institute

Scaffolding and Shoring Institute

Sheet Metal and Air Conditioning Contractors' National Association

Southern Building Code Congress

Southern Cypress Manufacturers' Association

Southern Hardwood Lumber Manufacturers' Association

Southern Pine Inspection Bureau

Steel Deck Institute

Steel Door Institute

Steel Joist Institute

Steel Window Institute

Stucco Manufacturers' Association

Thermal Insulation Manufacturers' Association, Inc.

Tile Council of America, lnc.

Truss Plate Institute, Inc.

West Coast Lumber lnspection Bureau

Western Wood Moulding and Millwork Producers

Western Wood Products Association

Wire Reinforcement lnstitute

Wood and Synthetic Flooring Institute

Zinc lnstitute

\section{Federal Government}

Commerce, Department of

National Bureau of Standards

Office of Engineering Standards Services

Defense, Department of

Housing and Urban Development, Department of

Labor, Department of

Occupational Safety and Health Administration

\section{AUTOMATIC DATA PROCESSING (ADP) (17)}

American Bankers' Association

American Feed Manufacturers' Association

American National Standards Institute

Computer and Business Equipment Manufacturers' Association

Construction Specifications Institute

Council of National Library Associations

Data Processing Management Association

Graphic Communications Computer Association
National Association of Blue Shield Plans

Society for Information Display

Transportation Data Coordinating Committee

\section{Federal Government}

Agriculture, Department of

Departmental Information Processing Standards

Commerce, Department of

National Bureau of Standards

Office of ADP Standards Management

\section{INDUSTRIAL (TECHNICAL AND TRADE)}

Abrasive Grain Association

Acoustical and Insulating Materials Association

Adhesive and Sealant Council

Air-Conditioning and Refrigeration Institute

Air Diffusion Council

Air Moving and Conditioning Association

Alumina Ceramic Manufacturers' Association

Aluminum Association

American Association of Advertising Agencies and the

Magazine Publishers Association's Joint Committee on

Magazine Advertising Reproduction

American Ceramic Society, Inc.

American Concrete Pipe Association

American Congress on Surveying and Mapping

American Council of Independent Laboratories, Inc.

American Defense Preparedness Association

American Electroplaters' Society

American Footwear lndustries Association

American Foundrymen's Society

American Gas Association

American Gem Society

American Hardboard Association

American Hot Dip Galvanizers' Association

American Hotel and Motel Association

American Institute of Steel Construction, Inc.

American Institute of Timber Construction

American lnsurance Association

American Iron and Steel lnstitute

American Ladder Institute

American Leather Chemists' Association

American Lumber Standards Committee

American Paper Institute

American Petroleum lnstitute

American Plywood Association

American Society for Abrasive Methods

American Society of Cinematographers

American Society of Electroplated Plastics, Inc.

American Wax Importers and Refiners' Association

American Wood Inspection Agency

American Wood-Preservers' Association

American Wood-Preservers' Bureau

Architectural Precast Association

Architectural Woodwork Institute

Asbestos Textile Institute

Asphalt Roofing Manufacturers' Association

Associated Cooperage Industries of America, Inc.

Associated Locksmiths of America, lnc.

Associated Master Barbers and Beauticians of America Baking Industry Sanitation Standards Committee

Barre Granite Association

Battery Council International

Bicycle Manufacturers' Association of América, Inc.

Bituminous Pipe Institute

Book Manufacturers' Institute

Brick lnstitute of America

Builders Hardware Manufacturers' Association

Building Owners and Managers' Association International

Can Manufacturers' Institute 
Canvas Products Association International

Carpet and Rug Institute

Cast Iron Soil Pipe lnstitute

Ceilings and Interior Systems Contractors Association

Cemented Carbide Producers' Association

Chain Link Fence Manufacturers' Institute

Chemical Specialties Manufacturers' Association

Coffee Brewing Center

Color Association of the United States, Inc.

Composite Can and Tube Institute

Comprcssed Gas Association, Inc.

Concrete Reinforcing Stcel Institute

Construction Specifications Institute

Contractors Pump Bureau

Cooling Tower Institute, Inc.

Cordage Institute

Cotton Warehouse Association of America

DFA of California

Dairy and Food Industries Supply Association

Door Operator and Remotc Controls Manufacturers'

Association

Dry Color Manufacturers' Association

Edison Electric Institute

Elastic Fabric Manufacturers' Council of Northern Textile Association

Electrical Apparatus Service Association, Inc.

Expanded Shale Clay and Slate Institute

Expansion Anchor Manufacturers' Institute

Facing Tile Institute

Federation of Societies for Paint Technology

Felt Manufacturers' Council of Northern Textile Association

Fibre Box Association

Fine Hardwoods-American Walnut Association

Flat Glass Marketing Association

Forging Industry Association

Gas Appliance Manufacturers'Association

Gemological Institute of America

Glass Tempering Association

Gray and Ductile Iron Founders' Society Inc.

Gypsum Association

Gypsum Roof Deck Foundation

Hack and Band Saw Manufacturers' Association

Hardwood Dimension Manufacturers' Association

Hardwood Plywood Manufacturers' Association

Hoist Manufacturers' Institute

Indiana Limestone Institute of America, Inc.

Industrial Diamond Association of America, Inc.

Industrial Fasteners Institute

Industrial Safety Equipment Association

Institute of Printed Circuits

Institute of Scrap Iron and Steel

Instrument Society of America

Inter-Society Color Council

International Association of Milk, Food and Environmental Sanitarians

International Association of Plumbing and Mechanical Officials

International Association of Wall and Cciling Contractors

International Municipal Signal Association

International Nonwovens \& Disposables Association

Investment Casting Institute

Jewelers Vigilance Committee

Joint Industrial Council

Juvenile Products Manufacturers' Association

Lead Industries Association

Library Binding Institute

Magnetic Materials Producers' Association

Malleable Founders' Society

Manufacturing Chemists' Association

Marking Device Association

Material Handling Institute, Inc.

Metal Cookware Manufacturers' Association

Metal Ladder Manufacturers' Association

Metal Powder Industries Federation

Metal Tube Packaging Council of North America

Milk Bottle Crate Manufacturers' Council
Mo-Sai Institute Inc.

National Association of Architectural Metal Manufacturers

National Association ol Bedding Manufacturers

National Association of Broadcasters

National Association of Food Chains

National Association of Furniture Manufacturers, Inc.

National Association of Glue Manufacturers

National Association of Metal Name Plate Manufacturers, Inc.

National Association of Pipe Coating Applicators

National Association of Plastic Fabricators

National Association of Plumbing-Heating-Cooling Contractors

National Association of Wiping Cloth Manufacturers

National Audio-Visual Association, Inc.

National Automatic Merchandising Association

National Automatic Sprinkler and Fire Control Association

National Builders' Hardware Association

National Cargo Bureau, Inc.

National Clay Pot Manufacturers

National Concrete Masonry Association

National Cottonseed Products Association

National Crushed Stone Association

National Electrical Contractors' Association

National Electrical Manufacturers' Association

National Firc Protection Association

National Flaxseed Processors' Association

National Forest Products Association

National Hardwood Lumber Association

National Industrial Leather Association

National Lime Association

National Lubricating Grease Institute

National Microfilm Association

National Mineral Wool Insulation Association, Inc.

National Oak Flooring Manufacturers' Association

National Paper Box Association

National Particleboard Association

National Printing Ink Research Institute

National Retail Merchants' Association

National Roofing Contractors' Association

National Sand and Gravel Association

National Sash and Door Jobbers' Association

National Scale Men's Association

National Slag Association

National Soft Drink Association

National Swimming Pool Institute

National Terrazzo and Mosaic Association, Inc.

National Wholesale Hardware Association

National Wooden Pallet and Container Association

National Woodwork Manufacturers' Association

Natural Gas Processors' Association

North American Lumber Association

Northeastern Lumber Manufacturers' Association

Northern Hardwood and Pine Manufacturers' Association, Inc.

Painting and Decorating Contractors of America

Paper Stationery and 'Tablet Manufacturers' Association, Inc.

Paperboard Packaging Council

Perlite Institute

Photo Chemical Machining Institute

Photographic Society of America

Polyurethane Manufacturers' Association

Pressure Sensitive Tape Council

Printing Industries of America Inc.

Pulverized Limestone Association

Railway Tie Association

Red Cedar Shingle and Handsplit Shake Bureau

Redwood Inspection Service

Refractories Institute

Resilient Tile Institute

Resistance Welder Manufacturers' Association

Rubber Manufacturers' Association

Rubber Reclaimers' Association, Inc.

Salt Institute

Scaffolding and Shoring Institute

Sheet Metal and Air Conditioning Contractors' National Association

Soap and Detergent Association

Society of Die Casting Engineers 
Society of the Plastics Industry

Southern Cypress Manufacturers' Association

Southern Hardwood Lumber Manufacturers' Association

Southern Pipe Inspection Bureau

Specialty Wire Association

Sports Car Club of America, Inc.

Spring Manufacturers' Institute

Sprinkler Irrigation Association

Steatite Manufacturers' Association

Steel Bar Mills Association

Steel Door Institute

Steel Shipping Container Institute

Steel Structures Painting Council

Steel Window Institute

Stucco Manufacturers' Association

Sump Pump Manufacturers' Association

Tanners' Council of America

Technical Association of the Pulp and Paper Industry

Thermal Insulation Manufacturers' Association, Inc.

Thread Institute, Inc.

Tile Council of America, Inc.

Tin Research Institute, Inc.

Tire and Rim Association

Vacuum Cleaner Manufacturers' Association

Variable Resistive Components Institute

Water Conditioning Foundation

West Coast Lumber Inspection Bureau

Western Wood Moulding and Millwork Producers

Western Wood Products Association

Whey Products Institute

Wire Reinforcement Institute

Wood and Synthetic Flooring Institute

Zinc Institute

\section{TEXTILES AND FABRICS, AND CLOTHING (19)}

(Including upholstery, yarns, fibers, tire cords, nonwoven fabrics, and bedding materials.)

American Association of Textile Chemists and Colorists American Home Economics Association

American National Standards Institute

American Society for Testing and Materials

Association of Bedding and Furniture Law Officials

Book Manufacturers' Institute

Canvas Products Association International

Color Association of the United States, Inc.

Elastic Fabric Manufacturers' Council of Northern Textile

Association

Felt Manufacturers' Council of Northern Textile Association

International Nonwovens and Disposables Association

National Association of Bedding Manufacturers

National Association of Furniture Manufacturers, Inc.

National Association of Hosiery Manufacturers

National Association of Wiping Cloth Manufacturers

National Knitwear Manufacturers' Association

National Retail Merchants' Association

Tanners' Council of America

Thread Institute, Inc.

\section{Federal Government}

Commerce, Department of

National Bureau of Standards

Office of Engineering Standards Services

\section{SANITATION (20)}

American Association of Cereal Chemists

American Concrete Pipe Association

American National Standards Institute
American Society of Sanitary Engineering

Baking Industry Sanitation Standards Committee

Can Manufacturers Institute

Cast Iron Soil Pipe Institute

Dairy and Food Industries Supply Association

Family Camping Federation of America

Food Processing Machinery and Supplies Association

International Association of Milk, Food and Environmental Sanitarians

Linen Supply Association of America

National Association of Plumbing-Heating-Cooling Contractors

National Automatic Merchandising Association

National Canners' Association

National Clay Pipe Institute

National Environmental Health Association

National Institute of Infant Services

National Sanitation Foundation

National Soft Drink Association

Plumbing and Drainge Institute

Soap and Detergent Association

Water Pollution Control Federation

Whey Products Institute

Federal Government

Agriculture, Department of

Animal and Plant Health Inspection Service

Housing and Urban Development, Department of

\section{PUBLIC INTEREST (21) \\ (Including social welfare)}

American Association of Poison Control Centers

American Library Association

Association for Education of the Visually Handicapped

Building Officials and Code Administrators International, Inc.

Family Camping Federation of America

International City Management Association

International Conference of Building Officials

National Accreditation Council

National Automobile Theft Bureau

National Easter Seal Society for Crippled Children and Adults

National Federation of Licensed Practical Nurses

National Formulary

National Safety Council

National Society for the Prevention of Blindness, Inc.

Special Libraries Association

Water Systems Council

\section{Federal Government}

Agriculture, Department of

Commerce, Department of

National Bureau of Standards

Consumer Product Safety Commission

Environmental Protection Agency

Federal Communications Commission

Health, Education and Welfare, Department of

Housing and Urban Development, Department of

Labor, Department of

Transportation, Department of

Treasury, Department of

Bureau of Alcohol, Tobacco and Firearms

\section{ENERGY (22)}

American Association of Petroleum Geologists

American Gas Association

American National Standards Institute

American Nuclear Society 
American Society for Testing and Materials Association of Edison Illuminating Companies

Atomic Industrial Forum

Electrical Generating Systems Marketing Association Illuminating Engineering Society

International District Heating Association

National Electrical Manufacturers' Association

Natural Gas Processors Association

\section{Federal Government}

Atomic Energy Commission

Interior, Department of

Bonneville Power Administration

\section{PACKAGING AND PAPER (23)}

(Including paper products, and all other packaging and wrapping materials; containers, crates and boxes; and packaging machinery.)

American National Standards Institute

American Oil Chemists' Society

American Paper Institute

American Society for Testing and Materials

Anti-Friction Bearing Manufacturers' Association

Chemical Specialties Manufacturers' Association

Composite Can and Tube Institute

Fibre Box Association

Food Processing Machinery and Supplies Association

Glass Container Manufacturers' Institute, Inc.

Gummed Industries Association, Inc.

Manufacturing Chemists' Association

Metal Tube Packaging Council of North America

National Association of Food Chains

National Canners' Association

National Cottonseed Products Association

National Paper Box Association

National School Supply and Equipment Association

National Soft Drink Association

National Wooden Pallet \& Container Association

Packaging Machinery Manufacturers' Institute
Paper Stationery and Tablet Manufacturers' Association, Inc. Paperboard Packaging Council

Pressure Sensitive Tape Council

Printing Industries of America Inc.

Society of the Plastics Industry

Steel Shipping Container Institute, Inc

Technical Association of the Pulp and Paper Industry

Western Wooden Box Association

\section{Federal Government}

Commerce, Department of

National Bureau of Standards

Office of Engineering Standards Services

Joint Committee on Printing, Congress of the United States

\section{INSTRUMENTATION, AND MEASUREMENT AND WEIGHING DEVICES (24)}

American Hospital Association

American National Standards Institute

Association for the Advancement of Medical Instrumentation Cooling Tower Institute, Inc.

Industrial Safety Equipment Association

Instrument Society of America

National Scale Men's Association

Optical Society of America

Radio Technical Commission for Aeronautics

Scientific Apparatus Makers' Association

United States Testing Company, Inc.

\section{Federal Government}

Agriculture, Department of

Packers and Stockyards Administration

Atomic Energy Commission

Commerce, Department of

National Oceanic and Atmospheric Administration, Marine Environmental Metrology

National Conference on Weights and Measures, NBS

Treasury, Department of

Bureau of Customs 


\subsection{Subject Index}

This is a subject index of key words extracted from the summaries of organizations included in this $\mathrm{Di}$ rectory. It is a key word(s) approach to any standards or standards-related activities or other important activ. ities within the scope of the organizations. Since the full association names appear in the text of the Directory, only the key words in the association names appear in the subject index. The exceptions are for affiliated organizations, and for the names of state and Federal agencies. The states are indexed by name only; no key words were extracted from the state summaries. The Federal agencies are indexed after the pattern for the associations but, in addition, are indexed under the departments and their primary agencies, as well as the independent agencies. Page numbers refer to the page on which the summary begins and not necessarily to the page on which the key word(s) appear.

\section{A}

Abrasive Methods

Page

Abrasives

Abstract Writing -

Accident Prevention -----10 26

Accident Reports-Railroad - 195

Accounting -- Accounting, Cost -

Accounting Practices-Dental Trade - 19

Accreditation Council _._. 107

Acoustical and Insulating Materials

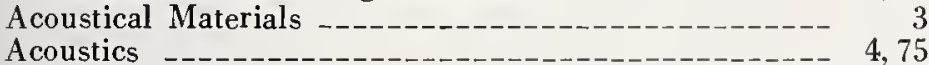

Acoustics (- A 15

Adhesives -

Adhesives and Sealants

ADP Standards Management _- 182

Advertising -

Advertising-Outdoor - 159

Advisory Commission on Textbook Specifications _-_-_ 59

Aerial Photography - 44

Aeromedical Standards 195

Aeronautics -

Aerosols _-

Aerospace Data Systems

Aggregates -_.

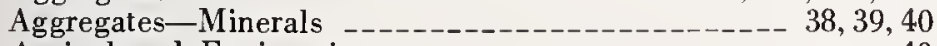

Agricultural Engineering - 40

Agricultural Marketing Service 177

Agriculture, Department of _... 176

Air and Water Programs _._._- 185

Air-Conditioners -.-

Air-Conditioning

Air-Conditioning Systems _-_._._. 197

Air Ducts -

Air Moving Devices _._-_-_-_-_-_-_-_- 6

Air Pollution Control - $\quad 6$

$\begin{array}{ll}\text { Air Traffic Control } & 195 \\ \text { Airborne Contaminants } & 189\end{array}$

Airborne Contaminants --189
Airborne Respirable Chest Concentrations

Aircraft

Aircraft Locknut Manufacturers' Association

Airfields -

Airports --_-_-_-_-_-_-_-_- 35

Airspace Utilization

Alarm Systems-Fire _-_-_-_-_-_-_-_-_-_-_ 103

Alarms

Alcohol

Allied Weight Engineers - 147

Alloys-Metal
Alloys-Steel Bars

Alloys-Tin

Alumina Ceramic

Aluminum

Aluminum Wares 102

AM and FM Tuners

Ambulances -_-_-_-_-_- 159, 160

American National Standards - 29

Ammunition -

Amplifier Distortions-TV

Amplifiers -

Analysis-Seeds _-_-_-_-_-_-_-_-_-_-_-_-_- 56

Analysts-Psychoanalysis -

Analytical Chemists

Anchors, Concrete --

Anesthesia-Gas - Anesthesiology

Animal and Plant Health Inspection Service

Animal Drugs _- 187

Animal Feeds -

Animal Glues -

Animal Health Technicians _- 54

Animal Nutrition - 105

Animal Welfare - 178

$\begin{array}{lr}\text { Animals-Pet Dogs }- \text { P } & 59 \\ \text { Annunciators } & 91\end{array}$

Antennas-Mobile -

Anti-Friction Bearings - 48

Antibiotic Drugs _- 187

Antifreezes-Engines - 39,40

Apparel _-

Apparel-Protective Headgear -

Appearance Tests _- 39,40

Appliances _-

Appliances-Gas

Appliances-Gas-Burning - 21

Appliances-Household -Hon 23

Appraising-Diamonds _- 82

Archery _- 48

Architects/Architecture - 25

Architectural Glass and Aluminum 75

Architectural Metal Manufacturers 107

$\begin{array}{ll}\text { Architectural Precast Concrete } & 49 \\ \text { Architectural Woodwork }--1 & 49\end{array}$

Arizona, State of

Armament Systems

Armheld Carriers -

Aromatic and Flavor Materials

Arrows and Bows -

Arsenic - - 188

Arsine _-_. 188

Art Materials - 71

Artificial Internal Organs

Artificial Limbs and Braces _._. 13

Asbestos -

Asbestos-Cement Products _. 39,40

Asphalt Applications -.- 77

$\begin{array}{ll}\text { Asphalt Roofing } & 49 \\ \text { Asphalts } & \end{array}$

$\begin{array}{rr}\text { Asphalts } & 49 \\ \text { Athletic Equipment } & 122\end{array}$

Athletic Rules and Events

Athletic Sports
Atmospheric Analysis

Atomic Energy Commission $\begin{array}{rr}180 \\ \text { A }\end{array}$

$\begin{array}{ll}\text { Atomic Industry } & 57 \\ \text { Attic Space Ventilators } & 85\end{array}$

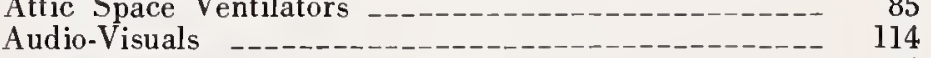

Audiology _. 14

Automated Clearing Houses-Banking - 13

Automatic Data Processing -

Automatic Door Operators _._-_________-__-_-_ 73

Automatic Merchandising - 114

Automobile Thefts

Automobiles _._.

Automobiles-Sports Cars _...- 152

Automotive Electrical Components _-___-_______ 159, 160

Automotive Engineering _-_- 148 
Automotive-Friction Materials

Automotive/Mechanical

Aviation

Aviation Electronics

$\mathbf{B}$

Baby Cribs

183,184

Baby Services

125

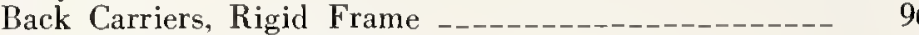

Bacteriological Standards -

Baking Industry Sanitation

Baking Utensils

Bale Preparations (Cotton)

Ball and Roller Bearings

Balls, Golf

Band Saws

Banding-Birds

Bank Cards

Bankers

Banking

Bar Supports-Concrete

Barber

Barges, Tank-Chlorine

Barre Granite

Barrels

Barriers-Roadside

Bars-Steel

Baseballs

Bathing Facilities

Bathtubs

Batteries

Beams-Shorin

Bearing Steels

Bearings -

Beautician

Bedding

Bedding Mate--o--

Behavioral Sciences

Bellows Expansion Joints _-_-_-_-_-_-_-_-_-_-_- 77

Belt Drives -

Benzene 188

Beryllium --_-_-_-_-_-_-_-_-_-_-_-_-_-_- 188

Beverages-Spirits _- 196

Bibliographic References and Entries -_-_-_-_-_-_- 70

Bicycle Manufacturers

Bicycles -

Bikeways _-_-_-_-_-_-_-_-_-_-_-_-_-_-_-_-_ 165

Binders Binding, Book

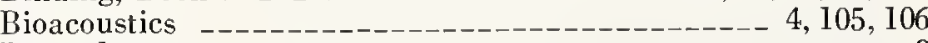

Bioanalysts - 9

Biochemistry ---

Biological Research _-_-_-_-_-_-_-_-_-_-_-_-_- 58

Biological Stains --.- 58

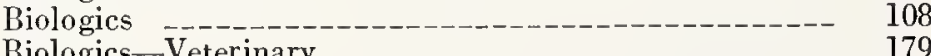

Biologics-Veterinary --_-_- 179

Biomechanics - - 105, 106

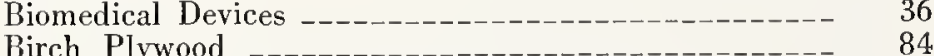

Bird Banding and Breeding Studies - 74

Bituminous Materials for Highway Construction _-_._- 38,39

Bituminous Pipes _-_- 58

Blast Furnaces

Blind, Instructors for the -

Blind and Visually Handicapped-Library Services _-_- 27

Blind and Visually Handicapped-Schools and Agencies 107

Blue Shield Plan

Board of Standards Review-

American National Standards

Boating Safety

Boats -

BOCA Codes

Body Measurements

Boiler and Pressure Vessel Inspectors _- 115

Boiler and Pressure Vessel Plates
Boiler Codes

Boilers-Heating

Bonneville Power Administration

Books

Border Terriers

Boring, Test

Bottlers

Bottles-Soft Drin

Bowling

Bows and Arrows

Box-Covering Papers

Boxes-Fibreboar

Boxes-Paper and Paperboard

Boxes, Wooden

Boxsprings ------

Brain Trauma Research

Brake Drums

Brake Linings and Shoes

Brakes - -

Brandy and Wine - 168

Brass 59,69

Brazing -

Breath Testers-Evident Alcohol

Breathing Machinery-Components - 41

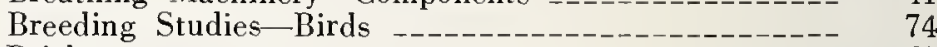

Bricks - Studies Birds - 60

Bricks-Glazed -- 77

Bridge Inspections - 169

Broadcasters -

Bronze

Bronze Ingots

Buckles and Ties-Cotton Bales - 70

Builders Hardware -_-_-_-_- 60, 75, 116

Building Board - 129

Building Codes -- 150

Building Construction - 39,40

Building Officials _-_-_-_-_-_ 60,94

Building Owners and Managers - 61

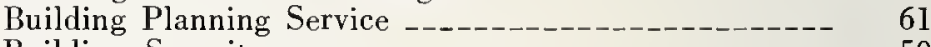

Building Security --_-_-_-_-_-_-_- 50

Building Stone

Building Stone-Limestone -

Buildings-Concrete -

Buildings-Metal -

Buildings-Structural Steel _-_-_-_-_-_-_-_- 25

Bureau of Alcohol, Tobacco and Firearms _._._. 196

Bureau of Customs _. 196

Burglar Alarm Systems Switches -

Burner Fuels

Buses-Motor -

Business Equipment

Butter 177

Buyers-Purchasing Agents ... 113

C

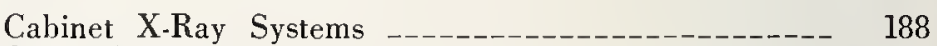

Cable, Electric - 75

Cable Television -116

Cables -

Cables and Wires

Cables-Flexible Flat - 90

Cables-Insulated Power - 91

Cadmium - 188

Calibration _- 183

Calibration Laboratories-Information --_-_---_--- 193

Camporounds -

Camping -- 78

Camping - Products Canvas -

Cancer Programs -

Canning Machinery -- 81

Cans -

Canvas Products - 61

Car Seats - 96

Carbide Cutting Tools -

Carbon Black - 39,40 
Carbon Monoxide --.- 188

Carbonated Beverages _..._-_- 133

Carbonated Solf Drink Bottles _-_-_-_-_- 82

Carcinogen -

Cardiac Valves --_--_-_-_-_-_-_-_-_-_-_-_- 51

Cargo Ship Construction

Cargoes

Carpeting -

Carpets -- 197

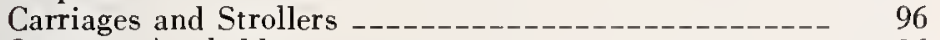

Carriers, Armheld _. 96

Cars - Art 196

Cartography

Cartons --

Cased Borings _. 157

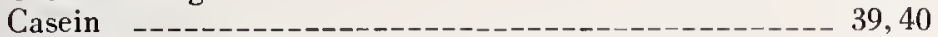

Cassette Recorders-Lapse Time Counters _-_._-_- 114

Cast Iron Soil Pipes -

Cast Metallics _.._- 21

Cast Metals _-_-_-_-- 148

Casters -

$\begin{array}{ll}\text { Casting -- } & 96 \\ \text { Cating } & \end{array}$

Casting-Iron - 172

Catheters -Welfare -

Ceiling/Floor Assemblies -

Ceilings -

Ceilings and Walls

Cellulose -- 39,40

Cement -

Cemented Carbide Producers _- 63

Ceramic Compositions _-_- 153

Ceramic Educational Council _- 15

Ceramic Materials _-_._-_._- 39, 40

Ceramic Tile _. 158

Ceramics - 15

Ceramics-High Alumina -

Cereal Chemistry -

Cereal Sciences - $\begin{array}{r}9 \\ \text { Certification Services }\end{array}$

$\begin{array}{ll}\text { Certification Services --- } & 75 \\ \end{array}$

Chain Link Fences -

Chains -

Chalk -..-_-_- 71

Chambers of Commerce - 163

Change Rooms - 189

Checks-Bank -

Cheeses _-_- 177

Chemical Analysis of Metal _._. 39, 40

Chemical Engineering _- 25

Chemical Feeding Equipment

Chemical Specialties _- 63

Chemicals and Chemical Compounds -

Chemicals-Industrial _. 39,40

Child Psychoanalysis _-_-_ 35

Chimneys-Concrete -

Chlorine -

Chromic Acid -

Chrysotile Asbestos Fibre 49

Cigars -

Cinematographers ---

Circuitry - Circuis 90

$\begin{array}{lr}\text { Circuits-Pneumatic - } & 91 \\ \text { City Laws }\end{array}$

City Laws - -129
City Management

Civil Engineering -

Clay -

Clay and Concrete Pipe and Tile 38

Clay, Modeling

Clay Pipes _- 117

Clay Pots-Flower - 117

Cleaners-Vacuum 164

Cleaning Compounds - 163

Clearinghouse for Standards

Clerical Operations, Methods-Time-Measurement _-_-- 97

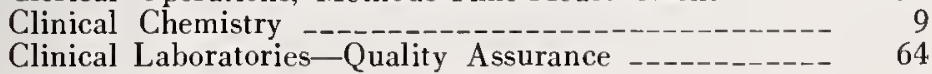

Clinical Laboratory Tests and Practices

Clocks

Clocks-Spacecraft

Closures, Container

Clothing-Police

Clubs, Golf

Clutch Facings

Coal

Coal Mine Dust Personal Sampler Units

Coal Mine Health

Coal Mines

Coatings - 193

Coatings-Decorative and Protective

Coatings-Electroplated and Metallic - 20

Coatings-Pipes - 112

Coatings-Steel Structures _-_-_-_-_-_-_-_-_-_-_- 155

Code Administrators _- 60

Coding_Packaging _- 159

Coffee Brewing and Coffee Grinds

Coffeemakers -

Coinage --_-_- 196

Coke -

Coke Oven Emissions 188

Color -

Color Additives

Color Council -

Color-Dry -

Color Materials _-_- 71

Color Standards--Paper 191

Colorado, State of 169

Colorants -_-_-_-_-_-_-_-_-_-_-_- 65

Colored-Stone Evaluation

Colorimetry _-

Colorists

Colour Index - 12

Combustible Solids

Commerce, Department of - 180

Commercial Food Preparation, Service and Equipment ${ }_{-} \quad 110$

Commercial Practices _-_-_-_-_-_-_-_-_-_-_-_ 163

Commercial Standards _-_- 181

Commodities-Fruit _- 59

Commodity Coding

Communication Equipment _.

Communications

Communications-Air Transport Networks _-_-_-_ 6

Communications-Highway -- 11

Company Member Council-ANSl 29

Composite Cans and Tubes _-__- 65

Compressed Gases

Computer and Business Equipment

Computers - 72

Concrete -

Concrete Aggregates

Concrete and Clay Pipe and Tile

Concrete Masonry

Concrete Pipes 17

Concrete-Precast Architectural

Concrete Reinforcing

Concrete Reinforcing Steel

Concrete, Structural-Lightweight

Conditioning - Water -W 165

Connecticut, State of - 169

Consensus, National-ANSI _A 29

Construction/Building _. 15

Construction Equipment and Supplies

Construction Industry - 68

Construction-Mobile Homes - 104

Consumer Council-ANSI _- 29

Consumer Product Safety Commission

Consumer Products _- 183

Contact Lenses -

Contacts _- $38,39,40$

Containers -

Containers-Barrels

Containers-Cans -C

Containers-Cargo 
Containers for Animals

Containers for Distilled Spirits

Containers Glass

Containers-Industrial Metal

Containers -Shipping _-

Containers Used to Transport Food Products _.

Containers-Wooden Boxes W 167

Contractors, Electrical _- 119

Contractors-Heating, Air Conditioning

and Refrigeration

Contractors Mechanical

Contractors Pumps

Control Devices

Control Surveying

Control Valves

Control-Weight

Controls

Converting Machinery-Packaging

Conveyors

Cooking

Cookware

Cooling Contractors

Cooling Towers

Cooperage

Copper and Copper Alloy

Cordage

Core Drilling

Corn Refiners

Corrosion Engineers

Corrosion Protection

Corrosion Tests

Corrugated and Solid Fibreboard

Cosmetics

Cost Records

Cotton

Cotton Dust

Cotton Warehouses

Cottonseed Products

County Engineers

Crafts

Cranes

Crates

Crayons

Credit Cards

Crib Mattresses

Cribs, Full Size

Cribs, Juvenile

Crippled Children and Adults

Cross Ties

Crude Petroleum

Crushed Stone

Cryogenic Gas _._._. 135

Crystallography _-_._.

Culverts --

$\begin{array}{ll}\text { Custom Hollow Metal Doors and Frames } & 107\end{array}$

Customs Oils

Cutting Tools 63

Cycles-Motor Driven _. 165

Cypress

\section{D}

Dairy Equipment

Dairy Product Examination

Dairy Products-Milk

Dairy Supplies and Equipment

Data Interchange-Banks

Data Processing Management _._._._._._.

Decking-Roof

Decking-Steel

Defense, Department of

Defense Materiels

Defense Preparedness

Dehumidifiers _.
Dental Materials

Dental Trade

Dentistry

Detectors-Weapon

Detergents ---

Devices-Dental

Diagnostic X-Ray

Dialyzers

Diamond Appraising and Cutting -

Diamond Walnuts -

Diamond Wheels

Diamonds - Industrial -

Diaper Services

Die Cast Metals

Die Castings

Die Forgings

Dies _._._.

Diffusers - Ceiling _._-_._. 5

Disinfectants
Disposables

$\begin{array}{llr}\text { Disposal Systems-Sewerage } & 189 \\ \text { Distilled Spirits } & 73\end{array}$

Distribution Lines-Electric

District Heating Systems _........-

Documentation

DODISS -

Dog Clubs-Pure Breds _...

Dogs-Welfare _-

Door Jambs and Frames

Door Locks, Magnetic _... 197

Door Operators _._._._. 73

Doors -

Doors-Steel

Drainage _._.

Drainage-Highway - -195

Dressing Tables-Juvenile

Dried Fruits

Drinking Water ---

Driver Licensing

Drums -Steel --

Dry Cleaning and Washing

Dry Color

Dry Goods _- 130

Dry Milk _-_-_-_-_- 92

Drywall and Its Taping

Duct Construction _-_-_-_-_-_- 146

Dumwaiters _..._.

Duplicating-Paper

Dust Explosion Hazards

Dwelling Requirements _._._-___-__-__-__-_ 189

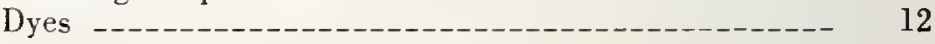

\section{$\mathbf{E}$}

Earth Moving Vehicles _-_-_-14- 148

Earth Sciences -_-_-_-_-_-_- 105

Edison Electric -

Edison Illuminating - 54

Education - -

Educators - 119

Elastic Fabrics -_.

Elastomers Thermosetting _-_________ 140

Electric Facilities _-__- 177

Electric Fuse Manufacturers' Build _._- 88

Electric Generators-Ultrasonic _- 161

Electric Motors _-_-_-_-_-_- 75

Electric Ranges --_- 23

Electric Systems

Electric Utility Equipment -

Electrical _-_-_-_-_-_- 122

Electrical and Electronics Engineers - 88

Electrical Apparatus - 190
El

$\begin{array}{ll}\text { Electrical Apparatus Services - } & 75 \\ \text { Electrical Cables- } & 91\end{array}$

Electrical Cables-Insulated Power
Electrical Conductors -19 
Page

Electrical Contractors _._._._. 119

Electrical/Electronic _-_-_-__-_-_-_-_-_-_-_- 75

Electrical Generating Systems and Marketing _-..---- 75

Electrical Inspectors --_--_-_-_-_-_------- 92

Electrical Insulating Materials

Electrical Manufacturers _-_-_-_- 120

Electrical Systems-Mobile Homes - 104

Electrical Systems-Truck Trailers -

Electrical Testing -

Electricity -

Electrification --_- 177

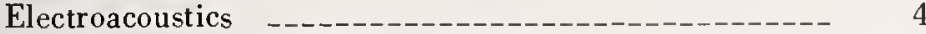

Electrodeposited Metallic Coatings -

Electroencephalography _._. 20

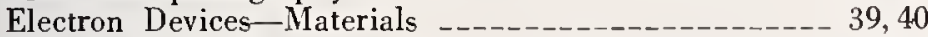

Electron Diffractions

Electronic Data Interchange -

Electronic Product Radiation Control _- 187

Electronics -

Electronics and Electrical Engineers ---

Electroplated Coatings --_-_- 20

$\begin{array}{lr}\text { Electroplated Plastics - } & 42 \\ \text { Elevators } & \end{array}$

Emergency Equipment

Emissions -

End Mills -

Energy Research-Atomic - 57

Engine Antifreezes - 39,40

Engine Tests -

Engineering and Traffic Operations _._._. 195

Engineering-Chemical -

Engineering-Electrical and Electronics -

Engineering Geologists -55

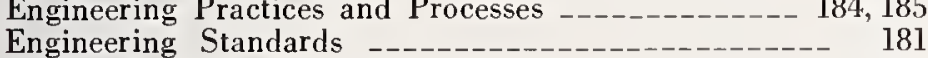

Engines-Aircraft -

Enologists --------------------------- 42

Entomology - -16

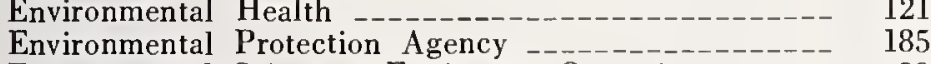

Environmental Sciences-Equipment Operations _-_- 89

Enzymes -

Equipment

Equipment-Aircraft

Equipment and Appliances-Gas _- 81

Equipment and Machinery-Electrical ----------- $\quad 75$

$\begin{array}{rr}\text { Equipment-Dairy - } & 92 \\ \text { Equipment Maintenance } & \end{array}$

Equipment Maintenance - ---190
Fquipment Operation

Escalators

Essential Oils - 76

Etchings-Photo

Evidential Breath Alcohol Testers

Exchangers _... 161

Executive Standards Council-ANSI _- 29

Expansion Anchors -

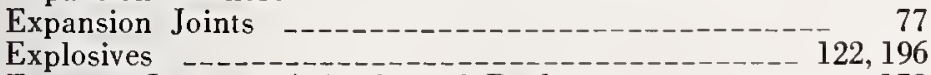

Exports-Imports, Animals and Poultry

Extinguishing Systems _-_-_- 122

Extruded and Tubular Products

Eye Protection -

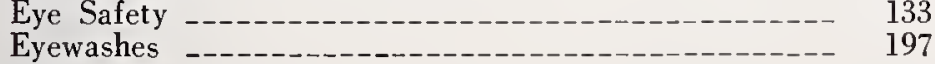

\section{$\mathbf{F}$}

Fabrics

$12,39,40$

Fabrics-Canvas

Fabrics-Elastic _._. 74

Facing Tiles - 77

Factory-Built Housing 104

Factory Mutual System

Fans-Exhaust _._._. 85

$\begin{array}{lr}\text { Fans-Power and Centrifugal } & 6 \\ \text { Farm and Industrial Equipment } & 78\end{array}$
Farm Products _- Page

Fasteners-Industrials _. 86

Fatigue - -

Federal Aviation Administration 194

Federal Catalog Systems _._.

Federal Communications Commission

Federal Highway Administration 195

Federal Housing Administration 189

Federal Information Processing Standards (FIPS)

Federal Motor Vehicle Safety Standards _-_____-_- 196

Federal Railroad Administration

Federal Specifications and Standards _.

Federal Standards and Specifications Information --- 182

Feed -

Feed-Animal _-

Felts -

Fences-Chain Link

Ferro-Alloys -

Ferrous and Nonferrous Minerals-Initial Processing -- 25

Ferrous Castings _-______- 39,40

Ferrous Filler Metals -

Ferrous Foundry Industry

Fertilizers ---

Fiber Boxes - 79

Fiber Cans -

$\begin{array}{lr}\text { Fiber Ropes }-1 & 69 \\ \text { Fiberboard }-(129\end{array}$

Fibers - 39,40

Fibre-See Fibers

Fibrous Glass

Field and Track

Fields

Filing Systems for Product Data

Filler Metals, Nonferrous _-_- 39

Filling Materials-Bedding ---54

Film (Radiographic) -Dental _- 19

Filters-Water - - 165

Finishes-Aluminum

Finnish Plywood

Fir and Hemlock Doors

Fire Alarm Systems-Municipal

Fire Apparatus

Fire Control and Protection

Fire Extinguishers - 194

Fire Extinguishing -

Fire Prevention -

Fire Prevention and Protection

Fire Prevention Code -- 26

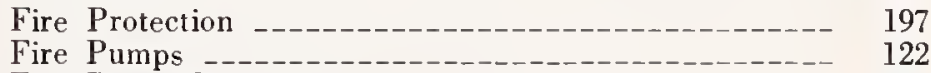

Fire Radio Services _- 94

Fire-Rated Custom Metal Doors and Frames 107

Fire Tests - 39,40

Firearms _- 151,196

Firearms-Rifles _-_-_-_-_-_-_-_-_-_-_-_-_-_ 130

Fishing Tackle 20

$\begin{array}{ll}\text { Fittings and Valves - } & 98 \\ \text { Fixtures Lighting } & \end{array}$

Flammability Codes for Camping Tents

Flammable Fabrics _...

Flammable Liquids

Flanges, Valves and Fittings _-_- 98

Flat Glass - 80

Flaxseed Processors 122

Flexible Barrier Materials

Floor/Ceiling Assemblies

Floor Finishes -

Floor Measurement

Floor Measurements-Office Building Industry --_--- 61

Floor Surfaces _- 168

Floor Trucks _._._._. 62

Floor Underlayment-Particleboard 129

Flooring _-__-__- 129, 168

$\begin{array}{lr}\text { Flooring-Hardwood } & 84 \\ \text { Flooring-Maple, Beech and Birch }\end{array}$ 
Flooring-Resilient Tile -

Floors-Concrete - 16

Floors/Floor Assemblies - 3

Florida, State of _-_- 169, 170

Flowmeters

Fluid Controls

Fluid Power Systems _-_-_-_-_- 122

Fluorescent Ballasts and Starters

Fly Lines

$\mathrm{FM}$ and $A \mathrm{M}^{-}$Tuners

Food and Drug Administration

Food Chains

Food Chemicals Codex

Food Engineering

Food Manufacturers

Food Processing Machinery and Supplies

Food Supplies and Equipment

Foodservices

Footwear

Foreign National Standards-lnformation

Forest Products

Forging
For gings-Steel - St

Forms-Business

Forms-lnstrumentation -

Forms-Invoices _-__- 109

Forms-Mass Property _._- 147

Forms, School Bus Accident Reporting - 159, 160

Founders, Malleable _-_- 98

Foundries 21,90

Foundries-Steel -

Foundry Industries -

Frames and Mountings-Optical _-_-_-_-_-_-- 136

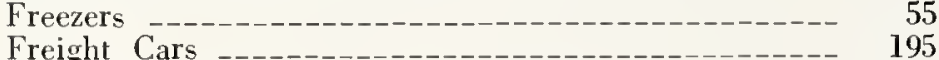

Freight-Cars, Claims, Containers - 52,53

Friction Materials

Fruit Exchanges - 59

Fruit Inspections -

Fruits _-_._. 177

Fuel, Fire and Explosion of Fuel

Fuel Handling and Storage

Fuels 39,40

Full Size Cribs -

Fungicides - 185

Furniture - 110

Furniture-Juvenile - -

$\begin{array}{ll}\text { Furniture Upholstered } & 54 \\ \text { Fuses, Electric } & \end{array}$

\section{G}

Gages

43,189

Galvanized Sheets

Galvanizing Industry

Gas

Gas and Vapor Detector Tube Systems

Gas Appliances and Equipment

Gas-Compressed

Gas-Handling and Transport -

Gas, Natural-Drilling and Production

Gas Pipelines

Gas Processors -

Gaseous Fuels -

Gases

Gaskets - 39,40

Gasoline -

Gauges-Pneumercator -

Gear Generating Tools _-_ 102

Gears --_-_-_- 22

Gemology -

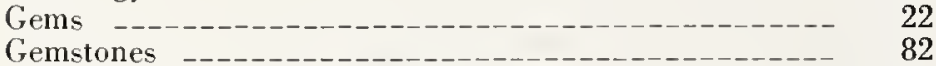

Gemstones
General Services Administration -185

Generating Plants

Generator and Motor Rebuilding
Geological Survey _...

Geologists-Engineering - 55

Gcologists-Petroleum - 11

Georgia, State of _-_ 170

Glass

Glass Containers - 82

Glass, Flat -

Glass Tempering - 82

Glaucoma Screening -_-_-_-_-_-_-_-_-_-_-_- 133

Glazed Brick -.

Glazing Systems -

Glue Products - 110

Golf _--_-nt Procurement Mandates 163

Government Procurement Mandates _-___-_-_ 185, 186

Government-Urban _... 93

Governmental Industrial Hygienists _-_- 17

Grade-Trademarks for Plywood - 33

Grading-Diamonds -

Grading-Lumber -

Grading of Abrasives -

Grading Rules -

Grading-Soybeans - -

Grain _-_-_-_- 177

Grain Loading Plans and Cargo

Granite Monuments -

Graphic Arts 141

Graphic Arts-Packaging _-_..- 157

Graphic Symbols-TV _- 116

Graphite - 39,40

Grass and Soil -

Gravel -

Gravel and Sand

Gray and Ductile Iron Founders -

Grease Lubrication - 127

Greases-Lubricating - 39,40

Grinding Wheels -. 83

Ground-Water _-

Guarding Devices

Guinea Pigs-Welfare -

Gummed Paper Products _- 83

Guns -.-_-

Gymkhanas (Driving Maneuvers)

Gymnastics --- 7

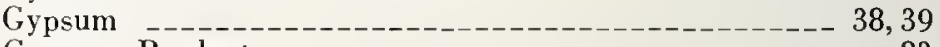

Gypsum Products

Gypsum Roof Decks -

\section{H}

Hack Saws

Hairstylists

Halogenated Organic Solvents

Organic Solvents -

Hamsters-Welfare

Hand Tools Institute

Handicapped _.

Handicapped-Audio and Speech _________._. 14

Handicapped-Communicatively _-_-_-_-_- 14

Handicapped-Partially Sighted - 133

Handicapped-Schools and Agencies

Handsplit Shakes

Hardboard

Hardware -

Hardware-Builders

Hardwood -

Hardwood and Pine -

Hardwood Flooring - 129

Hardwood Lumber

Hardwood Plywood 84

Hazardous Materials

Hazardous Substances -

Hazards to Health-Control of

Headgear-Protective - 146

Headphones -190

Health, Education and Welfare, Department of - 186

Health, Physical Education, and Recreation $---{ }_{-1}, 8,105,106$ 
Hearing Protectors -...-_-_-_-_-_- 181, 182

Hearths, Open _.

Heat Stress --_-_-_-_-_-_- 191

Heaters, Unit-Hot Water and Steam (Industrial) 6

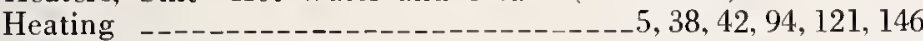

Heating Contractors

Heating-Mobile Homes _..._- 104

Helmets _._._.

Hemlock and Fir Doors

Herbs

Hides and Skins - 156

High Chairs _-_._- 96

High Fidelity -_-_-_-_-_-_- 90

Highway Bridge Decks _-_-_-_- 16

Highway Mobile Equipment _-_-_-_-_-_-_-_-_-_- 67

Highway Research _-_. 105

Highway Safety _-_-_-_-_-_-_- 117

Highway Traffic -

Highway Traffic Safety _-_-_-_-_-_-_-_-_-_-_- 165

Highway Transportation _-_-___-_-_-_-_- 91

Highways

Hobs and Shaper-Cutters _-_._-_._- 22

Hoists -

Hollow Metal Manufacturers' Association _.___-_ 107

Home Appliances -_-

Home Economics -

Home Lighting _-_._-_-_-_- 23

Home Ventilating - -

Homes-Mobile _- 75, 104

Homes_Plumbing -

Hook Lifters _. 101

Hoops ---

Horology -

Hospital Purchasing -

Hospital Supplies, Equipment and Facilities _- 23

Hospitals _-_._- 16, 23

Hot Dip Galvanizers

Hotels and Motels -_-

Housing _- 189

Housing and Urban Development, Department of - 189

Housing-Healthful _- 35

Housing, Manufactured _- 75

Housing-Mobile Homes

Humidifiers - 55

Hydraulic Fluids - 39

Hydraulic Hoists _-_- 159

Hydrofoils - 149

Hydrology -

Hydrometers _._.-._. 196

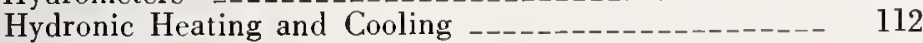

I

Identification Codes

lllinois, State of

Illuminating Engineering

Illumination

Importers-Waxes - Wa

Imports-Exports, Animals and Poultry

Independent Laboratories _._.

Independent Testing

Industrial and Farm Equipment

Industrial Aromatic Hydrocarbons

Industrial Chemicals

Industrial Diamonds

Industrial Fasteners -

Industrial Hygiene

Industial Hygiene

Industrial Hygiene Instruments - - 188

Industrial Parks

Industrial Safety Equipment

Industrial Scales

Industrial Trucks _-

Industrial Water

Infant Services

Information
Information Displays _-_._- 147

Information Processing _- 66, 72, 176

Information-Standards _-___-___ 182

Information-Standards Laboratories

Information-Water Data _._._. 190

Ingot Brass _- 59

Inks-Marking _-_- 101

lnks-Printing -

Inks-Proofing - 8,98

Inks-School Use -

Insecticides -_-_-_-_-_-_-_-_-

Inspection and Testing of Supplies-Government _---- 185

Inspection - Commodities _-_- 177

Inspection-Lumber -

Inspection Mechanics and Procedures -- 10

Inspection Services _.....

Inspection Services-Animals and Plants

Inspection Tables _. 38

Inspection-Tobacco - 177

Inspection-Wood - 47

Instructional Materials 132

Instrument Ball Bearings _-_._- 48

Instrumentation-Crystallographic - 18

Insulated Power Cable Engineers 91

Insulating Materials -

$\begin{array}{rr}\text { Insulating Materials-Electrical - } & 39 \\ \text { Insulation-Mineral Wool } & \end{array}$

Insulation-Thermal

Insulin

Insurance --_-_-_-_-_- 26, 29

Insurance Plans - 108

Interdepartmental Screw Thread Committee _...-..- 189

Interior, Department of the 190

Interior Systems

Intcrnational Critical Tables _- 105

International Standards Council-ANSI _-_._- 29

International Standards-Information

Interscholastic Sports -

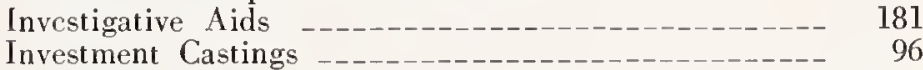

$\begin{array}{lr}\text { Investment Castings } & 96 \\ \text { Invoice Forms }-109\end{array}$

Iron $26,55,82$

Iron-Scrap -

Irrigation Systems _- 153

1SO Member Body (International Organization

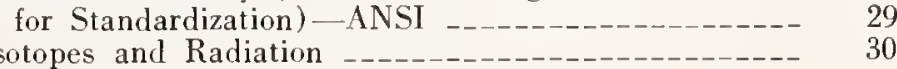

\section{J}

Jams _- 177

Jewelers' Vigilance Committee - 22

Jewelry -

Jewelry-Gems -12
Joint Committee on Printing

$\begin{array}{lr}\text { Joint Committee on Printing } & 191 \\ \text { Joint Industrial } & 96\end{array}$

Joint Sealants

Joist Construction-Concrete

Joists and Rafters

Joists-Steel _-_-_- 155

Justice, Department of _-- 191

Juvenile Products _._-_-_-_-_-_-_-_ 96

$\mathbf{K}$

Kansas, State of - 170

Kegs _-

Kentucky, Commonwealth of - 170

Key Blank Boxes _. 50

Knitwear - - 126

\section{L.}

Labeling

Labor, Department of _-_-_-_- 191

Laboratory Animals _- 105

Laboratory Apparatus -_-_-_- 145 
Laboratory Schools (Medical)

Lacquers

Ladders

Laminated (Plastic) Products

Laminated Timber

Lamips

Land Surveying

Landscape Architects

Landscaping -Industrial Parks _- 111

Laser Products - 188

Lasers - 51, 197

Lathing - -

Law Enforcement Standards Laboratory --_---_--- 181

Lawn Mowers-Power -

Lawns - Traffic -

Lead

Leather 39,125

Leather Industry _- 27

Leather Tanning -- 156

Lenses

Librarianship _- 27, 70

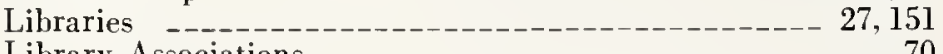

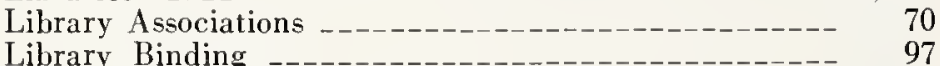

Library Binding ---151
Library Equipment and Supplies -

Library Systems _-_-_-_-_-_- 93

Lifesaving Devices -

$\begin{array}{lr}\text { Light Hydrocarbons - } & 39 \\ \end{array}$

Lighting - 23,85

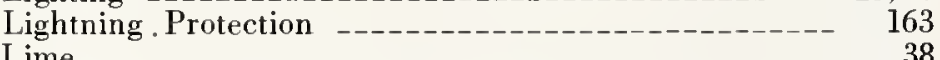

Lime - Limestone 38

Limestone-Pulverized - 141

Linen Supply _.

Lipids - 31

Liquefied Petroleum Gases ___ 39

Listing Bodies

Livestock -

Livestock Remedies _- 51

Livestock Scales _-_-_-_-_-_-_-_-_-_-_-_ 178

LNG --_-_-_-_- 135

Loading Ramps - 101

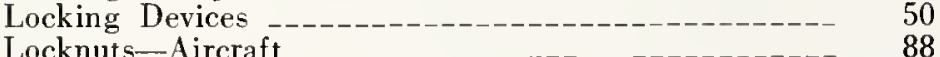

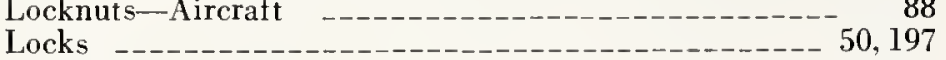

Locksmiths - 50

Locomotive Inspection _... 195

Loss-Prevention _- 77

Loudspeakers _- $\quad 90$

LP-Gas (Propane and Butane) _-__-_-_-_-_-_ 135

Lubricants - Greases

Lubricating Greases -

Lubrication Engineers -

Lumber

Lumber-Hardboard -

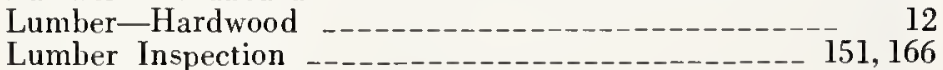

Lumber-Preservatives --_--_-_- 123

Lumber Products _... $\quad 123$

$\begin{array}{ll}\text { Luminaires } & 75 \\ \text { Lung Disease Prevention } & \end{array}$

\section{M}

Machine Input Records

Machine Tools _-_-_- 4,96

Machinery and Equipment-Electrical

Machinery-Construction _-_-_-_-_- 67

Machinery-Conveyors -

Machinery-Packaging _ 137

Machinery-Ships _-

Machinery-Soil Working -

Magazine Publishers
Magnetic Ink Character Recognition (MICR)

Magnetic Materials

Magnetic Properties

Magnetic Stripe Encoding

Magnetic Switches

Magnetic Tape Tracks

Maintenance Area Work, Methods-Time-Measurement

Malleable Founders

"Man at Work"

Management-Data Processing

Managers and Building Owners

Manufacturing Chemists

Manufacturing Engineers

Map Symbols Geology

Maple Flooring

Mapping

Marble

Marine Engineers

Marine Environmental Metrology

Maritime

Maritime Administration

Marketing

Marketing-Fruit

Marking-Birds

Marking Devices

Marking Paint-Pavement

Markings for Dangerous Goods

Maryland, State of

Masonry

Masonry-Brick and Block

Masonry, Concrete

Masonry Units

Material Handling

Material Protection

Materials

Materials Evaluation

Materials Handling

Materials Handling

Materials Handling-Hazardous --_-_-_-_-_-

Materials Handling-Lime - L -

Materials Handling-Radioactive

Materials-Nuclear

Materials-Roofing

Materials Testing

Mattresses

Mattresses, Crib -...-

Mattresses-Flamability

Measurement

Measurement and Sampling

Measurement Devices

Measurement for Audio Amplifiers and Tuners

Measurement Standards-Information

Measurement-Temperature

Measurements for Stretch Socks and Anklets --.--

Measuring Devices-Weighing

Meat and Poultry Inspection

Mechanical Engineering

Mechanical Fasteners

Mechanical Officials

Mechanical Shock an

Mechanical Shock

Medical Devices

$$
\text { Vibration }
$$

Medical Instrumentation

Medical Milk

(1)

Medical Psychoanalysts

Medical Rehabilitation

Medical Vocabulary

Medicine and Surgery, VA

Mental Illness

Merchant Marine Safety

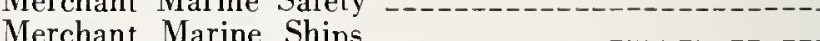

Merchant Ship Construction

Merchant Ships

Mercury Handling

Mercury, Inorganic

Metal Bar Grating 
Metal Bearing Ores-Sampling and Analysis _-_-_-_- 39

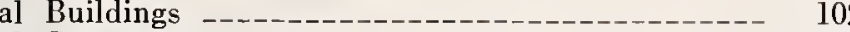

Metal-Chemical Analysis

Metal Cookware

Metal Cutting Tools _-

Metal Finishes and Stairs

Metal Ladders

Metal Powders -

Metal-Recycling _-_-_-__-_- 113

Metal Thicknesses -

Metal-Tin -..-_- 159

Metal Tube Packaging _-_- 103

Metallic Coated Products - 38

Metallic Coatings -

Metallic Materials for Thermostats and for

Electrical Resistance -_-_-_-_-_-_-_- 38

Metallography _-_-_-_-_-_-_-_-_-__-__-_-_-_-_ 37, 39

Metallurgical Practices

Metallurgical Society _-

Metallurgy -

Metals - 37

Metals, Light and Alloys - 38

Metals, Nonferrous and Alloys _- 38

Metals, Precious -

Metals-Welding of - 47

Meteorological Instruments

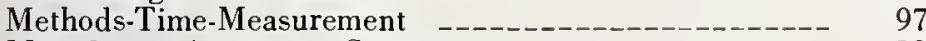

Metrology-Armament Systems _- 19

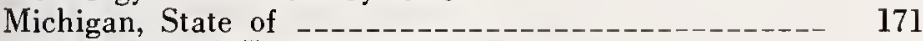

Microbiological Examination of Foods - 35

Microelectronics _-_-_-_-_-_-_-_-_-_-_-_-_- 38

Microelectronics-Microcircuits 192

Microfiche --_-

Microfilm -

Micrographics

Microscope-Work under the,

Methods-Time-Measurement _-_-_-_-_-_- 97

Microscopes-Electron

Microwave Diathermy Systems _...- 188

Microwave Ovens -

MIL Specs and Standards _-_-_-_-_-_-_-_-_-_ 184

Military Procurement Mandates

Milk Bottle Crates

Milk-Dry _-_..- 92

Milk-Equipment

Milk Products

Mill Buildings - 55

Millers-Rice _-_-_-_-_-_-_-_-_-_-_-_ 144

Milling Cutters _- 102

Millwork -

Mineral Wool

Minerals Industries

Mines - 180

Mining - 25,28

Mining Enforcement and Safety Administration _...-- 190

Minitrack Signal Source

Minnesota, State of 171

Mint

Missouri, State of

Mobile Antennas

Mobile Home Parks - 189

Mobile Homes

Mobilization Readiness

Model Codes -

Model Laws - 129

Model Railroads -- 128

Modeling Clay

$\begin{array}{lr}\text { Modulation } & 192 \\ \text { Moldings-Hardwood }- \text { Ha } & 84\end{array}$

Monies

$\begin{array}{ll}\text { Monorails } & 104 \\ \text { Montana, State of - } & \end{array}$

Mortars

Mortgage Inspections - 18

Mosaic

Motels and Hotels
Motion Pictures --.-_- 4l, 149

Motor and Generator Rebuilding _._._. 10, 75

Motor Bus Owners _._._. 111

Motor Vehicle Administrators

Motor Vehicles -

Motorboats -

Motorcycles -

Motors _-_-_-

Mouldings and Millwork

Mouldings-Wood _- W-_- 167

Moving Walks _-

Municipal Administrators - 93

Municipal League _-_-_- 129

Municipal Signals

Music Industry Codes _-

$\mathbf{N}$

Name Plate Data-Sump Pumps _-_-_-___-_ 156

Name Plates _-_-_-_-_-_-_-_-_-_-_-_-_-_-_ 11

National Aeronautics and Space Administration

(NASA) _- 192

National Association of Furniture Manufacturers, Inc. - 110

National Building Code _-_- 26

National Bureau of Standards

National Certified Pipe Welding Bureau _._._._- 101

National Clearinghouse for Standards

National Conference of Standards Laboratories

National Conference on Weights and Measures --_---- 193

National Environmental Balancing Bureau

National Highway Traffic Safety Administration _-_-_- 195

National Institute for Occupational Safety and Health

National Institute of Ceramic Engineers

National Machine Tool Builders Association

National Oceanic and Atmospheric Administration --_- 184

National Standards

Nationwide Consumer Testing Institute - 164

Natural Gas _-

Natural Gas-Drilling and Production

Naval Architects and Marine Engineers _-_-_-_._._- 149

Naval Stores _-_-_-_-_- 39,177

Navigational Facilities

Needle/Syringe Handling _-_-_-_-_-_-_-_-_-_ 197

Neutron Diffraction

New Jersey, State of

New York, State of

Noise ---osure 4

Noise-Exposure -

Noise Levels

Nondestructive Testing -

Nonmetallic Materials _. 21

Nonwoven Fabrics - 39

Nonwovens and Disposables

North Carolina, State of 173

Northern Textile Association - 74,79

Nuclear -

Nuclear Energy _-_-_-_-_- 57

Nuclear Facilities

Nuclear Reactor Fuel Cycle

Nuclear Science

Numerical Data - 105

Nurseries _- 10

Nurserymen -- 10

Nurses-Practical _-_- 122

Nurses, Practical-Licensed -Lo 122

Nursing -

Nursing Homes

Nuts-Walnuts

\section{0}

Oak Flooring _-_-_- 129

Occupational Medicine and Surgery _-_-_-_-_-_-_- 87

Occupational Protection _- 31

Occupational Safety - 188

Occupational Safety and Health Administration _-_-_-_ 191

Oceanographic Instrumentation 
Offstreet Parking

Office Machines

Office of Telecommunications

Office of Water Data

Oil Chemistry

Oil-Drilling and Production

Oils

Oils-Essential

Oilseed Products

Ophthalnic Frames

Ophthalmic Lenses

Ophthalmology-Instruments _._._-

Optical Manufacturers

Optical Society

Optics

Optometry -

Ordinances - 117

Ordnance _.

$\begin{array}{lr}\text { Oregon, State of } & 173 \\ \text { Ores, Metal Bearing-Sampling and Analysis } & 39\end{array}$

$\begin{array}{lr}\text { Ores, Metal Bearing-Sampling and Analysis } & 39 \\ \text { Organic Lead } & 188\end{array}$

Organizational Member Council-ANSI _._. 29

Orthotics -

OSHA -..- 191

Outdoor Power Equipment _._.

Overhead Handling Hoists _-_-_-_-_-_-_---_--- 85

Overhead Traveling Cranes

\section{$\mathbf{P}$}

Pacemake

Packagin

Packaging Machiner

Packers and Stockyards Act

Packers and Stockyards

Packers and Stockyards_Scales and Weighing

Pails

Paint

Painting and Decorating-Workmanship 137

Painting-Steel Structures _- 155

Paints

Paints-School Use _._-_. 71

Pallet Racks -

Pallets _-

Pan-American Coffee Bureau

Panel Tubing -

Paneling-Hardboard -

Paper Paper and Paperboard

Paper Box _- 129

Paper-Recycling _-_-_-_-_-_-_-_-_-_-_-_-_-_-_-- 113

Paperboard Packaging

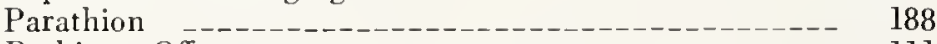

Parking-Offstreet _._-_- 111

Parks _-

Parks-Mobile Home

Particleboard _._-_-_-_-_-_-_-_-_-_-_-_-_-_-_- 129

Parts _-_-_-_-_-_-_-_-_-_-_-_-_- 184

Paste --11

Pathologists -

Paved Streets _._- 111

Pavement -16

$\begin{array}{ll}\text { Peanut Butter } & 177\end{array}$

Periodicals

Periodicals-Binding

Perlite

Personal Protective Devices

Pesticides

Petrolatum _-_-_-_-_-_-_- 39

Petroleum _-

Petroleum Engineers

Petroleum-Geologists

Petroleum Products

Pewter _-_-_-_-_-_-_-_- 159

Pharmaceutical Products

Pharmaceuticals
Pharmacopeia

Pharmacy

Pharmacy, Practice of

Phonograph Pickups

Photo Chemical Machining

Photogrammetry

Photographic Images

Photographic Interpretation

Photographic Materials

Photography

Photography-High Speed

Physical Education

Physical Fitness

Physicians

Pigments-Organic and lnorganic -

Pine Inspection _-_-_-_-_-_-_-

Pipe Coating Applicators

Pipe-Concrete

Pipe Fabrication

Pipe Fittings

Pipe Line Contractors

Pipe Lines-Asphalt Coatings -----------------

Pipes

Pipes-Bituminous

Pipes-Concrete

Pipes-Soil, Cast Iron

Piping-Power Plant, High Pressure

Piping Systems

Planning County Road Systems

Plant and Animal Health lnspections

Plant Engineering-Steel

Plant Spray Oils

Plants

Plastering -------

Plastic Fabricator

Plastics

Plastics-Electroplated

Plastics-Polyurethane

Plates-Metal Connector

Platform Trucks

Play Yards

Playground Equipment (Safety)

Playing Rules

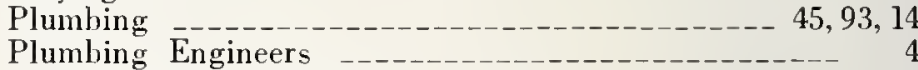

$\begin{array}{ll}\text { Plumbing-Heating-Cooling Contractors } & 112\end{array}$

Plumbing-Mobile Homes __.________________- 104

Plywood

Plywood-Birch

Plywood-Finnish

Plywood-Hardwood

Plywood-Preservatives

Pneumercators

Podiatry

Poison Control

Poison Prevention

Police

Police Body Armo

Police Service

Polishes

Polyurethanes

Pool Equipment

Portable Cribs

Potentiometers

Pots (Flower) - Clay

Poultry and Meat Insped

Poultry Scales

Powder Actuated Fastening Systems

Powder Metallurgy and Magnetic Cores

Power Brakes-Railroad

Power Equipment-Outdoor

Practical Nurses

Precast Architectural Concrete

Precast Concrete Panels

Precious Metals and Stones

Preservatives-Wood 
Pressure Sensitive Tapes

Pressure Vessel Inspector

14

Prevention of Blindness

Printed Circuit Boards

Printed Wiring Boards

Printing

Printing Industries

Printing Ink

Product Safety

Product Standards -

Products of Recycled Materials ___________ 113

Programming Languages _._._-_._-_._-_._- 72

Project Management _-_-_-_-_-_-_-_-_-_- 141

Propellers

Property Requirements _-_-_-_-_- 189

Property Surveys _-_-_-_-_- 18

Propulsion Machinery-Ships _- 180

Prosthetics _-.......- 13

Protection-Agri Plant -

Protection-Face and Eye 31

Protective Clothing -

Protective Devices _-_-_-_-_-_-_-_-_-_- 188

Protective Devices, Personal

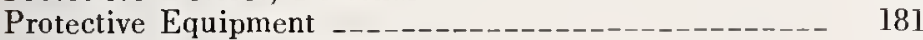

Protective Equipment-Personal _..- 87

Protective Headgear _-_-_-_-_-_-_-_-_-_-_-_ 146

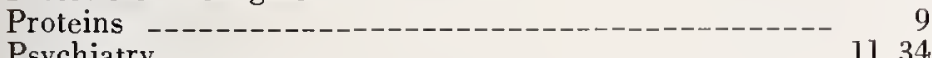

Psychiatry ---

Psychology $-1,-15$
Public Administration

Public Health

Pulp - 157

Pulp and Paper

Pulverized Limestone -

Pumps

Purchasing _-_-_-__-_- 109, 111

Purchasing Management _..- 113

\section{Q}

Qualified Products Lists-Government

Quality Control

Quality Control for Softwood Lumber

Quality Control-Wood - W

Quality Engineering Field

\section{$\mathbf{R}$}

Rabbits - Welfare

Races, Car

Racks

Radiation and Isotopes - 30

Radiation Control

Radiation Effects

Radiation Protection _...-..-

Radio Equipment and Operations

Radio Frequencies

Radio Frequency

Radio-Telegraphy -

Radioactivity in Food and Drugs

Radioisotopes and Radiation Effects

Radiological Health

Radios-Aeronautical

Rafters, Trussed

Rail Steel Bars

Railroad Cross Ties _-_-_-_-_-_-_- 143

Railroad Materials-Steel

Railroad Models --- 128

Railroads - 52

Railroads-Federal 195

$\begin{array}{ll}\text { Ranges-Electric } & 23 \\ \text { Reactor Research and Development }-180\end{array}$

Reactors

Reamers

Record Players
Recording and Reproducing

Recreation

Recreational Vehicles -

Recreational Vehicles-Plumbing

Recycling -_-__- 113

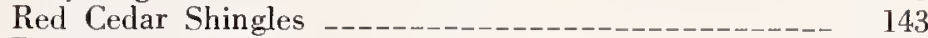

Redwood Inspection _- 143

Reference Standards -

Reference Standards-Insecticides _-_-_-_-_-_-_-_ 76

Refractories _-

Refractories Institute _-_-_-_-_-_-_-_-_-_-_-_- 144

Refrigerated Transport _-_- 159

Refrigerating - -

Refrigeration -_-_-_-_-_- 5, 121

Refrigeration-Truck Trailers

Refrigerator Doors _-__- 183

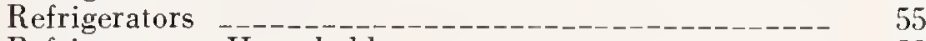

Refrigerators-Household - 23

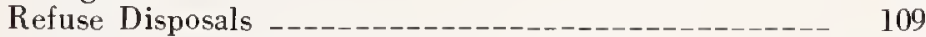

Regional Standardizing Bodies-Information

Rehabilitation Facilities _-_- 65

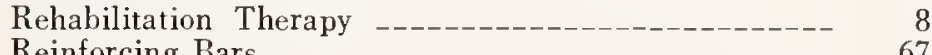

Reinforcing Bars -

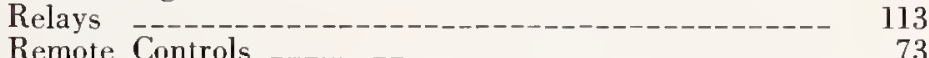

Remote Controls -

$\begin{array}{rr}\text { Report Literature Formats } & 70 \\ \text { Reproducing and Recording }---10 & \end{array}$

Reproduction of Advertisements

Research Projects

Residential Lighting - 23

Resilient Tiles _- 144

Resistance Welders _._. 144

Resistive Components _-__- 164

Respirable Chest Concentrations, Airborne -

Respiration-Gas -

Respirators

Respiratory Disease Control -

Respiratory Equipment _-_- 41

Respiratory Protective Devices _- 188

Retail Merchants

Reverse Osmosis _- 165

Rhode Island, State of

Rice Millers

Rifles -

Rims, Tire -

Road Builders -

Road Programs _- 109

Roadbuilding Machinery _-_-_-_-_-_-_-_-_-_-_ 148

Roads

Roadway Desion - 11

Rodenticides 185

Roller Bearings

Roof Decks-Gypsum - 83

Roof Decks-Steel _- 154

Roof Units-Concrete - 16

Roofing -

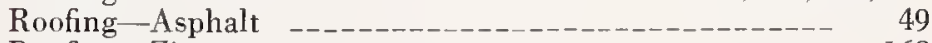

Roofing-Zinc _- 168

Ropes -

Rotameters _._- 91

Rotating Apparatus (Rebuilt)

Rotors

Rubber

Rubber Reclaimers

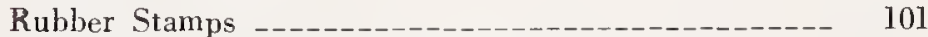

Rugs

Rural Electrification Administration

\section{$\mathrm{S}$}

Safety _-

Safety Council

Safety Engineers _-_-_-_- 44

Safety Equipment-Electrical

Salt

Sampling and Analysis of Metal Bearing Ores _.....- 39

Sampling Procedures _- 38 
Sand and Gravel

Sanitary Engineering

Sanitation

Sanitation-Dairy Processors

Sash and Door Jobbers

Saws-Hack and Band

Scaffolding

Scaffolds

Scales

School Buses

School Supply and Equipment

Scientific Apparatus

Scrap Iron and Steel

Scrap Rubber

Screw Threads

Screws-Socket, Tapping Cap, Machine and Wood Types

Sealants and Adhesives

Sealants-Joint

Sealing Tape

Seals

Seating Folding and Telescopic

Secondary School Athletes

Security Devices and Systems

Security Requirements-Airports

Security Systems

Seed Analysis

Seeds

Serial Publications

Service Cords-Sump Pumps

Sewer Pipes

Sewer Systems-Clay Pipe

Shale

Sheet Metal and Air Conditioning Contractors

Shingles

Shipping -

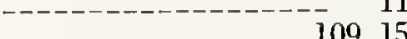

Ships 149,180

Ships and Vibration-Mechanical

Shoes

Shoring --

Showers, Safety

Sidings-Hardboard

Signal Controllers-Traffic

Signal Heads-Traffic -

Signal Inspection

Signal Sources, Minitrack

Signal Systems-Railroad

Signals-Municipal

Silica Glass

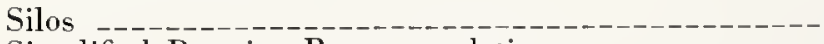

Simplified Practice Recommendations

Single-Family Dwellings

Ski Teachers

Skid Resistance

Skins and Hides

Slag

Slate

Slings-Ropes

Smith-Doxey Act

Soaps

Social Sciences

Society of Mining Engineers

Society of Petroleum Engineer

Socket Screw Products Bureau

Sod Producers

Soft Drink Bottles

Soft Drinks

Softwood

Soil and Grass

Soil Moisture

Soil Pipes

Soil Test Devices

Soil Working Machinery

Soils

Soils Exploration-Subsurface
Soldering

Solders

Solid Waste Management

Solvents

Sonics

Sorptive Mineral Materials

Sound Transmission

Sound-Underwater

Soybeans

Space Flight Data Systems

Space Flight Equipment

Space Rating

Space Systems

Space Veh

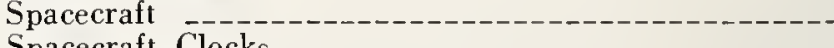

Spacecraft Clock
Specialty Wire

Spectroscopy

Speech Patholog

Speed Reducers-Gear Motor

Spices

Spirits-Brandy and Wine

Spirits-Distilled

Spirits-Wine

Sporting Arms

Sports-Athletic

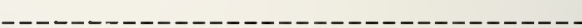

Sports Equipment

Springs

Sprinkler Installations

Sprinkler Irrigation

Sprinklers

Sprinklers, Automatic

Stainless Steel

Stains-Biological

Stair Treads and Risers

Stairs-Metal

Standard Book Numbers

Standard Reference Material

Materials-Petroleum _........

Standardization

Standards Engineers

Standards Laboratories

State Boards of Examiners in Veterinary Medicine

State High Schools

State Highway Officials

State Specifications and Standards-Information

Stationery

Statistical Methods

Statistics-Agricultural

Statistics-Bird Populations _...-

Statistics-Book Publishing

Statistics-Commerce

Statistics-Fertilizer

Statistics-Heating Systems

Statistics-Library _-_-_-_-__-

Statistics-Packaging

Staves

Steam Traps

Steam Turbine

Steatite

Steel

Steel Bar Mills

Steel Door

Steel Founder

Steel Joists

Steel Piping Material

Steel-Pressure Vessel Plate

Steel Rails

Steel Reinforcing Bars and Spirals

Steel-Scrap

Steel Sheet, Strip Bar, Rod and Wire 
Steel Shipping Containers _._. 155

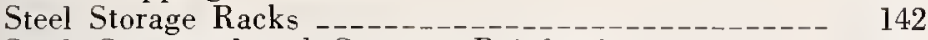

Steel, Structural and Concrete Reinforcing --_---- 39

Steel Structures Painting _-_- 155

Steel Windows _-

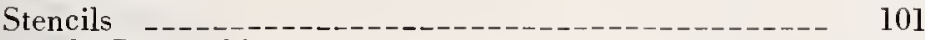

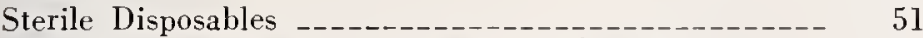

Stockyards and Packers-Scales and Weighing _._-_._ 177

Stone-Crushed -_-_-_-_-_-_-_-_-_-_-_-_ 118

Stones, Precious _-

Storage Batteries _-_- 57

Storage-Crops _-_- 132

Storage-Racks _-_-_-_-_-_-_-_-_-_-_-_-_-_ 142

Storage Systems-Mechanical _- 101

Storage Tanks-Chlorine _-_-

Storerooms for Explosive Materials

Storm Drains - 17

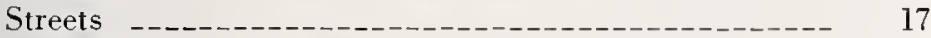

Strollers and Carriages

Structural Clay Products _-_-_-_-_-_-_-_-_-_-_ 15, 60

Structural Glazed Tile

Structural Sandwich Constructions _-_-_-_-_-_-_-- 39

Structural Steel -_-

Structural Timber Fabricating _-_-_-_-_-_-_-_-_- 26

$\begin{array}{lr}\text { Structures-Aluminum } & 7 \\ \text { Structures-Concrete }--16\end{array}$

$\begin{array}{ll}\text { Structures-Silos } & 132 \\ \text { Structures, Steel-Protection } & \end{array}$

Structures, Steel-Protection - 155
Stucco

Substations-Electric - 177

Sulfonates

Sulfur Dioxide - 188

Sulfuric Acid _-

Sump Pumps _-_-_-_- 156

Sunglasses _-_-_-_-_-_-_-_-_-_- 136

Supplies-School _-_- 132

Supply Services _-_- 185

Surface Finishes

Surgeons _-_-_- 16

Surgical Instruments

Surveying - 18
Swimming

Swimming

Swimming Pools, Public-Health _-_-_-_-_- 35

Swings -

$\begin{array}{lr}\text { Switch Ties - } & 143 \\ \text { Symbology }-1-0-1\end{array}$

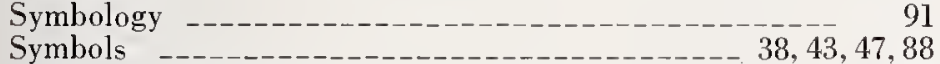

Symbols-Fluid Power - 122

Symbols, Graphic-TV -

Symbols, Map-Geology _-_______ 55

Symbols-Springs -

Symbols-Terramechanics

Synthetic Chemicals --_-_-_-- 76

Synthetic Fiber Ropes 69

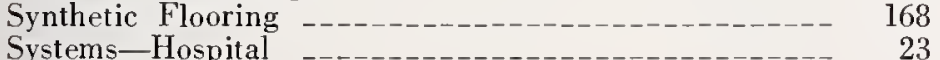

\section{$\mathbf{T}$}

Tablets

Tank Cars, Trucks, and Barges-For Chlorine

Tanker Vessels

Tanks, Storage-Chlorine

Tanners

Tape Equipment

Tapes-Pressure Sensitive _-_- 141

Tapping Screw Service Bureau

Taps

Tarpaulins

102,189

Teaching Profession 119

Technical Communications _-_._- 147

Teleconmunications

Telecommunications, Office of

Telegraph

Telemetry

157

91. 192
Telephone Facilities

Telephone Systems 177

Telephones _- 177

Television, Cable -

Television Receivers 187

Televisions _-_._-_._- 114, 149

Temperature, Effect of _-

Temperature Measurement

Tempered Glass Products

Tennessee, State of 174

Tent Fabrics _- 61

Terrain Characteristics

Terrain-Vehicle Systems

Terramechanics _-_- 95

Terrazzo - 134

Testing and Materials

Testing, Independent _... 75

Tetraethyl Lead _-_._- 188

Tetramethyl Lead _-_-_-_- 188

Texas, State of _-

Textbooks - -

Textile Chemists

Textile Materials _-_..- 39

Textile Rentals _- 97

Textiles -

Textiles-Asbestos -

Textiles-Felt _- 79

Textiles-Recycling - 113

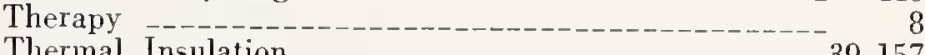

Thermal Spraying

Thermocouples _- 91

Thermometers _-_- 196

Thesaurus Rules and Conventions 70

Thin Films _- 46

Thread -

Threaded Products 189

$\begin{array}{ll}\text { 3-A Sanitary Programs } & 72 \\ \text { Ties and Buckles-Cotton Bales } & 70\end{array}$

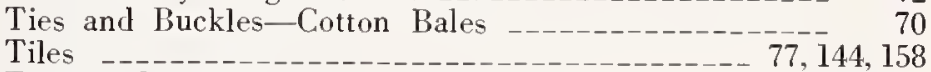

Timber Construction - 26

Timber-Preservatives

Time

Tin -159

Tinplate _-_- 159

Tire Cords - 39

Tires -

$\begin{array}{lr}\text { Tires and Wheels-Steel } & 39 \\ \text { Tires and Whecls_-Truck Trailers } & 160\end{array}$

Tires, Stecl 39

Tobacco -

Toilet Facilities

Toluene --_-n-_- 188

Tone Command

Tools 140,148

Tools-Hand Power

Tools-Hand Service _- 88

Tools-Machine -

Tools-Marking 101

Tools-Powder Actuated Fastening Systems _-_-_-_- 140

Tools, Power (Rebuilding) 75

Towers, Cooling - 68

Toxic Substances _- 188

Track and Field _-__-_-_-_-_- 7

Tracking _- 192

Tracks-Railroad - 195

Tractors and Machinery -10
Tractors-Farm -148

Tractors-Farm - -148
Trade

Trade Catalogs and Directorics _-_- 70

Trading Procedures 163

Traffic and Engineering Operations _-_-_-_-_-_-_ 195

Traffic Audit _- 159

Traffic Control and Laws _-_- 12

$\begin{array}{lll}\text { Traffic Enginecring } & 11 \\ \text { Traffic Engineers } & \end{array}$ 
Traffic Laws

Traffic Operations

10,117

Traffic Safety

Trailer Trucks

Trailers-Truck

Train Speeds

Trailis

Transducers

Transformer Rebuilding

Transformers (Rebuilt)

Transliteration

Transmission Lines

Transmission of Radio Wave

Transmissions-Mechanical Power

Transportation

Transportation Data -

Transportation, Department of

Transportation Noise

Transportation Officials

Transportation Products

Trapped Residual Determination

Trash Container

Treasury, Department of the

Tree Nuts

Trichloroethylene

Trim-Hardwood

Trimmers

Truck Body and Equipment

Truck Trailers

Trucks

Trucks-Floor, Platform, and hand

Trucks-Industrial

Trucks, Tank-Chlorine

Trucks-Trailer

Truss Plate

Trussed Rafters

Tuberculosis Treatment

Tubes

Tubular Exchanger Equipment

Tuners, AM and FM

Turf

Twine

Twist Drills

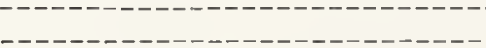
$\mathbf{U}$

Ultrasonic Therapy

Ultrasonics

Ultrasound

Ultraviolet Radiation

Uniform Building Code

Uniform Fire Code

Uniform Mechanical Code

United States Cap Screw Service Bureau

United States Coast Guard

United States Machine Screw Service Bureau

United States Member Body of the International

Organization for Standardization (ISO)

United States Wood Screw Service Bureau

Universal Product Code

Upholstered Furniture

Urban Development

Urban Government

Utah, State of

Utilities-Water

-

\section{V}

V-Belt Drive Systems

Vacuum Cleaners

Vacuum Science and Technology

Value Engineering

Valves

80, 115

Valves and Fittings _-_-_-_-_- 98

Varnish _..._-_._- 39

Varnishes

Vascular Prostheses _- 51
Vegetable Oils

Vehicle Equipmen

Vehicle Records and Procedures

Vehicles

Vehicles-Aircraft

Vehicles-Buses

Vehicles, Recreational

Vehicles-Soil Working

Vending

Ventilation

Ventilation Equipment (Home)

Ventilation Exhaust Systems

Vessels

Vessels-Review and Inspection

Veterans Administration Blue Card

Veterinary Biologics

Vibration and Shock-Mechanica

Virginia, Commonwealth of

Vision

Visual Materials

Visually Handicapped

Viticulturists

Vitrified Clay Pipe

Vitro Diagnostic Produ

Voluntary Product Standards

W

Walk-Through Metal Detectors

Walkers-Juvenile

- - - - - - - - - - -

Walls and Ceiling

Walnut (Wood)

Walnuts

Washing and Dry Cleaning

Wastewater Management

Wastewater Plants and Utilities

Watches

Watchmakers

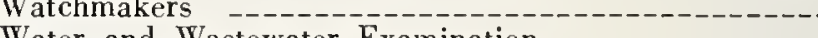

Costewater Examination

Water Colors - -
Water Conditioning

Water Cooling Tow

Water Data

Water Data Coordination, Office of

Water-Drinking

Water Pollution Control

Water Softeners _-_-

Water Supply Systems

Water Systems

Water Tanks

Water Wells

Water Works

Watercraft

Waterproofing

Wax Importer

Wax Polishes

Waxes

Weapons

Weighing

Weighing Machines

Weight Engineers

Weightlifting

Weights and

Welding

Welding Machine

Wells, Water
West Virginia, State of

Wheat
Page 
Wheels

Wheels and Tires-Steel

Wheels and Tires-Truck Trailers 160

Wheels-For Diamonds

Wheels-Grinding _-_-_-___- 83

Whey Products

White Wares

Windows

Windows-Mobile Homes

Wine and Brandy -_- 168

Wine Specialists

Wiping Cloths _-_- 113

Wire 151

Wire Diameters

Wire-Insulated - 91

Wire Reinforcement 168

Wires and Cables _-_._- 94

Wiring - 55, 119

Wisconsin, State of - 176

Wood - 39

Wood and Synthetic Flooring 168

Wood-Hardwood -

Wood Inspection -
Wood-Lumber

Wood Particleboard 167

Wood-Plywood

Wood Preservatives

Wood Products _-

Wood Shingles _-_-_-_-_- 143

Wooden Box

Woodwork

Wool Felt - 79

Work Methodology-Methods-Time-Measurement _-_-- 97

Wrought Iron Bars and Sheets

Wyoming, State of - 176

XYZ

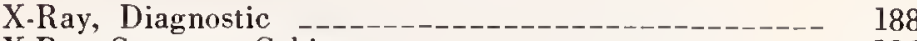

X-Ray Systems, Cabinet _-_- 186

X-Rays - -

Yachts

Yarns - 39

Zinc -

Zippers - 39 


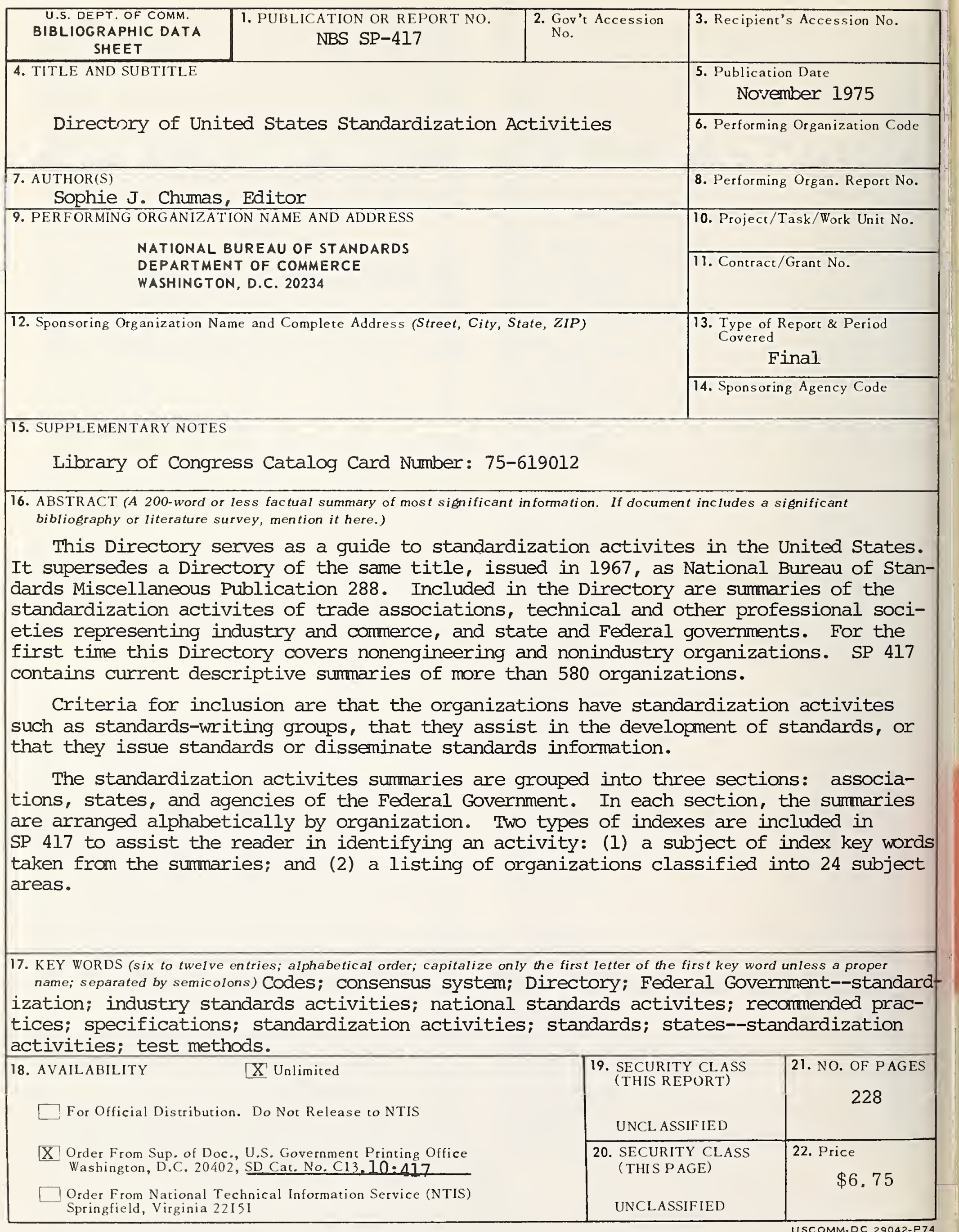

